\title{
Aportes conceptuales y derivaciones tecnológicas en Psicología y Educación
}

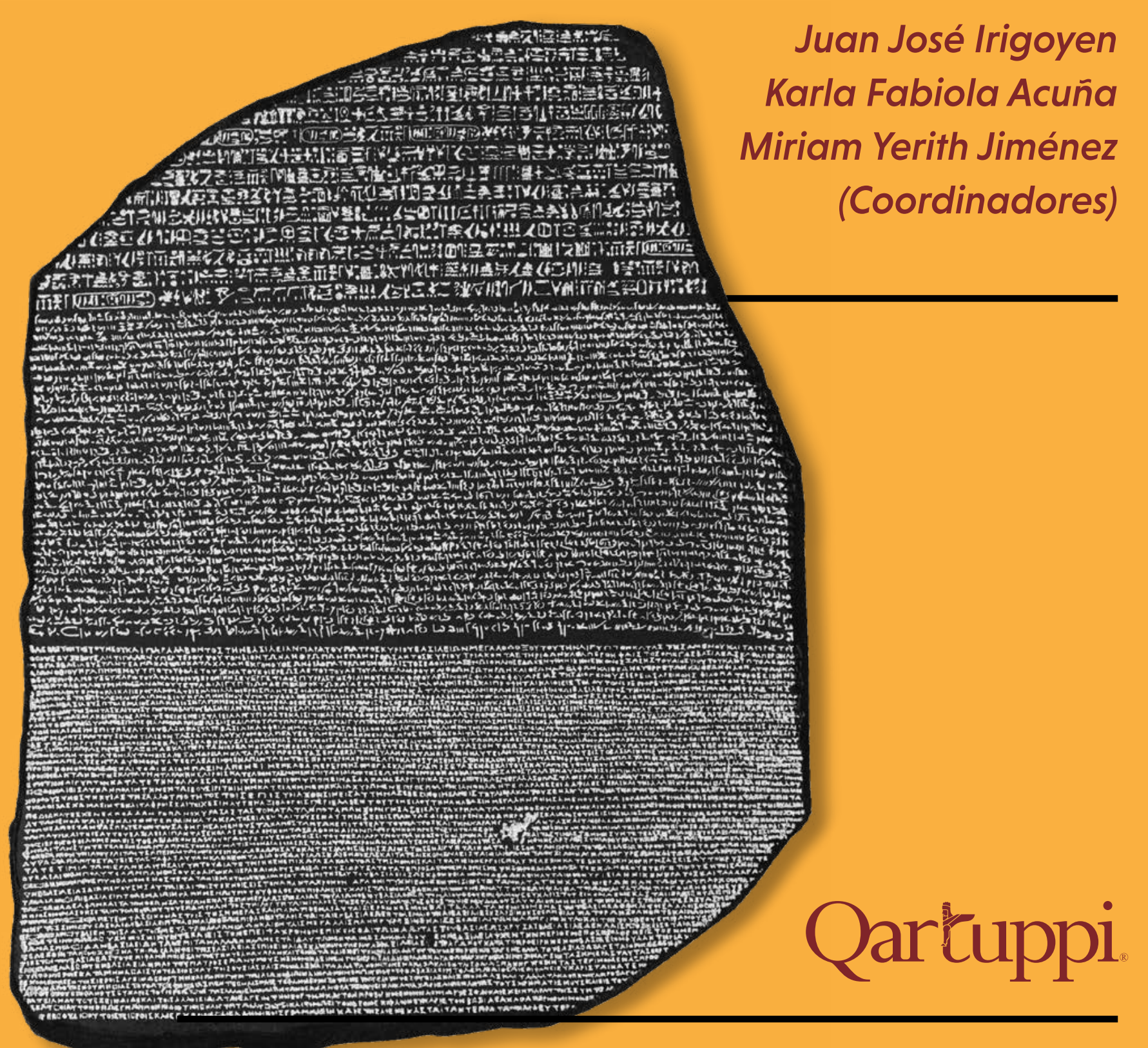





\section{Aportes conceptuales y derivaciones tecnológicas en Psicología y Educación}




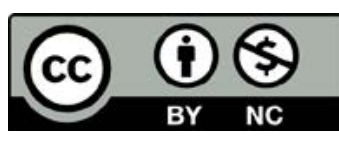

Esta obra está bajo una Licencia Creative Commons

Atribución-NoComercial 4.0 Internacional.

https://creativecommons.org/licenses/by-nc/4.0/deed.es

Comité Científico y de Revisión Técnica:

Dr. Luis Enrique Fierros Dávila. Universidad de Sonora. México.

Dra. María Oliva Márquez Sánchez. Universidad Autónoma de Madrid. España.

Mtro. Francisco Javier Obregón Salido. Universidad de Sonora. México.

Dr. Luis Alberto Quiroga Baquero. Universidad Santo Tomás. Colombia.

Dr. José Santacreu Mas. Universidad Autónoma de Madrid. España. 


\title{
Aportes conceptuales y derivaciones tecnológicas en Psicología y Educación
}

\author{
Juan José Irigoyen \\ Karla Fabiola Acuña \\ Miriam Yerith Jiménez \\ (Coordinadores)
}

Qartuppi. 
La referencia sugerida para esta obra es:

Irigoyen, J.J., Acuña, K.F., \& Jiménez, M. (2017). Aportes conceptuales y derivaciones tecnológicas en Psicología y Educación. Hermosillo: Qartuppi. http://doi.org/10.29410/QTP.17.01

Aportes conceptuales y derivaciones tecnológicas en Psicología y Educación

1era. edición, enero 2017.

ISBN 978-607-97326-8-4

DOI 10.29410/QTP.17.01

D.R. (C) 2017. Qartuppi, S. de R.L. de C.V.

Calle Real 63, Col. Villa Satélite

Hermosillo, Sonora 83200 México

http://www.qartuppi.com

Edición: Qartuppi, S. de R.L. de C.V.

Diseño Editorial: Daniel Castro Dávila 


\section{Contenido}

9 Presentación

Juan José Irigoyen, Karla Fabiola Acuña y Miriam Yerith Jiménez

11 Prólogo

Josep Roca i Balasch

17 Capítulo 1

Organización y caracterización de las distintas prácticas en Psicología:

Matriz Científica Interconductual

Winter Edgar Reyna Cruz, Jesús Sánchez Serrano, Ramsés Alejandro Reyes Anguiano y Manuel Hernández Reyes

43 Capítulo 2

Competencias y habilidades: implicaciones de su naturaleza disposicional

Enoc Obed De la Sancha Villa y Ricardo Pérez-Almonacid

57 Capítulo 3

Análisis del desarrollo psicológico: un estudio de la historia de efectividad de universitarios Germán Morales Chávez, Edgar Chávez Hernández, Benjamín Peña Pérez,

Alfredo Hernández Corona y Claudio Carpio Ramírez

85 Capítulo 4

La intervención educativa desde el modelo de campo Interconductual: algunos datos iniciales

Ulises Delgado Sánchez, Jorge Guerrero Barrios, Fernanda Gabriela Martínez Flores

y Néstor Velarde Corrales 
103 Capítulo 5

Evaluación de la comprensión lectora en alumnos de secundaria, desde la Psicología Interconductual

Yolanda Guevara Benítez y Karlena Cárdenas Espinoza

131 Capítulo 6

Aprendizaje y transferencia de una estrategia de análisis de textos científicos desde la Web Diana Moreno Rodríguez

\section{Capítulo 7}

Efectos de las variaciones en los materiales de estudio y la retroalimentación sobre el modo lingüístico escribir

Karla Fabiola Acuña, Juan José Irigoyen y Miriam Yerith Jiménez

\section{Capítulo 8}

Lectoescritura técnica: el caso de la elaboración de resúmenes de artículos experimentales María Antonia Padilla Vargas, Elsy Georgina Cárdenas García y Cristiano Valerio dos Santos

\section{Capítulo 9}

Suplementación lingüística y corrección: efectos sobre el desempeño lector-escritor en estudiantes universitarios

Miriam Yerith Jiménez, Juan José Irigoyen y Karla Fabiola Acuña

\section{Capítulo 10}

Análisis de la habilitación lingüística de la escritura

Alfonso López Corral, Carlos Flores Aguirre y Carlos Torres Ceja

\section{Capítulo 11}

Herramientas psicológicas para solucionar problemas matemáticos en educación básica Luis G. Zarzosa Escobedo 


\section{Presentación}

La obra que el Seminario Interactum de Análisis del Comportamiento pone a consideración de psicólogos, educadores y personas interesadas en la vinculación de una visión objetiva de la Psicología, particularmente al ámbito de la Educación, es a todas luces un producto colectivo, así, tenemos que agradecer la confianza y deferencia que los diferentes colegas han depositado en este esfuerzo editorial.

Una de las intenciones fundamentales que guían la planeación, instrumentación y edición final de este manuscrito ha sido poner en manos de noveles investigadores y estudiantes interesados en la Psicología aplicada al ámbito de la Educación, productos de investigación e ideas en desarroIlo, que los diferentes grupos de investigación generan como información de primera mano.

Lejos de una visión de ciencia como asiento de sabiduría y poder, nos interesa comprender las condiciones concretas de su realización como hacer y decir, esto es, comportamiento científico, entendiendo por enseñanza científica una formación en el modo de comportarse, cuyo propósito es que se constituya en una práctica vinculada a hechos, decisiones y acciones individuales cotidianas.

Describir las prácticas, las formas de instrumentar y asignar una métrica a objetos de referencia, es decir, los comportamientos que formalmente se conciben como la actividad propia del científico, así como las condiciones que hacen más probable generarlas en los noveles científicos, ha sido el compromiso que los diferentes autores de esta obra han tratado de caracterizar, describir y proponer.

La presente obra resume el esfuerzo, el trabajo reflexivo y de investigación de colegas de instituciones como la Universidad de Guadalajara, la Universidad Nacional Autónoma de México, la Universidad Autónoma del Estado de Morelos, la Universidad Veracruzana, la Universidad Autónoma de Baja California, el Instituto Politécnico Nacional y la Universidad de Sonora, todos enfocados a que en la misma se presenten las diferentes propuestas con un nivel de claridad, pertinencia y coherencia posibles.

Agradecemos a los investigadores de las diferentes instituciones por la confianza puesta en nosotros como Coordinadores de esta obra, por su colaboración con planteamientos y reflexiones que más que dar respuestas unívocas generan preguntas de trabajo de investigación, que seguramente pueden generar derroteros en jóvenes investigadores y estudiantes de disciplinas afines a la Ciencia Psicológica y al ámbito de la Educación. 
Agradecemos particularmente al Dr. Josep Roca i Balasch (Liceu Psicològic), a la Dra. María Oliva Márquez Sánchez y al Dr. José Santacreu Mas (Universidad Autónoma de Madrid), al Dr. Luis Enrique Fierros Dávila y al Mtro. Francisco Javier Obregón Salido (Universidad de Sonora), y finalmente, al Dr. Luis Alberto Quiroga Baquero (Universidad de Santo Tomás, Bogotá, Colombia), por sus comentarios puntuales, su crítica constructiva, así como su tiempo y dedicación que en mucho han hecho de los diferentes escritos un mejor producto.

Juan José Irigoyen

Karla Fabiola Acuña

Miriam Yerith Jiménez

(Coordinadores) 


\section{Prólogo}

En la fase más temprana de mi primer trabajo como profesor de Psicología en una Facultad de Educación, me dolió profesionalmente escuchar de un compañero decir que la Psicología decía lo mismo que todo el mundo, pero lo hacía con otras palabras. Me sonó a desprecio, ya que era como si dijera que en realidad esta ciencia no aportaba nada nuevo al saber ordinario. El tema es que si solo fuera un comentario despectivo podía obviarlo, pero si esta visión del discurso psicológico era la común o mayoritaria entre otros profesionales y la sociedad en general, pensé que los psicólogos teníamos una tarea seria a realizar. Creo que la convicción de que esto último era cierto, fomentó la idea de trabajar para tener un discurso científico psicológico nuevo y que, además, fuera útil en el desarrollo formativo de los educadores.

Es por ello que siempre he tenido un gran respeto y admiración por el trabajo persistente de los colegas mexicanos, en el enfoque Conductual e Interconductual, por desarrollar un lenguaje nuevo en Psicología y una atención a los temas educativos como prioridad profesional. Veo, además, en esta publicación de Juan José Irigoyen, Karla Fabiola Acuña y Miriam Yerith Jiménez, otra muestra de aquella corriente de pensamiento básico para la definición y constitución del área de conocimiento de ciencias psicológicas y educativas, dentro de la ciencia general y de la Universidad.

Valoro, particularmente, el reconocimiento que se hace explícito en el título Aportes Conceptuales y Derivaciones Tecnológicas en Psicología y Educación del marco dinámico en el que debe de fundamentarse la relación entre la Psicología y la Educación: un diálogo interactivo entre discursos psicológicos e intervenciones educativas. Entiendo que todos los trabajos se mueven en este marco de interrelación y se hace de forma bien diversa, ya en la selección de los tópicos que va desde un planteamiento filosófico sobre matrices culturales hasta los retos educativos más concretos ligados a las nuevas Tecnologías de la Comunicación.

Mi aportación en este prólogo es una reflexión general hecha desde una perspectiva ya algo distante del universo académico y universitario; por razones de estado laboral y de dedicación a cosas que me distraen de él.

Crisis, criterio y crítica son tres palabras con la misma raíz en la palabra griega -kpíøı - que significa "decisión" y que a su vez proviene de otra palabra griega que refiere la acción de separar. Ahora las veo como descriptoras de los ciclos repetidos en el trato de conceptos y teorías en la actividad intelectual. Siempre se parte de un estado de crisis en el que hay que dilucidar sobre algo y resolverlo, luego viene normalmente la adopción de un criterio para hacerlo y ello conlleva un discurso que separa opciones y las valora como mejores o peores en términos de conocimiento. 
Las crisis más importantes en ciencia acostumbran a ser las que surgen en el intento de definición del objeto de estudio de cada ciencia particular. La Psicología, se ha dicho muchas veces, está en estado de crisis de definición permanente desde la aparición, en la cultura griega, de concepciones distintas sobre lo que eran las ideas y de dónde procedían. El estado de crisis, ahora, llega a su máximo cuando con la búsqueda de la definición de conceptos psicológicos, por medios informáticos, se produce una inundación de palabras que dan cuenta de infinidad de discursos en los que ya no se puede ver la crisis dicotómica habitual entre planteamientos dualistas y planteamientos naturalistas por la avalancha de discursos de todo tipo que hacen pensar en lo psicológico más como una producción artística individual que como un conocimiento organizado de una ciencia.

Las crisis se resuelven con criterio. Es decir, proponiendo y asumiéndose distinciones y definiciones que resultan claves para el conocimiento y la formación de cohesiones teóricas a partir de ellas. El criterio de objetividad en ciencia, por ejemplo, ha consistido en exigir evidencias que justifiquen y apoyen lo dicho por cada individuo que participa en una disciplina o materia.

Pero la resolución de una crisis acostumbra a llevar a otra crisis, o pone en evidencia que hay otra crisis no prevista por resolver. Así, describir objetivamente el comportamiento de un individuo no es lo mismo que explicar porqué se da. Tampoco intervenir en un aprendizaje escolar es lo mismo que describirlo. Se plantean así distinciones clave en ciencia para superar el estado de crisis que resulta de planteamientos insatisfactorios -por indiscriminados- anteriores o previos. Es por ello, entiendo yo, que se ha llegado a un planteamiento general de la ciencia en el que se distingue entre ciencias morfológicas, ciencias básicas -teóricas o explicativas- y ciencias tecnológicas, junto a la distinción de todas ellas respecto de disciplinas formales como son la lógica y la matemática.

Dentro de la actividad explicativa, la crisis clave se ha centrado y sigue centrada en el concepto de causa. El dilema general que la define es la de tomar causa como creación o generación de algo por otro algo o tomarla como relación. El perfil actual de la crisis de definición de lo psíquico y de lo humano, en general, viene dado por la reducción explicativa de lo mental al funcionalismo cerebral, con la postulación sistemática que la producción del pensamiento, la definición de cada personalidad y toda la conducta humana en general, es un efecto de la actividad neurofisiológica. Es decir, impera una concepción creacionista de causa.

Las crisis siguen, sin embargo, al interior de las posiciones que comparten un mismo criterio definitorio de causa. Así, el hecho de que las llamadas neurociencias ofrezcan una reducción explicativa de lo mental a lo material, se enfrenta a la postura dualista más creyente que rechaza la negación de la parte espiritual de los individuos humanos. Pero sucede lo mismo en el lado de los que defienden el concepto de causa como relación. Porque una vez agrupados los partidarios de esta definición relacional de causa, el tema que se plantea es: causa es relación, pero ¿relación entre 
qué? Algunos hablan de relación entre estímulos y respuestas y brindan el principio de objetividad ya que refieren que los estímulos y las respuestas son objetivables en su definición. Otros hablamos de relación entre reacciones orgánicas, que a su vez se basan en relaciones conmutativas fisicoquímicas. Pero hablar de "relaciones entre relaciones" inquieta a muchos y cuesta asumir este criterio relacional radical y global de la naturaleza.

Parte de la crisis viene del hecho de que el concepto de causa como relación es netamente un intangible. Es decir, es un concepto que refiere algo que ni se puede tocar, ni ver, ni oír, ni oler, ni degustar, ni sentir en general. Los intangibles son rechazados por los objetivistas aún cuando los intangibles refieren fenómenos existentes y son tan reales como las cosas tangibles. Piénsese, sino, en el condicionamiento pavloviano: se da una salivación en ausencia del estímulo que la provoca reactivamente y ello demuestra que se ha dado una relación funcional distinta a la reactiva original. Lo bueno del caso es que ni es tangible el condicionamiento ni tampoco lo es la reactividad como tal: con los mismos estímulos y respuestas tangibles se reconocen funciones intangibles distintas. $Y$ este es el tema: los intangibles se conocen, pero no sensorialmente sino asociativamente, es decir, con base a su registro por el funcionalismo propiamente psíquico. Aquí, por supuesto, empieza otra crisis. Mejor dicho: muchas otras crisis, porque junto a definir un criterio de distinción, reanimamos las crisis ligadas a los debates filosóficos ya históricos sobre la mente, el pensamiento, el conocimiento, el habla y el lenguaje y demás. No obstante todo ello, la Psicología actual tiene este reto de mostrar lo psíquico como un tipo de relación funcional que se basa en otras relaciones funcionales y se da también por mor de ellas, en una visión global de causa como relación e interdependencia funcional natural.

Pienso, centrándome en la definición de Psicología que he venido compartiendo con los que tienen la misma concepción de causa como relación, en el uso de los conceptos de comportamiento y conducta como descriptores iniciales; luego en la definición de conducta o comportamiento como acción y como relación; también en la diferencia entre objeto material y objeto formal cuando se habla de conducta en general. Sobre ello he escrito ya. Pero pienso también en la concepción dualista del hombre enfrentada a la concepción multifuncional que defiende la Psicología con enfoque naturalista. Pienso entonces en la concepción multifuncional de la naturaleza y cómo se resuelve la representación de la interdependencia funcional, para hacer frente a la complejidad que cada uno de los niveles funcionales por separado y luego en interdependencia, generan. También he escrito sobre ello al hablar de movimientos y causas, proponiendo criterios y realizando críticas para definir lo psicológico y ordenar sus contenidos junto a los de las otras ciencias naturales.

Ha habido en todo este proceso un uso circunstancial de distintas palabras, pero ha sido siempre para defender unos criterios -objetividad en lo descriptivo y relación en lo explicativo, 
básicamente-con lo que se ha promovido una concepción exclusivamente natural de los fenómenos psíquicos. Conducta, Comportamiento, Movimiento y Funcionalismo para subrayar el criterio dinámico de lo psíquico frente al criterio de extensión que lo define por su ubicación estática en el cuerpo. Condicionamiento, Constancia, Configuración, Contingencia, Conocimiento, Posicionamiento, Interpretación y siempre Asociación, por ser el concepto más general, para definir la relación construida entre reacciones orgánicas. Cambio, Variación y Ley para denotar lo cuantitativo y el concepto de Factor como causa en esta dimensión funcional. Aprendizaje, Desarrollo y Evolución, y el concepto de Determinante para dar cuenta de la tercera dimensión de lo psíquico en la que se trata de explicar las formas asociativas concretas y sus valores que pueden explicar el rendimiento individual diferencial y su evolución.

Llegados a este punto creo que asumir los estados de crisis conceptual, proponer criterios para resolverlos y realizar una crítica sistemática con pros y contras respecto de los conceptos en juego, define la normalidad laboral en ciencia. Normalidad que conlleva el uso del "instrumental" básico de las palabras para tratar de describir y explicar el funcionalismo psíquico dentro del funcionamiento global natural.

Un impedimento para este objetivo de la Psicología es que estos temas de crisis, criterios y críticas, especialmente sobre su definición, generan sentimientos encontrados. Teniendo en cuenta que un sentimiento es una actitud mental pero también una disposición emocional. Pero en esto hay que hacer como los deportistas de élite destacados, contracondicionan la ansiedad negativa de la competición por el goce de hacerla. Su objetivo es conseguir un estado de fluencia tal que el agonismo se realice como algo fácil y agradable que lleva a una experiencia de realización cumbre. No es una tarea fácil, pero es la definitiva de cara a ser un atleta completo.

Lamentablemente el debate crítico más general está actualmente abandonado, porque es incómodo y porque es más fácil investigar y publicar con base en marcos teóricos consolidados o reconocidos por su uso mayoritario. Actualmente estos marcos teóricos provienen mayormente de concepciones biologistas, pero también de modelos teóricos que vuelven a animismos primitivos y que el humanismo más mediocre ensalza porque toma como sagrada la singularidad personal y la supone sustentada en fuerzas creativas que emergen de un "interior" personal ignoto... Uno no deja nunca de sorprenderse de lo que se puede llegar a decir sobre lo psíquico y sobre cómo se explica en nuestra cultura que se supone evolucionada.

El resultado es que los temas que se acaban imponiendo como relevantes socialmente son los que resultan interesantes para los grupos dominantes en nuestra sociedad, sean económicos o sean ideológicos, pero en todo caso ajenos a los objetivos generales de la ciencia. La investigación en neurociencias y biología, por ejemplo, es enormemente superior a la centrada en fenómenos y 
procesos psicológicos y de educación. Y todavía en los temas de salud, no tiene comparación la cantidad de dinero destinado a curar -con una clase médica en una posición social más que influyente y con toda la industria que hace negocio con los medicamentos y el instrumental médico-, con la cantidad de dinero destinado a educar e investigar sobre los efectos de los hábitos saludables y no saludables de la población.

En la vida universitaria y particularmente en el tema de la producción intelectual, el objetivo es publicar en revistas de impacto y no lo es realizar la crítica a los criterios básicos de construcción de la ciencia. Prima el publicar por encima del qué publicar y, lo que es peor, actualmente el disponer de dinero para publicar es definitivo para hacerlo en aquellas revistas que le van a suponer a uno un reconocimiento académico mayor y un mejor salario.

Observando este estado de cosas lo que conviene es, precisamente, volver una y otra vez a los temas más generales de la Psicología que contribuyen a una concepción naturalista del hombre, frente a creencias e ideologías ocultistas y biologistas. También para instituir la Psicología que cimenta un área de conocimiento y que brinda a la Educación un planteamiento ordenado de los fenómenos psíquicos, sobre los que aquella debe de intervenir. $Y$ todavía, porque para el trabajo académico y universitario de profesores y alumnos, los temas de planteamiento general de la Psicología y la Educación son como el "mapa" de orientación conceptual básico. Con este mapa uno puede observar dónde se sitúa el trabajo que realiza y qué valor científico ponderado tiene.

En todo caso, decir que para superar realmente las crisis, disponer de criterios para la construcción de la ciencia general natural y ejercer la crítica sistemática, noble y desinteresada, habría que crear universidades libres. Evidentemente esta es una idea en otro plano. Pienso que seguramente una universidad libre solamente puede existir, actualmente, como organización paralela a la universidad oficial, y formada por profesores liberados de todos aquellos intereses -sobretodo económicos- que la regulan actualmente.

De hecho, esto es lo que hacemos cuando publicamos y leemos los trabajos con "espíritu crítico" y sin ningún otro interés que el académico. Esta es la manera, en todo caso, que entiendo que ha primado en la confección de esta obra y también la que va a primar, seguro, en su lectura.

Josep Roca i Balasch

Liceu Psicològic jrocabalasch@gmail.com 


\section{Capítulo 1}

\section{Organización y caracterización de las distintas prácticas en Psicología: Matriz Científica Interconductual}

Winter Edgar Reyna Cruz, Jesús Sánchez Serrano,

Ramsés Alejandro Reyes Anguiano y Manuel Hernández Reyes 
Winter Edgar Reyna Cruz psicologo.winter.reyna@gmail.com

Jesús Sánchez Serrano jesussanchez_2005@yahoo.com.mx Ramsés Alejandro Reyes Anguiano ramsesreyes21@yahoo.com Entelequia Social

Manuel Hernández Reyes manuhel.hr@gmail.com

Centro de Investigaciones Económicas Administrativas y Sociales Instituto Politécnico Nacional

Este trabajo es uno de los productos del seminario "Reflexiones en torno a la práctica profesional del psicólogo" coordinado al interior de Vestigum, línea de investigación y desarrollo de Entelequia Social S.C. 


\section{Capítulo 1}

\section{Organización y caracterización de las distintas prácticas en Psicología: Matriz Científica Interconductual}

La distinción entre la práctica científica, generalmente llamada básica, y la práctica tecnológica o profesional, muchas veces denominada aplicada, ha permitido con toda justeza diferenciar las disciplinas orientadas hacia la comprensión de un dominio empírico particular, de aquellas encargadas de la solución de demandas en campos sociales definidos. Lo anterior no significa que ambos tipos de prácticas estén desvinculados, es decir, que "lo básico" no tenga contacto con la vida social o que "la aplicación" sea independiente al conocimiento científico; por el contrario, ambas se encuentran relacionadas al menos por tres razones: a) la práctica científica se construye influenciada decisivamente por las prácticas concretas e ideológicas de una forma particular de relación social, b) la aplicación se nutre principalmente del trabajo intelectual especializado producto de la labor científica; y c) la práctica aplicada, al tratar con lo social, también tiene impacto en la práctica básica dado que modifica los referentes que la ciencia abstrae y explica (Kantor, 1978; Marx \& Hillix, 1976). Es, en este sentido, que una de las problemáticas características al interior de las diversas ciencias, ha sido la falta de vinculación entre estos tipos de prácticas; pues en ocasiones se ha ejercido ciencia sin una derivación clara a la aplicación, o bien, se realiza trabajo aplicado sin evidencia empírica que lo respalde.

La Psicología, como un modo particular de conocimiento o aplicación, no ha sido ajena a la problemática mencionada; sin embargo, dado su estado multiparadigmático (Ribes, 2000), esta relación se ha dado de una forma más pantanosa, pues no sólo se ha caracterizado por la carencia de vinculación entre el conocimiento científico y el tecnológico; sino también, por la falta de consenso y claridad respecto a si se trata de una disciplina científica o una profesional. Basta con revisar la evolución de la Psicología para poder ubicar precisamente dos tipos diferentes de desarrollo histórico en los que se han realizado esfuerzos para constituirla: uno científico y otro tecnológico (Rodríguez, 2005).

Sin pretensiones de ahondar en la problemática anterior, pues ello demanda una revisión exhaustiva aparte, vale señalar que los resultados actuales de dicho doble dilema, han desembocado en que bajo el seudónimo de Psicología se arropen: a) diferentes sistemas científicos, que parten de premisas, postulados y objetos de conocimiento diferentes; b) micro-teorías o micro-modelos informales sobre fenómenos específicos de la conducta, carentes de un fundamento onto-epistémico que las valide, resultado de la carencia de un modelo general sobre el comportamiento; c) aplicaciones sintetizadas o extrapoladas directamente del conocimiento científico, que surgen primordialmente de 
la preocupación de vincular el conocimiento científico psicológico en situaciones prácticas delimitadas socialmente, para la atención de la dimensión psicológica de un problema social; y d) técnicas, procedimientos e instrumentos desvinculados o desembarazados de cualesquier fundamento teóri$c o$, es decir, herramientas aplicables construidas de manera pragmática, motivados principalmente por las demandas sociales impuestas a la Psicología en su vertiente aplicada.

La mejor vacuna a esta situación es la edificación clara de un sistema científicamente válido que permita su vinculación con sus respectivos horizontes de aplicación en departamentos específicos de acción práctica; esto es, delimitar onto y epistemológicamente un objeto de estudio, del cual se establezcan las relaciones entre los sistemas subsiguientes y que permita, entre otras cosas, generar datos susceptibles de ser tratados para contar con conocimiento aplicable y así generar tecnologías para el ejercicio profesional (Kantor, 1978; Ribes, 2009).

La Psicología Interconductual es, tal vez, el sistema científico que mejor se ajusta a los criterios mencionados; desde el cual se han realizado diversas actividades que van desde las filosóficas hasta las aplicadas. Basta con revisar los diferentes sistemas científicos propuestos, modelos desarrollados, diseños utilizados, procedimientos y técnicas generados, que se han arropado bajo la etiqueta de "Interconductual”. Sin embargo, según Hernández y Reyna (2015), esta situación da la apariencia de que cada uno de estos y sus prácticas asociadas: a) estén desvinculadas, discontinuas, entre sí ( $v$. gr., no se realiza el mismo tipo de práctica cuando un psicólogo Interconductual hace el análisis conceptual de un concepto referente a la vida mental de las personas, a cuando genera un modelo que delimite la dimensión psicológica de un problema social); b) que se usen categorías pertinentes a un tipo de práctica, en otro tipo de práctica ( $v$. gr., usar categorías como medio de contacto o límite de campo, propias de la metateoría, en la práctica aplicada del psicólogo); e incluso, c) que se juzgue un tipo de práctica, con criterios pertinentes a otra ( $v$. gr., la práctica profesional a la luz de criterios que dan sentido a la práctica teórica).

De cara a esta situación y dada la carencia de un marco organizador que permita diferenciar, caracterizar y vincular las diferentes prácticas realizadas al interior de la Psicología Interconductual (i.e., filosofar, teorizar, crear herramientas para atender demandas sociales y aplicar dichas herramientas), en este capítulo se presenta una propuesta que pretende dar cobertura a los tres aspectos mencionados. Para cumplir con dicha labor, en primer lugar, se presenta brevemente las nociones fundamentales que dan sustento a esta.

\section{El continuo Interconductual, la Interconducta científica y la continuidad de la ciencia}

Una de las nociones más relevantes que dan sentido a la propuesta que se presenta en este capítulo, es la noción de continuidad propuesta por Jacob Robert Kantor, una de las categorías que de hecho ocupa un lugar preponderante en sus postulados acerca de la construcción científica en general, pues, por un lado, sobre esta noción articula y da sentido a su visión de ciencia; por otra parte, todo el sistema que edificó es defendido y sostenido sobre esta base; finalmente, critica y califica de inválidas a las visiones y construcciones disciplinares que carecen de continuidad (Hayes, 1994). 


\section{La noción de continuidad}

Para Kantor $(1953,1978)$, existen eventos y acontecimientos (i.e., campos de factores relacionados) que ocurren dentro o fuera de interacciones humanas; es decir, se presentan en situaciones en las que un observador, descriptor o manipulador hace o no contacto con ellos. Si bien es cierto que estos eventos se diferencian entre sí por sus particularidades, todos ellos son homogéneos; esto es, se encuentran estrechamente vinculados, unidos, unos con otros de tal manera que se corresponden. Es precisamente a este vínculo y correspondencia a lo que Kantor hace referencia cuando alude a la continuidad.

Cuando un observador, sea o no científico, describe los eventos considerando las diferencias entre ellos, lo hace para facilitar su comprensión o manipulación; pero no por ello pierden continuidad. En este sentido se hablaría de una descripción válida del evento. Caso contrario: cuando la descripción responde a criterios o creencias de orden cultural o a suposiciones de la persona que describe el evento, sin considerar los factores que lo configuran, la descripción se considera inválida, pues es discontinua con el acontecimiento descrito; es decir, lo que se dice de este no guarda ningún vínculo, unión o correspondencia (Hayes, 1994).

Respecto a las relaciones recíprocas entre un organismo con objetos, eventos u otros organismos, la situación no es para nada diferente: todos los tipos de interacciones de los organismos con su ambiente son continuos; es decir, constituyen puntos particulares, diferenciados entre ellos sólo en detalle, de un único y denso continuo conocido como Interconducta (Kantor, 1978). Cuando un individuo se enfrenta a este continuo Interconductual, pretendiendo describir alguno de los puntos o Interconductas que lo conforman, lo que hace es segmentarlo dadas las características distintivas del tipo de interacción que se busca explicar; pero ello no significa que los desvincule del todo del que forma parte. De esta manera, por ejemplo, la Interconducta religiosa, económica, deportiva o la científica, entre otras, se encuentran estrechamente vinculadas, siendo la única diferencia entre estas las particularidades de los factores participantes y la complejidad organizativa que define cada tipo de interacción.

En el caso específico de la Interconducta científica, para Kantor (1953) esta no es un tipo de actividad "mejor", más sofisticada o detallada que otros tipos de actividades; por el contrario, se trata sólo de una forma particular de Interconducta y como tal se encuentra directamente relacionada con todas las demás actividades humanas, al grado que es influenciada decisivamente por ellas. De esta forma, todas las actividades que se consideran típicamente científicas se encuentran con otros tipos de interacciones en un único continuo Interconductual.

\section{La ciencia como matriz cultural: sus relaciones de continuidad}

De acuerdo a Kantor (1990) para definir y entender la ciencia, resulta indispensable: a) hacer referencia a los tipos de Interconductas específicas con clases particulares de eventos que realiza el científico; y b) considerar las raíces de cualesquier sistema científico; esto es, las condiciones precientíficas que anteceden a la investigación organizada y a la acumulación de teorías.

Con respecto al tipo de interacciones específicas con clases particulares de eventos que dan especificidad a la ciencia, Kantor (1978) sugiere que la Interconducta científica emerge como una especialización del dominio Interconductual general; esto es, constituye evoluciones de los contac- 
tos ordinarios con los objetos y eventos con los que se interactúa, perfilándose como una empresa para la búsqueda de estructura, operación e interrelación de las cosas y eventos para su posterior predicción y control. En lo que respecta a las raíces de los sistemas científicos, todas las empresas científicas son instituciones especializadas situadas en matrices culturales particulares (Kantor, 1990). Una matriz cultural se define como aquella condición social que da cobertura al tipo de prácticas ideológicas y efectivas que caracterizan a un grupo cultural específico en un momento histórico particular. En suma, las matrices culturales se convierten no sólo en el terreno sobre el cual germinan y crecen instituciones particulares (v. gr., el arte, la religión, el deporte, la ciencia) sino además, representan el marco de referencia que regula, norma y da sentido a las interrelaciones particulares en cada institución.

En concordancia con lo anterior, Carpio, Pacheco, Canales y Flores (2005), señalan que la ciencia constituye un modo social de conocimiento, que puede ser caracterizada como una institución cultural encaminada a la generación de conocimiento para la explicación de los fenómenos de la realidad que, como toda cultura, se expresa como práctica colectivamente compartida. En este sentido, la definen en las tres dimensiones generales que tipifican a toda cultura: a) como producto, que refiere a los objetos formalizados de la ciencia ( $v$. gr., sus teorías, modelos, conceptos, métodos, técnicas, por mencionar algunos); b) como institución reguladora de las prácticas científicas que prescribe las normas y estándares de comportamiento generales valoradas como permisibles e ideales en una comunidad científica y c) como ciencia "viva", esto es, como prácticas colectivas compartidas en la que se incluye la práctica individual de las personas específicas que conforman un grupo científico con el fin de producir, aprender y compartir la producción de conocimiento científico.

Es así que la ciencia es susceptible de ser conceptuada como una matriz cultural, pues al hablar de ella se hace referencia al conjunto de condiciones reguladoras y posibilitadoras de las actividades llevadas a cabo por individuos particulares, sujetas a las normas o criterios que establece la comunidad científica, con la finalidad de generar nuevo conocimiento o nuevas representaciones de la realidad, a través de la definición de los hechos propios de su área de conocimiento, los problemas que se reconocen como legítimos, así como las estrategias idóneas de solución (Kuhn, 1971).

Una de las consideraciones inevitables al entender a la ciencia de esta manera, es la continuidad que guarda, como toda matriz cultural, al interior (i.e., con prácticas realizadas en diferentes sistemas científicos) y al exterior de esta (i.e., con las prácticas no científicas que se realizan en otras matrices):

A. Continuidad externa de la ciencia. Viendo a la ciencia como un sistema particular que parte de condiciones particulares específicas, tiene estrecha relación con diferentes sistemas, que pueden o no influir sobre ella, con los que coexiste en una matriz cultural global. El arte, la religión, el deporte, la economía; entre otras, conforman las instituciones y prácticas particulares no científicas que definen este primer tipo de continuidad.

B. Continuidad interna de la ciencia. Haciendo referencia a cada disciplina científica específica que conforman a la ciencia en general, este tipo de continuidad tiene que ver con el lazo que mantiene cada disciplina científica con otras disciplinas científicas. La vinculación que tiene la Psicología con la Biología, la Sociología, las Matemáticas, la Lógica; entre otros, 
proporcionan ejemplos claros de ello. Es importante señalar que todas las ciencias guardan continuidad entre ellas, aunque unas están mayormente relacionadas con otras.

Por otra parte, la conceptuación de ciencia que se presentó, hace necesario reconocer las relaciones varias que se mantienen en las distintas prácticas de una disciplina científica en los diferentes niveles sistemáticos que lo conforman. Kantor no sólo hizo hincapié, de manera decisiva, en que un sistema científico está contenido en otros sistemas que le dan sentido: la matriz cultural, el protosistema y el metasistema. Además de ello, del sistema científico se desprendían otros sistemas donde se departamentalizaba el conocimiento científico, o bien, donde este se aprovechaba o verificaba: los subsistemas, dentro de los que se encontraban los subsistemas aplicados. Todos estos sistemas conformaban, en suma, la matriz científica de una disciplina particular (c.f. Kantor, 1978). En atención a ello, es posible distinguir dos tipos particulares de continuidad en este sentido:

A. Continuidad ascendente de un sistema científico. Tiene que ver con el vínculo de la práctica realizada en el sistema científico con aquellas que se llevan a cabo en el sistema que permite su construcción, significancia, validez y evaluación; y de estas con los sistemas de mayor orden que lo contienen (i.e., la continuidad del sistema con el metasistema, del metasistema con el protosistema, y de este último con la institución cultural).

B. Continuidad descendente de un sistema científico. La cual se puede definir como el vínculo de la práctica en el sistema científico con la práctica realizada en los diversos sistemas (subsistemas) que de este se desprenden, bajo los cuales se organizan tipos específicos de actividades de estudio en campos particulares de acción.

De esos últimos tipos de continuidad de la ciencia nos ocuparemos más adelante; por lo pronto, nos enfocaremos en la continuidad externa e interna de la ciencia, para exponer, grosso modo, la siguiente noción que da sentido a la propuesta que se desarrolla más adelante.

\section{Matriz Científica General: organización sistemática de la continuidad externa e interna de la ciencia}

La serie de conceptualizaciones presentadas en el apartado anterior constituyen el terreno sobre el cual se ha edificado un sistema organizativo que rescata y permite analizar las relaciones de continuidad que mantienen las diferentes prácticas en ciencia. Este sistema, denominado Matriz Científica General-MCG- (Hernández, 2013), más allá de clasificar tipos de ciencia, organiza y relaciona las diferentes prácticas que caracterizan, en mayor o menor medida, cada disciplina en particular.

De acuerdo a Hernández (2013) la organización de las diversas disciplinas consideradas en la $M C G$, se realiza tomando el tipo de actividad que en mayor medida se realiza y la función que cumple dentro de la matriz. De esta forma se derivan cinco tipos de actividades: filosófica, teórica, tecnológica, profesional, interdisciplinar y transdiciplinar (ver Figura 1). Luego entonces, esta matriz abarca todas las disciplinas científicas (las filosóficas, factuales, tecnológicas, profesionales, humanas y sociales) que: a) se caractericen por realizar mayoritariamente un tipo de actividad particular; o bien; b) que dada la definición de su objeto de estudio, transitan por todas las actividades definidas 
en la matriz. Es así que la matriz representa una descripción de las relaciones de continuidad que mantienen las prácticas realizadas en ciencia, con las actividades de matrices culturales e incluso con las realizadas en otras disciplinas como la lógica o la matemática; esto es, con prácticas al exterior e interior de ella.

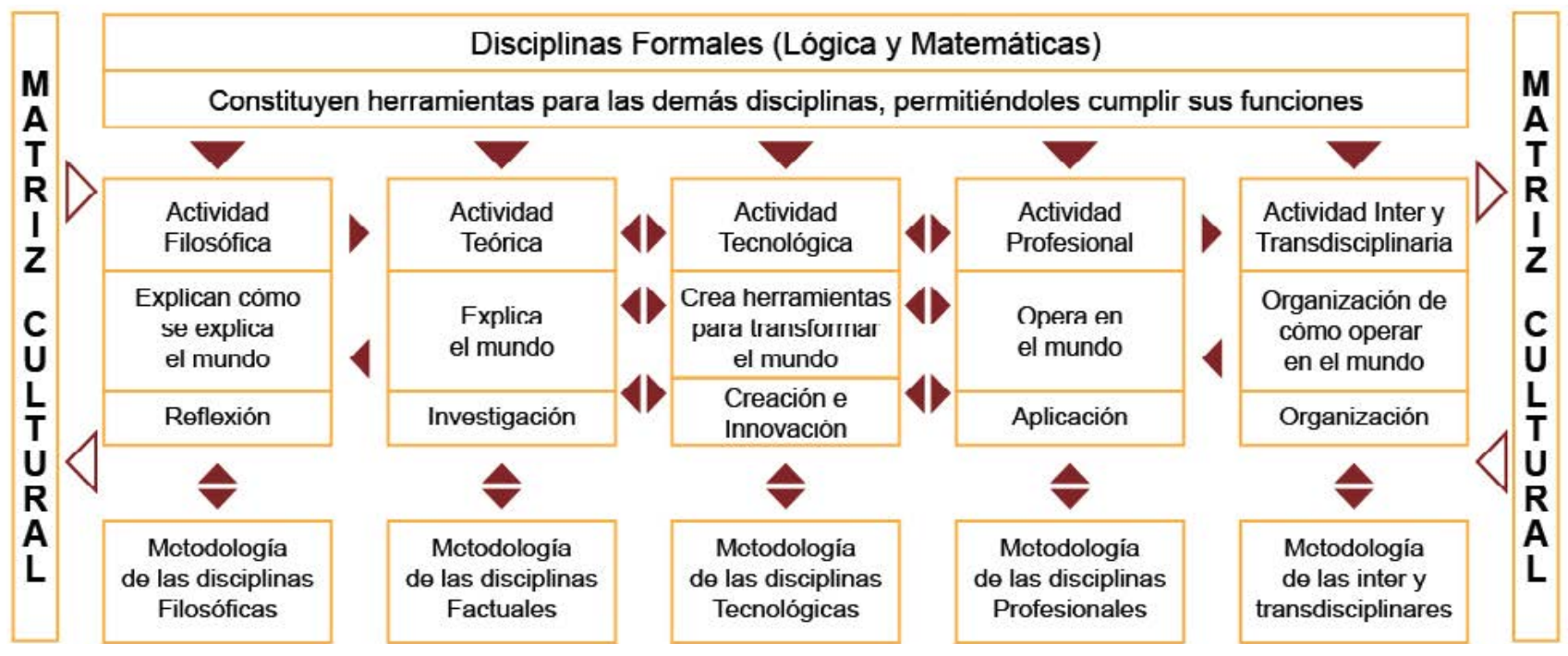

Figura 1. Matriz Científica General (adaptación realizada por Hernández y Reyna, 2015; a partir de Hernández, 2013).

No es la intención de este trabajo presentar a fondo la $M C G^{1}$, basta con señalar que una de las suposiciones que subyacen a dicha matriz, es que la actividad científica no consiste en un sólo tipo de práctica y, en efecto, no es aislada; sino que al menos existen cinco tipos de prácticas particulares que se realizan dentro de la ciencia, las cuales guardan estrechos vínculos y relaciones entre sí, afectándose e influyéndose unas a otras, en menor o mayor medida (Hernández y Reyna, 2015):

1. Actividad filosófica. Engloba aquellas prácticas que generalmente son conocidas como ontología, epistemología y filosofía de la ciencia. En términos generales el tipo de práctica característica es la reflexión sobre cómo la ciencia explica el segmento del mundo que pretende explicar; es decir, explicar cómo los científicos explican el mundo.

2. Actividad teórica. Tiene que ver con la comprensión de segmentos del mundo previamente delimitados, con la finalidad de generar interpretaciones o explicaciones de ello, en forma de teorías o leyes producto de la investigación y abstracción sistemática. La práctica definitoria es el análisis de los eventos particulares que en la actividad filosófica se definieron como pertinentes, con el fin de explicar de manera ordenada el "mundo" o "realidad". 
3. Actividad tecnológica. Se desarrolla primordialmente en ámbitos sociales definidos donde existe una demanda extra-científica a resolver y para lo cual genera instrumentos o procedimientos. De esta manera, la práctica definitoria es la creación de herramientas con las que se pretende el control y modificación de los fenómenos, aprovechando las teorías y leyes científicas para su aplicación a través de la síntesis de dicho conocimiento. De lo anterior se desprende que toda actividad tecnológica tenga la función de inventar o construir.

4. Actividad profesional. Se caracteriza por la aplicación de las herramientas, instrumentos y procedimientos generados en la actividad tecnológica, para la resolución de una problemática particular en un ámbito definido y delimitado por una institución social. Su finalidad es operar en el mundo.

5. Actividad interdisciplinar y transdiciplinar. Tiene como interés buscar la mejor manera de operar en un ámbito determinado, a través de la coordinación de diferentes disciplinas que en menor o mayor medida pueden proporcionar conocimiento, herramientas o tipos particulares de acción para solucionar un problema característico del ámbito que demande su actuar. La práctica definitoria es la organización de disciplinas con la finalidad de estructurar cómo operar en un ámbito determinado.

Por otra parte, otro de los beneficios de la $M C G$, dada la organización, distinción y definición de las prácticas que reconoce, es que es susceptible de ser aplicada al análisis de las particularidades de una disciplina específica, ya sea para ubicarla dentro de la matriz, o bien, para caracterizar los diferentes tipos de prácticas realizados en esta (Hernández y Reyna, 2015).

Por supuesto, la Psicología, -o más propiamente: las diferentes actividades del psicólogo-, es susceptible de ser analizada bajo la MCG, con miras a organizar las actividades que dentro de esta se realizan, así como distinguir puntualmente cada una de ellas; sin embargo, es preciso advertir que dicho análisis no se puede realizar a la Psicología en general; por el contrario, dado que la matriz organiza prácticas científicas y sus relaciones, sólo puede realizarse si: a) se trata de un sistema científico psicológico delimitado y diferenciado onto-epistemológicamente; b) guarda continuidad con los eventos que trata y con otras matrices culturales en los términos descritos líneas arriba y c) define sus ámbitos de aplicación y las relaciones, -igualmente continuas-, con el sistema teórico.

Partiendo de lo anterior, en el siguiente apartado se presenta un ejercicio de aplicación de la MCG, al sistema científico que cumple con los criterios mencionados: la Psicología Interconductual.

\section{La Psicología Interconductual como matriz cultural}

Jacob Robert Kantor, a quien se le puede considerar un filósofo de la Psicología (Ribes, 1994); no sólo definió y delimitó el objeto de estudio de la Psicología; además, estableció los límites y características particulares del dominio de la ciencia psicológica; definió cómo construir un sistema para describir y estudiar lo psicológico; y especificó los subsistemas de desarrollo de la Psicología, a partir de la departamentalización o especificación del sistema teórico (c.f., Kantor, 1924-1926; Kantor, 1978; Kantor y Smith, 2015). Presentar detalladamente la propuesta de Kantor escapa al objetivo de este trabajo; sin embargo, es indispensable analizar un aspecto fundamental de la Psicología 
Interconductual tal como la formuló Kantor: sus relaciones de continuidad. Lo cual da sentido a la propuesta que se presenta más adelante.

\section{Continuidad de la Psicología Interconductual}

Toda ciencia edifica sus constructos y proposiciones a partir del contacto con los eventos. Cuando la construcción científica se mantiene dentro de los límites del continuo Interconductual, además de determinar su validez, hace posible su vinculación con otras ciencias (Kantor, 1978). La Psicología Interconductual, al construirse considerando siempre la continuidad de sus proposiciones con los eventos, es susceptible de relacionarla con otras ciencias e incluso con otro tipo de actividades no científicas.

Si bien Kantor no hizo explicitas concretamente cuáles eran las relaciones de continuidad del Interconductismo con matrices culturales no científicas; es fácil suponer que, al igual que la ciencia en general, no existe como modo de conocimiento al margen de un contexto cultural particular que, por un lado, ha posibilitado o limitado su edificación y desarrollo; y por otro, en el que confluyen prácticas no científicas que pueden o no influir sobre ella. Kantor (1978) siempre consideró que los eventos que forman parte de la matriz cultural sobre los que se desarrolla una ciencia son el material de trabajo para el científico. No es gratuito, en este sentido, el análisis de Kantor (1933) y de Kantor y Smith (2015) de interacciones de percepción, emocionales, sentimentales, implícitas, intelectuales, aprendizaje, etcétera; si bien pretendía encarar de una forma diferente problemas, investigaciones y descripciones clásicas de la Psicología de su época, la descripción que hace de ellos es siempre referida a eventos presentes en la matriz cultural sobre la que se desarrolló el Interconductismo. Otro ejemplo de ello lo proporciona las creencias y suposiciones místicas, religiosas y creacionistas de las que Kantor siempre insistió liberar a la Psicología; a final de cuentas todas estas suposiciones eran tipos de Interconducta particulares existentes en la matriz sobre la que se desarrolló la Psicología Interconductual.

Por otra parte, haciendo referencia a la especificación de cada ciencia particular, todas ellas forman parte de lo que podríamos llamar el continuo científico general, en el que confluyen y están vinculadas todas las ciencias, como la Física, la Química, la Biología, entre otras; en el que la Psicología guarda continuidad con ellas. Por ello, es que Kantor hace mención de las relaciones de la Psicología con otras ciencias. Podemos organizar estas relaciones en dos niveles: el primero de ellos, tiene que ver con la selección de eventos psicológicos de otros dominios científicos, con los que se pueden crear diversas especializaciones o subsistemas ( $v$. gr., biopsicología, psicofisiología, cultoropsicología, zoopsicología, psicovarianza, psicolingüística, entre otros). El segundo nivel tiene que ver con lo que Kantor (1978) refería como las características comunes entre cada ciencia; pues al derivarse las ciencias de matrices culturales similares y al tratar con los eventos contenidos en ella, todas están conectadas e influenciadas unas con otras, de tal manera que pueden usar procedimientos comparables de observación, análisis e interpretación de ocurrencias singulares; pueden colaborar para enfrentar un problema general; o bien, un hallazgo en una, puede influir en otra. De ello se desprende los señalamientos de Kantor (1978) y de Kantor y Smith (2015) acerca de las relaciones de la Psicología con las Matemáticas, la Física, la Química, la Biología y la Antropología. 
Ahora bien, de la misma manera en que la Psicología Interconductual está estrechamente vinculada al exterior de ella, en ese mismo sentido lo está al interior de ella, en este caso, como sistema científico, con sistemas que lo fundamentan y con aquellos de los que es fundamento. La labor de Kantor en este tenor, fue la de imprimirle continuidad a dichos sistemas, tomando siempre como punto de partida y de regreso los eventos naturales con los que trata la Psicología.

Partiendo de lo anterior, y recuperando las nociones de continuidad ascendente y descendente del sistema científico descrito líneas arriba, es posible describir los vínculos al interior del sistema Interconductual considerando las relaciones que guarda con: a) sistemas anteriores de los que se desprende, los cuales parten del contacto con los eventos y sienta las bases para que el sistema teórico pueda comprenderlos y explicarlos; y b) con sistemas subsecuentes que se desprenden del sistema teórico Interconductual y que tratan con los eventos en aras de controlarlos o modificarlos:

A. Continuidad ascendente. De acuerdo con Kantor, para la construcción, significancia, validez y evaluación del Interconductismo, sólo es posible a través de un sistema que lo contenga donde estipulen las suposiciones básicas sobre lo psicológico (i.e., el metasistema), el cual, a su vez, está contenido en otro sistema donde se hacen explicitas las suposiciones respecto a la naturaleza de la ciencia para la formulación de definiciones y especificaciones para el sistema científico (i.e., protosistema o lógica de la ciencia) que, asimismo, depende de otro sistema, sobre el cual se edifica y se convierte en la condición que da orientación y posibilita su existencia (i.e., la institución cultura). A la relación del sistema científico con dichos sistemas de orden superior es lo que en este contexto se define como continuidad ascendente.

B. Continuidad descendente. Para Kantor el fin de toda ciencia es la descripción, la explicación, la predicción y control de los eventos. Las dos primeras son tareas del sistema teórico, mientras que las últimas son tareas de los subsistemas aplicados (Hayes, 1994). Estos subsistemas, para Kantor, se localizan dentro de la empresa científica, donde se aplican los principios generales del sistema teórico y cuya relación con este es bidireccional: la aplicación se "nutre" de la teoría, mientras que la verificación y explotación del conocimiento psicológico en los campos aplicados puede tener un impacto en el ejercicio explicativo de la Interconducta, promoviendo un cambio en el sistema general. En la propuesta de Kantor, los subsistemas aplicados son dominios especializados de la Psicología donde se aprovechan o verifican principios generales pero particularizados a dicho dominio específico, llevando a la práctica reglas de operación derivadas de la sistematización del campo científico general. Básicamente podemos distinguir dos tipos de actividades definidas por Kantor dentro de los subsistemas aplicados: la construcción de herramientas, técnicas y procedimientos; y la manipulación práctica de estas construcciones, en dominios especializados, para la modificación de un evento psicológico.

Bajo este contexto, es que no es extraño sostener que la Psicología Interconductual, es en suma una matriz cultural científica, la cual establece las normas o criterios que regulan y posibilitan las actividades que son llevadas a cabo por individuos particulares, llamados psicólogos, cuya finalidad es explicar y modificar las interacciones psicológicas. Ello da sentido a la aplicación de la MCG al caso de la Psicología. Empero, antes de presentar dicha aplicación y para dar mayor fuerza a la 
aseveración anterior, es necesario hacer mención, de modo breve, de cómo el Interconductismo se ha desarrollado, posibilitando la diversificación de las prácticas que han tenido lugar, -insistimosbajo la etiqueta de Interconductual.

\section{Práctica y desarrollo de la Psicología Interconductual}

La propuesta metateórica que Kantor desarrolló se ha convertido en el terreno sobre el cual se han edificado propuestas teóricas psicológicas en aras de definir categorías susceptibles de derivarse en lenguaje de datos con proyección empírica para la producción de explicaciones y leyes en torno al comportamiento.

Sin soslayar otras construcciones teóricas Interconductuales que parten de las proposiciones kantorianas ( $v$. gr., Roca, 1993; 1997; 2006), la obra que ha promovido en mayor medida el desarrollo y práctica de la Psicología Interconductual entre los hablantes de lengua hispana es Teoría de la Conducta, un análisis de campo y paramétrico (Ribes y López, 1985). Esta propuesta teórica ha permitido el desarrollo del ejercicio de la Psicología Interconductual en diferentes ámbitos teóricos o aplicados, dando lugar a la diversificación de las prácticas dirigidas a la producción de datos o a la modificación de eventos particulares. Hacer siquiera un concentrado de dichos avances demanda un trabajo exhaustivo aparte; sin embargo, podemos hacer un listado genérico de los diferentes ejercicios en los que la Psicología Interconductual se ha desarrollado:

A. Investigación experimental de las funciones Interconductuales. Estudio para dar sustento, refinar o modificar las categorías de cada una de las funciones descritas en la taxonomía de Ribes y López (1985).

B. Análisis histórico-conceptual. Análisis complementario a la investigación experimental; con la finalidad de delimitar la aplicabilidad y pertinencia de categorías del lenguaje ordinario y lenguaje técnico en la teoría psicológica.

C. Investigación experimental del desarrollo psicológico e individuación. Distingue la teoría de los procesos conductuales, de la estructuración del comportamiento en situaciones ecológicas o sociales donde hay demandas a cumplir, y de la forma idiosincrásica de relación de un individuo particular.

D. Investigación del desarrollo psicológico en ámbitos sociales. Estudio de la inteligencia, como categoría lógicamente análoga a la de competencia, para promover el desempeño efectivo en ámbitos sociales como el educativo.

E. Análisis de la dimensión psicológica en problemas sociales. Bajo el supuesto de que todo problema social tiene una dimensión psicológica, se analiza dicha dimensión en escenarios de acción social para el análisis de problemas particulares en estos ámbitos ( $v$. gr., el educativo, el hospitalario, el organizacional, entre otros).

F. Regulación de la dimensión psicológica en problemas sociales. Intervenciones particulares para solucionar demandas específicas en ámbitos socialmente delimitados. 
G. Solución de problemas individuales en el "ámbito clínico". Tomando como referencia los criterios y valoraciones de las prácticas sociales, se analizan y modifican problemas individuales en el "ámbito clínico".

H. Estudio de dimensiones sociales en las que tiene lugar el comportamiento individual. Análisis de las dimensiones políticas, morales y económicas, características de las dinámicas sociales, en los que el comportamiento tiene lugar, como medios de contacto que posibilitan diversas formas de relación social.

El listado anterior hace patente un aspecto fundamental del cual parte este trabajo: cuando se habla de Psicología Interconductual, no como un producto científico, sino como un tipo de relación y visión particular de y con los eventos definidos como psicológicos, no se hace referencia a un solo tipo de práctica. Por el contrario, existen prácticas psicológicas Interconductuales diferentes, cuya característica común en todas ellas es el análisis y modificación de la Interconducta tal como la definió Kantor. De hecho, si tuviéramos que decir lo anterior en palabras de este autor, diríamos que la Psicología Interconductual, como matriz científica particular, y las prácticas específicas que realizan los psicólogos Interconductuales, son un todo homogéneo y continuo compuesto por puntos particulares, distintos entre sí sólo en detalle.

Es necesario precisar, que todos los trabajos que se han realizado bajo el cobijo de la Psicología Interconductual, no son ni contrastables, equiparables o contradictorios, como si se tratara de un solo tipo de práctica realizada en ellos: son ejercicios diferenciados y particulares que responden a la lógica del sistema psicológico que se ha venido planteando. Por ello, cada práctica debe ser evaluada o analizada en su justa dimensión. Esto hace totalmente necesaria una matriz, como la MCG, que permita diferenciar, analizar y evaluar pertinentemente cada práctica dadas sus características específicas que las delinean como tipos de actividades distintivas. Dicha labor, se desarrolla a continuación.

\section{Matriz Científica Interconductual}

Partiendo de la matriz antes descrita y de la posibilidad de organizar y caracterizar las diferentes prácticas en Psicología Interconductual, a continuación se presenta un ejercicio de aplicación de dicha matriz al caso de la Psicología (ver Figura 2). Con ello se logra la edificación de una matriz particular para la disciplina, donde se reconozcan los vínculos entre cada práctica, así como la relación de la Psicología con otras matrices científicas y no científicas. Genéricamente podemos denominarla como Matriz Científica Interconductual, en aras de resaltar el carácter cultural de la ciencia psicológica y su particularidad como postura psicológica científica ordenada y coherente.

En términos generales en la matriz se reconocen, cuando menos, cinco tipos de prácticas diferentes, a saber: la filosófica, la teórica, la tecnológica, la profesional y la transdiciplinar. Todas ellas están vinculadas en diferentes grados y ninguna de ellas es ajena o independiente de las otras. Por ejemplo, la práctica profesional no está para nada aislada o totalmente alejada de la filosófica: la actividad profesional puede generar nuevos planteamientos a la práctica filosófica, a la vez que puede nutrirse de esta para guiar y refinar su actuar como profesión. Lo mismo ocurre con las demás prácticas. 
Como es el caso de la MCG, cada tipo de actividad está caracterizada y diferenciada de otras por la función que cumple y por la actividad distintiva. Así, por ejemplo, la función de la práctica teórica es explicar la Interconducta siendo la actividad analítica su característica definitoria. Por supuesto que ambos aspectos no son exclusivos de dicha práctica; sin embargo, se puede decir que es la que se realiza en mayor medida y por tanto le da sentido. En la Figura 2, se puede apreciar la función y tipo de actividad característica de cada práctica considerada en la matriz. Otro de los aspectos que se pueden apreciar, es que los recuadros que están por encima y debajo de la matriz, representan otras matrices científicas, como la Química, la Biología, la Física, con las que la Psicología puede y tiene vinculación. Por otra parte, los recuadros que se representan a los extremos, simbolizan otras matrices culturales no científicas como la Economía y la Política, que de igual forma están vinculadas con la práctica científica psicológica y que pueden o no influir sobre ella.

Con estos aspectos descritos, se ilustran las relaciones de continuidad que la práctica Interconductual, como matriz disciplinaria específica, guardan tanto al interior como al exterior de ella, así como la continuidad ascendente y descendente del sistema teórico Interconductual, tal como se analizó líneas arriba.

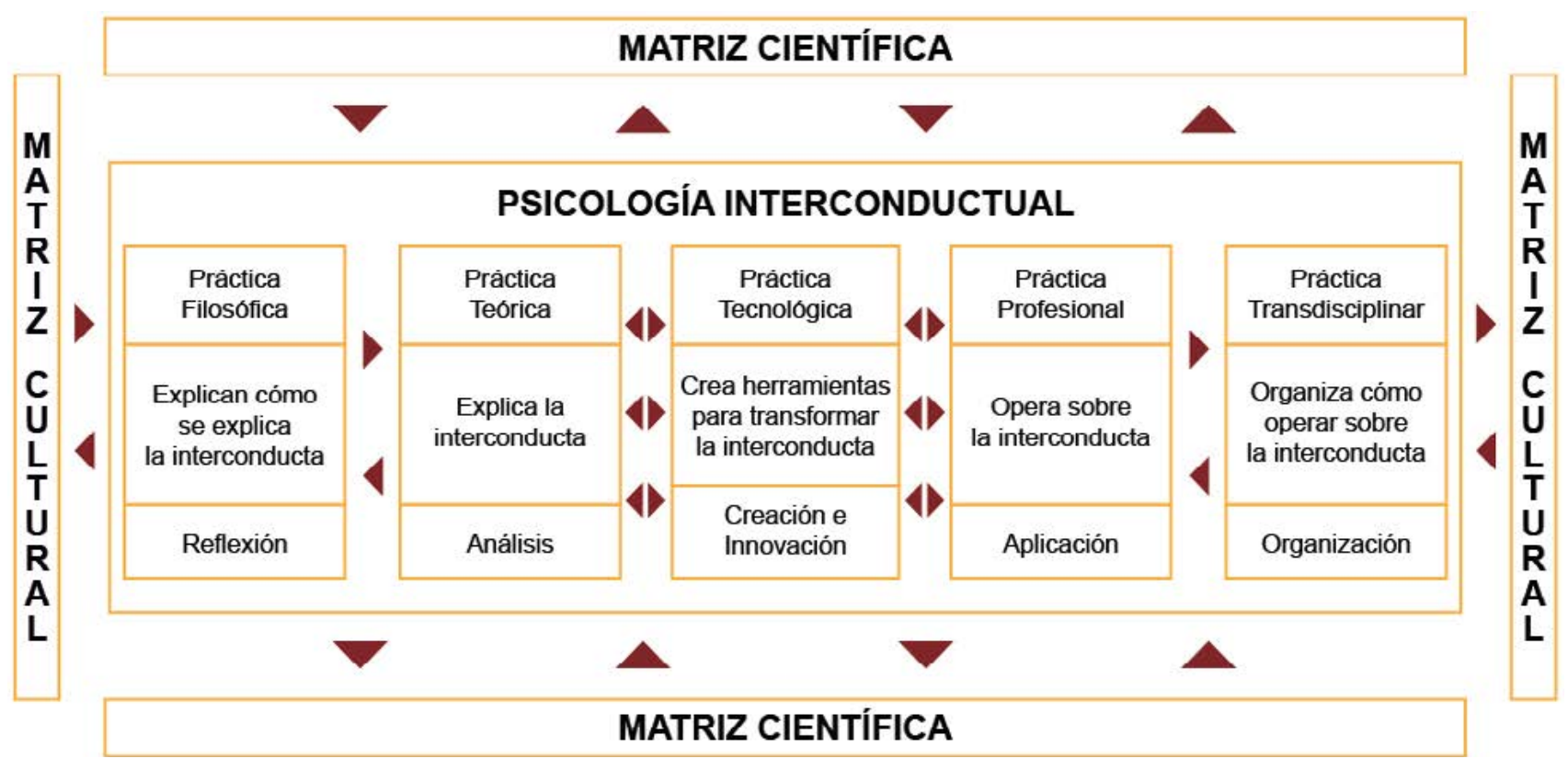

Figura 2. Matriz Científica Interconductual.

\section{Características definitorias de las distintas prácticas en Psicología}

Cada práctica considerada en la matriz tiene características especiales que le imprimen singularidad. Los criterios básicos considerados para dicha singularidad son: el tipo de actividad definitoria y la función que cumplen. Tomando lo anterior como punto de partida, se generaron otros criterios que permiten analizar y evaluar cada práctica considerada en la matriz. Si bien, dichos criterios fueron inicialmente pensados con miras a delinear y analizar en qué consiste la práctica profesional del psicólogo y sus funciones (Hernández y Reyna, 2015), son perfectamente aplicables a la caracterización de las demás prácticas de la matriz: 
A. Tipo de actividad. Básicamente se analiza el qué se hace en mayor medida al hacer referencia a cada tipo de práctica en particular.

B. Finalidad o función. Cada actividad realizada en cada práctica adquiere un sentido particular distinto al de otras prácticas. En términos generales este criterio hace referencia al porqué del hacer particular distintivo de cada práctica de la matriz.

C. Sistema o ámbito al que se ajusta. Cada práctica ajusta su actividad a reglas de operación particulares que son emanadas de un sistema o ámbito que le da cobertura. Con esta categoría, por un lado se analiza a qué sistema o ámbito se ajusta la actividad realizada en cada práctica; por otra parte, permite resaltar el carácter continuo de cada práctica debido a que delimita las relaciones de cada práctica entre sí (i.e., si se corresponde con la lógica y supuestos del sistema general así como del sistema que lo precede y que lo fundamenta).

D. Material de trabajo. Con ello se refiere a las cosas o eventos con los que se trata en cada tipo de práctica.

E. Tipo de lenguaje. Comprende los conceptos y categorías propios de cada práctica y que tienen sentido sólo al interior de cada una de ellas. Es importante aclarar que aunque una palabra puede ser usada en diferentes prácticas, su sentido es diferente. Al margen de ello, lo importante es que dichas categorías y expresiones se correspondan con la práctica particular que se esté realizando.

F. Fines de la investigación. En todas las prácticas reconocidas en la matriz se puede y se hace investigación; sin embargo, y a pesar de que los métodos, variables o técnicas de investigación usadas pueden ser parecidos, su orientación es diferente y persigue fines particulares en cada práctica. Con este criterio se analiza cuál es la finalidad de la investigación realizada en cada una de ellas.

Partiendo de estos criterios, en los apartados siguientes se presenta la caracterización de cada práctica que se considera en la Matriz Científica Interconductual.

\section{Práctica Filosófica}

Los postulados filosóficos han influido notoriamente sobre la edificación de un sistema científico psicológico (Montgomery, 2007). La intención de recurrir a la práctica filosófica es para dar fundamento, pertinencia y validez a la construcción de teorías y sistemas científicos (Kantor, 1978). Teniendo esto en cuenta se puede caracterizar esta práctica filosófica de la siguiente manera:

Tipo de actividad. La reflexión es la actividad característica de esta práctica, la cual consiste, siguiendo a Tomasini (1998), en un examen de los conceptos que emanan de los distintos simbolismos (como las estipulaciones y suposiciones científicas) y del lenguaje natural en general. En el caso particular de la ciencia Interconductual, por un lado, consiste en el análisis detenido de la lógica, proposiciones y supuestos que dan sentido a la manera en cómo se concibe la Interconducta y, derivado de ello, el cómo se pretende explicarla. Por otra parte, comprende el análisis conceptual de los términos o expresiones que se vuelven problemas de investigación, en aras de deslindar los genuinos problemas para la Psicología, de los sinsentidos que pueden permearla (Tomasini, 2004). 
Finalidad o función. Esta práctica está dirigida a explicar las normas que rigen la pertinencia de las prácticas en un contexto particular (Tomasini, 1998), por ello es que tiene la finalidad de explicar cómo se explica la Interconducta; esto es, en palabras de Kantor (1978): describir y presentar los supuestos básicos y sus antecedentes, así como su impacto en la construcción de teorías y sistemas. Con ello se logra establecer los límites y lógica categorial del sistema científico de la Psicología Interconductual.

Sistema o ámbito al que se ajusta. En lo que respecta al análisis de la lógica, proposiciones y supuestos del sistema Interconductual, la práctica se enmarca en el protosistema y el metasistema, esto es, la serie de lineamientos que establece Kantor en cuanto a la lógica de la ciencia Interconductual y a la construcción científica psicológica. Por otra parte, el análisis conceptual se ajusta la matriz cultural donde se usan de expresiones psicológicas, como práctica contextuada, por parte de los hablantes del lenguaje ordinario, por lo que los lineamientos de la filosofía de la Psicología (c.f., Montgomery, 2007; Tomasini, 2004) comprenden el marco de referencia que delimita la actividad reflexiva y los fines característicos de este tipo de práctica.

Material de trabajo. En la opinión de Tomasini (1998) la práctica filosófica es una actividad intelectual que depende de y trata con otras actividades como la religión, la política, la moral o la ciencia. En el caso particular de la así llamada filosofía de la ciencia, trata con la serie de lineamientos y conceptos teóricos y metodológicos que dan sentido y delimitan la práctica teórica (Montgomery, 2007); en este tenor, el material de trabajo de la práctica filosófica en Psicología Interconductual son los conceptos, teorías, métodos, leyes y criterios, propios de la práctica teórica; así como los diferentes términos referentes a la vida mental de la práctica cotidiana.

Tipo de lenguaje. La práctica filosófica está ligada al lenguaje, es decir, a formas de expresión prevalecientes en una matriz cultural particular (sea científica o no científica). Por ello, el lenguaje característico en esta práctica es un metalenguaje: un lenguaje que versa, trata y describe otros lenguajes (Ackoff, 2002). En este caso el metalenguaje de la Psicología es un lenguaje que trata, por un lado, acerca del lenguaje (conceptos y categorías) del sistema psicológico; y, por otra parte, sobre el lenguaje de los eventos naturales materia de trabajo de la Psicología: el lenguaje ordinario que hace referencia a la vida mental de las personas y sus actividades (c.f., Ribes, 2010; Tomasini, 2004).

Fines de la investigación. Una de las características primordiales de la práctica filosófica es la investigación conceptual, la cual consiste a grandes rasgos, en el rastreo de usos y expresiones para poder extraer las reglas que rigen sus límites y aplicaciones pertinentes. Por ello, la investigación en esta práctica está dirigida, en general, a establecer los límites y lógica categorial del sistema teórico; y en particular, el estatuto lógico y reglas de aplicación de conceptos, criterios, métodos y teorías del sistema Interconductual.

\section{Práctica Teórica}

Teorizar es siempre una actividad analítica, abstracta, cuyo producto fundamental es el establecimiento de leyes generales para comprender y explicar los eventos pertinentes de estudio para una ciencia en particular (Kantor, 1933; Ribes y López, 1985). En el caso de la Psicología, teorizar tiene que ver con la generación de leyes sobre el comportamiento que sirvan de base para la 
comprensión y explicación de los eventos psicológicos. Es importante señalar que la práctica teórica Interconductual, se ha llevado a cabo de distintas maneras y en diferentes dimensiones ${ }^{3}$; las cuales se pueden organizar en los tres primeros niveles propuestos por Díaz-González y Carpio (1996) de adaptación del conocimiento psicológico, a saber: a) Teoría general de la Conducta o de los procesos conductuales; b) investigación de la conducta humana derivada de la Teoría de la Conducta (i.e., teoría del desarrollo e individuación) y c) creación de modelos psicológicos de instituciones sociales; es decir, modelos donde se delimite la dimensión psicológica (de la salud, educación, laboral, del deporte) adecuados a las diversas instituciones sociales prestatarias de los servicios psicológicos.

Recuperar estos niveles es útil para este trabajo dado que facilita la caracterización de la práctica teórica Interconductual, puesto que, a pesar de que cada uno de esos niveles tienen particularidades especiales y están dirigidas a abarcar aspectos específicos de interés para cualesquier teoría del comportamiento, comparten como característica particular la generación de conocimiento en torno a los eventos psicológicos (i.e., leyes y teorías sobre la Interconducta). De esta manera la práctica teórica queda caracterizada de la siguiente forma:

Tipo de actividad. El análisis de eventos psicológicos es la actividad fundamental que se realiza en este tipo de práctica. Analizar en este contexto, se entiende como una actividad dirigida a conocer la estructura, operación y composición de los eventos pertinentes de estudio; en este caso el de la Interconducta. El análisis puede ser de la Interconducta en general (i.e., el análisis de los factores que posibilitan que se establezca); o bien, de los diferentes tipos de Interconductas particulares (v. gr., comprensión, emociones, motivación, inteligencia, etc.).

Finalidad o función. La actividad realizada va dirigida hacia la explicación de la Interconducta. A decir de Kantor (1978), la finalidad del análisis de los eventos es comprenderlos, por ello, explicar tiene que ver con sistematizar los eventos psicológicos, interrelacionando sus factores componentes en las situaciones en que ocurren para generar conocimiento acerca de estos.

Sistema o ámbito al que se ajusta. Sin perder de vista la distinción de los tres niveles mencionados anteriormente, la serie de actividades analíticas realizadas en esta práctica se ajustan a los criterios estipulados en el sistema científico en cuanto a investigación y generación de datos. Los dos primeros niveles mencionados (i.e., Teoría de la Conducta y teoría del desarrollo e individuación) ajustan su actividad principalmente al sistema teórico: el primero de manera exclusiva, el segundo aplicando o adaptando dicho sistema a situaciones particulares donde existen criterios de logro a satisfacer. Por su parte, en el tercer nivel (i.e., creación de modelos psicológicos de instituciones sociales), derivado del nivel anterior, la actividad se ajusta, además del sistema teórico, a los factores propios de la institución social donde se delimita la dimensión pertinente de análisis para el psicólogo.

3 Estas maneras y dimensiones de realizar práctica teórica son: a) investigación experimental de las funciones Interconductuales, b) investigación experimental del desarrollo psicológico e individuación, c) investigación del desarrollo psicológico en ámbitos sociales y d) análisis de la dimensión psicológica en problemas sociales. A pesar de las diferencias entre ellas, comparten como característica común que el fin que se persigue es explicar la Interconducta. 
Material de trabajo. Si la actividad característica de la práctica teórica es el análisis y su finalidad es la generación de leyes para explicar y comprender la Interconducta, entonces los eventos con los que trata así como su material de trabajo, se corresponden con las abstracciones producto de la sistematización de las regularidades de diferentes casos específicos, sin referirse a ninguno de ellos en particular. De esta manera, los eventos psicológicos sistematizados, -en los tres niveles mencionados-, se convierten en el material de trabajo del teórico, a partir de los cuales genera investigación para explicar el comportamiento (Kantor, 1978).

Tipo de lenguaje. Recuperando los señalamientos de Díaz-González y Carpio (1996), el lenguaje característico de este tipo de práctica es analítico, es decir un lenguaje que versa sobre operaciones o interrelaciones generales resaltando los factores relevantes de estos. En lo que respecta a la teoría general del comportamiento y del comportamiento humano, el lenguaje analítico característico es abstracto, es decir, constituye propiedades genéricas resultado de abstraer de los objetos y eventos regularidades y propiedades comunes. En lo que respecta a la generación de modelos psicológicos, el lenguaje es analítico-sintético, es decir, es el resultado de la adaptación del conocimiento analítico a situaciones concretas y singulares (v. gr., competencias docentes, ajuste lector, conductas de riesgo).

Fines de la investigación. La investigación característica de esta práctica va dirigida hacia la generación de teorías y leyes acerca de la Interconducta que permitan comprenderla y explicarla (Ribes y López, 1985).

\section{Práctica Tecnológica}

De acuerdo con Kantor (1978), la práctica tecnológica consiste de manipulaciones precisas para realizar adaptaciones o mejoras en situaciones o dominios sociales especializados. Por ello, la Interconducta tecnológica se caracteriza por la construcción o invención de técnicas, procedimientos o instrumentos, para generar mejoras o adaptaciones de interacciones prácticas contextuadas en ámbitos específicos donde se delimitan: a) los criterios valorativos que dan sentido a que una interacción particular sea un problema que deba resolverse, $b$ ) el contexto socio-cultural que estipula las normas propias de dichas prácticas sociales y que delimitan las posibilidades de acción del psicólogo, y c) las disciplinas relacionadas en ese campo (Rodríguez, 2003). Es así que esta práctica se corresponde al último nivel delimitado por Díaz-González y Carpio (1996) de adaptación del conocimiento psicológico a problemas específicos: metodologías integradoras a modo de herramientas aplicables. Partiendo de estas consideraciones, las características de la práctica tecnológica son las siguientes:

Tipo de actividad. La actividad característica de esta práctica es la creación, innovación de herramientas particulares; es decir, la construcción de técnicas, procedimientos e instrumentos para dar respuesta a una problemática particular, a partir de modelos de actuación psicológica disponibles o generados con la intención de trasladar el conocimiento psicológico a un ámbito no psicológico.

Finalidad o función. La construcción de los procedimientos de modificación o evaluación mencionados, persigue el fin de crear herramientas para modificar la Interconducta.

Sistema o ámbito al que se ajusta. La práctica tecnológica ajusta su actividad a dos sistemas diferentes que lo regulan: a) el modelo donde se delimita la dimensión psicológica de una institución social, b) la serie de normas y criterios estipulados en el ámbito social de acción. De esta 
manera, la creación de una herramienta sólo tiene sentido cuando la actividad se ajusta tanto al modelo psicológico en cuestión, como a la normatividad del ámbito social. Ambos sistemas o ámbitos, conforman lo que podríamos llamar el sistema tecnológico.

Material de trabajo. Las demandas sociales es la materia con la que trata la actividad tecnológica. Evidentemente el psicólogo debe delimitar su dimensión de análisis de dichas demandas, la correspondiente al comportamiento individual; sin embargo, el estudio, intervención y generación de herramientas, sólo tiene sentido a la luz de la valoración social que se haga de ellos (Rodríguez, 2003). Por ejemplo, "la deserción escolar" es una demanda social que, entre otras dimensiones, está conformada por personas que se relacionan de cierta forma en circunstancias específicas, por ello, construir una herramienta para evaluar o modificar dichas relaciones sólo tiene sentido en el contexto de dicha demanda impuesta.

Tipo de lenguaje. El lenguaje en este caso es sintético: el resultado de la adaptación del lenguaje analítico-sintético de los modelos psicológicos, ya no a situaciones particulares, sino a casos, objetos o eventos únicos y singulares de dichas situaciones concretas, de manera tal que es un lenguaje que vincula las categorías usadas en los modelos psicológicos o de identificación de la dimensión comportamental y las herramientas aplicables (Díaz-González y Carpio, 1996). Categorías como prácticas recreativas, hábitos de estudio, adherencia a la dieta, lectura estratégica, relaciones familiares, bienestar, entre otras, son ejemplos de este tipo de lenguaje.

Fines de la investigación. En la investigación tecnológica, se eligen variables y relaciones que se vinculan de manera directa, mediata o inmediatamente, con algún problema práctico en aras de modificarlo. En ocasiones este tipo de práctica puede generar aportaciones a la práctica teórica (Marx \& Hillix, 1976) la cual tiene como fin crear, mejorar, inventar o adaptar técnicas, procedimientos e instrumentos a las características peculiares de la demanda social en cuestión.

\section{Práctica Profesional}

Antes de caracterizar esta práctica es necesario realizar algunas aclaraciones. En primer lugar, se debe considerar que las profesiones se caracterizan por ser un conglomerado de técnicas y procedimientos de intervención o evaluación específicos para enfrentar y resolver problemas sociales definidos y propios de dicha profesión; en este sentido, hablar de la Psicología como si fuese una profesión incurriría en el error de pensar que existen problemas psicológicos genuinos y perfectamente identificables en las diversas dinámicas sociales. Sin embargo, en las dinámicas sociales, los eventos se pueden analizar considerando diferentes dimensiones ( $v$. gr., factores económicos, ambientes físicos, condiciones biológicas, contextos culturales, entre otros); entre las que se encuentra la dimensión del comportamiento individual, es decir, una dimensión psicológica. Por ello, vale la pena reiterar que la caracterización que se ha venido realizando no es de disciplinas, sino de prácticas concretas. Al caracterizar la práctica profesional en Psicología no se asume que esta sea una profesión. Simplemente se da por hecho la actividad de psicólogos en campos sociales donde se delimitan problemas según criterios morales, económicos, políticos, etc., los cuales están constituidos, entre otras dimensiones, por una psicológica. De esta manera, la actividad profesional psicológica se limita a los eventos psicológicos que conforman las demandas sociales y trata con ellos en ámbitos no psicológicos que enmarcan su actividad y sus relaciones con las prácticas profesionales de otras disciplinas (Rodríguez, 2003; 2005). 
Por otra parte, es indispensable aclarar la distinción que se realiza en este trabajo respecto a la práctica tecnológica y profesional. Si bien, tecnología y profesión están íntimamente relacionadas, muchas veces referidas como un mismo tipo de actividad, y no existen criterios universales para distinguirlas o puntualizarlas, lo cierto es que, visto desde la distinción de prácticas, no es lo mismo construir una herramienta para transformar ciertos aspectos del mundo, que usar dicha herramienta para producir resultados específicos o cambios particulares en dichos aspectos del mundo (Hernández y Reyna, 2015). En términos generales la distinción entre práctica tecnológica y práctica profesional que se realiza en este trabajo, se hace con miras a distinguir precisamente la diferencia entre estos dos tipos de actividades: crear y aplicar dichas construcciones.

Sin perder de vista lo anterior, la caracterización de esta práctica queda de la siguiente manera:

Tipo de actividad. La actividad característica de la práctica profesional es la aplicación de las herramientas, técnicas o procedimientos generados en la actividad tecnológica. Para ello sistematiza dichas herramientas para poder incidir en el problema que se le presenta, ya sea evaluándolo o modificándolo.

Finalidad o función. A partir de la aplicación de las herramientas tecnológicas, el fin que se persigue es modificar la Interconducta en ámbitos definidos según las demandas impuestas.

Sistema o ámbito al que se ajusta. El sistema tecnológico (el cual está conformado por el conocimiento científico sintetizado en un modelo psicológico y por las normas de la institución social que enmarcan el problema a resolver) comprende el primer marco regulador de la actividad profesional al delimitar las funciones de las herramientas disponibles y sus posibles usos y funciones. Por otra parte, el problema social ya definido comprende el segundo marco regulador de esta práctica al delimitar las posibilidades de acción del psicólogo (i.e., el qué puede aplicar y cómo puede aplicarlo).

Material de trabajo. En este caso los problemas individuales que tiene que resolver se convierten en su material de trabajo. Por problema individual se entiende la interacción particular valorada como problemática, anormal, desviada, etc., de la cual se exigen ciertas modificaciones para calificarla como adecuada o no problemática. De nueva cuenta se sigue trabajando con atribuciones o demandas sociales, pero acotados a casos individuales, a pesar de que se exija la modificación o atención de grupos, el tratamiento siempre será individual al trabajar con casos cuyas características son idiosincrásicas.

Tipo de lenguaje. El lenguaje característico de esta actividad es sintetizador, básicamente este lenguaje es el resultado de la vinculación del lenguaje sintético de la práctica tecnológica con el lenguaje ordinario o el de otras disciplinas que delimitan y refieren directamente los objetos, personas, factores participantes en situaciones singulares donde el problema es valorado (Díaz-González y Carpio, 1996). En general, los términos referentes a la vida mental de las personas en sus prácticas cotidianas, como depresión, personalidad, estrés, sueños, inteligencia, malestar, etc., son el tipo de términos que comprende este lenguaje. Básicamente es una adaptación del lenguaje tecnológico al lenguaje de las personas con las que el profesionista se relaciona, para poder comunicarse con ellos sin violar la lógica del sistema Interconductual (Reyna, Sánchez, Reyes, Obregón y Basañez, 2014).

Fines de la investigación. De la misma manera que en la práctica tecnológica, la investigación en esta práctica permite entender las condiciones particulares del comportamiento humano 
en dinámicas sociales; sin embargo, la característica fundamental de la investigación en la práctica profesional es el análisis de casos únicos. Sus fines básicamente están dirigidos a la solución del problema individual dadas las características únicas que lo constituyen (Hernández y Reyna, 2015).

\section{Práctica Transdisciplinar}

Esta práctica también demanda algunas aclaraciones respecto al uso que se hace en este trabajo cuando se habla de transdisciplina y, en ese sentido, de las diferencias con la interdisciplina y la multidisciplina. Siguiendo a Morín (2000), se conoce por Interdisciplina la conjunción de conocimientos aplicables, donde los métodos que han sido utilizados con éxito dentro de una disciplina, se transfieren a otra con la justificación de aplicarlos a un problema social. La Multidisciplina consiste en juntar dos o más disciplinas para que cada una aporte su visión específica según su dimensión de análisis. Por ello, autores como Ribes (2009) o Rodríguez (2003) lo consideran el terreno de acción por excelencia del psicólogo involucrado en algún sistema aplicado, pues aporta desde su dimensión: métodos, datos, técnicas, etc., útiles para encarar algún problema social.

Ahora bien, continuando con los señalamientos de Morín (2000) para el desarrollo de la investigación y el ejercicio interdisciplinar y multidisciplinar existen numerosos obstáculos: a) las diferencias metodológicas, b) las diferencias de lenguajes para explicar y comunicar dicha explicación de un problema, c) la descripción misma del problema, d) la fundamentación de los conocimientos; por mencionar algunos. Dados esos enredos, es que entra en juego la Transdisciplina: la actividad transdiciplinar consiste en una forma de organización de diferentes disciplinas para enfrentar un problema particular. De la misma manera este tipo de actividad tiene que ver con la ordenación del conocimiento que se genera a partir de dicha organización; conocimiento que no es posible de ser atribuido como propio a ninguna de las disciplinas organizadas, sino que le es propio a todas ellas (i.e., las trasciende). De esta manera, la práctica transdisciplinar busca la mejor manera de operar en un ámbito determinado para solucionar o analizar un problema, a través de la coordinación de diferentes disciplinas que en menor o mayor medida pueden proporcionar conocimiento, herramientas, o tipos particulares de acción para solucionar un problema característico del ámbito que demande su actuar. De igual manera, organizar el conocimiento que se produzca de la acción de las disciplinas organizadas.

Tal vez no exista literatura abundante donde la Psicología organice la participación de diversas disciplinas para analizar o modificar un problema social; un ejercicio de organización en este sentido es el trabajo realizado por Obregón, De la Rosa, Reyna, Reyes, Sánchez y Hernández (2015). Básicamente en dicho trabajo se organizó la actividad de diversos profesionales, como sociólogos, psicólogos y antropólogos, para analizar lo que en dicho trabajo se definió como conducta de voto dada una demanda socio-económica específica: conocer los factores que promueven que un ciudadano vote. En dicho trabajo, también, se organizó el conocimiento producto de dichos análisis y se generaron propuestas que también involucraban la participación de distintos profesionales. Todo ello se hizo tomando como eje articulador el comportamiento de las personas respecto de votar. Sin más preámbulo, la caracterización de esta práctica se traza de la siguiente manera:

Tipo de actividad. La práctica definitoria es la organización de las disciplinas donde se busque determinar los elementos que conforman el sistema social en el que se define el problema, el 
papel que cumple cada uno de los profesionistas involucrados, qué se pretende lograr en los usuarios de dicho sistema, los medios y costos que se invertirán para su realización, entre otros.

Finalidad o función. La finalidad de esta última actividad es estructurar el cómo operar en un ámbito determinado, en este caso organizar para modificar la Interconducta.

Sistema o ámbito al que se ajusta. Al ser una actividad que organiza la acción de otras disciplinas, el sistema social económico se convierte en el marco que estipula los criterios que dan dirección a la organización que debe realizarse para producir conocimiento particular o resultados específicos.

Material de trabajo. Los problemas socio-económicos que se definen, es la materia con la que se trabaja en esta práctica.

Tipo de lenguaje. El lenguaje característico lo podemos denominar puente el cual, básicamente, es un lenguaje común, (i. e, compartido) producto de la conjunción adaptada de los lenguajes técnicos o tecnológicos de otras disciplinas a las circunstancias que circunscriben el problema socioeconómico con el que se trata. Con dicho lenguaje se logra además, organizar los resultados del análisis e intervención de las diferentes disciplinas en su justa dimensión. Las categorías usadas en el lenguaje analítico-sintético, sintético y sintetizador, pueden ser ejemplos del lenguaje de este tipo.

Fines de la investigación. La investigación de esta práctica está encaminada a conocer los lineamientos generales constituyentes de la demanda socio-económica impuesta así como conocer las opciones de modificación pertinentes.

Tabla 1. Comparación de las características particulares de cada práctica considerada en la Matríz Científica Interconductual de acuerdo a los criterios propuestos.

\begin{tabular}{|c|c|c|c|c|c|c|c|c|}
\hline & \multicolumn{2}{|c|}{ Filosófica } & \multicolumn{3}{|c|}{ Teórica } & \multirow[b]{2}{*}{ Tecnológica } & \multirow[b]{2}{*}{ Profesional } & \multirow[b]{2}{*}{ Transdiciplina } \\
\hline & $\begin{array}{c}\text { Análisis } \\
\text { conceptual }\end{array}$ & $\begin{array}{c}\text { Análisis } \\
\text { de la lógica } \\
\text { proposiciones } \\
\text { y supuestos } \\
\text { del sistema }\end{array}$ & $\begin{array}{c}\text { Teoria } \\
\text { general } \\
\text { de la } \\
\text { conducta }\end{array}$ & $\begin{array}{c}\text { Teoria del } \\
\text { desarrollo e } \\
\text { individuación }\end{array}$ & $\begin{array}{c}\text { Modelos } \\
\text { psicológicos }\end{array}$ & & & \\
\hline Actividad & \multicolumn{2}{|c|}{ Reflexión } & \multicolumn{3}{|c|}{ Análisis } & $\begin{array}{l}\text { Creación/ } \\
\text { Innovación }\end{array}$ & Aplicación & Organización \\
\hline Finalidad & \multicolumn{2}{|c|}{$\begin{array}{l}\text { Explicar cómo se explica } \\
\text { la interconducta }\end{array}$} & \multicolumn{3}{|c|}{ Explicar la interconducta } & $\begin{array}{c}\text { Crear } \\
\text { herramientas }\end{array}$ & $\begin{array}{l}\text { Modificar la } \\
\text { interconduca }\end{array}$ & $\begin{array}{l}\text { Organizar para } \\
\text { modificar }\end{array}$ \\
\hline $\begin{array}{c}\text { Sistema al } \\
\text { que se ajusta }\end{array}$ & $\begin{array}{l}\text { Matriz } \\
\text { Cultural }\end{array}$ & $\begin{array}{l}\text { Metasistema/ } \\
\text { Protosistema }\end{array}$ & $\begin{array}{l}\text { Sistema } \\
\text { teórico }\end{array}$ & $\begin{array}{c}\text { Sistema } \\
\text { teóricol } \\
\text { Situaciones } \\
\text { de desarrollo }\end{array}$ & $\begin{array}{l}\text { Sistema } \\
\text { teóricol } \\
\text { Institución } \\
\text { social }\end{array}$ & $\begin{array}{c}\text { Modelo } \\
\text { psicológico/ } \\
\text { ámbito social }\end{array}$ & $\begin{array}{l}\text { Sistema } \\
\text { tecnológicol } \\
\text { problema } \\
\text { soclal }\end{array}$ & $\begin{array}{l}\text { Sistema social- } \\
\text { económico }\end{array}$ \\
\hline $\begin{array}{c}\text { Material } \\
\text { de trabajo }\end{array}$ & $\begin{array}{l}\text { Prácticas } \\
\text { ordinarias }\end{array}$ & $\begin{array}{l}\text { Prácticas } \\
\text { teóricas }\end{array}$ & \multicolumn{3}{|c|}{ Eventos sistematizados } & $\begin{array}{l}\text { Demandas } \\
\text { sociales }\end{array}$ & $\begin{array}{l}\text { Problemas } \\
\text { individuales }\end{array}$ & $\begin{array}{l}\text { Problemas } \\
\text { socio- } \\
\text { económicos }\end{array}$ \\
\hline Lenguaje & \multicolumn{2}{|c|}{ Metalenguaje } & \multicolumn{2}{|c|}{ Analítico } & $\begin{array}{l}\text { Analítico- } \\
\text { Sintético }\end{array}$ & Sintético & Sintetizador & Puente \\
\hline $\begin{array}{l}\text { Fines de la } \\
\text { investigación }\end{array}$ & \multicolumn{2}{|c|}{$\begin{array}{c}\text { Establecer la lógica categorial } \\
\text { del sistema teórico }\end{array}$} & \multicolumn{3}{|c|}{ Generar leyes sobre la interconducta } & $\begin{array}{c}\text { Construir, } \\
\text { mejorar, } \\
\text { inventar y/o } \\
\text { adaptar } \\
\text { herramlentas }\end{array}$ & $\begin{array}{c}\text { Solucionar } \\
\text { problemas } \\
\text { institucionales }\end{array}$ & $\begin{array}{l}\text { Solucionar } \\
\text { demandas } \\
\text { socio- } \\
\text { economicas }\end{array}$ \\
\hline
\end{tabular}


De esta manera quedan caracterizadas las prácticas consideradas en la Matriz Científica Interconductual, siguiendo los criterios propuestos. En la Tabla 1 se presenta un concentrado de la caracterización que se realizó. Como se mencionó, estos criterios son propuestas iniciales a las que se pueden agregar otros, modificar o eliminar algunos en aras de caracterizar de una mejor forma todas las prácticas mencionadas.

\section{Comentarios finales}

Es innegable que al hablar del ejercicio de la Psicología Interconductual no se hace referencia a un solo tipo de práctica particular, perfectamente delimitada. Por el contrario, esta se ha desarrollado en distintas prácticas con características particulares impulsadas por motivos distintos y llevadas a cabo en ámbitos diferentes, las cuales configuran el panorama Interconductual en general. Esto es que se hace necesario distinguir las particularidades de cada práctica para analizarlas y evaluarlas pertinentemente.

En consecuencia, la intención de este capítulo fue la de distinguir y caracterizar las distintas actividades realizadas por los psicólogos, como prácticantes del ejercicio científico, dentro de una matriz científica particular: la Psicología Interconductual. Por tanto, los beneficios inmediatos de esta propuesta es que proporciona un marco organizador de las diferentes actividades que se han realizado en la Psicología Interconductual, puntualizando sus características principales. Por supuesto, y es necesario resaltarlo, al distinguir cada práctica no se pretende desligarlas unas de las otras, pues a pesar de las diferencias radicales en cuanto a cómo se llevan a cabo cada una de ellas, todas comparten como característica principal el partir de una forma particular de ver el mundo, es decir, parten de la misma lógica, así como de las mismas proposiciones y suposiciones sobre las características fundamentales de los fenómenos psicológicos, es decir, en torno a la Interconducta.

Por supuesto, es necesario advertir que, los criterios de distinción y caracterización que se propusieron son bosquejos iniciales, los cuales pueden modificarse, ya sea ampliándolos, eliminando algunos o agregando otros, en aras de realizar la labor que se pretendió hacer aquí de manera mucho más efectiva. A pesar de ello, la relevancia del trabajo que se desarrolló en este capítulo radica en que:

1. Permite relacionar y ubicar las prácticas Interconductuales en un continuo que da luz respecto a la influencia y vínculo que tienen todas ellas.

2. Evita violar los criterios que definen una práctica y el uso descontextualizado de los términos que pertenecen a un tipo de práctica como si perteneciesen a otra o usarlos de manera indiscriminada.

3. Posibilita, dados los criterios de caracterización propuestos, analizar cada práctica en su justa dimensión y evaluarlas con pertinencia.

4. Sostiene que cada práctica no existe al margen de las otras, de tal manera que sus características y formas de ejercerlas guardan relaciones de consistencia entre sí.

5. Señala que el actuar concreto del psicólogo no se limita a realizar un solo tipo de práctica, puede y suele pasar de un tipo de práctica a otra casi de manera inadvertida. 
A manera de ejercicio sencillo, con fines meramente explicativos, vale la pena ilustrar los beneficios de la matriz. Para ello, y para vincular este capítulo con la temática que da motivo a algunos de los trabajos que conforman este libro, nos remitiremos a las aportaciones del psicólogo Interconductual al ámbito educativo.

Por poner un ejemplo se retoma el loable trabajo de Mares y Rivas (2002), el cual está especialmente dirigido a la descripción de una estrategia de intervención para el diseño de programas para la enseñanza de la lengua escrita. Analizándolo con los criterios propuestos, es posible señalar que: a) la actividad que realizan es la creación de un procedimiento, con la finalidad de crear una herramienta aplicable; b) el material de trabajo con el que tratan es una demanda social particular en el ámbito educativo: el desarrollo de competencias escritoras en niños de edad escolar pertenecientes a alguna institución de la Secretaría de Educación Pública; c) su actividad está regulada, por un lado, por los supuestos y propuestas de Kantor (1924-1926) y Ribes y López (1985) en relación al comportamiento psicológico y, en mayor medida, por un modelo psicológico que describe la continuidad del desarrollo de competencias orales y escritas, derivado del conocimiento científico psicológico al respecto (Mares y Rueda, 1993) y, por otra parte, por el sistema social educativo desde donde se hace patente la demanda a solucionar; d) las investigaciones citadas entorno a la intervención propuesta tienen como fin la evaluación, adaptación y mejora de dicha herramienta propuesta.

Dado el análisis anterior, es posible "clasificar" el trabajo citado dentro de la práctica tecnológica de la matriz; sin embargo, el ejercicio llevado a cabo por las autoras no se limita únicamente a este tipo de práctica. Por ejemplo, al describir varios de los planteamientos acerca de lo psicológico que dan sentido a su propuesta, la práctica que realizan es filosófica, pues especifican los supuestos básicos que adoptan para definir la dimensión psicológica de la demanda social con la que trabajan, así como sus características principales como fenómeno psicológico; es decir, reflexionan en torno a cómo se explica ese tipo de Interconducta históricamente construida: el desarrollo de habilidades escritas. Por otra parte, cuando al presentar las investigaciones en torno al desarrollo de la escritura y definiendo las diferencias entre el establecimiento y continuidad de competencias lectoras y escritoras, están realizando práctica teórica, pues la finalidad es explicar esa Interconducta en particular a partir de su sistematización.

Por supuesto que el trabajo citado, no es susceptible de ser evaluado como si sólo realizaran un tipo de práctica; más bien y aunque es evidente el vínculo e influencia que guardan entre sí, estas deben ser valoradas en su justa dimensión. Valga aclarar, además, que el anterior ejercicio no pretende ser exhaustivo ni tampoco representativo de todos los casos. Simplemente pretende ilustrar como, por ejemplo, en el ámbito educativo los psicólogos Interconductuales realizan diferentes actividades; ya sea analizar conceptualmente términos que se usan en dicho ámbito, como inteligencia, aprendizaje, competencias y su pertinencia dentro de los límites categoriales del sistema Interconductual; también, se generan explicaciones de la Interconducta que tiene lugar en los espacios educativos, como leer en diferentes niveles, escribir, enseñar, etc., partiendo de modelos de delimitación de la dimensión psicológica como modelos de interacción didáctica, comprensión lectora, desarrollo de habilidades y competencias, entre otros. En este sentido, los psicólogos Interconductuales generan herramientas aplicables e incluso las aplican. De todo ello se desprende la utilidad y necesidad de contar con una matriz como la que se propone en este capítulo. 
Para finalizar, es necesario considerar otro de los aspectos que le otorga aún mayor fuerza a la necesidad de distinguir las prácticas realizadas por los psicólogos Interconductuales: la enseñanzaaprendizaje de la Psicología Interconductual. Este punto viene a colación debido a que es necesario advertir que enseñar o aprender Psicología no se limita a enseñar o aprender un solo tipo de práctica ( $v$. gr., la generación de conocimiento en torno a la Interconducta); por el contrario, debe reconocerse que aprender a comportarse como lo hacen los Interconductistas significa aprender a realizar actividades como filosofar, teorizar, generar herramientas y aplicar dichas herramientas. En ese mismo sentido la enseñanza de la Psicología debe articularse en este tenor. La relevancia de estas anotaciones radica en que no es lo mismo enseñar o aprender, por ejemplo, la lógica, supuestos y proposiciones de la teoría o el análisis conceptual de un término, a aprender a crear herramientas o aplicar dichas herramientas para solucionar un problema socialmente impuesto. Por supuesto esto último, escapa a los objetivos del presente trabajo y será necesario ahondar en ello en otros espacios.

\section{Referencias}

Ackoff, R. (2002). El paradigma de Ackoff. Una administración sistémica. México: Limusa Wiley.

Carpio, C., Pacheco, V., Canales, C., \& Flores, C. (2005). Aprendizaje de la Psicología: un análisis funcional. En C. Carpio, \& J.J. Irigoyen. Psicología y educación. Aportaciones desde la Teoría de la Conducta (pp. 1-32). México: Universidad Nacional Autónoma de México.

Díaz-González, E., \& Carpio, C. (1996). Criterios para la aplicación del conocimiento psicológico. En J.J. Sánchez-Sosa, C. Carpio, \& E. Díaz-González (Coords.), Aplicaciones del conocimiento psicológico (pp. 39-49). México: Universidad Nacional Autónoma de México.

Hayes, L. (1994). Psicología Interconductual: básica y aplicada. En L. Hayes, E. Ribes y F. López (Coords.), Psicología Interconductual contribuciones en honor a J.R. Kantor (pp. 111-126). Guadalajara: Universidad de Guadalajara.

Hernández, M. (2013). ¿Qué es esa cosa llamada método? Tesis de Maestría. México: Centro de Investigaciones Económicas Administrativas y Sociales. Instituto Politécnico Nacional.

Hernández, M., \& Reyna, W. (2015, Noviembre). Práctica profesional de la Psicología: sus criterios y sus modelos. Ponencia presentada en el V Seminario Internacional sobre Comportamiento y sus Aplicaciones. México: Ciudad Universitaria.

Kantor, J.R. (1924-1926). Principles of Psychology. New York: Knopf.

Kantor, J.R. (1933). A Survey of the Science of Psychology. Bloomington: Principia Press.

Kantor, J.R. (1953). The Logic of Modern Science. Bloomington: Principia Press.

Kantor, J.R. (1978). Psicología Interconductual: Un ejemplo de construcción científica sistemática. México: Editorial Trillas.

Kantor, J.R. (1990). La evolución científica de la Psicología. México: Editorial Trillas.

Kantor, J.R., \& Smith, N.W. (2015). La ciencia de la Psicología: Un estudio Interconductual. Guadalajara: Universidad de Guadalajara.

Kuhn, T. (1971). La estructura de las revoluciones científicas. México: Fondo de Cultura Económica. 
Mares, G., \& Rueda, E. (1993). El habla analizada desde la perspectiva de Ribes y López: desarrollo horizontal. Acta Comportamentalia, 1 (1), 39-62.

Mares, G., \& Rivas, O. (2002). Diseño de programas para la enseñanza de la lengua escrita: un ejemplo. En G. Mares, \& Y. Guevara (Coords.), Psicología Interconductual: aportaciones en la investigación tecnológica (pp. 79-112). México: Universidad Nacional Autónoma de México. Marx, M., \& Hillix, W. (1976). Systems and theories in Psychology. New York: McGraw-Hill.

Montgomery, W. (2007). Psicología conductista y filosofía analítica: ¿una alianza conveniente para el siglo XXI? Revista Investigación en Psicología, 10 (2), 145-156.

Morín, E. (2000). La transdisciplinariedad. Francia: Du Rocher.

Obregón, A., De la Rosa, A., Reyna, W., Reyes, R., Sánchez, J., \& Hernández, M. (2015, Noviembre). La Psicología como herramienta versátil. Ponencia presentada en el V Seminario Internacional Sobre Comportamiento y sus Aplicaciones. México: Ciudad Universitaria

Reyna, W. (2016). Matriz Científica Interconductual: organización sistemática de las distintas prácticas en Psicología. Tesis de Licenciatura. México: Facultad de Estudios Superiores Iztacala. Universidad Nacional Autónoma de México.

Reyna, W., Sánchez, J., Reyes, R., Obregón, A., \& Basáñez, A. (2014, Noviembre). Los riesgos de la imprecisión conceptual en la solución de problemas sociales. Ponencia presentada en el XXIV Congreso Mexicano de Análisis de la Conducta. Guadalajara: Instituto Tecnológico y de Estudios Superiores de Occidente.

Ribes, E. (1994). ¿Qué significa ser interconductista? Revista Mexicana de Análisis de la Conducta, 20 (2), 227-239.

Ribes, E. (2000). La Psicología y la definición de sus objetos de conocimiento. Revista Mexicana de Análisis de la Conducta, 26 (3), 367-383.

Ribes, E. (2009). Reflexiones sobre la aplicación del conocimiento psicológico: ¿qué aplicar o cómo aplicar? Revista Mexicana de Análisis de la Conducta, 35 (1), 3-17.

Ribes, E. (2010). Lenguaje ordinario y lenguaje técnico: Un proyecto de currículo universitario para la Psicología. Revista Mexicana de Psicología, 27 (1), 55-64.

Ribes, E., \& López, F. (1985). Teoría de la Conducta. Un análisis de campo y paramétrico. México: Editorial Trillas.

Roca, J. (1993). Psicología: Un enfoque naturalista. Guadalajara: Universidad de Guadalajara.

Roca, J. (1997). Movimientos y Causas: Manifiesto para una Psicología natural. Acta Comportamentalia, 5 (1), 5-16.

Roca, J. (2006). Psicología: una introducción teórica. Girona: Documenta Universitaria.

Rodríguez, M. (2003). La inserción del psicólogo en el campo aplicado. Psicología y Ciencia Social, $5(1), 11-19$.

Rodríguez, M. (2005). El análisis contingencial. Un sistema de análisis Interconductual para el campo aplicado. México: Universidad Nacional Autónoma de México.

Tomasini, A. (1998). Las funciones de la Filosofía. Videoteca de Ciencias y Humanidades, México: Universidad Nacional Autónoma de México. Recuperado de http://www.filosoficas.unam. $\mathrm{mx} / \sim$ tomasini/ENSAYOS/FILOS.pdf

Tomasini, A. (2004). Ensayos de Filosofía de la Psicología. Guadalajara: Universidad de Guadalajara. 


\section{Capítulo 2}

Competencias y habilidades: implicaciones de su naturaleza disposicional

Enoc Obed De la Sancha Villa y Ricardo Pérez-Almonacid 
Enoc Obed De la Sancha Villa enocobed@hotmail.com

Facultad de Ciencias Humanas Universidad Autónoma de Baja California

Ricardo Pérez-Almonacid rperezalmonacid@gmail.com

Centro de Estudios e Investigaciones en Conocimiento y Aprendizaje Humano Universidad Veracruzana 


\section{Capítulo 2}

\section{Competencias y habilidades: implicaciones de su naturaleza disposicional}

El concepto de competencia conductual derivado de Teoría de la Conducta (TC, Ribes y López, 1985) ha cambiado desde su aparición como alternativa para el análisis del comportamiento inteligente (Ribes, 1981), hasta su mención como concepto técnico de interfaz para el análisis del desarrollo conductual y de la relación entre la enseñanza y el aprendizaje (Ribes, 2011; c.f. Ibáñez y De la Sancha, 2013). A pesar de los cambios que ha sufrido, ha conservado su definición a partir de los conceptos de habilidad, criterio de logro, criterio de ajuste y nivel de aptitud. Éstos ofrecen una inmensa riqueza analítica que se ha visto reflejada en una producción conceptual y empírica prolífica, no exenta, sin embargo, de una necesidad permanente de ajustes y precisiones conceptuales como las que se ofrecen en el presente escrito.

\section{Planteamiento del problema}

De manera predominante, una competencia ha sido planteada en términos de la satisfacción de un criterio de logro a partir de la reorganización funcional de habilidades (Ribes, 1990, 2006, 2008, 2011; Ribes, Moreno y Padilla, 1996). La satisfacción de un criterio de logro puede cumplirse a partir de formas cualitativamente diferentes de participación del individuo en la situación. A la complejidad de la relación que el individuo puede establecer cuando satisface el criterio de logro, en términos del tipo de desligamiento funcional implicado, se le ha denominado nivel de aptitud funcional (Ribes, 1989, 1990; Ribes et al., 1996).

Los cinco niveles de aptitud funcional, correspondientes a los niveles generales de organización conductual (Ribes y López, 1985), se han planteado como formas de organizar las habilidades, dando lugar a cinco tipos de competencias identificadas con su respectivo adjetivo funcional: competencias contextuales, suplementarias, selectoras, sustitutivas referenciales y sustitutivas no referenciales. Ribes et al., (1996) incluyeron a los criterios de ajuste para resaltar que es con respecto de estos que se puede predicar cierto nivel de aptitud al satisfacer un requisito conductual. Ribes (2006) conjugó los cuatro conceptos mencionados de la siguiente forma:

He descrito cinco niveles generales de aptitud (Ribes, 1990) que implican, por consiguiente, la posibilidad de estructurar funcionalmente las habilidades en cinco tipos de competencia. Esta clasificación se basa, entre otros factores, en los criterios de ajuste requeridos en términos de los resultados o logros (Ribes, 2006, p. 21). 
Así, por ejemplo, según Ribes et al. (1996), en el dominio de las prácticas científicas, una competencia intrasituacional diferencial podría ser identificar un evento empírico, y una competencia intrasituacional efectiva podría ser identificar, presentar y manipular eventos. Así mismo, Ribes (2006) mostró cómo la suma puede considerarse una competencia que a su vez puede cualificarse según la forma en la que el niño interactúa con la situación. Por ejemplo, si un niño reconoce que el número de canicas varía cada vez que se agrega una sucesivamente, sería una competencia diferencial; por su parte, sería una competencia precisa si lo hace igualando montones, añadiendo o sustrayendo canicas, etc. El autor señala: "cada forma de sumar implica una competencia distinta" (p. 21). Esta idea también fue resaltada por Varela y Ribes (2002) al precisar que la identificación de las competencias no sólo incluye al logro sino a la manera de obtenerlo, sugiriendo así que hay tantas competencias como maneras puedan identificarse, y funcionalmente hablando, tales maneras se entienden según los cinco tipos de organización funcional propuestos por Ribes y López (1985).

Por otra parte, Ribes (1990) precisa cómo las competencias (así como las aptitudes y habilidades) son categorías disposicionales (c.f. Ryle, 1949) y añade: "Ello significa que se les identifica a partir de ocurrencias en la forma de respuestas o acciones, las cuales, no obstante, no son biunívocas con dichos conceptos de capacidad" (p. 210). Ribes (2006) por su parte, precisó el carácter disposicional de la competencia afirmando: "Ser competente, por consiguiente, se refiere a que se puede hacer algo porque ya se ha hecho o porque se tiene conocimiento de lo que se tiene que hacer (...) tiene que ver con una tendencia, es decir, con la continuación de algo que ha ocurrido previamente" (p. 20). A diferencia de la capacidad como categoría modal solamente, la competencia se presenta como una capacidad específica a circunstancias en las que se ha satisfecho un requerimiento conductual (c.f. Ribes, 2011).

Con base en lo anterior puede reconocerse un aparente conflicto conceptual: si las competencias son disposiciones que no corresponden con ocurrencias específicas sino con un conjunto de estas históricamente registrado y susceptible de seguir siendo registrado ante ciertos requerimientos y condiciones, no podría predicarse que una competencia al mismo tiempo corresponde con la manera específica en la que se lleva a cabo la obtención de un logro en una situación particular. Hacerlo así sólo obedecería a una figura metonímica en la que se agota una disposición en una de sus ocurrencias pero no sería útil como concepto técnico que soporta una indagación experimental y teórica, pues lleva a la confusión de predicar de la disposición lo que sólo tiene sentido predicar de una de sus ocurrencias.

Si retomamos el ejemplo de la competencia de sumar diferencialmente, identificada a partir de las acciones que el niño mostró en una situación particular, entonces, la competencia no sería una disposición sino una categoría adverbial referida a la manera en la que el niño satisfizo el logro. Por su parte, si se sostiene que es una disposición, entonces no podría adjetivarse funcionalmente afirmando que es una competencia precisa (selectora) o efectiva (suplementaria), pues estos adjetivos se aplican a episodios singulares de conducta y no a tendencias o propensiones.

Al parecer, el carácter circunstanciado específico de los desempeños que satisfacen logros, llevó a Ribes $(2006,2011)$ a precisar que el concepto de competencia no sólo es disposicional sino que además se ajusta a los criterios lógicos de una categoría episódica (c.f. Ryle, 1949), lo cual recoge la idea ya mencionada por Varela y Ribes (2002) de que para hablar de competencia 
se requiere identificar un logro y una manera de obtenerlo. Pero, como el mismo Ryle (1949) lo presenta, las categorías disposicionales y episódicas pertenecen a dos ámbitos lógicos distintos aunque relacionados:

La tendencia a rumiar y el hábito de fumar cigarros no podrían existir a menos que hubiera procesos o episodios tales como rumiar y fumar cigarros. "Él está fumando ahora un cigarro" no es decir el mismo tipo de cosa que cuando se dice: "Él es un fumador", pero a menos que expresiones como la primera sean ciertas, expresiones como las segundas no podrían ser ciertas. La frase "fumar un cigarro" tiene tanto usos episódicos como usos de declaración de tendencias, derivados de aquéllos. Pero esto no siempre ocurre. Hay muchas expresiones que declaran tendencia y capacidad que no pueden ser empleados al mismo tiempo en reportes de episodios (p. 102).

Más adelante aclara: "La tentación de construir palabras disposicionales como episódicas y esta otra tentación de postular que cualquier verbo que tiene un uso disposicional debe también tener un uso episódico correspondiente, son dos fuentes de uno y el mismo mito" (p. 103).

\section{Esbozo de una propuesta}

En lo que sigue se presenta una reflexión de las implicaciones de concebir la competencia conductual como concepto disposicional, extensiva al concepto de habilidad, procurando defender que no son categorías episódicas aunque sus ocurrencias sean episodios. Se dice que alguien es competente cuando se espera un proceder efectivo ante un requerimiento de logro que no se agota con procedimientos invariantes sino que exige flexibilidad en la adaptación de estos a problemas específicos, gracias a que hay evidencia histórica de que lo ha hecho así en problemas del mismo tipo. Los episodios conductuales son las unidades mínimas que constituyen la evidencia a partir de la cual se predica la competencia y se definen tanto por el requerimiento de logro del tipo mencionado como por el proceso llevado a cabo para lograrlo, el cual a su vez es susceptible de caracterizar según los niveles de ajuste funcional.

El criterio de logro ha estado vinculado o ha sido igualado con el criterio de ajuste y el nivel de aptitud (Ribes et al., 1996). A pesar de que estos términos se implican mutuamente y se relacionan con los criterios de mediación y desligamiento funcional, forman parte de lógicas distintas. El criterio de ajuste funcional ayuda a identificar qué función de las propuestas en la taxonomía de Ribes y López (1985) se actualizó en un episodio (c.f. Pérez-Almonacid y Quiroga, 2010). Los niveles de aptitud se derivan de la taxonomía antes mencionada y hacen referencia "a la complejidad que establece el individuo con su entorno, en términos de su participación en la configuración de las características de la interacción misma y su independencia relativa respecto a las propiedades situacionales de la relación" (Ribes, 1990, p. 210). La aptitud implica una disposición a actuar de cierta manera en términos de la estructuración de las relaciones de una situación. Se es apto o "se tiene" la aptitud si en el pasado se ha cumplido con criterios funcionalmente equivalentes, y por lo tanto, se está en condiciones de participar en la estructuración de las relaciones de una nueva situación en formas cualitativamente específicas vinculadas con las participaciones pasadas. Los predicados para la 
conducta en función de criterios de ajuste (episódicos), y sus correspondientes criterios de aptitud (disposicionales), no son los de éxito o fracaso; la conducta simplemente es o está estructurada en cierto nivel funcional.

Por otra parte, los criterios de logro son requerimientos planteados al interior de los diferentes dominios de vida, culturales o institucionales y de los cuales siempre es posible sancionar éxito o fracaso. Los requerimientos de logro ${ }^{1}$ especifican diferentes tipos de desempeños: mencionar las capitales de los Estados, tirar al centro de la diana, pronunciar de cierto modo una palabra, resolver problemas algebraicos, utilizar el teorema de Pitágoras para resolver problemas, aumentar las ventas del mes, publicar un artículo científico en una revista especializada, convencer a un cliente indeciso, manejar eficientemente un programa informático, etc.; todos ellos son requerimientos de logro que se establecen cultural o institucionalmente de manera tácita o explícita y ante los cuales se requiere o sanciona el desempeño exitoso del individuo. La satisfacción de un requerimiento de logro siempre se obtiene en episodios que pueden caracterizarse según un criterio funcional pero un mismo logro puede implicar distintos niveles de ajuste funcional y un mismo criterio de ajuste se puede instanciar en la satisfacción de múltiples logros.

Los requerimientos de logro que se relacionan con un "saber hacer" (Ryle, 1949) se dividen en dos tipos según su amplitud: a) los que se logran con la implementación de uno o más procedimientos estándar, y b) los que no se logran de esa manera sino que requieren una integración de tales procedimientos en formas no rígidas sino adecuadas a cada problema que se plantee (es decir, de forma flexible). Los primeros son los que exigen el desarrollo de una habilidad, mientras que los segundos son los que exigen el desarrollo de una competencia. Por otra parte, las demandas que establecen los requerimientos pueden ser tácitas o explícitas, y siempre está disponible la constatación del surgimiento de un desempeño particular pertinente y su evolución ante situaciones diferentes a las usuales.

Además de los requerimientos de logro y los criterios de ajuste es factible reconocer también los criterios de pertinencia (Ribes, 2010; Pérez-Almonacid y Quiroga, 2010; Pérez-Almonacid, García y Ortíz, 2015). Aunque los requerimientos de logro y los criterios de pertinencia pueden incluirse uno respecto del otro, no son conceptos idénticos. El requerimiento de logro siempre incluye, tácita o explícitamente, el ajuste a un criterio de pertinencia; no obstante, el ajuste a un criterio de pertinencia no necesariamente puede calificarse como exitoso aunque sí como un ajuste con sentido o absurdo. Por ejemplo, una persona que hace una demostración matemática utilizando a los números como íconos está haciendo algo que no tiene sentido; no resiste en primera instancia un predicado de que lo está haciendo incorrectamente sino principalmente de que es absurdo. Es incorrecto cuando, aun tratando a los números como magnitudes, no realiza el procedimiento efectivo establecido en el dominio. El ajuste al criterio de pertinencia no se trata, entonces, de que sepa hacer algo con cierta destreza sino que, incluso si fuera torpe, lo que se hace tiene sentido. Como se sugiere en otro

1 Se usa el concepto de "requerimiento de logro" para distinguir mejor entre el criterio a satisfacer establecido al interior de cada dominio de vida o disciplinar, por un lado, y por otro, el criterio de ajuste y nivel de aptitud. Así mismo, es necesario distinguir entre el requerimiento de logro de una tarea y las medidas de logro planteadas como indicadores del ajuste funcional en un episodio (c.f. Ribes, 2007). 
lugar (Pérez-Almonacid et al., 2015), los criterios de pertinencia permiten predicados de comprensión mientras que los de logro permiten predicados de competencia o habilidad, que suelen verse entrelazados en un mismo episodio conductual.

Por otra parte, tal y como Ribes (2011) precisa, ser competente se distingue de por lo menos otras dos formas de satisfacción de un requerimiento de logro: del conocimiento de hechos y de ser hábil. Con respecto a lo primero, ser competente o "tener una competencia", tiene que ver con "saber hacer" algo de manera exitosa pero no con "saber qué" (Ryle, 1949), ser erudito, culto o estar informado respecto a algo (Ribes, 2011). Ser competente se predica a partir de casos en los que un individuo ha operado y realizado las acciones necesarias con -y ante- objetos físicos o simbólicos, personas u eventos, y ha obtenido efectos y resultados exitosos ante un determinado requerimiento de logro que implicaba resolver un problema; es conocimiento actuativo y no conocimiento de hechos o ligado a las fuentes (c.f. Ribes, 2007). En este sentido, recitar una poesía, recordar hechos históricos, saber acerca de la cultura griega, pueden ser logros o desempeños exitosos, pero no se vinculan con los usos de ser competente o tener una competencia.

Vinculado con lo anterior, ser hábil también se predica de la tendencia a satisfacer un requerimiento de logro a partir de intervenciones prácticas pero no se iguala con ser competente. Ser hábil se ha caracterizado especialmente como correspondencias de sistemas de respuestas ante morfologías de objetos (Ribes, 1989, 1990). Sin embargo, aunque esa característica es evidente en muchos casos, puede implicar el sesgo de ser interpretada como si la relación se agotara en una especie de ensamble rígido entre morfologías de respuestas y de objetos, como en el ejemplo de la habilidad de girar la chapa de las puertas. En su lugar, es útil resaltar que son tres los rasgos distintivos de la habilidad: a) el requerimiento exige suficientemente un procedimiento estándar y relativamente rígido; b) lo que se hace corresponde funcionalmente con ese requerimiento de una forma invariante, rutinaria o estereotipada; y c) tal invarianza se asocia comúnmente a un rango de características morfológicas tanto de los objetos como de las acciones correspondientes (c.f. Ribes, 1990). Esto define un tipo de variabilidad dictada por el tamaño de ese rango, que en cualquier caso es finito y eso mismo permite la invarianza de lo que se hace frente a los objetos y eventos. Por ejemplo, la persona que lleva las cuentas en un pequeño mercado, puede ser muy hábil para obtener el resultado de la suma de diferentes cantidades. Más allá de las morfologías específicas implicadas (que en todo caso son reconocibles pero no definitorias), el aspecto crítico es la invarianza del procedimiento en un rango relativamente finito de precios, productos y respuestas.

El hecho de que una misma habilidad suponga una correspondencia funcional invariante en cada episodio en el que se instancia, implica que el nivel funcional del desempeño es el mismo en cada uno de estos, lo cual difiere de la competencia, en la que pueden y suelen ser distintos. Así, entonces, es comprensible un uso metonímico de la adjetivación funcional en la habilidad, como por ejemplo habilidad selectora, queriendo decir que los episodios en los que se observa la rutina, esta se establece selectoramente y que por tanto, es altamente probable que en otras ocasiones se despliegue del mismo modo. Lo que es selector no es la disposición sino cada episodio interactivo que permite predicarla.

Lo anterior llama la atención de un asunto interesante: la relativa invarianza de las rutinas que definen a la habilidad, y que es necesaria para lograr la efectividad del desempeño, puede implicar 
que sea perceptible en una sola ocasión y que sea suficiente para predicar la habilidad aun cuando sea un concepto disposicional. Nótese por ejemplo el caso de un futbolista hábil en sostener el balón con un solo pie, o un pianista virtuoso con una pieza, o una cocinera diestra pelando papas. Sin embargo, el carácter disposicional de una relación no reside en que sea imposible identificarse en un solo episodio sino en los resultados esperables cuando se encuentran ciertas condiciones (c.f. Mumford, 1998). Por ejemplo, la solubilidad de una sustancia es una propiedad disposicional que consiste en que se disolverá si es introducida en un líquido. Si en una ocasión particular se introduce en agua y notamos que se disuelve predicamos que la sustancia es soluble; la disposición se realiza plenamente en una sola ocasión y por tanto es suficiente para predicarla. No obstante, esa ocasión no es necesaria para predicar la disposición, pues incluso si no se presentara nunca, la sustancia seguiría siendo soluble y lo podemos afirmar porque conocemos otras propiedades que nos permiten hacerlo. Así, entonces, el futbolista es hábil porque es muy probable que si se le pide en una prueba que no deje caer el balón con un solo pie lo hará efectivamente durante un periodo de tiempo notable. Pero no lo es debido a la ocasión específica en la que yo pude atestiguarlo, incluso aunque sea suficiente para que yo pueda predicar tal habilidad. $Y$ no se necesitan varias ocasiones para hacer tal predicado, así como tampoco en el caso de la solubilidad.

Incluso en el caso de la competencia el asunto es el mismo, aunque las "ocasiones" o episodios en los que se instancia no suelen ser perceptibles del mismo modo que el futbolista o la sustancia soluble. El atributo de flexibilidad, propio de la competencia, exige una muestra suficiente de episodios para poder afirmar que se cumplió tal atributo. Pero no es por esos episodios en particular que la competencia es una disposición, aunque sean suficientes para predicarla, sino porque la persona en cuestión tenderá a hacer las cosas de una manera igualmente flexible y efectiva en futuras ocasiones, si tiene el requerimiento de hacerlo.

Aquella muestra suficiente de episodios para predicar la competencia es una forma de evitar que un acto exitoso sea casual o debido a una capacidad. En el caso de la competencia, más que de la habilidad, coincide con la reflexión de Ryle (1949) de que no existen señales per se de que alguien sabe hacer algo, "sino una modesta colección de desempeños heterogéneos generalmente suficientes para establecer más allá de la duda razonable” (p. 46) si se sabe cómo hacer algo o no. La consistencia en el desempeño exitoso es el mejor indicador.

Así, entonces, ser competente se predica de la tendencia a satisfacer un requerimiento de logro en formas exitosas pero también variadas porque además tal requerimiento exige tal variabilidad y no puede ser satisfecho desplegando sólo un procedimiento estándar. Si el requerimiento sólo exige hacer las cosas de una sola forma y eso es suficiente para satisfacerse, no se necesita el desarrollo de una competencia. Esto recalca el carácter funcional del concepto: no sólo depende de lo que se hace y cómo se hace sino además de la naturaleza de lo que se pide. Ser competente no es conducta repetitiva, rutinaria o imitativa; es solucionar problemas que exigen flexibilidad, desplegando formas variadas y efectivas de hacer las cosas, como forma específica de comportamiento inteligente (Ribes, 1981, 1989). El desempeño inteligente se relaciona lógicamente con formas efectivas y variadas de proceder y no con formas estereotipadas o reproductivas ${ }^{2}$ de comportamiento. Este es el principal punto de contraste con la habilidad.

2 Por reproductivo se entienden los desempeños que aun siendo exitosos son copias, repeticiones o reproducciones de lo instruido. 
Estamos en condiciones, entonces, de ofrecer algunas implicaciones del concepto de ser competente, que aportan a lo elaborado en la literatura pertinente:

A. Ser competente se define a partir de un requerimiento de logro y no de un criterio de ajuste. Tal requerimiento de logro implica un criterio de pertinencia inherentemente, de manera que ser competente implica saber hacer ciertas cosas que resultan con sentido de acuerdo a ciertas prácticas sociales.

B. Lo que debe lograrse exige separar y unir, total y parcialmente, los procedimientos estándar que definen a las habilidades, de manera que el desarrollo de una competencia va de la mano con un tipo de requerimiento de logro: uno inclusivo de otros requerimientos. Esta flexibilidad pertinente a la competencia se actualiza progresivamente en cada uno de los episodios constitutivos hasta que se conforma una tendencia.

C. Ser competente no se predica confiablemente en un episodio particular donde se satisface un requerimiento de logro del tipo mencionado en el punto b), sino a partir de la tendencia observada a satisfacerlo en distintos episodios. El predicado de competencia, sin embargo, suele hacerse inferencialmente a partir de un episodio pero esto no es suficiente para propósitos experimentales, en los que se requiere constatar confiablemente la disposición y su rango de cobertura.

D. Es en cada episodio de los que constituyen la tendencia en donde puede identificarse una manera cualitativa de participación individual frente al requerimiento de logro. Dichas participaciones pueden vincularse con alguno de los niveles de organización funcional derivados de la taxonomía formulada por Ribes y López (1985).

E. En la medida en que la competencia no se agota en un episodio sino en la disposición a comportarse de cierta manera según la evidencia histórica, en principio no es posible aplicar un adjetivo propio de categorías episódicas a la probabilidad de que algo ocurra nuevamente. No sería pertinente, entonces, referirse a una competencia como selectora, o suplementaria, etc. Ser competente respecto de un requerimiento de logro podría implicar formas cualitativamente variadas de participación individual en los diferentes episodios constitutivos de la tendencia.

F. Aunque en algunos casos el cumplimiento del requerimiento de logro podría darse mayoritariamente en un mismo nivel funcional en todos los episodios, y por lo tanto, se podría hablar de una dominancia funcional o una competencia que en su desarrollo implicó niveles de aptitud de un solo tipo, eso no es necesario. Esta posibilidad de transición entre niveles funcionales asimétricos en una situación plantea la necesidad de adoptar estrategias diferentes que permitan cualificar la participación del individuo ante el requerimiento de logro. Algunas de estas estrategias podrían dirigirse a, por ejemplo: 1) la descripción de los niveles funcionales transitados ante los diferentes requerimientos durante los episodios; 2) la delimitación del rango entre niveles funcionales transitados; 3) el nivel de aptitud máximo en el que se desempeñó el individuo; o 4) el nivel funcional en el que se desempeñó predominantemente durante los episodios.

G. Ser competente es un concepto estrictamente relacional y no morfológico. Predicar que una competencia se ha desarrollado requiere un análisis relacional de lo que el individuo 
sabía hacer, los eventos o circunstancias a los que se expuso, los requerimientos de logro estipulados en la situación y por supuesto, el desempeño del participante ante tales situaciones y requerimientos. La adquisición de nuevas formas de desempeño exitoso, aun observado recurrentemente y con morfologías variadas, no se iguala con el desarrollo de competencias, ya que dichos desempeños podrían ser instancias de conducta imitativa, reproductiva o estereotipada. En este sentido, la simple especificación de requerimientos que implican variación no es suficiente para predicar la competencia. Ser competente es un concepto que sólo puede predicarse después del análisis relacional mencionado, y además, que las competencias no pueden enseñarse o instruirse directamente sino que su desarrollo debe implicar la búsqueda de condiciones para que dicha disposición se establezca.

Para ejemplificar lo mencionado, piénsese en una situación en la que se requiere el cálculo de la magnitud de un lado en polígonos regulares. En la medida en que esto tenga un resultado correcto y que haya formas variadas de proceder para lograrlo en un problema abierto, califica como una competencia como disposición de una persona; si sólo hubiese unas formas específicas e invariantes de llegar siempre a la solución, no calificaría como tal y sería sólo una habilidad: la persona sólo sería diestra en la aplicación de los respectivos algoritmos pero no necesariamente estaría en condiciones de resolver problemas novedosos que exijan combinaciones diferentes de tales algoritmos.

Lo que define que esa persona sea competente haciendo esos cálculos no es que lo haga en un nivel de ajuste funcional sino que sepa cómo resolver los diferentes problemas. Cada uno de estos puede exigir diferentes niveles funcionales de interacción en su propio proceso de solución, y entre problemas podría presentarse una dominancia funcional, de manera que no tiene sentido decir que al final la competencia corresponde a cierto nivel. En todo caso, la certeza en la identificación de la competencia supone evaluar si el individuo hace lo mismo siempre, qué tan diferentes son los problemas y sus componentes, qué tanta diferencia supone el logro en los diferentes casos, etc.

Finalmente, la transición entre el desarrollo de una habilidad y una competencia puede ilustrarse a partir de una secuencia progresivamente más inclusiva de habilidades que amplía el espectro de logros susceptibles de ser satisfechos. Esto invita a pensar por lo pronto en dos posibilidades teóricas del desarrollo competencial: una, como un modelo composicional, habilidad por habilidad (c.f. Gagné, 1962); o bien, como un modelo emergente en el que la competencia surge como reorganización no lineal del repertorio en función de logros más molares (c.f. una idea cercana en Reed, 1993). Este tópico, sin embargo, supera los alcances del presente capítulo. Podemos, en todo caso, ofrecer una ilustración de dicha transición basada en un esquema de jerarquía de requerimientos cada vez más inclusivos que promueven la integración de procedimientos estándar característicos de una habilidad.

Supóngase dos personas que inicialmente no pueden obtener el lado faltante de un triángulo rectángulo a partir del teorema de Pitágoras y deben aprender a hacerlo. El logro requerido es muy específico y la forma de satisfacerlo supone sólo el ejercicio de una rutina o técnica basada en la correspondencia entre cuadrados y la solución de una ecuación de primer grado. Ésta se les enseña paso a paso para obtener el cateto opuesto. Es factible analizar en cuál nivel funcional se desempe- 
ñan las personas en cada caso de solución de problemas ejemplares: es posible que los resuelvan contextualmente, si sólo copian la rutina; suplementariamente, si establecen nuevas relaciones algebraicas entre los términos de un problema, etc. Pero al final, la solución de los problemas en los que deben obtener el cateto opuesto sigue una rutina invariante y las personas puede aprender a hacerlo con destreza: adquieren una habilidad.

Supóngase ahora que las personas se enfrentan a una situación de prueba de transferencia o ampliación del rango de cobertura de esa habilidad: debe obtener no sólo el cateto opuesto sino también el adyacente y la hipotenusa. En la Figura 1 se presenta hipotéticamente el desempeño de ambos alumnos en las diferentes situaciones. El participante "a" en la situación de prueba utiliza la ecuación instruida para encontrar la longitud del cateto opuesto y posteriormente la adapta para obtener el cateto adyacente y la hipotenusa. El requerimiento de logro se amplió al incluir nuevos resultados pero estos se obtienen con una variación local en la rutina que lleva a su satisfacción: los términos de la ecuación se ajustan para obtener el lado deseado. La habilidad ya no es sólo obtener el cateto opuesto usando el Teorema de Pitágoras sino obtener cualquier lado de un triángulo rectángulo usando el Teorema. La probabilidad de que falle más veces aumenta pero a medida que incrementa la práctica, la habilidad como disposición se consolida. Es factible que en la situación de aprendizaje se haya aprendido a nivel selector y eso es evidente hasta el momento de la prueba en la que el procedimiento se adapta dependiendo de la información disponible; o bien, puede ser que se haya aprendido en un nivel contextual y que explícitamente se extienda por medio de enlaces verbales que indiquen que el procedimiento es análogo y lo haya seguido haciendo contextualmente, como es el caso que ilustra la Figura 1. Todo esto es susceptible de verificación experimental.

El participante "b", expuesto a las mismas condiciones de instrucción, también resuelve los tres problemas en la situación de prueba pero su proceder ante estos es diferente. Para el primer problema utiliza la ecuación aleccionada durante la fase de aprendizaje, de manera que es idéntico al participante "a" en este caso; sin embargo, en el segundo y tercer problema vincula lo instruido respecto a la lógica de las proporciones entre cuadrados y la ecuación implicada en el teorema, resolviendo los dos problemas restantes a partir de "comprobar" si realizando los cuadrados en cada lado del triángulo, igualando las áreas entre hipotenusa-catetos y obteniendo la raíz cuadrada del área que corresponde al lado faltante, podría obtener el mismo resultado. El tipo de participación mostrada ante los dos últimos problemas es cualitativamente diferente a la mostrada por el participante "a", ya que "b" no solamente reprodujo las relaciones a las que fue expuesto sino que vinculó elementos y estableció relaciones entre estos para obtener el resultado final.

El participante "b" satisfizo el mismo requerimiento de logro de formas variadas y no reproductivas respecto de lo instruido, siendo cada una de estas, no obstante, rutinas distintas. A diferencia del participante "a" que mostró una ampliación de la misma habilidad al aplicarla a nuevas condiciones del mismo tipo, el participante "b", además, satisfizo el requerimiento utilizando un procedimiento distinto. En este ejemplo se nota cómo no es suficiente esa evidencia para predicar con certeza que la persona ha desarrollado la habilidad de aplicar este nuevo procedimiento. No obstante, es un indicador de que la persona puede resolver el mismo requerimiento haciendo cosas distintas, que suponen niveles funcionales distintos, y por tanto, que su desempeño tiene visos de flexibilidad que apuntan hacia el desarrollo de una competencia. 


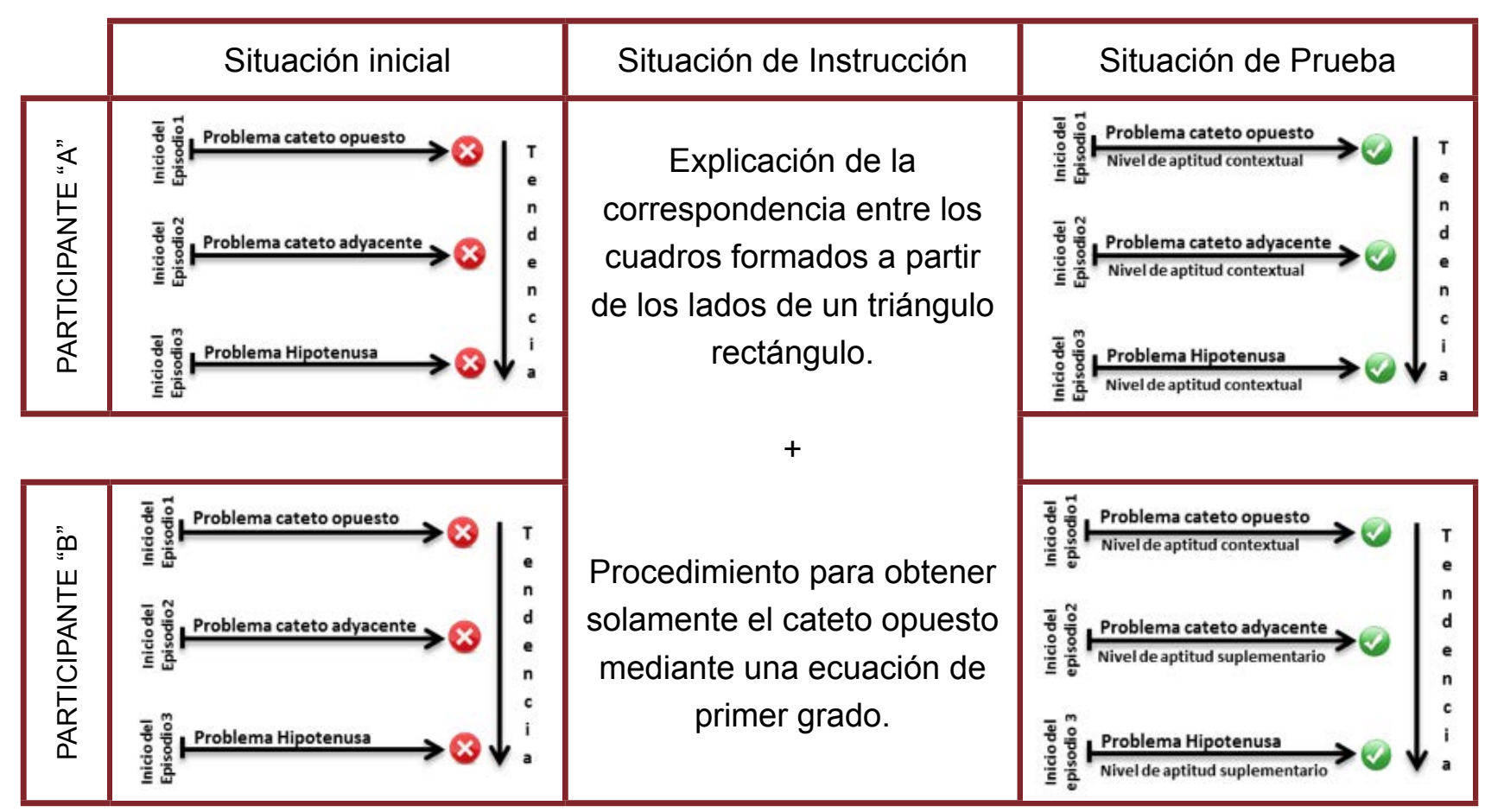

Figura 1. Ejemplo de transición de una habilidad a una competencia.

La competencia, no obstante, no va a desarrollarse hasta que el requerimiento de logro cambie. Si este sigue solicitando una solución que se agota aplicando una o más rutinas rígidas, por definición, no se exige ser competente sino sólo desplegar habilidades. En principio, para que se exija competencia el logro debe ser más inclusivo y por ende más abierto. Se trata de proponer auténticos problemas novedosos que no se resuelven con una o más rutinas sino con una combinación simultánea y secuencial de varias de estas, aplicables sólo en ciertos aspectos del proceso y con determinados valores paramétricos. Por ejemplo, si el requerimiento es el diseño de rampas en congruencia con diversas regulaciones arquitectónicas, la persona ajusta a cada caso algunas rutinas y procedimientos que incluso pueden ser combinados de forma novedosa, y que por tanto, en conjunto, no son invariantes. La dinámica de las competencias procede más por heurísticos que por algoritmos. Si una persona diseña rampas en condiciones muy variadas, atendiendo a diferentes materiales, restricciones, usos y regulaciones, merece con confianza el adjetivo de ser competente haciendo eso, lo cual incluye que es hábil haciendo ciertos cálculos, seguramente aplicando el Teorema de Pitágoras.

\section{Dos consideraciones metodológicas}

Será suficiente, por lo pronto, apuntar dos consideraciones metodológicas que se derivan del análisis anterior:

A. El estudio de las competencias requiere necesariamente un análisis diacrónico o longitudinal debido a su naturaleza disposicional. Esto puede beneficiarse ampliamente de los diseños intra-sujeto con muy pocas personas, con las que pueda hacerse un rastreo sistemático del devenir de su repertorio competencial en situaciones controladas. 
B. El análisis del desarrollo de una competencia requeriría principalmente la combinación de dos aspectos: 1) un requerimiento de logro que supere la aplicación de un procedimiento estándar, lo cual puede sugerir una jerarquía de requerimientos cada vez más inclusivos; y 2) el entrenamiento simultáneo de las habilidades pertinentes pero en sí misma no suficientes para la satisfacción de tal requerimiento. La indagación experimental podría consistir en verificar relaciones de necesidad y suficiencia de ciertos arreglos cualitativos y cuantitativos de secuencias de entrenamientos, sobre logros que precisan la integración y combinación de habilidades ante problemas novedosos que implican cada vez una mayor flexibilidad respecto de lo entrenado.

\section{Consideraciones finales: implicaciones educativas}

El análisis de las competencias en los contextos educativos ha perdido el referente (para una revisión detallada consultar De la Sancha, 2016), pues el concepto que allí se maneja cubre casos de diferente naturaleza categorial. La consecuencia de esto es que pierde utilidad como orientación para el diseño curricular e instruccional. La alternativa derivada de Teoría de la Conducta ha sido sugerente y tiene el potencial de impactar la educación en el aula pero aún se ha quedado corta; entre otras razones, porque las conclusiones obtenidas suelen basarse en pruebas breves y episódicas de desempeño y no en la verificación de auténticas tendencias, y porque ha habido un énfasis en el estudio de habilidades y no en el de competencias, según como se ha tratado el tema en este escrito.

Consideramos que un nuevo impulso puede provenir de tomar en consideración las reflexiones ofrecidas y emprender un programa de investigación que contemple las consideraciones metodológicas recién esbozadas, con compromisos específicos en las escuelas que exijan una comprensión auténtica del fenómeno y que derive fácilmente en una tecnología comprobable y útil.

Entre las principales implicaciones que la presente reflexión ofrece para la labor educativa, se entrevén las siguientes:

A. Las competencias, como tendencias consolidadas a resolver de forma flexible requerimientos de logro, no se enseñan sino que son resultados que se promueven.

B. El diseño curricular podría orientarse hacia la promoción del desarrollo de ciertas competencias en cada dominio disciplinar, cuidadosamente elegidas, pero se beneficiaría de una concepción jerárquica y progresiva de requerimientos de logro, de los cuales los más básicos pueden ser el fin mismo de una asignatura más que la competencia misma; esta sería el resultado último de un proceso de formación más largo e inclusivo. Esto invitaría a pensar en modelos ramificados y no seriales del diseño curricular, según los cuales los primeros momentos se concentren en el desarrollo de habilidades que progresivamente se van integrando hasta establecer las competencias.

C. El diseño instruccional tendría como fin la promoción de la satisfacción de los requerimientos de logro progresivamente dentro de la jerarquía. En cada episodio disponible para satisfacer el requerimiento se diseñarían situaciones didácticas en diferentes niveles funcionales dependiendo del tipo de requerimiento y de su lugar en la jerarquía de requerimientos que lleven finalmente hacia el de mayor inclusividad. El objetivo a mediano y largo plazo sería la integración explícita de los procedimientos estándar que se entrenan 
como práctica repetida, con miras a la satisfacción de estos requerimientos de mayor nivel en las situaciones con la mayor diversidad posible respecto de las situaciones previas.

\section{Referencias}

De la Sancha, E.O. (2016). Análisis experimental del desarrollo de competencias intrasituacionales: un ejemplo con el teorema de Pitágoras. Tesis Doctoral. México: Universidad Veracruzana.

Gagné, R. (1962). The acquisition of knowledge. Psychological Review, 69, 355-365.

Ibáñez, C., \& De la Sancha, E.O. (2013). La evolución del concepto de competencia en la Teoría de la Conducta. Acta Comportamentalia, 21, 377-389.

Mumford, S. (1998). Dispositions. Oxford University Press.

Pérez-Almonacid, R., García, L., \& Ortiz, D. (2015). El estudio psicológico de la comprensión. En M. Reyes, G. Mendoza, \& P. Barrera (Eds.), Algunas aportaciones psicológicas y sociológicas a la educación, Volumen II (pp. 77-101). México: NAUTILIUM.

Pérez-Almonacid, R., \& Quiroga, L. (2010). Lenguaje. Una aproximación Interconductual. Bogotá: Corporación Universitaria Iberoamericana.

Reed, S. (1993). A schema-based theory of transfer. En D. Detterman, \& R. Sternberg (Eds.), Transfer on trial: Intelligence, Cognition and instruction (pp. 39-67). New Jersey: Ablex.

Ribes, E. (1981). Reflexiones sobre el concepto de inteligencia y su desarrollo. Revista Mexicana de Análisis de la Conducta, 7, 107-116.

Ribes, E. (1989). La inteligencia como comportamiento: un análisis conceptual. Revista Mexicana de Análisis de la Conducta, 15 (Monográfico), 51-67.

Ribes, E. (1990). Psicología General. México: Editorial Trillas.

Ribes, E. (2006). Competencias conductuales: su pertinencia en la formación y práctica profesional del psicólogo. Revista Mexicana de Psicología, 23, 19-26.

Ribes, E. (2007). Lenguaje, aprendizaje y conocimiento. Revista Mexicana de Psicología, 24, 7-14.

Ribes, E. (2008). Educación básica, desarrollo psicológico y planeación de competencias. Revista Mexicana de Psicología, 25, 193-207.

Ribes, E. (2010). Teoría de la Conducta 2. Avances y extensiones. México: Editorial Trillas.

Ribes, E. (2011). El concepto de competencia: su pertinencia en el desarrollo psicológico y la educación. Bordón, 63, 38-43.

Ribes, E., \& López, F. (1985). Teoría de la Conducta. Un análisis de campo y paramétrico. México: Editorial Trillas.

Ribes, E., Moreno, R., \& Padilla, A. (1996). Un análisis funcional de la práctica científica: extensiones de un modelo psicológico. Acta Comportamentalia, 4, 205-235.

Ryle, G. (1949). The concept of mind. Chicago: The University of Chicago Press.

Varela, J., \& Ribes, E. (2002). Aprendizaje, inteligencia y educación. En E. Ribes (Ed.), Psicología del Aprendizaje (pp. 191-204). México: Manual Moderno. 


\section{Capítulo 3}

\section{Análisis del desarrollo psicológico: un estudio de la historia de efectividad de universitarios}

Germán Morales Chávez, Edgar Chávez Hernández, Benjamín Peña Pérez, Alfredo Hernández Corona y Claudio Carpio Ramírez 
Germán Morales Chávez gmoralesc@unam.mx

Edgar Chávez Hernández psic.edgarchavez@gmail.com

Benjamín Peña Pérez benjaminp.perezpsico@gmail.com

Alfredo Hernández Corona alfredohc2694@gmail.com

Claudio Carpio Ramírez carpio@unam.mx

Facultad de Estudios Superiores Iztacala Universidad Nacional Autónoma de México

Los autores desean agradecer a Alejandro Trejo por su valioso apoyo en la revisión a una versión preliminar de este trabajo. 


\section{Capítulo 3}

\section{Análisis del desarrollo psicológico: un estudio de la historia de efectividad de universitarios}

En este capítulo se presentan algunas consideraciones teórico-conceptuales y metodológico-experimentales que se desprenden del Modelo Interconductual del Comportamiento Creativo propuesto inicialmente por Carpio (2005) y socializado como programa de investigación en 2007 por Carpio, Canales, Morales, Arroyo y Silva, para el abordaje del desarrollo psicológico. Como una forma de mostrar el alcance empírico de las consideraciones, se presenta un estudio con universitarios en situaciones de lectura cuyos resultados permiten discutir el alcance empírico de los planteamientos vertidos en el manuscrito.

\section{El análisis del desarrollo psicológico desde una perspectiva Interconductual: nota preliminar}

La teorización de los procesos psicológicos como una forma de estudiar la evolución funcional de la conducta es parte necesaria en el desarrollo y curso de una Psicología científica, en tanto permite dar cuenta de las condiciones necesarias y suficientes bajo las cuales se estructuran los eventos psicológicos y las condiciones bajo las que dichos eventos cambian. En la medida en la cual se da cobertura a tales condiciones, el planteamiento de procesos básicos permite dar origen a otras formas de teorización que están orientadas a responder otras preguntas que también resultan relevantes, como lo son: a) el curso y dirección que sigue el comportamiento en diversos ámbitos sociales de actividad humana, y b) la singularización o individuación del comportamiento como formas consistentes de un individuo por comportarse en diferentes situaciones. En ambos casos de teorización, desarrollo e individuación, se debe mantener coherencia con la arquitectura conceptual de una teoría de procesos, así como con los compromisos ontológicos y epistémicos que definen la naturaleza de lo psicológico. Igualmente relevantes se tornan las diferencias que deben existir entre las tres teorizaciones, en plena correspondencia con sus preguntas por responder.

La teorización de procesos psicológicos desde una perspectiva Interconductual encuentra en la formulación de Emilio Ribes y Francisco López (1985) el planteamiento teórico realizado al amparo del meta-sistema de Jacob R. Kantor (1990) con mayor influencia, al menos en los países hispano-parlantes. De esta formulación se han realizado esfuerzos por construir una teoría del desarrollo psicológico con una inclinación por llevarlo a cabo al ámbito educativo particularmente (Ribes y 
Varela, 1994; Ribes, 1996; Mares y Rueda, 1993; Mares, 2001; Carpio, 2005; Silva, Arroyo, Carpio, Irigoyen y Jiménez, 2005; Carpio, Canales, Morales, Arroyo y Silva, 2007).

La teoría sobre procesos psicológicos de Ribes y López (1985) cobró la forma de una taxonomía que reconoce cinco niveles cualitativamente diferentes de interacciones o tipos de procesos psicológicos que van de menor a mayor complejidad funcional. Como formulación germinal, se encuentran en ella los primeros indicios de abordar el desarrollo psicológico que inicialmente fue considerado como la posibilidad de transiciones funcionales de la conducta. En este sentido, el desarrollo se dibuja en una dirección vertical -desarrollo funcional- que alude a los distintos niveles de organización funcional de la conducta. Un problema derivado de esta caracterización es que se complica distinguir entre la teorización de procesos psicológicos y su evolución, y una teorización exclusiva del desarrollo psicológico. Ribes (1996) considera que el desarrollo psicológico se da como cambios cualitativos en la conducta del individuo, ligada estrechamente a una jerarquía de procesos generales -la taxonomía de la conducta- interactuando en un eje funcional vertical. En palabras del autor:

[...] de acuerdo a esta perspectiva, el desarrollo se convierte en un asunto relativo a los cambios en la cualidad de la conducta a lo largo de un eje jerárquico de complejidad cualitativa, en el que las conductas particulares se pueden incluir en cualquier nivel de interacción. Las conductas como acciones y respuestas no cambian mucho durante el desarrollo. Lo que cambia es la manera en que se organizan funcionalmente (p. 270).

No obstante, parece que esta afirmación de Ribes pasa por alto que, en una teorización de procesos generales, las singularidades del comportamiento y los ámbitos en los que tienen lugar son irrelevantes en el proceder analítico, mientras que en una teorización del desarrollo psicológico las morfologías del comportamiento, las circunstancias, la dirección y los ámbitos de desempeño, son claves para teorizar y construir modelos al respecto. Cuando se describe el desarrollo con las mismas categorías con las que se analizan los procesos psicológicos generales, se hace evidente la nula distinción entre las categorías analíticas particulares de una teorización de los procesos estructurantes de lo psicológico y aquellas empleadas en la descripción del desarrollo. Se reconoce que existe una relación estrecha entre ambas teorías, sin embargo, su distinción estriba fundamentalmente en la generalidad de los procesos estructurantes y la especificidad de las habilidades y competencias conductuales, respectivamente. Aún y cuando los procesos psicológicos se refieren a habilidades y competencias concretas, es necesaria una teorización sobre el desarrollo psicológico con base en categorías exclusivas para describir y representar el desarrollo histórico del comportamiento de un individuo.

Con base en la taxonomía de Ribes y López, pero con reconocimiento de peculiaridades del desarrollo psicológico no consideradas por los autores aludidos, Mares y Rueda (1993) realizan un esfuerzo teórico por aproximarse a una conceptualización del desarrollo psicológico con especial énfasis en el desarrollo lingüístico. Estas autoras señalan que la taxonomía permite definir distintos niveles de interacciones, pero para dar cuenta de la ontogenia del lenguaje es necesario determinar la dirección, cambios, transformaciones y condiciones por las cuales un individuo se desarrolla 
psicológicamente. En coincidencia con Vygotski (1979), los procesos psicológicos superiores tienen como base para su desarrollo las relaciones sociales, en una fórmula en la que las condiciones biológicas facilitan ciertas interacciones, pero las condiciones convencionales o sociales, les dan sentido y dirección.

Para Mares y Rueda (1993), lo psicológico como interacción no sólo se desarrolla funcionalmente, sino también morfológicamente, como formas lingüísticas que incluyen escuchar, hablar, leer, escribir y que evolucionan de otras formas como el gesto y el dibujo. De esta manera concretan el planteamiento realizado por Mares (1988) de dividir el estudio del desarrollo psicológico lingüístico en dos vertientes: a) el desarrollo vertical que consiste en el análisis de las transiciones entre niveles funcionales, dando cuenta de sus transformaciones cualitativas; y b) el desarrollo horizontal, que consiste en el análisis de las transiciones lingüísticas al interior de un nivel funcional, que se dan como extensión del lenguaje, a esta forma de concebir el desarrollo psicológico se le ha denominado desarrollo morfológico competencial. De tal manera que el desarrollo psicológico es desarrollo lingüístico en tanto que se configuran los sistemas reactivos convencionales a partir de los sistemas reactivos sensoriales (Kantor \& Smith, 1975). El origen y curso evolutivo de las interacciones psicológicas humanas tiene como base el conjunto de relaciones de contingencia que definen los miembros de un grupo social. Al respecto, las autoras mencionan que:

[...] el arreglo de contingencias que definen la dirección del cambio lingüístico deriva principalmente de la normatividad construida e impuesta por el hombre. Este tipo de relaciones de contingencia se manifiestan al sujeto en desarrollo a través de sus interacciones concretas con otros seres humanos y con distintos productos de la cultura en escenarios definidos socialmente (Mares y Rueda, 1993, p. 45).

El punto de vista de Mares y Rueda (1993) ofrece una forma diferente de comprender el desarrollo psicológico; incorpora la participación conjunta de las relaciones con otros en el desarrollo de las destrezas y acciones del individuo en su dimensión morfológica y permite concebir la relación teórica que se establece con la evolución funcional de la conducta. Este trabajo representa un primer ejercicio conceptual de construir un acercamiento al desarrollo psicológico, en su sentido lingüístico, en correspondencia con una teorización de los procesos psicológicos. Como trabajo pionero dio origen a investigaciones en las que se evaluaban los efectos de entrenar un individuo en una forma lingüística y evaluarla en otra o en otros niveles, en particular en el nivel sustitutivo referencial, que de alguna manera parece sugerir que el desarrollo psicológico sigue un curso que va de lo gestual a lo oral, de lo oral a lo escrito y de lo situacional a lo sustitutivo (Mares, Rueda, Plancarte y Guevara, 1997; Mares et al., 2003; Mares, 2001; Mares, Rueda y Huitrón, 1986 citado en Mares y Rueda, 1993).

Otra forma de abordaje del desarrollo psicológico al amparo de la taxonomía de Ribes y López (1985), es el trabajo de Carpio, Pacheco, Hernández y Flores (1995) quienes recuperan el valor de incorporar la naturaleza social del comportamiento humano. Estos autores consideran que las interacciones psicológicas del individuo se desarrollan como prácticas compartidas por una comunidad de individuos que fincan el carácter social de las situaciones promotoras de dicho 
desarrollo. Proponen que, para la identificación del desarrollo psicológico del individuo, deben tener lugar comportamientos específicos valorados como adecuados por los miembros del grupo a través de criterios. Para ello recuperan la noción de criterio de ajuste (Carpio, 1994), que describe el requerimiento conductual que estructura e identifica las diferentes interacciones psicológicas, en su recuperación de la teoría de proceso; y que representa la demanda impuesta a un individuo en situaciones sociales por aquellos individuos que ya son expertos en determinada práctica, en su recuperación en la teoría de desarrollo. Con esta categoría, Carpio et al. (1995) conciben el desarrollo psicológico del individuo como ajuste a los criterios establecidos por los otros y que tienden a diversificarse y diferenciarse dependiendo del ámbito de desempeño funcional en el que participa. De modo ilustrativo, Carpio et al. (1995, p. 93) apuntan que:

Esta dimensión adquiere "realidad psicológica" en la forma de criterios de logro que el grupo social establece en cada situación interactiva en la que participa el individuo. Tales criterios varían en tipo y complejidad (algunos van desde la mera adecuación de la conducta alimenticia conforme determinados horarios, hasta la realización de tareas que involucran competencias conductuales complejas como las previstas en algunas situaciones escolares).

En relación con los diferentes escenarios en los que se desempeña psicológicamente un individuo, estos son construidos como prácticas grupales y se formalizan y valoran a través de instituciones como la familia, el trabajo, la escuela, la religión, la ciencia, entre otros. Nuevamente, la "realidad psicológica" consta de los criterios de valoración social que califican la conducta individual en su dimensión moral y al interior de tales escenarios. Se establece el conjunto de creencias como condiciones regulatorias del comportamiento humano.

En conjunto, estos trabajos constituyen el marco en el que se generó un planteamiento para el análisis de un tipo de fenómenos y que sirvió como referencia para el análisis del desarrollo de lo psicológico, del comportamiento creativo al desarrollo psicológico.

\section{Modelo Interconductual de Comportamiento Creativo}

El Modelo Interconductual de Comportamiento Creativo propuesto por Carpio et al. (2007) constituye un modelo representacional (Kuhn, 1962; Ribes, Moreno y Padilla, 1996) construido con base en los compromisos ontológicos y epistémicos del paradigma Interconductista. El propósito de dicho modelo es la representación abstracta y genérica de los elementos que componen la caracterización del comportamiento creativo y de aquellas condiciones y relaciones de contingencia bajo las cuales emerge. Como su nombre lo indica, el modelo fue propuesto para el análisis teórico y la investigación empírica del comportamiento creativo; en esa medida, no es formal ni explícitamente un modelo de desarrollo psicológico. En su formulación se reconoce el papel que juega la reactividad biológica en el despliegue del desempeño efectivo, así como el curso que sigue el desempeño efectivo de un individuo, en un ámbito particular, para configurar formas de comportamiento novedosas en otras situaciones y ámbitos, así como dar lugar a productos que son susceptibles de valoración y sanción social. Estas ideas, de manera general, permitieron establecer su relación con el desarrollo psicoló- 
gico del individuo y con una teoría de proceso al recuperarse dos nociones que en ella aparecían, habilidad y competencia:

El desarrollo psicológico puede ser conceptuado como el conjunto de procesos mediante los cuales la reactividad biológicamente potenciada en los organismos individuales por el desarrollo filogenético de su philum se ordena en múltiples configuraciones funcionales de respuesta (habilidades) y estas en disposiciones a la efectividad (competencias), procesos que se enmarcan y definen por el tipo, modo y circunstancias de los contactos particulares que los individuos tienen con ambientes específicos y las demandas conductuales que se les impone en estos momento a momento (Silva et al. 2005, p. 215).

De manera general, en este trabajo se sostiene que el comportamiento de un individuo está enmarcado socialmente en ámbitos, dentro de los cuales el grupo social impone una serie de criterios por cumplir a sus miembros. Cuando un individuo cumple con un criterio en una situación contingencial en la que no hay más que una forma de cumplir con dicho criterio, entonces se predica del individuo que es habilidoso, en tanto desarrolló una habilidad para cumplir con ese criterio. En todas y cada una de las situaciones, un individuo puede desarrollar tantas habilidades como criterios cubra en cada una de ellas. Como un elemento que señala una secuencia, se sostiene que, en un momento posterior, ese individuo que ha desarrollado habilidades en correspondencia con diferentes situaciones, ahora puede estar en condiciones de cumplir con criterios en situaciones en las que no hay una sola forma de cumplirlos. Esto conduce a una diversificación del comportamiento si el individuo cumple con esos criterios en tales situaciones, que son denominadas contingencialmente abiertas. Cuando un individuo muestra efectividad y variabilidad de su desempeño en situaciones diferentes, entonces se predica una tendencia a la efectividad de dicho individuo, dicha tendencia es denominada competencia y supone una equivalencia con el concepto de comportamiento inteligente (Carpio, 2008). Pero el desarrollo psicológico no se detiene con el comportamiento inteligente, ya que un individuo puede estructurar un tipo de situaciones en las que no hay criterios por cumplir (por ende, no puede predicarse ni la posible efectividad ni la existencia de habilidad), generando un criterio, y la situación con ello, así como las posibles formas de cumplirlos. Tales situaciones de forma analítica pueden denominarse contingencialmente ambiguas, dado que no hay criterio que las defina, mientras que el comportamiento que genera criterios y formas de cumplirlos, es denominado comportamiento creativo.

El planteamiento del comportamiento creativo en este trabajo, resultó relevante por muchas razones, de las cuales aquí sólo se destacará el hecho de que su postulación permite, por un lado, determinar el origen de los criterios que definen las diferentes situaciones en un ámbito. Por otro lado, permiten estimar que el desarrollo psicológico no es lineal, progresivo ni hacia adelante, sino diversificado, ramificado, heterogéneo. A lo que se agrega que existe una continuidad entre la habilidad, la competencia y la creatividad en una relación asimétrica, esto es, el comportamiento creativo requiere de la configuración del comportamiento inteligente y este requiere del desarrollo de una habilidad. Pero no todo aquel individuo que desarrolle comportamiento inteligente va a desarrollar comportamiento creativo. Finalmente, se resalta que el comportamiento creativo al dar origen a 
nuevos criterios, da origen a nuevas formas de actuar, transforman el grupo social y torna infinito el desarrollo psicológico, debido a que no existirá un número determinado de criterios por cumplir.

El Modelo Interconductual del Comportamiento Creativo (MICC) expresa una forma distinta de articular las nociones de habilidad, competencia y creatividad respecto de la forma particular en que se habían usado por los investigadores que trabajan siguiendo la formulación de Ribes y López (1985) a continuación algunas apreciaciones al respecto.

\section{De habilidades, competencias y ámbitos de desarrollo}

Un primer término que ha mostrado cambios a lo largo de tres décadas, es el de habilidad o destreza, que fue empleado por Ribes (1990) para describir el conjunto de respuestas relativamente variantes en su morfología, que está impuesta respecto de la naturaleza de los objetos de estímulo. Por ejemplo, cuando un individuo sujeta una taza, la forma que adopta la mano se da en relación con la forma de la taza, independientemente de cuál sea el propósito de sujetarla. En este sentido, la habilidad sucede como interacción individuo-medio en la que se resaltan sus características morfológicas (Varela y Ribes, 2002). Sin embargo, las propiedades funcionales de la habilidad se dan respecto del criterio impuesto al individuo, de tal manera que la habilidad queda definida como relación morfológico-funcional expresada como desempeño efectivo, ajustado a los criterios de logro específicos de una situación problema (Silva et al., 2005; Carpio, 2008).

En cuanto a la noción de competencia, Ribes y López (1985) emplearon el término para caracterizar en forma concreta las interacciones que mantiene un individuo con su entorno. Para estos autores, competencia se refiere a las propiedades morfológicas de la interacción entre las respuestas particulares del organismo con los objetos de estímulo propios de un sistema de contingencias. Asimismo, las competencias adquieren su carácter funcional al determinarse el grado de desligamiento funcional y el tipo de mediación dado un sistema de contingencias. El empleo analítico del término competencia seguido por Ribes y López, orientó el concepto de evolución funcional de la conducta.

Cinco años después, Ribes (1990) propuso que las competencias conductuales referidas en el marco de la planeación para la programación del comportamiento inteligente quedaban definidas como:

un conjunto de respuestas y/o habilidades que, a diferencia de estas últimas, no son invariantes respecto a la morfología de objetos y eventos, sino que pueden cambiar como ejercicio, dependiendo de las circunstancias en que se prescribe el criterio de efectividad funcional ( $p$. 210).

Puede apreciarse que los conceptos de habilidad y competencia han venido sufriendo cambios, lo cual es hasta cierto sentido esperable. Sin embargo, destacan por un lado, que han cambiado sus propias definiciones, por otro lado, lo mismo ha formado parte de una teorización de proceso que una de desarrollo, sin que se tracen nítidamente sus usos y límites.

Desde el punto de vista de Carpio et al. (2007), el término competencia describe, más que un conjunto de habilidades, una tendencia al desempeño efectivo en situaciones variadas. Esta 
perspectiva de análisis vuelve indistinto el tratamiento conceptual del comportamiento inteligente y la noción de competencia; hablar de un individuo inteligente es hablar de un individuo con disposición a resolver problemas variados, es decir, de un individuo competente. El desarrollo de competencias conductuales consiste en el ejercicio de habilidades en situaciones distintas, novedosas, que requieren una adecuación constante de tal desempeño (Carpio, 2008).

Dada la naturaleza social del comportamiento humano, es de esperar que la variedad de habilidades y competencias conductuales que desarrolla se encuentran definidas por las características de los ámbitos en que se desempeña. En términos del desarrollo, las interacciones psicológicas que mantiene el individuo con los objetos y otros individuos se organizan al interior de las instituciones en las que se comporta; el constante ejercicio promueve el desarrollo de hábitos conductuales cuyas morfologías son configuradas en la práctica que aprende.

Durante el curso de su vida, el individuo es capaz de participar activamente en diferentes ámbitos funcionales. De esta manera es que resulta posible decir que el desarrollo psicológico se diversifica en la vida del individuo. Las habilidades que desarrolla una persona como madre cuando enseña a su hijo a ir al baño por sí mismo o ejecutar las diferentes acciones para bañarse y vestirse, por ejemplo, son morfológica y funcionalmente distintas de aquellas que desarrolla la misma persona en calidad de trabajadora en una tienda departamental, colocando objetos en estantes o vendiendo cierto tipo de productos. En otras palabras, el mismo ser psicológico se desarrolla asimétricamente, construyendo historias de interacción diferentes en función de los ámbitos en los que se desempeña, como sostiene Chávez (2016):

Toda vez que lo psicológico se desarrolla en la ontogenia del individuo, por excelencia, se desarrollan historias de logro diferenciadas y diversificadas para cada individuo; dicho desarrollo como historia se expresa en forma continua durante la vida del ser psicológico. Es justamente a través de los logros -habilidades-y de la tendencia a logros variados -competencias- que la reactividad biológicamente potenciada en el individuo pasa a ser expresión psicológica en acto, como ajuste a los criterios impuestos por la cultura que hace peculiar el desarrollo humano (p. 51).

La noción de ámbito funcional en un sentido amplio comprende la delimitación y pertinencia del desarrollo de habilidades y competencias del individuo, constituye una categoría que permite delimitar la funcionalidad y pertinencia del comportamiento, así como su curso histórico. El ámbito en un modelo de representación para el análisis empírico del desarrollo, proporciona las directrices y matices del tipo de investigación que se realiza en el campo. Los logros de un individuo son dependientes siempre de los criterios que el grupo social de referencia del individuo, demanda en diversas circunstancias o ámbitos, lo cual permite apreciar el dinamismo de los criterios como su diversificación dentro del mismo grupo.

Finalmente, el concepto de comportamiento creativo en la obra de Ribes (1990) representa un caso de comportamiento exploratorio, es decir comportamiento variado que no cumple criterios, pero en los que sí existen criterios a la luz de los cuales es posible determinar su inefectividad. Mientras que en el trabajo de Carpio et al. (2007) el comportamiento creativo no es comportamiento 
exploratorio, ni puede ser valorado a la luz de los criterios de efectividad, ya que justamente esos criterios son generados por dicho comportamiento. Además de existir continuidad y dependencia entre el comportamiento inteligente y el creativo, relaciones que no se plantean en la obra de Ribes (1990). Esta continuidad en la configuración del comportamiento creativo, conduce a reflexionar sobre la secuencia e historia que pueden tener los logros o habilidades de un individuo y que impactan el análisis del desarrollo psicológico.

\section{Historicidad, secuencialidad y logro psicológico: consideraciones adicionales}

El carácter histórico y ajustivo de las interacciones psicológicas constituyen dos de las diferencias respecto de las interacciones físicas y biológicas, que fueron señaladas por Kantor y Smith (1975). La interconexión de los ajustes psicológicos de un individuo, constituye su experiencia conductual, misma que a su vez conforma los detalles característicos de su Historia Interconductual. Esta característica particular de las interacciones psicológicas ha permitido considerar un nivel de teorización que organice conceptualmente el desarrollo de la conducta del individuo.

Desde el punto de vista de Ribes $(1987,1996)$, una teoría del desarrollo psicológico consiste, fundamentalmente, en una teoría de la secuencialidad histórica de los procesos psicológicos del individuo. Sin embargo, esto puede conducir a reducir o simplificar el desarrollo psicológico a transiciones entre procesos psicológicos y de ahí a buscar una secuencia ascendente y lineal, sólo hay un pequeño paso.

El desarrollo psicológico consiste de la secuencialidad y organización conductual de las habilidades y competencias del individuo al interior de los escenarios o ámbitos en los que se inserta. El supuesto de secuencialidad en la teoría del desarrollo debe ser tratado como historicidad psicológica y no como sucesión de eventos discretos, aún y cuando sea a través de ellos que tenga sentido hablar de la ontogenia del individuo.

Toda vez que los objetivos científicos de una teoría del desarrollo como teoría de la secuencialidad psicológica son la descripción y predicción de colecciones de contactos efectivos (Ribes, 1996), el tipo de enunciados que formula son de carácter disposicional referidos a examinar tendencias de logro del individuo. El problema que compete a una teorización de esta naturaleza está directamente relacionado con lo que Kantor y Smith (1975) denominan Historia Interconductual; en la que se representa la influencia de las interacciones pasadas sobre las interacciones presentes del individuo con los eventos de estímulo que componen sus circunstancias fisicoquímicas, ecológicas y culturales.

En el trabajo de Carpio (2005) y Carpio et al. (2007), se ha representado implícitamente el supuesto de secuencialidad del desarrollo psicológico a través del Modelo Interconductual de Comportamiento Creativo (MICC). En dicho modelo, la secuencialidad está representada por el tipo de situaciones definidas contingencialmente en las que interactúa psicológicamente un individuo. Así, la secuencia en el desarrollo psicológico comienza con las Situaciones Contingencialmente Cerradas (SCC), sigue con las Situaciones Contingencialmente Abiertas (SCA), hasta llegar a las Situaciones Contingencialmente Ambiguas (SCAM). Sin embargo, esto no quiere decir de ninguna manera que el desarrollo, representado mediante situaciones, se dé en forma lineal. Al hablar de la secuencia de 
situaciones contingenciales, no se está diciendo que se presenten en momentos seguidos uno del otro o situaciones posteriores a otras; sino que se trata de secuencia de situaciones expresadas en un flujo o continuo. Lo que en otras palabras quiere decir que, las competencias desarrolladas por el individuo, no se dan en un momento diferente y posterior a las situaciones en las que se desarrollan las habilidades, sino que, las competencias se desarrollan mediante las habilidades y no después de ellas.

Desde la lógica del Modelo Interconductual de Comportamiento Creativo, las habilidades son caracterizadas como relaciones que se establecen entre un desempeño, una situación y un criterio de ajuste que define su estructura contingencial (Carpio et al., 2007). La habilidad como desempeño efectivo es identificada a través de la satisfacción de criterios de logro, los cuales constituyen la base del desarrollo psicológico del individuo al interior de los escenarios y ámbitos que especifican la pertinencia funcional de tal desarrollo. El compromiso con el supuesto de secuencialidad se encuentra intrínseco en el ajuste progresivo del individuo a los criterios de logro impuestos por la situación, otros individuos o el propio individuo. En otras palabras, la secuencialidad como supuesto teórico del desarrollo se expresa funcionalmente a través de la historia de logro particular del individuo en las condiciones genéricas del ámbito funcional en el que se desempeña.

Con base en la lógica de las categorías disposicionales (Ryle, 1949) y el tratamiento conceptual propuesto por Kantor y Smith (1975) y Kantor (1978), la Historia Interconductual del individuo se considera un factor disposicional que modula las probabilidades de contacto funcional entre el organismo y los eventos de estímulo. En términos del desarrollo psicológico, la historia de logro del individuo no representa una simple visión acumulada de las respuestas y la variabilidad morfológica que las distingue, sino que, en sentido estricto, la historia de logro configurada por el individuo constituye de manera general sus posibilidades de transformar psicológicamente una situación contingencial en otra. En términos de la secuencialidad como supuesto teórico, dicha representación integra las distintas situaciones como el desarrollo mismo del individuo, y no como momentos consecutivos.

Siguiendo los compromisos ontológicos y epistemológicos señalados por Carpio (2008) respecto de la definición de lo psicológico, a continuación, se muestran estos compromisos a través de preguntas, pero en particular, las pertinentes al desarrollo psicológico.

¿Qué se desarrolla? Desde el punto de vista de lo psicológico, lo que desarrolla el individuo son desempeños efectivos ante diferentes criterios y en diversas situaciones (habilidades), así como la tendencia a ser efectivo ante situaciones novedosas (competencias) y eventualmente, desarrolla una tendencia a generar nuevos criterios y sus formas de satisfacerlos (creatividad).

¿Dónde se desarrolla lo psicológico? El desarrollo tiene lugar en los ámbitos funcionales que se construyen en las diferentes esferas de actividad humana de un momento y espacio particular, en los que se desempeña el individuo. Las habilidades y competencias que este desarrolla se dan en las situaciones definidas por los criterios que a su vez son definidos en las prácticas convencionales de tales ámbitos. De esta manera, el desarrollo como ejercicio de habilidades ocurre en los escenarios particulares que componen el lenguaje, tornando así desarrollos asimétricos en el individuo en los distintos ámbitos a los que pertenece.

¿Cómo ocurre el desarrollo psicológico? Dada la naturaleza secuencial de las interacciones psicológicas del individuo, el desarrollo ocurre como ajuste conductual progresivo y diversificado 
a los criterios de logro impuestos por la situación, otros individuos y el propio individuo. Conformando de esa manera, la historia de ajuste como logros en los ámbitos en que se desempeña.

¿Cuándo ocurre el desarrollo psicológico? El desarrollo puede ocurrir a partir de la ontogénesis del individuo y termina con la muerte del mismo. Bajo este supuesto, lo psicológico siempre se desarrolla en un continuo y como construcción histórica y peculiar de la conducta del individuo.

¿Cómo se conoce el desarrollo de lo psicológico? Por medio de la observación, experimentación y análisis de la historia psicológica del individuo. Su conocimiento se da mediante la observación del curso histórico de las situaciones contingenciales en las que interactúa. Se conoce a través de la experimentación, es decir, generando condiciones controladas para su investigación empírica y dadas las limitaciones para identificar el tipo de historias de efectividad de un individuo: a) se pueden implementar diversas demandas que posibiliten tener muestras de lo que un individuo es capaz de cumplir en un ámbito particular, o b) construir historias de efectividad o de habilidades, imponiendo diferentes criterios, manipulando situaciones, e ilustrando formas de cumplir criterios. Se conoce con base en el análisis adoptado para su interpretación y su explicación.

Estas cuestiones y sus posibles respuestas permiten plantear preguntas pertinentes a este tipo de teorización, sugerir los criterios de enlace con otras formas de teorización y encuadrar la investigación empírica del desarrollo psicológico.

\section{Algunas consideraciones metodológicas para el análisis empírico del desarrollo}

El Modelo Interconductual de Comportamiento Creativo es el ejemplar metodológico (Kuhn, 1962) para el estudio empírico del desarrollo de habilidades, la promoción de competencias y la emergencia de comportamiento creativo. En otras palabras, el modelo como representación del desarrollo se vuelve el mapa de orientación conceptual y procedimental que guía el análisis mismo de la transformación psicológica del individuo en un ámbito en particular. Sin embargo, aún y cuando el modelo proporciona el ejemplar metodológico de representación del desarrollo psicológico, los estudios empíricos sobre el desarrollo psicológico que se han realizado todavía muestran más compromisos con una teorización de proceso en cuanto a su preocupación por promover interacciones psicológicas más complejas (sustitutivas) o variar valores, factores o condiciones como vía para la promoción de competencias. En una metáfora, se siguen realizando, en la mayoría de los casos, experimentos sobre el desarrollo psicológico siguiendo el mapa de los procesos psicológicos.

En el análisis experimental del desarrollo psicológico deben reconocerse dos premisas teóricas, una de carácter conceptual y otra de orden metodológico. La primera se refiere a qué se entiende por habilidad y competencia como categorías teóricas de un modelo de desarrollo psicológico. La segunda tiene que ver con los procedimientos y arreglos diseñados para el estudio empírico del desarrollo de habilidades y competencias, pero, sobre todo, se relaciona con los criterios de cambio metodológico que se siguen para el desarrollo de los procedimientos, arreglos y condiciones diseñadas. Dado que ya se ha descrito la primera premisa, daremos paso al desarrollo de la segunda premisa.

Concebir a la habilidad como la unidad básica del desarrollo psicológico implica redefinir los criterios de cambio metodológico seguidos en el estudio experimental del mismo. Si el objeto 
central de estudio empírico es el desarrollo de habilidades conductuales en el dominio particular de un ámbito funcional de desempeño, el criterio de cambio metodológico por excelencia está definido por el desempeño efectivo del individuo. En el análisis experimental se definen necesariamente criterios de cambio en las condiciones y fases que componen el experimento. La metodología empleada tradicionalmente en la investigación científica, y de modo particular para la investigación del comportamiento, establece criterios definidos por la cantidad de ensayos en cada bloque durante la fase experimental o aplicación de la variable independiente (Hernández-Sampieri, Fernández y Baptista, 2010). Otro tipo de criterios consisten en la imposición de intervalos de tiempo que definen la duración de las condiciones del experimento. Un criterio de cambio ampliamente considerado en los estudios psicológicos experimentales es la ejecución misma del sujeto o participante. No obstante, en la mayoría de las ocasiones su aplicación se torna indistinta en cuanto a si la ejecución del sujeto es correcta o incorrecta. También se ha establecido como criterio de cambio de las condiciones experimentales, el porcentaje de respuestas correctas, mientras más cercano al nivel más alto, mejor (p. ej., 80\% de efectividad).

Al evaluar empíricamente los factores que influyen en el desarrollo de habilidades, no puede prescindirse de establecer como criterio de cambio el desarrollo mismo de la habilidad, toda vez que representa el desempeño efectivo, el logro del individuo frente al criterio impuesto en una tarea experimental dada. El establecimiento de la habilidad mediante la satisfacción del criterio de logro impuesto por el investigador se presenta como indicador inmediato del desarrollo y al mismo tiempo señala el cambio en la tarea experimental o condición definida. De omitirse tal criterio metodológico habría que preguntarse entonces, cuál desarrollo. En el caso particular del análisis del desarrollo psicológico, no se puede asumir una postura que limita la participación del individuo (que finalmente es el que desarrolla una historia interactiva particular), en la que basta con exponer al sujeto frente a una situación experimental diseñada ex profeso, sino que es necesario promover condiciones para que tenga lugar el desempeño efectivo frente al criterio o permitir al individuo que elija entre aquello que puede cumplir y auspiciar que cumpla con demandas diferentes. En cualquier tipo de investigación, el individuo no permanece inerte durante las condiciones programadas, sino que es capaz de producir efectos diferentes a los esperados con el tipo de interacciones que despliega y dichas formas de actuación deben recuperarse reconociendo que el individuo se comporta en función de su repertorio conductual, no como el investigador desea o espera.

Es importante subrayar que de ninguna manera volver a la habilidad como el criterio de cambio cancela la posibilidad de seguir otros criterios de orden metodológico. Imponer un criterio de esta naturaleza no desvirtúa el análisis de las relaciones entre variables independiente y dependiente. Esta serie de consideraciones asociadas a esta redefinición de los criterios metodológicos seguidos en el análisis experimental del desarrollo psicológico, puede acotarse como sigue:

1. Según la concepción del desarrollo psicológico como construcción histórica de los ajustes secuenciales -logros- del individuo, el empleo de un criterio metodológico como el descrito anteriormente, resulta congruente y coherente teóricamente con dicha concepción.

2. Toda vez que el criterio metodológico consiste en el desarrollo de la habilidad como desempeño efectivo, su empleo se refiere a establecer la condicionalidad de cambio a una nueva situación, condición, fase o procedimiento durante el experimento. 
3. La investigación experimental sobre el desarrollo psicológico puede fincarse sobre el diseño de situaciones experimentales en las que un individuo cumpla con un criterio, más que en un conjunto de situaciones problema que se le presentan en la forma de ensayos. Hacerlo de esta manera rompe con la idea de un experimento con un número de ensayos definido por el investigador y da lugar a experimentos con situaciones problema en los que el desempeño del individuo es el propio indicador de la duración del experimento en tanto resuelve o no tales situaciones, lo cual establece una diferencia entre ensayos y situaciones problema, se puede tener un experimento con diferentes ensayos y mismo número de situaciones problema o viceversa.

Estas acotaciones pueden generar un conflicto con los criterios metodológicos consensuados, pero es necesario señalar que no es posible concebir la experimentación del desarrollo psicológico con base en el seguimiento de criterios metodológicos tradicionales, sino que, además de ellos, deben incorporarse criterios psicológicos coherentes con el aparato conceptual, categorías taxonómicas y de medida (Ribes et al., 1996) propias de una teoría del desarrollo psicológico.

La lógica seguida por la metodología de la investigación del comportamiento (Kerlinger y Lee, 2002) plantea el estudio propio de la conducta desde una perspectiva de análisis entre-grupos en la mayoría de los casos, pero que siempre borra la peculiaridad del comportamiento individual al promediar y obtener un "ser psicológico promedio". Los criterios para la construcción de los ensayos discretos que componen un bloque del procedimiento, no se salva de críticas, en particular porque ha contribuido a considerar que debe incorporarse al estudio de la conducta una suerte de homogeneización de las condiciones experimentales y sus componentes. Se dice normalmente que cierta cantidad de sujetos de un grupo fueron expuestos a cierto número de ensayos; el inicio y fin de los ensayos en la mayoría de las veces, señala el fin de una condición y el cambio a otra. Si se reconoce que el comportamiento psicológico se desarrolla y cambia en función del tipo de las situaciones problemas con las que interactúa el individuo, la segmentación episódica de las circunstancias que manipula y contabiliza el investigador, no obedecen a hablar de ensayos discretos, sino a las propias situaciones problema, sus propiedades y características. En este sentido, lo que para el investigador representa cierta cantidad de ensayos, para el individuo puede representar una misma situación problema. Finalmente, no puede soslayarse que la historia de los individuos que participan en un experimento, no es susceptible de "borrarse" ni "homogeneizarse" y que el efecto de "acarreo" que tantas veces es la variable extraña a eliminar, en el caso de la investigación sobre el desarrollo psicológico, es justamente un aspecto a evaluar, es la propia historia interactiva del individuo hecha acto y factor disposicional que no se puede eliminar.

Al proponer al desempeño efectivo como criterio de cambio metodológico en las condiciones de experimentación y estudio empírico del desarrollo psicológico, deben considerarse algunas características centrales de su empleo:

A. Las tareas experimentales diseñadas para el análisis empírico del desarrollo deben considerar los criterios de validez y relevancia ecológica pertinentes al dominio del ámbito funcional en que tiene sentido el desarrollo de las habilidades esperadas. Los procedimientos y diseños seguidos tradicionalmente por la Psicología Interconductual están directamente 
derivados de los procedimientos de discriminación condicional (Trigo y Martínez, 1994); la tarea de igualación de la muestra es empleada normalmente en la mayoría de los estudios experimentales sobre el comportamiento; su popularidad está basada en su alto grado de sistematización y el amplio espectro de fenómenos conductuales que pueden ser estudiados (Ribes, 1990). Sin embargo, dado que la tarea de igualación de la muestra nació en el área de experimentación de control de estímulos, su empleo como tarea experimental para el estudio empírico del desarrollo puede verse limitado, ya que, al emplearla como tarea experimental genérica no reconoce la complejidad de los diferentes dominios y las características de los ámbitos en los cuales interesa estudiar cómo un individuo se desarrolla psicológicamente. En esa medida, las tareas diseñadas para la investigación del desarrollo psicológico de los estudiantes de ciencias debieran considerar en su construcción características como las habilidades conceptuales, metodológicas y prácticas que requiere en su formación.

B. La evaluación del desarrollo está directamente relacionada con la habilidad configurada, misma que es identificable mediante la satisfacción del criterio de logro impuesto en la tarea. El desarrollo como ajuste secuencial del individuo se traduce en logros con base en un criterio cubierto; la medición del desarrollo consiste en la valoración puntual de los logros obtenidos en las distintas condiciones del entrenamiento y prueba de transferencia. La medición del desarrollo psicológico debe ser intra-individual, es decir, valorar los cambios del individuo respecto de sí mismo, pero en otro momento (Ribes, 1990). Es importante precisar que, al evaluar los cambios en la conducta individual como evidencia del desarrollo psicológico, aquello medible son los logros obtenidos por el individuo como ajuste psicológico a un criterio impuesto. Con ello se pretende distinguir que la noción de criterio de logro (Ribes, 1989) se torna pertinente en una teorización del desarrollo; mientras que la noción de criterio de ajuste (Carpio, 1994), tiene sentido a la luz de una teoría de procesos psicológicos. De lo anterior vale decir que todo logro es un ajuste, pero no todo ajuste es un logro.

C. El carácter longitudinal de los estudios empíricos sobre el desarrollo psicológico implica la observación episódica a lo largo de un tiempo definido. Arnau y Bono (2008) consideran que el objetivo de los estudios longitudinales es la descripción de los cambios horizontales en los periodos de aplicación de la variable independiente, tales cambios son reflejados con base en las mediciones repetidas que progresivamente representan los efectos potenciales del desarrollo. El desarrollo de habilidades por parte de un individuo también requiere de la delimitación de un tiempo para realizar la observación/experimentación, pero sin olvidar que no se puede definir a priori cuánto tiempo tomará el desarrollo de una habilidad o la emergencia de una competencia.

Todas las consideraciones descritas pretenden ser leídas a la luz de las implicaciones que conlleva la propuesta para el estudio empírico del desarrollo psicológico. Con base en la recuperación del papel que juega la continuidad habilidad-competencia-creatividad en una teoría del desarrollo y las consideraciones metodológicas implicadas, es posible pensar que existan diferencias entre los estudios realizados en los que se implementan condiciones variables sin tomar en cuenta la efectividad del individuo (c.f. Morales et al., 2010; Morales, Silva y Carpio, 2012) y los estudios en los que 
se varíen condiciones pero se emplee como criterio de cambio la efectividad. Para dar una primera respuesta a este planteamiento, se realizó un estudio experimental que tuvo por objetivo evaluar los efectos de la historia de efectividad controlada versus no controlada durante el entrenamiento sobre el desempeño efectivo en situaciones lectoras novedosas en estudiantes universitarios.

\section{Metodología}

Participantes. 22 estudiantes del primer semestre de la carrera de Psicología de la Facultad de Estudios Superiores Iztacala, todos ellos inscritos en la asignatura de Psicología Experimental Teórica I, con una edad de entre 18 y 24 años, considerar estudiantes de nuevo ingreso fue una manera de controlar la historia experimental.

Aparatos e Instrumentos. Se utilizó una computadora personal de escritorio PC-Getaway (ALL-INONE) con un sistema operativo Microsoft Windows 8 con acceso a internet mediante el cual se contactaba vía Gmail a los participantes. Un registro de ocurrencia elaborado en Word 2010 del paquete Office instalado en la misma computadora.

Procedimiento. Los participantes fueron asignados aleatoriamente a dos grupos: el de Historia de Efectividad No Controlada (HENC) y el de Historia de Efectividad Controlada (HEC). Cada Grupo con un total de 11 estudiantes.

Entrenamiento. Consistió en la elaboración de 15 tareas lectoras, distribuidas en 3 bloques con 5 tareas cada uno. Las tareas lectoras quedaron definidas y diferenciadas para cada bloque por el criterio de logro impuesto, el procedimiento de identificación implicado y el referente de lectura. El primer bloque de tareas consistió en el criterio de relación texto-definición; la estructura de la tarea lectora era la siguiente: se dividió la hoja en dos columnas, en la parte superior de la columna izquierda de la hoja se mostraba una instrucción general, enseguida se presentaba el fragmento de un texto -referente de lectura-, mientras que en la parte superior de la columna derecha de la hoja, se presentaba el criterio de logro impuesto y enseguida las opciones de respuesta disponibles que el participante debía identificar mediante el resaltado de la repuesta que consideraba correcta. El segundo bloque de tareas fue consistente en el criterio de relación definición-ejemplo; la estructura de las tareas fue prácticamente la misma, evidentemente sólo cambió el criterio de logro impuesto y por ende las opciones de respuestas disponibles. Por último, el tercer bloque de tareas se basó en el criterio de relación ejemplo-ejemplo. A diferencia de las estructuras de tarea anteriores, en este bloque se omitió el fragmento de texto, ya que no era necesario (véase Tabla 1).

Vía electrónica se les envío la tarea a resolver a los participantes en un día y hora fijados. En el correo se adjuntaba un documento de Word junto con un mensaje que decía: "Estimado alumno, te mando la tarea correspondiente al día de hoy. Por favor resuélvela y reenvíala en tu hora asignada. Gracias". Para el Grupo HENC el avance de los participantes durante el entrenamiento no fue condicional a su desempeño efectivo, es decir, los participantes pasaban de una tarea lectora a otra independientemente de su desempeño. Una vez que el participante reenviaba el documento simple- 
Tabla 1. Diseño general del Estudio.

\begin{tabular}{|c|c|c|c|c|c|c|}
\hline \multirow{2}{*}{$\begin{array}{c}\text { Grupo } \\
\mathrm{N}=11\end{array}$} & \multicolumn{3}{|c|}{ Entrenamiento } & \multicolumn{3}{|c|}{ Transferencia } \\
\hline & $\begin{array}{l}\text { Criterio de } \\
\text { relación }\end{array}$ & Procedimiento & $\begin{array}{l}\text { No. de } \\
\text { Tareas }\end{array}$ & $\begin{array}{l}\text { Criterio de } \\
\text { relación }\end{array}$ & Procedimiento & $\begin{array}{l}\text { No. de } \\
\text { Tareas }\end{array}$ \\
\hline HENC & $\begin{array}{l}\text { Definición - } \\
\text { Texto } \\
\text { Definición - } \\
\text { Ejemplo }\end{array}$ & Identificación & 5 & $\begin{array}{l}\text { Definición - } \\
\text { Texto } \\
\text { Definición - } \\
\text { Ejemplo }\end{array}$ & Identificación & 15 \\
\hline HEC & $\begin{array}{c}\text { Ejemplo - } \\
\text { Ejemplo }\end{array}$ & & 5 & $\begin{array}{l}\text { Ejemplo - } \\
\text { Ejemplo } \\
\text { Definición - } \\
\text { Definición }\end{array}$ & & \\
\hline
\end{tabular}

mente se le decía: "Hola, enhorabuena tu tarea ha sido registrada, gracias". Es importante señalar que no se indicaba si su desempeño era efectivo o inefectivo para no generar un efecto por este tipo de retroalimentación. Inmediatamente se registraba si su desempeño era efectivo o inefectivo. Esta forma de proceder se repitió hasta que los participantes concluyeron las tareas para cada condición durante el entrenamiento, si es que concluían las tareas.

Por otra parte, a los participantes del Grupo experimental (HEC), se les entrenó con base en un criterio de cambio metodológico condicional a su desempeño efectivo. En otras palabras, los participantes de este Grupo pasaban de una tarea lectora a otra si, y sólo si, se desempeñaban efectivamente frente al criterio de logro impuesto. En caso de no desempeñarse efectivamente, el participante recibía retroalimentación sobre su desempeño inefectivo y se programaban ensayos de corrección. De la misma manera que el Grupo con HENC, al Grupo con HEC se les enviaba por correo el documento de Word con la tarea a resolver, se redactaba el mismo mensaje de envío. Una vez que los participantes mandaban su tarea se registraba si su desempeño había sido efectivo o inefectivo. Si su desempeño era efectivo, se les enviaba el siguiente mensaje: "Hola, tu respuesta es correcta. Enhorabuena tu tarea ha sido registrada, gracias". Toda vez que su desempeño era efectivo, se les enviaban las tareas siguientes hasta concluir las tareas del entrenamiento. No obstante, siempre que su desempeño era inefectivo se les enviaba el siguiente mensaje: "Hola, tu respuesta es incorrecta. Por favor corrige tu tarea y envíala nuevamente. Gracias". Es importante mencionar que además de la retroalimentación proporcionada, se adjuntaba un documento que jugaba las veces de ensayo de corrección. Para evitar la posibilidad de una elección de respuesta azarosa, tanto en el entrenamiento como en los ensayos de corrección se variaba la posición de la respuesta correcta y el contenido de las opciones de respuesta incorrecta. En caso de que el participante no corrigiera su desempeño inefectivo en el primer ensayo de corrección, se volvía a presentar la retroalimentación junto con otro ensayo de corrección distinto del anterior. De tal manera que se proporcionaban tantos ensayos 
de corrección como errores cometidos por los participantes. En cuanto el participante corregía su desempeño de inefectivo a efectivo, se le decía que su respuesta era correcta y estaba en condición de resolver la siguiente tarea. Se procedió de la misma manera hasta concluir todas las tareas del entrenamiento.

Transferencia. Se aplicó a ambos grupos una evaluación caracterizada como transferencia. La evaluación consistió en la solución de 15 tareas novedosas para cada uno de los participantes en ambos grupos. Las tareas seguían la misma estructura de las que tuvieron lugar en el entrenamiento, sólo que estas implicaban un criterio de relación nuevo (Definición-Definición) y referentes de lectura también nuevos (véase Tabla 2). De igual manera, se envío vía electrónica un juego de tareas a cada participante y se solicitó que reenviaran el documento con sus respuestas. Cabe mencionar que no se presentó ningún tipo de retroalimentación durante toda la evaluación.

Tabla 2. Tipos de relación y referentes para cada condición.

\begin{tabular}{|c|c|c|}
\hline Condición & Referencia de Lectura & Criterio de Relación \\
\hline Entrenamiento & Sensación & $\begin{array}{r}\text { Texto-Definición, Definición-Ejemplo } \\
\text { y Ejemplo-Ejemplo }\end{array}$ \\
\hline Transferencia & $\begin{array}{c}\text { Sensación, Emoción } \\
\text { e Imaginación }\end{array}$ & $\begin{array}{r}\text { Texto-Definición, Definición-Ejemplo, } \\
\text { Ejemplo-Ejemplo y Definición-Definición }\end{array}$ \\
\hline
\end{tabular}

Resultados. Para determinar los efectos de la historia de efectividad controlada sobre la promoción del desempeño efectivo en situaciones novedosas, se realizaron diferentes tipos de comparaciones: 1) intra-sujeto y 2) entre-sujetos por tipo de tarea.

Análisis intra-sujeto. En la Figura 1 se muestra una comparación del desempeño individual durante el entrenamiento (barras color rojo) y en la prueba de transferencia (barras color amarillo) de los participantes del Grupo con HENC. En términos de los logros alcanzados durante el entrenamiento $(E)$, el P1 muestra mejoría en su desempeño durante la evaluación de transferencia $(T)$ (E, 8/15; T, 9/15); el P2 no presenta cambio alguno de condición a condición (E, 5/15; T, 5/15); el P3 presenta mejoría de condición a condición (E, 4/15; T, 5/15); el P4 disminuye su desempeño durante la transferencia $(E, 6 / 15 ; T, 5 / 15)$; el P5 también disminuye su desempeño $(E, 10 / 15 ; T, 9 / 15)$; para el P6 se muestran diferencias positivas al comparar su desempeño en la transferencia respecto del entrenamiento ( $E, 3 / 15 ; T, 5 / 15)$; por otra parte, el P7 disminuye su desempeño durante la transferencia $(E, 5 / 15 ; T, 3 / 15)$; los participantes $\mathrm{P} 8, \mathrm{P} 9, \mathrm{P} 10$ y $\mathrm{P} 11$ muestran mejoría en su desempeño en la transferencia respecto del entrenamiento (E, 4/15; T, 7/15), (E, 2/15; T 4/15), (E, 3/15; T, 6/15) y $(E$, 3/15; T, 4/15), respectivamente.

Los resultados presentados anteriormente permiten apreciar los cambios cuantitativos del desempeño individual de los participantes. Considerando este tipo de análisis puede sugerirse que 
las condiciones metodológicas generales seguidas para el entrenamiento de este Grupo no producen un efecto negativo, pero tampoco positivo sobre el desempeño individual de los participantes.

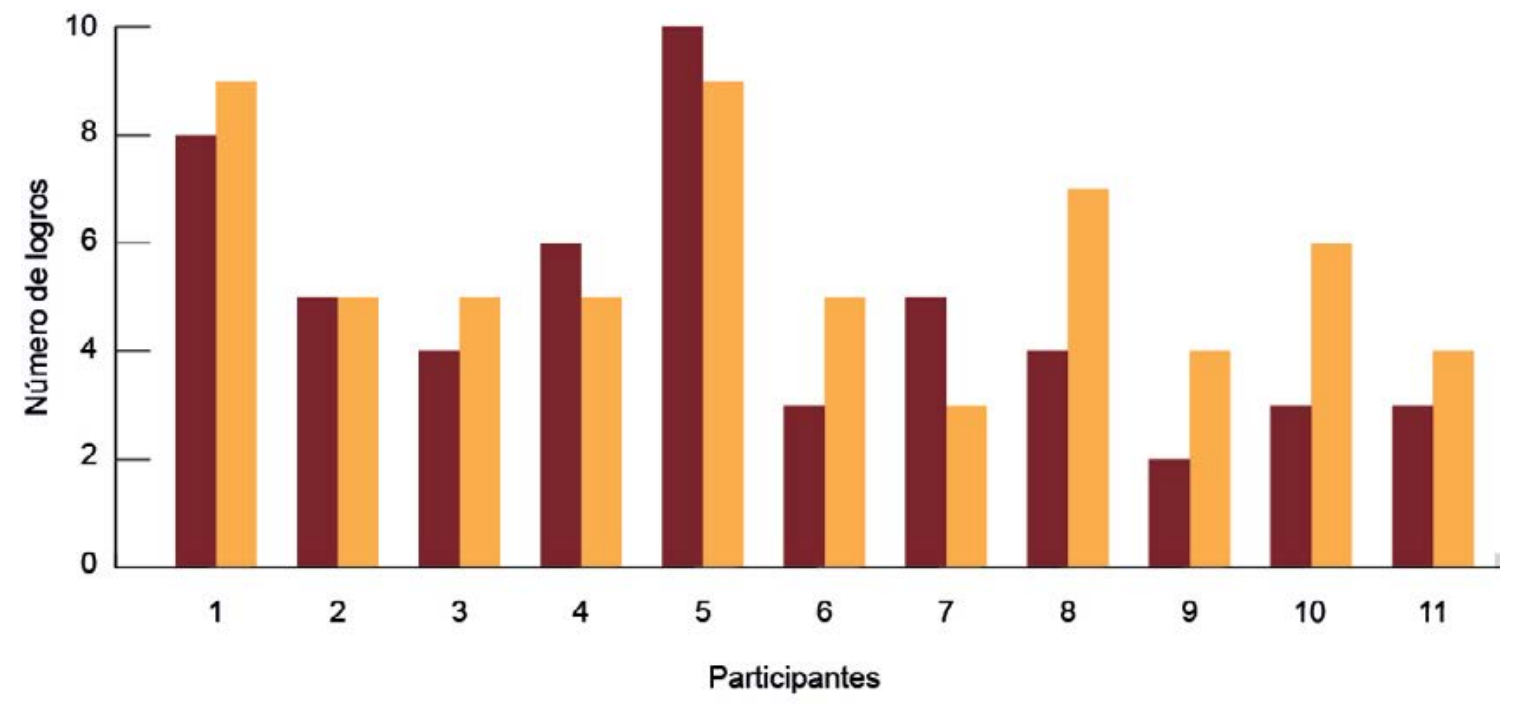

Entrenamiento

Transferencia

Figura 1. Logros obtenidos por participante del Grupo con Historia de Efectividad No Controlada durante el entrenamiento y transferencia.

Por otra parte, en una comparación del desempeño efectivo por participante en transferencia respecto del entrenamiento del Grupo con HEC, se aprecia lo siguiente. El P1 muestra una disminución de un logro en la transferencia respecto del entrenamiento ( $E, 4 / 15 ; T, 3 / 15)$; de igual manera, el P5 presenta la misma disminución, pero con cantidades de logro distintas (E, 8/15; T, 7/15). En cambio, los participantes P3, P4, P7, P10 y P11, presentan mejoría de un logro en la transferencia respecto de su historia de logro construida en el entrenamiento (E, 12/15; T, 13/15), (E, 11/15; T, 12/15), ( $E, 13 / 15 ; T, 14 / 15),(E, 7 / 15 ; T, 8 / 15)$ y (E, 8/15; T, 9/15), respectivamente. El P2 también presenta cambios positivos en su desempeño durante la transferencia (E, 8/15; T, 11/15); de igual manera, el P9 presenta una mejoría de dos logros (E, 11/15; T, 13/15). Finalmente, sólo el P6 no muestra diferencia alguna entre el entrenamiento y la transferencia ( $E, 4 / 15 ; \mathrm{T}, 4 / 15)$ (ver Figura 2).

Con base en estos resultados puede considerarse que las diferencias presentadas en cada participante respecto de sí mismo, están directamente relacionadas con la historia de logro individual construida durante el entrenamiento, pero sobre todo por las condiciones metodológicas particulares de su entrenamiento.

Análisis entre-sujetos por tipo de tarea. En un análisis de las historias de logro de los participantes del Grupo con HENC durante el entrenamiento para los tres tipos de criterio-relación impuestos en bloques de 5 tareas para cada tipo, se obtiene lo siguiente (ver Figura 3). Los participantes P1 y P5 alcanzan 8 y 10 logros respectivamente, en los tres tipos de relación entrenados. El resto de los participantes con excepción del P11 consiguen logros en dos tipos de criterios-relación, sin embargo, al considerar la sumatoria de logros obtenidos por todos los participantes, tanto en la relación 
Texto-Definición como para la relación Definición-Ejemplo, obtienen un total 23 logros. Lo anterior permite decir que a pesar de que al comparar las historias de logro entre participantes se muestran diferencias en la cantidad de logros obtenidos por tipo de relación, tales diferencias quedan borradas al considerar el común de logros obtenidos durante todo el entrenamiento.

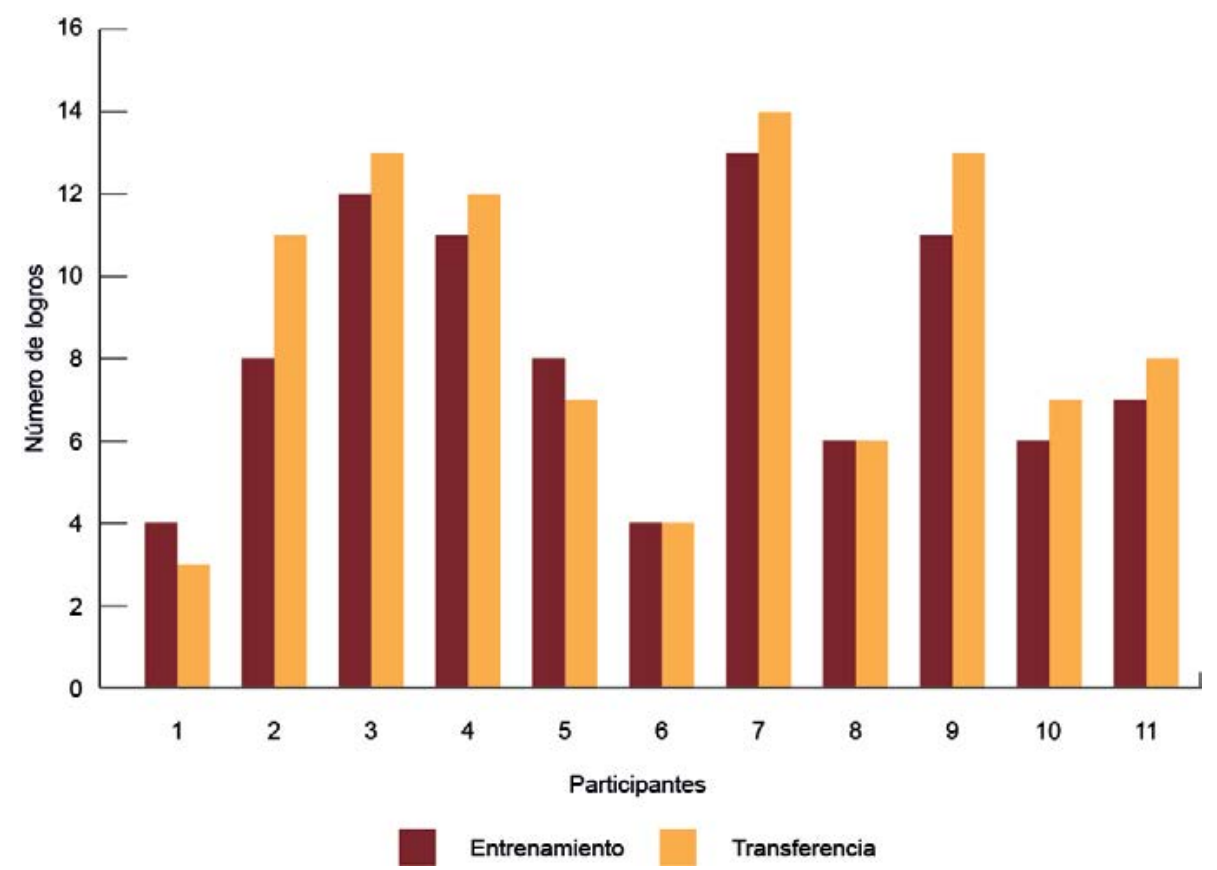

Figura 2. Logros obtenidos por participante del Grupo con Historia de Efectividad Controlada durante el entrenamiento y transferencia.

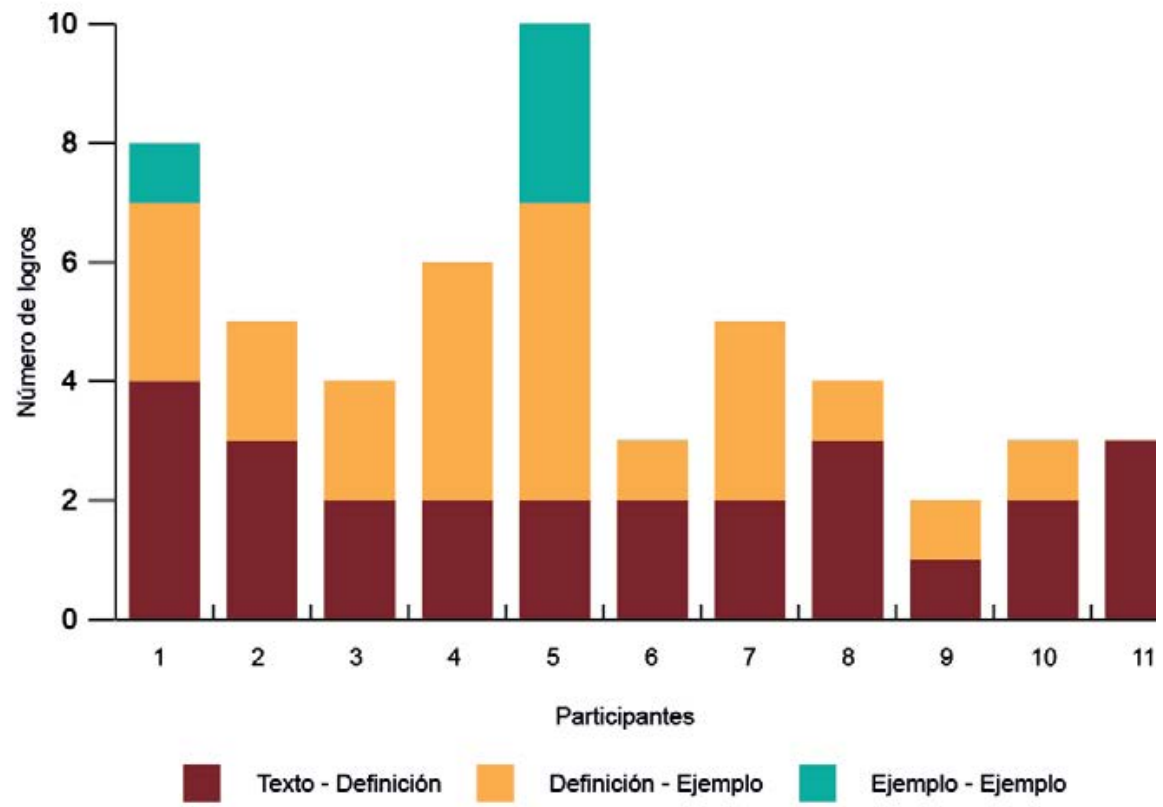

Figura 3. Logros obtenidos por participante del Grupo con Historia de Efectividad No Controlada para cada tipo de relación durante el entrenamiento. 
Siguiendo con el análisis del Grupo con HENC, al comparar los resultados obtenidos en la transferencia por participante se encuentra que seis de los participantes (P2, P3, P5, P6, P8 y P10) consiguen logros en todos los tipos de tareas novedosas, tanto aquellas con criterios de relación entrenados, pero con referentes de lectura nuevos como con referentes de lectura entrenados, pero criterios de relación novedosos. Por otra parte, solamente cuatro participantes obtienen logros en tres tipos de tareas novedosas (P1, P4, P9 y P11). Por último, sólo el P7 consigue logros en solo una de las tareas novedosas. Al considerar la cantidad de logros totales alcanzados por todos los participantes de este Grupo en la evaluación de transferencia, se obtienen 23 logros para la relación novedosa Definición-Definición, 16 para la relación entrenada pero referente de lectura novedoso (Texto-Definición), 14 logros en la relación Definición-Ejemplo y sólo 9 logros totales en el tipo de relación Ejemplo-Ejemplo, estableciendo en ese orden (de menor a mayor) la dificultad de las tareas realizadas en la transferencia. En la Figura 4 se muestran los resultados obtenidos por participante del Grupo con HENC durante la prueba de transferencia.

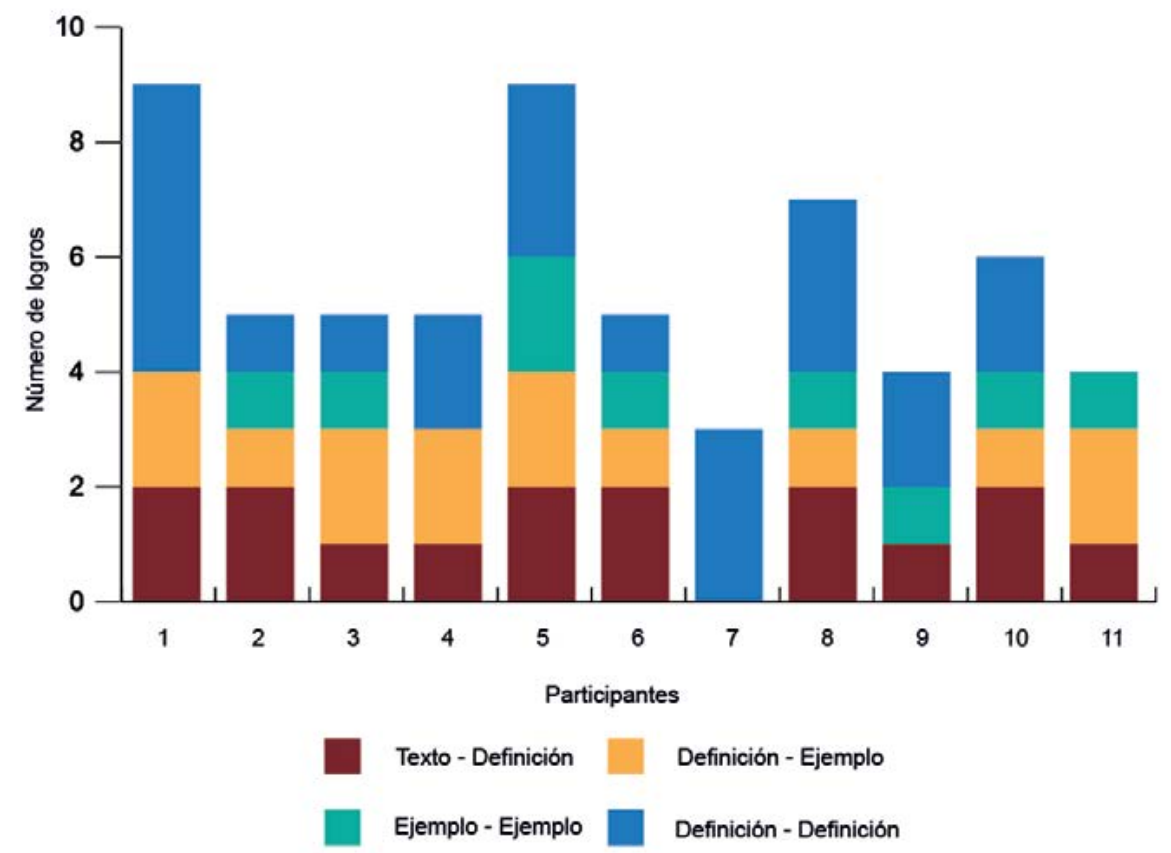

Figura 4. Logros obtenidos por participante del Grupo con Historia de Efectividad No Controlada para cada tipo de relación durante la transferencia.

Por otra parte, al realizar un análisis intra-grupo de los resultados obtenidos por los participantes pertenecientes al Grupo con HEC, se encuentra que cuatro de los participantes (P3, P4, P7 y P9) alcanzan logros frente a todas las tareas presentadas durante el entrenamiento, lo cual permite considerarlos como los participantes con un grado de desarrollo mayor respecto de los demás en términos de su historia de logro; además, son más participantes en esta condición respecto de los del Grupo con HENC. Cinco de los participantes consiguen logros en dos de las tareas presentadas (P2, P5, P8, P10 y P11) y finalmente, sólo dos consiguen logros en una tarea entrenada, lo cual 
permite considerarlos como los de menor grado de desarrollo del Grupo. Dado que el criterio de avance en este Grupo era condicional al desempeño efectivo de cada participante, puede apreciarse que, al considerar la cantidad total de logros obtenidos por todos los participantes para cada tipo de tarea, fue la relación Texto-Definición la que reúne más cantidad de logros (52 en total), seguida de la relación Definición-Ejemplo con 30 logros y finalmente, la relación Ejemplo-Ejemplo con un total de 7 logros. Cabe mencionar que estas puntuaciones totales son efecto directo del criterio de cambio empleado, por lo tanto, es considerable el distanciamiento entre participantes en términos de la historia de logro construida por cada uno. En la Figura 5 se muestran los resultados descritos.

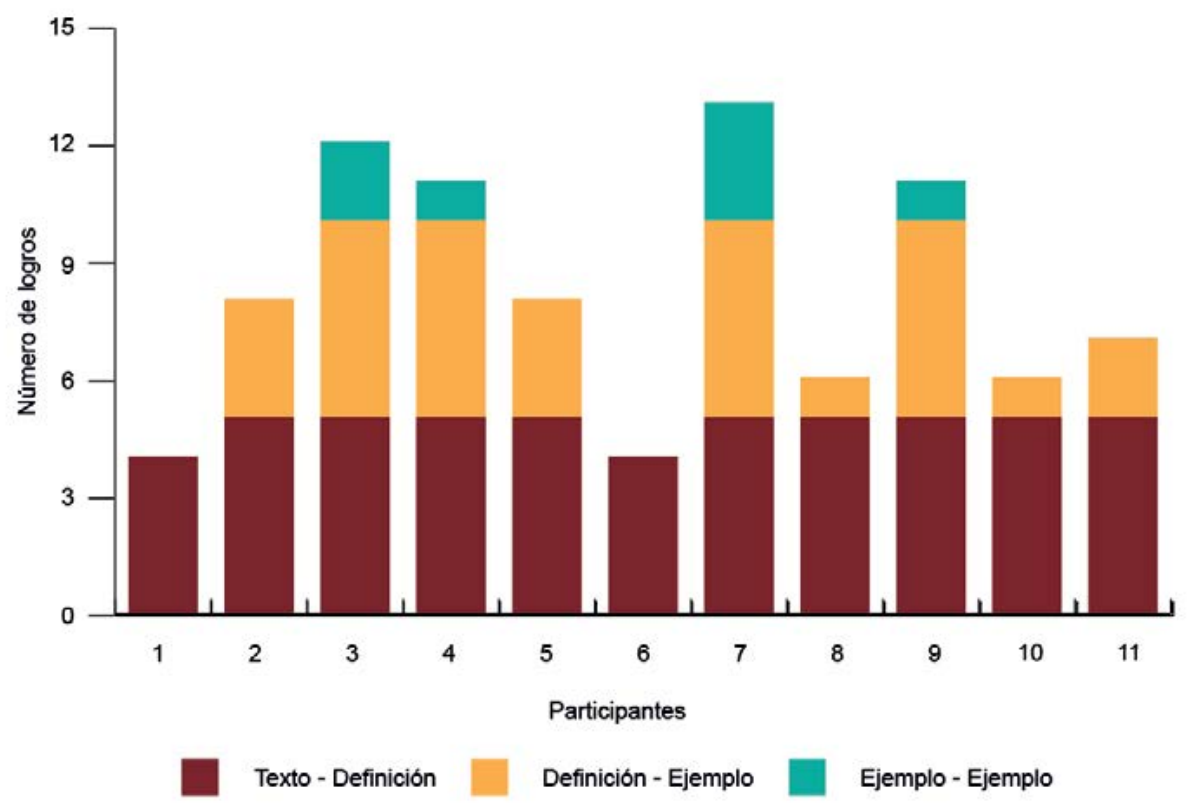

Figura 5. Logros obtenidos por participante del Grupo con Historia de Efectividad Controlada para cada tipo de relación durante el entrenamiento.

Siguiendo el análisis entre-sujetos del Grupo con HEC, los resultados presentados en la Figura 6 muestran el desempeño de cada participante durante la evaluación de transferencia. Puede notarse que ocho de los participantes (P2, P3, P4, P5, P6, P7, P9 y P10) consiguen logros en las cuatro tareas novedosas que constituyen la prueba de transferencia. Dos de los participantes (P8 y P11) obtienen logros en tres de las tareas presentadas y sólo el P1 consigue logros en dos de las tareas. Considerando la sumatoria de logros alcanzados por participante para cada tipo de relación, puede notarse que la relación Definición-Definición obtiene 32 logros colocándola así en la relación con mayor cantidad de logros alcanzados, le sigue la relación Texto-Definición con 26 logros totales, luego la relación Definición-Ejemplo con 22 logros y finalmente, la relación Ejemplo-Ejemplo con 19 logros. Retomando los datos obtenidos en este mismo análisis, pero del Grupo con HENC, existe consistencia en el orden de dificultad de las tareas elaboradas durante la transferencia (DefiniciónDefinición, Texto-Definición, Definición-Ejemplo y Ejemplo-Ejemplo). 


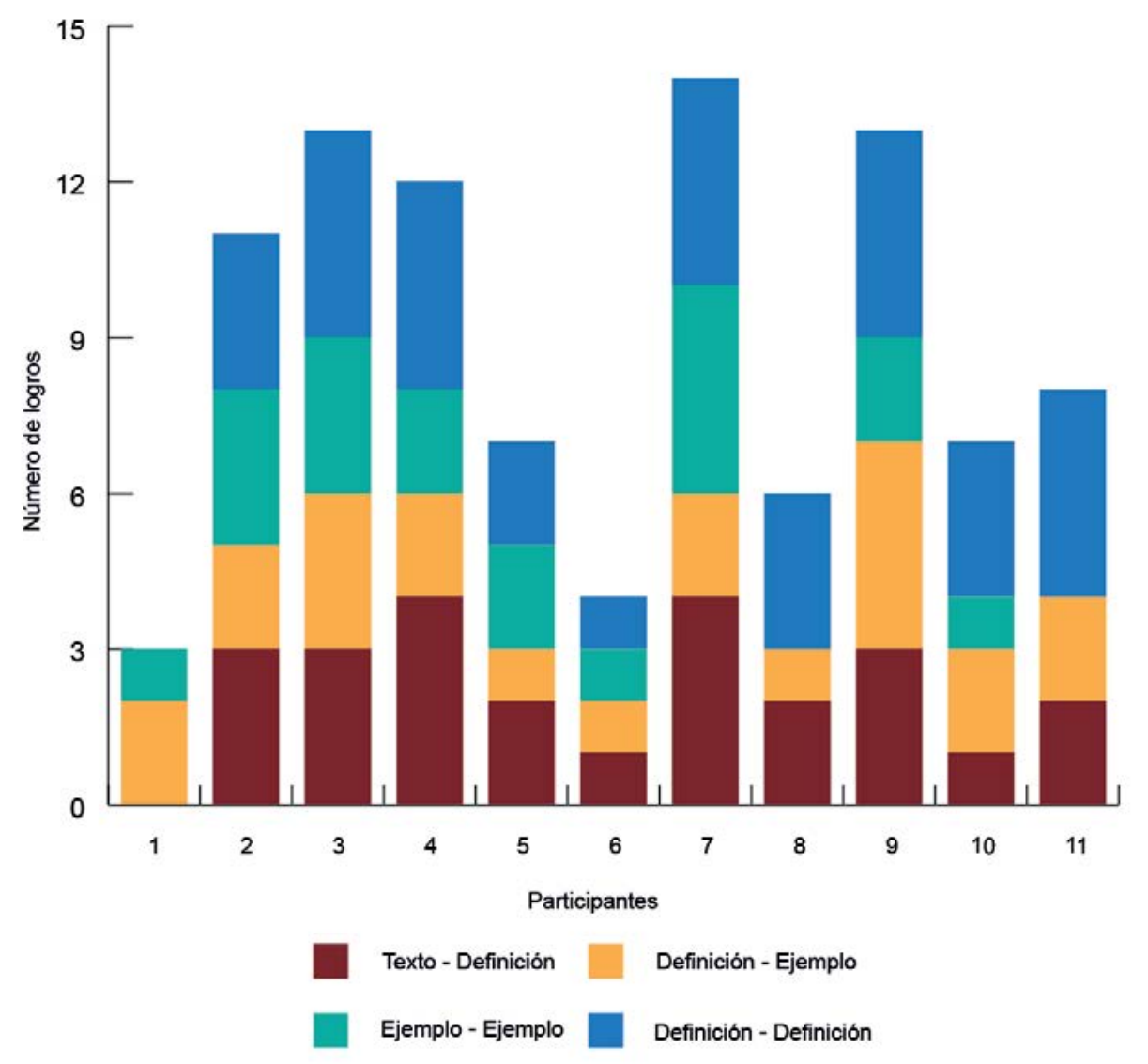

Figura 6. Logros obtenidos por participante del Grupo con Historia de Efectividad Controlada para cada tipo de relación durante la transferencia.

\section{Discusión}

El objetivo del presente trabajo de investigación fue evaluar los efectos de la historia de efectividad controlada versus no controlada sobre el desempeño efectivo en situaciones lectoras novedosas. De manera general, los hallazgos encontrados sugieren que controlar el establecimiento de la historia de efectividad de los participantes tiene efectos positivos directos al comparar ambos grupos y al realizar comparaciones intra-sujeto tanto durante el entrenamiento como en la evaluación de transferencia. Los resultados obtenidos en la transferencia pueden considerarse en función del tipo de entrenamiento que recibieron los participantes de cada Grupo (HENC y HEC), lo cual también permite decir que las consideraciones metodológicas a la hora del entrenamiento de habilidades lectoras se tornan críticas en la promoción de competencias evaluadas en situaciones lectoras novedosas.

En el Grupo con la historia controlada los participantes alcanzaron mayor cantidad de logros tanto en el entrenamiento como en la prueba de transferencia. Casi la mitad de los integrantes de este Grupo alcanzan diez logros, mientras que en el Grupo en el que no se controló la historia de efectividad, sólo un participante alcanzó diez logros durante el entrenamiento, pero ninguno durante la prueba de transferencia. Se podría objetar de que varios de los miembros de este último Grupo obtienen avances mayores en la prueba de transferencia respecto del entrenamiento, que los miem- 
bros del Grupo con historia controlada, pero aquí sí cobra relevancia el número total de logros de los individuos durante el entrenamiento y el número durante la prueba debido a lo siguiente: un individuo al que se le coloca en situaciones en las que avanza cuando ha cubierto un criterio o resuelto un problema, puede resolver más problemas, tantos como se le ilustre o permita resolver y ello genera una historia de efectividad "más amplia" que aquel individuo que enfrenta diferentes situaciones y avanza independientemente de cuántas resolvió. Puede ser que ambos enfrentaron diez situaciones problema, uno resolvió 9 de 10 (falló en la última) y el otro 5 de diez, ambos enfrentaron la misma cantidad de situaciones problemas, pero generaron diferente grado de desarrollo psicológico. Al cambiar de situaciones y sin ofrecer consecuencias a su desempeño, aquel individuo que tuvo una historia de desarrollo psicológico "más amplia", consigue continuar con un nivel parecido de desarrollo de habilidades.

Estos resultados respaldan empíricamente lo que se sostiene acerca del desarrollo psicológico, en particular, cuando en él se establece que la configuración de habilidades y su ejercicio en situaciones variables, es condición necesaria para promover el desarrollo de competencias. Por supuesto, es necesario realizar mayor investigación que permita evaluar los efectos del tipo de variaciones del desempeño para cumplir con un mismo criterio o formas invariantes de desempeño con criterios diferentes, considerando el desempeño efectivo como criterio de cambio. Es importante tener en cuenta que para solicitar a un individuo que cumpla con un criterio por medio de un desempeño variable, primero debe cubrirse dicho criterio de una forma particular y entonces solicitar la variación. De no hacerlo, no se abordará el comportamiento inteligente definido por el criterio de variabilidad y de efectividad, sino tal vez el comportamiento exploratorio que se caracteriza por variabilidad y no efectividad (Ribes, 1990).

Por otra parte, los resultados obtenidos analizados al interior de los grupos, representan evidencia importante acerca de la diferencia psicológica del desarrollo entre individuos pertenecientes al mismo Grupo. Esto permite sostener que aún y cuando se definen condiciones homogéneas para la experimentación, estas quedan subordinadas al desempeño mismo de los participantes durante el entrenamiento. Las diferencias presentadas entre los participantes de un mismo Grupo están directamente relacionadas con los logros obtenidos por cada uno para cada tipo de tarea implicada. Por ejemplo, en el caso del Grupo con HENC, las diferencias entre participantes se encuentran cruzadas por las historias de logro desarrolladas, si se comparan tales historias desarrolladas con las de los participantes del Grupo con HEC puede notarse que existen diferencias importantes en cuanto a las historias construidas con base en los logros de cada participante. En términos de logros obtenidos durante el entrenamiento, los participantes del Grupo con HENC desarrollaron historias de logro más "cortas" que los del Grupo con HEC, quienes en su mayoría desarrollaron historias más "largas" o "amplias".

Las diferencias psicológicas como historias de logro -cortas o largas- desarrolladas por los participantes de ambos grupos son diferenciadas al identificar el tipo de criterios que cumplieron durante el entrenamiento en las diferentes tareas lectoras. Además, se encontró que existe una relación directamente proporcional entre las historias de efectividad construidas durante el entrenamiento y el tipo de logros obtenidos en la transferencia. No es fortuito que las diferencias entre participantes de un mismo Grupo estuvieran directamente relacionadas con el desempeño efectivo de los mismos, 
incluso en el Grupo en que no se controló el desarrollo de una historia de efectividad. En efecto, los participantes que desarrollaron historias de logro más largas, tanto en el Grupo con HENC como en el Grupo con HEC, exhiben mayores posibilidades de logro en otras situaciones, es decir, muestran cierto grado de tendencia a desempeñarse efectivamente en tareas lectoras novedosas. En otras palabras, la imposición de un criterio de cambio metodológico condicional al desempeño efectivo como modo de control de la historia de efectividad, tiene un papel importante sobre el establecimiento de las precurrentes conductuales específicas que configura un individuo durante la condición de entrenamiento y, además, este tiene un efecto considerable en el desempeño durante la transferencia.

Los resultados encontrados en este trabajo reflejan la importancia particular que juega la historia psicológica de los individuos, ya que siguiendo a Arroyo (2002) y a Arroyo et al. (2008), la historia como colección de los contactos previos del individuo se expresa momento a momento en los diferentes ajustes conductuales a los criterios impuestos en cada situación. En ese sentido, los estudios sobre el desarrollo psicológico deben dirigirse a la creación de historias psicológicas de los individuos, siempre teniendo en consideración los ámbitos de desempeño funcional bajo los cuales queda justificada la pertinencia de dicho desarrollo. Los resultados encontrados en este estudio son coincidentes con los reportados por Arroyo et al. (2008) en términos de que los ajustes lectores previos que conforman el conocimiento del que disponen los individuos son integrativos al comportamiento futuro en otras situaciones de evaluación. En lo que respecta al análisis de los resultados del presente estudio cabe decir que controlar la historia de efectividad de los participantes durante el entrenamiento, se traduce en el valor predictivo que puede hacerse del desempeño posterior en situaciones lectoras novedosas, lo cual contribuye sustancialmente en los objetivos científicos particulares de una teoría del desarrollo psicológico y al modo singular de realizar investigación empírica congruente y coherente con los supuestos teóricos.

De modo general, los hallazgos encontrados contribuyen a sostener que considerar el desarrollo de la habilidad como criterio de cambio, para enfrentar una nueva situación permite controlar el desarrollo de una historia de efectividad, aunque quizá convenga hacer estudios posteriores en los que no sólo se controle la efectividad, sino también la inefectividad para observar sus efectos sobre el desarrollo psicológico. Por ello el desempeño efectivo resulta un criterio adecuado de cambio metodológico en la experimentación del desarrollo psicológico, pero habrá que realizar mayor cantidad de estudios que permitan dilucidar hasta dónde resulta conveniente controlar la historia de efectividad en relación con las condiciones variables que un individuo enfrenta y hasta qué punto la variación de condiciones, auspicia desempeños efectivos durante las pruebas de transferencia, tornando irrelevante la observación de la efectividad del individuo durante el entrenamiento.

\section{A manera de conclusión}

La investigación sobre el desarrollo psicológico desde una perspectiva Interconductual al amparo de la taxonomía de la conducta de Ribes y López (1985), ha mostrado extensiones, variedades y transformaciones importantes. En este trabajo se ha pretendido hacer un ejercicio de reflexión, con ciertos apuntes metodológicos llevados a la práctica, con el fin de aportar al progreso de la investigación en este campo. No se soslaya que las consideraciones vertidas en este trabajo tienen implicaciones importantes, se plantean algunas: 
A. En las formas dominantes de hacer investigación se pierde la congruencia entre los supuestos teóricos y los criterios metodológicos, ya que se rigen por procedimientos normalizados para la obtención de evidencia, que borran las peculiaridades teóricas desde donde se realiza la investigación y las características individuales de los participantes. En los lugares y condiciones que los manuales sobre metodología de la investigación señalan contaminación o errores a minimizar, se encuentra la existencia de los factores que resultan relevantes para la investigación sobre el desarrollo psicológico. Habrá que pensar si se opta por hacer investigación a la medida de los cánones de manuales y criterios editoriales de las revistas o se hace investigación conceptualmente congruente.

B. Los criterios de inclusión de los participantes en estudios sobre desarrollo psicológico requieren ajustes, en pleno reconocimiento de que los individuos ya cuentan con una historia cuando se incorporan a una investigación y a las limitantes que acarrea trabajar con individuos que no cuentan con algún tipo de historia en un ámbito social, como lo son los infantes. La construcción de historias interactivas es una posibilidad que subsana varios problemas de este tipo, pero plantea otros en tanto estudios longitudinales, como la duración de las investigaciones y lo poco práctico que puede resultar para el financiamiento y para el propio investigador en una dinámica en la que se exige publicar frecuentemente y ello a su vez, requiere hacer más investigaciones y de menor duración.

c. Es necesaria una transformación de las formas de representación de una historia interactiva de logros conseguidos y del propio desarrollo psicológico de los individuos, que trascienda representaciones de eventos discretos o puntuales en tiempo y espacio como si fueran ocurrencias. Cuestión que aquí se reconoce no se superó del todo, cuando se presentaron los datos en forma de logros conseguidos, pero en el entendido que se trata de un primer ejercicio, al interior de la línea, que busca romper con toda una historia sobre la forma de graficar datos psicológicos.

D. Presentar una y otra vez una misma situación problema a un individuo, puede generar efectos de orden afectivo, como abandonar los experimentos o las labores dentro de los ámbitos en los que se desenvuelve. Ese puede ser el costo de estudiar el desarrollo psicológico de esta manera, y quizás demande articular este tipo de investigaciones con la investigación sobre estilos interactivos, por ejemplo, sobre la tolerancia a la frustración (Ribes, 1990).

E. Si en ámbitos sociales como el educativo, se permitiera que un individuo avanzara a situaciones problema más complejas sólo sí ha solucionado las previas, entonces se tendrían aulas en las que se encuentran individuos que han demostrado habilidades en niveles previos y su progreso estaría definido por lo que lograron psicológicamente y no por criterios administrativos. En consecuencia, las escuelas no estarían organizadas por grados escolares sino por habilidades y competencias demostradas de sus estudiantes, es decir, por el nivel de desarrollo psicológico conseguido.

Es necesario expresar que los autores del capítulo desean que la lista de implicaciones negativas no sea mayor a la lista de bondades que pueden generar los ajustes a la investigación sobre el desarrollo psicológico desde la Psicología Interconductual. En todo caso, si lo que han planteado 
en este trabajo resulta en un ejercicio estéril para el progreso de sus investigaciones, ellos están dispuestos a enfrentar nuevamente la situación problema hasta su solución, todo en pro de su propio desarrollo psicológico en el ámbito de la ciencia.

\section{Referencias}

Arnau, J., \& Bono, R. (2008). Estudios longitudinales. Modelos de diseño y análisis. Escritos de Psicología, 2 (1), 32-41.

Arroyo, R. (2002). Análisis de la historia de referencialidad como factor modulador de la comprensión de textos. Tesis de maestría. México: Universidad Nacional Autónoma de México.

Arroyo, R., Morales, G., Silva, H., Camacho, I., Canales, C., \& Carpio, C. (2008). Análisis funcional del conocimiento previo: sus efectos sobre el ajuste lector. Acta Colombiana de Psicología, $11(2), 55-64$.

Carpio, C. (1994). Comportamiento animal y teoría de la conducta. En L. Hayes, E. Ribes, \& F. López (Coords.), Psicología Interconductual. Contribuciones en honor a J. R. Kantor (pp. 45-68). Guadalajara: Universidad de Guadalajara.

Carpio, C. (2005). Condiciones de entrenamiento que promueven comportamiento creativo: Un análisis experimental con estudiantes universitarios. Tesis de Doctorado. México: Universidad Iberoamericana.

Carpio, C. (2008). Análisis conceptual de las teorías de la creatividad y proposición de un modelo Interconductual. En C. Carpio (Coord.), Competencias profesionales y científicas del psicólogo. Investigación, experiencias y propuestas (pp. 159-247). México: Universidad Nacional Autónoma de México.

Carpio, C., Canales, C., Morales, G., Arroyo, R., \& Silva, H. (2007). Inteligencia, creatividad y desarrollo psicológico. Acta Colombiana de Psicología, 10 (2), 41-50.

Carpio, C., Pacheco, V., Hernández, R., \& Flores, C. (1995). Creencias, criterios y desarrollo psicológico. Acta Comportamentalia, 3 (3), 89-98.

Chávez, E. (2016). Aprendizaje de la ciencia a través del desarrollo secuencial de habilidades y competencias lectoras. Tesis de licenciatura. México: Universidad Nacional Autónoma de México.

Hernández-Sampieri, R., Fernández, C., \& Baptista, P. (2010). Metodología de la investigación. México: McGraw-Hill.

Kantor, J.R., \& Smith, N.W. (1975). The science of psychology. An Interbehavioral survey. Chicago: Principia Press.

Kantor, J.R. (1978). Psicología Interconductual. Un ejemplo de construcción científica sistemática. México: Editorial Trillas.

Kantor, J.R. (1990). La evolución científica de la Psicología. México: Editorial Trillas.

Kerlinger, F.N., \& Lee, H.B. (2002). Investigación del comportamiento. México: McGraw-Hill.

Kuhn, T. (1962). La estructura de las revoluciones científicas. México: Fondo de Cultura Económica. Mares, G. (1988). Análisis experimental de la relación entre diferentes competencias lingüísticas. Tesis de Maestría. México: Facultad de Psicología. Universidad Nacional Autónoma de México. 
Mares, G. (2001). La transferencia desde una perspectiva de desarrollo psicológico. En G. Mares, \& Y. Guevara (Coords.), Psicología Interconductual. Avances en la investigación básica (pp. 111-163). México: Universidad Nacional Autónoma de México.

Mares, G., Galicia, I., Pavón, S., Rivas, O., Sánchez,A., Garrido, A., \& Reyes, A. (2003). Comportamiento relacional en niños de primaria: Un estudio longitudinal. Acta Comportamentalia, 11 (2), 175-196.

Mares, G., \& Rueda, E. (1993). El habla analizada desde la perspectiva de Ribes y López: desarrollo horizontal. Acta Comportamentalia, 1 (1), 39-62.

Mares, G., Rueda, E., Plancarte, P., \& Guevara, Y. (1997). Conducta referencial no entrenada: el papel que juega el nivel funcional de entrenamiento en la generalización. Acta Comportamentalia, $5(2), 199-219$.

Morales, G., Cruz, N., León, A., Silva, H., Arroyo, R., \& Carpio, C. (2010). Morfología y función en el análisis empírico del ajuste lector. Suma Psicológica, 17 (1), 35-45.

Morales, G., Silva, H., \& Carpio, C. (2012). Enseñanza de la ciencia, comportamiento inteligente y lectura: el papel de las prácticas didácticas variadas. En Z. Monroy, R. León-Sánchez, \& G. Álvarez (Coords.), Enseñanza de la ciencia (pp. 397-411). México: Universidad Nacional Autónoma de México.

Ribes, E. (1987). La relación entre la investigación científica en Psicología y sus aplicaciones: no es tan fácil como se piensa. Revista Mexicana de Psicología, 4 (2), 154-158.

Ribes, E. (1989). La inteligencia como comportamiento: un análisis conceptual. Revista Mexicana de Análisis de la Conducta, 15 (Monográfico), 51-67.

Ribes, E. (1990). Psicología General. México: Editorial Trillas.

Ribes, E. (1996). Reflexiones sobre la naturaleza de una teoría del desarrollo del comportamiento y su aplicación. En S. Bijou, \& E. Ribes (Coords.), El desarrollo del comportamiento (pp. 267283). Guadalajara: Universidad de Guadalajara.

Ribes, E., \& López, F. (1985). Teoría de la Conducta. Un análisis de campo y paramétrico. México: Editorial Trillas.

Ribes, E., Moreno, R., \& Padilla, A. (1996). Un análisis funcional de la práctica científica: extensiones de un modelo psicológico. Acta Comportamentalia, 4 (2), 205-235.

Ribes, E., \& Varela, J. (1994). Evaluación interactiva del comportamiento inteligente: desarrollo de una metodología conceptual. Revista Mexicana de Análisis de la Conducta, 20 (1), 83-97.

Ryle, G. (1949). The concept of mind. Chicago: The University of Chicago Press.

Silva, H., Arroyo, A., Carpio, C., Irigoyen, J.J., \& Jiménez, M. (2005) Teoría del desarrollo y comportamiento creativo: algunas evidencias experimentales. En C. Carpio, \& J.J. Irigoyen, Psicología y educación. Aportaciones desde la Teoría de la Conducta (pp. 213-262). México: Universidad Nacional Autónoma de México.

Trigo, E., \& Martínez, H. (1994). Diseños y procedimientos de validación en Psicología Interconductual: discriminación condicional y estrategias longitudinales. Revista Mexicana de Análisis de la Conducta, 20 (1), 67-83.

Varela, J., \& Ribes, E. (2002). Aprendizaje, inteligencia y educación. En E. Ribes, Psicología del Aprendizaje (pp. 191-209). México: El Manual Moderno.

Vygotski, L.S. (1979). El desarrollo de los procesos psicológicos superiores. Buenos Aires: Editorial Grijalbo. 


\section{Capítulo 4}

\section{La intervención educativa desde el modelo de campo Interconductual: algunos datos iniciales}

Ulises Delgado Sánchez, Jorge Guerrero Barrios,

Fernanda Gabriela Martínez Flores y Néstor Miguel Velarde Corrales 
Ulises Delgado Sánchez ankhpsy@gmail.com

Jorge Guerrero Barrios jorgegbarrios2012@gmail.com

Fernanda Gabriela Martínez Flores maga.mtzf@gmail.com

Néstor Velarde Corrales velarde.nm@gmail.com

Universidad Autónoma del Estado de Morelos

Parte de este capítulo se desprende de las actividades realizadas por el Dr. Jorge Guerrero Barrios durante el disfrute de un año sabático en el Centro de Investigación Transdisciplinar en Psicología, UAEM, aprobado por el HCT de la FES Iztacala.

Fernanda Gabriela Martínez Flores y Néstor Miguel Velarde Corrales son estudiantes dentro del Programa de Doctorado en Psicología de la UAEM (PNPC).

Toda correspondencia dirigirla a: Ulises Delgado Sánchez. Centro de Investigación Transdisciplinar en Psicología. ulises.delgado@uaem.mx 


\section{Capítulo 4}

\section{La intervención educativa desde el modelo de campo Interconductual: algunos datos iniciales}

Un proyecto de intervención educativa por lo regular implica tres momentos: 1) el análisis de múltiples variables y factores que pueden constituirse en potenciadores o limitadores de las interacciones de aprendizaje, 2) el diseño de contingencias promotoras del aprendizaje, y su programación de acuerdo a un objetivo planteado y, 3) la implementación del programa elaborado y su seguimiento a través de condiciones novedosas, sobre las cuales no se intervino directamente. En ocasiones la identificación de las variables relevantes es relativamente simple y basta con llevar a cabo algunas sesiones de observación sistemática para aislarlas, e iniciar el manejo de las contingencias que conduzcan al aprendizaje. Sin embargo, en la mayoría de las ocasiones, el diseño de un proyecto de intervención educativa supone considerar la actuación simultánea de múltiples factores que, ante la carencia de un modelo general de la conducta sería muy difícil su comprensión y manejo, reduciendo la eficacia e impacto de la actuación del profesional de la Psicología sobre los usuarios de servicio.

Es importante insistir que la intervención educativa no es una actividad profesional guiada solamente por los indicios que va recolectando el psicólogo a partir de que se solicita su actuación, implica un trabajo de análisis teórico sistemático y congruente con un modelo general de lo psicológico. Es por ello que el presente capítulo tiene por objetivo proponer una metodología de trabajo en escenarios educativos, a partir de los postulados del modelo de campo Interconductual (Kantor, 1924, 1926, 1969) y los conceptos teórico-metodológicos de la teoría de la conducta (Ribes y López, 1985). La propuesta metodológica comprende cuatro etapas consecutivas: a) la identificación de los factores probabilizadores, posibilitadores y delimitadores, de las interacciones problemáticas, b) la identificación de los factores eficientes de las interacciones objeto de la intervención, a través de un diagnóstico exhaustivo de las interacciones funcionales, actuales y potenciales, c) el diseño de la intervención, que se propone parta de un análisis que se oriente a la promoción del aprendizaje de nuevas interacciones funcionales; y d) la determinación de las condiciones de transferencia/generalización, y la validación social de los cambios conductuales promovidos mediante la intervención profesional.

Previo al desarrollo de esta propuesta es pertinente abordar algunas generalidades en torno al modelo de campo interactivo, el aprendizaje y su generalización, ya que toda intervención educativa planeada desde la Psicología, se debe orientar a la promoción del aprendizaje. 


\section{El modelo de campo interactivo, el aprendizaje y la generalización}

El modelo de campo interactivo (Kantor \& Smith, 1975), postula que los eventos psicológicos son interacciones sincrónicas organismo $\leftrightarrow$ ambiente con un carácter continuo e ininterrumpido durante la vida del individuo. Dada la continuidad y sincronicidad de las interacciones psicológicas, propone analizarlas como segmentos molares o episodios consecutivos de interacción que pueden ser descritos con la siguiente ecuación: $E P=C(k, f e, f r, h i, f d, m d)$ en donde $E P$ representa un evento psicológico, $C$ un campo o sistema completo de factores en interacción, $k$ simboliza la unicidad del campo Interconductual, fe la función de estímulo del objeto estimulante, fr la función de respuesta de la acción del organismo, $h i$ el proceso de historia Interconductual, $f d$ los factores disposicionales que consisten en las circunstancias situacionales que influyen probabilísticamente en la función estímulo↔respuesta particular, y finalmente, $m d$ que simboliza los medios de contacto que posibilitan que los estímulos y respuestas (físicos, ecológicos y convencionales) se relacionen, facilitando la construcción de una relación funcional entre ellos (ver Figura 1).

Límite del Campo Psicológico

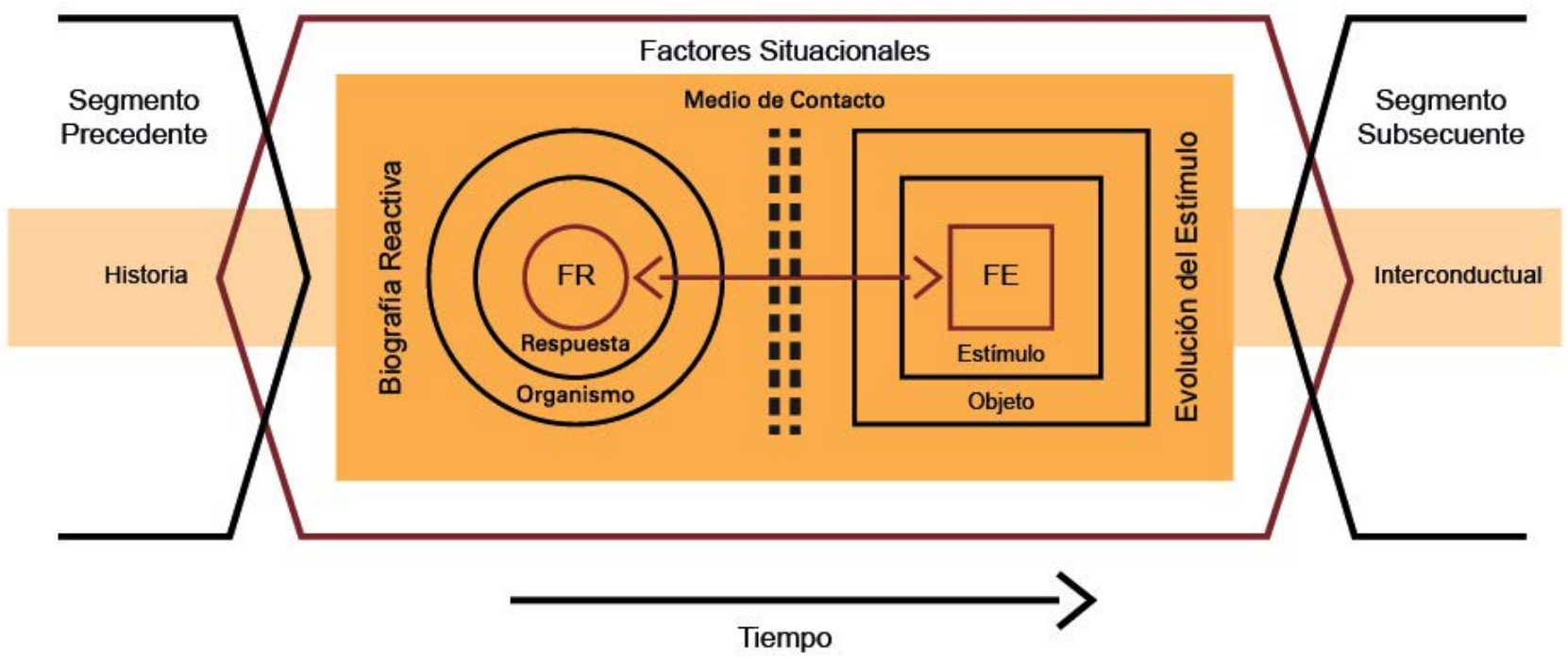

Figura 1. Segmento Interconductual (Kantor \& Smith, 1975).

La concepción del evento psicológico como un campo interactivo multifactorial sincrónico tiene varias implicaciones importantes para el análisis de la conducta, algunas de estas son: a) la postulación de la función estímulo↔respuesta como unidad de análisis, dado su carácter emergente a partir de la interacción de los factores del campo; b) el reconocimiento explícito de la historicidad de las interacciones psicológicas, como un elemento actual en el campo interactivo; y c) el reconocimiento del carácter ajustivo de toda interacción, originado a partir de la amplia diversidad de propiedades físicas, ecológicas y convencionales de los eventos de estímulo con los que se relaciona todo organismo, y de las capacidades reactivas de los organismos hacia estas propiedades del ambiente, en especial a su dinámica de cambio. Como un corolario de lo antes señalado, los eventos psico- 
lógicos se configuran como campos autocontenidos cualitativamente distintos, que construyen el soporte de todas las funciones psicológicas realizables por un individuo durante su vida (v.gr. pensar, sentir, percibir, soñar, etc.).

En continuidad con los planteamientos de Kantor (1969), Ribes y López (1985) propusieron una taxonomía de cinco funciones estímulo↔respuesta diferenciables a partir de la complejidad del sistema de condicionalidades que las hacen posibles y el grado de arbitrariedad entre sus eventos constitutivos. Las cinco funciones se proponen como niveles de interacción cualitativa, progresivamente incluyentes, que delimitan el alcance de las variaciones cuantitativas al interior de cada una de ellas. Las funciones interactivas propuestas por Ribes y López (1985), son: 1) contextual, que implica el ajuste por parte del individuo a la condicionalidad o contingencia entre dos o más estímulos, que además, no es alterable por sus acciones, como cuando se anticipa o se repite algo que se ha escuchado o cuando se copia textualmente un patrón gráfico presente; 2) suplementaria, que implica una actuación efectiva de parte del sujeto sobre la ocurrencia de un estímulo, que a su vez determina la funcionalidad de al menos otro estímulo antecedente a la respuesta misma, como cuando un niño responde preguntas literalmente mientras se lee un texto; 3) selectora, que describe el responder con un alto grado de precisión por parte del individuo, capaz de producir la condicionalidad entre una relación suplementaria y un factor estimulativo independiente, como cuando se clasifican objetos (p.ej. canicas) a partir de la consideración simultánea de algunas de sus propiedades comunes, o cuando se buscan los antónimos y sinónimos de palabras novedosas en un texto; 4) sustitutiva referencial, que comprende la transformación de las tres clases de interacción funcional previamente descritas a partir del responder convencional hacia ellas, esto es, que el individuo es capaz de atribuir propiedades a los objetos y eventos presentes, modificando con ello las circunstancias a las que responde al actualizar condicionalidades específicas de otra situación, como cuando se narra o se elabora una crónica acerca de lo acontecido en un momento y lugar diferente, o cuando se sigue un consejo; y 5) sustitutiva no referencial, que involucra la introducción por parte del sujeto de restricciones puramente convencionales y normativas en la forma de analogías, equivalencias, subordinaciones, etc., sobre las relaciones entre eventos lingüísticos con o sin historia de referencialidad, como cuando se comparan saberes y conocimiento médico acerca del mantenimiento de la salud, o cuando se establece el peso atómico como criterio ordenador de los elementos químicos conocidos, por encima de otros factores como el estado de agregación, el número de electrones, etc.

Las cinco funciones estímulo $\leftrightarrow$ respuesta antes descritas, conforman una taxonomía de cualidades del comportamiento en tanto interacción, que pretende agotar todas las manifestaciones de la vida psicológica de los individuos. Dado su carácter general, ninguna de las funciones estímulo↔respuesta se corresponde con alguna forma específica de conducta, por lo que toda referencia al comportamiento individual empleando directamente la taxonomía se limita a la identificación del nivel funcional de interacción que ajusta al comportamiento observado, esto es, contextual, suplementario, selector, sustitutivo referencial y sustitutivo no referencial. Alternativamente, el concepto de aptitud funcional (Ribes, Pineda \& Quintana, 2007) al atender tanto al nivel funcional de interacción como a la historicidad de las interacciones del individuo hace posible una referencia mucho más precisa de la complejidad interactiva del comportamiento individual, al destacar la tendencia del individuo a interactuar en un determinado nivel funcional, sobre los otros posibles. 
Una descripción más precisa de la interacción, ineludiblemente recae en el concepto de competencia interactiva que permite dar cuenta de la tendencia a comportarse de manera efectiva cumpliendo en forma sucesiva o simultánea los criterios de logro que tornan una situación en un problema o una tarea, que requiere respuestas especializadas; por ejemplo, se puede identificar a un psicólogo como competente en la redacción de artículos científicos, si cada vez que escribe sobre un experimento realizado, respeta con precisión los diferentes lineamientos de estilo requeridos para su eventual publicación (APA, Chicago, Harvard, MLA, etcétera).

La taxonomía de Ribes y López (1985) también contempla un modo aún más específico para describir el comportamiento, esto es, a partir del concepto de habilidad que apunta a la correspondencia invariante entre las morfologías de la respuesta y la morfología de los estímulos con los que se interactúa consistentemente, como cuando se es hábil para redactar una referencia bibliográfica comprobando cada dato requerido en la fuente consultada. Finalmente es pertinente subrayar que tanto las aptitudes como las competencias y las habilidades constituyen tendencias o disposiciones de interacción psicológica (Ryle, 1967), y por lo tanto, tienen un carácter necesariamente aprendido, pero de las cuales carece de sentido predicarse ni su observabilidad o inobservabilidad, ni su internalidad o exterioridad, además de que ninguna acción aislada del individuo puede tomarse como representativa de cualquiera de ellas, ya que la lógica de su identificación siempre depende de la ocurrencia histórica o presente de una amplia colección de acciones o respuestas ante eventos en las circunstancias pertinentes.

Dadas las características de la taxonomía de la conducta propuesta por Ribes y López (1985) el aprendizaje de cualquier comportamiento, por elemental o complejo que este sea, se concibe como un cambio en la funcionalidad de la conducta psicológica del individuo. Dicho cambio, siempre implica el logro o satisfacción de los criterios que norman el desempeño de la conducta que se aprende, por lo que la manera más apropiada para referirse a esta interacción, es señalando que se ha desarrollado una competencia interactiva. En términos Interconductuales se habla de aprendizaje cuando: a) una conducta adopta una nueva funcionalidad en una circunstancia dada; o b) un comportamiento funcional a una circunstancia determinada ocurre en circunstancias novedosas (Ribes, 2002). En el primer caso, la acción del individuo puede diferenciarse, integrarse, separarse o eslabonarse, configurando una acción oportuna y pertinente a las circunstancias a las que responde, conformando progresivamente un responder competente ajustado a uno o más criterios. En el segundo caso, el responder competente que ya ocurre con cierta regularidad se presenta ante circunstancias en las que no había ocurrido antes. En otras palabras, el aprendizaje no se refiere a la adquisición de nuevas respuestas por parte del individuo, sino más bien, se refiere a un cambio en la manera en cómo el individuo se relaciona con el ambiente, un cambio en las disposiciones de interacción funcional que supone una reorganización programada, tanto de las respuestas del individuo como de los estímulos con los que se relaciona, en situaciones relativamente constantes o recurrentes. Esta reorganización de la interacción del individuo tiene lugar cuando, en función de los criterios establecidos, se disponen las condiciones para el ejercicio de sus habilidades en forma novedosa, forjando en consecuencia, una competencia en un determinado nivel de complejidad funcional, o robusteciéndola, disponiendo condiciones para su ejercicio a través de los diferentes niveles funcionales que se reconocen en la taxonomía funcional de la conducta. 
De manera complementaria, Ribes (2002) ha señalado que existen cuatro condiciones o circunstancias en las que el individuo aprende: a) cuando tiene que hacer algo nuevo o diferente, b) cuando tiene que reconocer la circunstancia en la cual hacer algo que ya hace con pericia, c) cuando tiene que identificar qué hacer en una circunstancia nueva, y d) cuando tiene que hablar acerca de lo que se tiene que hacer en ciertas circunstancias y sobre cómo hacerlo.

Una implicación importante de la taxonomía propuesta por estos autores recae en el significado de los conceptos de transferencia y generalización del comportamiento aprendido. Ambos conceptos se refieren a las condiciones operacionales en las que se evalúa el aprendizaje, y en muchas ocasiones se les usa de manera indistinta o se privilegia el uso de alguno de ellos sobre el otro, como resultado del conjunto de supuestos que respaldan la investigación sobre el aprendizaje. Por esto mismo, es más común encontrar el término transferencia en estudios de tradición cognoscitivista, centrados en el proceso subyacente al aprendizaje, y el término generalización en estudios de corte conductual, centrados en el logro (Mares, 2001). En el caso de la presente taxonomía, se recuperan ambos términos procurando a cada uno de ellos un significado específico y diferenciado. De acuerdo con Ribes (1990) se identifica la transferencia del aprendizaje, cuando las habilidades desarrolladas durante un entrenamiento cimientan el responder del individuo ante variaciones sistemáticas a partir de la situación original de entrenamiento, y la capacidad del individuo para responder ante ellas, de acuerdo a lo aprendido, no decae, incluso cuando ello implica el despliegue de habilidades morfológicamente diferentes a las inicialmente adquiridas, lo que conduce a la consolidación de una competencia en un mismo nivel funcional. Por otra parte, se plantea que la generalización del aprendizaje ocurre cuando las variaciones introducidas respecto a la situación original de entrenamiento consisten en incrementos (o decrementos) en la complejidad de las relaciones estímulo↔respuesta, lo cual impone al responder del individuo, variaciones morfológicas sutiles y en ocasiones notables, pero invariablemente su reorganización en algún otro nivel funcional, correspondiéndose a la nueva estructura de las contingencias estimulativas dispuestas.

Es necesario señalar que tanto la transferencia, como la generalización del comportamiento aprendido parecen depender de un conjunto de factores ambientales comunes tanto a la tarea realizada en la situación de aprendizaje como a las tareas por realizar durante la prueba. Por ello es vital lograr un diagnóstico preciso antes de comenzar cualquier intervención educativa, así como la identificación de las condiciones ambientales en las que el individuo continuará luego de la misma.

\section{Primera Etapa}

Interacciones como objeto de la intervención. En esta sección se procurará eslabonar el modelo analítico descrito en la sección previa y los elementos comunes a las situaciones en las que son detectados los problemas que ameritan una intervención educativa. Existe un supuesto fundamental con el que debe iniciar toda actuación profesional, y es el siguiente: dado que el objeto de estudio de la Psicología es la interacción entre el responder de un organismo y la acción estimulante de objetos o eventos particulares, enmarcados por factores histórico-situacionales, el supuesto más importante que debe guiar el trabajo del psicólogo es que todo aquello con lo que se relaciona son interacciones. Tanto el reporte de quienes inicialmente manifiestan la problemática por resolver, como los actos valorados como problema, e incluso el proceder analítico al recolectar información 
e intervenir profesionalmente, todo ello son interacciones. El complejo entramado de interacciones que conforman el problema por resolver puede permanecer en un estado relativamente estático por semanas, meses, o años, o puede cambiar dinámicamente en cuestión de días. Esto es, los episodios de interacción "problema" se vuelven recurrentes y algunos de sus factores se mantienen relativamente constantes, facilitando su identificación.

Independientemente de cómo sea referida la posible problemática por aquellos que la reportan, el psicólogo debe proceder en su análisis, tratando de manera diferencial tanto los factores de la interacción constantes, como aquellos cuya dinamicidad es alta y ameritan un registro, directo, que dé cuenta de sus variaciones. Por último, debe determinar las interacciones sobre la cuales es necesario intervenir, y el cómo hacerlo.

Factores histórico-situacionales. De acuerdo a la Figura 1, toda interacción se encuentra situada en un continuo con respecto a los espacios y circunstancias en los que actúan los individuos, así como con respecto a los tiempos y momentos de vida en los que se presenta cada acto. Ambos conglomerados de variables al concurrir de manera consistente a través de la trayectoria de interacciones de cada individuo, adquieren una función disposicional que permite entrever la probabilidad de involucramiento en determinadas actividades. Desde una perspectiva de intervención, los factores histórico-situacionales ubican la problemática reportada en el continuo espacio-tiempo, es decir, en un punto determinado de su evolución. No se trata solamente de situar en el aquí y ahora la posible problemática, se trata de precisar su ubicación, tanto en el devenir ecológico de los organismos involucrados, como en la historicidad institucional que permea la vida de los individuos participantes en ella, y en la biografía de las relaciones cotidianas de las personas afectadas por ella.

Los factores históricos que sitúan la problemática se identifican o infieren por los vestigios observables en el presente (escenarios, objetos, el propio cuerpo del individuo, etcétera) o a partir de la aplicación de entrevistas, cuestionarios, escalas y otros instrumentos específicos a la problemática conductual analizada. Los factores situacionales se identifican principalmente a partir de la observación directa en los escenarios en los que ocurren los comportamientos valorados como problemáticos, aunque también existen escalas que permiten ubicar los diferentes factores que componen las situaciones compartidas por los individuos bajo análisis, por ejemplo, el Home -Observation for Measurement of the Environment (Palacios y Lera, 1992) y la guía PORTAGE (Bluma, Shearer, Frohman y Hilliard, 1978). La integración de la información histórico-situacional recabada, permite identificar condiciones probabilizadoras de los comportamientos valorados como problemáticos y delimitará su ámbito de ocurrencia (ver Tabla 1).

El resultado más importante que se revela en esta primera etapa, es la posibilidad de identificar las cosas, eventos, objetos y personas que han permanecido relativamente constantes en la evolución de la posible problemática. Esto mismo permite dirigir la indagación de manera focalizada hacia quienes con su presencia o acción adquieren o asumen un papel funcional importante en el origen y mantenimiento de la problemática bajo análisis. Finalmente, se tiene una primera aproximación a las prácticas llevadas a cabo en las situaciones identificadas y los criterios valorativos asociados a las mismas. 
Tabla 1. Lista de cotejo relativa a los factores básicos para el análisis de las interacciones problema.

\begin{tabular}{|c|c|c|c|}
\hline \multirow{2}{*}{$\begin{array}{c}\text { DIMENSIONES DE ANÁLISIS } \\
\text { Factores Histórico-Situacionales } \\
\text { (probabilizadores, delimitadores y posibilitadores) }\end{array}$} & \multicolumn{2}{|c|}{$\begin{array}{l}\text { INFORMACIÓN } \\
\text { DISPONIBLE }\end{array}$} & \multirow[t]{2}{*}{ OBSERVACIONES } \\
\hline & SI & NO & \\
\hline \multicolumn{4}{|l|}{$\begin{array}{l}\text { Evolución histórica de la familia e institución educativa } \\
\text { (momentos importantes relativos } \\
\text { a su origen y cambio a través de los años) }\end{array}$} \\
\hline \multicolumn{4}{|l|}{ Familiograma u organigrama } \\
\hline \multicolumn{4}{|l|}{ Dinámica familiar e institucional } \\
\hline \multicolumn{4}{|l|}{$\begin{array}{l}\text { Expectativas a lograr en la organización familiar } \\
\text { e institucional }\end{array}$} \\
\hline \multicolumn{4}{|l|}{$\begin{array}{l}\text { Lugares en los que se llevan a cabo las actividades } \\
\text { cotidianas }\end{array}$} \\
\hline \multicolumn{4}{|l|}{$\begin{array}{l}\text { Disponibilidad e idoneidad de los materiales con los } \\
\text { que se llevan a cabo las actividades cotidianas }\end{array}$} \\
\hline \multicolumn{4}{|l|}{$\begin{array}{l}\text { Roles o puestos de cada persona indicada } \\
\text { en el familiograma u organigrama }\end{array}$} \\
\hline \multicolumn{4}{|l|}{$\begin{array}{l}\text { Identificación de roles y funciones, específicas, } \\
\text { compartidas e intercambiables (proveedores, } \\
\text { administradores, etc.) }\end{array}$} \\
\hline \multicolumn{4}{|l|}{$\begin{array}{l}\text { Distribución y permanencia de las actividades } \\
\text { cotidianas }\end{array}$} \\
\hline \multicolumn{4}{|l|}{$\begin{array}{l}\text { Normatividad relativa al cumplimiento de las } \\
\text { actividades encomendadas o asumidas } \\
\text { por cada persona }\end{array}$} \\
\hline \multicolumn{4}{|l|}{$\begin{array}{l}\text { Identificación de los sistemas de recompensa } \\
\text { y castigo establecidos y quiénes tienen } \\
\text { la responsabilidad de administrarlos }\end{array}$} \\
\hline \multicolumn{4}{|l|}{$\begin{array}{l}\text { Propiedades de las consecuencias manejadas } \\
\text { (tipo, forma, calidad, cantidad, etc.) }\end{array}$} \\
\hline \multicolumn{4}{|l|}{$\begin{array}{l}\text { Diagnóstico de las condiciones orgánicas de los } \\
\text { individuos involucrados en las interacciones problema }\end{array}$} \\
\hline $\begin{array}{l}\text { Ubicación de las actividades en el contexto } \\
\text { de los ciclos biológicos pertinentes }\end{array}$ & & & \\
\hline
\end{tabular}




\begin{tabular}{|l|l|l|l|}
\hline \multicolumn{1}{|c|}{ Factores eficientes } & SI & NO & OBSERVACIONES \\
\hline $\begin{array}{l}\text { Catalogación de la(s) conducta(s) problema de } \\
\text { acuerdo a los informantes }\end{array}$ & & & \\
\hline $\begin{array}{l}\text { Factores que anteceden al comportamiento } \\
\text { problemático en la casa }\end{array}$ & & & \\
\hline $\begin{array}{l}\text { Factores que anteceden al comportamiento } \\
\text { problemático en la escuela }\end{array}$ & & & \\
\hline $\begin{array}{l}\text { Factores que anteceden al comportamiento } \\
\text { problemático en otros lugares en los que se presenta }\end{array}$ & & & \\
\hline $\begin{array}{l}\text { Características especificas de la frecuencia, duración, } \\
\text { magnitud y vigencia del comportamiento problemático } \\
\text { en la casa }\end{array}$ & & & \\
\hline $\begin{array}{l}\text { Características específicas de la frecuencia, duración, } \\
\text { magnitud y vigencia del comportamiento problemático } \\
\text { en la escuela }\end{array}$ & & & \\
\hline $\begin{array}{l}\text { Características específicas de la frecuencia, duración, } \\
\text { magnitud y vigencia del comportamiento problemático } \\
\text { en otros lugares }\end{array}$ & & & \\
\hline $\begin{array}{l}\text { Efectos que tiene la conducta problemática en cada } \\
\text { uno de los miembros de la familia }\end{array}$ & & & \\
\hline $\begin{array}{l}\text { Efectos que tiene la conducta problemática en el } \\
\text { director, maestra y compañeros de grupo del niño }\end{array}$ & & & \\
\hline $\begin{array}{l}\text { Efectos que tiene la conducta problemática en las } \\
\text { personas que se encuentran en lugares públicos }\end{array}$ & & & \\
\hline $\begin{array}{l}\text { Consecuencias que tiene la conducta problemática en } \\
\text { los diferentes escenarios }\end{array}$ & & & \\
\hline
\end{tabular}

\section{Segunda Etapa}

Morfologías de respuesta. La dimensión morfológica de las respuestas valoradas como problemáticas es el punto de entrada al análisis de las dimensiones funcionales del comportamiento. El lego hace contacto principalmente con las formas del comportamiento, narrando sus características de manera indiscriminada e indisociada de sus efectos y las valoraciones de las mismas.

Las morfologías de comportamiento y sus propiedades dinámicas (frecuencia, duración, magnitud, etc.) deben catalogarse con la mayor precisión posible, auxiliándose de estrategias de 
operacionalización, a fin de eliminar la ambigüedad inicial. Hecho esto, debe de identificarse las propiedades funcionales de dichas morfologías. Esto es, cuáles efectos (inmediatos, demorados, singulares, múltiples, directos, indirectos, etc.) tienen sobre los objetos, eventos, animales y personas que rodean al individuo que las realiza. Por igual, qué resultados y productos derivados del ejercicio de las topografías especificadas en el análisis debe hacerse en términos de las correspondencias entre las topografías de respuesta como de las topografías de los estímulos relacionados.

Mediación del comportamiento problema. En tanto cada uno de los individuos involucrados en las problemáticas llevan consigo una historia de interacción, en común e independiente, es vital determinar la naturaleza de los vínculos mediacionales entre la conducta del individuo que presenta la problemática, y quienes le rodean. Tanto el individuo que se relaciona de manera problemática, como los que le rodean, pueden desempeñar el rol de mediador o de mediado, de las relaciones de contingencia en las que participan. La complementariedad de estos papeles no es tan elemental como en el proceso comunicativo ordinario, descrito en la función sustitutiva referencial (Ribes y López, 1985). Las mediaciones alrededor de una problemática pueden concretarse en la adopción de diferentes roles sociales, tales como: a) auspiciador, cuando el individuo facilita las condiciones para que el problema ocurra; b) disposicional, cuando el individuo genera estados de ánimo o regula inclinaciones; c) regulador de una tendencia, cuando el individuo no genera la tendencia, pero la regula como si fuera un catalizador (Ribes, Díaz-González, Rodríguez y Landa, 1986).

La mediación también compromete la tipificación del nivel de aptitud funcional de las interacciones relacionadas con la problemática. En general, la identificación de los niveles de interacción funcional permite ubicar las características y complejidad del comportamiento problema así como las estrategias de entrenamiento a llevar a cabo. Por otra parte, las formas concretas o roles sociales de la mediación hacen posible establecer quiénes deben ser partícipes de la intervención y de qué manera. La consideración conjunta de todos estos factores, como se ilustra en la Tabla 2, permite establecer un diagnóstico de la problemática. Si es procedente intervenir, se debe trazar un plan de intervención considerando algunos de los lineamientos de la siguiente etapa.

Tabla 2. Lista de cotejo relativa al diagnóstico de la problemática.

\begin{tabular}{|c|c|c|c|}
\hline DIMENSIONES DE ANÁLISIS & \multicolumn{2}{|c|}{$\begin{array}{l}\text { INFORMACIÓN } \\
\text { DISPONIBLE }\end{array}$} & OBSERVACIONES \\
\hline Análisis del problema & SI & NO & \\
\hline $\begin{array}{l}\text { Identificación de las morfologías de respuesta } \\
\text { valoradas como problemáticas }\end{array}$ & & & \\
\hline $\begin{array}{l}\text { Identificación de las formas de suplementación de } \\
\text { dichas respuestas }\end{array}$ & & & \\
\hline
\end{tabular}




\begin{tabular}{|l|l|l|l|}
\hline $\begin{array}{l}\text { Efectos, resultados o productos derivados de dichas } \\
\text { respuestas }\end{array}$ & & & \\
\hline $\begin{array}{l}\text { Identificación de respuestas potencialmente } \\
\text { problemáticas, pero no valoradas como tales }\end{array}$ & & & \\
\hline $\begin{array}{l}\text { Efectos, resultados o productos derivados de dichas } \\
\text { respuestas }\end{array}$ & & & \\
\hline $\begin{array}{l}\text { Ubicación de las funciones desempeñadas por los } \\
\text { agentes sociales asociados al mantenimiento de la } \\
\text { respuesta problemática (auspiciador, disposicional, } \\
\text { regulador) }\end{array}$ & & & \\
\hline $\begin{array}{l}\text { Determinación de la duración y periodicidad de las } \\
\text { relaciones identificadas }\end{array}$ & & & \\
\hline $\begin{array}{l}\text { Valoración de respuestas alternativas a las que } \\
\text { cumplen con el perfil funcional de problemáticas }\end{array}$ & & & \\
\hline
\end{tabular}

\section{Tercera Etapa}

Desmantelamiento de las contingencias. El diagnóstico llevado a cabo a partir de la recolección y análisis de información durante la segunda etapa, permite establecer un sistema de hipótesis relativas a cómo evolucionó el problema, en qué medida las condiciones situacionales influyen en la presencia del problema, las morfologías de respuesta involucradas en la conducta problema, los factores de mantenimiento del mismo y el conjunto de factores disposicionales y valorales que están asociados a las conductas problema. A partir de este punto es necesario determinar los objetivos de la intervención. Estos pueden ir en tres direcciones: 1) hacia el establecimiento de repertorios conductuales no presentes por el momento, 2) hacia el cambio en los factores disposicionales asociados a las conductas problema y 3 ) hacia el marco de valoración de las prácticas consideradas problemáticas. Es pertinente señalar que estas tres direcciones en las que los objetivos pueden dirigirse no son excluyentes entre sí.

En el primer caso es necesario establecer repertorios de comportamiento que complementen e incluso lleguen a sustituir a las conductas problema en el propio individuo. Múltiples técnicas promotoras del aprendizaje pueden implementarse considerando el nivel funcional en el cual se desempeña el individuo. Son especialmente útiles las técnicas de modificación de conducta (Ribes, 1984), sobre todo cuando se busca establecer comportamientos en niveles no sustitutivos. Igualmente, los procedimientos de cambio conductual basados en la imitación (Bandura y Walters, 1974) son valiosos con escolares de ciclo básico y medio básico. Por último, si los comportamientos que se tiene por objetivo establecer se estructuran en los niveles sustitutivos, los procedimientos de reestructuración cognitiva (Ellis y Grieger, 1990), terapia de aceptación y compromiso (Hayes, Strosahl y Wilson, 2015), así como el análisis contingencial (Ribes et al. 1986). 
En el segundo caso, la modificación de los factores disposicionales involucra individuos, situaciones y cosas, que a través de múltiples contactos se constituyen en condiciones relativamente constantes a la ocurrencia del comportamiento problemático e incluso lo probabilizan. En tales casos, el objetivo se orienta al entrenamiento de las personas que desempeñan un papel de auspiciador, disposicional o regulador de tendencias, ya que estas deben ser entrenadas para actuar de manera diferente ante las conductas problema, a fin de romper con la secuencia funcional de los comportamientos que dan soporte a la conducta problema. En cuanto a los eventos y cosas, la meta es orientar a los participantes a que presten atención diferencial a los eventos que influyen en las disposiciones, o reubiquen los objetos que influyen en las mismas.

En el tercer caso, la actuación sobre el marco de valoración de los comportamientos eje de la intervención, compromete una labor de cambio de actitudes, intereses, creencias, motivos, etc., que se ha configurado históricamente, por lo que es posible que presente fuerte resistencia al cambio. Los procedimientos propuestos por Ribes et al. (1986), para el cambio de las macrocontingencias, puede contribuir a desarrollar nuevas interpretaciones de lo correcto y lo moral en torno a las prácticas compartidas. Los puntos sugeridos previamente pueden cotejarse de acuerdo al contenido de la Tabla 3.

Tabla 3. Lista de cotejo relativa al análisis de soluciones.

\begin{tabular}{|l|c|c|c|}
\hline \multicolumn{1}{|c|}{ DIMENSIONES DE ANÁLISIS } & \multicolumn{1}{|c|}{$\begin{array}{c}\text { INFORMACIÓN } \\
\text { DISPONIBLE }\end{array}$} & OBSERVACIONES \\
\hline \multicolumn{1}{|c|}{ Análisis de soluciones } & SI & NO & \\
\hline $\begin{array}{l}\text { Identificación de repertorios conductuales } \\
\text { pertinentes para sustituir las conductas actuales }\end{array}$ & & \\
\hline $\begin{array}{l}\text { Determinación de las formas de entrenamiento } \\
\text { pertinentes al aprendizaje de los repertorios } \\
\text { alternativos }\end{array}$ & & \\
\hline $\begin{array}{l}\text { Identificación de los factores disposicionales } \\
\text { asociados a la conducta problema }\end{array}$ & & \\
\hline $\begin{array}{l}\text { Determinación de las formas de entrenamiento } \\
\text { pertinentes al aprendizaje de disposiciones } \\
\text { alternativas }\end{array}$ & & \\
\hline $\begin{array}{l}\text { Identificación del marco de valoración de las } \\
\text { prácticas consideradas problemáticas }\end{array}$ & & \\
\hline
\end{tabular}

Moldeando el cambio psicológico. La intervención derivada del diagnóstico debe ser lo más completa con respecto a los procesos conductuales a modificar. Los diferentes comportamientos a tra- 
bajar deben ser considerados contemplando al menos dos aspectos. Por un lado, la obtención de resultados rápidos y tangibles para que los participantes no abandonen la intervención, y por otro, la sincronicidad de los tratamientos, a fin de que los cambios en las morfologías de las respuestas no ocurran antes o después de otros cambios ambientales que deben relacionarse con ellas, desfavoreciendo así la reconfiguración de las funciones interactivas. La planeación debe favorecer el desarrollo del comportamiento, dado que no se trata sólo de subsanar déficits o excesos conductuales, se trata de cambiar la vida de las personas favorablemente. Debe buscarse el aprendizaje a partir del diseño de condiciones en las que el aprendiz se desempeñe de manera variada y efectiva.

La intervención en sentido estricto, debe programarse de manera que permita dar seguimiento al cambio individual ya que cada individuo tiene un ritmo diferente de aprendizaje. De igual forma los criterios a satisfacer deben establecerse con precisión de modo que los participantes en las actividades de aprendizaje muestren de manera indiscutible y consistente los comportamientos funcionales por adquirir.

\section{Cuarta Etapa}

Condiciones de transferencia, generalización y validación social. En la medida que el cambio de toda problemática educativa depende de nuevos aprendizajes enfatizaremos la importancia de establecer condiciones de transferencia y generalización de los aprendizajes promovidos. En muchas ocasiones pareciera que una intervención educativa basta evaluarla con una postprueba. Sin embargo, el diseño de condiciones de evaluación bajo la lógica de medidas repetidas, permite graduar el desvanecimiento de las condiciones construidas durante el entrenamiento.

La extensión de los repertorios adquiridos hacia conductas diferentes a la entrenada y a escenarios diferentes de aquel en el que se realizó el entrenamiento, depende del manejo explícito de diferentes técnicas sistematizadas por Stokes y Baer (1977). Las técnicas más recomendables para los propósitos de una intervención educativa son:

- Modificación secuencial de los escenarios de entrenamiento, a fin de que estos fueran progresivamente más semejantes físicamente al escenario natural en el que se espera se presente la conducta entrenada.

- $\quad$ Exposición a ejemplares múltiples de la relación entrenada, a fin de que la variedad de estímulos respecto a los cuales se presenta la respuesta a generalizar sea suficientemente amplia.

- $\quad$ Contingencias indiscriminables, que de manera semejante a las estrategias anteriores procuran una distribución del reforzamiento impredecible para los sujetos, a fin de que su conducta pueda quedar controlada por consecuencias naturales.

El inicio de toda intervención educativa depende del reporte de los individuos que de acuerdo a sus propias valoraciones determinan que ciertas morfologías de respuesta de otro individuo son inapropiadas, no pertinentes, e incluso no funcionales. Esas mismas personas, y otros individuos en escenarios en los que se extienden las conductas clasificadas como problema, deberán validar si el cambio conductual promovido es funcional y socialmente ajustado a las características del comportamiento deseable en la comunidad de pertenencia de los individuos participantes. 


\section{Comentarios finales}

El presente capítulo ha procurado delinear una aproximación general acerca de cómo debe hacerse una intervención educativa manteniendo el enfoque Interconductual de campo (Kantor, 1969; Ribes y López, 1985). Este esfuerzo puede considerarse inicial en la medida de que existen diversos trabajos recepcionales y publicaciones que dicen estar llevando a cabo una intervención educativa Interconductista. Aún falta mucho por depurar en esta iniciativa, sin embargo, coincide en algunos puntos con el análisis contingencial propuesto por Ribes et al. (1986), y en otros lo retoma expresamente.

Los estudios de Velarde (2014), Ramírez (2015) y Moreno (2016), tienen como común denominador el ubicarse como intervenciones diseñadas desde el modelo Interconductual. Velarde (2014) reportó una investigación aplicada que tuvo como objetivo mejorar las competencias de comprensión lectora (poesía) en alumnos de sexto grado de primaria de una escuela rural indígena, en el Estado de Morelos. Su método de trabajo se ajustó a un modelo de intervención que se denomina Programa de Instrucción Funcional (PIF) que promueve situaciones de aprendizaje jerarquizadas, en las que el alumno puede interactuar con los objetos de conocimiento en cinco niveles de aptitud funcional, en las que tiene que completar un criterio de aptitud funcional para poder pasar al que sigue. En este estudio participaron 22 alumnos que fueron seleccionados aleatoriamente ya que en la valoración inicial de su desempeño no mostraron un nivel muy distinto al de la mayoría de sus compañeros. El programa de intervención integró actividades de evaluación que sirvieron para saber si los alumnos han conseguido cumplir totalmente con cada uno de los criterios establecidos, de acuerdo a los niveles de aptitud funcional.

El programa de intervención constó de 6 sesiones en las que se abordaron tres subunidades de aprendizaje. Después de la implementación de la intervención se realizó una evaluación final y se compararon con la inicial en ambos grupos. Los resultados mostraron mejoras en comprensión de lectura, en las tareas específicas poemas 1 y poemas 2 que componen la evaluación del quinto bloque de estudios de la asignatura de español para sexto grado, en los niños que participaron en el grupo de intervención. De acuerdo con Velarde (2014), los niveles a los que se ajustaron la mayor parte de los estudiantes que participaron en este grupo, fueron los tres primeros niveles de aptitud funcional.

Por otra parte, Ramírez (2015) llevó a cabo un programa de intervención basado en la Psicología Interconductual, para mejorar la producción de textos narrativos de los alumnos de sexto grado de primaria. Este programa de intervención se diseñó para favorecer competencias en producción de textos narrativos mediante una planeación didáctica en la cual se especificó el criterio de logro de acuerdo a distintos niveles funcionales y una evaluación para corroborar si el criterio de logro se cumplió o no. En este estudio participaron 53 alumnos de sexto grado de una primaria pública del estado de Morelos. De estos, 21 participaron en el Programa de Enseñanza Funcional (PEF), mientras que el resto fue parte del grupo control. El programa de intervención constó de seis sesiones, en las que se realizaron actividades relativas a los bloques uno y dos de la asignatura de español para sexto grado de primaria, y se efectuaron actividades con los temas biografía, autobiografía y cuento de misterio y terror. Los resultados mostraron que los alumnos que fueron parte del grupo experimental, mejoraron su desempeño general en la elaboración de textos narrativos, particularmente en el tema de autobiografía. 
Por último, Moreno (2016) evaluó el efecto de una estrategia de intervención para el desarrollo de competencias de planeación funcional con alumnos de octavo semestre del turno matutino de una Escuela Normal privada en el Estado de Morelos. Participaron 17 estudiantes con edades entre 21 y 34 años, inscritos en dos grupos en la licenciatura de español. Ambos grupos fueron expuestos a tareas idénticas variando el tema de referencia en la asignatura de español, mediante un diseño cuasiexperimental con pre y postprueba y contraprueba. Los resultados mostraron mejoras en las habilidades de los participantes para el diseño de unidades de enseñanza-aprendizaje y se probó la efectividad del programa de intervención en ambos grupos.

Estos avances iniciales aún carecen de una adecuada contextualización de las problemáticas socialmente relevantes, no sólo en el sentido que la política nacional determina, si no desde la perspectiva de los usuarios reales. Hace falta una problematización que no parta sólo desde la política o desde la teoría, que se ubique en la circunstancia de los usuarios y no vea a estos sólo por sus características como población de estudio. Adicionalmente, hace falta analizar la lógica del cambio psicológico, ya que no todo aprendizaje conduce necesariamente a cambios en el nivel funcional de interacción. Por igual, estos resultados de intervención educativa, nos lleva a la problemática de establecer categorías más precisas para lograr la identificación de los aprendizajes, tanto cuantitativa como cualitativamente, y la recuperación de la validación social como factor ecológico que permita valorar el impacto legítimo del trabajo realizado.

\section{Referencias}

Bandura, A., \& Walters, R. (1974). Aprendizaje social y desarrollo de la personalidad. Madrid: Alianza. Bluma, S., Shearer, M., Frohman, A., \& Hilliard, J. (1978). Manual: Guía Portage de Educación Preescolar. Proyecto Portage. Wisconsin, E.U: CESA.

Ellis, A., \& Grieger, R. (1990). Manual de terapia racional emotiva. Volumen 2. Bilbao: DDB.

Hayes, S.C., Strosahl, K., \& Wilson, K. (2015). Terapia de aceptación y compromiso. Bilbao: Desclée de Brouwer.

Kantor, J.R. (1924-1926). Principles of Psychology. Granville: Principia Press.

Kantor, J.R. (1969). Interbehavioral Psychology. Chicago: Principia Press.

Kantor, J.R., \& Smith, N.W. (1975). The science of Psychology. An Interbehavioral survey. Chicago: Principia Press.

Mares, G. (2001). Transferencia desde una perspectiva de desarrollo psicológico. En G. Mares y Y. Guevara (Coords.), Psicología Interconductual. Avances en la investigación básica. México: Universidad Nacional Autónoma de México.

Moreno, R.I. (2016). Efectos diferenciales de planeación y procesos didácticos en el desarrollo funcional de competencias en estudiantes normalistas. Tesis de Doctorado. Universidad Autónoma del Estado de Morelos.

Palacios, J., \& Lera, M. (1992). Cuestionario de la vida diaria del niño. Traducción de la Escala HOME. Mimeo (Home Observation for Measurement of the Environment). Madrid: Visor.

Ramírez, A. (2015). Enseñanza funcional para la producción de textos narrativos en sexto grado de primaria. Tesis de Maestría. Universidad Autónoma del Estado de Morelos. 
Ribes, E. (1984). Técnicas de modificación de conducta. Su aplicación al retardo en el desarrollo. México: Editorial Trillas.

Ribes, E. (1990). Psicología General. México: Editorial Trillas.

Ribes, E. (2002). Psicología del Aprendizaje. México: El Manual Moderno.

Ribes, E., \& López, F. (1985). Teoría de la Conducta. Un análisis de campo y paramétrico. México: Editorial Trillas.

Ribes, E., Pineda, L.A., \& Quintana, C. (2007). A functional analysis of the acquisition of languaje as behavior. Brazilian Journal of Behavior Analysis, 3 (2), 161-180.

Ribes, E., Díaz-González, E., Rodríguez, M.L., \& Landa, P. (1986). El Análisis Contingencial: una alternativa a las aproximaciones terapéuticas del comportamiento. Cuadernos de Psicología, 8, 27-52.

Ryle, G. (1967). El concepto de lo mental. Buenos Aires: Paidós.

Stokes, T.F., \& Baer, D.M. (1977). An implicit technology of generalization. Journal of Applied Behavior Analysis, 10, 349-367.

Velarde, N.M. (2014). Efectos del programa de instrucción funcional en comprensión lectora de alumnos de sexto grado. Tesis de Maestría. Universidad Autónoma del Estado de Morelos. 


\section{Capítulo 5}

\section{Evaluación de la comprensión lectora en alumnos} de secundaria, desde la Psicología Interconductual

Yolanda Guevara Benítez y Karlena Cárdenas Espinoza 
Yolanda Guevara Benítez yolaguevara@hotmail.com

Facultad de Estudios Superiores Iztacala Universidad Nacional Autónoma de México Karlena Cárdenas Espinoza karlenacardenas@hotmail.com

Facultad de Estudios Superiores Acatlán Universidad Nacional Autónoma de México 


\section{Capítulo 5}

\section{Evaluación de la comprensión lectora en alumnos de secundaria, desde la Psicología Interconductual}

El presente capítulo presenta una exposición de los fundamentos teóricos del Interconductismo que sirvieron de base para la elaboración de un instrumento que evalúa la comprensión lectora en diversos niveles funcionales (selector, sustitutivo referencial y sustitutivo no referencial), a ser aplicado con estudiantes de secundaria. Después se describe el procedimiento seguido para la validación del instrumento, los textos y los reactivos que lo constituyen, así como una guía para su calificación, siguiendo los criterios del nivel funcional que evalúan los reactivos. También se incluye un resumen de los resultados obtenidos de la aplicación del instrumento, citando los artículos en los que las autoras reportaron dichos datos, así como un resumen de los resultados obtenidos de la aplicación de un programa de intervención para promover la comprensión lectora en diversos niveles funcionales, con estudiantes mexicanos de secundaria.

\section{Fundamentos teóricos Interconductuales}

Entre los principales postulados del modelo psicológico Interconductual (Kantor, 1980) está la concepción del comportamiento como la práctica de acciones por parte de un individuo, que guardan una estrecha relación con diversos factores del medioambiente circundante, constituido este último por objetos, personas y eventos de distinta naturaleza. El comportamiento es, entonces, una interacción entre el individuo y el ambiente, en donde se presenta una mutua influencia entre ambos.

La explicación Interconductual toma en consideración que el individuo no establece contacto con todos y cada uno de los elementos que se encuentran en su medioambiente, sino sólo con algunos de ellos. De los objetos, personas y eventos con los que sí establece contacto un individuo se dice que cumplen funciones de estímulo, y a los contactos que establece el individuo con dichos estímulos se les denominan funciones de respuesta. Las funciones de estímulo y las funciones de respuesta pueden variar de una especie a otra, de un individuo a otro, e incluso de un momento particular a otro: "Una interacción supone la interacción particular de los estímulos del medio y de las respuestas del individuo. Dichas relaciones son formas de mediación (contacto) de las contingencias entre ambos elementos participantes de la interacción" (Varela, 2008, p. 76).

Para comprender el desarrollo del comportamiento humano, la Psicología Interconductual hace notar que cada segmento de interacción Interconductual de una persona es un contacto único e irrepetible. Al establecerse varios segmentos Interconductuales sucesivamente, se va constituyen- 
do la historia de interacciones de dicho individuo. Por lo tanto, las interacciones que una persona establezca en un momento particular de su vida van a estar influidas por los estímulos particulares con los que entre en contacto, pero también, por la historia Interconductual que ha establecido a lo largo de su vida, con ese y con otro tipo de estímulos. Al conjunto de factores que influyen en las interacciones de un segmento particular se les denomina factores del campo Interconductual.

A lo largo de una vida humana se establecen formas cualitativamente distintas de contacto con el ambiente, influidas por diversos factores: "A estas formas cualitativamente distintas de contacto organismo-ambiente se les denomina funciones conductuales" (Ribes y López, 1985, p. 82), porque dependen de la forma en que se organizan los diferentes elementos del campo psicológico. La conducta, como proceso interactivo de contacto entre el individuo y el ambiente, es evolutiva, y se desarrolla en formas cualitativamente distintas que delimitan los diversos niveles organizativos de lo psicológico. El desarrollo de habilidades y competencias en un individuo se presenta cuando es capaz de comportarse de maneras sucesivamente más complejas.

El individuo en desarrollo va complejizando sus niveles de interacción en conductas de diversa índole: "La evolución psicológica se da, como proceso, en la transición de los niveles funcionales más simples a los más complejos [...] las funciones complejas incluyen, como componentes, las formas de organización que caracterizan a las funciones menos complejas" (Ribes y López, 1985, p. 65).

Entre las conductas más complejas, típicamente humanas, puede ubicarse el lenguaje. Su desarrollo implica que la persona adquiere, primero, niveles simples de interacción lingüística (a través de la mediación de las personas de su entorno, que ya dominan el código lingüístico propio de su comunidad), y a lo largo de su historia personal va conformando nuevos niveles de dominio del lenguaje, que se asocian con el grado de desligamiento que va teniendo respecto de los objetos, personas y eventos presentes en el contexto (tiempo y espacio).

En el desarrollo ontogenético del ser humano, el lenguaje, a diferencia de los animales, es un sistema reactivo no sólo biológico sino social. La aparición del lenguaje es independiente de otras formas de función mediadora, pero su convergencia con ellas produce las formas de mediación que son idiosincrásicas y exclusivas del hombre (Ribes y López, 1985, p. 86).

El lenguaje es un sistema o repertorio de gestos, acciones y símbolos hablados y escritos, que están estructurados de manera organizada (a través de códigos e idiomas), cuyo dominio permite a un individuo interactuar con otros, así como mediar su comportamiento, es decir, influir en él. Es una característica exclusivamente humana que sólo se desarrolla por el hecho de vivir e interactuar continuamente en un ambiente social y cultural. Pérez-Almonacid y Quiroga (2010) explican que, desde la Psicología Interconductual, el lenguaje es analizado como práctica, porque a la Psicología le interesa lo que los individuos hacen, y la actividad verbal humana es parte fundamental de las interacciones sociales. Por ello, el estudio de la conducta lingüística (gestual, corporal, oral y escrita) debe ubicarse considerando las prácticas sociales que la hacen posible y que le dan sentido.

La noción de lenguaje como práctica permite estudiar cómo la actividad de las personas se corresponde con la organización de la práctica lingüística a nivel social. Es decir, analiza los usos lingüísticos: qué, cómo, bajo qué condiciones y qué resultados se obtienen a partir de lo que el indi- 
viduo dice, lee, gesticula o escribe (Pérez-Almonacid y Quiroga, 2010).

La diferencia fundamental entre la comunicación lingüística que el hombre establece con su entorno y la denominada "comunicación animal" es que en esta última el organismo no puede desprenderse de la relación directa que debe establecer con los objetos físicos presentes en un lugar y espacio determinados (contexto); es decir, los sistemas reactivos característicos de toda especie animal están limitados por su incapacidad para producir convenciones que puedan referir funcionalmente cosas. En cambio, el lenguaje humano está constituido por convenciones lingüísticas variadas, que permiten referir y ser referido a diversos aspectos de la realidad, que pueden corresponder al aquí y al ahora, pero también pueden corresponder a tiempos y espacios distintos de los presentes.

Con base en la Psicología Interconductual, Ribes y López (1985) desarrollaron una taxonomía de la conducta que toma en cuenta los diferentes grados de complejidad en que puede presentarse el comportamiento humano, dependiendo de los factores que quedan integrados en un campo Interconductual, incluyendo el nivel de desligamiento respecto a los objetos, personas y eventos presentes (o ausentes) en tiempo y espacio. Guevara (2006) explica que la taxonomía de Ribes y López sistematiza el análisis del comportamiento, a través de la categorización cualitativa de cinco diferentes niveles de interacción -de complejidad inclusiva- que un individuo establece con su ambiente.

En el nivel más simple del comportamiento, el individuo actúa dependiendo absolutamente de las circunstancias físicas contextuales presentes, por ello fue denominada como función contextual. Este es el primer tipo de conducta que los humanos desarrollan. Pero en la medida en que el individuo establece nuevas interacciones con su entorno físico y social, aprende a desligarse del aquí y el ahora, desarrollando conductas en los niveles de complejidad intermedia (suplementaria y selectora). Es así como el comportamiento humano se va haciendo más complejo, hasta llegar a trascender completamente las circunstancias inmediatas, es decir, los objetos, personas y eventos presentes en la situación. Ese logro evolutivo sólo es posible a través del uso convencional del lenguaje.

Cuando una persona se comporta ante las palabras como si estuvieran presentes los objetos, personas y eventos que se denominan a través de ellas, se dice que esa persona se está comportando en un nivel sustitutivo; porque el uso convencional del código lingüístico sustituye los contactos directos con aspectos del contexto presente, cumpliendo las funciones estímulo que originalmente cumplieron dichos contactos contextuales.

De la misma manera en que el niño adquiere habilidades y competencias del lenguaje oral, las interacciones con su ambiente social van introduciéndolo poco a poco en el uso del lenguaje escrito. A esas primeras aproximaciones se les llama alfabetización inicial, y constituyen una etapa del desarrollo humano que ocurre generalmente durante los años preescolares. La alfabetización inicial depende de diversos aspectos. En primer lugar, de que el niño tenga una vida cotidiana dentro de un ambiente rico en estímulos alfabetizadores, donde interactúe con libros, cuentos, letreros, recados y otros productos relacionados con la lectura y la escritura, y que a partir de ello aprenda diversas características del lenguaje escrito. También se requiere que establezca interacciones constantes y variadas con otras personas, en las que se utilice el lenguaje oral, así como aproximaciones a la 
lectura y la escritura. El papel de los padres y educadores es fundamental, dado que son quienes median el aprendizaje temprano del lenguaje oral y de las primeras aproximaciones a la lectura y la escritura (Guevara, Rugerio, Delgado y Hermosillo, 2010).

Cuando el niño ha tenido suficientes interacciones y aproximaciones al lenguaje escrito puede desarrollar habilidades de lecto-escritura formal, lo que generalmente ocurre durante los primeros años escolares. En un sistema de enseñanza ideal, que incluya la programación de experiencias adecuadas con materiales escritos, así como prácticas didácticas que promuevan interacciones de los alumnos con dichos materiales, los alumnos podrán avanzar en sus grados de dominio de la lengua escrita.

Retomando la taxonomía de Ribes y López (1985), los niños desarrollarían, primero, interacciones a nivel contextual, y poco a poco avanzarían hacia interacciones suplementarias y selectoras; es decir, se desligarían cada vez más de las situaciones presentes en tiempo y espacio, durante su ejercicio de las habilidades de lectura y escritura. Ese avance les permitiría alcanzar grados de dominio de la lengua escrita que se corresponden con los niveles sustitutivos, en donde hay un desligamiento absoluto de las condiciones presentes en tiempo y espacio, y todas las interacciones que establece el individuo son a través del uso del lenguaje, en este caso, del uso comprensivo del código escrito para lectura y escritura.

Mares, Rueda, Rivas y Rocha (2009) recuperan la delimitación de los cinco niveles funcionales de la conducta para explicar las diferencias entre diversas habilidades lectoras que se adquieren y se promueven en el contexto del salón de clases: se ubica el Nivel 1 (contextual) cuando los alumnos participan en actividades escolares, ajustándose a los estímulos que se les presentan (que requieren desligamiento mínimo del aquí y el ahora), y únicamente son escuchas o repetidores de la información; un profesor promueve interacciones contextuales en el aula cuando estructura actividades que sólo requieren que los estudiantes lean un texto o repitan información. El Nivel 2 (suplementario) se presenta en los alumnos cuando se involucran en interacciones produciendo cambios en el ambiente físico o social (lo que implica un mayor grado de desligamiento); se promueven estas interacciones en el aula cuando se organizan situaciones para que los estudiantes realicen actividades prácticas de manipulación del ambiente, a partir de los contenidos de la lectura. En el Nivel 3 (selector), los alumnos pueden hablar o actuar sobre un objeto de maneras diversas, la conducta pertinente en cada caso es cambiante de momento a momento en función de la presencia de otros elementos; hay desligamiento de una relación fija entre un objeto y una acción, y el alumno elige cómo comportarse en cada caso; un profesor promueve este nivel cuando involucra a sus estudiantes en tareas que requieren seleccionar un producto lingüístico que responda a preguntas particulares del tipo "qué", "quién”, "dónde", "cuándo", o bien cuando plantea un problema que implica seleccionar y ejecutar la operación adecuada. En el Nivel 4 (sustitutivo referencial), los alumnos llevan a cabo interacciones con un desligamiento casi absoluto de la situación presente, porque refieren (o son referidos) de manera lingüística situaciones pasadas o futuras, es decir, interactúan lingüísticamente con objetos, personas o eventos no presentes en tiempo y espacio; en el aula se promueve este nivel en los estudiantes cuando se estructuran actividades para que ellos describan, de manera hablada o escrita, situaciones no presentes en tiempo y espacio. El nivel de interacción más complejo es el sustitutivo no referencial (Nivel 5), cuando el lenguaje entre los participantes no se limita a referir y describir 
eventos, sino que se manejan juicios argumentados o se explican relaciones entre eventos; se dice que un profesor promueve esto cuando pide a sus estudiantes que analicen fenómenos y establezcan relaciones de causalidad, comparación, correspondencia o diferencia (Mares et al., 2009).

Los planteamientos Interconductuales permiten comprender los eventos psicológicos en el campo educativo. Tales eventos comprenden tanto las condiciones de enseñanza como los eventos de aprendizaje. Por supuesto, los profesores, o personas a cargo de cualquier tipo de instrucción, desempeñan uno de los papeles más importantes en este campo, porque son quienes tienen como función explícita la transmisión de la cultura, fijar metas de aprendizaje y llevar a cabo técnicas para lograr que el aprendizaje de los alumnos ocurra. Otro papel importante es atribuible al contexto educativo, porque los factores contextuales influyen sobre lo que se enseña y lo que se aprende, así como sobre las metas educativas o tipo de habilidades a desarrollar.

No debe perderse de vista que los procedimientos de enseñanza y los desempeños académicos son principalmente eventos psicológicos, es decir, formas específicas de Interconducta que se presentan en formas cualitativamente distintas de contacto individuo-ambiente, a las que Ribes y López (1985) denominaron funciones conductuales, explicando su relación de interdependencia con diversos factores en el campo Interconductual. Los distintos tipos de funciones (o relaciones entre los factores del campo) se estructuran en diferentes momentos, a lo largo de la historia interactiva de un individuo.

Diversas investigaciones realizadas en aulas mexicanas (Fuentes, 2007; Guevara, 2006; Mares y Guevara, 2004; Mares, Guevara, Rueda, Rivas y Rocha, 2004; Mares et al., 2009) han analizado las interacciones que promueven los profesores de primaria. Los hallazgos indican que las actividades de instrucción se encaminan con mayor frecuencia a que los alumnos copien y repitan información previamente leída o expuesta por el profesor. Es decir, que el nivel funcional de lectura y escritura más ejercitado en el aula es el contextual. También se pudieron ubicar algunas actividades encaminadas a promover el nivel suplementario, cuando se ponía a los estudiantes a realizar ejercicios; o bien, a promover el nivel selector, cuando se pedía a los alumnos que resolvieran cuestionarios o que seleccionaran ejemplos de conceptos. Pero la constante, en las aulas de las escuelas primarias estudiadas, fue que se dejaba de lado el desarrollo de actividades referenciales y analíticas.

Considerando los planteamientos de la Psicología Interconductual, Fuentes (2010) explica que para que pueda hablarse de comprensión lectora deben ocurrir dos dimensiones funcionales: leer textualmente y leer comprensivamente. Con esa base, es importante señalar que para lograr la comprensión de los alumnos de educación básica, es necesario que ellos establezcan interacciones en los diversos niveles funcionales; por lo tanto, es necesario que los materiales de lectura y las acciones didácticas de los profesores estén encaminados a promover y evaluar el desarrollo de competencias de lectura textual y comprensiva en los cinco niveles de desempeño.

Mares (2008) señala que las interacciones lectoras que se requiere que los alumnos estructuren con los textos escolares (particularmente con los que abordan temas científicos) deben concentrarse en los niveles sustitutivo referencial y sustitutivo no referencial. Ello se hace necesario porque los estudiantes deben entrar en contacto (indirecto) con hechos o eventos no presentes, encontrar relaciones entre eventos y desarrollar la capacidad de analizar los fenómenos científicos. 
Una comprensión limitada — que no incluya los cinco niveles funcionales- puede llevar a que el alumno tenga problemas para aplicar el conocimiento o para generalizar lo aprendido; mientras que desarrollar habilidades lectoras en niveles de aptitud funcional sustitutiva referencial y no referencial favorece que se presente la generalización (transferencia) del aprendizaje hacia otros temas y otras situaciones.

Reconocer diferentes tipos de competencias de comprensión lectora implica identificar diferentes modos de leer los textos; por ello se requiere enseñar a los alumnos las diversas maneras de interactuar con el referente de una lectura (Fuentes, 2007). La adquisición de habilidades de comprensión lectora requiere de la exposición a una gama variada de situaciones en las que se exhiban desempeños heterogéneos. Para que la competencia lectora se presente de manera generalizada, es necesario que se desarrolle en todos los niveles funcionales, con diferentes contenidos, y ante distintas situaciones (Morales et al., 2010).

De lo anterior se deriva que el alumno de educación básica, primaria y secundaria, debe desarrollar competencias para la comprensión lectora de diversos temas (literarios, matemáticos, de ciencias sociales y naturales, de temas cotidianos, etc.), y la mejor manera de lograrlo es a través de una historia interactiva con textos y profesores que promuevan la adquisición y ejercicio de muy diversas interacciones lingüísticas.

Irigoyen, Jiménez y Acuña (2007) aclaran que ser un lector competente implica la posibilidad funcional de responder efectivamente en tareas diferentes, mostrando diversos niveles funcionales de comportamiento. Lo deseable sería que dicho grado de competencia lectora fuera alcanzado por los alumnos al terminar su educación secundaria, pero los datos disponibles al respecto indican que los alumnos de este nivel educativo parecen estar lejos de alcanzar esa meta.

González, Barba y González (2010) explican que el bajo rendimiento académico que se identifica en los alumnos de secundaria es un problema que se arrastra desde la primaria. Señalan que las escuelas no han sido capaces de promover hábitos lectores en los estudiantes, pero sobre todo, no han podido desarrollar en ellos habilidades de comprensión lectora. Esto se debe a que la comprensión lectora no está planteada como objetivo educativo explícito en los planes curriculares, y a que las únicas oportunidades que tienen los estudiantes para desarrollar tales competencias se circunscriben, casi exclusivamente, a las que se brindan en los cursos de Lengua y Literatura. Por ello, es necesaria la programación explícita de la enseñanza de estrategias de comprensión lectora sobre diversos temas y en diversas asignaturas, lo cual facilitará su uso generalizado.

Si se toma en consideración lo expuesto hasta aquí, es clara la necesidad de contar con instrumentos que permitan evaluar la comprensión lectora en alumnos de secundaria, y que den cuenta de los niveles funcionales que muestran en su interacción con textos de diversa índole. Sobre dichas bases, será posible delimitar situaciones de instrucción que permitan promover la comprensión lectora en el aula de secundaria.

\section{Elaboración del instrumento}

Con base en los señalamientos expuestos, se desarrolló un instrumento conformado por dos pruebas; cada prueba incluye un texto y un conjunto de reactivos para evaluar la comprensión lectora en los tres niveles funcionales más complejos (selector, sustitutivo referencial y sustitutivo no refe- 
rencial). Uno de los textos corresponde a un tema literario y tiene una estructura narrativa, el otro corresponde a un tema de biología y tiene una estructura expositiva.

Para la elección de los textos se tomaron en consideración los señalamientos de Pérez (2005), en el sentido de que existen evidencias de que los lectores pueden comprender y retener más fácilmente los textos con una prosa narrativa que los textos de tipo expositivo. Entre las principales razones está el hecho de que los textos con prosa narrativa suelen emplear un lenguaje más sencillo y referirse a temas que están más vinculados con la vida cotidiana de las personas, además de que la narración suele incluir explicaciones y relaciones de causalidad entre los acontecimientos narrados. Por su parte los textos expositivos se caracterizan por abordar temas de índole científica, emplear términos técnicos y presentar relaciones lógicas entre acontecimientos, con la finalidad de informar o de explicar al lector algún fenómeno.

Siguiendo los planteamientos de la Psicología Interconductual, un instrumento que pretenda medir la comprensión lectora ha de enfocarse en, al menos, un texto narrativo y un texto expositivo, cada uno con estructura, temática y lenguaje distintos. En este caso, para la primera prueba se eligió un fragmento del cuento La persona promedio como astronauta (Asimov, 1992). Para la segunda prueba se eligió un fragmento de la lectura denominada Análisis del desarrollo histórico de métodos de manipulación genética (Limón, Mejía y Aguilera, 2007). En ambos casos se cuidó que el nivel de dificultad correspondiera a alumnos de primer grado de secundaria. Se agregaron a pie de página las definiciones de algunos conceptos que se consideraron pertinentes, y se cuidó que ambos textos fueran similares en extensión (de aproximadamente 970 palabras).

Ahora bien, para el diseño de los reactivos se tomaron como base las definiciones de Mares et al. (2009) sobre habilidades lectoras en los tres niveles de mayor complejidad o aptitud funcional (selector, sustitutivo referencial y sustitutivo no referencial). Cada uno de los cuestionarios estuvo conformado por ilustraciones (obtenidas libremente de Internet) y nueve preguntas de elaboración propia, dirigidas a evaluar respuestas del alumno, de acuerdo con las definiciones de los tres niveles funcionales. Los tres reactivos para evaluar el nivel selector se relacionan con tareas que requieren elegir un producto lingüístico contenido en el texto; los tres reactivos correspondientes al nivel sustitutivo referencial requieren que el alumno describa por escrito situaciones no presentes en tiempo y espacio, relacionadas con los aspectos referidos en la lectura, y los tres reactivos relacionados con el nivel sustitutivo no referencial implican emitir juicios argumentados o explicaciones sobre los eventos contenidos en el texto, o relaciones entre ellos.

\section{Proceso de validación del instrumento}

El objetivo fue someter a un proceso de validación por jueces el instrumento desarrollado, incluyendo textos, dibujos y preguntas de evaluación.

Los jueces expertos fueron cinco profesores universitarios con diez años o más de experiencia en investigación educativa y en el dominio del modelo psicológico Interconductual. A cada uno de los jueces se les solicitó que emitieran su opinión en relación a cuatro aspectos del instrumento: 1) pertinencia de la extensión y complejidad léxica de cada texto, en función del nivel escolar de los alumnos de primer grado de secundaria; 2) pertinencia de los reactivos (actividades y preguntas) para evaluar las respuestas del alumno en cada uno de los niveles funcionales que se pretendía eva- 
luar; 3) pertinencia de los criterios definidos para considerar como correctas las respuestas en cada nivel, y 4) pertinencia de las ilustraciones que se incluyeron en los cuestionarios del instrumento.

Los textos, ilustraciones y reactivos que contaron con la aprobación de cuatro de los cinco jueces fueron conservados, y aquellos aspectos que no cumplieron con dicho criterio fueron revisados y modificados, atendiendo a las recomendaciones y sugerencias de los jueces expertos. Se realizaron algunos ajustes en los textos, en cuanto a léxico y longitud, para lograr una extensión y un grado de complejidad léxica similar en los textos. También se llevaron a cabo algunas modificaciones en la redacción de algunos reactivos y en las actividades a realizar por parte del alumno, hasta lograr que los jueces coincidieran en que los nueve reactivos medían el nivel funcional que pretendían evaluar.

El Anexo 1 presenta el texto de la prueba sobre el tema narrativo literario titulado Viajeros en el espacio. El Anexo 2 corresponde a los nueve reactivos para evaluar los tres niveles funcionales de comprensión lectora relacionados con dicho tema. El Anexo 3 presenta el texto expositivo de biología Métodos de manipulación genética y el Anexo 4 los nueve reactivos para evaluar la comprensión lectora relacionada con dicho tema. Los Anexos 5 y 6 corresponden a las respectivas guías para la calificación de las pruebas, siguiendo los criterios del nivel funcional que evalúan los reactivos.

\section{Resumen de los resultados obtenidos de la aplicación del instrumento de evaluación}

Guevara, Cárdenas y Reyes (2015) reportan los resultados de la aplicación de los instrumentos validados, con el objetivo de analizar las características del desempeño de una muestra de estudiantes mexicanos de secundaria, en la comprensión lectora de los textos. Los participantes fueron 90 estudiantes, inscritos en primer grado, en una escuela secundaria pública de la Ciudad de México.

Los resultados indicaron que los estudiantes mostraron bajos porcentajes de respuestas correctas en ambas pruebas, siendo indicativos de que no habían desarrollado muchas habilidades de comprensión lectora durante su estancia en la escuela primaria (y en los primeros dos meses de secundaria), en lo que respecta a los tres niveles de complejidad evaluados. En cuanto al tema literario, el $50 \%$ de respuestas correctas como porcentaje promedio indicó deficiencias, y en el caso del tema de biología el desempeño resultó extremadamente bajo (31\% de respuestas correctas). La diferencia entre los desempeños en ambos tópicos resultó estadísticamente significativa.

También se reportó que, en el tema literario, los desempeños de los alumnos se presentaron en los tres niveles funcionales evaluados, y el mayor porcentaje de respuestas se ubicó en el nivel funcional más complejo, el sustitutivo no referencial. Por el contrario, en el tema de biología los porcentajes de los tres niveles funcionales fueron bajos, siendo extremadamente bajos los niveles sustitutivo referencial y sustitutivo no referencial. Las autoras discuten la posibilidad de que los lectores menos hábiles se comporten en niveles funcionales de menor complejidad, independientemente del tema de lectura del que se trate.

Si bien los datos reportados por Guevara et al., (2015) no pueden ser generalizados a toda la población escolar mexicana de secundaria, sí muestran evidencia de la necesidad de evaluar la comprensión lectora considerando distintos niveles de complejidad, y de que tales evaluaciones se encaucen a conocer las diferencias en los desempeños de los estudiantes en distintos temas.

Cárdenas y Guevara (2013) Ilevaron a cabo un estudio para evaluar los efectos de un progra- 
ma de intervención dirigido a promover comprensión lectora, en distintos niveles de complejidad funcional, con alumnos mexicanos de primer grado de secundaria. Se trabajó con tres grupos escolares que fueron asignados aleatoriamente, uno como grupo control y los otros dos como experimentales; con un grupo experimental se aplicó un programa de intervención cuyos materiales de lectura correspondieron a temas literarios, mientras que en el otro grupo experimental el programa se relacionó con temas de Biología.

Los resultados indicaron que ambos grupos experimentales alcanzaron altos niveles de comprensión lectora, sin diferencias entre ellos, pero sí hubo diferencias de ambos grupos experimentales con respecto al grupo control. Por ello, las autoras concluyen que la intervención fue adecuada para promover la comprensión lectora y para lograr la transferencia de las habilidades desarrolladas, hacia otros temas no entrenados.

Las características de los materiales utilizados para promover la comprensión lectora, así como las actividades realizadas para lograr cada nivel de aptitud funcional son descritas en el trabajo de Cárdenas y Guevara (2013). Sin embargo, vale la pena reiterar la importancia de programar la instrucción de la comprensión lectora incrementando sucesivamente el grado de complejidad de los intercambios lingüísticos en el aula, para favorecer interacciones sustitutivas con los textos académicos.

El marco de la Psicología Interconductual permite desarrollar instrumentos de evaluación y programas de intervención para disminuir el serio problema educativo que se presenta en las aulas mexicanas de educación básica. Por ello, los aspectos aquí descritos, así como los lineamientos que aparecen en las obras citadas, pueden servir como guía para futuras investigaciones que se dirijan al estudio de la comprensión lectora en estudiantes de diversos grados académicos, así como para el diseño y aplicación de programas encaminados a promover la comprensión lectora en diversos niveles funcionales y con diversos tipos de texto. Ello permitiría cumplir con un objetivo educativo importante: formar lectores competentes.

\section{Referencias}

Asimov, I. (1992). Receta del Tiranosaurio. Volumen II. Fragmento del cuento La persona promedio como astronauta (pp. 61-71). México: Edamex.

Cárdenas, K., \& Guevara, Y. (2013). Comprensión lectora en alumnos de secundaria. Intervención por niveles funcionales. Journal of Behavior, Healt \& Social Issues, 5 (1), 67-83. http://doi. org/10.5460/jbhsi.v5.1.38727

Fuentes, M.T. (2007). Las competencias académicas desde la perspectiva Interconductual. Acta Colombiana de Psicología, 10 (2), 51-58.

Fuentes, M.T. (2010). La comprensión lectora: revisión teórica desde la perspectiva cognoscitiva, conductual e Interconductual. En M.T. Fuentes, J.J. Irigoyen, \& G. Mares, Tendencias en Psicología y educación. Revisiones temáticas. Volumen 1 (pp. 128-166). México: Red Mexicana de Investigación en Psicología Educativa. 
González, M.J., Barba, M.J., \& González, A. (2010). La comprensión lectora en educación secundaria. Revista Iberoamericana de Educación, 53 (6), 1-11.

Guevara, Y. (2006). Análisis Interconductual de algunos elementos que constituyen la enseñanza básica. Revista Mexicana de Investigación Educativa, 11 (30), 1037-1064.

Guevara, Y., Cárdenas, K., \& Reyes, V. (2015). Niveles de comprensión lectora en alumnos de secundaria. Una comparación por tópico. Actualidades en Psicología, 29 (118), 13-23. http:// doi.org/10.15517/ap.v29i118.14619.

Guevara, Y., Rugerio, J., Delgado, U., \& Hermosillo, A. (2010). Análisis de los logros académicos de niños de primer grado, en relación con sus habilidades iniciales. Revista Mexicana de Investigación Educativa, XV (46), 803-821.

Irigoyen, J.J., Jiménez, M., \& Acuña, K. (2007). Evaluación de la comprensión lectora en el aprendizaje de la ciencia psicológica. En J.J. Irigoyen, M. Jiménez, \& K. Acuña (Eds.), Enseñanza, aprendizaje y evaluación. Una aproximación a la pedagogía de las ciencias (pp. 213-246). Hermosillo: Universidad de Sonora.

Kantor. J.R. (1980). Psicología Interconductual. Un ejemplo de construcción científica sistemática. México: Editorial Trillas.

Limón, S., Mejía, J., \& Aguilera, J. (2007). Ciencias 1. Biología. Fragmento de la lectura Análisis del desarrollo histórico de métodos de manipulación genética (pp. 246-253). México: Castillo.

Mares, G. (2008). Promoción de competencias a través de textos para la enseñanza de las ciencias naturales. En G. Mares (Coord.), Diseño psicopedagógico de textos: diversos enfoques (pp. 171-200). México: Universidad Nacional Autónoma de México.

Mares, G., \& Guevara, Y. (2004). Propuesta para analizar la práctica educativa durante la enseñanza de las ciencias naturales en educación primaria. En J.J. Irigoyen y M. Jiménez, Análisis funcional del comportamiento y educación (pp. 9-34). Hermosillo: Universidad de Sonora.

Mares, G., Guevara, Y., Rueda, E., Rivas, O., \& Rocha, H. (2004). Análisis de las interacciones maestra-alumnos durante la enseñanza de las ciencias naturales en primaria. Revista Mexicana de Investigación Educativa, 9 (22), 721-745.

Mares, G., Rueda, E., Rivas, O., \& Rocha, H. (2009). Maneras de leer que promueven el aprendizaje y su transferencia. México: Universidad Nacional Autónoma de México.

Morales, G., Cruz, N., León, A., Silva, H., Arroyo, R., \& Carpio, C. (2010). Morfología y función en el análisis empírico del ajuste lector. Suma Psicológica, 17 (1), 35-45.

Pérez, M.J. (2005). Evaluación de la comprensión lectora: Dificultades y limitaciones. Revista de Educación, 121-138. Recuperado de http://www.revistaeducacion.mec.es/re2005/re2005_10. pdf

Pérez-Almonacid, R., \& Quiroga, L. (2010). Lenguaje: Una aproximación Interconductual. Bogotá: Corporación Universitaria Iberoamericana.

Ribes, E., \& López, F. (1985). Teoría de la Conducta. Un análisis de campo y paramétrico. México: Editorial Trillas.

Varela, J. (2008). Conceptos básicos del Interconductismo. Guadalajara: Universidad de Guadalajara. 


\section{ANEXO 1: texto de la prueba sobre el tema narrativo titulado Viajeros en el espacio}

\section{"Viajeros en el espacio"}

\section{1. ¿Qué planeta elegir?}

¿Viajeros en el espacio? ¿Para todos los que tengan boletos? Todavía suena incómodamente improbable. Han pasado treinta y dos años desde que el hombre, por vez primera, lanzó un objeto en órbita alrededor de la Tierra, veinte desde que por primera vez los seres humanos caminaron por la Luna. No obstante, la persona promedio parece no haberse acercado nada a la posibilidad de ser un astronauta requerido. También, aunque pudiéramos viajar a nuestro arbitrio - con tan sólo comprar un boleto en el puerto espacial y despegar-, ¿a dónde iríamos?

El único objeto cercano en el espacio es la Luna. Tan sólo se necesitan tres días para llegar. Pero, francamente, una vez que usted haya visto un cráter y un paisaje lunares, ya habrá visto todo. No es nada más que una desolación sin aire ni agua.

¿Algún otro lado? Mercurio es como la Luna, con la única diferencia de ser mucho peor, si consideramos el calor y las radiaciones del cercano Sol. Y Venus, aunque bastante más lejos del Sol que Mercurio, todavía es más caliente y mucho peor: su atmósfera de bióxido de carbono es noventa veces más densa que la nuestra, su temperatura es lo suficientemente caliente cono para derretir plomo, y sus nubes son ricas en ácido sulfúrico.

En la otra dirección, Marte es mejor que la Luna aunque no se trata exactamente de un lugar demasiado acogedor, pero en las circunstancias presentes está a unos nueve meses de distancia. Podemos ingeniarnos formas para llegar allá un poco más rápido, pero es difícil ver cómo es que Marte podría ser atractivo para que un visitante informal hiciera todo un viaje:
En cuanto a cualquier cosa más lejos que Marte, significaría un viaje que duraría años.

Durante el vuelo podemos ver pasar un cometa o asteroide ocasionales al atravesar el sistema Tierra-Luna pero, honestamente, no habría mucho que ver.

\section{El Transbordador}

Entonces, ¿nos conformamos con dejar todo a los astronautas profesionales y a sondas sin tripulación?

¡Por supuesto que no! El espacio no se va a quedar como está, y la razón es el Transbordador.

El Transbordador es una nave espacial de uso repetido. Es un caballito de batalla, un camión para el vacío. Puede poner en órbita a seres humanos y material, para después volver por más. Con suficientes Transbordadores trabajando, con el tiempo podemos llevar suficiente material al espacio para ensamblar, digamos, una estación solar destinada a capturar energía solar, convertirla en microondas, y enviarla en un haz hacia la Tierra para su conversión en electricidad.

Significará una enorme inversión inicial, en especial porque necesitaremos docenas de dichas estaciones, pero la energía que capturemos rápidamente hará que el complejo sea, primero, autosuficiente $y$, segundo, enormemente productivo. Ni siquiera tendremos que recurrir a la Tierra en cuanto a metales y otros materiales necesarios para construir estas estaciones. Gracias al Transbordador y a sus sucesores -mejorados y más elaborados- podremos establecer una estación minera en la Luna. En el espacio, el material lunar podrá ser convertido en suelo, concreto, vidrio y una variedad de metales. 
En el espacio también se construirán observatorios y laboratorios para poder estudiar el universo y llevar a cabo experimentos que harán uso de las propiedades especiales del espacio: altas y bajas temperaturas, radiaciones, vacíos, falta de gravedad.

En cuanto a todo esto, en el espacio pueden construirse fábricas automatizadas de tal forma que la mayor parte de los procesos industriales terrestres más intrincados puedan subirse desde la superficie planetaria que contaminan hasta ponerlos en el espacio, donde nos ofrecerán los beneficios de la industrialización sin sus peligros.

\section{Construyendo una nueva civilización}

Para poder construir y conservar todas estas estructuras espaciales seguramente será deseable construir colonias: mundos autosuficientes, quizá tan grandes que tengan varios kilómetros de circunferencia y con capacidad para sostener de diez mil a diez millones de personas.

Lo más probable es que estas colonias estén en la órbita lunar, ya sea a cuatrocientos millones de kilómetros adelante de ella durante su desplazamiento alrededor de la Tierra, o a cuatrocientos millones de kilómetros atrás, las dos posiciones más estables.

Entonces, sí contemplamos al futuro, ya no veremos al espacio cercano como es ahora: la Tierra, una Luna vacía y nada más. A diferencia, veremos una Luna ocupada y plena de actividad, con docenas de colonias espaciales que las preceden y la siguen, junto con cientos de estaciones de energía, observatorios, laboratorios y fábricas, todos en órbita entre la Tierra y la Luna.
¿De verdad sucederá todo esto? $\mathrm{Si}$, así será, a menos que los seres humanos deliberadamente decidan no hacerlo, ya sea por miopía o falta de temple.

Habrá quienes, primero, querrán "resolver los problemas de la Tierra". Pero estos problemas serán insolubles mientras no salgamos al espacio. Estamos saturando a una Tierra agotada que ya no puede sostenernos. A menos que ampliemos nuestro alcance y recurramos a fuentes más allá de la Tierra sufriremos un colapso y la civilización languidecerá y morirá.

Pero aunque intentemos hacerlo, ¿lo lograremos en tan sólo cien años?

¡Sin duda alguna! -imagínense ustedes de vuelta en 1869, cuando la maravilla tecnológica más importante era el cable atlántico. Todavía faltaban diez años para la luz eléctrica, veinte para el automóvil, treinta y cinco para el avión. Pero si contamos desde 1869, cien años, tan sólo un siglo, vimos al hombre de pie en la Luna ... y estos días nos estamos moviendo con mayor rapidez.

Entonces, si el mundo es como yo lo preveo, seguramente la gente podrá ingresar a la astronáutica a voluntad (a reserva de que puedan hacer sus reservaciones en la nave espacial y conseguir boleto).

Con energía solar del espacio tendremos suficiente electricidad para separar el agua en hidrógeno y oxígeno. Si se utiliza al hidrógeno como combustible, podrá combinarse con el oxígeno para volver a formar agua. Así funcionarán nuestras naves espaciales, y todo lo que usaremos será la luz del Sol, que durará miles de millones de años.

(998 palabras) 


\section{ANEXO 2: reactivos de la prueba sobre el tema narrativo titulado Viajeros en el espacio}

1a. Mira esta imagen. Identifica qué apartado de la lectura ilustra y coloca sobre la línea el nombre del apartado que le corresponda.

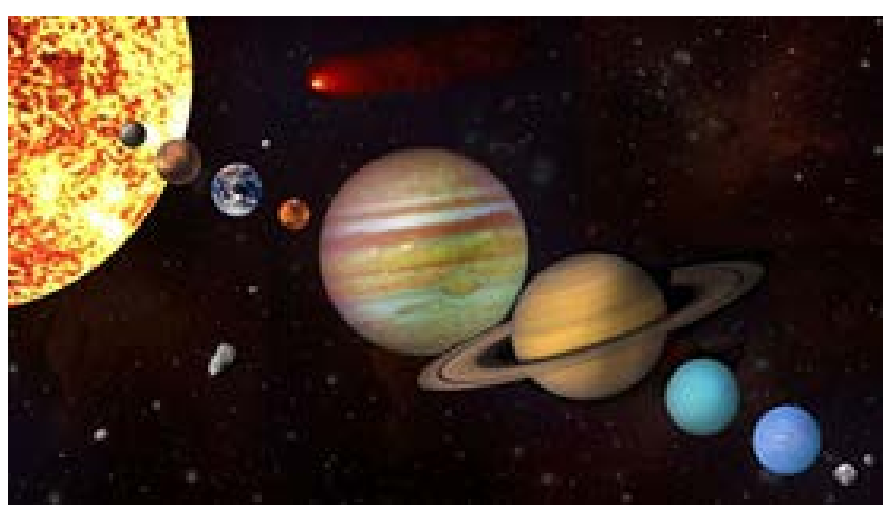

1b. Mira esta imagen. Identifica qué apartado de la lectura ilustra y coloca sobre la línea el nombre del apartado que le corresponda.

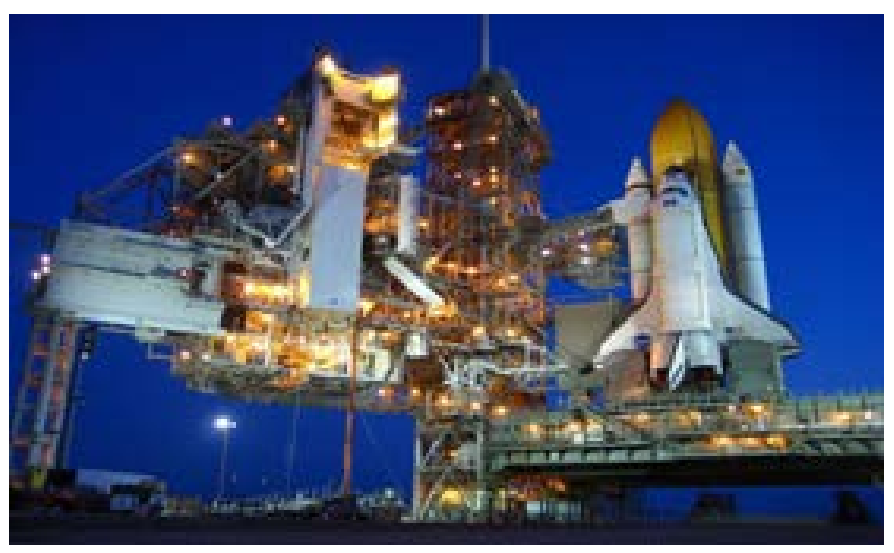

Por favor responde lo siguiente:

2. Según la lectura, en Mercurio y Venus no hay vida porque.... 
3. La distancia a la que se encuentran los planetas Júpiter, Saturno, Urano y Neptuno implicaría un viaje espacial que duraría años.

4. Relaciona esta imagen con el texto, y escribe algo con respecto a esa parte de la lectura.

5. Relaciona esta imagen con el texto y escribe algo con respecto a esa parte de la lectura.

6. De los recursos tecnológicos mencionados en la lectura, ¿cuáles usas tú y para qué?
- Cierto ( )

- Falso ( )
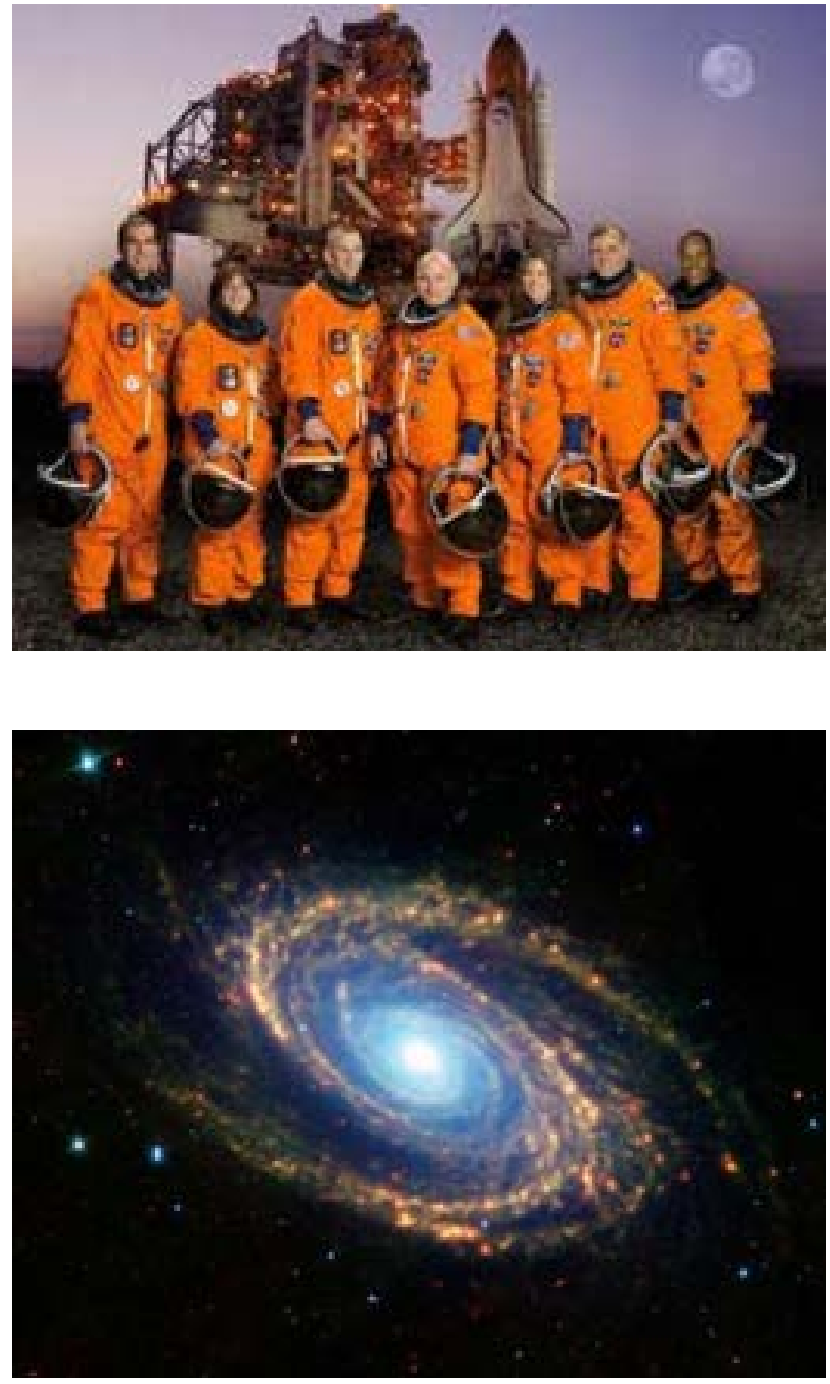
7. Menciona dos cosas en las que se parecen un avión y el transporte que se describe en el texto.

8. ¿De qué crees que podría alimentarse el ser humano en las colonias espaciales? Argumenta tu respuesta con lo que sabes del tema.

9. Después de haber leído el texto, ¿crees que se basa en información sobre el espacio exterior, cierta o falsa? Argumenta tu respuesta con lo que sabes del tema. 


\section{ANEXO 3: texto de la prueba sobre el tema expositivo de biología titulado Métodos de manipulación genética}

\section{"Métodos de manipulación genética"}

A lo largo de muchos años el ser humano ha modificado genéticamente plantas y animales para mejorar sus propiedades y obtener beneficios en su producción.

Hasta la primera mitad del siglo XX comenzaron a aplicarse nuevos procedimientos producto del avance de la ciencia y la tecnología. En este tiempo ya se sabía que todos los seres vivos están formados por células, que en el núcleo se encuentra la información hereditaria y que el óvulo y el espermatozoide son las células que dan origen a un nuevo organismo, lo que permitió desarrollar técnicas de inseminación artificial para el ganado; este procedimiento consiste en depositar el semen de un macho (del cual se quieren reproducir ciertas características para su descendencia) en una hembra que también tiene características deseables.

En cuanto a la agricultura, durante la década de 1950 comenzaron a desarrollarse técnicas de cultivo de tejidos vegetales. Actualmente, esta técnica es muy utilizada para obtener plantas de ornato y conservar especies en peligro de extinción.

\section{La biotecnología}

La biotecnología es el uso de seres vivos o de compuestos obtenidos a partir de ellos para obtener productos de valor para los seres humanos. Los principales objetivos de la biotecnología son obtener mejores medicamentos y alimentos, así como curar y prevenir enfermedades en los seres humanos.

La biotecnología es el mejor ejemplo de cómo la ciencia y la tecnología se retroalimentan una a la otra. Por ejemplo, todos los conocimientos científicos que se lograron acerca de la heren- cia, la estructura del ADN y los genes durante la primera mitad del siglo $X X$, fueron utilizados en la segunda mitad del mismo siglo para crear técnicas y procedimientos de manipulación genética; así surgió la ingeniería genética, la cual es un campo de conocimiento de la biotecnología. Veremos a continuación algunas líneas de investigación muy importantes de la ingeniería genética.

\section{Genoma humano}

Se le llama genoma a la totalidad de genes que tiene una especie. En 1990 se inició lo que se conoce como Proyecto Genoma Humano, el cual consistió en que instituciones e investigadores de todo el mundo se unieron para descubrir todos los genes que caracterizan a la especie humana, es decir, para conocer su número, su ubicación en los cromosomas, así como cuántos tipos de genes hay para cada característica, y en qué secuencia están ubicados en los cromosomas.

Se encontró que tenemos entre treinta y cuarenta mil genes, más o menos el mismo número que algunos anfibios y mamíferos; la diferencia radica en la manera en que nuestros genes se organizan y expresan las características humanas.

Actualmente el proyecto se ha dado por concluido, pero los científicos ahora investigan cómo actúa cada gen para determinar las características, cuáles genes transmiten enfermedades hereditarias y cómo sería posible curarlas a través de la terapia genética, la cual consiste en "cambiar" esos genes e introducir otros que no causen tales enfermedades. 


\section{Reproducción asistida}

La reproducción asistida es cualquier procedimiento que se utiliza para lograr la unión de un espermatozoide y un óvulo de manera no natural. Como ya se mencionó, la inseminación artificial se ha utilizado desde la primera mitad del siglo $\mathrm{XX}$, y se efectuó por primera vez en seres humanos en la década de 1970.

En 1960 se comenzó a experimentar la fecundación in vitro en animales, la cual consiste en extraer un óvulo de la hembra, unirlo con un espermatozoide y unos días después colocarlo en la matriz de la misma hembra o de otra.

El primer "bebé de probeta" logrado mediante una fecundación in vitro nació en 1978. En la actualidad la fecundación in vitro ayuda a las parejas que no pueden tener hijos.

\section{Células madre o troncales}

En la segunda mitad del siglo XX no sólo se intentó el cultivo de tejidos vegetales, sino también de tejidos animales. Pero resultó una tarea difícil; hasta la década de 1980 no se había logrado cultivar más que pequeñas cantidades de piel humana y algún otro tipo de tejido como el hepático. Pero por lo general el tejido moría o crecía muy lentamente; sin embargo, con el desarrollo de la biotecnología surgieron nuevos procedimientos que han permitido avances asombrosos.

Los científicos descubrieron que algunas células específicas en cada órgano, llamadas células madre o troncales, (incluyendo el cordón umbilical) pueden desarrollarse de manera más rápida. En 1998, el estadounidense James Thomson descubrió que si las células se toman de un embrión es más fácil que puedan desarrollarse tejidos y órganos. Así, existen dos tipos de células madre según de dónde se tomen: las embrionarias y las órgano específicas.

Aún están en investigación los procesos que permiten obtener órganos y tejidos completos a partir de células madre; pero los resultados son muy prometedores. Por ejemplo, de las células madre embrionarias han logrado obtener neuronas, músculo cardiaco, hueso, cartílago, piel, etc. En teoría, de esas células podrían obtenerse los más de 200 tipos de células que hay en el cuerpo humano. En cambio, de las células madre órgano específicas sólo se obtiene el tipo de órgano del que provienen. Con estos órganos y tejidos se podrían salvar miles de vidas.

\section{Clonación}

Un clon es una célula o un organismo genéticamente idéntico al que le dio origen; puede obtenerse por reproducción asexual a partir de una célula u organismo. La clonación se presenta de manera natural en muchos organismos, principalmente en plantas, por medio de la reproducción vegetativa. En los animales no es muy común, pero conoces ejemplos como el de las esponjas y las planarias.

En 1997 en el Instituto Roslin en Escocia, se clonó por primera vez en la historia a un mamífero, la oveja Dolly. Los científicos han encontrado que los animales clonados presentan enfermedades degenerativas o mutaciones. A los seis años, Dolly fue sacrificada debido a una enfermedad degenerativa. 


\section{ANEXO 4: reactivos de la prueba sobre el tema expositivo de biología titulado Métodos de manipulación genética}

1a. Mira esta imagen. Identifica qué apartado de la lectura ilustra y coloca sobre la línea el nombre del apartado que le corresponda.

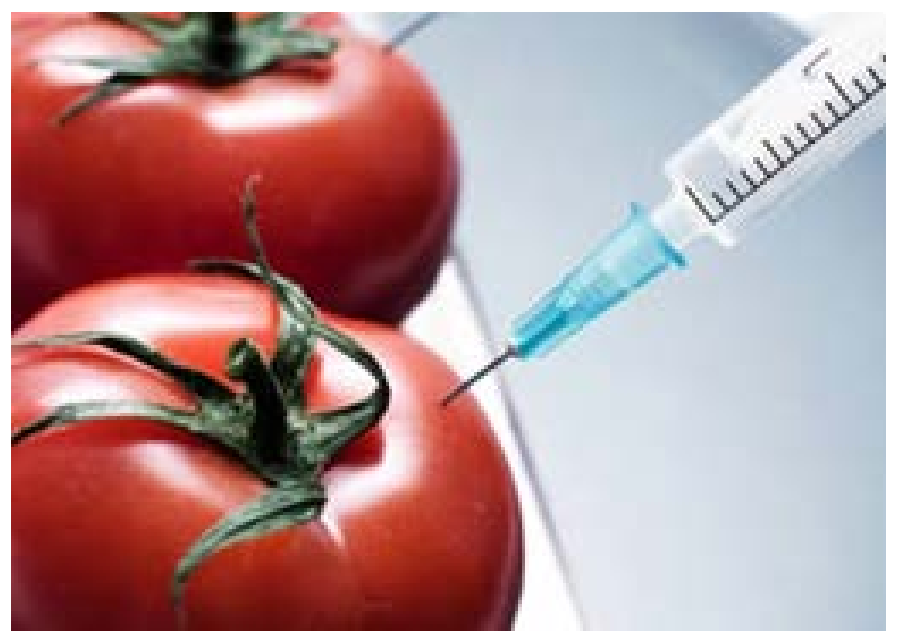

1b. Mira esta imagen. Identifica qué apartado de la lectura ilustra y coloca sobre la línea el nombre del apartado que le corresponda.

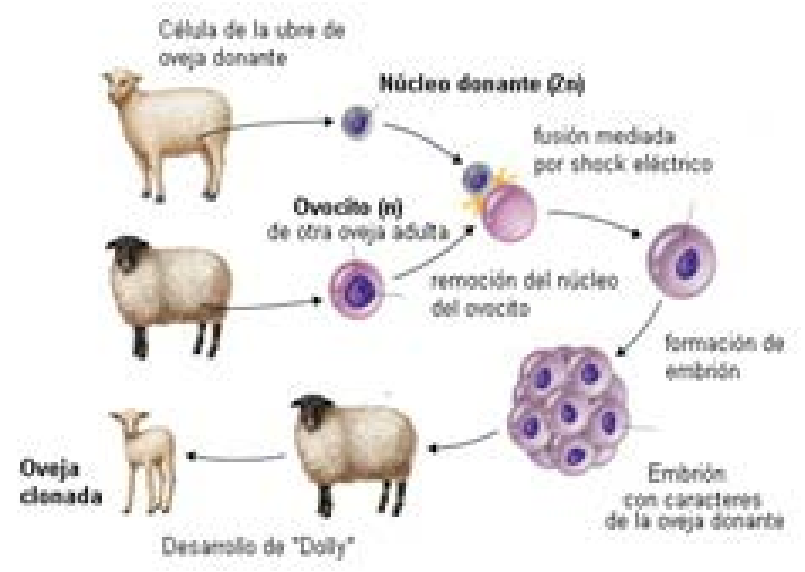

2. Relaciona esta imagen con el texto y escribe algo con respecto a esa parte de la lectura. 
3. Relaciona esta imagen con el texto, y escribe algo con respecto a esa parte de la lectura.

4. Relaciona esta imagen con el texto, y escribe algo con respecto a esa parte de la lectura.
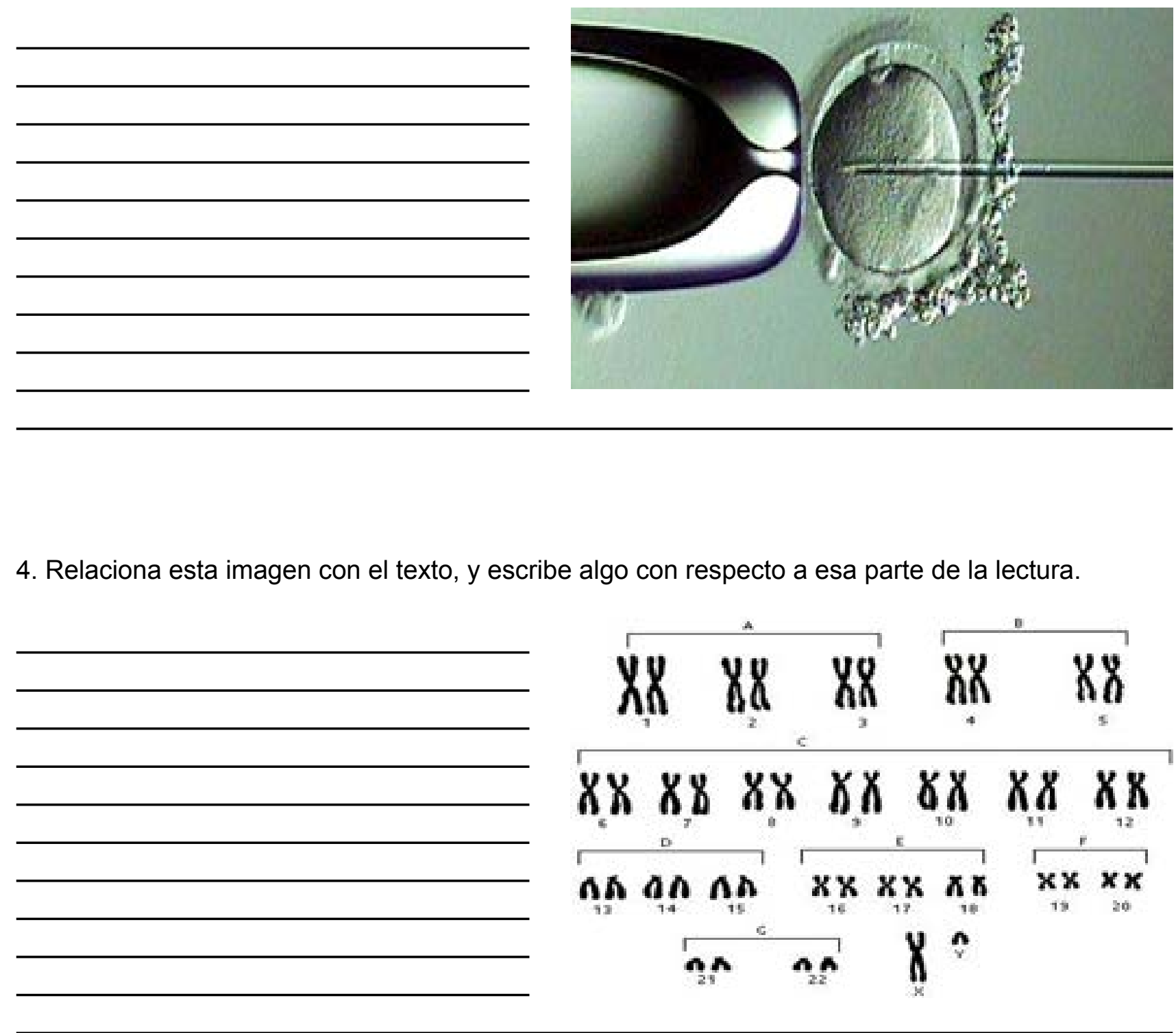


\section{Por favor responde lo siguiente:}

5. Selecciona de esta lista los principales objetivos de la biotecnología.
- Obtener mejores alimentos.

- Obtener mejores medicamentos.

- Curar enfermedades.

- Estudiar a los seres vivos.

- Prevenir enfermedades.

- Crear nuevas especies.

6. Las células madre también se llaman y se encuentran en

7. ¿Cuál crees que sea la aplicación de la biotecnología más benéfica para la humanidad? Argumenta tu respuesta con lo que sabes del tema.

8. ¿Consideras que en México debe aprobarse la obtención de células madre de embriones? Argumenta tu respuesta con lo que sabes del tema.

9. ¿Qué consecuencias nocivas crees que pueda llegar a tener la manipulación genética? Argumenta tu respuesta con lo que sabes del tema. 
ANEXO 5: guía para la calificación de la prueba sobre el tema narrativo literario titulado Viajeros en el espacio

\section{INSTRUCTIVO PARA CALIFICAR LOS REACTIVOS SOBRE EL TEXTO NARRATIVO "VIAJEROS EN EL ESPACIO"}

Las preguntas 1a y $1 \mathrm{~b}$ fueron diseñadas como parte de un solo reactivo para evaluar nivel selector. Asigne .5 a cada una de las respuestas correctas.

1a. Mira estas imágenes. Identifica qué apartado de la lectura ilustran y coloca sobre la línea el nombre del apartado que les corresponda.

\section{Respuesta correcta:}

\section{¿Qué planeta elegir?}

1b. Mira esta imagen. Identifica qué apartado de la lectura ilustra y coloca sobre la línea el nombre del apartado que le corresponda.

Respuesta correcta:

\section{El Transbordador}

Los reactivos-preguntas 2 y 3 fueron diseñados para evaluar nivel selector.

Por favor responde lo siguiente:

2. Según la lectura, en Mercurio y Venus no hay vida porque....

3. La distancia a la que se encuentran los planetas Júpiter, Saturno, Urano y Neptuno implicaría un viaje espacial que duraría años.
Ejemplo de respuesta correcta: La temperatura es demasiado elevada. La atmósfera de los planetas es inapropiada.

- Cierto (X) Respuesta correcta

- Falso ( )

Los reactivos-preguntas 4, 5 y 6 fueron diseñados para evaluar el nivel sustitutivo referencial.

4. Relaciona esta imagen con el texto, y escribe algo con respecto a esa parte de la lectura. 


\section{Ejemplo de respuesta correcta:}

La imagen es de unos astronautas y la relaciono con la lectura que dice que en cien años cualquiera podría ir al espacio. Me imagino en unos años a mí y a mi familia viajando por el espacio en una nave como pasa en las películas.

5. Relaciona esta imagen con el texto, y escribe algo con respecto a esa parte de la lectura.

\section{Ejemplo de respuesta correcta:}

Es la imagen de la galaxia y la relaciono con la lectura que dice que en el espacio se verán colonias, estaciones de energía, observatorios, laboratorios y fábricas en órbita entre la tierra y la luna. Va a cambiar cómo se ve.

6. De los recursos tecnológicos mencionados en la lectura, ¿cuáles usas tú y para qué?

\section{Ejemplo de respuesta correcta:}

Luz eléctrica para usar la computadora, ver televisión. jugar videojuegos. El automóvil para transportarme a la escuela o para salir de paseo. El avión cuando viajo de vacaciones con mi familia.

\section{Los reactivos-preguntas 7, 8 y 9 fueron} diseñados para evaluar el nivel sustitutivo no referencial.

7. Menciona dos cosas en las que se parecen un avión y el transporte que se describe en el texto.

8. ¿De qué crees que podría alimentarse el ser humano en las colonias espaciales? Argumenta tu respuesta con lo que sabes del tema.
En todos los casos, se evalúa la congruencia de los argumentos planteados para justificar la respuesta.

Ejemplo de respuesta correcta:

Ambas son naves de uso repetido. Transportan seres humanos. Transportan una amplia variedad de objetos. Medios de transporte de alta velocidad.

Ejemplo de respuesta correcta:

Con agua y energía eléctrica podríamos tener animales y plantar verduras y frutas. 
9. Después de haber leído el texto, ¿crees que se basa en información sobre el espacio exterior, cierta o falsa? Argumenta tu respuesta con lo que sabes del tema.

\section{Ejemplo de respuesta correcta:}

Creo que es cierto lo que dice de los planetas y también de que ya hay muchos adelantos en la tecnología. 
ANEXO 6: guía para la calificación de la prueba sobre el tema expositivo de biología titulado Métodos de manipulación genética.

\section{INSTRUCTIVO PARA CALIFICAR LOS REACTIVOS SOBRE EL TEXTO EXPOSITIVO DE BIOLOGÍA “MÉTODOS DE MANIPULACIÓN GENÉTICA”}

Las preguntas 1a y $1 \mathrm{~b}$ fueron diseñadas como parte de un solo reactivo para evaluar nivel selector. Asigne .5 a cada una de las respuestas correctas.

1a. Mira estas imágenes. Identifica qué apartado de la lectura ilustran y coloca sobre la línea el nombre del apartado que les corresponda.

\section{Respuesta correcta: La biotecnología}

1b. Mira esta imagen. Identifica qué apartado de la lectura ilustra y coloca sobre la línea el nombre del apartado que le corresponda.

Respuesta correcta: Clonación

Los reactivos-preguntas 2, 3 y 4 fueron diseñados para evaluar nivel sustitutivo referencial.

2. Relaciona esta imagen con el texto, y escribe algo con respecto a esa parte de la lectura.

Ejemplo de respuesta correcta:

La imagen es de la reproducción celular y la relaciono con lo que dice la lectura sobre las células madre que permiten desarrollar tejidos y órganos. Me asombra que actualmente sea posible "cultivar" partes del cuerpo humano a partir de las células y me imagino que en el futuro los seres humanos podrán vivir mucho más reemplazando sus partes dañadas.

3. Relaciona esta imagen con el texto, y escribe algo con respecto a esa parte de la lectura.

\section{Ejemplo de respuesta correcta:}

La imagen corresponde al proceso de fecundación in vitro y la relaciono con la parte de la lectura que menciona el desarrollo que ha tenido la reproducción asistida desde el siglo XX. Me imagino que pronto se podrán escoger algunas características de los seres humanos al reproducirse por esta vía. 
4. Relaciona esta imagen con el texto, y escribe algo con respecto a esa parte de la lectura.

Ejemplo de respuesta correcta:

La imagen representa los pares de cromosomas del ser humano, lo relaciono con la parte de la lectura en la que se habla del Proyecto genoma humano, en el que se definieron las características de los genes, su ubicación y número con respecto a los cromosomas. Creo que en el futuro la terapia genética podría remplazar a las medicinas que tomamos hoy en día.

Los reactivos-preguntas 5 y 6 fueron diseñados para evaluar nivel selector.

Por favor responde lo siguiente:

5. Selecciona de esta lista los principales objetivos de la biotecnología.

6. Las células madre también se llaman troncales y se encuentran en órganos y cordón umbilical.

Los reactivos-preguntas 7,8 y 9 fueron diseñados para evaluar el nivel sustitutivo no referencial.

7. ¿Cuál crees que sea la aplicación de la biotecnología más benéfica para la humanidad? Argumenta tu respuesta con lo que sabes del tema.

8. ¿Consideras que en México debe aprobarse la obtención de células madre de embriones? Argumenta tu respuesta con lo que sabes del tema.
- Obtener mejores alimentos.

- Obtener mejores medicamentos.

- Curar enfermedades.

- Estudiar a los seres vivos.

- Prevenir enfermedades.

- Crear nuevas especies.

Se evalúa que los términos sean idénticos a los mencionados en la lectura.

En todos los casos, se evalúa la congruencia de los argumentos planteados para justificar la respuesta.

Ejemplo de respuesta correcta:

La creación de células madre que permiten obtener órganos y tejidos humanos podría salvar muchas vidas, ya que no sería necesario esperar la donación de un órgano compatible sino que podrían cultivarlo del propio paciente.

Ejemplo de respuesta correcta:

Creo que debe investigarse mucho, y que antes de que lo hagan con humanos deberían estar seguros de que no lastimarán al feto. Si logran eso, me parece que sí deberían obtener células madres de embriones porque después podrían usarse para desarrollar cualquier órgano que se necesite. 
9. ¿Qué consecuencias nocivas crees que pueda llegar a tener la manipulación genética? Argumenta tu respuesta con lo que sabes del tema.
Ejemplo de respuesta correcta:

Creo que en el futuro la clonación podría ser usada para copiar a otras personas y robarles sus cosas o la información que tengan. También podrían, como vemos en las películas. crear virus como armas para atacar a los seres humanos. 


\section{Capítulo 6}

Aprendizaje y transferencia de una estrategia de análisis de textos científicos desde la Web

Diana Moreno Rodríguez 
Diana Moreno Rodríguez dianamoreno90@gmail.com

Facultad de Estudios Superiores Iztacala Universidad Nacional Autónoma de México 


\section{Capítulo 6}

\section{Aprendizaje y transferencia de una estrategia de análisis de textos científicos desde la Web}

Por mucho tiempo una de las preocupaciones de los profesores universitarios, ha sido proporcionar a sus estudiantes estrategias que les permitan analizar los textos científicos que día a día son revisados y analizados en clase, un ejemplo de estos son los artículos publicados en revistas científicas. Una de las estrategias que ha sido exitosa es la propuesta por Santoyo (2001), misma que ha sido probada en clases presenciales, abstrayéndose de las e-herramientas para probar su eficacia, dicha estrategia implica habilidades relacionadas desde la identificación del objetivo de estudio, hasta el análisis conceptual. Asimismo, el aprendizaje de dicha estrategia también implica un proceso de transferencia, en el sentido de que los aprendices pueden aplicar la estrategia aprendida en los trabajos de investigación desarrollados por ellos mismos. El presente capítulo tiene como objetivos mostrar un desarrollo tecnológico, cuya meta es que los usuarios (estudiantes de Psicología), aprendan una estrategia para el análisis de textos científicos en su modalidad de artículos de investigación y evaluar la transferencia del aprendizaje de dicha estrategia. Dicha transferencia fue evaluada a través de la aplicación de la estrategia aprendida, en una situación totalmente novedosa para los participantes. Los resultados mostraron que no es suficiente evaluar el aprendizaje a través de las pruebas de pretest y postest, las cuales sólo son un indicador de una posible mejoría de los aprendices. La demanda de la aplicación de las habilidades aprendidas por los usuarios del sistema, en los trabajos de investigación desarrollados por ellos mismos, reveló su capacidad de análisis y transferencia a situaciones novedosas.

El éxito en la universidad depende de un sin número de habilidades académicas, incluyendo la lectura. En este contexto los profesores asumen que sus estudiantes han adquirido dicha habilidad en el nivel medio superior o en los previos. La realidad es que los estudiantes universitarios carecen de las habilidades de lectura necesarias para desempeñarse de manera adecuada en la universidad, especialmente porque la lectura en la universidad difiere enormemente de la lectura del bachillerato. En el nivel universitario las habilidades para resumir, analizar críticamente, sintetizar e integrar información son esenciales sin importar el campo disciplinar en el que se encuentre inmerso el estudiante. La ausencia o nula presencia de estas habilidades da como resultado que los universitarios empleen estrategias no universitarias para leer textos académicos.

La vida académica de los jóvenes universitarios gira alrededor de la lectura científica, pero como señalamos previamente, los jóvenes universitarios en muchos de los casos carecen de las habilidades necesarias para enfrentarse a este tipo de textos. Argudín y Luna (1994) consideran que 
los estudiantes para su supervivencia o aprobación académica echan mano de varios recursos tales como: parafrasear un texto, copiar cuando debe resumir, leer de manera fragmentada, etc. De tal forma que la nula enseñanza de la lectura estratégica y la consecuente torpeza en dichas habilidades, hacen muy probable que el estudiante tenga un rendimiento académico pobre, un aprendizaje deficiente y un desarrollo profesional fuera de los estándares aceptables. Para Alarcón y Fernández (2006) la falta de habilidad para leer "bien" en un estudiante universitario, puede ser una limitante importante para su aprendizaje, sobre todo cuando sólo es capaz de leer en un sentido técnico. Este tipo lector no es capaz de usar la lectura como herramienta para profundizar y ampliar sus conocimientos en el área específica de su formación. Los autores señalan que los estudiantes universitarios leen, pero se les dificulta ir más allá de lo textual, p.ej., realizar una interpretación y evaluación de lo leído.

Hermida (2009), identificó dos maneras de aproximarse a la lectura académica o científica, por una parte, existe la lectura superficial en la que se acepta de manera tácita la información contenida en el texto, en este tipo de lectura los estudiantes consideran la información como hechos aislados y sin ninguna conexión. Y por la otra, una aproximación profunda, en donde el lector utiliza habilidades como las de analizar, sintetizar, solucionar problemas, entre otras. Este tipo de lector es capaz de seguir la estructura y la línea de argumentación del autor, hace conexiones a partir de los conceptos y principios, y los usa para solucionar problemas en un nuevo contexto. Stone (2013) utilizó la clasificación propuesta por Hermida (2009) e identificó 44 características de los lectores superficiales (ver Anexo 1).

Carlino (2002) en su reflexión menciona que las dificultades en la lectura de los estudiantes universitarios se deben en parte a que los textos académicos o científicos, predominantes en el nivel universitario, no están dirigidos a los aprendices de una ciencia, sino a los científicos. Estos textos dan por sentado conocimientos previos que los alumnos no poseen, p.ej., hacen referencia a las posturas o estudios de otros autores sin explicarlos. Los universitarios leen textos en donde la posición de un autor parece justificada a partir de otras posiciones que solamente son citadas, pero no tratadas de manera explícita; otro caso son los textos en donde un autor polemiza con otros autores o colegas desconocidos para el lector. En ambos casos, lo que el texto explica tiene sentido, sólo en el marco de la discusión de lo que se da por sentado o no es explicado. Para Carlino (2002) estos textos no explican las ideas de fondo, ya que el marco conceptual del que se parte se da por conocido.

Pero los problemas para entender lo leído no provienen sólo de los textos, las dificultades también se originan en las expectativas de los docentes sobre sus alumnos (Carlino, 2002). Estas expectativas no son explicitas, los profesores asumen que los alumnos saben qué se espera de ellos, y son evaluados en función de un modelo de lectura, lo que conlleva un modelo de lector ideal, los profesores suelen dar por supuesto que los estudiantes, al leer, saben cómo analizar lo leído. En este sentido, aquello que los docentes suelen demandar de lo leído, no está en el texto mismo, sino que sólo puede ser derivado en la medida en que el lector tenga ciertos conocimientos (del que los universitarios suelen carecer) y pueda mostrar un comportamiento específico sobre el texto. Los profesores son conscientes de qué encontrar en los textos científicos (diferentes posturas, argumentos para sostenerlas, contraargumentos, relaciones con otros textos, consecuencias de lo que se afirma) 
no es precisamente encontrarlas, sino más bien buscarlas. $Y$ esta búsqueda exige, por parte de quien lee, operar sobre el texto con determinadas categorías de análisis, categorías que provienen de y caracterizan a una determinada comunidad lectora, la científica.

Son bastos los estudios que demuestran una y otra vez evidencias de la incompetencia de los universitarios en la lectura. Peredo (2001) demostró que las habilidades de lectura están ligadas a la escolaridad, ya que mientras más escolarizado está el lector, este posee habilidades más sofisticadas. De manera específica encontró que los lectores con estudios universitarios, son capaces de localizar y discriminar información, pero además utilizan estrategias como plantear preguntas, establecer relaciones o vínculos extratextuales. Los lectores con posgrado tienen más recursos para reportar sus "procesos mentales" (poseen más habilidades metacognitivas), este tipo de lectores además de hacer lo que hacen los lectores universitarios, poseen habilidades para localizar ideas y argumentos, son capaces de realizar análisis conceptuales abstractos a partir de reflexiones y establecer vínculos con otras lecturas. Lo que sugiere es que muy probablemente, como profesores universitarios, estemos exigiendo y demandando en los estudiantes de los primeros semestres, habilidades que están fuera de sus posibilidades y que corresponden a niveles escolares más avanzados.

Fregoso (2009) llevó a cabo un meta-análisis sobre esta problemática, su artículo lo tituló 40 años de aportes desde la investigación y la intervención didáctica para caracterizar el problema con la lectura en la educación formal. En esta publicación, cita algunos estudios que demuestran cómo es que los estudiantes universitarios tienen dificultades para comprender los materiales asignados, acostumbran memorizar y reproducir detalles sin importancia, además de ser incapaces de relacionar dos ideas no vinculadas explícitamente en un texto, y de comparar ideas semejantes expresadas en documentos diferentes, incluso pueden leer dos o tres veces el mismo texto y no entenderlo.

Zarzosa (1997), analizó la naturaleza y origen de las dificultades de lectura y escritura entre universitarios de varios semestres escolares. Los datos de su estudio mostraron que sólo un tercio de los conceptos fueron definidos correctamente por los estudiantes, el contexto favoreció la definición correcta sólo cuando los estudiantes en una condición previa no respondieron o sus definiciones fueron cercanas a lo correcto. Por otra parte, los estudiantes fueron incapaces de detectar inconsistencias lógicas en un texto. Los datos revelaron la necesidad de los estudiantes de recibir indicaciones claras acerca de cómo debe realizar su lectura, es decir, se requiere de una ayuda explícita de lo que se espera de ellos.

En otro estudio realizado por Zarzosa, Moreno y Cepeda (1998) se evaluaron las estrategias de planeación, regulación, recuerdo y evaluación de la lectura (estrategias propuestas por Miholic, 1994), en estudiantes universitarios de diferentes grados. Los autores observaron que el grado escolar no predijo una mejoría en el reconocimiento de las mejores estrategias para lectura, asimismo se observó una deficiencia importante en los estudiantes en las estrategias de planeación y regulación.

Hernández, Rodríguez y Vargas (2012), observaron que cerca de la mitad de los estudiantes universitarios de ingeniería encuestados ocasionalmente vuelven a leer el texto cuando algo no les queda claro, pocas veces subrayan o toman notas, y casi nunca tratan de relacionar el contenido del texto con lo ya saben o conocen acerca del tema, y menos aún no tratan de recordar lo leído. Estos mismos autores señalan que estas estrategias son de utilidad para los lectores que se enfrentan a textos académicos. 
Ahora bien, el aprendizaje de una disciplina consiste en desarrollar el conocimiento de las formas de ser, de pensar, escribir y ver el mundo de los expertos de cualquier disciplina. La lectura de textos académicos o científicos publicados por los expertos permite a los estudiantes sumergirse en la cultura de la disciplina y aprender sus convenciones, el discurso y el conocimiento (Erickson, Peters \& Strommer, 2006). Estienne y Carlino (2004) coinciden al mencionar que leer en la universidad es una forma de acceder al conocimiento, a un tipo de lenguaje compartido, a ciertas reglas de uso, a modos de hacer. Al respecto, Norris et al. (2008) señalan que la "lectura es una herramienta para aprender y hacer ciencia" (p. 769), "por tanto la relación entre la lectura y la ciencia es una relación íntima” (p. 773). En otras palabras, la importancia de la lectura radica en que a partir de esta, los estudiantes pueden apropiarse de la disciplina en cuestión, de la misma forma como lo hacen los científicos.

Tenopir y King (2004) entrevistaron a un número importante de científicos, los autores encontraron que estos invierten dos terceras partes de su tiempo en actividades de lectura, esto es 553 horas al año o el $23.2 \%$ de su tiempo de trabajo, además de que la lectura es su principal fuente de inspiración. En un estudio más reciente, Tenopir y Volentine (2012), observaron que los científicos invierten entre el $69 \%$ y el $77 \%$ de su tiempo escribiendo y leyendo. Con relación al tiempo invertido en la lectura de un artículo, los científicos invierten en promedio 45 minutos -por artículo-, y una hora y media por libro (capítulo) y 34 minutos en cualquier otro tipo de publicación. Por otra parte, los científicos en promedio al mes leen 25 artículos, dos libros o capítulos de libros, y siete publicaciones de otro tipo, cabe destacar que en su mayoría (59\%) leen artículos recientes, de no más de 18 meses de publicación. Cuando se les pidió que calificaran la importancia de los artículos científicos, la mayoría de ellos los consideró que eran absolutamente esenciales, muy importantes o importantes (68\%). Algunos de ellos de manera anecdótica señalaron: “...los artículos son de importancia fundamental para mi investigación...; son el núcleo de mi actividad investigativa...; es la sangre viva de mi trabajo... son diametralmente importantes, sin ellos esto sería imposible..." Finalmente, al cuestionarles sobre la influencia de la lectura -y de manera específica la de los artículos- sobre su trabajo, los científicos señalaron lo siguiente: “...es crucial para acceder a la información más reciente en mi campo de investigación, esto me permite perfeccionar mi investigación...”; otros de los encuestados dijeron, "...son fundamentales para la investigación y la obtención de recursos..."; "...son el sistema nervioso central de la vida académica..."; “...sin ellos, sería imposible hacer y enseñar ciencia...”, “...[los artículos académicos] son de extrema importancia, no podría prescindir de ellos, porque me hacen consciente de lo que han hecho los colegas de todo el mundo, me enseña nuevos métodos y técnicas, y me hacen pensar acerca de la investigación con una perspectiva diferente, mejorando la posibilidad de descubrir algo nuevo...". Para los autores y a partir de los reportes de los científicos, la importancia de la lectura académica no puede resumirse en una sola palabra, su impacto está en todas las actividades de los científicos.

Estienne y Carlino (2004) señalan de manera muy atinada que es una falsa creencia de los profesores, pensar que leer es una habilidad que se adquiere de una vez y para siempre, cuando en realidad esta puede sufrir modificaciones, según el momento, la situación, los objetivos, y el contenido que se lee. En el contexto universitario, los docentes esperan que los estudiantes lean de un modo específico: p.ej. que identifiquen los conceptos centrales del texto, que expongan y organicen 
las ideas principales del autor, que respondan preguntas de análisis, que establezcan relaciones entre autores o diferentes textos, que emitan un juicio de valor, etc. La realidad es que no lo hacen, porque ellos leen como pueden o como saben hacerlo, y esto es muy diferente de lo que los profesores esperan que hagan. Esta situación se ve acrecentada en parte, porque los profesores en muchas ocasiones no tienen claro cuál es el objetivo de la lectura, y aún más grave no se les enseña cómo hacerlo, y la queja fuera de toda lógica es “...es que no leen...”, cuando en realidad los estudiantes leen como pueden o como lo han hecho a lo largo de su trayectoria escolar.

Como señalamos previamente los estudiantes universitarios deben asumir nuevos roles como lectores, adaptándose a nuevas situaciones, contenidos y textos. Una de las situaciones novedosas para los estudiantes, es la lectura de artículos científicos, la novedad está en la estructura que estos adoptan en las publicaciones periódicas o revistas científicas. Cuando se trata de reportes de investigación empírica, la estructura de dichos textos es compleja como se muestra en el análisis y representación realizada por Kando (1997), la cual se muestra en el Anexo 2.

Un artículo científico por definición es un documento en donde se presentan los resultados de una investigación original, por lo general tiene una estructura convencional, y cuya función principal es la de comunicar. Para Day (1998) y Graham (s.f.), este tipo de documentos son altamente estilizados con componentes claramente identificables y específicos, aunque estos componentes pueden variar según el campo disciplinar. Sus componentes por lo general son: Introducción, Método, Resultados y Discusión (acrónimo IMRYD). En el Anexo 3, se muestra la anatomía de un artículo de investigación, dicha propuesta es de la American Society of Plant Biologist (2013), en donde se pueden identificar sus componentes y el contenido de manera sintética.

Cuando se trata de explorar las estrategias que podrían seguir los estudiantes universitarios para analizar los artículos de investigación empírica, nos encontramos con dos tipos de estas. Por una parte, tenemos aquellas que sólo atinan a plantear una serie de recomendaciones o pasos, pero no muestran las evidencias de su efectividad. Madooei (s.f.) en su propuesta, además de describir de manera breve la estructura o elementos que conforman un artículo científico, propone una estrategia que incluye tres pasos. En el primer paso (involucramiento), el autor recomienda leer en primera instancia la introducción, no el resumen, y responder diversas preguntas, p.ej. ¿de qué se trata el artículo?, ¿cuál es el problema que se trata de resolver?, ¿por qué el problema es importante?, ¿cuál es la solución que se propone?, ¿el problema es de tu interés?, etc. En el segundo paso (repaso general), el objetivo principal es entender e identificar las ideas clave del artículo, para lo cual recomienda leerlo de adelante para atrás, tomar notas y responder seis preguntas generales y 17 específicas, p.ej. ¿el artículo propone un método?, ¿cuáles son las contribuciones principales?, ¿cómo es el método evaluado?, ¿cuáles son los hallazgos?, ¿cómo los autores demuestran o prueban lo planteado?, ¿cuál es la figura más importante?, ¿pueden los hallazgos aplicarse en otro contexto? Finalmente, en el tercer paso (ir más allá), el autor recomienda leer con más detenimiento el artículo, hacer diagramas y figuras, leer las referencias, consultar otras fuentes de información (libros, documentos on-line), además de los website de los autores. Las preguntas que el lector debe responder son 8, p.ej. ¿el problema de investigación es importante?, ¿las contribuciones son importantes?, ¿las conclusiones de los autores son correctas?, entre otras. En este paso el lector debe evaluar el artículo en términos de su contribución, originalidad, sus fortalezas y debilidades. 
Otra propuesta semejante es la de Graham (s.f.), esta autora presenta cuatro pasos secuenciales para el análisis de un artículo científico, en cada uno de los pasos explica qué analizar para poder responder a una serie de preguntas. Al paso 1 lo denomina El artículo como un todo, en donde hace una serie de recomendaciones antes de iniciar la lectura formal, p.ej. identificar algo acerca del propósito, la audiencia, y el contenido. Las preguntas que recomienda para dicho análisis son: ¿quién escribió el artículo?, ¿cuáles son sus "credenciales”?, ¿a qué audiencia está dirigido?, ¿de qué trata el artículo? y ¿qué recursos utilizó el autor? El paso 2 se identifica con la etiqueta Determinación del propósito, estructura y dirección del artículo, en este caso y una vez que se ha analizado de manera somera el artículo como un todo, el lector debe encontrar la tesis del autor antes de terminar la introducción, así como la evidencia que apoya dicha tesis. Algunas de las preguntas que deben responderse son: ¿cuál es la tesis principal del autor?, ¿cuáles son las evidencias que el autor presenta?, ¿cuáles son los límites que el autor pone al estudio?, y ¿cuál es el punto de vista de los autores? El paso 3 tiene el rótulo de Lee el artículo, pon atención en la escritura y presentación, en este paso señala Graham, no sólo se trata de saber qué dice el autor, sino también del cómo lo dice. En este paso el lector debe comprender cómo el autor presenta la evidencia, además de seguir la línea de argumentación del autor. La autora recomienda poner atención a expresiones como: por ejemplo, como dijo Phillips (2010), sin embargo, en resumen, a pesar de, etc. También es necesario considerar el "nivel" de las oraciones y párrafos, al inicio del artículo -señala la autora- ya que se localizan expresiones generales (nivel simple), que pueden ser utilizadas a lo largo del trabajo, en el nivel medio se resume o discute el problema en términos específicos y de manera más profunda. El lector deberá estar atento al lenguaje de los autores ya que ellos están especulando o cuestionando ciertas evidencias, p.ej. "es probable que", "parece que", "es claro que”, para la autora el énfasis en este tipo de expresiones hace que los argumentos sean o no convincentes. Finalmente en el paso 4: Crítica y evaluación del artículo, Graham señala que el lector debe terminar la lectura, considerando su punto de vista personal, pero en un sentido razonado y no como opiniones superficiales. En síntesis el lector deberá hacer un juicio, comparando el artículo con lo que dicen otros autores al respecto, algunas preguntas que pueden guiar dicha evaluación son: ¿es clara la organización del artículo?, ¿existen problemas gramaticales o en la estructura de las frases u oraciones?, ¿hay algo que el autor no contestó?, ¿qué hizo en su caso?, ¿cuáles son las implicaciones del trabajo en el campo disciplinar o en la sociedad en general?, el lector debe cuestionarse qué aprendió de la lectura y de la información vertida en el artículo analizado.

Otro tipo de propuestas relacionadas con el análisis de artículos de investigación científica, son aquellas en donde el análisis es visto como un proceso de toma de decisiones, en el que cada decisión se basa en el interrogatorio sobre diferentes aspectos del artículo analizado.

En primer término tenemos el planteamiento de Ramey (1999), este autor presenta un diagrama de flujo bien estructurado, en donde están representadas las decisiones que se tomarán después de responder una serie de preguntas, y cuyas respuestas en todos los casos son dicotómicas (es importante señalar que esta propuesta está más dirigida al área clínica). En general son cuatro los momentos que el lector debe tener presente. La pregunta inicial es: ¿el estudio es relevante? Si/ No, para responder esta pregunta deberá responder, tres preguntas más: ¿el artículo es potencialmente útil? Si/No, se deberá continuar con el resumen, en este caso se debe juzgar la conclusión, 
y decidir si esta es válida y tiene un valor práctico Si/No, y finalmente considerar el contexto, en el sentido de su valor práctico, es decir si los resultados pueden ser incorporados a la práctica profesional Si/No. Si las tres respuestas son afirmativas significa que sí es relevante el artículo y por tanto es recomendable leerlo. En el segundo momento del proceso, el lector debe tener claro cuál es su interés o razón al leer un artículo (tres preguntas, cada una con las opciones Si/No); en el tercer momento se deberá considerar si los resultados son válidos (controles, metodología, con diferentes preguntas $\mathrm{Si} / \mathrm{No}$ ), y en el cuarto y último momento la pregunta general es relativa a los resultados y si estos son importantes Si/No. En este caso se enfatiza la interpretación de las pruebas estadísticas, y se destacan los errores más comunes en los que suelen caer los investigadores cuando interpretan dichas pruebas, p.ej. niveles de significancia e intervalos de confianza. Es importante señalar que el autor describe de manera detallada los criterios que deben considerarse, en la toma de decisiones, una vez que se ha decidido leer un artículo de investigación.

Subramanyam (2013) hace una propuesta semejante a la de Ramey (1999), en el sentido de que visualiza la lectura de un artículo de investigación, como un proceso de toma decisiones, aun cuando el énfasis está en las preguntas que los lectores deben responder. En primer término explica los tipos de artículos que se publican en las revistas científicas, además de explicar detalladamente cada uno de los componentes de un artículo y las preguntas que deberá responder el lector. Cabe resaltar que para este autor, el proceso de toma de decisiones sólo está en los primeros componentes de un artículo (título y resumen), ya que de esto dependerá si se lee o no en su totalidad. El grueso de las preguntas está en las secciones ya conocidas por todos (ver Anexo 4).

Otro tipo de propuestas además de considerar algunos de los elementos antes descritos, prueban y desarrollan sistemas basados en las Tecnologías de la Información y la Comunicación (TIC). Zarzosa (2004) desarrolló un sistema al que denominó "Cuestionando al autor" (http://www. psicología.iztacala.unam.mx) el cual tiene como objetivo principal desarrollar en estudiantes universitarios habilidades relacionadas con la lectura estratégica. El sistema tiene como característica principal que el profesor puede diseñar las lecciones de aprendizaje. Sus características principales abarcan: 1) una ventana en la que se presenta una guía, indicaciones o material de estudio; 2) una sección destinada a preguntas o problemas a resolver relacionados con el material de estudio; 3 ) una ventana adicional en la cual se presentan las alternativas de solución a las preguntas planteadas y 4) la retroalimentación correspondiente. El autor señala que a través de este sistema el desempeño lector fue eficiente: reconoce expresiones que sintetizan afirmaciones del autor sin deformaciones, identifica las proposiciones principales de un texto, articula y jerarquiza los conceptos claves y juzga la suficiencia y utilidad del texto en cuestión. Para desarrollar cada una de estas habilidades siempre están presentes diferentes tipos de cuestionamientos, p.ej., para reconocer expresiones que sintetizan afirmaciones del autor sin deformaciones, el lector debe sistemáticamente hacerse las siguientes preguntas, ¿cuál es el punto central del mensaje?, ¿de qué nos está hablando?, ¿cuál es el planteamiento del autor?, o para identificar las proposiciones principales de un texto las preguntas adecuadas abarcarían ¿hay alguna idea nueva en esta sección que resulte significativa?, ¿crees que el autor está haciendo un nuevo planteamiento?

La evaluación empírica del sistema fue llevada a cabo por Zarzosa, Luna, De Parres y Guarneros (2007) quienes trabajaron con 50 estudiantes de Psicología divididos en dos grupos: experi- 
mental y control. El grupo experimental trabajó en cuatro lecciones consecutivas y el control sólo en una (la cuarta lección). Al término de esta secuencia ambos grupos fueron evaluados. Los resultados mostraron diferencias significativas entre los grupos en el manejo de la estrategia. Los autores señalan que la participación en las lecciones en un periodo relativamente corto promueve de manera efectiva la lectura estratégica de textos expositivos y argumentativos.

Por su parte Varnhagen y Digdon (2002) llevaron a cabo un estudio con el objetivo de enseñar a los estudiantes a leer y pensar críticamente acerca de reportes de investigación a través de un módulo interactivo basado en la Web, al que llamaron La lectura de la investigación. El programa inicia con la descripción del género de "reporte de investigación empírica", así como con una serie de preguntas -a las que llaman guías- y que un lector crítico debe considerar mientras lee un reporte. Las preguntas guías son la parte esencial de la estrategia las cuales hacen alusión a cada una de las partes del reporte. Los autores adaptaron las preguntas de algunas guías ya propuestas en otras investigaciones y las clasificaron como preguntas factuales y de pensamiento crítico, a las primeras las definieron como lo específico de la investigación, lo suficiente para evaluarla y a las segundas, como preguntas que requieren inferencia y pensamiento crítico, estas se presentan en formato abierto para involucrar a los estudiantes a pensar creativa y críticamente acerca de lo que leen (ver Anexo 5).

En la segunda parte del programa la Lectura de la Investigación, se presenta un resumen de un reporte de investigación empírica que va acompañado por las preguntas factuales y de pensamiento crítico. Los estudiantes debían trabajar en el resumen, además de hacerse dichas preguntas mientras leen el reporte. Esta parte de la Lectura de la Investigación, es como una plantilla que el instructor puede modificar según el reporte que se esté analizando, de tal forma que el instructor modifica la plantilla al editar el resumen y las preguntas en un procesador de palabras y lo publica en el sitio o Web.

Varnhagen y Digdon (2002) observaron un cambio importante en las habilidades de pensamiento crítico para analizar artículos científicos, aun cuando no encontraron correlación entre la habilidad de pensamiento crítico y el examen de ejecución. Ante la pregunta de si prefieren la enseñanza de estos temas a través de Internet o de manera tradicional, el 46\% prefieren "algo o mucho Internet", el 52\% prefieren "algo o mucho la manera tradicional”, y el 3\% dijo "no tener preferencia".

Una estrategia que consideramos es sustancialmente diferente a las presentadas en las páginas precedentes, es la propuesta por Santoyo (2001). Dicha estrategia tiene como objetivo que los estudiantes jueguen un papel activo en un sentido disciplinario (p.ej. analizando y emitiendo juicios sobre lo leído). Para Santoyo (2001) el análisis de textos científicos es una habilidad metodológica y conceptual, es decir "aquella involucrada en la solución y planteamiento de problemas científicos, conceptuales y profesionales" (p. 10) que es producto del aprendizaje. Dicha estrategia consta de nueve categorías, estas categorías incluyen: la justificación de un trabajo, los objetivos de investigación, los supuestos básicos, la unidad de análisis, la estrategia del autor, el análisis de la consistencia interna y externa, cursos de acción alternativos, las conclusiones del autor y la conclusión propia (ver definiciones, Anexo 6).

Cabe destacar que a diferencia de las propuestas mencionadas, no se sigue la estructura de un artículo de investigación en sentido estricto, -situación que sí se observa en algunas de las 
propuestas presentadas-, además de que el análisis que hace el lector no obedece a un contenido específico de fácil identificación. Por ejemplo, en el caso de la identificación de los supuestos básicos, el lector debe identificar o deducir los supuestos de un planteamiento teórico o aplicado, es decir, debe analizar las bases conceptuales en las que se basa un argumento, además de analizar su congruencia considerando su origen epistemológico. El análisis de los supuestos básicos, por lo general, no se encuentra de manera explícita en un artículo de investigación, por lo que se requiere de cierto conocimiento teórico o conceptual antecedente.

Es importante resaltar dos cosas, por una parte, en ninguna de las estrategias descritas se hace alusión a los elementos descritos por Santoyo (2001) respecto al análisis de artículos de investigación, y por otra, tampoco se detalla el cómo enseñar dichas estrategias. En general pareciera que el análisis debe ser sección por sección y con una serie de preguntas ad hoc. Santoyo (2001) describe de manera detallada las actividades didácticas que deberá seguir un profesor para que un estudiante llegue a dominar la estrategia, los contenidos (p.ej. conceptos), así como el nivel de ejecución que se espera del estudiante (p.ej. nivel deducción, concreto, abstracto, etc.).

La estrategia se ha probado en diferentes estudios, p. ej., Cepeda, López y Santoyo (2009), la emplearon con estudiantes universitarios a través de sesiones semanales y textos programados, sus datos demostraron un incremento importante en el uso adecuado de la estrategia. Asimismo, Espinoza, Santoyo y Colmenares (2010) después de implementar un curso a estudiantes de Psicología, observaron el dominio de la estrategia, tanto en el manejo de las categorías, como en el nivel de ejecución, específicamente en los niveles conceptuales o abstractos, niveles por definición más complejos.

La literatura presentada hasta este momento muestra las dificultades que los estudiantes universitarios presentan cuando emprenden la tarea de leer textos científicos, así como diferentes propuestas o estrategias para dar fin a las limitaciones de los estudiantes, o para desarrollar habilidades encaminadas a su mejor comprensión y análisis de textos. Sin embargo, existe una cuestión que también resulta importante y es la necesidad de contar con una prueba empírica de que las habilidades desarrolladas -no importa a través de qué estrategia-, han sido transferidas, condición que en la literatura está ausente.

La transferencia del aprendizaje es definida como la aplicación del conocimiento aprendido en un contexto a un nuevo contexto (Bransford, Brown \& Cocking, 2000). En el caso que nos ocupa, si los estudiantes logran aprender una estrategia para comprender y analizar los textos científicos -p.ej. artículos empíricos-, se esperaría que pudieran emplear dicha estrategia en una variedad importante de textos. Sin embargo, la pregunta que sobresale es ¿cómo garantizar la transferencia del aprendizaje? La literatura señala que en la transferencia del aprendizaje, están involucradas un sinnúmero de variables, p.ej., desde las características del aprendiz, como la personalidad, las habilidades cognitivas, hasta la programación de las actividades de entrenamiento (Burke \& Hutchins, 2007).

En esta última condición es necesario enfatizar que en el diseño de sistemas de aprendizaje, el diseño instruccional juega un papel preponderante. Burke y Hutchins (2007) argumentan que si se parte de un modelo instruccional y se incorporan todos sus elementos en un programa educativo o de entrenamiento, estará garantizada la transferencia del aprendizaje. Burke y Hutchins (2007) 
demostraron que llevar a cabo un análisis de necesidades (educativas y de entrenamiento), la definición de objetivos de aprendizaje (definidos conductualmente), la especificación de métodos y estrategias (principalmente la práctica y la retroalimentación), la programación de una gran variedad de ejemplos, el modelamiento conductual y el apoyo tecnológico, estará garantizada la transferencia del aprendizaje. En el meta-análisis llevado a cabo por estos autores, se demuestra a través de un sinnúmero de evidencias, que en todos los casos en los que se consideró el diseño instruccional con los elementos antes mencionados, la transferencia del aprendizaje estuvo presente. Finalmente cabe destacar que la transferencia del aprendizaje es un buen criterio para evaluar el impacto de cualquier programa educativo.

A partir de lo expuesto en las páginas precedentes y de la necesidad de contribuir en la promoción de las habilidades relacionadas con el análisis de textos científicos, el presente trabajo tiene tres objetivos principales: 1) describir un sistema de aprendizaje en línea (Laboratorio Virtual de Lectura Estratégica -LAVLES-) el cual fue construido a partir de los elementos del diseño instruccional; 2) mostrar evidencias de los efectos de dicho sistema, sobre el conocimiento y aplicación de dicha estrategia en una muestra de estudiantes universitarios y; 3) mostrar evidencias de la transferencia del aprendizaje.

\section{Método}

Participantes. 140 estudiantes de la carrera de Psicología de una Universidad pública del Estado de México.

Diseño. Se utilizó un diseño pretest-postest de un solo grupo (pretest -intervención- postest), el cual señala que el grupo bajo estudio es evaluado antes y después de un tratamiento (Campbell y Stanley, 1978), en este caso antes y después de haber participado en el LAVLES. Las variables dependientes fueron: 1) el aprendizaje sobre el uso de la estrategia de análisis de textos científicos (medida en términos del porcentaje de aciertos en pretest y postest) y 2) la transferencia del aprendizaje a través de la autoevaluación de los trabajos de los usuarios.

Descripción del sistema. La entrada al sistema se inicia con tan solo teclear la siguiente dirección http://tlali.iztacala.unam.mx/lectura_estrategica. Una vez que el usuario ha entrado al Laboratorio Virtual de Lectura Estratégica deberá leer con detalle cada una de las etiquetas desplegables que se le muestran en la pantalla y registrarse haciendo clic en la etiqueta denominada $\mathbf{R}$ e g i s $\mathbf{t}$ r o. Al proporcionar la información solicitada e ingresar entre otras cosas su nombre y número de cuenta, el sistema automáticamente le asignara al usuario un login y un password, mismo que deberá de teclear cada vez que intente trabajar en el Laboratorio.

Una vez que el estudiante entra al laboratorio y aparece la bienvenida, en la parte inferior de dicha pantalla hay diversos botones de acceso rápido a diferentes componentes del sistema, p.ej., el botón de Menú inicial lleva al usuario al menú principal en donde se localizan las etiquetas de cada uno de los módulos, el botón Resumen de actividades en el cual el usuario visualiza toda su ejecución hasta ese momento. 
El sistema incluye dos evaluaciones: 1) evaluación sobre el conocimiento de conceptos básicos acerca del Análisis Experimental de la Conducta, conocimientos sobre metodología experimental, conocimiento sobre la existencia de algunas revistas científicas, así como la estructura de los artículos publicados en este tipo de revistas y, 2) evaluación pretest/postest, en la que se valora el manejo de la estrategia de Análisis de Textos Científicos que aprenderá (en este trabajo sólo presentamos datos de estas pruebas). Tanto el pretest como el postest están divididos en dos partes, la primera de ellas evaluó los conceptos básicos de cada una de las categorías de la estrategia, y en la segunda se evaluó el manejo de la estrategia frente a un artículo de investigación empírica, la cual consistió en analizar un reporte de investigación de corte experimental y responder a veinte preguntas de opción múltiple (algunos reactivos tenían más de una respuesta correcta) las preguntas estuvieron principalmente relacionadas con la aplicación de la estrategia.

El aprendizaje de la estrategia de análisis de textos se inició propiamente con el módulo de justificación, y después continuó con los siete módulos restantes, los 8 módulos debían ser trabajados de manera consecutiva, es decir, primero debían trabajar sobre el módulo denominado justificación y posteriormente el de objetivos, continuar con el de supuestos básicos, después unidad de análisis y así sucesivamente. Ahora bien, cada módulo estuvo constituido por 4 secciones, diseñadas a partir de una lógica de complejidad creciente, es decir, de lo más sencillo de adquirir como lo es identificar el concepto en cuestión y sus componentes, hasta las recomendaciones de cómo identificar en un artículo de investigación cada uno de los elementos de la estrategia en un artículo. Un usuario podría concluir la parte 1 y continuar con las partes restantes en días posteriores, siempre y cuando sean en orden consecutivo (1, 2, 3 y 4). Al término de cada una de estas secciones se incluyeron una serie de ejercicios o evaluaciones las cuales debían ser resueltas, para poder pasar a la siguiente sección, la evaluación debía estar resuelta correctamente. Para cada reactivo de la evaluación existió la retroalimentación correspondiente, es decir, para cada opción seleccionada apareció un texto que indicaba si era correcta o incorrecta y por qué.

Textos presentados. Se presentaron 57 textos diferentes del ámbito conductual cuya extensión y número de palabras dependió del módulo en cuestión, por ejemplo, los textos del módulo de objetivos tuvieron una extensión en promedio de 555 palabras, caso contrario a la extensión de los textos presentados en el módulo de estrategia del autor la cual fue de 1137 palabras. En los primeros sólo se presentó el análisis de la introducción del artículo, mientras que en el segundo fue necesario presentar además de la introducción la metodología descrita por los autores. Es importante señalar que algunos textos fueron presentados como ejemplos, otros como ejercicios y otros más como parte de las evaluaciones. Los artículos mostrados fueron de corte experimental de investigación básica, tanto con humanos como infrahumanos, de investigación aplicada, de las áreas de clínica, educación, salud y educación especial. Los trabajos de corte teórico fueron los menos, estos sólo se emplearon para ilustrar los supuestos básicos.

Los usuarios podían ingresar a cada uno de los módulos los cuales correspondían a uno de los elementos de la estrategia de análisis de textos científicos propuesta por Santoyo (2001). Es importante señalar que las definiciones de cada uno de los elementos que conformaron la estrategia se modificaron sin perder la esencia de las definiciones originales (ver Anexo 7). Asimismo, durante el 
proceso de construcción del LAVLES estuvo presente el diseño instruccional, con la finalidad de garantizar el aprendizaje de la estrategia y en su caso la transferencia del aprendizaje, un ejemplo de la programación se muestra en el Anexo 8. Al término de los ocho módulos los estudiantes contestaron nuevamente una evaluación final o postest, que fue exactamente igual a la evaluación inicial.

Procedimiento. La promoción del LAVLES incluyó principalmente la difusión entre los estudiantes de la carrera de Psicología, dicha promoción incluyó diferentes estrategias, tales como carteles, separadores de libros, visitas a los salones de clases, participación en el 5to Coloquio Nacional de Investigación Estudiantil en Psicología, entre otras.

En la Fase de Intervención el equipo de investigación y la responsable del proyecto revisaron de dos a tres veces a la semana los mensajes de los usuarios, resolvieron todas las dudas planteadas y en muchos casos les indicaron nuevamente su login y password para poder ingresar al Laboratorio. Asimismo, a intervalos regulares se hacía un levantamiento de información de aquellos usuarios que terminaban el laboratorio, en ese momento se mandaban hacer las constancias respectivas y una vez que se contaba con ellas se les contactaba vía Internet. Dado que la mayoría eran estudiantes de la institución en la que se hizo la difusión, se les citaba para hacerles entrega de su constancia.

Para evaluar la transferencia del aprendizaje a un grupo de estudiantes se les solicitó que a partir de lo aprendido en el LAVLES, analizaran uno de los reportes de investigación elaborado por ellos mismos, específicamente los reportes de investigación entregados en la materia de Psicología Aplicada Laboratorio II, por dos razones: 1) la estructura de dichos reportes es la misma que la de los artículos analizados en el LAVLES; y 2) la aproximación teórica de dichos trabajos corresponde también a la abordada en el laboratorio, es decir, el Análisis Experimental de la Conducta.

Resultados. Dado que el pretest y el postest fueron divididos en dos partes se llevó a cabo un análisis adicional para determinar las posibles diferencias entre ambos, ya que cada una de estas evaluó habilidades diferentes, como se recordará la Parte 1 evaluó el reconocimiento de las definiciones de cada elemento de la estrategia y la Parte 2 la aplicación de la estrategia en un artículo de investigación.

El análisis reveló diferencias significativas en el porcentaje de aciertos entre la Parte 1 del pretest $\left(t_{(139)}=-24.108 p<0.000\right)$ y postest, asimismo se observaron diferencias significativas en la Parte 2 entre el pretest y postest $\left(t_{(139)}=-7.509 p<0.000\right)$. Estos datos son un indicador del aprendizaje de las definiciones de cada elemento de la estrategia (Parte 1), así como de la capacidad de los participantes para aplicar las habilidades aprendidas a lo largo del Laboratorio en un texto diferente a los utilizados durante su aprendizaje (Parte 2).

Aun cuando este análisis demuestra cambios importantes del pretest al postest como indicadores del aprendizaje de la estrategia, al realizar un análisis minucioso pudimos identificar dos datos importantes: 1) que había diferencias en los puntajes obtenidos en el pretest entre los participantes, es decir, se observó que había estudiantes que obtuvieron puntajes bajos, otros puntajes relativamente medios $o$ altos $y, 2$ ) que había participantes que aumentaron considerablemente sus puntuaciones del pretest al postest, y otros de manera moderada o casi insignificante. Por lo que se decidió 
dividir a los participantes en tres grupos de acuerdo a las puntuaciones obtenidas en el pretest. De esta forma el Grupo 1 estuvo conformado por los estudiantes que se ubicaron abajo del percentil 25 (calificaciones menores a 10 puntos), el Grupo 2 entre el percentil 25 y 75 (calificaciones entre 11 y 15 puntos) y finalmente el Grupo 3 arriba del percentil 75 (calificaciones superiores a 16 puntos). La Tabla 1 muestra los detalles de dicha clasificación.

Tabla 1. Media de aciertos en el pretest y postest para los tres grupos

\begin{tabular}{|c|c|c|c|}
\hline Grupos & Percentiles & $\begin{array}{c}\text { Media de aciertos } \\
\text { en el pretest }\end{array}$ & $\begin{array}{c}\text { Media de aciertos } \\
\text { en el postest }\end{array}$ \\
\hline $\begin{array}{c}\text { Grupo 1 (GB) } \\
(\mathrm{n}=45)\end{array}$ & $25(10)$ & 7.56 & 18.64 \\
\hline $\begin{array}{c}\text { Grupo 2 (GM) } \\
(\mathrm{n}=64)\end{array}$ & $75(15)$ & 12.91 & 20.58 \\
\hline $\begin{array}{c}\text { Grupo 3 (GA) } \\
(\mathrm{n}=31)\end{array}$ & $100(16)$ & 18.19 & 21.97 \\
\hline
\end{tabular}

Como se puede apreciar en la Tabla 1, los estudiantes del Grupo 1 (puntaje bajo) tuvieron una ganancia de 11 puntos en promedio del pretest al postest, los participantes en el Grupo 2 (puntaje medio) avanzaron 7 puntos, mientras que el Grupo 3 (puntaje alto) sólo 3 puntos. Estos datos sugieren que los más beneficiados fueron los usuarios que obtuvieron puntuaciones bajas en el pretest, es decir los del Grupo 1 (puntaje bajo).

Transferencia del Aprendizaje. Como se mencionó en la sección de procedimiento, para evaluar la transferencia del aprendizaje a un grupo de estudiantes se les solicitó que analizaran uno de los reportes de investigación elaborados por ellos mismos, específicamente, los diseñados y llevados a cabo para la materia de Psicología Aplicada Laboratorio II. En esta sección sólo se describe el análisis llevado a cabo en una muestra de 17 reportes $^{1}$. Para este análisis los 17 reportes fueron analizados por dos jueces, quienes leyeron cuidadosamente dichos reportes, mismos que fueron categorizados considerando los elementos esenciales de la estrategia aprendida a través del LAVLES.

El análisis que se presenta consideró diferentes operaciones: 1) se presenta en primer término la definición de cada elemento de la estrategia; 2) la variedad de análisis encontrados agrupados por categorías (Tipo 1, J2, AC3, con la inicial de la categoría) y 3) se presentan pequeños extractos como ejemplos de dicha variedad.

Justificación de un trabajo de investigación. Es la presentación de argumentos teóricos, metodológicos o sociales que expresan de manera explícita o implícita el por qué estudiar un problema. El examen de la justificación, indico que los estudiantes mostraron tres tipos generales análisis.

1 Los extractos presentados fueron transcritos de manera textual, de tal forma que los problemas de redacción y en su caso, los de ortografía, se dejaron intactos. 
Tipo J1. Representado por las evaluaciones más completas, ya que señalan el ¿por qué? del estudio, el tipo de argumento utilizado y si la justificación es explícita o implícita. En el Laboratorio se describen y ejemplifican los tipos de argumentos que un autor puede utilizar, como lo son los argumentos metodológicos, sociales, teóricos y de comparación, así como el hecho de que una justificación puede ser explícita o implícita. Los casos que a continuación se presentan son pequeñas muestras textuales de lo escrito por los estudiantes. Este último análisis nos sugiere qué estudiantes de los tres grupos lograron hacer una evaluación crítica de las justificaciones de sus trabajos, indicador de la transferencia del conocimiento adquirido.

(GA) “...La justificación que se planteo en este estudio, fue el de mejorar las condiciones para lograr una mejor respuesta en el trabajo de la discriminación en niños con dislexia, ya que en estudios anteriores se empleo el uso de instigadores pero solamente en combinación par; es decir, el uso de instigadores físicos y visuales o visuales y verbales, así que se incluyo" para este, el uso en conjunto para un mejor resultado de físicos, visuales y verbales. Encontrándose de manera implícita en este trabajo la justificación ya que no se menciona en el texto, pero se puede deducir o relacionar de acuerdo a los argumentos teóricos que se presentan..."

(GA) “...en el artículo el tipo de justificación que se presenta en la introducción contiene argumentos metodológicos, pues en este trabajo en la parte de la introducción se presentan diferentes técnicas que han sido utilizadas por diferentes autores para el tratamiento del TDAH, las cuales han demostrado ser eficaces, sin embargo, dos de estas técnicas, la asignación y selección de una tarea, así como la entrega de un reforzador pequeño inmediato y uno grande demorado, no habían sido conjugadas en un tratamiento, siendo este el argumento metodológico; la combinación de estas dos técnicas para aumentar el mantenimiento de un niño en una tarea, además de tomar en cuenta la atención, la cual no había sido atendida por los estudios citados en el trabajo. Este argumento esta de manera explícita, pues en el trabajo se aprecia en la introducción cual es el propósito de dicho trabajo..."

(GM) “...tipo de argumento: el tipo de argumento es social, ya que nos expone la relación del problema a tratar con conceptos sociales. El estudio se realizo para resolver un problema de relevancia social y práctico, que en este caso fue, resolver el problema que tiene los niños que padecen TDAH, para concentrarse al realizar una tarea o para mantener la atención, ya que el individuo presenta conductas impulsivas como interrumpir las actividades que los demás compañeros están realizando así como la dificultad para terminar un trabajo o seguir instrucciones. Este estudio contribuye a resolver un problema que es de interés para la sociedad y en particular para los profesores..."

(GB) “...El estudio tiene argumentos metodológicos que expresan de manera explícita el por qué se realizó el estudio. En el estudio realizado por Ferrari, De Rose y Mcllvane (1993) aplicaron los entrenamientos de exclusión y selección a todos los participantes, al final de cada entrenamiento se aplicaron pruebas de discriminación y nombramiento. Finalmente se 
pudo observar que el porcentaje de errores fue menor en exclusión en comparación a la de selección, sin embargo no se puede afirmar que un entrenamiento es mejor que otro, ya que no se aislaron las variables y en los resultados no se observó la eficacia de cada uno de ellos. Tomando en cuenta las limitaciones de este último estudio, en este se aplicaron los entrenamientos de exclusión y selección por separado..."

(GM) “...El presente estudio se realizó para comparar diferentes técnicas (instigación y verbalización) de clasificación ya que en investigaciones previas sólo se han evaluado estas de manera separada más no se ha hecho un estudio que hiciera una comparación entre ellas. El tipo de explicación es explicita ya que se menciona el propósito tal cual en el texto..."

(GB) “...Se realizó esta investigación para contrastar los métodos que se han utilizado en investigaciones previas (Grote, 1996; Duarte y Baer, 1994; Grote y Rosales, 1997; Fjellstrom, 1988) estos métodos son: recordatorios, verbalizaciones en voz baja o simplemente no implementar ninguna instrucción, ya que no es claro cual de ellas es más efectiva para desarrollar la tarea de clasificar en especial en la fase de generalización y no se ha realizado un estudio que compruebe la efectividad de métodos de instigación y verbalización en voz baja..."

Tipo J2. Evaluaciones cuya característica principal es una explicación del porqué se llevó a cabo el estudio sin mencionar el tipo de argumento o si es explícita o implícita dicha justificación, los extractos presentados son transcripciones típicas con estas características que corresponden a un caso del Grupo Alto y tres del Grupo Medio. Al igual que en el caso anterior podemos decir que estos participantes también lograron transferir el conocimiento, solo que son más sintéticos en su análisis.

(GA) “...El estudio realizado por Ferrari, De Rose y Mcllvane (1993) compararon los entrenamientos de exclusión y selección para la enseñanza de nuevas relaciones condicionales entre los estímulos auditivos/visuales, donde se aplicaron pruebas de discriminación y nombramiento. Donde se pudo observar que los niños con problemas de aprendizaje aprenden mejor a través de la exclusión, ya que el porcentaje de errores fue menor en comparación a la de selección, sin embargo no se puede afirmar que un entrenamiento es mejor que otro, ya que no se aislaron las variables y en los resultados no se observó la eficacia de cada uno de ellos. Tomando en cuenta las limitaciones de este último estudio, en este se aplicaron los entrenamientos de exclusión y selección por separado..."

(GM) “...El propósito del presente estudio, fue combinar el estudio hecho por Binder, Dixon y Ghezzi (2000), acerca de dar un reforzador grande demorado o un reforzador pequeño inmediato, con el estudio realizado por Powell y Nelson (1997), sobre asignar o dar a elegir una tarea académica, para disminuir las conductas impulsivas y lograr mantener en la tarea a un niño con TDAH..." 
(GM) “...Dé Rose, Ferrari y Mcllvane (1993) realizaron un estudio donde compararon el entrenamiento de exclusión contra el de selección en el aprendizaje de nuevas -relaciones condicionales auditivo/visual donde se aplicaron el entrenamiento de exclusión y el de selección de manera sucesiva, terminado cada entrenamiento se aplicaron pruebas de discriminación y nombramiento. Al final los resultados mostraron que en exclusión el porcentaje de errores fue menor en comparación al de selección, sin embargo no podernos afirmar que uno sea mejor fue otro ya que no se aislaron la variables, por tal motivo en este estudio se aplicaron los entrenamientos de exclusión y selección uno a cada participante en el aprendizaje de nuevas relaciones condicionales auditivo/visual. Evaluar el aprendizaje de nuevas relaciones condicionales entre estímulos empleando los 2 entrenamientos: exclusión y selección por separado, trabajando con dos participantes donde al P1 se le aplicó el entrenamiento de exclusión y al P2 el entrenamiento de selección..."

(GM) “...El trastorno por Déficit de atención con hiperactividad (TDAH), es una de las alteraciones mas frecuentes en la infancia, en este trastorno los niños presentan dificultad para concentrarse para realizar una tarea o mantener la atención, esto acompañado de conductas impulsivas como levantarse de su asiento e interrumpir las actividades que los demás compañeros están realizando. Una conducta indeseable que se presenta con mucha frecuencia en niños con TDAH, es la incapacidad de mantenerse en alguna tara asignada Muchos estudios se han enfocado en resolverlo este trastorno por diferentes procedimientos: dar un reforzador grande demorado o un pequeño inmediato, y asignar o dar a elegir una tarea académica, para disminuir conductas impulsivas..."

Tipo J3. En esta última categoría podemos ubicar a los estudiantes cuya evaluación se caracterizó por la transcripción textual de sus trabajos, en este caso, los extractos de sus introducciones. El caso más notorio es el caso del grupo Bajo que además de copiar presentó un resumen de su investigación, los otros dos casos copiaron parte de sus introducciones, las cuales no presentamos. Es evidente que en este caso los participantes ubicados en esta categoría no lograron transferir o generalizar el conocimiento adquirido.

(GB) “...En el estudio realizado por Ferrari, De Rose y Mcllvane (1993) aplicaron los entrenamientos de exclusión y selección a todos los participantes, al final de cada entrenamiento se aplicaron pruebas de discriminación y nombramiento. Finalmente se pudo observar que el porcentaje de errores fue menor en exclusión en comparación a la de selección, sin embargo no se puede afirmar que un entrenamiento es mejor que otro, ya que no se aislaron las variables y en los resultados no se observó la eficacia de cada uno de ellos. Tomando en cuenta las limitaciones de este último estudio, en este se aplicaron los entrenamientos de exclusión y selección por separado. Con el objetivo de evaluar el aprendizaje de nuevas relaciones condicionales auditivo/visual entre estímulos empleando dos entrenamientos exclusión y selección por separado, se trabajó con dos participantes a uno de ellos se le aplicó el entrenamiento de exclusión y al otro el entrenamiento de selección. Situación experimental: ...Las sesiones 
se llevaron a cabo en una guardería, se les pidió un salón a las autoridades de la institución, con ventilación adecuada y cortinas cerradas para evitar distracciones. “ ...VD: Número de respuestas correctas (el participante señaló y nombró al mismo tiempo el estímulo que igualo a la muestra). VD: Número de respuestas correctas en nombramiento (el participante debía nombrar correctamente el estímulo que le presentaba el experimentador). VD: Numero de respuestas correctas en señalar (el participante debía señalar el estímulo que igualara a la muestra) Diseño: El diseño que se utilizó fue A-B-C ..." “...Resultados: El autor también menciona los principales resultados. Durante la fase de preentrenamiento, los 2 participantes aprendieron a discriminar a través de la tarea de la igualación a la muestra. En la figura 4 se muestran los porcentajes que obtuvo el participante 2, tanto en el preentrenamiento como en el entrenamiento de selección (el cual se dividió en ensayos de entrenamiento y de control), en donde se puede observar que al inicio de la fase del preentrenamiento logró alcanzar el $100 \%$ de aciertos..."

Objetivos de un trabajo de investigación. Identificación y deducción de los propósitos de un trabajo de investigación, derivados de la justificación y los antecedentes del trabajo. Al igual que en el caso anterior se identificaron tres tipos de evaluaciones:

Tipo Ob1. En la primera de ellas podemos ubicar a un participante del Grupo Medio, cuyo análisis fue el más completo, ya que además de explicitar el objetivo, describió paso a paso cómo identificar este, de dónde se deriva dicho objetivo, así como las variables involucradas y la relación que se trataba de encontrar entre dichas variables.

(GM) “...leer la introducción del trabajo... Identificar los argumentos introductorias: Adelman, et al (1997), por medio de la asignación y elección de una tarea académica y el uso del Ritalin, lograron reducir tanto las conductas impulsivas como los trastornos del sueño, en un niño con TDAH. Powell y Nelson (1997), con el método de asignación y elección de una tarea académica, se busca que un niño con TDAH permaneciera en la tarea asignada, logrando dicho objetivo. Flood, Flood y Masuda (2002), mediante un análisis funcional, buscaban determinar los factores que intervenían para que el niño no se mantuviera en la tarea, encontrando que la atención de los compañeros eran una fuente de distracción. Utilizaron un método, donde los compañeros reforzaban las conductas de mantenerse en las tareas asignadas. Kodak, Grow y Northup (2004) mediante un análisis funcional, tiempo fuera y un reforzamiento no contingente, buscaban disminuir las conductas de fuga y escape y aumentar el mantenimiento de atención en una tarea deportiva. Binder Dixon y Ghezzi (2000) buscaban disminuir conductas impulsivas y aumentar el autocontrol en niños con TDAH dándoles a escoger entre un reforzador pequeño inmediato, indicándoles que si escogían el reforzador grande retardado, se les asignaría una tarea durante cierto. Mc. Dowell y Kema (2001), buscaban que un niño con TDHA, se mantuviera en la tarea con la técnica de fluidez. Señalar las variables que los autores mencionan. VD: mantenerse en la tarea y poner atención. VI reforzador pequeño inmediato cuando elige la tarea (dulces) y reforzador grande demorado cuando se le asigna la tarea (juguetes). Identificar la relación de variables: Se busca observar que relación hay 
entre entregar un reforzador pequeño inmediato cuando el participante elija la tarea académica o un reforzador grande demorado cuando se le de a realizar la tarea al participante, con el aumento de las conductas poner atención y permanecer en la tarea. . identificar el objetivo de investigación: El presente estudio evaluó los efectos de aplicar un reforzador grande demorado cuando a un niño se le asignó la tarea académica y un reforzador pequeño inmediato cuando se le dio a escoger la tarea académica, sobre la conducta de mantenerse en la tarea..."

Tipo Ob2. En este caso el estudiante vincula y deriva el objetivo de la justificación planteada en el trabajo.

(GA) “...En los estudios descritos se ha encontrado que el uso de instigadores ha tenido éxito en el incremento de la discriminación, ya que al resaltar las características que se desean ser aprendidas se ha tenido mayor eficacia hacia un incremento en la discriminación, en dichos estudios solo han trabajado con uno o dos instigadores, pero ninguno ha empleado instigadores físicos, visuales y verbales en un solo estudio, por lo que en este estudio lo que se pretendió fue evaluar los efectos de los instigadores físicos, visuales y verbales sobre la discriminación de las letras b y d en un niño de edad primaria..."

Tipo Ob2. Otro caso en el análisis de los objetivos es cuando se transcribe el objetivo del trabajo, además de señalar si es explícito o implícito, sin más explicación. En los seleccionados el objetivo fue explícito.

(GA) “...el objetivo en este trabajo esta de manera explícita, pues en el trabajo se puede leer que este evaluara los efectos de aplicar un reforzador grande demorado cuando a un niño se le asigna la tarea académica y un reforzador pequeño inmediato cuando se le da a escoger la tarea académica, sobre la conducta de mantenerse en la tarea y la atención. Este objetivo esta basado en los argumentos metodológicos presentados en el trabajo, es decir de la justificación del trabajo. En el objetivo se describe una relación entre variables, las cuales son: el tratamiento, la combinación de las técnicas de selección y asignación de una tarea con la entrega de un reforzador pequeño inmediato y uno grande demorado; con las conductas de mantenerse en la tarea y la atención que el niño emplea..."

(GB) “...El objetivo esta dentro del trabajo de manera explícita. Con el objetivo de evaluar el aprendizaje de nuevas relaciones condicionales auditivo/visual entre estímulos empleando dos entrenamientos exclusión y selección por separado, se trabajó con dos participantes a uno de ellos se le aplicó el entrenamiento de exclusión y al otro el entrenamiento de selección..."

Tipo Ob3. En este último ubicamos a los estudiantes que sólo transcribieron el objetivo de su trabajo sin argumentación alguna. 
(GA) “...El objetivo es evaluar el aprendizaje de nuevas relaciones condicionales auditivo/ visual (señalar y nombrar), a través de las pruebas de discriminación y nombramiento empleando los entrenamientos de exclusión y selección por separado..."

(GM) “...Con el objetivo de evaluar el aprendizaje de nuevas relaciones condicionales auditivo/ visual entre estímulos empleando los entrenamientos exclusión y selección por separado..."

(GM) “...El objetivo del presente estudio por lo tanto fue evaluar los efectos de los métodos: voz baja, recordatorios, sobre la adquisición de la habilidad de clasificar durante la fase de generalización..."

Supuestos Básicos. Son los elementos conceptuales de una explicación a partir de aspectos genéricos derivados de un modelo teórico, los cuales nos permiten identificar los fundamentos del fenómeno bajo estudio.

En este análisis queremos resaltar que los supuestos más referidos fueron: la conducta como objeto de estudio de la psicología, control de estímulos, el objetivo de la ciencia es la predicción y control, selección por las consecuencias, la triple relación de contingencia y las causas de la conducta se localizan en el ambiente.

Tipo SB1. El estudiante especifica el supuesto del que se trata y explica en su trabajo en donde lo ubica, el análisis abarca las diferentes partes del reporte (Introducción, Método y Resultados) los supuestos identificados son hasta 5 , lo que hace a dicho análisis extenso².

(GA) “...Es importante señalar que el objetivo de este estudio se centro en la conducta (una aproximación teórica conductual) y no en otra disciplina como una entidad mental, sino solo en la conducta, de ahí podemos puntualizar que se cumple el postulado señalado por Skinner en que "el estudio de la ciencia psicológica es la conducta y sólo la conducta..." “... para ayudar a la solución de este problema se puede hacer uso de un efectivo control de estímulos, el cual se refiere a cuando hay una amplia probabilidad de que una respuesta particular ocurra ante la presencia de un estimulo antecedente particular... En este texto que forma parte del ler. Reporte de investigación se puede señalar el postulado que formulo Skinner que menciona que "La conducta operante puede ser puesta bajo control de estímulos antecedentes" "...En el texto se observa que a través de instigadores como condición medioambiental se pretende encontrar un cambio en la discriminación del niño. Y se observa el uso del cuarto postulado que nos dice que "La selección por consecuencias es el principal modo causal por el cual el ambiente determina los resultados los sistemas vivos..." "... hasta el $76.21 \%$ de correcta discriminación ante b y d, así continuo incrementando en la fase de desvanecimiento, aun eliminando paulatinamente los instigadores con un porcentaje del $77.3 \%$ Estos resultados nos muestran como la conducta puede ponerse bajo el control de estímulos antecedentes, concretamente la discriminación..” " .... Igualmente en este estudio queda demostrado

2 En este caso particular no se presenta el análisis completo por cuestiones de espacio. 
que a partir de la observación científica se pueden llevar a cabo juicios relacionados con los antecedentes y consecuencias de la conducta, esta aseveración se relaciona con el supuesto que involucra a la triple relación de contingencia (ERC) como método de analítico de la conducta operante Estas evidencias son una condición a partir de la cual podemos señalar que la conducta es función o depende de los estímulos antecedentes. En este sentido queda demostrada la relación funcional entre el tipo instigadores y la correcta discriminación a través del reforzamiento de la misma en el niño..."

Tipo SB2. En una segunda variedad los estudiantes copian de manera textual un párrafo de la introducción de su trabajo y toman algunos enunciados para ubicar el supuesto, sin embargo, no existe ninguna explicación. Ejemplos de este análisis son los extractos que mostramos a continuación:

(GM) “...Dentro de la psicología existen diferentes conductas las cuales se encuentran bajo control de estímulos, Mayer y Sulzer (1983) plantean que se presenta cuando hay una gran probabilidad de que una respuesta particular suceda en presencia de un estímulo antecedente. (En este enunciado nos señala que la causa de la conducta está localizada en el ambiente) Evaluar el aprendizaje de nuevas relaciones condicionales entre estímulos empleando los entrenamientos de exclusión y selección. (En este enunciado se encuentra la metodología ya que existe una relación entre variables.) Para facilitar la exclusión se hace uso de los instigadores, Skinner (1957) los definió como una forma de estimulación agregada a los estímulos discriminativos (SD) que aumentan la probabilidad de que se den las respuestas apropiadas cuando por factores de la naturaleza motivacional de control de estímulos hacen que la ejecución momentánea sea probable. (En este enunciado nos habla de la predicción y el control..."

(GB) “...Dentro de la psicología existen diferentes conductas las cuales se encuentran bajo control de estímulos, Mayer y Sulzer (1983) plantean que se presenta cuando hay una gran probabilidad de que una respuesta particular suceda en presencia de un estímulo antecedente. (La conducta es le objeto de la psicología y la Triple relación de contingencias, es decir que un estimulo antecedente, respuesta y reforzamiento) Un ejemplo cotidiano es cuando ante las luces del semáforo los automovilistas discriminan, ya sea avanzar con luz verde o detenerse con luz roja (La conducta ocurre como resultado de las condiciones ambientales concretas: selección por consecuencia) A través del control de estímulos o discriminación se pueden establecer relaciones condicionales entre estímulos los cuales consisten en la selección de un objeto en sus diferentes modalidades (señalar, nombrar, subrayar, etc.), en función de una petición específica, Müller, Pérez y Williams (2005). (Experimentación, al manipular instrucciones) Se ha demostrado que los niños normales pueden aprender relaciones condicionales entre estímulos mediante objetos desconocidos, en presencia de un objeto conocido, es decir mediante la exclusión. (Experimentación al manipular los objetos y ver su efecto en la enseñanza de las relaciones condicionales) Para facilitar la exclusión se hace uso de 
los instigadores, Skinner (1957) los definió como una forma de estimulación agregada a los estímulos discriminativos (SD) que aumentan la probabilidad de que se den las respuestas apropiadas cuando por factores de la naturaleza motivacional de control de estímulos hacen que la ejecución momentánea sea probable. (Experimentación al manipular variables, predicción y control para obtener un respuesta apropiada la usar los instigadores)..)

Tipo SB3. En la tercera y última variedad, el estudiante sólo transcribe una parte de su introducción sin ninguna explicación. A continuación se muestra un ejemplo o enunciado de los supuestos.

(GB) “...Dentro de la psicología existen diferentes conductas las cuales se encuentran bajo control de estímulos, Mayer y Sulzer (1983) plantean que se presenta cuando hay una gran probabilidad de que una respuesta particular suceda en presencia de un estímulo antecedente. A través del control de estímulos o discriminación se pueden establecer relaciones condicionales entre estímulos los cuales consisten en la selección de un objeto en sus diferentes modalidades (señalar, nombrar, subrayar, etc.), en función de una petición específica (Müller, Pérez y Williams, 2005). Se ha demostrado que los niños normales pueden aprender relaciones condicionales entre estímulos mediante objetos desconocidos, en presencia de un objeto conocido, es decir mediante la exclusión. Para facilitar la exclusión se hace uso de los instigadores, Skinner (1957) los definió como una forma de estimulación agregada a los estímulos discriminativos (SD) que aumentan la probabilidad de que se den las respuestas apropiadas cuando por factores de la naturaleza motivacional de control de estímulos hacen que la ejecución momentánea sea probable. Otra de las tareas para establecer relaciones condicionales es la tarea de igualación a la muestra, en esta se emplean dos tipos de estímulo, uno llamado estímulo muestra (EM) que es el que actúa como estímulo condicional para provocar una respuesta sobre los estímulos llamado de comparación (ECO) de entre los cuales se debe elegir uno que iguale al estímulo muestra con base en un criterio predeterminado..."

Unidad de Análisis. Son los elementos básicos que constituyen al objeto de conocimiento de una teoría dentro de una disciplina, y que han sido establecidos a través de un consenso. Es la materia prima del trabajo conceptual y metodológico. Se pueden identificar diversos niveles que van desde la definición de la variable dependiente hasta aspectos conceptuales, esto es, como variable dependiente, como categoría conceptual y como objeto de conocimiento.

Tipo UA1. En el primer grupo de análisis podemos ubicar al menos un caso, en donde el estudiante identifica y ejemplifica las tres modalidades de Unidad de Análisis: como variable dependiente, como categoría conceptual y como objeto de conocimiento.

(GA) “...Como se habrá observado a lo largo de la introducción se enfatiza la conducta de dislexia como problema de discriminación, por lo que podemos concluir que la conducta es la unidad de análisis en su modalidad categoría conceptual. Ahora bien como objeto de conocimiento la unidad de análisis es el comportamiento en general En este caso se presenta 
que el autor desea disminuir la conducta de dislexia en el niño de tal manera que la unidad de análisis como variable dependiente esta representada por la lectura, copia y dictado correctos dado que fue esta conducta la que trataron de lograr y mantener y que por tanto también midieron. En este trabajo de investigación se mencionan diversos conceptos tales como línea base, reforzador, instigadores, entrenamiento, desvanecimiento. En este sentido podemos señalar que la unidad de análisis como categoría conceptual es precisamente el concepto de discriminación y la tasa de respuestas correctas como unidad de análisis en su modalidad de variable dependiente..."

Tipo UA2. Un segundo caso está representado por los estudiantes que sólo identifican y ejemplifican una modalidad de Unidad de Análisis, específicamente como variable dependiente, señalando la conducta a medir o la medida utilizada.

(GM) "La unidad de análisis se presenta como las variables que los autores de manera explícita definieron para poder medirlas, las variables de interés fueron. El número de respuestas correctas (el participante señaló y nombró al mismo tiempo el estímulo que igualo a la muestra). Número de respuestas correctas en n nombramiento (el participante debía nombrar correctamente el estímulo que le presentaba el experimentador). Numero de respuestas correctas en señalar (el participante debía señalar el estímulo que igualara a la muestra)".

(GB) “...La unidad de análisis se presenta como variable dependiente ya que los autores de manera explícita definen y miden la variable de interés. $V \mathrm{D}$. Número de respuestas correctas el participante señaló y nombró correctamente el estimulo que igualó a la muestra)..."

(GB) “... La unidad de análisis en este estudio fue la conducta en términos generales, más específicamente, la conducta de clasificar, (discriminando) y secundariamente la conducta de hablar en voz baja..."

Tipo UA3. En este tercer grupo se ubican los análisis que muestran un total desconocimiento y confusión sobre la unidad de análisis.

(GM) “...Se tomó como VD el entrenamiento de exclusión que ocurre cuando se presenta 1 EM (estimulo muestra) y 4 ECO (estímulos comparativos) 3 conocidos y 1 desconocido; en tanto que el entrenamiento de selección se presenta cuando el EM y los ECO son desconocidos..."

(GA) “...Unidad de análisis: en este trabajo, lo que se pretende es el aumento en el mantenimiento de una tarea, así como en la atención que un niño emplea, siendo esto la unidad de análisis de este trabajo como variable dependiente, pues lo que se pretendía de estas conductas era su modificación, es decir que ambas aumentaran..." 
Estrategia del Autor. La estrategia del autor informa al lector del porqué y cómo se realizó el estudio, implica por una parte la presentación de argumentos, evidencias, justificaciones, condiciones, limitaciones, contradicciones, contrastaciones, etc., y por otra, la descripción de las decisiones metodológicas o estrategia metodológica utilizada, siendo las características más importantes las relacionadas con el diseño de investigación, las comparaciones, la manipulación experimental, el análisis de datos, el análisis estadístico, las definiciones, el procedimiento, el control de variables, el muestreo y la interpretación de resultados.

Tipo EA1. En una primera agrupación tenemos los análisis en donde los estudiantes describen el planteamiento del problema o justificación y los vinculan con la estrategia seguida, mencionando únicamente el diseño utilizado.

(GA) “... el estudio realizado por Mcllvane et. al., no se demostró cual de los dos e n tr e na mientos era mas eficaz para el aprendizaje de nuevas relaciones condicionales, por ello en el presente estudio se llevaron acabo de forma independiente ambos entrenamientos usando el diseño A- B-C, (A) línea base, (B) intervención y (C) pruebas de aprendizaje..”.

(GM) “...El presente estudio se realizó por que en el estudio de Mcllvane et. al., no se demostró cual de los dos entrenamientos era mas eficaz para el aprendizaje de nuevas relaciones condicionales, empleando los mismos entrenamiento pero de manera independiente usando el mismo diseño que ellos $\mathrm{ABC}$, utilizando reforzadores y trabajando con un número menor de participantes..."

(GB) “...El presente estudio se realizó por que en el estudio de Mcllvane et. al., no se demostró cual de los dos entrenamientos era mas eficaz para el aprendizaje de nuevas relaciones condicionales, por eso en este estudio se llevaron acabo de forma independiente usando el mismo diseño que ellos ABC..."

Tipo EA2. Tenemos el caso en donde se hace una descripción paso a paso de lo que implica la identificación de la estrategia del autor desde la identificación del objetivo hasta la descripción de resultados, pasando por la metodología y los resultados, sin señalar la relación necesaria entre cada elemento.

(GM) “...La estrategia del autor leer con cuidado todo el artículo e identificar justificación y los argumentos introductorios: ya redactados en justificación. Identificar el objetivo o propósito del estudio: El presente estudio evaluó los efectos de aplicar un reforzador grande demorado cuando a un niño se le asignó la tarea académica y un reforzador pequeño inmediato... Identificar la hipótesis que se pretende estudiar así como la posible relación que se busca entre ellas. Si a un niño diagnosticado previamente con TDAH, se le dan reforzadores pequeños inmediatos.... Identificar las variables que se pretenden estudiar así como la posible relación que se busca entre ellas. VD: mantenerse en la tarea y poner atención. VI reforzador pequeño inmediato cuando elige la tarea (dulces) y reforzador grande demorado cuando se le asig- 
na la tarea (juguetes); Identificar las variables definidas y medidas y en su caso la VI. La VD, se medirá mediante un registro de muestreo de tiempo, registrando sólo si la conducta ocurrió o no (porcentaje de intervalo); Identificar el diseño: en este estudio se empleo el diseño $\mathrm{N}=1$ tipo A-B- $\mathrm{C}$. Resultados más importantes: En línea base el porcentaje de intervalo fue bajo, en la fase de intervención este intervalo aumento y en desvanecimiento las conductas se presentaron con un porcentaje de intervalo regular... Argumentos que explican el por que de los hallazgos: podemos decir que el tratamiento fue efectivo al observar un aumento en el porcentaje de intervalo de las conductas ya mencionadas, esto debido al reforzador que le fue entregado al participante..."

Tipo EA3. Por otra parte, tenemos los análisis en donde los estudiantes transcriben el procedimiento de su trabajo incluidos los resultados y parte de la discusión, observándose una vinculación aparente entre ellos.

(GB) “...La presente investigación se realizó porque se quería conocer cuál de las técnicas para clasificar (que previamente se revisaron) era la más efectiva, para lo que se utilizó una replica de la investigación de Grote (1996), efectuando cambios en el diseño. Se utilizaron los tres componentes de dicha investigación pero se agregaron dos fases más, la primera fue una segunda fase experimental en la que, después de haber pasado por los tres componentes, los niños fueron sometidos a técnicas diferentes individualmente con el fin de que uno de los niños aprendiera la técnica del recordatorio, otro la de verbalizar en voz baja y el tercero permaneció como niño control. Lo anterior fue una condición que se modificó con respecto a la investigación de Grote. La segunda fase que se aumentó en el diseño fue la de generalización con el fin de conocer si con nuevos estímulos los niños realizaban la tarea tal como lo aprendieron en la segunda fase experimental. Con las modificaciones anteriores se logró conocer cual de las técnicas era la mejor, así mismo se pudo controlar las variables extrañas como la memorización al cambiar en las tres fases los estímulos a clasificar. Por otra parte, la manera en que se presentaron y analizaron los resultados resultó conveniente debido a que se puede apreciar la diferencia entre sujetos así como los efectos de las dos diferentes técnicas sobre la conducta de clasificar..."

Tipo EA4. En este caso tenemos un análisis muy extenso en escritura, pero sin la vinculación entre los elementos del escrito, es decir, entre la justificación, el objetivo, la manipulación de variables, fases, resultados, comparaciones entre fases, etc.

(GA) “...En el trabajo se presentan tanto los argumentos como la justificación de la realización del trabajo, en el caso de los argumentos se presentan los siguientes: En la literatura científica, se puede encontrar varios estudios que han evaluado, con diversas técnicas, el mantenimiento de tareas y la reducción de conductas impulsivas en niños con TDAH, tai es el caso del estudio realizado por Powell y Nelson (1997). La justificación que se da del por que realizar el estudio, es la de que estas dos técnicas han demostrado ser eficaces, sin embargo 
estas dos no se habían utilizado... En cuanto a la metodología, esta fue estructurada tomando en cuenta como y qué es lo que se iba a medir, el qué, son las conductas o la variable dependiente y el como fue anotar por día mediante un registro de muestreo de tiempo, si ocurrió o no la conducta... Otro de los aspectos es el diseño utilizado, la manipulación experimental, procedimiento, el control de variables, las comparaciones, análisis e interpretación de datos. En este caso el diseño utilizado fue un diseño A B A C.. El procedimiento es el siguiente: en el trabajo primero se realizo una fase de preevaluación, para diagnosticar correctamente al participante con TDAH.... Una vez realizadas las fases anteriores se dio inicio a la fase de línea base... Una vez que en esta fase se obtuvo una estabilidad en los datos se prosiguió a dar inicio a la fase de intervención....En la última fase que fue de desvanecimiento...Los resultados obtenidos fueron los esperados, el análisis de estos se hizo a partir de comparaciones entre las fases; el porcentaje obtenido en línea base de las conductas mantenerse en la tarea y poner atención ... en comparación con los datos obtenidos en la intervención, donde se alcanzó un porcentaje de hasta ..."

Tipo EA5. Finalmente, observamos los casos en donde únicamente se hace una transcripción del procedimiento seguido, así como, de los resultados obtenidos, sin explicación alguna. La presentación en todos los casos es muy extensa.

(GM) “...Una vez realizadas las fases anteriores se dio inicio a la fase de línea base la cual tuvo una duración de $30 \mathrm{~min}$. Se realizo con el fin de saber cual era el nivel de las conductas a medir (la atención y el mantenimiento) sin la intervención de la técnica o variable independiente. Una vez que en esta fase se obtuvo una estabilidad en los datos se prosiguió a dar inicio a la fase de intervención. Esta fase tuvo una duración de $30 \mathrm{~min}$. y el fin de esta fue observar lograr el aumento de las conductas de mantenerse en la tarea en la presencia de la técnica o la variable independiente. En esta fase se introdujo la técnica..."

Análisis de la Consistencia Interna y externa. Es la estructuración lógica de los componentes del planteamiento del problema, en donde, la justificación, los supuestos básicos, el objetivo, la hipótesis, la estrategia, los resultados y las conclusiones, se vinculan lógicamente de acuerdo a un marco conceptual. La consistencia externa implica la vinculación expresa que se realiza entre las propuestas y las conclusiones del planteamiento analizado, y los hallazgos aportados por otros estudios. También implica la descripción de las posibles aplicaciones de los hallazgos encontrados.

Tipo ACIE1. En esta categoría tenemos dos casos, en primer término, para la consistencia interna, cuyo análisis se caracterizó porque los estudiantes mencionan la vinculación entre el planteamiento del problema, la justificación, el objetivo, la estrategia y los resultados, todo bajo una explicación explícita. En el segundo, el análisis de la consistencia externa, los participantes juzgan y explican si esta está presente o no, a partir de las implicaciones prácticas del estudio y su vinculación con otros trabajos de investigación. 
(GA)“...Análisis de consistencia interna:: en esta se vincularon tanto el planteamiento del problema como la justificación indica que el estudio se realizó para utilizar en combinación las técnicas de selección o asignación de una tarea y la entrega de un reforzador pequeño inmediato y uno grande demorado para evaluar los efectos en el aumento del mantenimiento en una tarea, así como en la atención de un niño con TDAH, ya que ambas técnicas no habían sido usadas en conjunto, así como tampoco se había evaluado los efectos de estas en el aumento de la atención. Lo anterior va relacionado con el objetivo, pues precisamente este evaluaría dichos efectos de entregar un reforzador pequeño inmediato si el niño seleccionaba la tarea o de entregarle un reforzador grande demorado si a este le era asignada la tarea. Tanto la justificación, el planteamiento del problema y el objetivo se relacionan con la estrategia, ya que esta estuvo encaminada a demostrar una relación funcional entre la técnica o variable independiente y las conductas o variable dependiente, tal como se mencionó en la estrategia del autor. En cuanto a los resultados, estos se vinculan tanto al planteamiento, la justificación, el objetivo y la estrategia; pues nos dan a conocer que efectivamente se cumple el objetivo y la relación funcional entre las variables, es decir, que la técnica de entregar un reforzador pequeño inmediato cuando al niño se le asigna la tarea influye en el aumento tanto de la conducta de mantenerse en la tarea como en la atención en un niño con TDAH...."

(GA)“...Consistencia externa: las propuestas y conclusiones del planteamiento evaluado se vinculan con los argumentos y hallazgos de otros trabajos, pues en los trabajos ya citados, los resultados fueron que ambas técnicas, aunque por separado, han favorecido en el aumento del mantenimiento de una tarea en niños con TDAH, además en las conclusiones se menciona que los hallazgos de este trabajo pueden ser utilizados en otras actividades que no sean de tipo académico, como los quehaceres de la casa, en actividades deportivas o recreativas, así como además de favorecer el mantenimiento también favorece al aumento de la atención..."

(GB) “...Análisis de consistencia: Al analizar que la justificación del trabajo, es decir, no se habían comparado las diferentes técnicas, tiene validez con respecto al objetivo de conocer cual de ellas era la más efectiva, podemos decir que el trabajo tuvo una buena consistencia interna, pues también se utilizó un buen diseño estratégico a fin de alcanzar el objetivo, que se obtuvo al final de la investigación como lo arrojan los resultados al mostrarnos que la técnica más efectiva fue la de verbalizaciones en voz baja con respecto a la técnica de recordatorio y el niño control. Probablemente, esta diferencia entre técnicas, se debió a que a diferencia de la técnica de recordatorio, la técnica de verbalización en voz baja ayudó al participante a no tener dependencia al instigador, sino que, por medio de la auto-instrucción, le fue más fácil clasificar sin ninguna ayuda o instrucción, como lo era en la fase de generalización..."

(GB) "...Consistencia externa. Si existe hay consistencia externa en el trabajo ya que aunque no se retomen los trabajos citados en la introducción pueden tener consistencia externa porque los autores señalan en las conclusiones las posibles aplicaciones prácticas de los hallazgos..." 
Tipo ACIE2. Otro tipo de análisis encontrado es aquel en donde los estudiantes sólo señalan si existe o no consistencia interna o externa, mencionando algunos elementos memorísticos -como definiciones- pero sin ninguna explicación.

(GA) “...Consistencia interna: Existe consistencia interna ya que hay vinculación entre el planteamiento del problema, los argumentos de la justificación, el objetivo, las estrategias y los resultados..."

(GB) “...Consistencia interna: El trabajo si tiene consistencia interna ya que existe una coherencia entre el planteamiento del problema, el objetivo, los resultados y las conclusiones..."

Tipo ACIE3. En este caso, en el análisis hay una confusión acerca de ambos conceptos dadas las explicaciones y los textos de los que se derivan.

(GA)“...Lo señalado en la sección de resultados no nos permite identificar las posibles implicaciones que se dieron en el trabajo, por lo que podemos juzgar que no cuenta con consistencia externa, si se considera a esto último como un criterio para la evaluación de este punto..."

Tipo ACIE4. Por último, tenemos aquellos análisis en donde sólo se muestran copias textuales del trabajo original sin ninguna explicación.

(GB) “...Análisis de consistencia interna: El propósito principal del presente estudio, fue el de evaluar los efectos de los métodos: verbalizaciones en voz baja y recordatorios, sobre la adquisición de la habilidad de clasificar en la fase de generalización. Las técnicas empleadas dentro de la investigación, tenían la tarea de instigar el razonamiento en los participantes, para así lograr la correcta clasificación de los estímulos (figura,, marca y color)..."

Cursos de Acción Alternativos. Es una propuesta alterna o creativa para nuevos estudios, planteamientos o procedimientos experimentales. Dicha propuesta puede ser una replica, una variación metodológica o un planteamiento totalmente nuevo.

Tipo CAA1. Los usuarios mencionan la necesidad de hacer un nuevo estudio, indicando incluso las variables a manipular, evaluar o relacionar, sin embargo, no hay una justificación clara del por qué hacerla o esta es muy precaria.

(GA) “...Del presente estudio para corroborar se podría hacer una réplica de los entrenamientos de exclusión y selección se aplicarían a 3 grupos, en el primer grupo se aplicaría los dos entrenamientos de forma sucesiva, al segundo grupo la exclusión y al tercer grupo la selección, todos con sus respectivas pruebas para comprobar resultados..." 
(GB) “...Si en un futuro se quisiera hacer una repica de este estudio habría ciertas cosas a considerar para ser modificadas como son el tipo de sujetos ya que nosotros usamois niños sanos sin ninguna discapacidad mental y seria interesante saber cuales serian los resultados de este si los niños tuvieran alguna discapacidad, algo más podría ser que hubiera tres grupos al primero se le aplicar exclusión al segundo selección y al tercero los dos entrenamientos para así saber corno se comportan ante estas contingencias..."

Tipo CAA2. Los participantes mencionan la necesidad de hacer un nuevo estudio, mencionando incluso las variables a manipular, evaluar o relacionar, incluyendo una justificación.

(GM) “...Se puede seguir investigando más acerca de estos 2 entrenamientos aplicándolos por separado, ya que también se podría realizar con un número mayor de sujetos, utilizando 3 grupos en donde a uno se le aplique Jos dos entrenamientos juntos, a otro solo el entrenamiento de exclusión y al otro el entrenamiento de selección y así se haría una mejor comparación..."

(GB) “...En futuras investigaciones sería factible intentar trabajar con participantes que durante la línea base se encuentren en el mismo nivel para que las técnicas implementadas no se vean afectadas por el conocimiento previo, sin embargo, considero que las diferencias entre los sujetos con los cuales se trabajo en esta investigación no fue tan significante pues siempre entre sujetos existirá una diferencia pues no existen niños idénticos entre si..."

(GM) “...Con base es; los resultados obtenidos sugiero que se realice una réplica de este estudio con la finalidad de ampliar, corroborar y contrastar nuestros hallazgos con nuevas investigaciones pero con la modificación del número de participantes (aplicándose a 3) y el tipo de entrenamiento para cada uno. Al participaste 1 el entrenamiento de exclusión, al participante 2 selección y el participante 3 el entrenamiento de selección seguido al de exclusión tal como lo hicieran De Rose. Ferrari y Mcllvane (1993) en el aprendizaje de nuevas relaciones condicionales auditivo/visual evaluando el aprendizaje de cada uno de los participante..."

Tipo CAA3. Aquí ejemplificamos aquellos casos en los que los estudiantes sólo mencionan que harían una réplica, caracterizándose por ser un texto muy breve.

(GB) “... abre una puerta, para la realización de un estudio posterior, donde se deberán valorar y encontrar participantes, que cuenten con habilidades semejantes a la hora de clasificar..."

Tipo CAA4. Es un texto confuso ya que dan un argumento de otro elemento de la estrategia para hacer una variación metodológica.

(GB) “....En el estudio existe una relación entre la justificación, el objetivo, el diseño de investigación, los resultados y las conclusiones y por lo tanto la propuesta es una replica en donde 
se cambiara el sexo de los niños, también las letras utilizadas tenían nombres similares eso también pudo interferir y seria interesante conocer si se encontrarían los mismo resultados con otro tipo de estímulos..."

Conclusión propia. Es la presentación de una opinión personal o juicio de valor, respecto al trabajo revisado. Se pueden presentar argumentos y juicios que evalúan la importancia de la investigación, las implicaciones teóricas y prácticas, asimismo, el lector puede realizar una vinculación de los hallazgos del trabajo evaluado con otras investigaciones.

Tipo CP1. Se sintetiza el estudio mencionando el propósito de este, asimismo existe una interpretación de los resultados, finalmente se hace una propuesta metodológica para estudios posteriores.

(GA) “...Este procedimiento sirvió para enseñar discriminaciones a un niño de ocho años de edad, habiéndose de el uso de instigadores visuales, verbales y físicos, con un reforzador que hacia aumentar la conducta blanco. Puede concluirse que un procedimiento de discriminación combinando tras tipos de instigadores puede servir para enseñar discriminaciones mas acertadas en un corto tiempo con pocos errores a niños de ocho años de edad. Este estudio demostró que los niños con desarrollo normal pueden aprender discriminaciones en pocos ensayos y en un tiempo corto, esto sugiere que los niños se acoplan en una temprana edad a reeducar su conducta de discriminación específicamente sobre las letras b y d. Es necesario realizar investigación para conocer si este procedimiento puede ser reducido, si se demuestra que la omisión de algunas fases produce resultados semejantes a los presentados en este estudio. Asimismo, esta estrategia podría probarse con niños con mas temprana edad o en su defecto de mayor edad y así demostrar que sujetos con características diferentes a los participantes en este estudio, también pueden aprender la discriminación correctamente...?

Tipo CP2. Se sintetiza el estudio mencionando el propósito de este, asimismo, existe una interpretación de los resultados los cuales se relacionan con otros estudios.

(GA) “...los hallazgos de este estudio son importantes porque este aborda una tema que es de actualidad, como lo es el TDAH, nos da una técnica, la de entrega de un reforzador pequeño inmediato cuando el niño escoge la tarea a realizar, o entregar un reforzador grande demorado cuando al niño se le asigna la tarea a realizar, que puede ser de utilidad aumentar el mantenimiento en la tarea así como la atención, que puede representar para el niño un mejor desempeño escolar. Los resultados de este estudio se pueden comparar con los obtenidos tanto por Powell y Nelson (1997), así como por Binder, Dixon y Ghezzi (2000). Los primeros utilizaron la asignación y selección de la y los segundos con el mismo fin utilizaron la entrega de un reforzador pequeño inmediato y uno grande y demorado. Además de coincidir con los resultados de estos autores, el estudio demostró la eficacia de la combinación de las dos técnicas ya mencionadas para aumentar la atención..." 
(GM) “...Las pruebas muestran que el entrenamiento de selección es eficaz para la discriminación y el de exclusión para el nombramiento. Ambos participantes lograron aprender nuevas relaciones condicionales. Podemos concluir que tanto el entrenamiento de exclusión como el de selección son eficaces para el aprendizaje de nuevas relaciones condicionales auditivo/visual, estos hallazgos concuerdan con los expuestos por Mcllvane, Munson y Stoddard (1988) quienes trabajando sólo con el entrenamiento de exclusión, concluyeron se logró la discriminación y el nombramiento de nuevos estímulos, La diferencia entre ambos estudios es que en este además del entrenamiento de exclusión se aplicó selección, superando así el estudio de estos autores. Otro punto importante que mencionar es que no podemos decir que un entrenamiento sea mejor que otro, ya que la diferencia en el numero de errores en ambos no fue significativa, esto contradice a De Rose, Ferrari y Mcllvane (1993) quienes afirmaron que el entrenamiento de exclusión es más eficaz que el entrenamiento de selección en la enseñanza de nuevas relaciones condicionales auditivo/visual. Nosotras por el contrarío, podemos decir al respecto que ambos entrenamientos son eficaces en la enseñanza de nuevas relaciones condicionales auditivo/visual..."

Tipo CP3. Se describe lo mencionado en las conclusiones de los autores del estudio y además se hace una conclusión personal.

(GB) “...Se mencionaron los principales resultados, asimismo se hace referencia al objetivo y el autor realizo una vinculación del trabajo evaluado con estudios citados en la introducción, igualmente se mencionan las limitaciones del estudio. El presente estudio fue realizado con el propósito de avaluar el aprendizaje de nuevas relaciones condicionales entre estímulos empleando 2 entrenamientos: exclusión y selección individualmente, es decir al participante 1 se le aplico el entrenamiento de exclusión y al participante 2 el entrenamiento de selección. Los resultados obtenidos concuerdan con los reportados anteriormente por Mcllvane, Munson y Stoddard (1988) ya que en estos datos también se encontró que se pueden aprender nuevas relaciones condicionales mediante la exclusión. Estos resultados parecen indicar que ninguno de los dos entrenamientos es mejor que otro, sino que los dos son útiles para la enseñanza de nuevas relaciones condicionales y exclusión puede ser útil para el aprendizaje del nombramiento, por el contrario selección de acuerdo a este estudio puede emplearse para la enseñanza de discriminación empleando la tarea de igualación a la muestra..."

Tipo CP4. Se concluye sobre los efectos de la variable independiente, pudiendo o no mencionar los antecedentes del trabajo o algunos problemas metodológicos.

(GA) “...Finalmente los resultados de ambos entrenamientos no demuestran con claridad cuál de los dos es más eficaz para el aprendizaje de las relaciones condicionales auditivo/ visual, debido a que en los resultados de ambas pruebas existió una diferencia significativa, ya en el entrenamiento de exclusión tuvo mayor efecto sobre el nombramiento en comparación del entrenamiento de selección el cual tuvo mayor respuesta en discriminación..." 
(GB) “... Tomando como punto de partida el estudio de Ferrari, De Rose y Mdlvane (1993) en el cual los entrenamientos que llevaron acabo los hicieron de forma sucesiva, después de haber hecho la replica de su estudio se puede llegar a la conclusión de que la exclusión es mejor que la selección para el nombramiento sin embargo la selección es mejor para discriminar..."

(GB) “....en cuanto a te relación entre la auto-instrucción y la correcta clasificación, se puede afirmar que esta técnica es de gran ayuda, para instigar este razonamiento en niños preescolares de 5 años, logrando el número más alto de clasificaciones correctas al implementar esta técnica, sin necesidad de un instigador. Una de las limitantes de mayor relevancia en este estudio, es el hecho de que el participante 1 contaba desde el principio del estudio, con mejores habilidades al clasificar; al ser comparado con los participantes 2 y 3 , así pues, no se puede afirmar con certeza, que la mejoría en sus habilidades al clasificar, se puedan atribuir completamente, a la introducción de la variable Independiente..."

Tipo CP5. Sintetizan los resultados, los efectos de la variable independiente y se plantea una pregunta, así como las implicaciones del trabajo, pero sin una justificación clara.

(GM) “...Los resultados fueron que en ambos entrenamientos se obtuvo un mayor porcentaje en discriminación, el participante 2 logró mayor porcentaje que el participante 1, con una diferencia del $10 \%$. Por otro lado el participante 1 logró un mayor porcentaje de aciertos en nombramiento, en comparación al participante 2 con una diferencia del $8 \%$, como se puede observar las diferencias no son muy significativas. Con estos resultados podríamos llegar a la conclusión de que la exclusión es un poco más eficaz para el nombramiento y que por el contrario la selección es un poco mas eficaz para la discriminación, pero tomando en cuenta que a comparación del entrenamiento de exclusión en el entrenamiento de selección, se incito al participante presentándole el estimulo correcto mas grande en comparación a los demás estímulos, nos podríamos preguntar ¿Qué si esto fue lo que provoco que se lograra mayor porcentaje de aciertos en el entrenamiento de selección..."

Estos análisis muestran el aprendizaje de los participantes, usando como criterios las calificaciones obtenidas en el pretest y postest, así como los análisis de sus propios trabajos de investigación como indicador de la transferencia del aprendizaje.

\section{Conclusiones}

Los resultados del presente estudio demuestran la factibilidad de incluir las nuevas tecnologías en la enseñanza de habilidades relacionadas con la lectura y más concretamente, para el análisis de textos en su modalidad de artículos de revistas científicas. En primer término, es importante señalar algunas consideraciones respecto al diseño del sistema. Creemos que el haber tomado como punto de partida las reglas del diseño instruccional garantizó el aprendizaje de la estrategia, así 
como su transferencia. La definición de objetivos de aprendizaje, el tipo de conocimiento a adquirir (declarativo, conceptos, principios, etc.), la elaboración del análisis de tareas de las actividades y la evaluación del aprendizaje momento a momento, nos permitió una visión clara y precisa de lo que se esperaba aprendieran los estudiantes en cada uno de los módulos y al término del taller. Coincidimos con De la Orden (1990) cuando señala que cualquier sistema instruccional deberá contar dentro de sus componentes esenciales, con una base teórica que organice el conocimiento, defina la metodología para su desarrollo y dirija la toma de decisiones instruccionales relacionadas con herramientas y estrategias pedagógicas involucradas. Tanto De la Orden (1990) como Merril, Li y Jones (1991), asumen que el diseño instruccional permite generar y prescribir formas organizadas de enseñanza fundamentadas en principios teóricos subyacentes al cómo debe enseñarse en función del cómo se aprende, elementos presentes en la construcción del Laboratorio Virtual de Lectura Estratégica.

En este trabajo los participantes fueron capaces de identificar las definiciones de cada componente de la estrategia, así como su aplicación en un contexto diferente al entrenado, pero parecido al demandado en sus clases presenciales. Pero ¿qué elementos facilitaron el aprendizaje de la estrategia? Sin lugar a dudas fue el sistema de enseñanza desarrollado en todo su conjunto (LAVES). No podemos decir que fue un elemento en especial, puesto que en cada módulo existieron diversos componentes programados a partir de diferentes tipos o niveles de conocimiento o complejidad, iniciando con el conocimiento declarativo hasta el procedimiental. La presentación de una definición y su desglose permitió que el participante identificara las palabras clave de esta, lo que se vio favorecido en el momento en el que el usuario hacía clic en cada palabra. El mostrar ejemplos concretos derivados de la definición, llevaba de la mano al participante a identificar, si un fragmento de un artículo de investigación era o no un ejemplo del elemento que estaba siendo analizado. El examinar relaciones condicionales dentro de los textos, permitió a los usuarios identificar relaciones entre los elementos de un trabajo de investigación y en un momento posterior a establecer este mismo tipo de relaciones en otros trabajos analizados, p.ej., determinar las relaciones de dependencia entre la pregunta de investigación y las variables definidas, la pregunta de investigación y las condiciones experimentales a las que deberán someterse los participantes del estudio, entre otras. Finalmente, cuando hablamos de los procedimientos los participantes debían identificar cada uno de los pasos para llegar a la aplicación de un elemento de la estrategia.

De esta forma podemos decir que los ejemplos, las explicaciones y los ejercicios en conjunto, su pertinencia y cuidadosa selección, jugaron un papel determinante para que los participantes demostraran el aprendizaje de la estrategia y su transferencia.

Por otra parte, es importante señalar que el análisis puntual y detallado de las calificaciones en el pretest y postest, sugiere que los niveles de entrada jugaron un papel importante para el aprendizaje de la estrategia de análisis de textos. Esto quedó demostrado al encontrar que aquellos estudiantes que iniciaron con una puntuación media o relativamente alta, incrementaron sólo tres puntos en el postest. Sin embargo, aquellos participantes que en la preevaluación o pretest obtuvieron calificaciones bajas, mostraron un incremento de hasta 11 puntos, el cual fue significativo. La conclusión a la que podemos llegar con estas evidencias es que los estudiantes con habilidades incipientes o limitadas en el análisis de textos, fueron los más favorecidos, ya que al parecer lograron desarrollar estas habilidades a niveles semejantes a los de los usuarios que entran con dichas habili- 
dades más desarrolladas. Por otra parte, creemos que el efecto del taller sobre los participantes con puntuaciones altas en el pretest es tan sólo de ejercitación de aquellas habilidades ya adquiridas en otro momento.

Es importante resaltar dos consideraciones importantes, por un lado, la estrategia de análisis de textos científicos se relaciona con la habilidad genérica de lectura de textos científicos, pero no necesariamente con el análisis conceptual, aun cuando una parte de la estrategia incluye dicho análisis (Unidad de Análisis); por el otro, la estrategia propuesta por Santoyo (2001), tiene la bondad de que puede ser aplicada para analizar artículos de investigación en cualquier disciplina científica, esto obedece principalmente a que los trabajos de investigación publicados en revistas científicas tienen la misma estructura y parten de la misma visión acerca de cómo hacer investigación empírica, lo que la convierte en una estrategia con innumerables ventajas.

Como señalamos en la introducción de este trabajo, la transferencia ocurre cuando lo que se aprende en una situación facilita el aprendizaje o desempeño en otras situaciones, o como señala Wenzelburger (1987): “...la transferencia de aprendizaje ocurre cuando el aprender en un contexto determinado o con un conjunto de recursos, impacta en el rendimiento de otro contexto o con otros materiales..." (p.1).

La transferencia es importante porque supone que un alumno que ha realizado un proceso de transferencia ha sido capaz de aplicar el conocimiento adquirido a una situación novedosa, es decir, puede ponerlo en práctica, esto sin lugar a dudas es un indicador de que el estudiante realmente aprendió.

En el caso específico que nos ocupa las preguntas que se tratarian de responder fueron: 1) ¿las calificaciones obtenidas en el postest reflejan en realidad las habilidades y conocimientos aprendidos en el Laboratorio (LAVLES)? y, 2) ¿qué información valiosa proporciona la evaluación de habilidades, lo más parecida a situaciones reales? Estas preguntas fueron respondidas con la información obtenida a través de los informes de los participantes y análisis que los estudiantes hicieron de sus propios reportes de investigación entregados.

Dicho análisis mostró que aun cuando los estudiantes obtuvieron calificaciones altas en el postest, estas son sólo un indicador de todo el conjunto de habilidades adquiridas por su paso en el Laboratorio. De esta forma, consideramos que la evaluación de sus propios trabajos reflejaría de manera más objetiva las habilidades desarrolladas y, por tanto, la transferencia del aprendizaje. En primer término, porque el análisis solicitado implicó un proceso de reflexión exhaustivo, el cual debía ser plasmado o desarrollado en un escrito -habilidad más compleja que la de seleccionar opciones en las evaluaciones- y en segundo término, porque no se encontraron diferencias cualitativas entre los grupos (Alto, Medio y Bajo), ya que no se observó un patrón en el cual se concentraran los análisis de un grupo en particular, todos los análisis sin importar el grupo de procedencia se ubicaron en cualquiera de las categorías. Es importante señalar que los primeros casos de cada categoría general son los mejores análisis y aquí pudimos ubicar a participantes de los tres grupos, lo que sugiere que no importa si a través del LAVLES se adquirieron nuevas habilidades o simplemente se afinaron o ejercitaron, estas podrán transferirse de manera eficiente a una situación diferente a la entrenada, indicador de que el aprendizaje fue transferido. No obstante, esta afirmación puede ser cuestionada dada la muestra tan pequeña de los reportes analizados. 
Cabe hacer notar que no todos los participantes -que entregaron su reporte-, transfirieron las habilidades adquiridas en el Laboratorio, como es el caso de los estudiantes que únicamente transcribieron extractos de sus trabajos, y aun cuando nuestra evaluación sugería que había alguna correspondencia con el elemento de la estrategia referido, no existía argumentación alguna al respecto, es obvio que en estos casos no hay indicios de transferencia.

Todos estos resultados en conjunto muestran la importancia de tomar diferentes medidas para la evaluación del aprendizaje, como lo son las medidas directas, transformadas en bases eficientes, las cuales permitieron recolectar diversos datos. Sin embargo, existe la necesidad de complementar dicha información con aquellas que se pueden obtener enfrentando a los usuarios a situaciones más reales con el fin de evaluar la transferencia del aprendizaje y que en este caso fueron más de tipo cualitativo. La manera de proceder en este trabajo, es un ejemplo de la necesidad de buscar nuevas estrategias de evaluación del aprendizaje, coincidimos con Lavié (1999) cuando señala que el uso de las nuevas tecnologías en la educación también nos lleva a pensar en nuevas estrategias de evaluación del aprendizaje.

\section{Referencias}

Alarcón, P.L., \& Fernández, P.J. (2006). La lectura crítica como herramienta básica en la educación superior. Revista Graffylia, 6, 46-55. Recuperado de http://www.filosofia.buap.mx/ Graffylia/6/46.pdf

American Society of Plant Biologist (2013). ¿What is a scientific paper? Recuperado de http://www. aspb.org

Argudín, Y., \& Luna, M. (1994). Habilidades de lectura a nivel superior. Sinéctica, 5. Recuperado de http://ixil.izt.uam.mx/pd/lib/exe/fetch.php/trimestre0:referencias:habilidades_lec_nivel_ superior.pdf

Bransford, J.D., Brown, A.L., \& Cocking, R.R. (2000). Learning and transfer. In L. Bransford, A. Brown, \& R. Cocking (Eds.), How people learn: brain, mind, experience, and school (pp. 5178). Washington, DC: National Academy Press.

Burke, L., \& Hutchins, H. (2007). Training transfer: an integrative literature review. Human Resource Development Review, 6 (3), 263-296. http://doi.org/10.1177/1534484307303035

Campbell, D., \& Stanley, J. (1978). Diseño experimentales y cuasiexperimentales en la investigación social. Buenos Aires: Amorrortu Editores.

Carlino, P. (2002). ¿Quién debe ocuparse de enseñar a leer y a escribir en la universidad? Tutorías, simulacros de examen y síntesis de clases en las humanidades. Lectura y Vida: Revista Latinoamericana de Lectura, 23 (1), 6-14.

Cepeda, M.L., López, M.R., \& Santoyo, C. (2009, Septiembre). Réplica de una estrategia de análisis de textos científico en estudiantes Universitarios de primer ingreso. Ponencia presentada en el X Congreso Nacional de Investigación Educativa, Veracruz: World Trade Center Veracruz.

Day, R. (1998). How to write and publish a scientific paper. Phoenix: ORYX PRESS.

De la Orden, A. (1990). Del plan curricular al diseño de instrucción. Bordón, 42 (3), 247-255. 
Erickson, B.L., Peters, C.B., \& Strommer, D.W. (2006). Teaching first-year college students. San Francisco: CA Jossey-Bass.

Espinoza, J., Santoyo, C., \& Colmenares, L. (2010). Mejoramiento de habilidades de análisis estratégico de textos en estudiantes universitarios. Revista Mexicana de Análisis de la Conducta, 36 (1), 65-86.

Estienne, V., \& Carlino, P. (2004). Leer en la universidad: aprender y enseñar una cultura nueva. UNI-PLURINERSIDAD, 4 (3).

Fregoso, G. (2009). 40 años de aportes desde la investigación y la intervención didáctica para caracterizar el problema con la lectura en la educación formal. Cuadernos de Educación y Desarrollo, 1 (5), Recuperado de http://www.eumed.net/rev/ced/05/gfp.htm

Graham (s.f.). A guide to reading and analysing academic articles. Recuperado de https://es.scribd. com/document/310482956/Article-Readingguide

Hermida, J. (2009). The importance of teaching academic reading skills in first year university courses. The International Journal of Research and Review, 3, 20-36.

Hernández, C., Rodríguez, N., \& Vargas, A. (2012). Los hábitos de estudio y motivación para el aprendizaje de los alumnos en tres carreras de ingeniería. Revista de Educación Superior, XLI(3-163), 67-87. Recuperado de http://www.scielo.org.mx/pdf/resu/v41n163/v41n163a3. pdf

Kando, N. (1997, April). Text-level structure of research papers: implications for text-based information processing system. Ponencia presentada en 19th Annual BCS-IRSG Colloquium on IR Research, Aberdeen: Scotland.

Lavié, J.M. (1999, Septiembre). La evaluación del aprendizaje a través de Internet. Presentado en EDUTEC. Nuevas tecnologías en la formación flexible y a distancia. Sevilla: Universidad de Sevilla.

Madooei, A. (s.f.). The art of reading research paper. Manuscrito inédito School of Computing Science, Simon Fraser University, Canada.

Merril, M.D., Li, Z., \& Jones, M.K. (1991). Instructional transaction theory: and introduction. Educational Thechnology, 31 (6), 7-12.

Miholic, V. (1994). An inventory to pique students' metacognitive awareness of reading strategies. Journal of Reading, 38 (2), 84-86.

Norris, S., Philips, L., Smith, M., Guilbert, S., Stage, D., Baker, J., \& Weber, A. (2008). Learning to read scientific text: do elementary school comercial reading programs help? Science Education, 765-798. http://doi.org/10.1002/sce.20166

Peredo, M.A. (2001). Las habilidades de lectura y la escolaridad. Perfiles Educativos, XXIII (94), 5769.

Ramey, D. (1999, December). How to read a scientific paper. Presentado en Annual Convention of the AAEP. Albuquerque: Nuevo México.

Santoyo, C. (2001). Estrategias de avance en comprensión, análisis y evaluación de textos científicos y profesionales. En C. Santoyo (Comp.), Cuadernos de planeación de alternativas docentes, Volumen II. Aportaciones al estudio de la formación en habilidades metodológicas y profesionales en las Ciencias del Comportamiento (pp. 9-49). México: Universidad Nacional Autónoma de México. 
Stone, R. (2013). A teacher's guide to academic reading: focusing on the academic Reading demands of ELS learners. All Theses and Disertation. Paper 3882.

Subramanyam, R. (2013). Art of reading a journal article: methodically and effectively. Journal of Oral and Maxillofacial Pathology, 17 (1), 65-70. http://doi.org/10.4103/0973-029X.110733

Tenopir, C., \& King, D. (2004). Communication patterns of engineers. Hoboken, NJ: Wiley.

Tenopir, C., \& Volentine, R. (2012). The value scholarly reading in the life sciences. Ideas in Ecology and Evolution, 5, 63-73. http://doi.org/10.4033/iee.2012.5b.14.f

Varnhagen, C., \& Digdon, N. (2002). Helping student's reports of empirical research. Teaching of Psychology, 29 (2), 160-165.

Wenzelburger, E. (1987). La transferencia en el aprendizaje. Revista de Educación Superior, XV (1), 52-66.

Zarzosa, L. (1997). La lectura y escritura en una población universitaria. Enseñanza e Investigación en Psicología, 2 (1), 91-123.

Zarzosa, L. (2004). Relación entre nociones teóricas, entrenamiento y evaluación: el caso de la comprensión de textos. Revista electrónica de Psicología Iztacala, VII (4),109-128.

Zarzosa, L., Luna, D., De Parrés, T., \& Guarneros, E. (2007). Efectividad del uso de una interfaz para la lectura estratégica en estudiantes universitarios. Un estudio exploratorio. Revista Electrónica de Investigación Educativa, 9 (2). Recuperado de http://redie.uabc.mx/vol9no2/ contenido-zarzosa.html

Zarzosa, L., Moreno, D., \& Cepeda, M.L. (1998, Agosto). Estrategias de lectura de estudiantes universitarios. Ponencia presentada en el XVIII Coloquio Interno de Investigación de la Facultad de Estudios Superiores Iztacala, Tlalnepantla: Estado de México. 


\section{Anexo 1}

Características de los lectores superficiales (Stone, 2013)

1. Dificultades para comprender textos

2. Dificultades para integrar recursos

3. Confianza excesiva en las inferencias basadas en texto

4. Dificultades para entender el contenido y las estrategias

5. Problemas para encontrar un significado más allá significado literal

6. Se olvidan de cómo y qué leen

7. Memorizan información nueva o desconocida

8. Problemas para monitorear significados (lectura pasiva)

9. Uso poco frecuente de estrategias de lectura

10. Problemas para poner remedio a sus dificultades en la lectura

11. Confianza en las predicciones iniciales

12. Ven sus problemas de lectura como algo que no tiene remedio

13. Problemas para enfocarse en su propósito

14. Problemas para identificar las situaciones que afectan el monitoreo, la integración y la comprensión

15. Incompetencia

16. Tienen un vocabulario limitado

17. Problemas con el lenguaje formal o avanzado

18. Comprensión limitada -dado el vocabulario tan pobre que manejan-

19. Falta de experiencia

20. Desconocimiento de la estructura de los textos académicos

21. Dificultades para analizar la organización del texto

22. Dificultades para encontrar los significados implicados

23. Dificultades para entender los componentes de un texto

24. Limitada o nula interacción con el texto

25. No relacionan el texto con el conocimiento o experiencia previa

26. No relacionan la evidencia textual con conclusiones

27. No evalúan la lógica de un argumento

28. Ausencia de habilidades de pensamiento crítico

29. Uso y conocimiento de un número limitado de estrategias de lectura

30. Ausencia de habilidades nemotécnicas

31. Falta de autoconfianza

32. Problemas para responder preguntas de análisis, síntesis y evaluación

33. Dificultades para sintetizar textos

34. Dificultades para generalizar información 
35. Dificultades para comparar y discriminar diferentes ideas

36. Dificultades para estimar el valor de una teoría

37. Dificultades para estimar el valor de evidencia

38. Dificultades para identificar los significados o intenciones de un escritor

39. Dificultades para identificar la opinión de un escritor

40. Habilidades pobres o limitadas en el manejo de un diccionario

41. Poca fluidez en la lectura

42. Incapacidad para transferir conocimiento y habilidades a nuevos contextos

43. Dificultades para identificar las ideas principales

44. Dificultades para identificar señales contextuales 


\section{Anexo 2}

Representación de la estructura de un artículo científico (Kando, 1997).

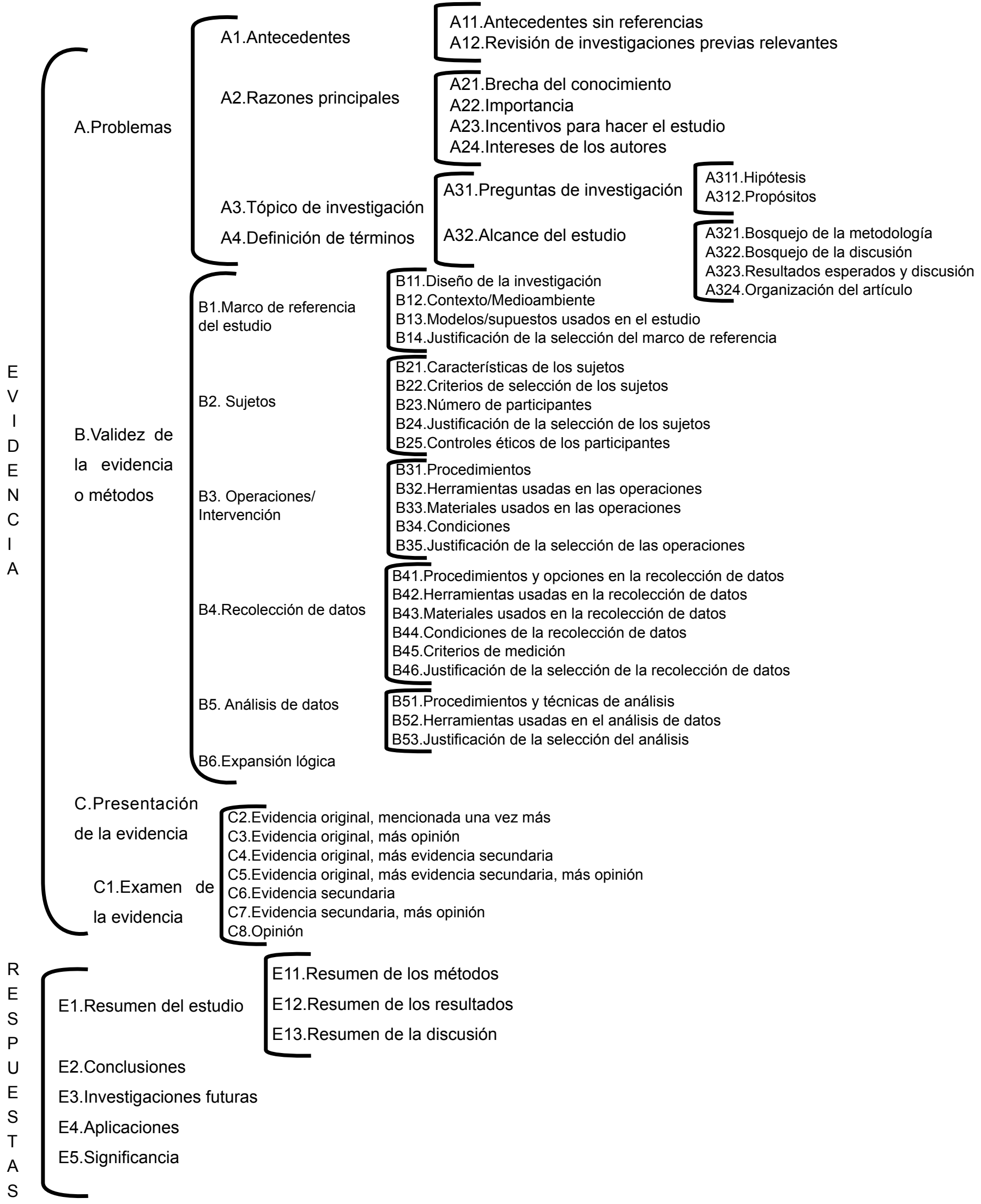




\section{Anexo 3}

Anatomía de un artículo científico

Tomado y modificado de American Society of Plant Biologist (2013) www.aspb.org

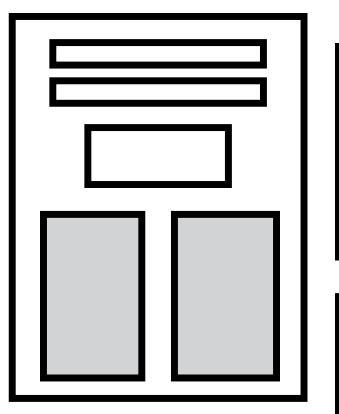

Título

Información de los autores

Resumen: Síntesis del estudio y de los hallazgos más importantes.

Introducción: Descripción del conocimiento existente y estudios realizados previamente sobre el tópico bajo estudio. Asimismo, se menciona el o los objetivos del estudio, por lo general están señalados al final de esta. En

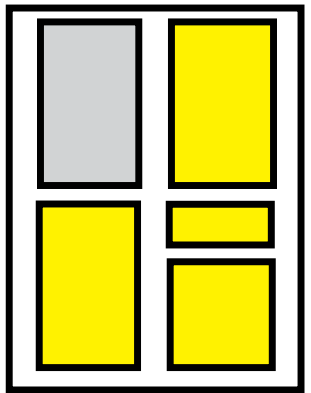
ocasiones se menciona la hipótesis que será probada.

Método: En esta sección los autores describen los detalles de cómo se llevó a cabo el estudio. Además de describir las características de los participantes, los materiales, aparatos herramientas e instrumentos utilizados, definición de las variables medidas y cómo se recolectaron los datos. El procedimiento es dividido en fases o condiciones, las cuales son etiquetadas según el área de conocimiento, diseño utilizado o tipo de estudio.
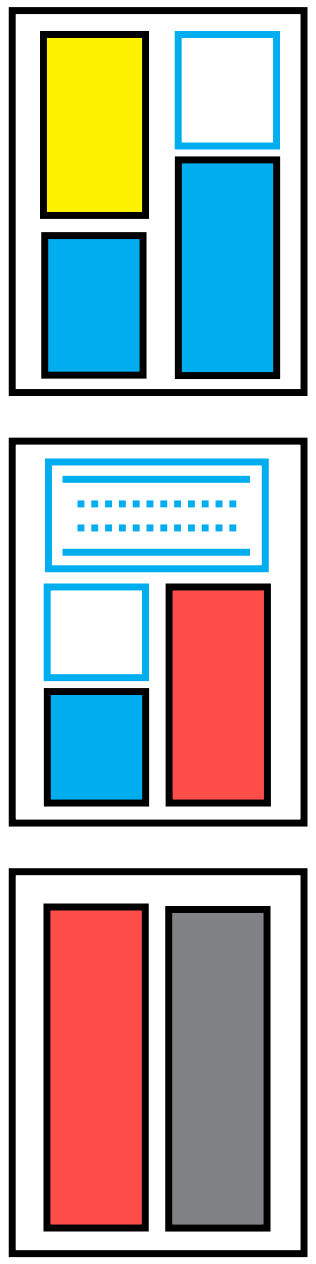

Resultados: Una de las partes más importantes de los estudios empíricos es la sección de resultados, en esta los autores del estudio dan los detalles de los resultados encontrados, generalmente estos son representados a través de tablas y figuras (gráficas). En esta sección los autores hacen un análisis detallado de los resultados apoyándose en análisis estadísticos, mismos que son justificados ampliamente y son representados con las notaciones correspondientes.

Discusión: Para algunos investigadores, esta es la parte más importante de un artículo científico ya que es aquí en donde los autores responden las preguntas de investigación que se plantearon, y el significado del análisis e interpretación de los datos presentados. Generalmente los resultados son comparados con otros estudios, las implicaciones del estudio, sus limitaciones, y las directrices para futuros estudios.

Referencias: Es la lista de todos los artículos, libros, etc., citados dentro del texto y que sirvieron de apoyo para justificar el estudio. Cabe destacar que los autores siguen el formato de campo disciplinar en cuestión (APA, Harvard, etc.). 


\section{Anexo 4}

Preguntas que el lector deberá responder en el análisis de un artículo de investigación, según Subramanyam (2013).

\begin{tabular}{|c|c|}
\hline Componente & Preguntas \\
\hline General & $\begin{array}{l}\text { 1.¿qué tipo de artículo es? } \\
2 \text { 2.¿cuál es el título? } \\
\text { 3.¿quiénes son los autores? }\end{array}$ \\
\hline Introducción & $\begin{array}{l}\text { 4.¿cuál es el problema de investigación? } \\
\text { 5.¿se mencionan algunos trabajos previos sobre el tópico? } \\
\text { 6.¿por qué el estudio se llevó a cabo? } \\
\text { 7.¿cuáles fueron los objetivos del estudio? } \\
\text { 8.¿cuál fue la hipótesis del estudio? }\end{array}$ \\
\hline $\begin{array}{l}\text { Materiales } \\
\text { y método }\end{array}$ & 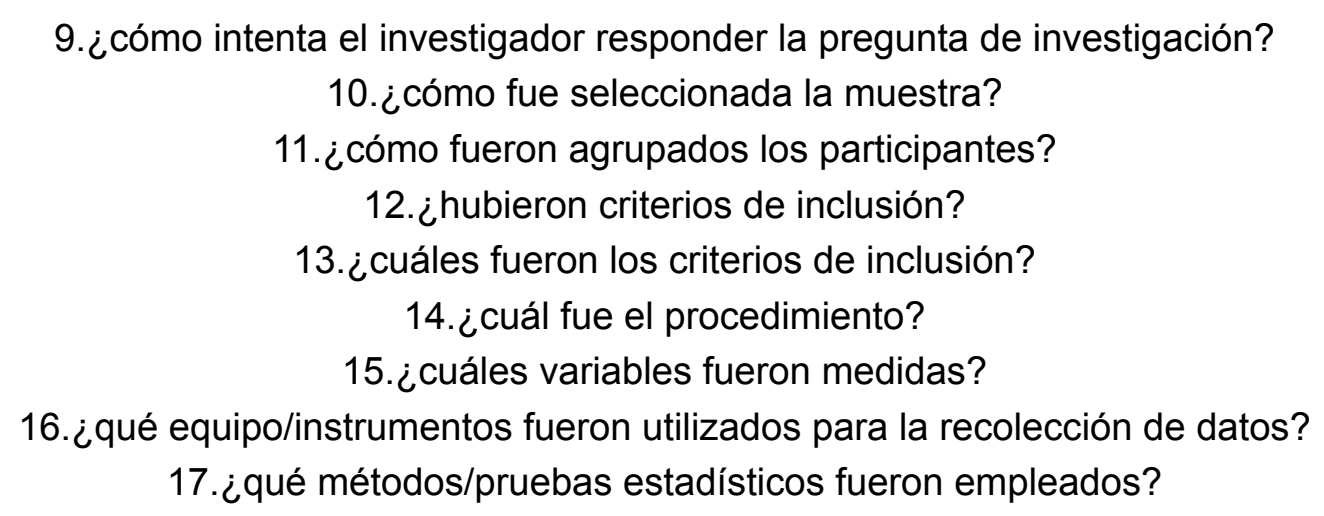 \\
\hline Resultados & 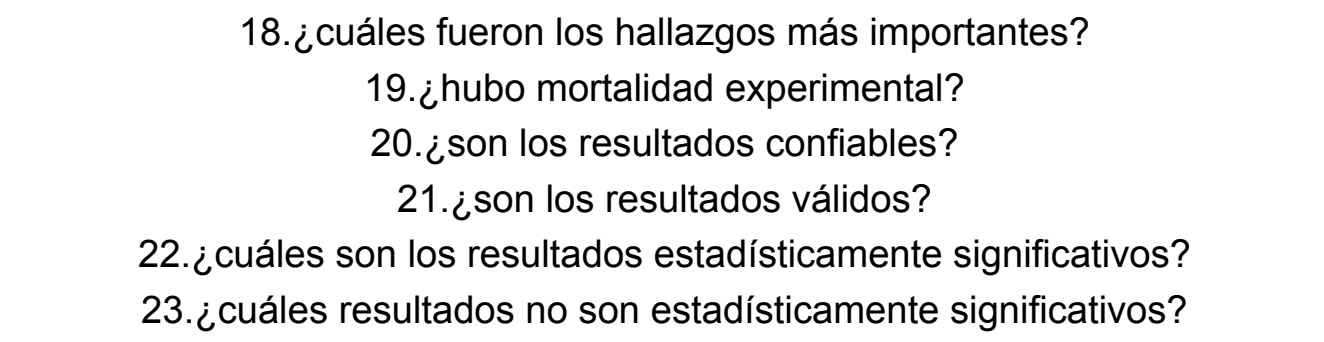 \\
\hline Discusión & $\begin{array}{l}\text { 25.¿los resultados responden la pregunta de investigación? } \\
26 . ¿ \text { ¿cuáles son las interpretaciones de los datos? } \\
27 . \text { ¿el análisis de los datos es pertinente a la pregunta de investigación? } \\
\text { 28.¿los resultados presentados son diferentes o semejantes a otros estudios } \\
\text { 29.¿cuáles son las fortalezas y limitaciones del estudio? } \\
\text { 30.¿hay alguna extrapolación de los hallazgos más allá del rango de datos? }\end{array}$ \\
\hline
\end{tabular}




\begin{tabular}{|c|c|}
\hline Conclusiones & $\begin{array}{c}\text { 31.¿cuáles son las conclusiones? } \\
\text { 32.¿las conclusiones se basan en los datos y análisis? } \\
\text { 33.¿son las conclusiones razonables y lógicas? } \\
\text { 34.¿los resultados son útiles en la práctica profesional? } \\
\text { 35. ¿el estudio valió la pena? } \\
\text { 36. ¿el lector tiene alguna pregunta que no haya sido respondida en el } \\
\text { artículo? }\end{array}$ \\
\hline Referencias & $\begin{array}{c}\text { 37. ¿son las referencias pertinentes a los requisitos de la revista en cuestión? } \\
\text { 38.¿todas las citas están escritas de manera correcta? } \\
\text { 39.¿todas las referencias citadas están en el texto? }\end{array}$ \\
\hline
\end{tabular}

Nota. En el $46 \%$ de las preguntas, están implicadas sólo respuestas dicotómicas Si/No. 


\section{Anexo 5}

Preguntas propuestas por Varnhagen y Digdon (2002).

1. ¿Quién hizo la investigación?

2. ¿Dónde fue publicada?

3. ¿Cuáles son las preguntas de investigación?

4. ¿Quiénes son los participantes en el estudio?

5. ¿Cuál es el diseño de la investigación?

6. ¿Cuáles son las medidas?

7. ¿Cuáles son los resultados más importantes del estudio?

8. ¿Cuáles son las conclusiones señaladas por los investigadores a partir de los resultados?
1. ¿De dónde surgen las preguntas de investigación?

2. ¿Es importante la investigación? Si/No, ¿por qué?

3. ¿Son los participantes apropiados para el estudio? Si/No, ¿Por qué?

4. ¿Es el diseño de investigación adecuado para responder a las preguntas de investigación? Si/No, ¿Por qué?

5. ¿Las medidas son apropiadas para dirigir las preguntas de investigación? Si/No, ¿Por qué?

6. ¿Qué consideraciones éticas son importantes y que hay que tener en cuenta?, ¿son todas ellas consideradas en el artículo? $\mathrm{Si} /$ No, ¿Por qué?

7. ¿Los resultados pueden usarse para responder a las preguntas de investigación? Si/No, ¿Por qué?

8. ¿Los resultados pueden generalizarse más allá del contexto del estudio? Si/No, ¿Por qué?

9. ¿Las conclusiones son importantes? Si/No, ¿Por qué? 


\section{Anexo 6}

Muestra las categorías de la estrategia propuesta por Santoyo (2001).

\begin{tabular}{|ll|}
\hline Categoría & Definición \\
\hline
\end{tabular}

Justificación de un trabajo de investigación

Enumeración o descripción de las causas, motivos o razones para hacer una cosa.

Objetivos de un trabajo de investigación

Propósitos o metas de un trabajo.

Aquél objeto o materia que no se expresa en

Supuestos básicos una proposición, pero es aquello que depende, o en qué consiste o se funda la verdad.

Unidad de análisis

Propiedades de todo fenómeno.

Estrategia de argumentación o presentación de

Estrategia del autor evidencia, limitaciones, falacias, contradicciones, contrastaciones, según el caso.

Análisis de la consistencia interna y externa

Confrontación lógica de la argumentación y el análisis de la consistencia.

Respuestas creativas de parte del lector, pro-

Cursos de acción alternativos posición de nuevos estudios, planteamientos o procedimientos de intervención.

Se trata de analizar y evaluar las resoluciones

Conclusión del autor tomadas sobre la materia luego de haberlas tratado.

Conclusión propia

Opinión personal o juicio de valor respecto al trabajo revisado. 
Anexo 7

Definiciones utilizadas y modificadas de la propuesta original de Santoyo (2001).

\begin{tabular}{|c|c|}
\hline Categoría & Definición \\
\hline Justificación & $\begin{array}{l}\text { "...es la presentación de argumentos teóricos, metodológicos o } \\
\text { sociales que expresan de manera explícita o implícita el por qué de } \\
\text { estudiar el problema..." }\end{array}$ \\
\hline Objetivo & $\begin{array}{l}\text { "...la expresión implícita o explícita de los propósitos de un trabajo que } \\
\text { se derivan lógicamente de los elementos introductorios de justificación } \\
\text { y los antecedentes del trabajo, generalmente describen una relación } \\
\text { entre variables..." }\end{array}$ \\
\hline Unidad de análisis & $\begin{array}{l}\text { “...son los elementos básicos que constituyen al objeto de conocimiento } \\
\text { de una teoría dentro de una disciplina, y que han sido establecidos a } \\
\text { través de un consenso. Es la materia prima del trabajo conceptual y } \\
\text { metodológico. Se pueden identificar diversos niveles que van desde } \\
\text { la definición de la variable dependiente, hasta aspectos conceptuales, } \\
\text { esto es, como variable dependiente, como categoría conceptual, } \\
\text { como objeto de conocimiento..." }\end{array}$ \\
\hline
\end{tabular}

Supuestos básicos

“...son los elementos conceptuales de una explicación a partir de aspectos de un modelo teórico que permiten ubicar los antecedentes y definiciones del fenómeno que se estudia..."

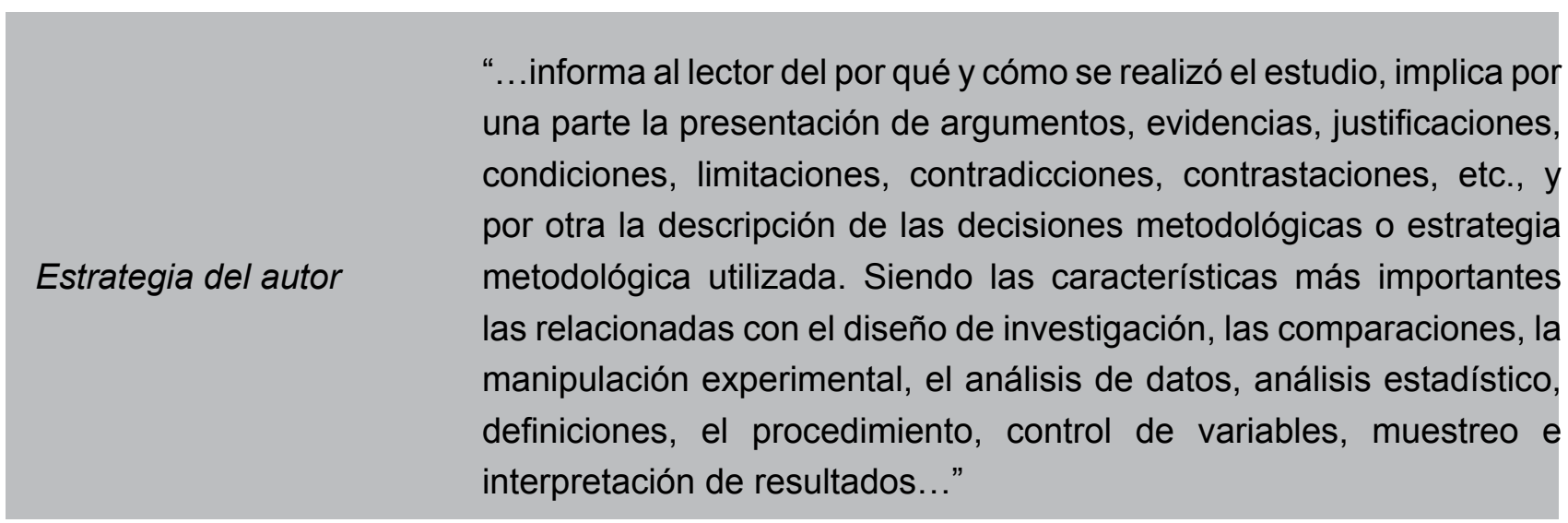

Consistencia externa

“...Es la presentación de argumentos y juicios que evalúan la importancia de la investigación, las implicaciones teóricas y prácticas, y la vinculación del trabajo con los resultados de otras investigaciones..." 
“...se refiere al análisis de la estructuración lógica de los componentes de un trabajo de investigación, es decir donde se vinculan lógicamente

Consistencia interna de acuerdo a un marco conceptual, el planteamiento del problema, la justificación, los supuestos básicos, el objetivo, las hipótesis, la estrategia, los resultados y las conclusiones..."

Conclusión

“...implica la vinculación expresa que se realiza entre las propuestas y las conclusiones del planteamiento analizado, con los argumentos y hallazgos aportados por otros. También implica la descripción de las posibles aplicaciones de los hallazgos encontrados..."

Cursos de acción alternativos
"...Es una propuesta alterna o creativa para nuevos estudios, planteamientos o procedimientos experimentales. Dicha propuesta puede ser una réplica, una variación metodológica o un planteamiento totalmente novedoso..." 


\section{Anexo 8}

Muestra un ejemplo del diseño instruccional en la construcción del LAVLES

\section{Consistencia Interna}

- Vinculación lógica de argumentos. Unión de las ideas o argumentos que se deducen unos de otros.

- Contrastación de argumentos. Enunciados en donde se muestran evidencias y su relación o no con los supuestos, hipótesis o problemas planteados en el trabajo de investigación.

- Justificación. Presentación de argumentos teóricos, metodológicos o sociales que expresan, ya sea de manera explícita o implícita, la importancia de estudiar el problema que se expone en un trabajo, así como las contribuciones que se tendrían al estudiarlo; esto es, el por qué de estudiar este problema.

\subsection{Conocimiento declarativo Objetivos}

1. Los alumnos localizarán la definición de análisis de la consistencia interna y externa (señalando, escogiendo o marcando un opción).

2. Los alumnos a partir de una serie de definiciones asignarán el nombre correspondiente a la categoría de análisis de la consistencia interna y externa.

3. Los alumnos identificarán los elementos críticos que componen la definición de análisis de la consistencia interna y externa.

4. Los alumnos identificarán una definición completa (con todas las proposiciones) del concepto de consistencia interna y externa.

\section{Actividades instruccionales}

Se deberá tener un banco de posibles definiciones, tratando de que se abarque un número considerable de definiciones del concepto de análisis de la consistencia interna y externa, de tal forma que el estudiante sea capaz de identificar la correcta. Primero se le presenta al alumno la definición, para después realizar algunos ejercicios que garanticen dicho conocimiento o identificación de la misma.

- Se mostrará la definición de la categoría con la etiqueta que lo identifica.

- Se mostrarán y enfatizarán las proposiciones clave dentro de la definición.

- Se mostrarán y enfatizarán los elementos no críticos.

- Se muestra una definición completa de la categoría.

- Se muestra una definición incompleta de la categoría.

\section{Ejercicios y evaluación}

- Se darán algunas definiciones de la categoría y el alumno deberá señalar si es verdadera o falsa dicha definición. 
- Se darán las definiciones y el alumno seleccionará la etiqueta correcta.

- Se presentarán definiciones alternativas y el alumno señalará la etiqueta correcta.

- Se le darán varias definiciones y el alumno clasificará cuáles corresponden y cuáles no, a la categoría.

- Se presentarán componentes críticos de la definición y el alumno los relacionará con su respectiva descripción. 


\section{Capítulo 7}

Efectos de las variaciones en los materiales de estudio y la retroalimentación sobre el modo lingüístico escribir

Karla Fabiola Acuña, Juan José Irigoyen y Miriam Yerith Jiménez 
Karla Fabiola Acuña karla.acuna@unison.mx

Juan José Irigoyen juanjose.irigoyen@unison.mx Miriam Yerith Jiménez miriam.jimenez@unison.mx

Seminario Interactum de Análisis del Comportamiento Universidad de Sonora Desiderio Ramírez Romero. 


\section{Capítulo 7}

\section{Efectos de las variaciones en los materiales de estudio y la retroalimentación sobre el modo lingüístico escribir}

Señalar la ausencia de habilidades y competencias de los estudiantes en relación con el aprendizaje de la ciencia, o enfatizar las graves deficiencias de la formación en este ámbito, sin generar los espacios de discusión teórica y de derivación tecnológica que evidencien las maneras idóneas del cómo enseñar y del cómo aprender, se considera una tarea infructuosa. En este sentido Benito (2009) señala que:

en los últimos años se ha instalado con especial énfasis el interés por indagar los motivos de la creciente crisis de la educación científica, manifestada en las dificultades de aprendizaje de los alumnos, quienes parecen aprender menos ciencia de la que se les enseña, a la vez que presentan menor interés por lo que aprenden. A ello se suma la sensación de frustración por parte de los docentes acerca del éxito de sus esfuerzos por la enseñanza de las ciencias (p. 28).

Una de las exigencias que el mundo contemporáneo le impone a las Instituciones de Educación Superior en lo que a ciencia y tecnología refiere es la formación de profesionales competentes, capaces de trabajar ante situaciones de cambio, de trabajo en equipo e interacciones mediadas por diversas tecnologías que también están en constante variación. La necesidad de auspiciar habilidades y competencias de innovación y de generación de conocimiento, no es una tarea que pueda abordarse desde una sola dimensión analítica, se ha discutido en otros espacios que responder a los desafíos que enfrenta la educación -científica y tecnológica- requiere de criterios administrativos, de gestión institucional, instruccionales, que permitan establecer un grado de correspondencia entre lo planeado como criterio normativo y las prácticas educativas cotidianas (Acuña, Irigoyen y Jiménez, 2011).

Reducir la brecha entre las exigencias impuestas por la Sociedad del Siglo XXI y la formación de los estudiantes en el ámbito científico y tecnológico, requiere de aproximaciones más coherentes teóricamente y más parsimoniosas metodológicamente, que permitan generar líneas de estudio, investigación e intervención para promover alternativas de abordaje en relación con los actores, las prácticas y los escenarios del ámbito de la educación.

En un intento por incidir en esta problemática, específicamente con propuestas vinculadas al proceso educativo; autores como Duart y Sangrà (2000) mencionan que se han formulado modelos 
de enseñanza-aprendizaje que incluyen el uso de las Tecnologías de la Información y la Comunicación (TIC). Los autores discuten tres modelos de la educación superior: modelos centrados en el estudiante, modelos centrados en el profesorado y modelos centrados en los medios.

Por su parte, Contreras (2009) sugiere que los modelos de enseñanza-aprendizaje establecen roles y dinámicas para los participantes del proceso educativo (profesores y alumnos), centrándose básicamente en el rol asignado al estudiante en el proceso de aprendizaje; la autora agrupa los modelos de enseñanza en pasivos y activos. Para la autora, el modelo pasivo es aquel que se lleva a cabo por parte del profesor mostrando este un papel transmisor de conocimientos. En este modelo es importante contar con los materiales educativos adecuados para promover el aprendizaje de los estudiantes y para el cumplimiento de los objetivos educativos. En el modelo activo, los materiales están principalmente enfocados hacia el proceso de aprendizaje donde el alumno es quien los manipula y utiliza directamente, permitiéndole al alumno trabajar, investigar, descubrir y construir los objetos de conocimiento.

No obstante, centrar la actividad en alguno de los actores o factores del proceso educativo ha sido cuestionado por autores como Carretero (2000) e Ibáñez (2007), siendo necesaria la consideración de todos y cada uno de los factores que participan en una situación de enseñanza-aprendizaje, con el fin de generar las circunstancias propicias que posibilitan el aprendizaje del estudiante. Un dato importante es que en los modelos anteriores no se menciona ni el objetivo instruccional ni el área de conocimiento que se enseña-aprende, lo cual se considera un elemento de suma relevancia, ya que es el elemento que le otorga sentido de pertinencia al hacer tanto del profesor como del estudiante.

Moreno (1990) advierte en relación a esto que no es posible hablar de una relación entre sujetos o actores como algo independiente de lo que se enseña-aprende, ya que estos cobran sentido como práctica social:

el conocer y los conocimientos que la Educación suponen no se dan en el vacío; son actos, procesos o resultados de individuos concretos. Parece por tanto que la interacción mutua entre individuo-medio resulta ser la mejor forma de representar lo que el conocimiento y el conocer significan (pp. 21 y 23).

A diferencia de los modelos antes mencionados, la propuesta de Interacción Didáctica enfatiza de igual manera a los factores participantes en la interacción de enseñanza-aprendizaje. Todos los factores son sincrónicamente necesarios en la configuración del episodio de interacción. Dicho modelo representa una propuesta teórica y metodológica bajo una lógica de campo que permite analizar las variables relevantes en las interacciones docente-estudiante-materiales de estudio (Carpio e Irigoyen, 2005; Irigoyen, Acuña y Jiménez, 2011; Irigoyen, Jiménez y Acuña, 2007).

La propuesta se caracteriza por una noción de causalidad interdependiente en tiempo sincrónico, en su aplicación al proceso educativo implicaría la consideración de factores como: ámbito disciplinar, objetivo instruccional, profesor, estudiante y materiales de estudio. En palabras de Hayes (1994): 
un campo multifactorial describe un evento psicológico en un punto particular del tiempo, específicamente en el momento presente. Todos los factores que se describen como participantes en un campo Interconductual, intervienen en el momento presente, ninguno de ellos participa en mayor o menor extensión que el otro (p. 113).

Esta propuesta modelar de interfaz para el análisis del proceso educativo, ha permitido caracterizar las variables que probabilizan el aprendizaje de la ciencia; los estudios particularmente se han realizado en el ámbito de la ciencia psicológica. La propuesta ha posibilitado:

- Analizar la relación profesor-estudiante. Los resultados indican que las maneras de mediar instruccionalmente por los profesores tienen un efecto en cómo el estudiante establece contacto con los materiales de estudio y los criterios disciplinares. Las modalidades más utilizadas son las discursivas-expositivas dejando a un lado modalidades más variantes y acordes al tipo de habilidades que se establecen (sean estas de corte conceptual o procedimental) Irigoyen, Jiménez y Acuña (2004).

- $\quad$ Analizar la interacción profesor-materiales de estudio. Los resultados señalan que no existe correspondencia entre el decir y hacer del profesor en términos de la planeación y su implementación en lo que ha enseñanza, aprendizaje y evaluación refiere (Acuña, Irigoyen y Jiménez, 2009).

- $\quad$ Analizar la relación estudiante-materiales de estudio. Los resultados muestran que la modalidad en la que se presenta el material tiene un efecto en el desempeño ante el tipo de tarea solicitada y la modalidad lingüística implicada -observar, escuchar, leer, señalar, hablar, escribir- (Acuña, Irigoyen y Jiménez, 2013; Irigoyen, Acuña y Jiménez, 2015).

\section{Aprendizaje de la ciencia y lenguaje}

En el contexto de la enseñanza-aprendizaje de la ciencia, las distintas situaciones de aprendizaje explicitan cierto tipo de desempeños lingüísticos que idealmente se corresponden o deberán corresponderse funcionalmente con diferentes situaciones, como juegos de lenguaje.

Ribes, Cortés y Moreno (1992) encontraron en el concepto de juego de lenguaje de Wittgenstein (1953) algunos puntos de apoyo para caracterizar las prácticas lingüísticas como prácticas sociales, en las cuales es posible incluir las de la práctica científica. Con base en los planteamientos de Wittgenstein, los autores sostienen que el lenguaje enmarca toda la conducta humana y que es imposible pensar en una actividad humana que se realice al margen del lenguaje. Los autores identifican tres dimensiones en las que el lenguaje tiene lugar, se origina y otorga sentido como práctica individual:

A. El lenguaje como medio, el cual está instaurado en la convención como criterio normativo, en donde la conducta humana se vuelve significativa para y a través de los otros. Aprender el lenguaje es aprender sus distintos modos de ocurrencia, estos modos a decir de autores como Fuentes y Ribes (2001); Varela (2004); Gómez y Ribes (2008) pueden ser de naturaleza reactiva (observar, escuchar, leer) o activa (señalar, hablar, escribir). 
B. El lenguaje como instrumento, implica que necesariamente hay una afectación en la conducta de los otros, sea directa o indirectamente, de tal manera que el lenguaje se convierte en la herramienta para caracterizar los usos efectivos y pertinentes del decir y del hacer, y

C. El lenguaje como límite y circunstancia, tiene que ver con el dominio práctico en el que la conducta de los individuos se significa, así como las posibilidades de trascender partiendo de la situacionalidad como respuestas a las dimensiones y propiedades fisicoquímicas de los eventos, hasta lograr en un momento dado la generación de nuevos criterios.

Por su parte Pérez-Almonacid y Quiroga (2010), plantean que hay dos formas de concebir al lenguaje (como sistema lingüístico): como producto y como práctica. El lenguaje como producto ha sido el campo de interés de la denominada Psicolingüística en la cual se analizan los productos de las interacciones lingüísticas de los individuos y de los grupos de acuerdo con los "estilos", es decir, con base en el patrón de convenciones sociales o individuales, identificados en los productos del lenguaje: textos, grabaciones, códigos, transcripciones, entre otros. En tanto práctica o actividad, el lenguaje se ha estudiado como el aspecto pragmático y, por ende, ha centrado el análisis en los usos lingüísticos: qué se "dice", en qué condiciones, con qué resultados, de qué manera, etc.

Esta distinción que hacen los autores está basada en la diferenciación que hace Kantor (1936) entre lenguaje muerto y lenguaje vivo. El primero tiene que ver con los productos y vestigios del lenguaje, por ejemplo, registros diversos como textos, códices, grabaciones, etc. El segundo tiene que ver con la práctica lingüística como acto individual, ya sea mediante el habla, la escritura o cualquier otra modalidad lingüística.

Así entonces, en lo que toca a la Psicología como la disciplina encargada del análisis funcional del comportamiento del individuo con respecto a aspectos específicos del medio, su tarea estaría relacionada con estudiar las dimensiones individuales e interactivas del lenguaje como práctica y como sistema de relaciones prácticas.

El lenguaje como práctica es la propuesta a la que nos apegamos en el presente manuscrito, es decir, el lenguaje concebido como interacciones lingüísticas (entre un referidor -el que habla o escribe-, un referido -a quien se le habla o escribe- y un referente -de lo que se habla o se escribe-) dentro de un contexto social particular, lo cual permite analizar cómo se adquieren, se ejercitan y se transforman las dimensiones morfológicas y funcionales de tales repertorios convencionales (Acuña, et al., 2013; Mares, 2001; Pacheco y Villa, 2005; Ríos-Checa, 2011).

Lo que define entonces al lenguaje, recuperando la noción de campo psicológico, es la circunstancia interactiva de la situación en la que tiene lugar, lo que se dice o se hace, es decir, qué es lo que se habla, se lee o se escribe, de qué manera y en qué condiciones o circunstancias tiene lugar dicho comportamiento. Bajo estos supuestos, es importante la consideración de las diferentes modalidades lingüísticas y cómo estas pueden otorgarse complementariedad (p.ej. hablar para posteriormente escribir, leer para después escribir, observar-escuchar para después hablar y escribir, escribir para posteriormente hablar, entre otros), permitiendo así, analizar todos y cada uno de los elementos que configuran un episodio y episodios subsecuentes, como sistemas de relaciones entre personas con respecto a otras personas y objetos-eventos del medio. 
Para Ribes et al. (1992) citando a Wittgenstein (1953) señalan que: "Aún cuando el lenguaje ocurre siempre en una acción (escribir, leer, hablar, gesticular, etc.) es algo más que acciones con una morfología especial. Es "...la totalidad, constituida por el lenguaje y las acciones con las que está enlazado” (p. 67). Al respecto, Pérez-Almonacid y Quiroga (2010) comentan:

ninguna morfología de respuesta es en sí misma definitoria. Así mismo, esto llega a marginar la relevancia de diferenciar los modos lingüísticos, pues son asumidos como morfologías que cumplen una misma función, entendida esta como un mismo efecto ambiental. Tal marginación implica el desconocimiento de las peculiaridades y posibilitaciones conductuales de los diferentes modos, que se asocian con la riqueza de la conducta humana (p. 63).

Bajo esta lógica, el lenguaje abarca el ambiente, las costumbres y prácticas, las palabras y su estructuración como discurso y estructura, y la conducta global que tiene lugar como una forma de vida. Tomasini (1994) señala en este sentido que: "Compartir una forma de vida es concebir las cosas de la misma manera, describir el mundo con el mismo aparato conceptual, sentir los mismos tipos de presiones sociales, tener los mismos valores, etc." (p. 111). De esta manera, el análisis del lenguaje y su aprendizaje debe considerar cómo se desarrolla la reactividad diferencial respecto a las acciones de otras personas y de los objetos en circunstancias específicas, es decir, cómo es que los individuos llegan a establecer la integración de eventos con morfología verbal y no verbal en su interacción con otros individuos.

Por ello, la recuperación de las modalidades lingüísticas en el análisis del aprendizaje de la ciencia se torna relevante, ya que posibilita caracterizar cuál es la modalidad de presentación de los materiales de estudio, así como el modo lingüístico implicado y su efecto facilitador ${ }^{1}$ o habilitador en los diferentes episodios didácticos, con el propósito de generar las condiciones idóneas para una enseñanza de la ciencia más efectiva y un contacto más pertinente del estudiante con respecto a los criterios que la disciplina de conocimiento le prescribe.

\section{La escritura como modo lingüístico}

Líneas arriba se enfatizaba que el comportamiento humano tiene lugar en la forma de lenguaje, a partir del lenguaje y solamente es posible entenderlo en un medio dado por el lenguaje. De tal manera que lo que se enseña-aprende en la práctica científica, son las maneras y los usos de lenguaje que cada disciplina prescribe, como modos lingüísticos.

El modo lingüístico es una categoría que hace referencia a la forma en que ocurre la respuesta en su dimensión lingüística. Como se mencionó anteriormente, estos modos lingüísticos han sido divididos para motivos de análisis en: a) modos reactivos (observar, escuchar y leer) y b) activos (señalar/gesticular, hablar y escribir). Gómez, Zepeta, García y Molina (2015) suponen que las respuestas de naturaleza lingüística ocurren en distintos modos que, dada su morfología arbitraria, se

1 Este fenómeno ha sido analizado como translatividad, el cual consiste en un efecto de facilitación de lo aprendido en un modo lingüístico, sobre un modo nuevo de ocurrencia; depende de la facilidad de adquisición del comportamiento en el modo precedente (Gómez y Ribes, 2008). 
adquieren inicialmente como tres modos complementarios reactivos y activos: observar-gesticular/ señalar; escuchar-hablar; y leer-escribir. La adquisición de los modos reactivos antecede a la de los activos y es necesaria para retroalimentar la precisión y eficacia de los modos activos. Bajo estos supuestos los modos lingüísticos se han estudiado experimentalmente utilizando primordialmente preparaciones de igualación a la muestra empleando distintos tipos de instancias, pero particularmente estímulos que consisten en figuras geométricas. Sin pretender ser exhaustivos algunos de los estudios realizados en esta dirección han sido los de Varela, et al. (2001); Camacho, Irigoyen, Gómez, Jiménez y Acuña (2007); Gómez y Ribes (2008, 2014); Gómez, et al. (2015); Quiroga, Peña y Padilla (2013).

La relación entre las modalidades lingüísticas ha sido abordada por distintas perspectivas teóricas (Vygoskty, 1979; Bereiter \& Scardamalia, 1987; Dockrell \& Connelly, 2009; Shanahan, 2006; Mares, 2001; Pacheco, Ramírez, Palestina y Salazar, 2007).

Basándose en la propuesta de campo (Kantor \& Smith, 1975) y la propuesta de Teoría de la Conducta (Ribes y López, 1985), en México se ha realizado investigación sobre el desarrollo del lenguaje en la modalidad lingüística hablar y escribir en niños escolares, particularmente en términos de la ubicación espacio-temporal del escucha, la familiaridad con este, la gramática y el estilo; así como la familiaridad y complejidad de los contenidos (Mares, Ribes y Rueda, 1993; Mares, Rueda y Luna, 1990).

Mares (2001) elaboró una propuesta para analizar el desarrollo lingüístico, la cual le ha permitido examinar a partir de diversos estudios experimentales con niños que inician educación primaria, cómo ocurre el aprendizaje de nuevas morfologías lingüísticas y el dominio de contenidos al cambiar de la modalidad lingüística hablar a la de escribir. En sus estudios (Mares, et al., 1993) han subrayado la importancia que tienen las condiciones en las que se aprende una determinada habilidad y las morfologías reactivas involucradas en esta como factores que posibilitan su transferencia a situaciones novedosas.

Mares (2008) identifica que entre la modalidad lingüística de hablar y la de escribir hay diferencias en términos de las convenciones que constituyen sus respectivas gramáticas, estilos y esquemas de organización discursiva, específicamente la autora sostiene que las convenciones vinculadas con la modalidad escrita son más precisas. En sus palabras:

Existe una continuidad funcional entre las competencias involucradas en el dominio de la lengua hablada y escrita [...] las competencias de lectura y escritura que el niño requiere aprender, pueden ejercitarse en el modo hablado y transferirse al modo escrito, o facilitar su aprendizaje. La influencia también se da en el otro sentido, del modo escrito al hablado ( $p$. 181).

Asimismo, señala que existen diferencias importantes entre los campos conductuales en el dominio de la modalidad lingüística hablar y los implicados en el dominio de la modalidad lingüística escribir, en términos de que la relación escucha-hablante y la relación lector-escritor conllevan distancias temporales y espaciales distintas con respecto a la ubicación de los participantes. En el segundo caso, el lector y el escritor interactúan con alguien no presente ubicado en un contexto 
distinto, situación que obliga al desarrollo de competencias que le permiten ajustarse a lectores y escritores ausentes situados en otros contextos. Aun cuando mucho del trabajo realizado por la autora se llevó a cabo con niños de primaria, se considera que dicha lógica puede ser aplicada a la relación lector-escritor universitario.

Por su parte, Pacheco, et al. (2007) realizaron una aproximación empírica a la relación entre las conductas del leer y escribir a nivel universitario. Los datos obtenidos sugieren que el desempeño de los participantes en la evaluación de habilidades lectoras, se relaciona con el desempeño evaluado en las habilidades escritoras, en función del tipo de demandas impuestas en las tareas empleadas (criterio de ajuste). Asimismo, que la participación de los estudiantes en situaciones lectoras en niveles de mayor abstracción (interacciones sustitutivas) se relaciona con su participación en interacciones escritoras en esos mismos niveles.

De manera general los datos apoyan la noción de evolución psicológica de las interacciones lingüísticas, las cuales tienen lugar en niveles de abstracción menor hacia aquellos de mayor desligamiento, y que dicha evolución se da en la medida en que el individuo participa en los sistemas reactivos convencionales, desarrollando morfologías, ejercitándolas en situaciones y dominios específicos, y derivando los criterios que regulan su ejercicio. De tal manera que la participación del individuo (o en este caso el estudiante) en los sistemas reactivos convencionales no ocurre como respuestas aisladas, sino como configuraciones de morfologías convencionales y no convencionales en circunstancias específicas (ante objetos y eventos específicos).

En un intento por formular categorías analíticas y derivaciones paramétricas de mayor pertinencia en el análisis del desarrollo lingüístico en el aprendizaje de la ciencia, y que son un antecedente del trabajo que aquí se presenta, se llevaron a cabo dos estudios con el propósito de evaluar la comprensión de materiales con contenido científico en estudiantes universitarios -de ciencias biológicas y de la salud y ciencias sociales-, en donde se varió: a) la explicitación del criterio de ajuste, b) la modalidad de presentación de los materiales de estudio (texto y audio), c) el modo lingüístico involucrado en la tarea y su secuencia (hablar-escribir; escribir-hablar), y d) los criterios de tarea (identificar y formular). Los resultados encontrados fueron: a) la explicitación del criterio tiene un efecto facilitador sobre el desempeño lector y escritor de contenidos científicos, b) el desempeño en el modo lingüístico hablar y escribir fue mayor ante la modalidad textual que la auditiva, c) las variaciones en la secuencia de presentación de las modalidades lingüísticas muestran diferencias significativas si primero escriben y posteriormente hablan, que si primero hablan y después escriben y d) las tareas de identificación son las que mayor porcentaje de aciertos presentan. Lo anterior sugiere que el desempeño de los participantes parece depender más del modo lingüístico, del tipo de tarea y su nivel funcional que del contenido de los materiales (Acuña, et al. 2013).

\section{La escritura en el contexto de la enseñanza-aprendizaje de la ciencia}

La escritura en el contexto de la formación científica se convierte en una pieza clave para la generación y difusión del conocimiento. Autores como Shaw (2000) enfatizan el análisis de la enseñanza-aprendizaje de la escritura en disciplinas específicas, ya que se considera que es para los estudiantes universitarios una oportunidad para aprender acerca de su área de conocimiento, así como también una posible contribución a su disciplina. 
Cassany (2006) y Pacheco (2010) reconocen que la escritura en el ámbito científico es un requisito para aprender, pero también un medio y un modo de hacer ciencia, y no sólo una forma de evaluar el aprendizaje. Al mismo tiempo coinciden en que la enseñanza de la escritura de textos científicos debe ser explícita, sistemática y apegada a los lineamientos que siguen los científicos del área específica y no informal. Sin pretender ser exhaustivos a continuación se mencionan dos de las propuestas destacadas, ya que presentan importantes derivaciones tecnológicas para la enseñanza de la escritura.

Para Arias (2013) la Psicolingüística ha sido la aproximación teórica que ha derivado más propuestas con respecto a la escritura. Los modelos que más se han popularizado son aquellos que han mostrado posibilidades pedagógicas para desarrollar estrategias para enseñar y aprender la escritura, como el de Hayes y Flower (1980) y el de Bereiter y Scardamalia (1987).

El modelo más influyente acerca de los procesos de la escritura ha sido el de Hayes y Flower (1980). Este modelo supone que el proceso general de la escritura está compuesto por tres subprocesos (planificar, editar y revisar), los cuales se han utilizado de manera tradicional para describir el proceso de escritura: "pre-escritura, escritura y re-escritura". La novedad del modelo de Hayes y Flower (1980) es que considera a estos procesos como recursivos y no lineales, es decir, que no son pasos jerarquizados, sino procesos que se utilizan una y otra vez según sea necesario, los cuales son controlados por un mecanismo monitor. En este modelo el proceso de revisión comienza después del proceso de edición, cuando el escritor lee y corrige el texto, es decir, evalúa el texto producido y lo compara con el texto deseado.

Posteriormente Hayes (1996), realizó una profunda revisión de este primer modelo propuesto con Flower casi treinta años atrás. Hayes lo completó con una descripción exhaustiva de todos y cada uno de los procesos cognitivos que lo componen, y en segundo lugar, con una amplia discusión sobre los elementos influyentes en la escritura como son el contexto, la motivación y la memoria. Los procesos cognitivos descritos en el modelo original se mantienen, pero se han reconceptualizado. Por ejemplo, el proceso de revisión se ha ampliado -el cual es denominado interpretación textual-, pero bajo el control del esquema específico de la tarea de revisión. De tal manera que este proceso de interpretación posibilita al escritor elaborar un texto de mejor calidad dado que le permite ir leyéndolo y comprendiéndolo al mismo tiempo que lo edita o transcribe. Al respecto podemos señalar que los escritores expertos revisan más adecuadamente el material que componen, resultando un texto de mayor calidad que el de los novatos.

Otro de los modelos influyentes que toma en cuenta estas diferencias entre escritores novatos y expertos es el de Scardamalia y Bereiter (1992). Su propuesta incluye dos modelos, uno es de decir el conocimiento y otro el de transformar el conocimiento. En el primer modelo -"más simple"- el escritor recupera de su memoria lo que sabe sobre un tema y lo expresa directamente en el papel. En el segundo modelo, el escritor considera el contexto, es decir, tiene en cuenta al lector y analiza qué quiere lograr con su texto; así el escritor reconsidera lo que conoce sobre el tema para adecuarlo a las necesidades y características tanto de la audiencia (lectores potenciales) como de su propio objetivo, esto es, los escritores expertos tienen presente al posible lector y también el propósito de lo que se quiere lograr en él con su texto. Es importante mencionar que en este modelo aun cuando se centra la atención en el proceso de revisión, lo conceptualizan de forma diferente, es decir, la revisión no es considerada de forma explícita, sino implícita. 
La herramienta metodológica más utilizada en estos modelos para analizar la escritura es el análisis del protocolo, el cual consiste en solicitar al escritor que diga en voz alta todo lo que hace mientras escribe, de tal manera que se registra todo el proceso de composición escrita, incluidos errores y frases incompletas. Por su parte Bereiter y Scardamalia (1987) apuntan hacia a la necesidad de ampliar las posibilidades metodológicas y emplear, además del protocolo, la observación natural y estudios que permitan comprender de manera más integral el proceso de composición escrita.

Algunas de las ventajas de las propuestas antes mencionadas son la consideración de los elementos que participan en el proceso de composición escrita (los elementos de la situación de escritura, como el problema retórico y el texto) y las relaciones entre el lenguaje oral y el escrito, por ejemplo, en el modelo de Bereiter y Scardamalia (1987), se enfatiza la importancia del primero sobre el segundo (aun cuando la estructura en términos de morfologías sea diferente). Además, ambas propuestas coinciden en señalar que elaborar un texto implica para el escritor aprender a anticipar cómo será leído. Sin embargo, algunos aspectos de distinción con la propuesta del presente manuscrito son la atribución de factores internos a los escritores con procesos y subprocesos que se ubican en la memoria del escritor lo cual hace difícil su análisis empírico y, por ende, su evaluación.

Retomando estos y otros enfoques (el comunicativo de la escritura y el social de la escritura) Ríos-Checa (2011) realizó un análisis de los supuestos teóricos relacionados con la escritura y sus implicaciones en cuanto a la enseñanza. El autor presenta una propuesta para la enseñanza de la escritura tomando como referencia las interacciones de interdependencia entre el referidor (el que habla o escribe), el referido (al que se le habla o escribe -que también puede ser el mismo referidor-) y el referente (de lo que se habla o se escribe) bajo prácticas auspiciadas por los diferentes modos lingüísticos, en donde el estudiante pueda comportarse en correspondencia con la conducta del mediador (profesor o escritor) ya sea con eventos y sus posibles relaciones, como situaciones referidas.

Plantear dicha propuesta para la enseñanza de la escritura a nuestro juicio presenta como ventaja la consideración del escritor y las características de lo que se escribe, el lector potencial, los criterios que se deben cumplir al escribir, así como las características disposicionales de la situación (Pacheco y Villa, 2005; Pacheco, 2010), en la que se pueden incluir los modos lingüísticos, como desempeños que puedan correlacionarse con un desempeño efectivo como hablante, lector, observador y escucha.

Esto nos lleva a considerar dichos elementos en la relación auspiciada entre el profesor-estudiante-materiales de estudio, y cómo puede irse mediando el contacto con referentes disciplinares en relación con las modalidades de los materiales de estudio (audio, video, hipertexto, página web, etc.), la modalidad o modalidades lingüísticas implicadas y el tipo de tarea. Por ello, es importante llevar a cabo un análisis experimental de cuáles son los usos idóneos de los materiales y sus modalidades para enseñar-aprender mediante las TIC.

En un análisis conceptual Quiroga y Padilla (2014) plantean en relación con los modos lingüísticos y su aplicación en los procesos de enseñanza-aprendizaje mediante las TIC que:

es común entonces, encontrar una gran cantidad de herramientas tecnológicas vinculadas como soportes pedagógicos, los cuales, en la mayoría de los casos, no evidencian una fundamentación en términos del conocimiento analítico multi e interdisciplinar que valide 
su aplicabilidad en contexto, su efectividad en el proceso enseñanza-aprendizaje y su contribución en la mejora de la calidad de la formación académica (p. 11).

El estudio de la relación entre los materiales de estudio, las modalidades de mediación que pudiera utilizar el docente, la modalidad lingüística implicada y los criterios de tarea sugeribles para cada caso, se presenta a continuación. Se realizaron dos estudios con estudiantes universitarios, los cuales tuvieron como objetivo: evaluar el efecto de las variaciones en la modalidad del objeto referente, la modalidad lingüística implicada (leer-señalar, leer-escribir, observar/leer-señalar, observar/ leer-escribir, observar/escuchar/leer-señalar, observar/escuchar/leer-escribir) ante tareas que involucran categorías de corte procedimental; mientras que el segundo objetivo fue igual que el primero, pero a diferencia de este, se le presenta información al estudiante acerca de su ejecución (a manera de retroalimentación) en relación con el material de estudio que se había leído.

En el primer estudio participaron 21 estudiantes de la Licenciatura en Psicología, los cuales al momento de la evaluación estaban inscritos en segundo y cuarto semestre. Los participantes fueron asignados aleatoriamente a una de las tres condiciones del estudio: texto sin suplemento (Condición 1, ver Figura 1), texto suplementado con imágenes (Condición 2, ver Figura 2) y texto suplementado con video (Condición 3, ver Figura 3), quedando conformada cada condición por siete participantes. Se utilizaron dos textos de corte científico como materiales de estudio, cuya presentación se diseñó en plataforma Web, respetando el contenido y el formato de los mismos. El primer material de estudio (un texto sin suplemento) se utilizó para caracterizar el desempeño competencial de los participantes. El criterio de selección de los participantes fue la obtención de porcentajes de aciertos dentro de la triada intermedia (entre 33 y $66 \%$ de aciertos) en esta evaluación. El material de apoyo para trabajar en la situación experimental fue un artículo de divulgación científica con una extensión de 5000 palabras, este fue dividido en 7 segmentos (de entre 500 y 800 palabras cada uno), posterior a cada uno de los segmentos se presentó un conjunto de preguntas relacionadas con los mismos, sumando un total de 24 preguntas. Las preguntas fueron elaboradas en función de cuatro tipos de tareas: 1) identificar conceptos referidos a una clase de eventos; 2) identificar conceptos referidos a un procedimiento; 3) relacionar el concepto con un ejemplo y 4) elaborar un ejemplo de un procedimiento. Al final se solicitaba la elaboración de una conclusión de cuando menos un párrafo acerca de lo que contenía el material de estudio. Es importante mencionar que el artículo no se modificó para motivos del diseño y elaboración de los segmentos, más bien se suplementó con imágenes o videos los ejemplos originales presentados por el autor del artículo.

En el segundo estudio también participaron 21 estudiantes de la Licenciatura en Psicología, los cuales al momento de la evaluación estaban inscritos en primer y tercer semestre, al igual que en el primer estudio también se asignó al azar a los estudiantes a una de las tres condiciones, las cuales quedaron conformadas por siete participantes.

La situación experimental se llevó a cabo de la misma manera para ambos estudios, en una sala exenta de ruidos con cubículos individualizados ubicados en el Laboratorio de Ciencia y Comportamiento Humano. Para su aplicación se utilizaron 20 computadoras con audífonos. 


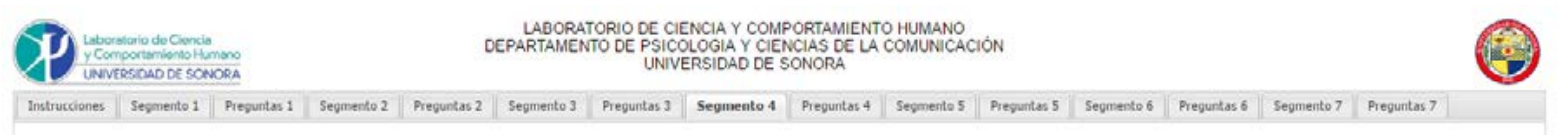

Procedimientos para enseñar discriminaciones condicionales

Hay varias formas de enseñar una discriminación condicional El empleo de cada procedimiento depende del tipo de participante y del tipo de tarea que se vaya a estudiar Cuando la enseñanza se realıza con propósitos aplicados y/o de resolución de problemas), el procedimiento depende del tipo de operante que se desee establecer. Para enseñar la 1gualación idéntica a la muestra (cuando la muestra y la comparación correcta son siempre iguales -por ejemplo, cuando el niño tiene que igualar el dibujo idéntico al que se le presenta) se emplean técnicas diferentes de las que se emplean para enseñar la igualación arbitraria a la muestra. En una relación arbitraria la muestra y la comparación correcta son diferentes (no comparten ninguna propiedad; ejemplo: color, tamaño, forma, etc.) En participantes humanos unormales» de pocos antos de edad, la igualación idéntica a la muestra se produce de forma generalizada sin enseñanza previa; sin embargo, en ciertas personas con retardo, es necesario probarla para que emerja (Pérez-González, McDonough y Greer, 1998) o enseñarla explicitamente.

\section{El aprendizaye de la igualación identica y de la igualación arbitrarza}

La igualación idéntica a la muestra se aprende con relativa facilidad Excepto personas con retraso mental severo, todas las personas pueden aprender una discriminación condicional en la que la muestra y la comparación correcta sean idénticas. Los niños autistas que tienen una enseñanza adecuada aprenden con relativa facilidad este tipo de discriminaciones condicionales). Para las personas con retraso grave con los cuales los procedimientos nomales de ensetianza de discriminaciones condicionales no sirven para que aprendan igualación idéntica a la muestra existen procedimientos especificos

$$
\text { El procedimiento general de aprendizaje de discriminaciones condicionales }
$$

El procedimiento más sencillo para enseilar una discriminación condicional consiste en establecer una contingencia de cuatro términos sin añadir más elementos al procedimiento Entonces, se presentan todos los tipos de ensayos desde el primer momento de enseinanza y se refierzan diferencialmente las selecciones correctas (e. \& Sidman. 1971 , Sidman y Cresson, 1973), para ello, se presentan aleatoriamente todas las muestras en sucesivos ensayos y se presentan todas las comparaciones en posiciones aleatorias. En ocasiones hay tantos lugares como comparaciones, otras veces se aumenta el número de posiciones para evitar que se desarrolle una preferencia por la posición (Sidman y Stoddard, 1967; Stoddard y Sidman, 1967). Este procedimiento sencillo hace que muchos participantes cometan muchos errores y que personas con problemas de aprendizaje no puedan aprender cuando se emplea este procedimiento.

Figura 1. Ilustra la Condición 1: Texto sin suplemento.

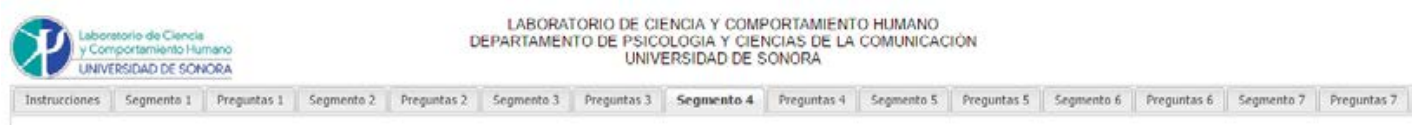

Procedimientos para enseñar discriminaciones condicionales

Hay varias formas de enseñar una discriminación condicional. El empleo de cada procedimiento depende del tipo de participante y del tipo de tarea que se vaya a estudiar. Cuando la enseñanza se realiza con propósitos aplicados yo de resolución de problemas). el procedimiento depende del tipo de operante que se desee establecer. Para enseñar la igualación idéntica a la muestra (cuando la muestra y la comparacion correcta son siempre iguales -por ejemplo, cuando el ntito tiene que igualar el dibujo idéntico al que se le presenta) (ver Figura 11) se emplean técnicas diferentes de las que se emplean para ensenar la igualación arbitraria a la muestra. En una relación arbitraria la muestra y la comparación correcta son diferentes (no companten ningusa propiedad, ejemplo color, tamaño, forma, etc.) En participantes humanos unormalesn de pocos años de edad, la igualación idéntica a la muestra se produce de forma generalizada sin enseñanza previa; sin embargo, en ciertas personas con retardo, es necesario probarla para que emerja (Pérez. González, McDonough y Greer. 1998) o enseñarla explicitamente.

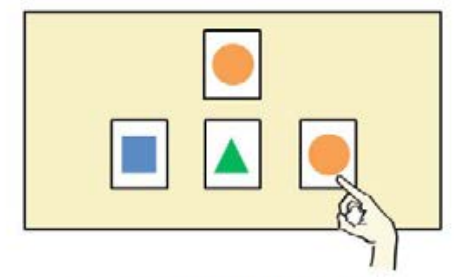

Figura 11. Igualación iđéntica a la muestra

El aprendizaje de la igualación idéntica y de la igualación arbitraria

La igualación identica a la muestra se aprende con relativa facilidad Excepto personas con retraso mental severo, todas las personas pueden aprender una discriminación condiciona en la que la muestra y la comparación correcta sean idénticas. Los niños autistas que tienen una enseñanza adecuada aprenden con relativa facilidad este tipo de discriminaciones condicionales). Para las personas con retraso grave con los cuales los procedimientos normales de enseñanza de discriminaciones condicionales no sirven para que aprendan igualación idéntica a la muestra existen procedimientos especificos

$$
\text { El procedimiento general de aprendizaje de discriminaciones condicionales }
$$

El procedimiento más sencillo para enseñar una discriminación condicional consiste en establecer una contungencia de cuatro térmmos sin añadur más elementos al procedimiento Entonces, se presentan todos los tipos de ensavos desde el primer momento de enserlanza y se refuerzan diferencialmente las selecciones correctas (e. g. Sidman. 1971. Sidman y Cresson, 1973), para ello, se presentan aleatoriamente todas las muestras en sucesivos ensayos y se presentan todas las comparaciones en posiciones aleatorias. En ocasiones hay tantos lugares como comparaciones, otras veces se aumenta el nuimero de posiciones para evitar que se desarrolle una preferencia por la posición (Sidman y Stoddard, 1967: tantos lugares como comparaciones, otras veces se aumenta el numero de posiciones para evitar que se desarrolle una preferencia por la posictón (Sidman y Stoddard, 1967 ;
Stoddard y Sidman, 1967). Este procedimento sencillo hace que muchos participantes cometan muchos errores y que personas con problemas de aprendizaje no puedan aprender cuando se emplea este procedimiento (ver Figura 12)

Figura 2. Ilustra la Condición 2: Texto suplementado con imágenes. 


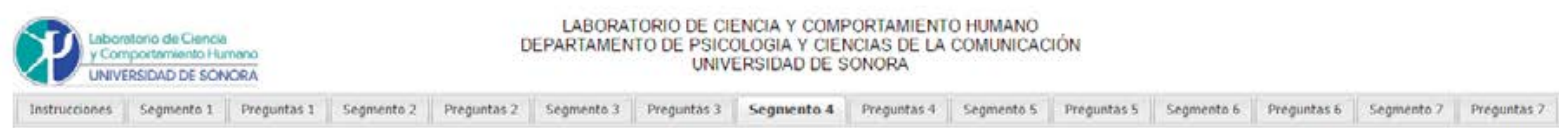

Procedimientos para enseñar discrimunaciones condicionales

\begin{abstract}
Hay varias formas de enseñar una discriminación condicional. El empleo de cada procedimiento depende del tipo de participante y del tipo de tarea que se vaya a estudiar. Cuando la enseñanza se realiza con propósitos aplicados y/o de resolución de problemas), el procedmmento depende del tipo de operante que se desee establecer. Para enseñar la 1gualación idéntica a la muestra (cuando la muestra y la comparación correcta son siempre iguales -por ejemplo, cuando el niño tiene que igualar el dibujo idéntico al que se le presenta) se emplean técnicas diferentes de las que se emplean para enseñar la igualación arbitraria a la muestra. En una relación arbitraria la muestra y la comparación correcta son diferentes (no comparten minguna propiedad, ejemplo color, tamano forma, etc.) En partscipantes humanos cnomalesn de pocos años de edad, la 1gualacion idèntica a la muestra se produce de forma generalizada sin ensenianza previa; sin embargo, en ciertas personas con retardo, es necesario probarla para que emerja (Pérez-González, McDonough y Greer, 1998) 0 enseñarla explicitamente.
\end{abstract}

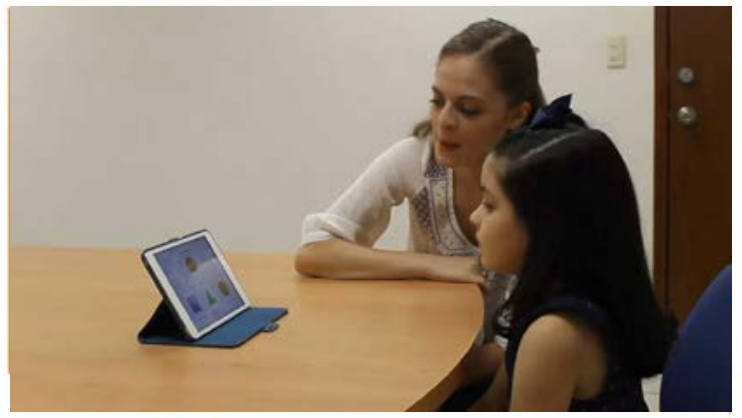

Video 10. Igualación idéntica a la muestra

El aprendizaje de la igualación idéntica y de la igualación arbitraria

La igualación idéntıca a la muestra se aprende con relatıva facilidad Excepto personas con retraso mental severo, todas las personas pueden aprender una discrimmación condicional en la que la muestra y la comparación correcta sean idénticas. Los niños autistas que tienen una enseñanza adecuada aprenden con relativa facilidad este tipo de discriminaciones condicionales). Para las personas con retraso grave con los cuales los procedmientos normales de enseñanza de discriminaciones condicionales no sirven para que aprendan igualación idéntica a la muestra existen procedimientos especificos.

El procedimiento general de aprendizaje de discriminaciones condicionales

El procedminto más sencillo para enseǹar una discrimmación condıcional consiste en establecer una contmgencia de cuatro térmmos sm aĩadır más elementos al procedımento Entonces, se presentan todos los tipos de ensayos desde el primer momento de enseñanza y se refuerzan diferencialmente las selecciones correctas (e. g., Sidman, 1971 , Sidman y

Figura 3. Ilustra la Condición 3: Texto suplementado con video (Para reproducir el video, dar clic en la fotografía).

La duración de la sesión la estableció la ejecución de los participantes, la cual consistió en promedio de 1 hora 15 minutos. Las evaluaciones fueron programadas y diseñadas para plataforma Web (HTML, Javascript, PHP y MySQL). Las respuestas de los participantes fueron guardadas directamente en una base de datos (MySQL). En la pantalla del computador aparecía una ventana de registro, en donde se solicitaba expediente, nombre y semestre y un botón para guardar la información. Se le pedía que confirmara que la información estuviera correcta, en caso de que así lo fuera, el sistema pasaba a la evaluación inicial mostrando las siguientes instrucciones: "Estimado alumno(a) a continuación se te presentará un texto y preguntas relacionadas con el mismo, es necesario que lo leas detenidamente, ya que esto te permitirá contestar una serie de preguntas". Cuando estés listo da clic en el botón "Iniciar". Al presionar el botón "Iniciar" se activaban las pestañas de los siete "Segmentos" y las "Preguntas" correspondientes a cada uno.

A cada segmento le correspondía un conjunto de preguntas con variaciones en el tipo de tarea, el participante podía leer los segmentos cuantas veces lo deseara (no había límite de tiempo); para el caso del segundo estudio, posteriormente a la emisión de la respuesta se le presentaba al participante información acerca de su ejecución, con el propósito de retroalimentarla y dar información importante del reactivo en cuestión, y en caso de que lo requiriera, pudiera modificarlo (como 
se muestra en la Figura 4 y 5). El participante tenía dos oportunidades de responder cada una de las preguntas, cuando se respondía el segundo intento el sistema bloqueaba automáticamente el reactivo y las opciones de respuesta.

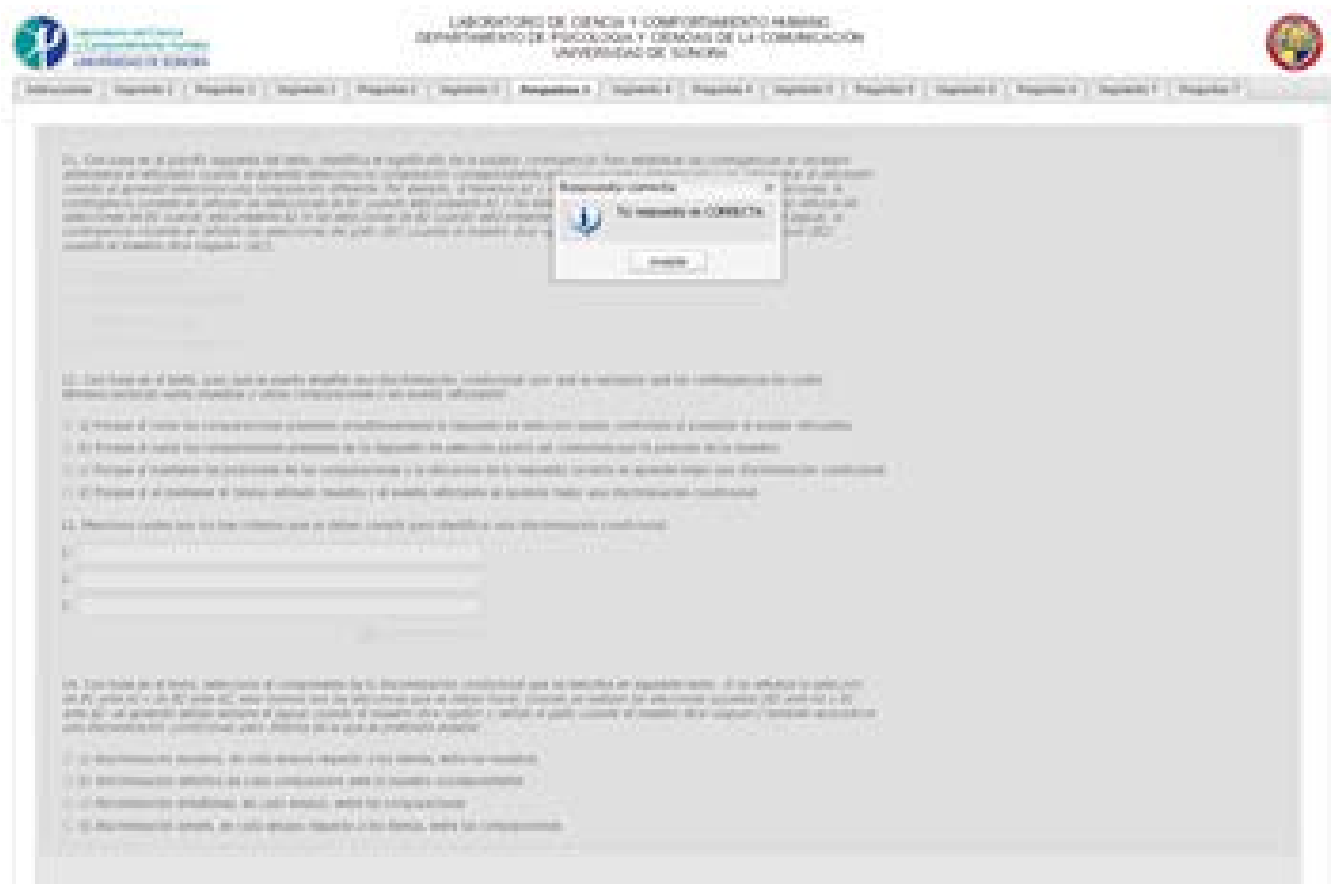

Figura 4. Muestra la información brindada al responder correctamente la tarea.

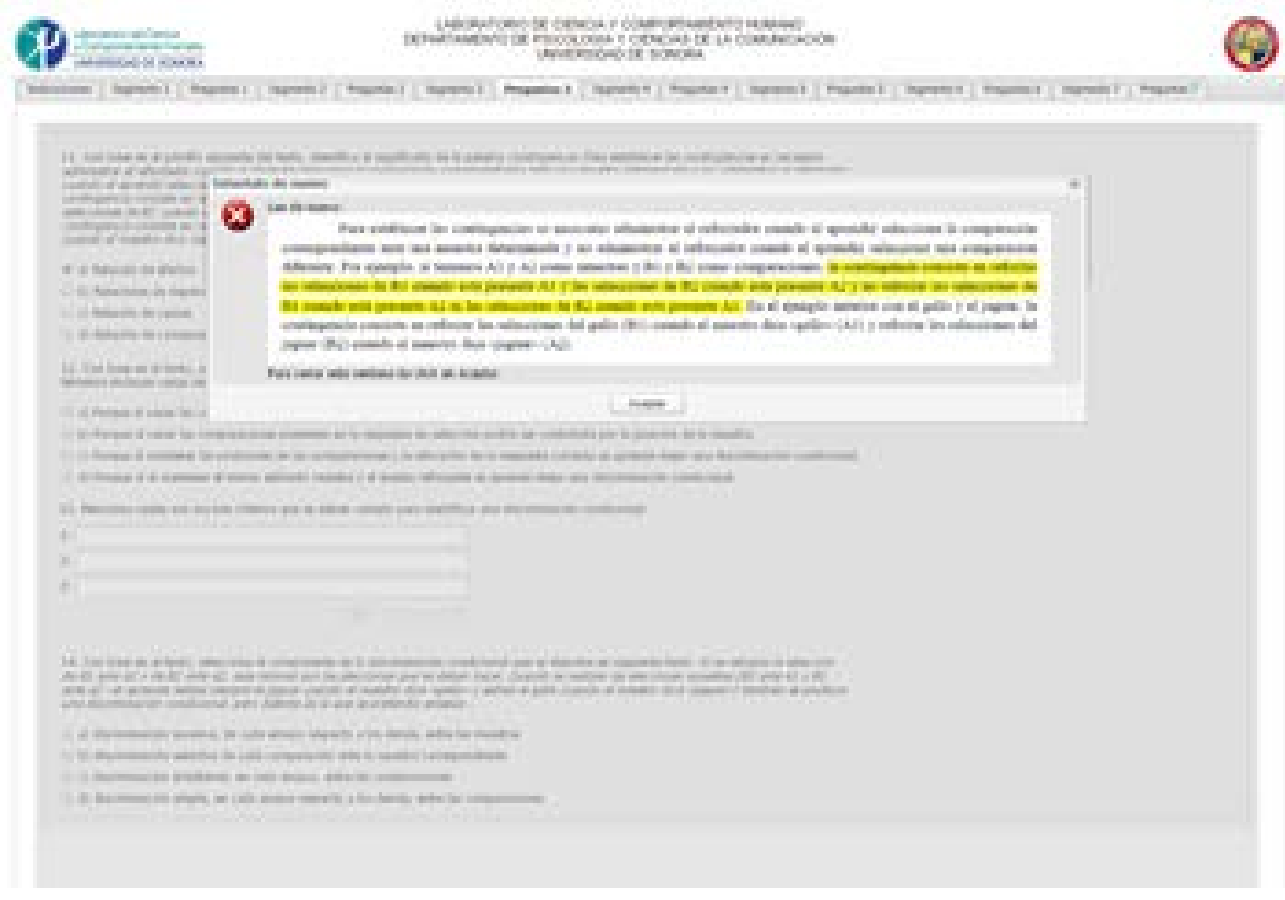

Figura 5. Muestra la información brindada al responder de manera incorrecta la tarea. 
Las respuestas a cada una de las tareas fueron evaluadas en términos de aciertos y errores, en el primer caso entendido como la correspondencia de la respuesta del estudiante con el requerimiento prescrito en la tarea y en el segundo, como la no correspondencia. Al finalizar los siete segmentos, se le presentaba la tarea de escritura, en donde el estudiante tenía que modificar mediante lo escrito las relaciones entre los eventos y su funcionalidad en correspondencia con lo observado, escuchado o leído del material de estudio. Dichos resultados son los que enfatizaremos en el presente trabajo.

\section{Resultados y discusión}

Al hacer un análisis por tipo de tarea para cada una de las Condiciones, los desempeños de los estudiantes muestran lo siguiente. Para la Condición 1 de texto sin suplemento (ver Figura 6), aquellas tareas que implican la identificación de conceptos referidos a eventos (Tarea 1) o procedimientos (Tarea 2) presentan mayor porcentaje de aciertos tanto para los alumnos de segundo semestre (T1: 75\% y T2: 65\%) como para los alumnos de cuarto semestre (T1: 85\% y T2: 75\%); para los participantes de texto sin suplemento con retroalimentación el porcentaje de aciertos en estas tareas es, para primer semestre (T1: $90 \%$ y T2: $80 \%$ ), para los de tercer semestre (T1: $100 \%$ y T2: 95\%); en cuanto a las tareas que involucran relacionar el concepto con un ejemplo (Tarea 3) y elaborar un ejemplo de un arreglo procedimental (Tarea 4), presentan menor porcentaje de aciertos independientemente del semestre y de la presentación de la retroalimentación: para los alumnos de segundo (T3: 65\% y T4: $35 \%$ ) y cuarto semestre (T4: $60 \%$ y T4: 45\%); para los participantes que recibieron retroalimentación el porcentaje de respuestas correctas incrementa aun cuando no en la misma proporción como en las tareas anteriores (T1 y T2), para primer semestre (T3: 70\% y T4: 50\%) y tercero (T4: 70\% y T4: $60 \%$ ). Esto parece indicar que el tipo de información presentada apoya el ajuste a criterios de tarea que involucran habilidades conceptuales, pero no necesariamente instrumentales. Para que el estudiante elabore pertinentemente un arreglo procedimental requiere que se le modele a manera de retroalimentación (mediante imágenes, fotografías, dibujos) las maneras del cómo se hace.

Los resultados para la Condición 2 de texto suplementado con imágenes también se muestran en la Figura 6. Al igual que en la Condición 1 las Tareas 1 y 2 presentan el mayor porcentaje de aciertos. En segundo semestre los porcentajes son: T1: $80 \%$ y T2: 75\%, para los de cuarto semestre son: T1: $85 \%$ y T2: $90 \%$; el desempeño para los participantes con retroalimentación en estas mismas tareas son los siguientes: para primer semestre (T1 y T2: 90\%), para tercer semestre (T1: 100\% y T2: 95\%). Al igual que en la Condición 1 las ejecuciones en las Tareas 3 y 4 decrementan en porcentaje de aciertos, para los alumnos de segundo (T3: $65 \%$ y T4: $70 \%$ ) y para los de cuarto (T3: $60 \%$ y T4: $70 \%$ ); para los alumnos que obtienen retroalimentación se presenta un ligero aumento en el porcentaje de aciertos: para primer semestre, T3: 70\% y T4: 50\%, y para tercero T3 y T4: $80 \%$.

En relación con los resultados de la Condición 3 de texto suplementado con video (ver Figura 6) encontramos que el porcentaje de aciertos con respecto a las Tareas 1 y 2 para los estudiantes de segundo semestre es T1: $80 \%$ y T2: $65 \%$, para los de cuarto semestre es T1: $85 \%$ y T2: $70 \%$; para los estudiantes que se les presentó retroalimentación es para primer semestre T1: 90\% y T2: 80\%, para los de tercer semestre es T1: $85 \%$ y T2: $95 \%$. En las Tareas 3 y 4 los estudiantes de segundo semestre obtienen los siguientes porcentajes: T3: $80 \%$ y T4: $85 \%$, para los estudiantes de cuarto 
semestre son: T3 y T4: 75\%, para los de la condición de retroalimentación son en primer semestre: T3: $70 \%$ y T4: $55 \%$, y tercero T3: $95 \%$ y T4: 60\%. Si bien en esta condición las Tareas 3 y 4 aumentan en porcentaje de aciertos ante el texto suplementado con video, no se muestran los mismos efectos para el caso de texto suplementado con video y que incluía retroalimentación. Este resultado se puede interpretar de la siguiente manera, que al presentarles la retroalimentación (a manera de texto) dificultó el identificar un procedimiento y elaborar su representación gráfica.

A continuación, se presentan los resultados de la tarea de escritura, la cual consiste en redactar cuando menos un párrafo acerca de lo que se había observado, escuchado y leído. Los desempeños son analizados a partir de dos categorías: morfológicas (como el uso de conceptos técnicos, uso y tipo de conectivos y extensión de la referencia) y funcionales (como el uso de conceptos técnicos pertinentes y tipo de relaciones formuladas, ya fuera entre variables o entre variables y procedimiento) (ver Tabla 1). El mayor promedio de ocurrencia para la categoría uso de conceptos técnicos es en la condición de texto suplementado con imagen y con retroalimentación (138 conceptos en promedio), seguido por texto sin suplementación pero con retroalimentación (131 conceptos), posteriormente texto sin suplementación y sin retroalimentación (84 conceptos), luego fue texto suplementado con video (81 conceptos), texto suplementado con imagen (72 conceptos) y finalmente, texto suplementado con video y con retroalimentación (65 conceptos). Como comentario, este dato parece ir en contrasentido de lo que se esperaría con respecto al uso del video como herramienta "tecnológica", toda vez que el observar hechos o eventos con dinamicidad parecería otorgar mayor contacto con los referentes disciplinares, lo cual no necesariamente es así.

Si observamos los resultados en cuanto al uso de conceptos técnicos utilizados de manera pertinente, encontramos el mismo orden por condición, con mayor puntaje de ocurrencia (con 107 conceptos) texto suplementado con imagen y retroalimentación, seguido por texto sin suplementación pero con retroalimentación (con 99 conceptos), texto sin suplementación y sin retroalimentación (con 66 conceptos), posteriormente texto suplementado con video (con 59 conceptos), seguido por el texto suplementado con video y retroalimentación (con 50 conceptos) y finamente, texto suplementado con imagen (con 49 conceptos). En cuanto a la categoría morfológica extensión de la referencia también se encuentra mayor puntaje para la condición de texto suplementado con imagen y retroalimentación (con 1136 palabras promedio), seguido de texto sin suplemento con retroalimentación (con 1129 palabras), texto sin suplemento (con 692 palabras), texto suplementado con video (con 639 palabras promedio), invirtiéndose el orden al final, primero el texto sin suplemento (con 692 palabras) y texto suplementado con video y retroalimentación (con 580 palabras promedio) (ver Figura 7).

Esto parece indicar que la retroalimentación tiene un efecto positivo en el desempeño de los estudiantes, pero no en todas las tareas. Este dato coincide con estudios sobre la "cualidad" de la retroalimentación brindada a los estudiantes. Parr y Timperley (2010) llevaron a cabo un estudio para evaluar el contenido de la retroalimentación (mediada por el profesor) y su efecto en el proceso de aprendizaje de 375 estudiantes de sexto de primaria a lo largo de un curso. Los autores señalan que la retroalimentación es un elemento clave en la escritura, pero que dicha retroalimentación debe contener ciertas características para lograr un efecto positivo entre el desempeño real y el esperado. Asimismo concluyen que la evaluación del aprendizaje está planeada para proveer información 
C1. Texto sin suplemento

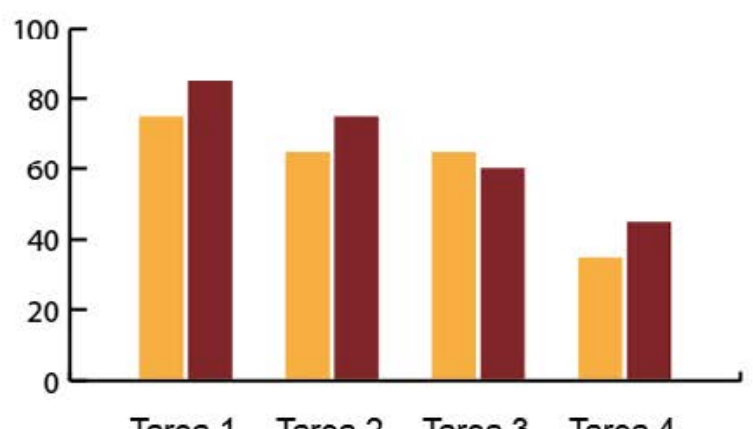

Tarea 1 Tarea 2 Tarea 3 Tarea 4

C2. Texto suplementado con imágenes

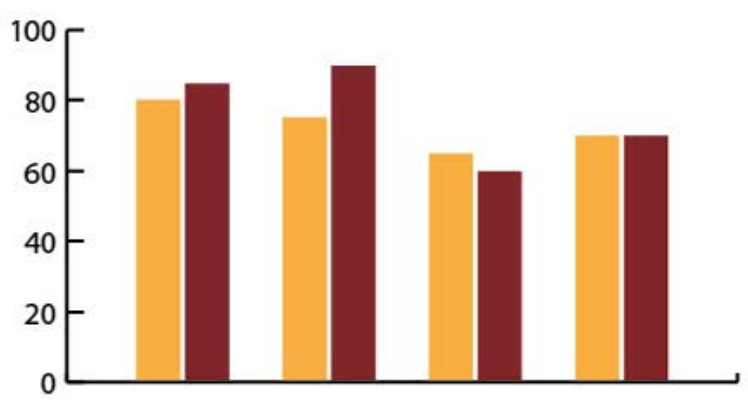

Tarea 1 Tarea 2 Tarea 3 Tarea 4

C3. Texto suplementado con video

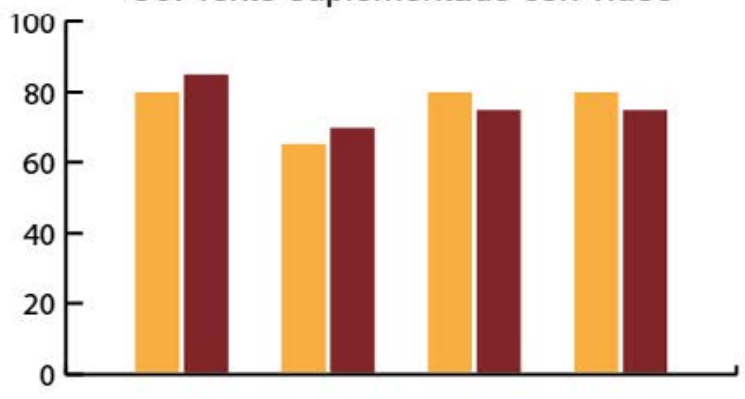

Tarea 1 Tarea 2 Tarea 3 Tarea 4
C1. Texto sin suplemento + Retro

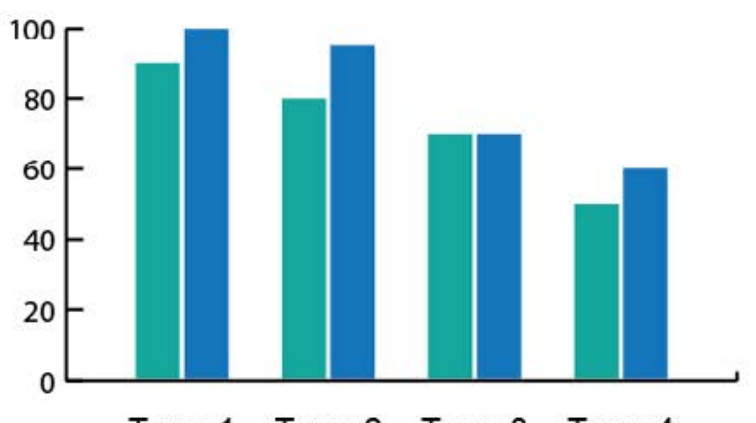

Tarea 1 Tarea 2 Tarea 3 Tarea 4

C2. Texto suplementado con imágenes + Retro

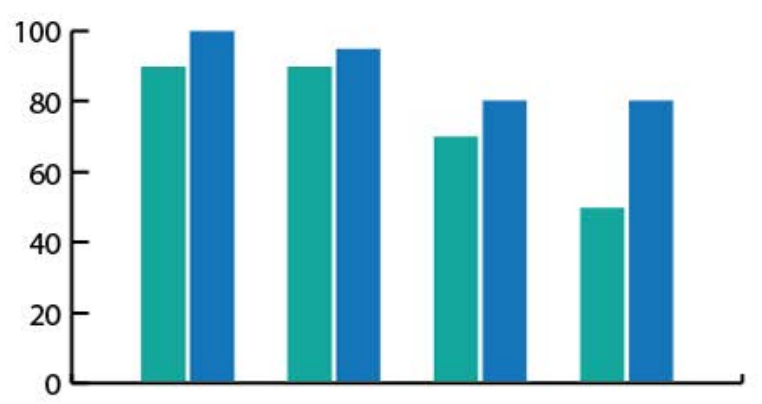

Tarea 1 Tarea 2 Tarea 3 Tarea 4

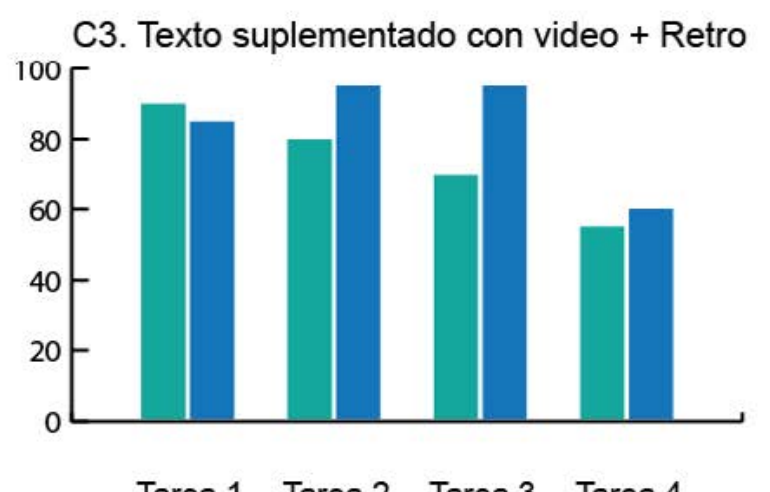

Tarea 1 Tarea 2 Tarea 3 Tarea 4

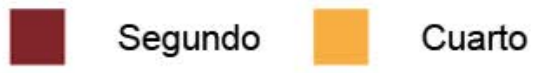


acerca del desempeño de los estudiantes y que puede ser usada para modificar la enseñanza y para auspiciar mayor aprendizaje.

Con respecto a la categoría formal uso de conectivos se encuentra que en su mayoría los estudiantes utilizan conectivos aditivos como el "y", no así conectivos de causalidad y aclaratorios. El mayor porcentaje en el uso de conectivos lo obtuvo la Condición 1 texto sin suplementación y sin retroalimentación (con 27 conectivos), seguido de la condición texto sin suplementación pero con retroalimentación, dato importante con respecto a la presentación del material de estudio y sus variaciones.

En la categoría funcional relación entre variables y relación entre variables y procedimiento se encuentra que el promedio de ocurrencias es en general muy bajo. Los promedios más altos (con cuatro relaciones formuladas) es para la Condición 3: texto suplementado con video y para la Condición 1: texto sin suplemento, en el resto de los casos se presentan resultados poco consistentes como para atribuirle un efecto al papel de la modalidad del material de estudio o a la retroalimentación. Por ejemplo, la posibilidad de establecer relaciones entre variables, y entre variables y procedimiento podría ser más atribuida al papel de la modalidad del material de estudio que a la retroalimentación, ya que las condiciones que tuvieron efectos más positivos fueron las de texto suplementado con video (con y sin retroalimentación).

En cuanto al tipo de relaciones que formulan los estudiantes universitarios, parece mostrarse la ejecución de los participantes más sensible a la modalidad de presentación de los materiales de estudio que a la retroalimentación. Esto podría relacionarse con el tipo de información que se le presenta al estudiante a manera de retroalimentación, faltaría por ejemplo, elaborar situaciones de evaluación-corrección del desempeño escritor, en donde se modelen las maneras idóneas de la escritura a nivel universitario; sobre todo considerando la redacción con sentido disciplinar. Uno de los aspectos nodales de la versión modificada del modelo de Hayes y Flower (Hayes, 1996) comentado en la sección anterior.

Una propuesta en este sentido es la Crone-Todd, Eyre, Hutchens, Jones y Pear (2007), los autores llevaron a cabo un estudio de serie de tiempos en donde utilizaron un método (CAPSI), el cual consiste en: a) un sistema personalizado de instrucción en donde la escritura es el medio principal para aprender el material; b) el dominio de la unidad antes de continuar avanzando en las subsiguientes unidades; c) el progreso de los estudiantes está determinado por su propio ritmo; d) una supervisión permanente por parte de revisores expertos (otros estudiantes) para proveer retroalimentación y ayudar a administrar el programa.

Es importante mencionar que la inclusión de las Tecnologías de la Información y la Comunicación en el proceso educativo ha permitido introducir variaciones en la modalidad de los materiales de estudio que puede utilizar el profesor y el estudiante. Por ello, consideramos que estos resultados pueden ser un referente empírico para el profesor en el cual sustentar su quehacer pedagógico-didáctico, de cómo planear e implementar sus secuencias didácticas en relación con la modalidad de presentación de los materiales de estudio y los criterios solicitados. Esto con el propósito de entrenar lectores y escritores competentes.

El modelo de interacción didáctica hasta el momento ha mostrado utilidad empírica para caracterizar y analizar las interacciones que ocurren en el proceso de enseñanza-aprendizaje, 
Tabla 1. Muestra los resultados del desempeño de escritura por Condición. Categorías formales: uso de conceptos técnicos, uso de conectivos y extensión de la referencia. Categorías funcionales: conceptos técnicos usados de manera pertinente, relaciones entre variables y relaciones entre variables y procedimiento.

\begin{tabular}{|c|c|c|c|c|c|c|c|c|c|}
\hline \multirow[b]{3}{*}{ Condición } & \multicolumn{6}{|c|}{ Categorías formales } & \multicolumn{3}{|c|}{ Categorías funcionales } \\
\hline & \multirow{2}{*}{$\begin{array}{l}\text { Concep } \\
\text { técnicos }\end{array}$} & \multicolumn{4}{|c|}{ Conectivos } & \multirow{2}{*}{$\begin{array}{c}\text { Ext. de } \\
\text { referencia }\end{array}$} & \multirow{2}{*}{$\begin{array}{l}\text { Pertinencia } \\
\text { conceptos } \\
\text { técnicos }\end{array}$} & \multirow{2}{*}{ Rel v's } & \multirow{2}{*}{$\begin{array}{c}\text { Rel V's y } \\
\text { Proc }\end{array}$} \\
\hline & & Adit & Caus & Aclara & Tot & & & & \\
\hline C1. Texto & 84 & 22 & 5 & 0 & 27 & 692 & 66 & 2 & 4 \\
\hline $\begin{array}{l}\text { C2. Texto } \\
\text { imagen }\end{array}$ & 72 & 10 & 0 & 0 & 10 & 385 & 49 & 2 & 1 \\
\hline $\begin{array}{l}\text { C3. Texto } \\
\text { video }\end{array}$ & 81 & 13 & 1 & 0 & 14 & 639 & 59 & 3 & 4 \\
\hline $\begin{array}{c}\text { C1. Texto + } \\
\text { Retro }\end{array}$ & 131 & 21 & 1 & 0 & 22 & 1129 & 99 & 2 & 0 \\
\hline $\begin{array}{l}\text { C2. Texto } \\
\text { imagen + } \\
\text { Retro }\end{array}$ & 138 & 14 & 2 & 1 & 17 & 1136 & 107 & 3 & 0 \\
\hline $\begin{array}{l}\text { C3. Texto } \\
\text { video + } \\
\text { Retro }\end{array}$ & 65 & 12 & 1 & 0 & 13 & 580 & 50 & 3 & 3 \\
\hline
\end{tabular}

Conceptos técnicos utilizados

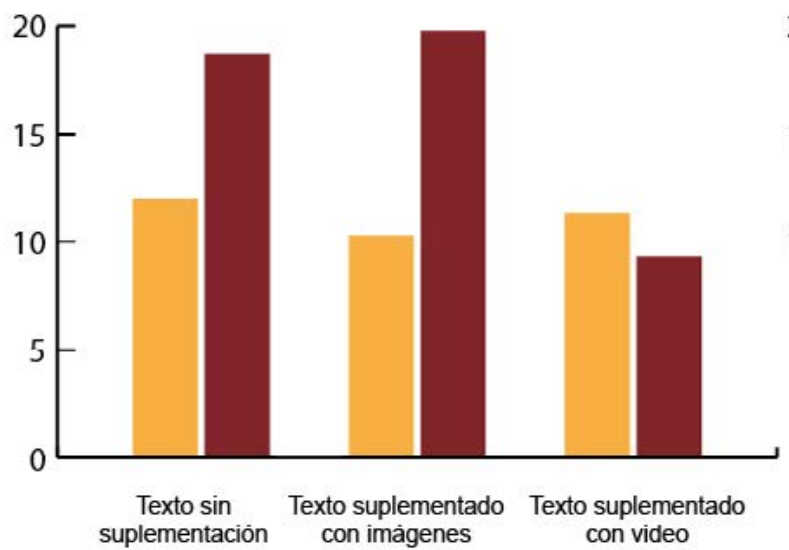

Sin retroalimentación

Con retroalimentación
Conceptos técnicos utilizados pertinentemente

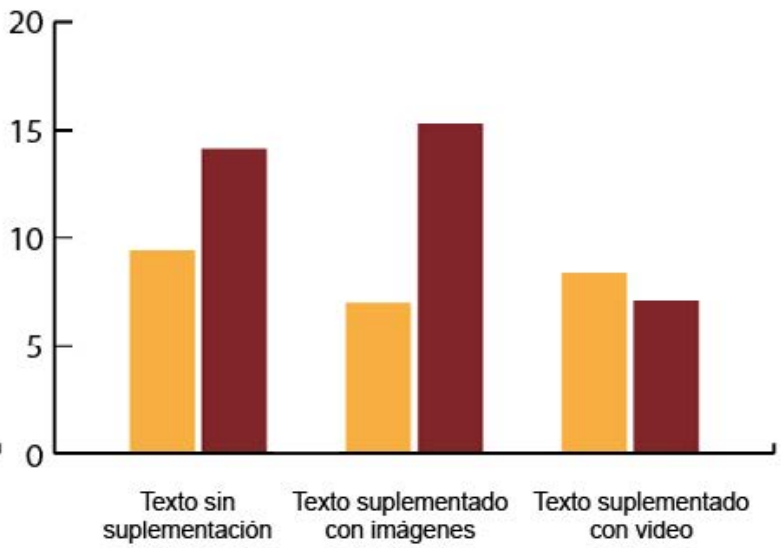

Sin retroalimentación
Con retroalimentación

Figura 7. Presenta el porcentaje promedio de ocurrencia de la categoría morfológica: uso de conceptos técnicos y categoría funcional: conceptos técnicos utilizados pertinentemente. 
incluyendo aquellas interacciones mediadas por las TIC. Por ende, mucho de lo que aquí se ha descrito abona a la discusión conceptual y la metodológica de los procesos educativos. Consideramos habría que continuar diseñando y realizando estudios que incluyan las distintas variaciones entre el tipo de competencia a enseñar, la modalidad del material de estudio, la modalidad lingüística involucrada y el tipo de tarea. En el caso específico del análisis de la escritura, llevar a cabo estudios que permitan evaluar los momentos del desarrollo competencial de la escritura, así como la habilitación auspiciada por los demás modos lingüísticos. Esto es, la caracterización de cómo el estudiante se va convirtiendo en un lector, hablante y escritor habilidoso dentro de su área de formación.

\section{Referencias}

Acuña, K., Irigoyen, J.J., \& Jiménez, M. (2009). Análisis de la percepción del desempeño docente en profesores de ciencias. En J. Varela, F. Cabrera, \& J.J. Irigoyen. Estudios sobre Comportamiento y Aplicaciones (pp. 89-118). Guadalajara: Universidad de Guadalajara.

Acuña, K., Irigoyen, J.J., \& Jiménez, M. (2011). Normativas de calidad y desempeños académicos. Algunas reflexiones sobre el proceso educativo. Revista de Educación y Desarrollo, 17 (abrilJunio), 23-31.

Acuña, K., Irigoyen, J.J., \& Jiménez, M. (2013). La comprensión de contenidos científicos en estudiantes universitarios. México: Qartuppi.

Arias, D. (2013). La escritura como proceso, como producto y como objetivo didáctico. Tareas pendientes. Tinkuy: Boletín de Investigación y Debate, 19, 33-46.

Benito, M. (2009). Debates en torno a la enseñanza de las ciencias. Perfiles Educativos, XXXI (123), 27-43.

Bereiter, K.D., \& Scardamalia. M. (1987). The phsychology of written composition. New York: Routledge.

Camacho, J., Irigoyen, J.J., Gómez, D., Jiménez, M., \& Acuña, K. (2007). Adquisición y transferencia de modos lingüísticos en tareas de discriminación condicional sin retroalimentación reactiva. Enseñanza e Investigación en Psicología, 12 (1), 79-91.

Carpio, C., \& Irigoyen, J.J. (2005). Psicología y Educación. Aportaciones desde la Teoría de la Conducta. México: Universidad Nacional Autónoma de México.

Carretero, M. (2000). Construir y enseñar las ciencias experimentales. Buenos Aires: Aique.

Cassany, D. (2006). Tras las líneas. Sobre la lectura contemporánea. Barcelona: Editorial Anagrama.

Contreras, O. (2009). La educación mediada por las tecnologías de la informática y la comunicación.

En M. Monroy, O. Contreras, \& O. Desatnik. Psicología Educativa (pp. 573-601). México: Universidad Nacional Autónoma de México.

Crone-Todd, D., Eyre, H., Hutchens, S., Jones, J., \& Pear, J. (2007). The effect of changing grading criteria on student Writing. The Behavior Analyst Today, 8 (1), 35-42.

Dockrell, J., \& Connelly, V. (2009). The impact to oral language skills on the production of written text. Teaching and Learning Writing, Monograph series II, 45-62. 
Duart, J. M., \& Sangrà, A. (2000). Formación universitaria por medio de la web: un modelo integrador para el aprendizaje superior. En J.M. Duart y A. Sangrà (Comps.), Aprender en la Virtualidad (pp. 23-50). España: Editorial Gedisa.

Flower, L., \& Hayes, J.R. (1980). The dynamics of composing: making plans and juggling constraints. In L. Gregg \& E. Steinberg (Eds.). Cognitive processes in writing: an interdisciplinary approach (pp. 31-50). Hillsdale, NJ: Lawrence Erlbaum Associates.

Fuentes, M.T., \& Ribes, E. (2001). Un análisis funcional de la comprensión lectora como interacción conductual. Revista Latina de Pensamiento y Lenguaje, 9 (2), 181-212.

Gómez, D., \& Ribes, E. (2008). Adquisición y transferencia de una discriminación condicional del primer orden en distintos modos de lenguaje. Acta Comportamentalia, 16 (2), 183-209.

Gómez, D., \& Ribes, E. (2014). Adquisición y transferencia de una discriminación condicional de segundo orden en distintos modos de lenguaje. Journal of Behavior, Health \& Social Issues, 6 (1), 89-106.

Gómez, D., Zepeta, E., García, Z., \& Molina, C. (2015). Habilitación de los modos activos de lenguaje a partir del modo reactivo observar. Acta Colombiana de Psicología, 18 (1), 13-24.

Hayes, J.R. (1996). A new framework for understanding cognition and affect in writing. In C.M. Levy, \& S. Ransdell (Eds.) The Science of writing: Theories, methods, individual differences and applications (pp. 1-27). Mahwah: Lawrence Erlbaum Associates.

Hayes, J.R., \& Flower, L. (1980). Identifying the Organization of Writing Processes. In L.W. Gregg, \& E.R. Steinberg (Eds.). Cognitive Processes in Writing (pp. 3-30). Hillsdale, NJ: Erlbaum.

Hayes, L. (1994). Psicología Interconductual: básica y aplicada. En L. Hayes, E. Ribes, \& F. López. Psicología Interconductual. Contribuciones en honor a J.R. Kantor (pp. 111-126). Guadalajara: Universidad de Guadalajara.

Ibáñez, C. (2007). Un análisis crítico del modelo del triángulo pedagógico. Una propuesta alternativa. Revista Mexicana de Investigación Educativa, 12 (32), 435-456.

Irigoyen, J.J., Acuña, K., \& Jiménez, M. (2011). Interacciones Didácticas en Educación Superior. Algunas consideraciones sobre la evaluación de desempeños. En J.J. Irigoyen, K. Acuña, \& M. Jiménez. Evaluación de desempeños académicos (pp. 73-95). Hermosillo: Universidad de Sonora.

Irigoyen, J.J., Acuña, K., \& Jiménez, M. (2015). Aprendizaje de contenidos científicos: efecto de la modalidad del objeto referente. En F. Cabrera, Ó. Zamora, H. Martínez, P. Covarrubias, \& V. Orduña. Estudios sobre Comportamiento y Aplicaciones, Volumen IV (pp. 195-223). México: Universidad de Guadalajara-CONACYT.

Irigoyen, J.J., Jiménez, M., \& Acuña, K. (2004). Evaluación del ejercicio instruccional en la enseñanza universitaria. Enseñanza e Investigación en Psicología, 9 (2), 293-302.

Irigoyen, J.J., Jiménez, M., \& Acuña, K. (2007). Aproximación a la pedagogía de la ciencia. En J.J. Irigoyen, M. Jiménez, \& K. Acuña. Enseñanza, aprendizaje y evaluación. Una aproximación a la pedagogía de las ciencias (pp. 13-44). Hermosillo: Universidad de Sonora.

Kantor, J.R. (1936). An objetive psychology of grammar. Granville: Principia Press.

Kantor, J.R., \& Smith, N. (1975). The science of psychology. An interbehavioral survey. Chicago: Principia Press. 
Mares, G. (2001). La transferencia desde una perspectiva de desarrollo psicológico. En G. Mares, \& Y. Guevara (Comps.). Psicología Interconductual. Avances en la investigación básica (pp. 111-163). México: Universidad Nacional Autónoma de México.

Mares, G. (2008). Promoción de competencias a través de textos para la enseñanza de las ciencias naturales. En G. Mares. Diseño Psicopedagógico de textos. Diversos Enfoques (pp. 171200). México: Universidad Nacional Autónoma de México.

Mares, G., Ribes, E., \& Rueda, E. (1993). El nivel de la funcionalidad en lectura y su efecto sobre la transferencia de lo leído. Revista Sonorense de Psicología, 7 (1), 32-44.

Mares, G., Rueda, E., \& Luna, S. (1990). Transferencia de los estilos lingüísticos en tareas referenciales. Revista Sonorense de Psicología, 4 (1), 84-97.

Moreno, R. (1990). Análisis epistemológico de algunos aspectos sustantivos y metodológicos de la educación. Investigación en la Escuela, 12, 19-27.

Pacheco, V. (2010). ¿Se enseña a escribir a los universitarios? Análisis y propuestas desde la teoría de la conducta. México: Universidad Nacional Autónoma de México.

Pacheco, V., \& Villa, J. (2005). El comportamiento del escritor y la producción de textos científicos. Revista Mexicana de Investigación Educativa, 10 (27), 1201-1224.

Pacheco, V., Ramírez, L., Palestina, L., \& Salazar, M. (2007). Una aproximación al análisis funcional de las relaciones entre las conductas de leer y escribir en estudiantes de Psicología. En J.J. Irigoyen, M. Jiménez, \& K. Acuña. Enseñanza, aprendizaje y evaluación. Una aproximación a la pedagogía de las ciencias (pp. 247-275). Hermosillo: Universidad de Sonora

Parr, J., \& Timperley, H. (2010). Feedback to writting, assessment for teaching and learning and student progress. Assessing Writing, 15, 68-85.

Perez-Almonacid, R., \& Quiroga. L. (2010). Lenguaje: una perspectiva Interconductual. Bogota: Corporación Universitaria Iberoamericana.

Quiroga, L., \& Padilla, M.A. (2014). El concepto de modo lingüístico y su aplicación en los procesos de enseñanza-aprendizaje mediante las TIC's. Journal of Behavior, Health \& Social Issues, 6 (1), 9-22.

Quiroga, L., Peña, T., \& Padilla, M.A. (2013). Efectos del tipo de entrenamiento y del modo lingüístico sobre el ajuste a contingencias convencionales. Acta Comportamentalia, 21 (1), 68-82.

Ribes, E., Cortes, A., \& Romero, P. (1992). Quizá el lenguaje no es un proceso o tipo especial de comportamiento: algunas reflexiones basadas en Wittgenstein. Revista Latina de Pensamiento y Lenguaje, 1 (1), 58-73.

Ribes, E., \& López, F. (1985). Teoría de la Conducta. Un análisis de campo y paramétrico. México: Editorial Trillas.

Ríos-Checa, A. (2011). Escribir: tres teorías y una proposición para su enseñanza. En J.J. Irigoyen, K. Acuña, \& M. Jiménez. Evaluación de desempeños académicos (pp. 43-71). Hermosillo: Universidad de Sonora.

Scardamalia, M., \& Bereiter, C. (1992). Dos modelos explicativos de los procesos de composición escrita. Infancia y Aprendizaje, 58, 43-64. 
Shanahan, T. (2006). Relations among oral lenguage, reading, and writing development. In C.A. MacArthur, S. Graham, \& J. Fitzgerald (Eds.). Handbook of writing research (pp. 171-183). New York: Guilford.

Shaw, S. (2000). Writing in a psychology classroom: learning and adopting the APA epistemology. Dissertation Abstracts International, 6, 5A, 17-34.

Tomasini, A. (1994). Lenguaje y anti-metafísica. Cavilaciones wittgensteinianas. México: Grupo Editorial Interlínea.

Varela, J. (2004). Consideraciones y estudio de la educación extracurricular basada en los modos lingüísticos. En J.J. Irigoyen, \& M. Jiménez. Análisis Funcional del Comportamiento y Educación (pp. 35-74). Hermosillo: Universidad de Sonora.

Varela, J., Padilla, M.A., Cabrera, F., Mayoral, A., Fuentes, M.T., \& Linares, G. (2001). Cinco tipos de transferencia: de la dimensión lingüística a la basada en propiedades morfológico-geométricas de los estímulos. Revista Mexicana de Análisis de la Conducta, 27, 363-383.

Vygotsky, L.S. (1979). El desarrollo de los procesos psicológicos superiores. Buenos Aires: Editorial Grijalbo. 


\section{Capítulo 8}

\section{Lectoescritura técnica: el caso de la elaboración de resúmenes de artículos experimentales}

María Antonia Padilla Vargas, Elsy Georgina Cárdenas García y Cristiano Valerio dos Santos 
María Antonia Padilla Vargas tony.padilla2008@gmail.com

Elsy Georgina Cárdenas García elsy.gcg@gmail.com

Cristiano Valerio dos Santos cristiano.valerio@academicos.udg.mx

Centro de Estudios e Investigaciones en Comportamiento Universidad de Guadalajara 


\section{Capítulo 8}

\section{Lectoescritura técnica: el caso de la elaboración de resúmenes de artículos experimentales}

El ejercicio de competencias lectoescritoras es fundamental tanto en la formación de nuevos psicólogos como en la de nuevos investigadores. Sin embargo, diversos estudios han mostrado que el comportamiento lectoescritor de los estudiantes de educación media y superior en general es deficiente (Cárdenas y Guevara, 2013; Pacheco, 2010; Padilla, Fuentes y Pacheco, 2015), y que a pesar de ello no existe en los planes curriculares de las universidades un programa orientado a auspiciar habilidades en tal sentido (Aguilera et al., 2006). Por ello se vuelve indispensable analizar los factores que afectan la lectoescritura técnica (disciplinar) con el objeto de que a mediano plazo, estar en posibilidades de diseñar planes curriculares efectivos que permitan que los futuros investigadores (cuando inicien su formación como tales) sean capaces de leer y escribir de manera eficiente.

Es importante precisar que desde la perspectiva en la que se realizó el presente trabajo, "leer y escribir se conceptualizan como relaciones de interdependencia entre el individuo que lee o escribe y los otros elementos participantes en el campo contingencial" (Pacheco, Ramírez, Palestina y Salazar, 2007, p. 252), como el texto que se lee o escribe, el individuo que lee o escribe el texto (según sea el caso) y los aspectos del entorno o la situación en la que se lee o escribe (Pacheco, Ortega, Morales y Carpio, 2012; Pacheco y Villa, 2005).

Las habilidades y competencias lectoescritoras en general, pero particularmente de textos científicos (dado el lenguaje técnico disciplinar que implican), están moduladas por la historia referencial de quien lee o escribe (Pacheco et al., 2007; Padilla, Tamayo \& González-Torres, 2013), es decir, si la persona está familiarizada o no con la lectura y escritura de este tipo de textos. Otros de los factores que afectan las interacciones lectoescritoras son los criterios de logro a los que el comportamiento debe ajustarse, las características del referente con el que se debe entrar en contacto, los factores disposicionales y las habilidades lingüísticas del individuo (Pacheco, 2010; Pacheco et al., 2007; Pacheco, Ortega y Carpio, 2013).

Irigoyen, Acuña y Jiménez (2013) proponen considerar el término “comprensión" (en este contexto) como la descripción de los logros del estudiante con respecto al criterio de logro establecido, ya que se puede leer de diferente manera dependiendo del objetivo que se pretenda lograr (por ejemplo, si se pide a un alumno que lea un texto para que identifique cuántos verbos hay en este o para que describa su contenido, el nivel de comprensión de dicho texto será distinto). En nuestro trabajo, nos interesa identificar las variables relacionadas a la lectura con comprensión eficiente de un texto, y definimos el criterio de logro para lectura con comprensión eficiente cuando el lector 
sea capaz de identificar las ideas principales del texto con el que interactúa y organizarlas de forma coherente.

Al diseñar el presente proyecto de investigación surgió la duda de cuál podría ser una tarea experimental apropiada para analizar la lectoescritura técnica, es decir, que permitiera analizar las variables implicadas en dicho fenómeno. Al respecto, se consideró pertinente trabajar con la elaboración de resúmenes de artículos experimentales dadas las características con que cuentan: a) cumplen con el criterio de incluir términos técnicos; b) un resumen es un texto breve que evita problemas de fatiga al elaborarlo; y c) existen criterios claros respecto de qué elementos ( $y$ en qué orden) deben integrarlo (estipulados por la APA, 2010). Para escribir el resumen de un texto, es necesario que el sujeto identifique las ideas principales del texto en cuestión y que las organice de manera coherente en un escrito conciso. Por tanto, escribir un resumen es una actividad que puede evidenciar la comprensión lectora.

Según el Manual de Estilo de Publicaciones de la American Psychological Association (2010), un resumen es un escrito breve que condensa el contenido principal de un artículo, lo que permite a los lectores entrar en contacto con este de forma rápida. Un resumen bien elaborado puede ser el punto más importante de un artículo, ya que la mayoría de las personas tienen su primer contacto con este al leer sólo su resumen, y con frecuencia deciden sobre la base del mismo si van a leer el texto completo o no. El número de palabras que lo deben integrar varía de una revista a otra pero por lo general van de 150 a 250. También se deben incorporar al resumen palabras clave para facilitar al usuario encontrarlo en los buscadores especializados.

Dado que por lo general el resumen de un artículo es el único elemento de tal artículo almacenado en las bases de datos bibliográficas, debe elaborarse con sumo cuidado ya que es la parte más leída de este (Díez, 2007). Un resumen bien escrito aumenta las probabilidades de que se lea el trabajo completo, lo que incrementa las posibilidades de ser citado (Sousa, Driessnack \& Flória-Santos, 2006).

Hay diferentes tipos de resúmenes, pero el que es de interés en el presente trabajo es el originado a partir de un artículo experimental. En este, se debe incluir solamente el objetivo o propósito del trabajo (en una frase si es posible); las características pertinentes de los participantes (población); la tarea empleada; el procedimiento que se siguió; los resultados principales; una discusión concisa; y una lista de tres a cinco palabras clave (APA, 2010; Díez, 2010; Sousa et al., 2006).

De acuerdo con el manual de la APA (2010), un resumen adecuado debe ser preciso (no incluir información que no aparezca en el artículo), coherente, legible y conciso (hacer cada frase máximamente informativa). Según Silva (2010) un resumen es una versión en miniatura del artículo en cuestión. A pesar del papel tan importante que juega el resumen de un artículo experimental, a la fecha se han llevado a cabo pocos estudios en los que se analicen las variables implicadas en su elaboración. Los únicos trabajos encontrados al respecto son los de Pacheco et al. (2007) y Padilla y Suro (2007).

Por un lado, Pacheco et al. (2007) realizaron una investigación con el propósito de identificar una posible relación entre el comportamiento lector y escritor. Expusieron a estudiantes de Psicología, de 2do y 6to semestre, a cinco artículos distintos de los cuales debían hacer una serie de tareas después de leer cada texto. El diseño constó de cuatro sesiones, pero sólo en la primera se 
les solicitó que elaboraran un resumen bajo la instrucción de que debían escribirlo de manera que lo entendiera uno de sus compañeros de primer semestre. Los indicadores considerados para evaluar la elaboración de los resúmenes fueron: propósito (objetivo), temas principales mencionados, conclusiones, errores ortográficos cometidos, extensión (número de párrafos), así como la vinculación entre los diferentes párrafos. Los datos mostraron que el promedio de aciertos logrado fue del $68.2 \%$ en los estudiantes de 2 do semestre y de $77.3 \%$ en los estudiantes de 6 to semestre.

Por su parte, Padilla y Suro (2007) llevaron a cabo el seguimiento competencial de un grupo de cinco investigadores en formación que estaban estudiando una maestría en Ciencia del Comportamiento. Se evaluaron las competencias que estos ejercitaron a lo largo de los cuatro semestres que duraba su entrenamiento. Una de las competenciales evaluadas fue la elaboración de reportes experimentales (elaborarlos implicaba escribir el resumen respectivo), encontrando que, en la primera evaluación (al ingresar a la maestría), el promedio de dominio competencial en dicha actividad fue del $25 \%$, mientras que, en la última evaluación (al culminar el último semestre), su dominio fue de aproximadamente $50 \%$. Si bien los estudios mencionados arrojaron información valiosa respecto de la elaboración de resúmenes, faltaría analizar con el mayor detalle posible las variables implicadas en la elaboración de resúmenes de textos experimentales, por ejemplo, el tipo de contacto que establecen los participantes con el texto del cual elaborarán el resumen respectivo, el tipo de información que incluyen en dicho resumen, etc. Dado lo anteriormente mencionado, el presente estudio se realizó con el objetivo de explorar las variables implicadas en la elaboración de resúmenes de artículos experimentales, en estudiantes de licenciatura.

\section{Método}

Participantes. El estudio se llevó a cabo con dos muestras diferentes. En la Muestra 1, participaron voluntariamente, por invitación directa, 21 estudiantes (18 mujeres y 3 hombres) de una Licenciatura en Psicología de una Universidad Pública Mexicana con edades entre 20 y 27 años. Los participantes cursaban los semestres intermedios de la carrera. En la Muestra 2, participaron voluntariamente, por invitación directa, 24 becarios (17 mujeres y 7 hombres) de un verano de investigación, estudiantes de diferentes licenciaturas (15 de Psicología, 4 de Ciencias de la Educación, 2 de Enfermería, 1 de Educación para la Salud, 1 de Veterinaria y 1 de Biología) provenientes de distintas universidades del país, con un rango de edad entre 19 y 31 años, quienes realizaban una estancia en el Centro de Estudios e Investigaciones en Comportamiento (CEIC) como parte del Verano de Investigación 2014. Dichos estudiantes cursaban entre el 4 to y el 10 mo semestre de la carrera.

Dado el bajo desempeño observado en los participantes de la Muestra 1, que eran estudiantes regulares de licenciatura, se decidió llevar a cabo una réplica directa del estudio con estudiantes que estaban participando en un verano de investigación, bajo el supuesto de que este tipo de alumnos podría mostrar un mayor grado de motivación hacia la tarea dado su interés en las actividades científicas.

Diseño. Debido a que el estudio fue exploratorio, todos los participantes se expusieron a las mismas condiciones (ver Tabla 1). La tarea implicó leer dos artículos experimentales, seleccionar de estos 
las oraciones que el participante considerara más relevantes (también podía deseleccionar las oraciones si cambiaba de opción al respecto), acomodar dichas oraciones según la importancia que considerara tenían y escribir el resumen correspondiente de cada uno de los artículos previamente leídos. Todos los participantes fueron expuestos a tres condiciones: 1) elaboración de un resumen inicial, 2) receso de 10 minutos, y 3) elaboración de un segundo resumen.

Tabla 1. Diseño Experimental empleado.

\begin{tabular}{|c|c|c|c|c|c|c|}
\hline \multicolumn{4}{|c|}{ Sesión 1} & \multicolumn{3}{|c|}{ Sesión 2} \\
\hline Fase 1 & Fase 2 & Fase 3 & & Fase 1 & Fase 2 & Fase 3 \\
\hline $\begin{array}{c}\text { Seleccionar } \\
\text { oraciones }\end{array}$ & $\begin{array}{c}\text { Ordenar } \\
\text { oraciones } \\
\text { seleccionadas }\end{array}$ & $\begin{array}{l}\text { Elaborar } \\
\text { resumen }\end{array}$ & Receso & $\begin{array}{c}\text { Seleccionar } \\
\text { oraciones }\end{array}$ & $\begin{array}{c}\text { Ordenar } \\
\text { oraciones } \\
\text { seleccionadas }\end{array}$ & $\begin{array}{l}\text { Elaborar } \\
\text { resumen }\end{array}$ \\
\hline
\end{tabular}

Aparatos y Escenario. El experimento se llevó a cabo en cubículos individuales del laboratorio de aprendizaje humano del Centro de Estudios e Investigaciones en Comportamiento (CEIC), así como en el laboratorio de conducta social (para la parte del receso). Los cubículos estaban equipados con una silla, un escritorio y sobre este una computadora personal, mientras que el laboratorio de conducta social contaba con una mesa redonda de $1.30 \mathrm{~m}$ de diámetro y 8 sillas. Dichos espacios contaban con ventilación e iluminación adecuadas. Se creó un programa ex profeso para presentar la tarea (ver las pantallas respectivas en el apartado de Procedimiento), el cual automáticamente guardaba los datos, posteriormente estos se exportaban a Microsoft Office Excel 2010 para su análisis.

Se emplearon dos artículos experimentales (ver la referencia de tales artículos en el Anexo A) en los que se analizaban los efectos de la retroalimentación y las instrucciones en tareas de discriminación condicional. Dichos estudios fueron llevados a cabo en el marco del Análisis Experimental de la Conducta y tenían una extensión de once a doce cuartillas. Se eligieron tales artículos debido a que pertenecían a una misma área de conocimiento, y eran similares en extensión, el lenguaje técnico empleado y el fenómeno analizado.

Procedimiento. Los participantes resolvían la tarea individualmente. Antes de exponerse al estudio debían leer y, en su caso, firmar un formato de consentimiento informado en el que se explicaban los objetivos, características e implicaciones del experimento. En caso de que el participante aceptara ser parte del estudio, se le entregaba una hoja con las instrucciones iniciales, las cuales se muestran a continuación:

\section{¡BIENVENIDO(A)!}

Antes que nada, gracias por participar en este estudio. El objetivo final de esta tarea es que elabores el resumen de un artículo que leerás. 
Según el Manual de estilo de publicaciones de la American Psychological Association, un resumen es un sumario completo acerca del contenido de un artículo, el cual permite que los lectores reconozcan con rapidez tal contenido. Un resumen bien elaborado puede ser la parte más importante de un artículo porque, por lo general, la mayoría de las personas tendrá su primer contacto con un artículo al leer su resumen, y con frecuencia los lectores deciden, con ver el resumen, si leerán o no el artículo completo. El resumen debe ser compacto en su información, pero también legible, bien organizado, de corta extensión, y completo. Un buen resumen debe ser: preciso, completo, conciso, coherente y legible.

Una vez leída tal parte, se iniciaba con la primera fase de la Sesión 1 (Artículo 1), cuyas instrucciones fueron:

Esta tarea está compuesta de varias pantallas, en cada una de las cuales aparecerán cinco oraciones que forman parte de un artículo científico, en el orden en que el autor las escribió. Cada artículo está compuesto de varias pantallas. Tú puedes avanzar o retroceder entre estas, usando los botones denominados "Anterior" y "Siguiente". Tu tarea consiste en seleccionar las oraciones que creas pertinentes para elaborar el resumen del artículo. En caso de que en tu computadora no apareciera la oración completa, podrás verla moviendo la barra de desplazamiento que está en la parte de abajo. Podrás seleccionar tales oraciones haciendo clic en el cuadrado que se encuentra en la parte izquierda de cada una. Si en algún momento cambiaras de opinión respecto de la pertinencia de alguna oración que hubieras elegido, podrás deseleccionarla haciendo clic nuevamente en el cuadrado correspondiente. Además, en la parte inferior izquierda, aparecerá un recuadro que dice "Tablas y Figuras" con algunos botones. Al hacer clic sobre esos botones, aparecerá una nueva ventana con la tabla o figura correspondiente, la cual necesitarás revisar para entender los resultados. En caso de que tengas dudas respecto de algún aspecto de la tarea, podrás consultar estas instrucciones todas las veces que lo desees, haciendo clic en el botón que dice "Instrucciones". Si estás listo(a) para iniciar con la tarea, haz clic en el botón que dice "Continuar".

Es importante mencionar que los participantes podían consultar dichas instrucciones cuantas veces lo desearan durante la realización de la tarea. La pantalla a la que los participantes se exponían en esta fase se muestra en la Figura 1. 

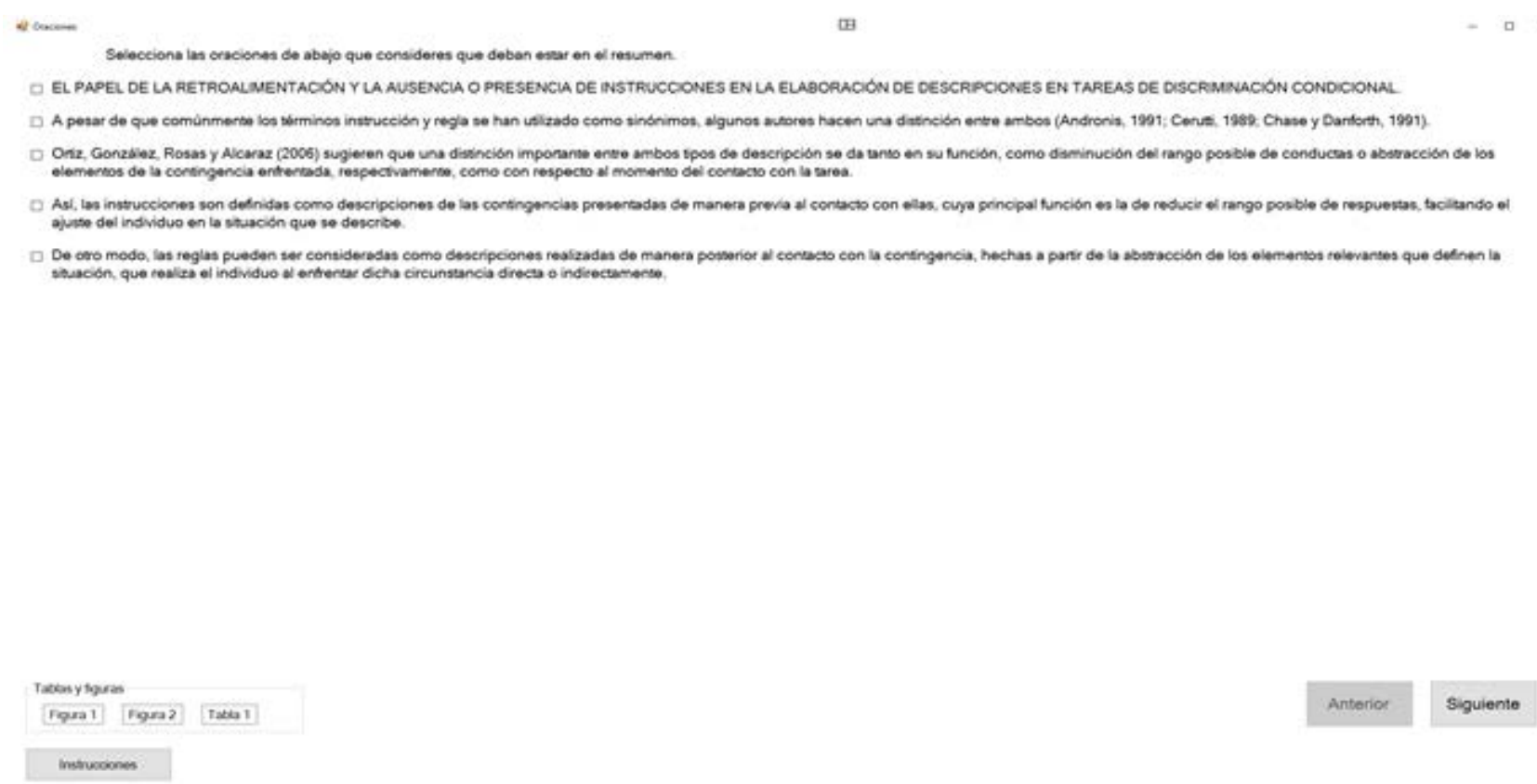

Figura 1. Pantalla correspondiente a la Fase 1 del estudio.

Al terminar se le exponía a la Fase 2, con las siguientes indicaciones:

En la siguiente pantalla aparecerán las oraciones que tú elegiste en la sesión previa, en el orden en el que las seleccionaste. Dado que el objetivo de esta tarea es que elabores un resumen del artículo previamente revisado, en esta sesión tendrás la oportunidad de modificar el orden de las oraciones seleccionadas, con el objetivo de facilitarte tal tarea, si así lo consideras pertinente. Para ello, selecciona con el cursor la oración cuyo orden quieras cambiar y después haz clic en los botones "Arriba" o "Abajo", según corresponda. Una vez que hayas hecho todos los cambios que desees, selecciona el botón que dice "Listo". En caso de que tengas dudas respecto de algún aspecto de la tarea, podrás consultar estas instrucciones todas las veces que lo desees, haciendo clic en el botón que dice "Instrucciones".

La pantalla a la que los participantes se exponían se muestra en la Figura 2. 


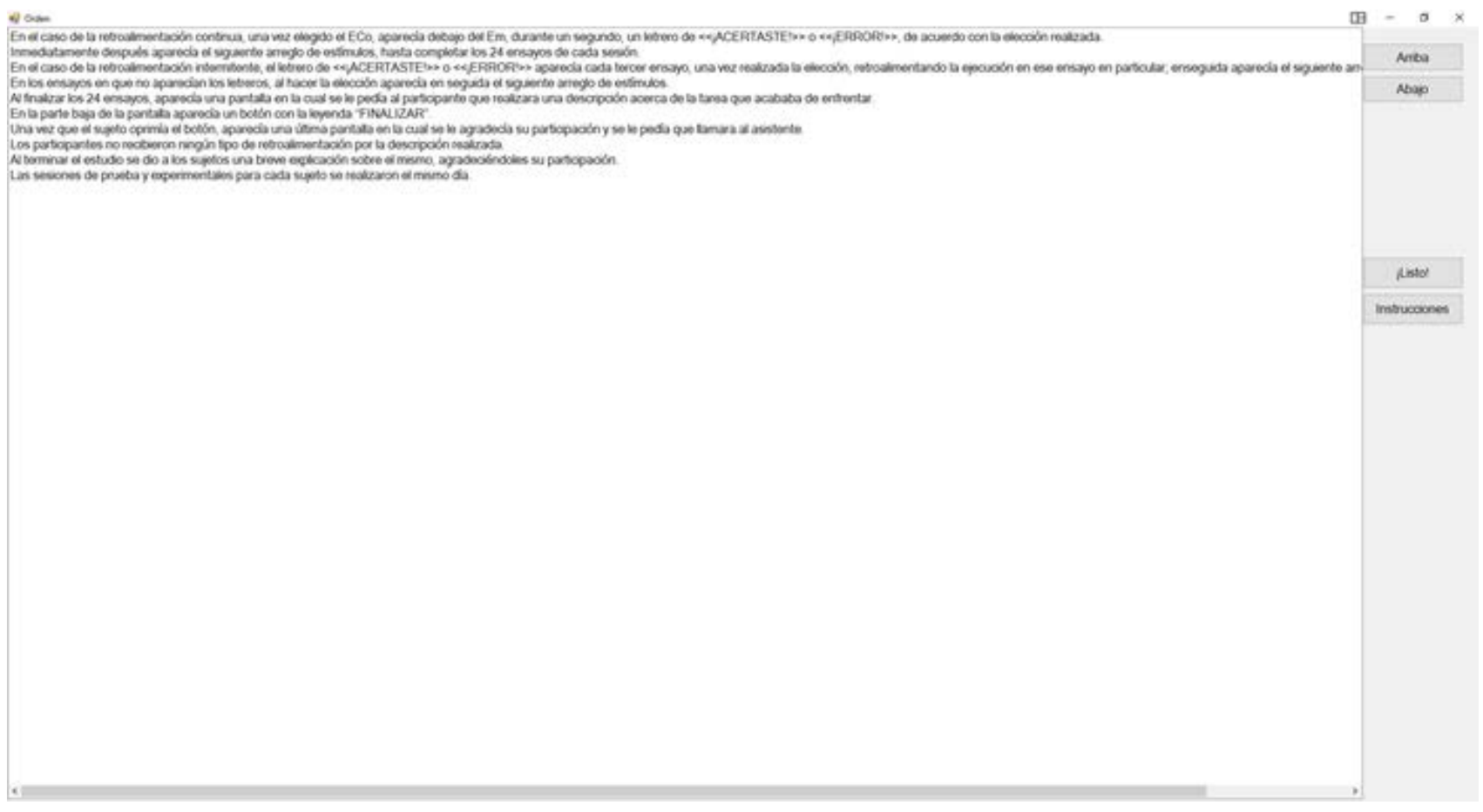

Figura 2. Pantalla correspondiente a la Fase 2 del estudio.

Una vez terminada dicha fase, se le exponía a la tercera y última fase de la primera sesión, con las siguientes instrucciones:

En esta parte de la tarea lo que debes hacer es escribir el resumen del artículo en el espacio que aparecerá en la pantalla. Para ello, debes usar la información de las oraciones que seleccionaste previamente, las cuales aparecerán en una nueva ventana cuando hagas clic en el botón que dice "Ver oraciones". Tú puedes avanzar o retroceder entre estas, usando los botones denominados "Anterior" y "Siguiente". En caso de que en tu computadora no apareciera la oración completa, podrás verla moviendo la barra de desplazamiento que está en la parte de abajo. Si tienes dudas respecto de algún aspecto de la tarea, podrás consultar estas instrucciones todas las veces que lo desees, haciendo clic en el botón que dice "Instrucciones". Al terminar de elaborar tu resumen, haz clic en el botón "Finalizar".

La pantalla a la que los participantes se exponían se muestra en la Figura 3. 
Figura 3. Pantalla correspondiente a la Fase 3 del estudio.

Al concluir la parte anterior se llevaba al participante a otro laboratorio (el de conducta social) en el que se le proporcionaba agua, alimentos ligeros y se le permitía acceso a revistas de divulgación científica durante 10 minutos antes de iniciar con la Sesión 2, la cual constaba de las mismas fases que la Sesión 1 pero con un artículo diferente. Al terminar se le agradecía por su participación y se le entregaba la cantidad exacta que hubiera requerido para pagar el transporte de su domicilio a las instalaciones del centro de investigación y de regreso.

Resultados. Los datos recabados de ambas muestras se analizaron tanto en términos cuantitativos como cualitativos. Se registró el número y tipo de oraciones seleccionadas identificando cuáles de esas correspondían a la información crítica del artículo, el orden final de las oraciones seleccionadas, la consulta de tablas y figuras (cuáles y cuántas veces se revisaron), el número de palabras empleadas en cada uno de los resúmenes elaborados, y el número y tipo de aspectos incluidos en los resúmenes elaborados (objetivo, población, tarea, procedimiento, resultados, discusión y conclusiones, y palabras clave).

En relación a la fase de selección, en la Muestra 1 se observa que el $33.33 \%$ de los participantes seleccionan entre 16 y 30 oraciones en el Artículo 1 mientras que en el Artículo 2 el $56.14 \%$ de los participantes seleccionan entre 16 y 30 oraciones en la primera fase del estudio. Los participantes de la Muestra 2 seleccionan entre 25 y 65 oraciones en el Artículo 1 y entre 15 y 44 en el Artículo 2 (de un total posible de 115 y 69 oraciones, respectivamente).

Con el objeto de capturar el dato relativo al tipo de oraciones seleccionadas así como cuáles de estas correspondían a la información crítica del artículo se calculó un índice de efectividad de selección. Las oraciones de cada artículo se clasificaron en oraciones críticas, auxiliares y no 
pertinentes. Se consideraron oraciones críticas las que contenían información sin la cual el resumen estaría incompleto (información crítica), es decir, frases centrales relativas a: objetivo, población, tarea, procedimiento, resultados, discusión y conclusiones. Las oraciones auxiliares eran las que contenían información adicional en cualquiera de las secciones previamente mencionadas pero que no sería adecuado incluir en el resumen por tratarse de aspectos muy puntuales o sumamente detallados. Finalmente, las oraciones no pertinentes eran las que no debían ser incluidas en los resúmenes como el título del artículo, la lista de referencias, los pies de página, etc.

El índice se obtuvo dividiendo el número de oraciones críticas seleccionadas por el participante entre el número de oraciones críticas del texto, en cada elemento de los que debe contener un resumen (objetivo, población, tarea, procedimiento, resultados y discusión). El resultado de ello se multiplicó por el número de oraciones críticas seleccionadas por el participante entre el número de oraciones seleccionadas en cada uno de los seis apartados que contiene un artículo experimental: introducción, población, aparatos, procedimiento, resultados, y discusión; el resultado obtenido se multiplicó por un factor que daba más peso a apartados que contenían un mayor número de oraciones (en el artículo experimental al que se expuso a los participantes).

Por ejemplo, en uno de los artículos, el apartado de introducción tenía un total de 29 oraciones, sólo una de las cuales era crítica, mientras que el apartado de población tenía un total de 2 oraciones, 1 de las cuales era crítica. Se consideró que un participante que seleccionara la oración crítica del apartado de introducción era más eficiente que el que seleccionara una oración del apartado de población, y para capturar tal aspecto se utilizó dicho factor de ajuste. El cálculo previamente descrito se realizó para cada uno de los elementos que debe contener un resumen: objetivo, población, tarea, procedimiento, resultados, discusión. El índice que se muestra a continuación (ver Figura 4) es resultado de promediar el puntaje resultante de cada uno de los diferentes elementos mencionados.

En la Muestra 1, prácticamente todos los participantes (excepto el P13 en el Resumen 2) estan por debajo del .5 de efectividad al seleccionar las oraciones de los diferentes elementos en ambos resúmenes, lo que implica que son poco eficientes al identificar las oraciones críticas de los artículos a los que se les expuso. Destaca el hecho de que en 15 de los 21 participantes mejoran (algunos mucho más que otros) el índice de efectividad de selección del Resumen 1 al 2 (los que más mejoran en dicho aspecto fueron P4, P12, P13, P14, P16, P19 y P21). En la Muestra 2, todos los participantes (con excepción del P22) estan por debajo del .4 de efectividad en ambos resúmenes. Ello implica que, al igual que los participantes de la Muestra 1, son poco eficientes al identificar la información crítica de los artículos experimentales a los que fueron expuestos. Aunque en este caso en 17 de los 24 participantes se observa una mejora en la selección de oraciones críticas en el Artículo 2 con respecto al 1 (los que mejoran más en dicho aspecto son el P6, P19 y P22).

En lo que respecta al dato relativo al orden final de las oraciones seleccionadas por cada participante, en la Muestra 1 se observa que el orden final que dan a las oraciones que seleccionan se corresponde con el orden que dichas oraciones tienen en el artículo (por ejemplo, el P1 selecciona al final, en dicho orden, las siguientes oraciones: 12, 29, 100,108). Sólo en algunos casos los participantes dejan las oraciones en un orden diferente al que tienen en el artículo correspondiente. A diferencia de la Muestra 1, en la Muestra 2 se observa que la mayoría de los participantes deja, en su 

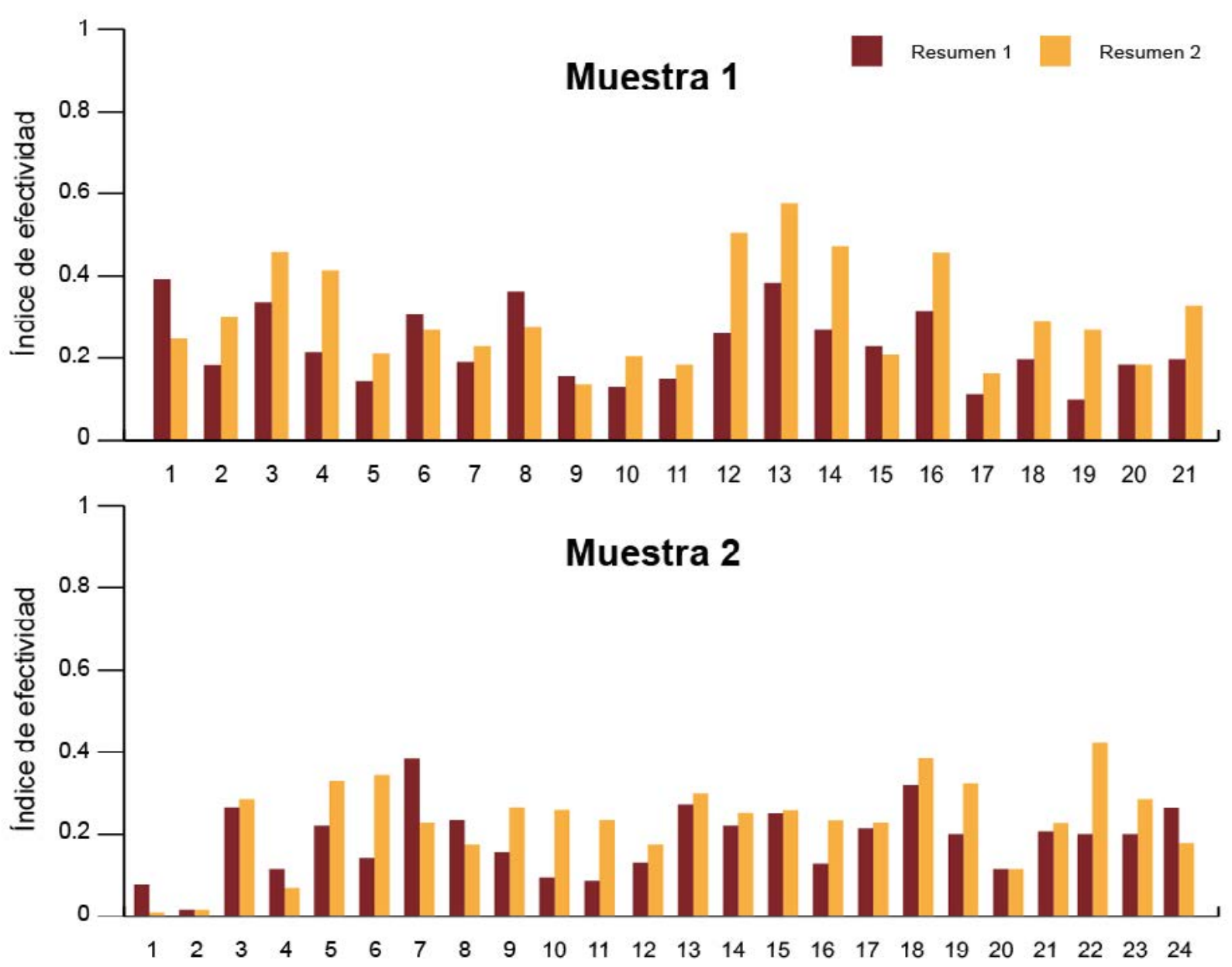

Figura 4. Índice promedio de efectividad de selección de oraciones para las Muestras 1 y 2, en ambos artículos.

acomodo final, muchas oraciones en un orden diferente al que tienen en el artículo correspondiente, es decir, oraciones del inicio del texto a mitad de la lista, etc.

Es importante mencionar que las oraciones aparecían en el orden en el que se seleccionaban $y$, dado que el participante podía avanzar hacia adelante y hacia atrás en el programa durante la fase de selección, el orden final de las oraciones seleccionadas podía ser diferente al que tenían en el artículo en cuestión. Por otra parte, se analizó qué porcentaje de las oraciones empleadas por los participantes al elaborar su resumen correspondían a oraciones críticas. Los datos muestran que en la Muestra 1 sólo 11 de los 21 participantes emplean más del $60 \%$ de las oraciones críticas tanto en el Resumen 1 como en el 2. El resto corresponde a oraciones auxiliares. Sólo algunos participantes incluyen información no pertinente (el título fue la única oración de este tipo incluida). Se encuentra que por lo general los participantes ponen en sus resúmenes la información de las oraciones seleccionadas. No se observa algún tipo de correspondencia entre el número o tipo -críticas, auxiliares, etc.- de oraciones seleccionadas y el desempeño de los participantes en ninguno de los dos resúmenes. 
Un dato destacado al respecto fue que algunas de las oraciones críticas son seleccionadas por un gran número de participantes. Las oraciones más seleccionadas en el caso del Resumen 1 contienen información relativa a: objetivo, procedimiento, población y discusión, mientras que en el caso del Resumen 2 las más seleccionadas corresponden a: objetivo, población, procedimiento, resultados y discusión. En ambos resúmenes se seleccionan más oraciones de las secciones de procedimiento y discusión. Por otro lado, respecto al porcentaje de las oraciones empleadas por los participantes de la Muestra 2 al elaborar su resumen, que corresponden a oraciones críticas, los datos muestran que sólo 11 de los 24 participantes emplean más del $60 \%$ de las oraciones críticas en el Resumen 1 y 10 de los 24 en el 2 . El resto corresponde a oraciones auxiliares.

También se encuentra que por lo general los participantes ponen en sus resúmenes la información de las oraciones seleccionadas aunque en este caso sí se observa correspondencia entre el número y tipo (oraciones críticas) de oraciones seleccionadas y el desempeño de los participantes ya que, en lo general, los participantes que emplean más oraciones críticas en sus resúmenes fueron los que muestran el mejor desempeño, en ambos resúmenes. Al igual que en el caso de la Muestra 1, se observa que algunas de las oraciones críticas son seleccionadas por un gran número de participantes, mientras que en otros ello varía mucho. Las oraciones más seleccionadas por ambas muestras son las mismas en el caso del Resumen 1 y contienen información relativa a: objetivo, procedimiento, población y discusión (aunque se observa que 15 de los 24 participantes eligen una oración que corresponde a evidencia, lo que no se observa en la Muestra 1), mientras que, en el caso del Resumen 2, las más seleccionadas corresponden a: objetivo, población y procedimiento. En el Resumen 1, se seleccionan más oraciones de las secciones de procedimiento y discusión, mientras que en el 2 de objetivo y procedimiento.

Por otra parte, en lo relativo a la consulta de las tablas y figuras de los artículos empleados (las cuales se podían consultar cuantas veces se deseara durante la fase de selección de oraciones y de elaboración del resumen), en la Muestra 1, se encuentra que los participantes las consultan por lo menos en una ocasión, aunque la mayoría sólo hacía "revisiones" rápidas, de unos cuantos segundos, y conforme transcurrían las fases del estudio las consultaban cada vez menos. Algo que destaca es que dos de los tres participantes que tienen el mejor desempeño (P7 y P15) son de los pocos que consultan tablas y figuras durante la elaboración del Resumen 2 (ver Figura 5).

En la Muestra 2, se observa que todos los participantes (excepto P9 y P24) las consultan por lo menos en una ocasión, aunque, también en este caso, la mayoría sólo hace "revisiones" rápidas, de unos cuantos segundos, y conforme transcurren las fases del estudio las consultan cada vez menos. Algo que destaca es que los participantes que inician mal y mejoraron su desempeño en el Resumen 2 con respecto al 1 son quienes consultan por más tiempo tanto las figuras como las tablas.

En cuanto al número de veces que consultan las oraciones seleccionadas no se observa ningún tipo de relación entre ello y el desempeño en ninguna de las muestras. La ejecución en lo que respecta al número de elementos (objetivo, población, tarea, procedimiento, resultados, discusión y conclusiones, y palabras clave) incluidos en los resúmenes 1 y 2 se clasificó en tres categorías: 1) los que lo hicieron mal al inicio y no mejoraron en el segundo resumen (el criterio para considerar que había mejora era agregar dos elementos o más en el Resumen 2 con respecto al 1); 2) los que 
lo hicieron mal al inicio y mejoraron en el segundo resumen; 3) los que empeoraron en el Resumen 2 con respecto al $1 \mathrm{y} ; 4$ ) los que habían tenido un buen desempeño al elaborar el Resumen 1 y se mantuvieron así en el Resumen 2. En la Figura 5 puede observarse que el $81 \%$ de los participantes de la Muestra 1 se ubica en la categoría 1 (barras de color amarillo), el 14\% en la 2 (barras de color verde), y el $5 \%$ en la 3 (barras de color azul). Los elementos incluidos con mayor frecuencia son la discusión, el objetivo, el procedimiento y la población, en ese orden de frecuencia de inclusión. La mayoría de los participantes incluye los elementos en un orden diferente al que la APA considera deben tener.

En la Muestra 2, seis de los participantes se ubican en la categoría 4, es decir, desde el Resumen 1 incluyen cuatro elementos o más. Por otra parte, siete de los participantes se ubican en la categoría 1, es decir, incluyen entre ninguno (P1, P2, P11, P19 y P21) y tres elementos (P4 y $\mathrm{P} 17)$ en ambos resúmenes. En esta muestra, cinco de los participantes tienen un bajo desempeño
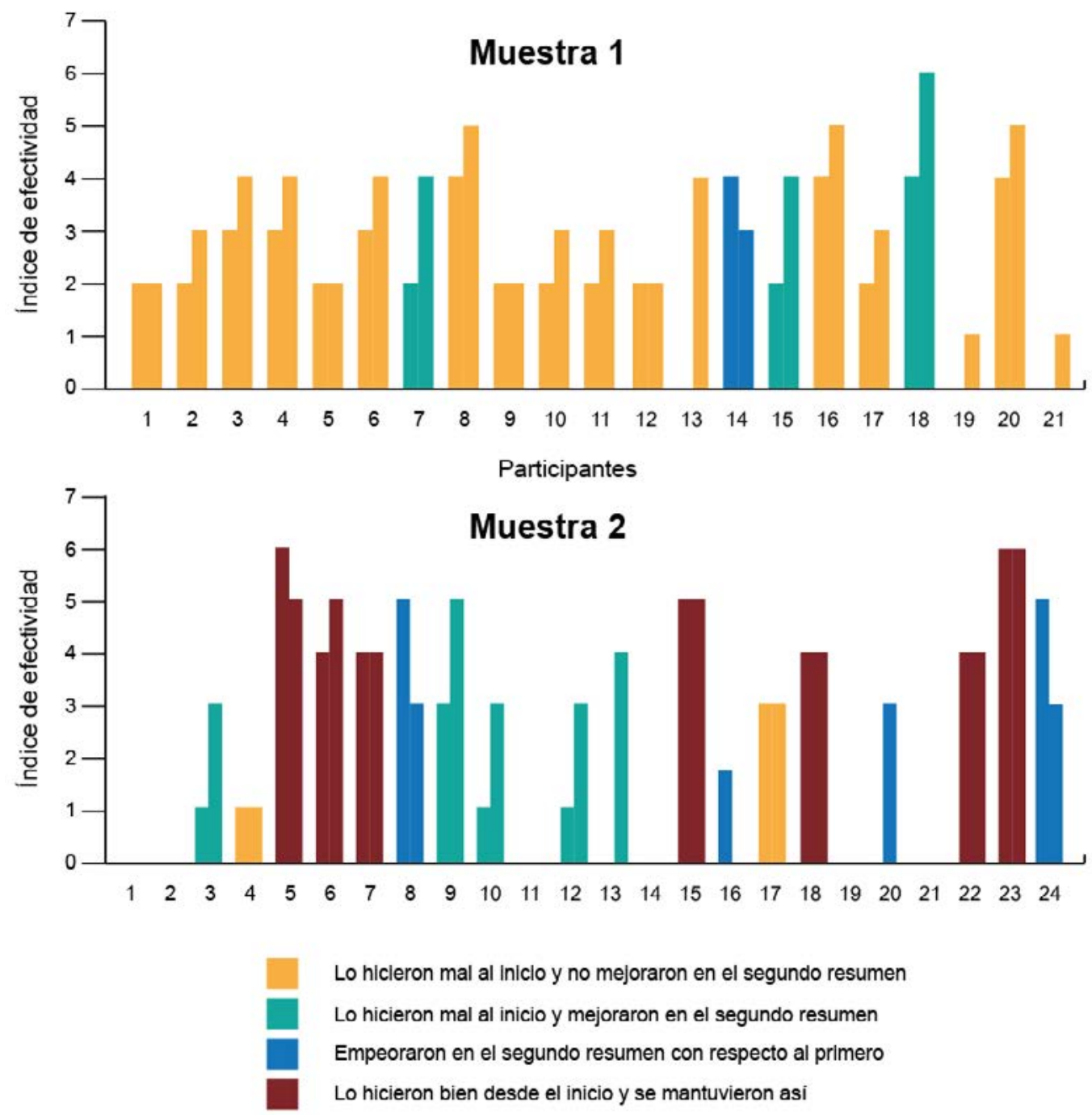

Figura 5. Número de elementos incluidos en los dos resúmenes. La primera columna de cada participante corresponde al dato del Resumen 1 y la segunda columna, al del Resumen 2. 
en el Resumen 1 pero lo mejoraron al agregar dos o más elementos en el Resumen 2 (P3, P9, P10, P12 y P13) mientras que cuatro lo empeoran al incluir en el Resumen 2 menos elementos que en el Resumen 1. Los elementos incluidos con mayor frecuencia en ambos resúmenes son el objetivo, el procedimiento, los resultados y la población, en ese orden de frecuencia de inclusión. Algo destacable fue que la mayoría de los participantes incluye los elementos en un orden diferente al que la APA considera deben tener, aunque todos los que mencionan el objetivo (en el Resumen 1) lo incluyen en primer lugar, es decir, en el lugar correcto.

En lo relativo al análisis cuantitativo de los datos, en la Muestra 1 el promedio del número de palabras empleadas en los resúmenes elaborados es de 306 y 297 (Resumen 1 y 2, respectivamente). El $57.14 \%$ de los resúmenes del Artículo 1 y el $62 \%$ de los resúmenes del Artículo 2 se apegan a los criterios de la APA en cuanto a extensión (250 palabras o menos). En la Muestra 2 sólo el 29.17\% de los participantes emplean 250 palabras o menos en el Resumen 1 (el número de palabras promedio fue de 435), mientras que en el Resumen 2 lo hizo el 50\% (palabras promedio: 381 ).

Al respecto destaca el caso de un participante de la Muestra 1 (P20) que al elaborar el resumen prácticamente transcribe completo el artículo previamente leído. Averiguando al respecto (analizando sus latencias de respuesta), se identifica que dicho alumno había copiado el artículo poco a poco: observaba brevemente el documento, escribía un par de palabras, regresaba al escrito y volvía a escribir otro poco y así consecutivamente (justamente para evitar que los participantes copiaran y pegaran el texto al elaborar el resumen dicha función había sido deshabilitada del programa computacional al que se expusieron).

Debido a lo anterior se calculó un índice de desempeño que penalizaba las palabras que rebasaban las 250 (criterio estipulado por la APA en cuanto a la extensión máxima que debe tener el resumen de un artículo experimental) mediante una función hiperbólica (ver Figura 6). La razón de dicha penalización era que un participante que prácticamente transcribiera el artículo completo tendría, por ende, todos los elementos que debe contener un resumen (siete) por lo que parecería que su desempeño fue mejor que el de un participante que hubiera incluido cinco elementos, por ejemplo, pero dicho dato sería artificioso, es decir, un desempeño de tal naturaleza no implicaría que el participante identificó qué elementos debía incluir en su resumen, además de que un resumen debe presentar de manera breve el contenido de un artículo, y transcribirlo todo no cumple con dicho criterio.

El índice de desempeño se obtuvo al dividir el número de elementos que cada participante incluía en su resumen entre el número total de elementos que un resumen debe contener según la APA (7), multiplicando el resultado por una función hiperbólica. De acuerdo con dicho índice los valores más cercanos a 1 representan mejores ejecuciones tomando en consideración el número de elementos incluidos y la extensión del resumen elaborado (ver Figura 7).

Como puede observarse en la Figura 7, al hacer el ajuste "castigando" las palabras excedentes, el desempeño de los participantes disminuye con respecto al de la Figura 5, lo que indica que muchos participantes habían transcrito gran parte de los artículos en cuestión al elaborar el resumen. En la Muestra 1, al elaborar el Resumen 1, el desempeño es bajo en casi todos los participantes, mientras que siete de los participantes mejoran su desempeño al elaborar el segundo resumen, agregando dos o más elementos y disminuyendo la extensión del resumen. 


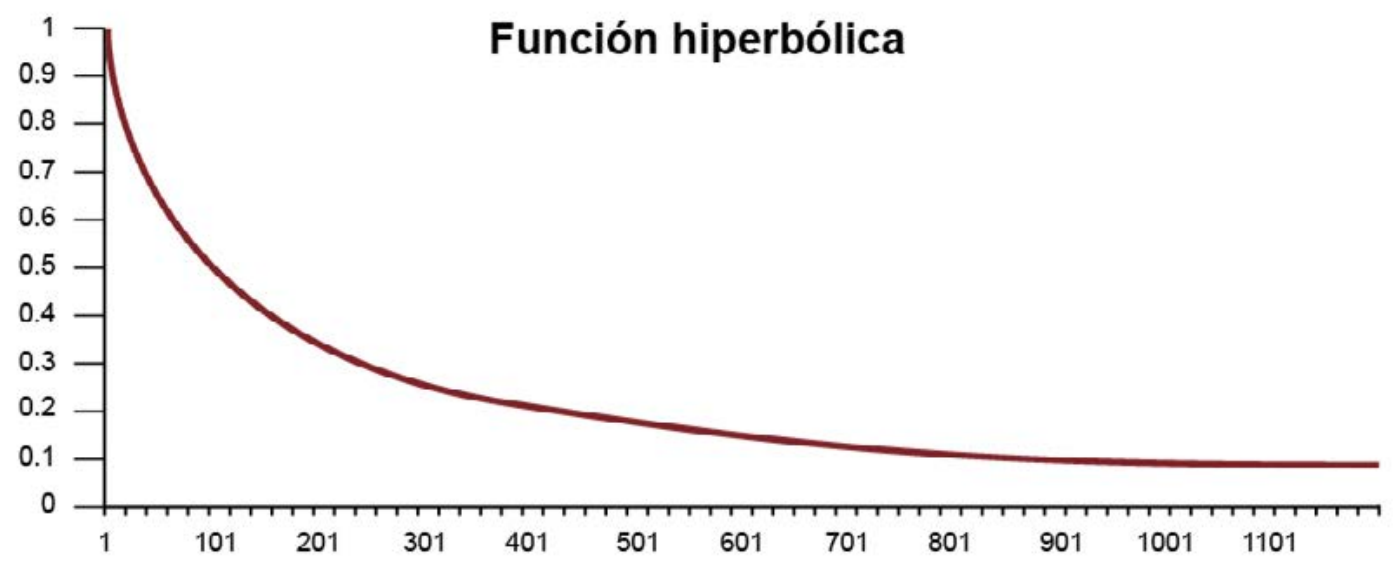

Figura 6. Función hiperbólica empleada para penalizar las palabras excedentes de 250.

Por otra parte, en la Muestra 2 se observan menos participantes en las categorías 2 y 4 , que pueden considerarse como los mejores desempeños; y muchos más en la categoría 1, la del peor desempeño. Es decir, también en este caso muchos de los participantes habían transcrito gran parte de los artículos a los que se expusieron.
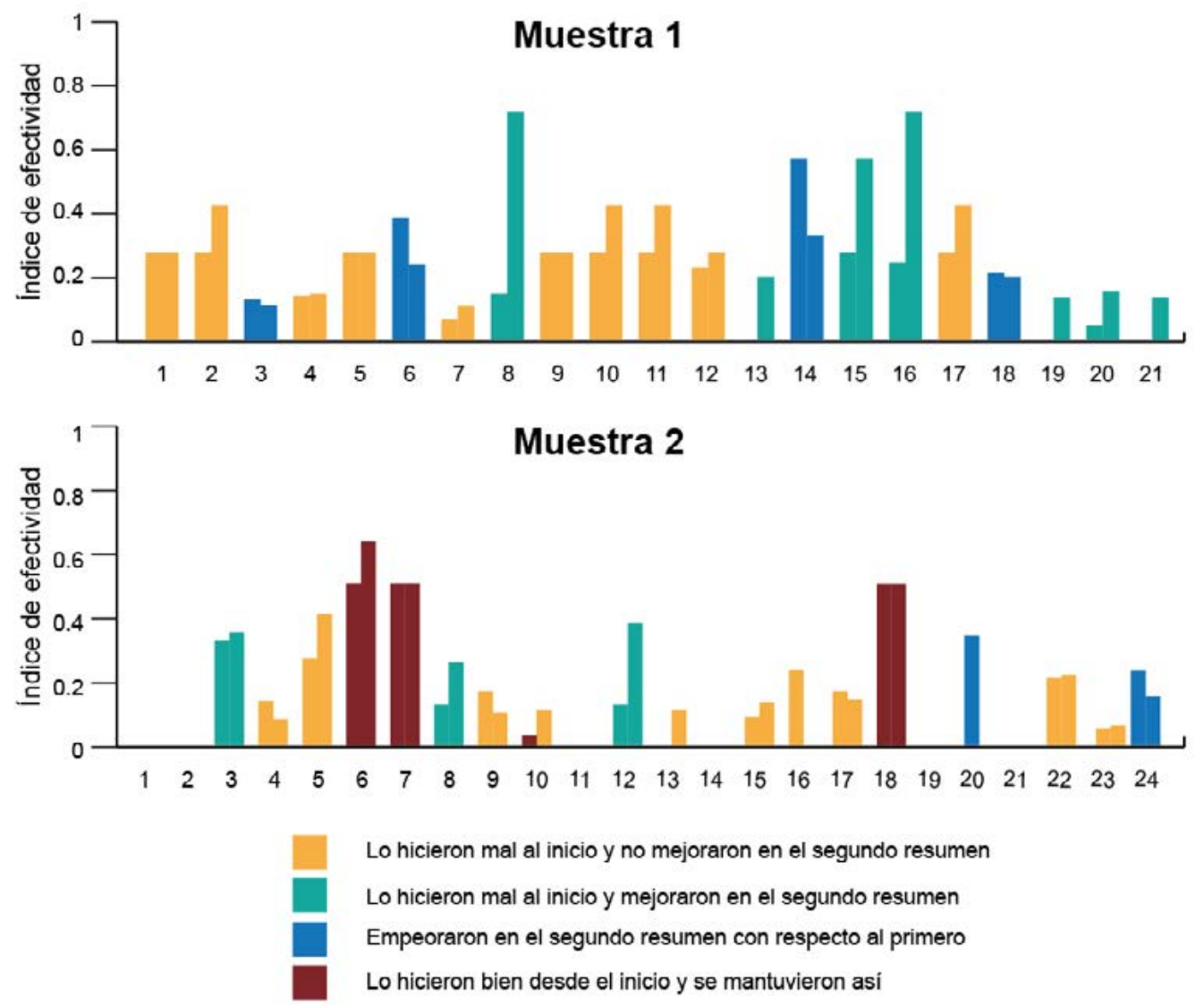

Figura 7. Índice de desempeño al elaborar los dos resúmenes. 
Al contrastar el índice de efectividad de la selección de oraciones con el índice de desempeño en la elaboración de resúmenes, no se encuentra ninguna relación en la mayoría de los participantes de ambas muestras, ya que quienes mejor se desempeñaron en la identificación de la información crítica de los dos textos a los que se les expuso (fase de selección) no necesariamente mostraron los mejores desempeños al elaborar los resúmenes respectivos y viceversa.

En el caso de la Muestra 2 sí se observa, en algunos casos, una relación entre desempeño en la selección de oraciones y en la elaboración de resúmenes; ello se registra en algunos de los participantes que muestran el peor desempeño en ambos aspectos (ver P1, P2, P4 y P20). Así como en algunos de los que muestran el mejor desempeño (ver P3, P6, P7, P8 y P18). En el caso de los Participantes 7 y 8 es importante hacer una aclaración ya que a pesar de que disminuyen su índice de efectividad de selección del Resumen 1 al 2, de entrada habían mostrado uno de los índices más altos, particularmente el P7.

En cuanto a la información contenida en los resúmenes elaborados, el $71 \%$ de los participantes de la Muestra 1 derivan sus escritos de lo leído en los artículos en el Resumen 1, mientras que en el Resumen 2 lo hizo el 85\%; el resto de los participantes incluyen, en ambos resúmenes, información que no estaba en los textos, como datos, términos e incluso experimentos. Cabe destacar que dicha información era pertinente (en el contexto del área de investigación del artículo leído previamente). En la Muestra 2, se observa que el $83.33 \%$ de los resúmenes del Artículo 1 se derivan de lo expuesto en este, mientras que en el Artículo 2 el 100\% de los participantes derivan sus resúmenes del artículo correspondiente. Por otro lado, el $83.33 \%$ de los participantes redactan su primer resumen en tercera persona; a diferencia de un $95.83 \%$ en el segundo resumen.

Comparación de los resultados de las dos muestras. Con fines comparativos, se analizarán algunos aspectos particulares del desempeño de ambas muestras. Por ejemplo, respecto del porcentaje de participantes que incluye cada uno de los diferentes elementos que debe contener un resumen, de ambas muestras, se observa que: a) hay una mejora en dicho aspecto de la elaboración del segundo resumen con respecto al primero; b) los elementos que con mayor frecuencia se incluyen en ambas muestras, en los dos resúmenes, son el objetivo y la discusión, mientras que el que menos se incluye en ambas muestras y en ambos resúmenes es el de resultados (ver Figura 8).

Si se hace una comparación entre el tipo de elementos que los participantes seleccionan (ver Figura 9) al exponerse a cada uno de los artículos, puede observarse correspondencia entre el tipo de aspectos seleccionados por más participantes y lo que la mayoría incluyó en sus resúmenes, es decir, los elementos más seleccionados son el objetivo y la discusión, en ambas muestras, y el menos seleccionado es el de resultados. Algo destacable es que en ambas muestras un mayor porcentaje de participantes selecciona más elementos en el Resumen 2 que en el 1.

A pesar de que todos los elementos son seleccionados por lo menos por el $50 \%$ de los participantes (ver Figura 9) ello no se refleja en la elaboración de los resúmenes dado que algunos de tales elementos son incluidos por un porcentaje mínimo de participantes o por ninguno (ver en la Figura 8 el caso del elemento Tarea en el Resumen 1 de ambas muestras y del de Resultados en los dos resúmenes de ambas muestras). De manera similar al caso de la selección de elementos, en ambas muestras un mayor porcentaje de participantes incluye más elementos en el Resumen 2 que en el 1. 

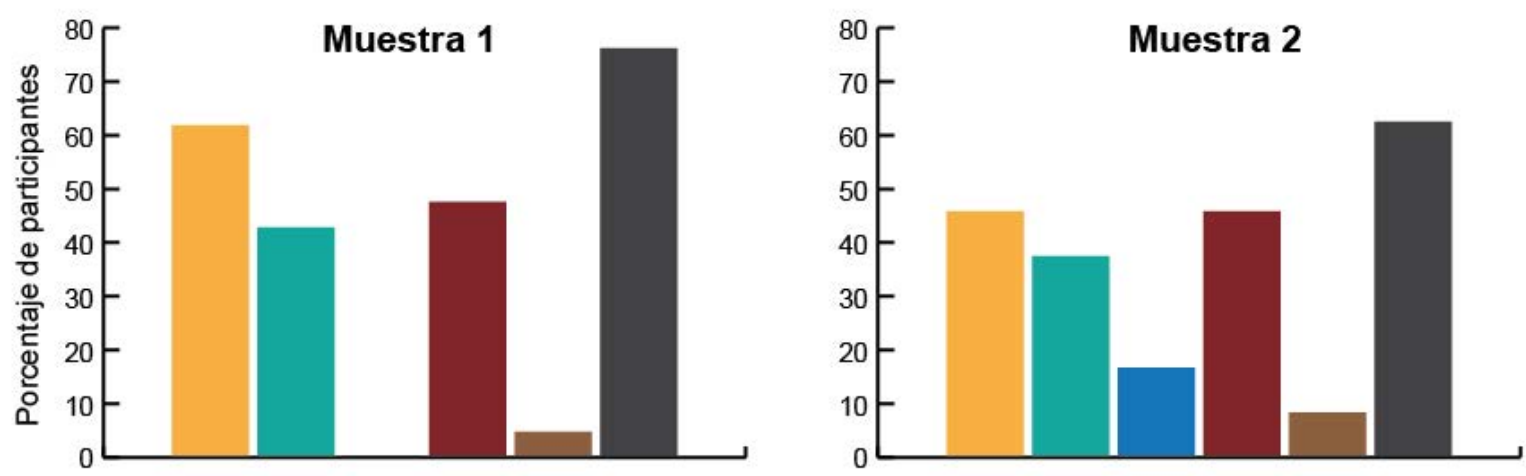

Elementos del resumen elaborado del Artículo 1
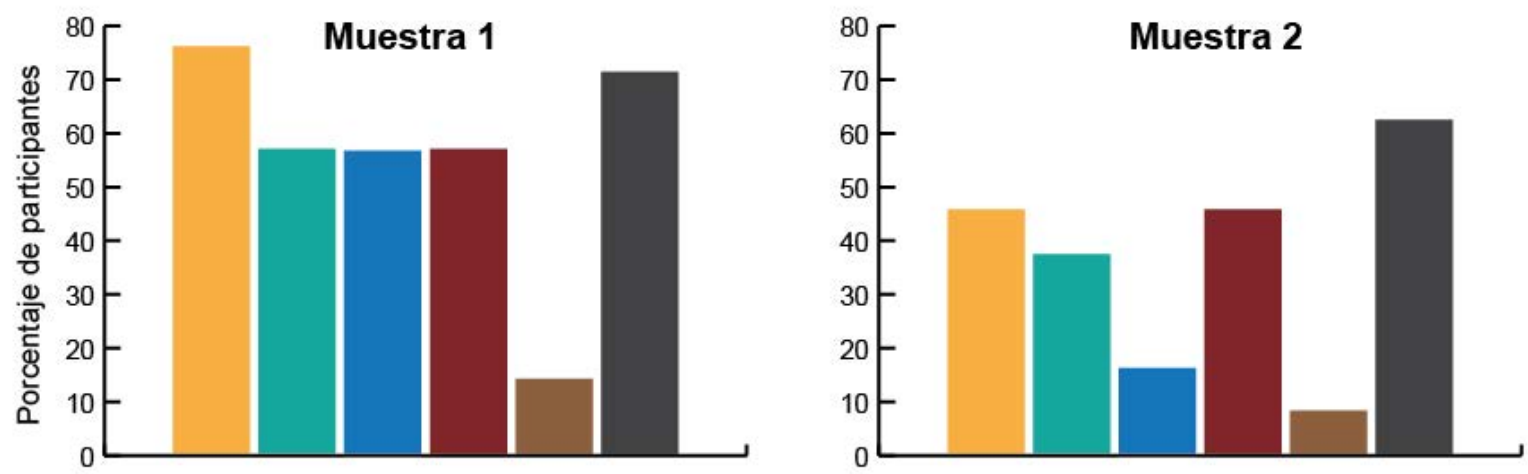

Elementos del resumen elaborado del Artículo 2

Objetivo

Población

Tarea

Procedimiento

Resultados

Discusión

Figura 8. Porcentaje de participantes de cada muestra que incluye cada uno de los elementos de un resumen en los dos resúmenes elaborados.

Además se identificó qué era lo que los participantes hacían con el artículo previamente revisado cuando debían elaborar un resumen de este, si lo copiaban o lo parafraseaban: en dicho sentido se identificaron dos tipos posibles de paráfrasis, la mecánica, que implica sustituir por sinónimos o frases alternas las expresiones que aparecían en el texto (López, 2010), o la paráfrasis constructiva, que implica reelaborar el enunciado, dando origen a otro con características distintas, pero conservando el mismo significado (López, 2010), o bien, si los participantes hacían creaciones originales, es decir, si incluían en sus resúmenes información que no estaba en el artículo respectivo.

La Figura 10 muestra que en ambas poblaciones, en los dos resúmenes, prevalece la combinación de dos o más estrategias de escritura. Al analizar de qué estaban compuestas tales combinaciones, pudo identificarse que lo más frecuente es que parafrasearan mecánicamente el artículo, 

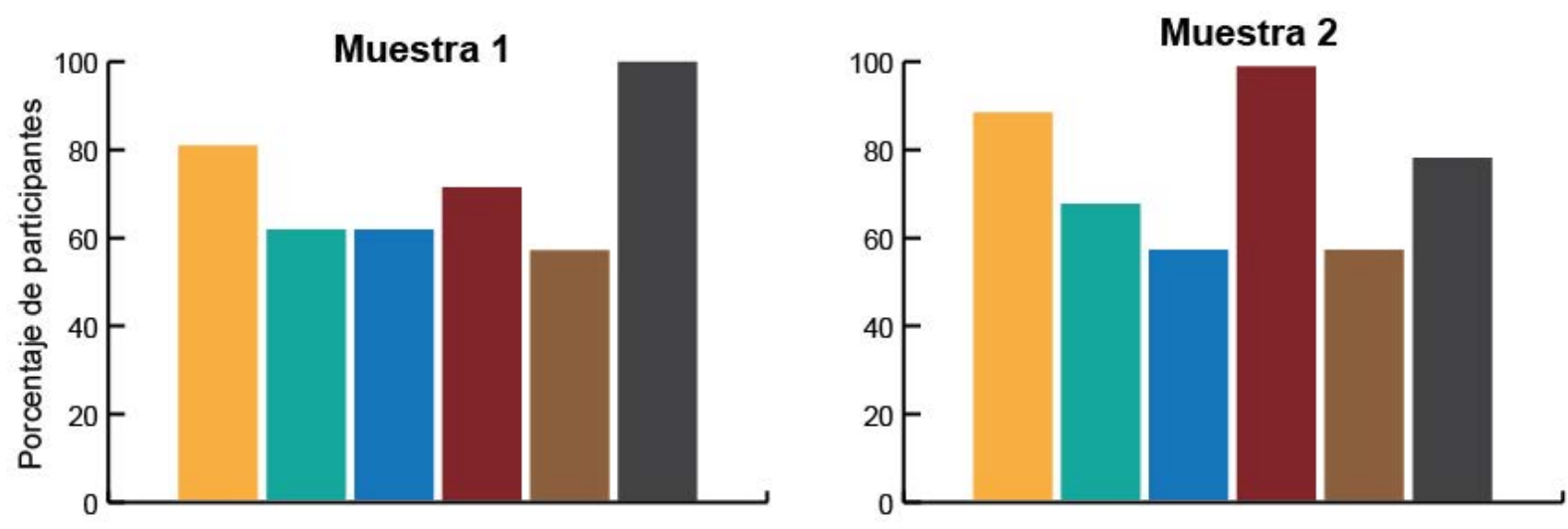

Elementos seleccionados del Artículo 1
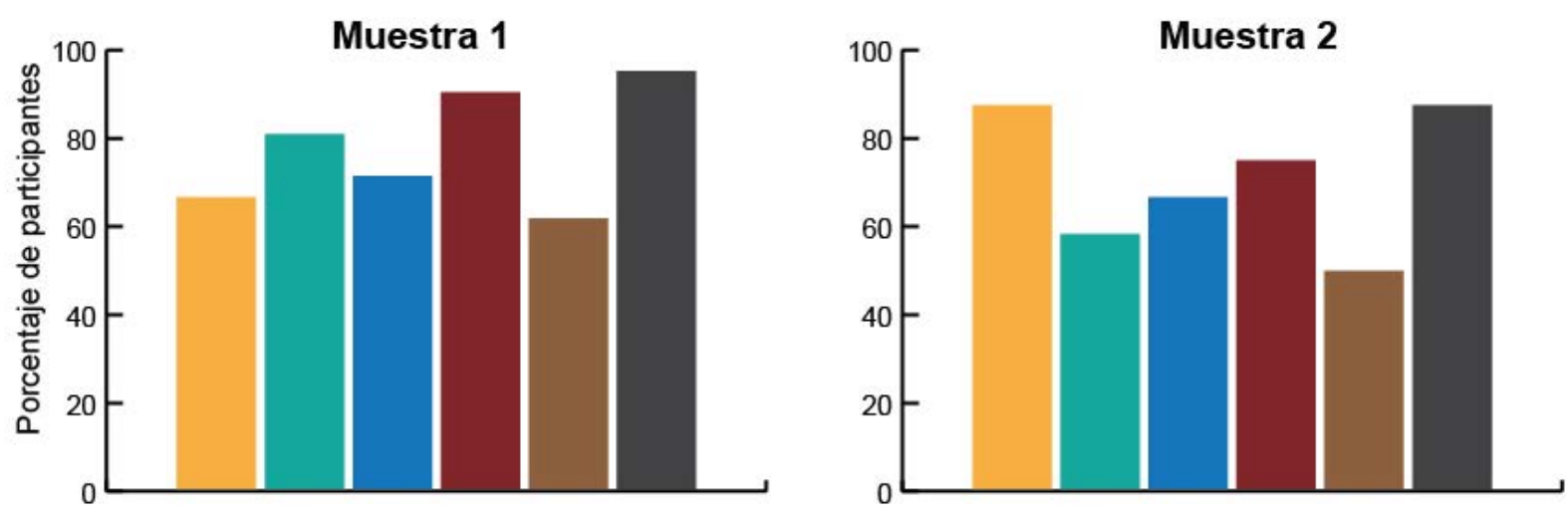

Elementos seleccionados del Artículo 2

Objetivo $\square$ Población $\square$ Tarea $\square$ Procedimiento

Resultados Discusión

Figura 9. Porcentaje de participantes de cada muestra que selecciona (al revisar los dos artículos) cada uno de los elementos que debe incluir un resumen.

o bien que lo copiaran, en ese orden. En general, se observa que los participantes de la Muestra 2 emplean la copia con menor frecuencia que los participantes de la Muestra 1 y con mayor frecuencia agregan información que no estaba en los artículos revisados. Algo interesante al respecto fue que la información agregada era pertinente ya que se relacionaba con el contenido del artículo en cuestión. Por ejemplo, se proponía una nueva investigación, se hacía una interpretación propia de los datos del artículo revisado, etc.

El análisis respecto de quiénes agregaban información que no estaba en los artículos por tipo de formación (psicólogos o de otras carreras), muestra que con excepción del P20 (alumno de la carrera de Ciencias de la Educación) todos los que agregan información eran estudiantes de Psicología. 


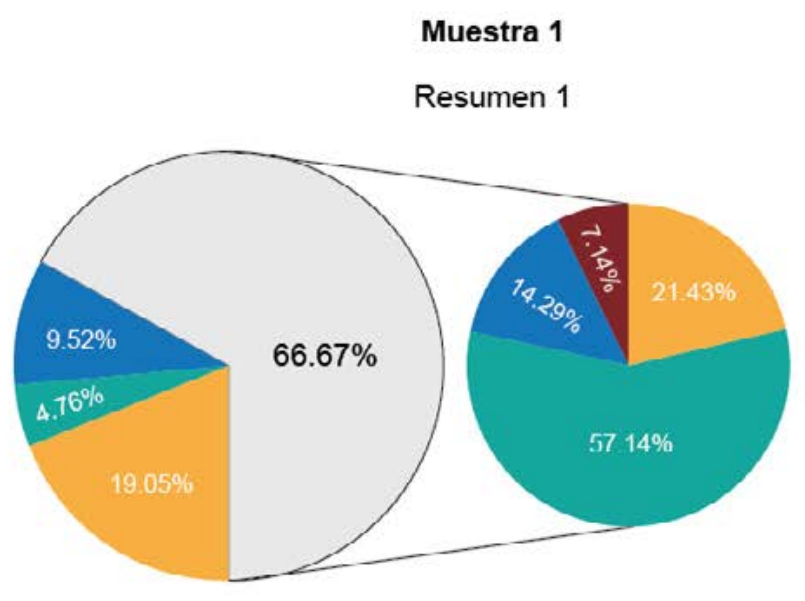

Resumen 2

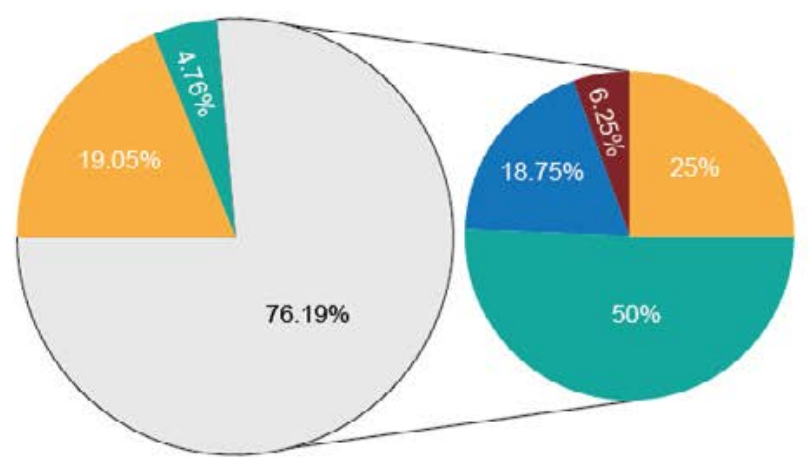

Muestra 2

Resumen 1

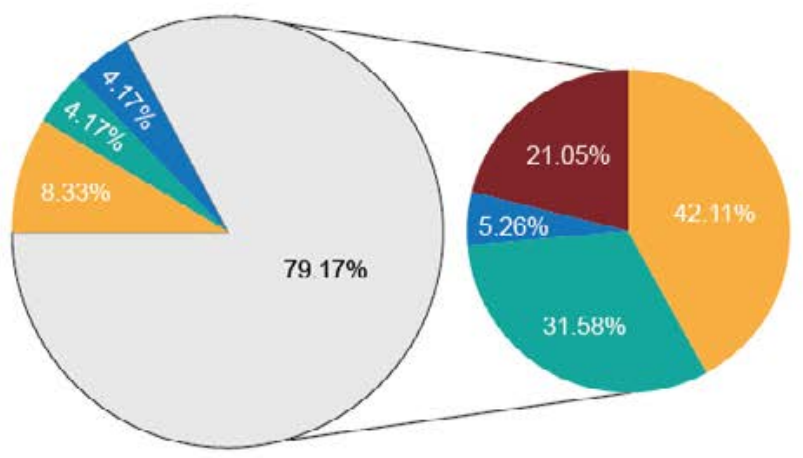

Resumen 2

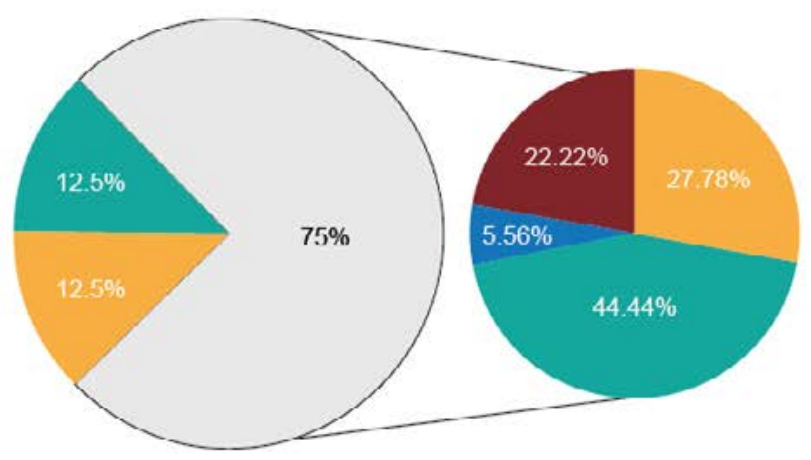

Paráfrasis Constructiva

Creación Original

Figura 10. Porcentaje de participantes de ambas muestras que copiaron, parafrasearon o incluyeron información nueva al elaborar sus dos resúmenes.

Con el objeto de dar confiabilidad al análisis de datos realizado se envió a un grupo de cuatro jueces (investigadores con gran experiencia en la dictaminación de artículos) un compendio de 12 de los resúmenes elaborados por los participantes de la Muestra 2 (seis del Resumen 1 y seis del Resumen 2). El criterio para seleccionar dichos resúmenes fue la extensión, es decir, se seleccionaron dos breves, dos regulares y dos extensos. Se pidió a los jueces que asignaran el puntaje que consideraran tenía el resumen en cuestión y comentaran el criterio empleado para determinar dicho puntaje. La instrucción que se proporcionó a los jueces fue la siguiente:

Con el fin de validar criterios que nos permitan calificar el desempeño de universitarios, al elaborar resúmenes de artículos experimentales, nos gustaría contar con su valiosa colaboración dada su experticia como revisor de artículos científicos.

Para ello le agradeceríamos si pudiera calificar, de 0 a 100, con base en los lineamientos de 
la APA cada uno de los resúmenes que se adjuntan. Además de indicarnos los criterios que haya empleado para otorgar dicho puntaje.

Dicha información la podrá capturar en el formato que se adjunta con tal fin.

Los resúmenes fueron elaborados como parte de un estudio que tiene por objetivo analizar las condiciones en las que se aprende a realizar actividades científicas (entre estas, a elaborar resúmenes de artículos previamente leídos).

Lamentamos enviarle tal cantidad de trabajo pero consideramos que es necesario analizar toda esta muestra ya que captura la diversidad de los desempeños observados en los participantes. Sentimos no darle más información respecto del estudio pero creemos que ello podría sesgar su revisión, sin embargo, si después de realizado el presente análisis, deseara conocer más detalles respecto de la investigación con mucho gusto se los daremos.

Al realizar la comparación entre el puntaje asignado por los diferentes jueces se observa que tres de los cuatro jueces coinciden en la mayoría de sus apreciaciones, es decir, asignan a los mismos resúmenes los puntajes más altos y más bajos. El juez que coincide menos con los puntajes asignados por el resto de los jueces sí lo hace en el 67\% de las ocasiones. Por otra parte, al comparar los puntajes asignados por la mayoría de los jueces con el que habían obtenido los participantes empleando el índice de desempeño se observa que prácticamente hay coincidencia en todos los casos.

\section{Discusión}

El objetivo del presente estudio fue explorar las variables implicadas en la elaboración de resúmenes de artículos experimentales, en estudiantes de licenciatura. Para ello se expuso a dos muestras de alumnos de dicho nivel educativo a una preparación que implicó que seleccionaran, de dos artículos experimentales diferentes, las oraciones que consideraran pertinentes, las ordenaran como creyeran conveniente y elaboraran su respectivo resumen.

Dado que era un estudio exploratorio no se manipuló ninguna variable. La diferencia entre ambas muestras estribaba en que la Muestra 1 estuvo compuesta por estudiantes regulares de licenciatura mientras que la Muestra 2 estuvo integrada por becarios de un verano de investigación. Se decidió trabajar con la Muestra 2 a partir de observar el bajo desempeño de los participantes de la Muestra 1 en la elaboración de resúmenes de artículos experimentales bajo el supuesto de que los participantes de la Muestra 2 podrían tener un mejor desempeño debido a su mayor interés en las actividades científicas.

Los resultados muestran que la ejecución de ambas muestras fue similar en lo general ya que prácticamente en todos los aspectos identificados el desempeño de la gran mayoría de los participantes fue bajo. A continuación se discutirán las posibles razones de tales desempeños.

Las habilidades lectoescritoras se ven afectadas por las características del referente con el que se entra en contacto. Por tanto, los bajos resultados observados en general en la mayoría de los participantes de ambas muestras podrían deberse al lenguaje técnico de los artículos experimentales a los que se les expuso, es decir, a la falta de historia de referencialidad de los participantes con 
este tipo de textos (Pacheco, 2010). Ello se supone a partir de resultados previos obtenidos tanto con estudiantes de bachillerato como de licenciatura en quienes se ha observado la dificultad que muestran al interactuar con materiales técnicos (Padilla et al. 2013; Padilla y Fernández, 2014; Padilla, Tamayo y González-Torres, 2010; Tamayo, Padilla y González-Torres, 2009).

Además, el bajo desempeño observado en la mayoría de los participantes de las dos muestras tanto al seleccionar las oraciones críticas como al elaborar los resúmenes podría deberse a la complejidad de los textos a los que se les expuso, ya que por un lado contenían términos técnicos con los que los participantes no estaban familiarizados y por otra parte tenían una estructura y una lógica compleja. En diferentes estudios se ha observado que los alumnos de este nivel académico suelen mostrar un mejor desempeño en tareas que involucran interacciones en un nivel simple, en contraposición a actividades que requieren un nivel de interacción más complejo (Pacheco et al., 2007; Padilla et al., 2013; Padilla y Fernández, 2014; Padilla et al., 2015).

González, Barba y González (2010) señalan que las deficiencias observadas en la lectoescritura de materiales científicos (escritos con un lenguaje técnico) pueden deberse a que por lo general en los ámbitos escolares se trabaja en la comprensión lectora sólo a través de cursos de Lengua y Literatura, y el problema con dicha estrategia es que los textos literarios (que emplean una prosa narrativa) y los científicos (con prosa expositiva) son diferentes. Se ha observado que la prosa narrativa es mucho más fácil de comprender y retener que la expositiva, probablemente debido a que los textos narrativos relatan acontecimientos que les ocurren a ciertos personajes en un determinado período de tiempo mientras que los textos expositivos se caracterizan por presentar relaciones lógicas entre acontecimientos (Pérez, 2005).

Dado que la mayor parte de la instrucción educativa con universitarios se basa en materiales escritos en un lenguaje técnico (Ibáñez y Ribes, 2001), las deficiencias lectoescritoras de los estudiantes en este nivel impedirán que sean capaces de lograr un aprendizaje eficiente de las diversas materias relacionadas con temas científicos.

Los datos recabados en el presente trabajo muestran que los participantes no fueron lectores eficientes ya que no llevaron a cabo una lectura comprensiva de los artículos a los que se les expuso (Irigoyen, Jiménez y Acuña, 2007), lo cual se evidenció en su incapacidad de seleccionar las oraciones críticas de los textos. Fuentes (2010) menciona, la comprensión lectora implica dos dimensiones funcionales: leer textualmente y leer comprensivamente. Dados los resultados del presente estudio aparentemente los participantes sólo estaban leyendo textualmente, ya que en ambas muestras el índice de efectividad en la selección de oraciones críticas estuvo por debajo de .5 (Muestra 1) y de .4 (Muestra 2), lo que implica que: a) los participantes no identificaron todas las oraciones críticas o; b) seleccionaron mucha información no pertinente.

El no ser capaz de identificar la información más importante de un artículo experimental puede tener como efecto que al elaborar el resumen respectivo la información que se agrega no sea la pertinente o no sea suficiente, tal y como se observó en los resultados de ambas muestras, ya que como los datos mostraron, la mayoría de los participantes de la Muestra 1 incluyó sólo entre dos y cuatro elementos de los seis que debe contener un resumen (objetivo, población, tarea, procedimiento, resultados y discusión) mientras que la mayoría de la Muestra 2 incluyó entre tres y cinco de tales elementos. El que el objetivo y la discusión hayan sido los elementos que con mayor frecuencia 
se incluyeron en ambas muestras, en los dos resúmenes, pudo deberse a que dichos elementos fueron más fáciles de identificar para los participantes como elementos que debían incluirse en un resumen o bien a que tales elementos, por alguna razón, tuvieron mayor saliencia en los textos a los que se les expuso. Al respecto podría aventurarse la hipótesis de que dado que esos apartados de un artículo experimental suelen estar escritos con un mayor número de términos técnicos que la sección de Método, por ejemplo, los participantes hayan llegado a la conclusión de que debido a que eran más complejos probablemente eran más importantes y por lo tanto debían ser incluidos en el resumen. Pero habría que analizar en concreto dicho aspecto para poder tener la certeza de que ello efectivamente fue la razón de dicho resultado.

Por otra parte, en la Muestra 2, se registró el caso de tres participantes que tuvieron un buen desempeño desde el principio y lo mantuvieron a lo largo de la tarea. El que los participantes de la Muestra 2 tuvieran un mejor desempeño en tales aspectos respecto de la Muestra 1 podría deberse a varias razones: a) a un mayor nivel de historia de referencialidad con la tarea, ya que podría ser que dado que estaban participando en un verano de investigación, antes de este (dado su interés en actividades científicas) y durante este (como parte de sus labores como becarios del verano) podrían haberse expuesto a la lectura de artículos experimentales (con su respectivo resumen), lo que podría haber impactado en su desempeño en dicho sentido, aunque su ejecución en la selección de oraciones parece indicar que no fueron capaces de identificar la información central de los artículos a los que se les expuso (ya que su índice de desempeño en promedio fue peor que el de la Muestra 1); b) otra posible razón para la diferencia en el desempeño entre ambas muestras podría deberse a un mayor nivel de motivación hacia la tarea a la que se les expuso dado el interés de los participantes de esta muestra en formarse como investigadores, ya que como se mencionó antes, un aspecto que puede afectar el desempeño en este tipo de tareas son los factores disposicionales (Padilla et al., 2015).

Otro aspecto en el que los participantes de la Muestra 2 mostraron un desempeño diferente al de la Muestra 1 fue el relativo a la inclusión de información (al elaborar los resúmenes) que no estaba en los artículos respectivos ya que más del $20 \%$ de la información que integraba ambos resúmenes correspondió a aspectos agregados (en la Muestra 1 sólo entre el 6\% y el 7\% incluyó información de esta naturaleza). La inclusión de información de este tipo probablemente se deba a la realización de lecturas previas ya que dicha información era pertinente al tema en cuestión. Refuerza el anterior supuesto el hecho de que al identificar quiénes agregaron información que no estaba en los artículos por tipo de formación (psicólogos o de otras carreras), se observó que con la excepción de un alumno de la carrera de Ciencias de la Educación todos los que agregaron información eran estudiantes de Psicología, es decir, al parecer su historia de referencialidad implicaba el conocimiento de investigaciones diferentes que de alguna manera se vinculaban con las de los artículos a los que se les expuso. Destaca el hecho de que los participantes hubieran sido capaces de vincular tales lecturas con el tema particular al que se les expuso.

Algo sobresaliente fue que en ambas muestras se observó en la gran mayoría de los participantes (independientemente de su nivel de desempeño final) una mejora en la elaboración del Resumen 2 con respecto al 1, la cual podría deberse a dos posibles razones: a) dado que los dos artículos a los que se les expuso pertenecían a una misma área de conocimiento y analizaban un fenómeno 
similar (ver sección de aparatos), ello incrementó su historia de referencialidad respecto al tema, lo que pudo tener como efecto dicha mejora; o bien, b) dicha mejora también podría ser resultado del fenómeno denominado Retest, ya que se ha observado en diferentes estudios que el hecho de que un individuo se exponga más de una vez a una misma tarea, incluso si no recibe retroalimentación, auspicia una mejora en el desempeño a partir de la segunda exposición (Anastasi y Urbina, 1998) dado que elaborar en dos ocasiones distintas un resumen podría permitir al participante identificar los elementos que deben integrarlo.

Un dato destacable fue que, en ambas muestras, los participantes que mostraron una mejora en su desempeño fueron los que consultaron las tablas y figuras durante la elaboración del Resumen 2. Ello pudo deberse a un contacto más adecuado con el contenido de los artículos a los que se les expuso, es decir, al parecer tales participantes pudieron identificar el vínculo existente entre las figuras y tablas de los textos y la información de los artículos además de que fueron capaces de "leer" de manera adecuada la información contenida en estas. Lo que implica que probablemente la mayoría de los participantes carecía de las habilidades requeridas para entrar en contacto con ese tipo de material. Es decir, al parecer tales estudiantes estaban leyendo sólo textualmente, no comprensivamente, en el sentido que señala Fuentes (2010). El establecimiento de un contacto pertinente (es decir, una lectura comprensiva) con el contenido de los artículos se evidencia con otro hallazgo, el de que los participantes que mostraron el mejor desempeño fueron los que consultaron un mayor número de veces las oraciones seleccionadas. Además de que dicho número disminuyó ligeramente del Artículo 1 al 2, aunque el desempeño en el Resumen 2 mejoró lo que sugiere que su ejecución se volvió más eficiente. Algo relevante fue que, en la Muestra 1, dos de los tres participantes que mostraron el mejor índice de desempeño fueron de los que menos errores de ortografía y gramática tuvieron, lo que parece evidenciar el vínculo entre las habilidades lectoescritoras y el desempeño en la tarea a la que se expuso a los participantes.

Es importante precisar que dado que no se manipularon variables no se esperaba per se una mejora en el desempeño del Resumen 1 al 2 . Sólo se registró dicho dato con el objetivo de identificar si la mera exposición repetida auspiciaba algún tipo de efecto, lo que fue el caso, como se mencionó previamente. Otro aspecto que vale la pena comentar es que dado que este era un estudio exploratorio cuyo objetivo era identificar las posibles variables que afectan la lectoescritura de resúmenes de artículos experimentales, no se estipuló ningún criterio de logro, factor que pudo fomentar la gran variabilidad conductual observada en los participantes de ambas muestras. Dada dicha variabilidad fue necesario englobar el desempeño de los participantes en las cuatro categorías ya mencionadas: 1) los que lo hicieron bien desde el inicio y mantuvieron ese desempeño, 2) los que lo hicieron mal al inicio y no mejoraron en el segundo resumen, 3) los que lo hicieron mal al inicio y mejoraron en el segundo resumen, y 4) los que empeoraron en el Resumen 2 con respecto al 1.

Los resultados generales del presente estudio coinciden con lo ya encontrado en el área respecto de lo deficiente que es el comportamiento lectoescritor de los estudiantes de este nivel educativo (Aguilera et al., 2006). Lo que hace indispensable analizar las posibles variables implicadas en la lectoescritura en general y en la técnica en particular. Para ello se sugiere seguir realizando estudios al respecto empleando la presente estrategia que demostró su utilidad para analizar el fenómeno de la lectoescritura técnica. Pero para continuar con el análisis del área se considera importante empe- 
zar a manipular variables que se supone afectan la lectoescritura, como la historia de referencialidad de los participantes, el criterio de logro estipulado para la realización de la tarea, el tipo de referente al que se exponga a los participantes así como sus factores disposicionales.

Es importante puntualizar que una posible limitación del presente estudio fue la falta de heterogeneidad de los participantes de la segunda muestra ya que eran estudiantes de diferentes carreras, de distintas universidades de la República Mexicana y de diferentes grados académicos, por lo que en futuros estudios se sugiere controlar dichos aspectos.

\section{Referencias}

Aguilera, G., Alcaraz, R., Cabrera, R., Cabrera, N., Galicia, X., Hickman, H., Mares, G., Mejía, O., Quintanar, F., \& Robles, S. (2006). Comisión de evaluación del plan de estudios vigente (Documento interno). México: Facultad de Estudios Superiores Iztacala.

American Psychological Association (APA). (2010). Publication Manual. American Psychological Association: Washington, DC.

Anastasi, A., \& Urbina, S. (1998). Tests psicológicos. México: Pearson Educación.

Cárdenas, K., \& Guevara, Y. (2013). Comprensión lectora en alumnos de secundaria. Intervención por niveles funcionales. Journal of Behavior, Health \& Social Issues, 5 (1), 67-83. http://doi. org/10.5460/jbhsi.v5.1.38727

Díez, B. (2007). El resumen de un artículo científico. Qué es y qué no es. Investigación y Educación en Enfermería, 25 (1), 14-17.

Fuentes, M.T. (2010). La comprensión lectora: revisión teórica desde la perspectiva cognoscitiva, conductual e Interconductual. En M.T. Fuentes, J.J. Irigoyen, \& G. Mares, Tendencias en Psicología y educación. Revisiones temáticas. Volumen 1 (pp. 128-166). México: Red Mexicana de Investigación en Psicología Educativa.

González, M.J., Barba, M.J., \& González, A. (2010). La comprensión lectora en educación secundaria. Revista Iberoamericana de Educación, 53 (6), 1-11.

Ibáñez, C., \& Ribes, E. (2001). Un análisis Interconductual de los procesos educativos. Revista Mexicana de Psicología, 18 (3), 359-371.

Irigoyen, J.J., Acuña, K., \& Jiménez, M. (2013). La comprensión lectora y su evaluación en el contexto escolar. Revista Mexicana de Investigación en Psicología, 5 (1), 56-81.

Irigoyen, J.J., Jiménez, M., \& Acuña, K. (2007). Evaluación de la comprensión lectora en el aprendizaje de la ciencia psicológica. En J.J. Irigoyen, M. Jiménez, \& K. Acuña. Enseñanza, aprendizaje y evaluación. Una aproximación a la pedagogía de las ciencias (pp. 213- 245). Hermosillo: Universidad de Sonora.

López, H. (2010). Sistema Institucional de Evaluación: La evaluación del desempeño del escolar en el ámbito Lector y Escritor (Documento interno). Bogotá: Colegio Antonio José de Sucre I.E.D.

Pacheco, V. (2010). ¿Se enseña a escribir a los universitarios? Análisis y propuestas desde la Teoría de la Conducta. México: Universidad Nacional Autónoma de México. 
Pacheco, V., Ortega, M., Morales, G., \& Carpio, C. (2012). Escribo, luego existo: reflexiones acerca de la autorreferencia. En V. Pacheco, C. Carpio, \& G. Morales (Coords.), La Autorreferencia: Promoción del comportamiento complejo desde diferentes perspectivas conceptuales (pp. 57-80). México: Universidad Nacional Autónoma de México.

Pacheco, V., Ortega, M., \& Carpio, C. (2013). Efectos de la respuesta del lector y del uso de ejemplos sobre la composición escrita. Revista Colombiana de Psicología, 22 (1), 13-34.

Pacheco, V., Ramírez, L., Palestina, L., \& Salazar, M. (2007). Una aproximación al análisis funcional de la relación entre las conductas de leer y escribir en estudiantes de Psicología. En J.J. Irigoyen, M. Jiménez, \& K. Acuña (Eds.), Enseñanza, aprendizaje y evaluación. Una aproximación a la pedagogía de las ciencias (pp. 247-276). Hermosillo: Universidad de Sonora.

Pacheco, V., \& Villa, J.C. (2005). El comportamiento del escritor y la producción de textos científicos. Revista Mexicana de Investigación Educativa, 10 (27), 1201-1224.

Padilla, M.A., \& Fernández, G. (2014). Efectos de manipular características textuales del referente en la lectoescritura de textos científicos. Revista Mexicana de Análisis de la Conducta, 40 (3), 47-71.

Padilla, M.A., Fuentes, N., \& Pacheco, V. (2015). Efectos de un entrenamiento correctivo en la elaboración y fundamentación de preguntas de investigación. Acta Colombiana de Psicología, 18 (2), 87-100.

Padilla, M.A., \& Suro, A.L. (2007). Identificación de las competencias de investigación adquiridas por investigadores en formación. En J.J. Irigoyen, M. Jiménez, \& K. Acuña (Eds.), Enseñanza, aprendizaje y evaluación. Una aproximación a la pedagogía de las ciencias (pp. 137-168). Hermosillo: Universidad de Sonora.

Padilla, M.A., Tamayo, J., \& González-Torres, M.L. (2010). Análisis de la posible relación entre la elaboración de preguntasinformalesydeinvestigación. IPyE:PsicologíayEducación, 4(7), 1-21.

Padilla, M.A., Tamayo, J., \& González-Torres, M.L. (2013). Does asking pertinent non-academic questions make you a better researcher? The link between non-academic and research questions. New York: Nova.

Pérez, M.J. (2005). Evaluación de la comprensión lectora: Dificultades y limitaciones. Revista de Educación, 121-138. Recuperado de http://www.ince.mec.es/revistaeducacion/re2005/ re2005_10.pdf

Silva, D. (2010). El resumen del artículo científico de investigación y recomendaciones para su redacción. Revista Cubana de Salud Pública, 36 (2), 179-183.

Sousa, V., Driessnack, M., \& Flória-Santos, M. (2006). Cómo escribir el resumen de un artículo para publicación, Revista Cubana de Salud Pública, 19 (3), 13-16.

Tamayo, J., Padilla, M.A., \& González-Torres, M.L. (2009). Efectos de criterios de logro diferenciales en la elaboración de preguntas informales, en estudiantes de preparatoria, licenciatura y posgrado. Acta Colombiana de Psicología, 12 (1), 27-39. 


\section{ANEXO A}

Artículos que los participantes debían leer:

1. Guerrero, A., \& Ortiz, G. (2007). El papel de la retroalimentación y la ausencia o presencia de instrucciones en la elaboración de descripciones en tareas de discriminación condicional. Acta Colombiana de Psicología, 10 (1), 5-13.

2. Islas, A., \& Flores, C. (2007). Papel de la retroalimentación en la adquisición y transferencia de discriminaciones condicionales en estudiantes universitarios. Enseñanza e Investigación en Psicología, 12 (1), 65-77. 


\section{Capítulo 9}

Suplementación lingüística y corrección: efectos sobre el desempeño lector-escritor en estudiantes universitarios

Miriam Yerith Jiménez, Juan José Irigoyen y Karla Fabiola Acuña 
Miriam Yerith Jiménez miriam.jimenez@unison.mx

Juan José Irigoyen juanjose.irigoyen@unison.mx

Karla Fabiola Acuña karla.acuna@unison.mx

Seminario Interactum de Análisis del Comportamiento Universidad de Sonora

Se agradece la participación como asistentes de investigación a: Libia Mendoza, Sergio Barceló, Pedro Rey y Desiderio Ramírez. 


\section{Capítulo 9}

\section{Suplementación lingüística y corrección: efectos sobre el desempeño lector-escritor en estudiantes universitarios}

El análisis de las interacciones psicológicas y su ajuste a un medio convencional, identifica al lenguaje como el soporte en la conformación del conocimiento, entendido este como sinónimo de la práctica individual y social del individuo:

Las convenciones no son nada más que las interacciones lingüísticas, y estas constituyen mediaciones complejas entre individuos con base en los sistemas reactivos establecidos socialmente, en forma autónoma de la naturaleza de los objetos, eventos o individuos con los que pueden relacionarse (Ribes, 1982, p. 75).

El lenguaje es la circunstancia de las prácticas sociales y sus criterios; comunica mediante el habla y la escritura; mediante el lenguaje afectamos y nos relacionamos con los demás y con nosotros mismos, el lenguaje es la dimensión funcional del comportamiento humano (Ribes, 2000). La relevancia teórica y empírica que el lenguaje pudiera tener para una Teoría de la Conducta es incuestionable.

El abordaje del lenguaje en Teoría de la Conducta se relaciona con el estudio de los procesos sustitutivos (Ribes y López, 1985; Ribes, 1990a; 1990b) y de los modos lingüísticos (Fuentes y Ribes, 2001). El modo lingüístico hace referencia a la forma en que ocurre la respuesta en su dimensión lingüística. Se agrupan en reactivos (observar, escuchar, leer -texteo-) y activos (gesticular/ señalar, hablar, leer -lectura comprensiva- y escribir). Camacho y Gómez (2007), Fuentes y Ribes (2001, 2006) y Camacho, Irigoyen, Gómez, Jiménez y Acuña (2007) aducen respecto a los modos lingüísticos que: a) cada modo tiene propiedades funcionales específicas y por consiguiente, las variables que tienen que ver con su adquisición y desarrollo son diferentes; b) la adquisición de los modos reactivos puede ser condición necesaria para la adquisición de los activos y; c) en los episodios lingüísticos los modos pueden ocurrir intercalados y su aparición inicial no depende de su carácter reactivo o activo.

Los modos lingüísticos se incluyen como un elemento analítico importante al estudio de los episodios de interacción didáctica debido a que es necesario modificar la enseñanza en su sentido verbalista y discursivo por una enseñanza que disponga situaciones de aprendizaje que permitan la exhibición del desempeño del estudiante no sólo como escucha, aunado al uso de las Tecnologías de la Información y la Comunicación y la consecuente diversificación de los medios y recursos didácticos (Irigoyen, Acuña y Jiménez, 2015). 
El análisis y promoción de la conducta inteligente y el desarrollo de competencias en dominios de conocimiento se relacionan con la participación del lenguaje como sustitución de contingencias (Carpio, Pacheco, Canales y Flores, 1998; Ribes, 1989, 1990a; Varela, 1998; Varela y Ribes, 2002). La conducta sustitutiva referencial comprende interacciones en las que el individuo modifica las variables situacionales al responder a propiedades no presentes y no aparentes en tiempo y espacio: "Al responder de este modo introduce nuevas circunstancias en la situación y, por consiguiente, no sólo altera transformando su situacionalidad interactiva, sino que también altera la de aquellos otros individuos con los que necesariamente se relaciona" (Ribes, 1990a, p. 213). En el caso de la conducta sustitutiva no referencial:

el individuo no sólo reacciona a los eventos mismos sino a sus contactos sustitutivos con dichos eventos, proceso que le permite no sólo desligarse del tiempo y espacio en que tienen lugar los eventos, sino también de los eventos concretos mismos [...] Podríamos decir que la propia conducta referencial o la de otros adquiere la cualidad de objeto de estímulo, y se interactúa sustitutivamente con dichas condiciones de estímulo (Ribes, 1982, p. 95).

En desarrollos posteriores, el autor indica que: "En la sustitución extrasituacional, la conducta del mediador establece un nuevo criterio de ajuste al mediado, y dicha contingencia se satisface en la medida en que el mediado cumple con tal requerimiento" (Ribes, 2012, p. 23). Y en lo que concierne a la conducta sustitutiva no referencial, añade: "Se pierden todos los marcos de referencia relativos a contingencias situacionales. Las contingencias tienen lugar como relaciones entre episodios puramente lingüísticos y los criterios categoriales que delimitan su funcionalidad" (p. 23).

En este sentido, ninguna forma de práctica individual es descontextuada y fuera de los límites funcionales que establece el lenguaje. El lenguaje es concebido como el medio en el cual la conducta es significativa; como instrumento que hace posible actuar respecto a otros individuos y a los acontecimientos socialmente significativos y como una forma de vida, como circunstancia que da sentido a las prácticas convencionales (Ribes, Cortes y Romero, 1992). El lenguaje como medio comprende "la red total de significados de la práctica social y los productos en los que una actividad particular puede tener sentido" (Ribes et al. 1992, p. 62). Aprender el lenguaje como medio refiere a aprender acciones, palabras y su uso, y aprender sobre los objetos y las palabras. Nominar y contextualizar objetos y eventos a partir del discurso de otros; identificar relaciones entre eventos, circunstancias y personas; y reproducir (hablar y escribir) de acuerdo a las convenciones del grupo, son algunas de las actividades comprendidas en el aprendizaje del lenguaje como medio.

La posibilidad de modificar las relaciones de condicionalidad en el ambiente mediante el lenguaje, representa su uso como instrumento, el cual se relaciona con el uso efectivo respecto al comportamiento de otros, así como los objetos y acontecimientos funcionales: "Se convierte en un instrumento cuando el individuo aprende los significados de sus propias acciones cómo y mediante palabras" (Ribes et al. 1992, p. 63), siendo el significado el resultante del uso pertinente en un contexto particular (situaciones y propósitos).

El lenguaje como forma de vida es la circunstancia y criterios que dan sentido a las prácticas: "La práctica se da como lenguaje dentro del lenguaje" (Ribes et al. 1992, p. 64). Más adelante 
comentan: "No sólo nos relacionamos con el mundo mediante el lenguaje, sino que relacionamos al mundo con nosotros en términos de los significados comprendidos en la práctica de un juego o conjunto de juegos de lenguaje" (p. 65). La capacidad de mediar lingüísticamente la interacción de otros respecto a funciones convencionales de los eventos y acontecimientos caracteriza al lenguaje como una forma de vida, en la que la ciencia, el arte, la religión, la moral, son instancias prominentes de aquel.

La ciencia constituye un modo social de conocimiento, y en este sentido se puede hablar de los juegos de lenguaje en ciencias (Ribes, 1993; Ribes, Moreno y Padilla, 1996). Aprender los juegos de lenguaje en ciencias es aprender a comportarse de conformidad a las circunstancias y criterios que definen los distintos ámbitos de su quehacer. Consideramos entonces que el aprendizaje de una disciplina científica o profesión consiste en la adquisición de formas de hacer y decir en términos conceptuales, operacionales y de medida como actividades en contextos particulares. Estas formas de hacer y decir se establecen mediadas por el lenguaje como contexto de significación de dichas interacciones.

En este contexto se considera a la lectura y la escritura como competencias fundamentales para el aprendizaje y la enseñanza de dominios disciplinares y profesionales a nivel universitario, ya que ambas constituyen el medio y el modo por excelencia para el ejercicio de los diferentes juegos de lenguaje. El lenguaje escrito es una herramienta de pensamiento de alto valor académico y social, debido a que trasciende, como producto, el espacio y el tiempo.

Frecuentemente se da por supuesto que al ingresar a la Universidad el estudiante ya cuenta con el repertorio de competencias necesarias que harán su tránsito exitoso. Diversos estudios destacan que, a nivel universitario, se adolece de competencias lectoras y escritoras requeridas en este nivel de formación: respecto a la lectura y escritura de textos científicos (Guevara, Guerra, Delgado y Flores, 2014), la lectura de gráficos, la argumentación con base en información de un texto y la comunicación de ideas complejas (Irigoyen et al. 2009), la lectura inferencial referente a los modos de organización de orden explicativo y argumentativo (Perilla, Rincón, Gil y Salas, 2004), en tareas que demandan establecer relaciones entre definiciones, pertinencia de un ejemplo o relaciones entre conceptos (Irigoyen, Jiménez y Acuña, 2004) y en las habilidades escritoras, las cuales no les permiten cubrir los requerimientos mínimos para escribir un reporte de investigación (Pacheco, Reséndiz y Mares, 2010).

Resulta necesario entonces evaluar el papel que juegan los diferentes factores que participan en la estructuración de los episodios de interacción didáctica, promotores del ejercicio de la lectura y la escritura, a saber: los criterios de dominio y de tarea, las características del referente, el arreglo instruccional, la historia de mediación, entre otros.

Como se comenta en párrafos anteriores, el estudio de los procesos sustitutivos se relaciona con el aprendizaje de competencias en dominios de conocimiento debido a que los objetos, hechos y situaciones de las que se habla, se lee y se escribe en ciencias, son abstracciones de la realidad empírica. Además, las interacciones entre individuos respecto a los objetos de conocimiento -objetos referentes- son mediadas por el discurso didáctico.

Una competencia es la disposición al cumplimiento de logros de manera efectiva y variada ante situaciones inéditas. Las competencias implican: a) la interrelación de saberes teóricos, 
conceptuales y procedimentales, así como aspectos actitudinales que permitan desempeñarse ante una situación problema; b) la posibilidad de transferencia en el sentido de que las situaciones problema varían (objetos, hechos, relaciones entre sucesos) y se requiere su ajuste a las variaciones en los requerimientos de la situación problema; y c) niveles y grados de suficiencia variables (Irigoyen, Jiménez y Acuña, 2011).

La planeación e implementación de situaciones que disponen el ejercicio de competencias acordes a los criterios de la disciplina que se enseña-aprende la lleva a cabo el agente enseñante, cuya función además radica en evaluar y retroalimentar dicho desempeño. La retroalimentación es una de las estrategias que se emplean para la habilitación competencial en dominios de conocimiento. En el caso del desempeño escritor, la retroalimentación cumple el propósito de indicarle a quien escribe los aspectos que requieren revisión y corrección acorde a los criterios de forma (sintácticos y semánticos) y disciplinares (coherencia y congruencia dado el juego de lenguaje).

En la línea del Análisis Conductual, Crone-Todd, Eyre, Hutchens, Jones y Pear (2007) señalan que la retroalimentación es similar a los procedimientos de moldeamiento y desvanecimiento instrumentados por la comunidad verbal o el grupo convencional de referencia, ya que acercan a los noveles miembros al cumplimiento de los criterios a nivel "experto".

Para que la retroalimentación contribuya al desarrollo de la escritura requiere de características particulares como: a) que la retroalimentación permita al escritor valorar dónde se encuentra respecto a los criterios de calidad deseados; b) que le indique al escritor cuáles son las características claves para el desempeño de calidad y, c) indique el qué y el cómo se tiene que hacer para reducir la brecha entre el desempeño actual y el desempeño deseado. Uno de los puntos en los que insisten Parr y Timperley (2010) hace alusión a los criterios de calidad, esto es, aquellos criterios que permiten juzgar su valor.

Enseñar a escribir demanda que quien enseña, sea capaz de trabajar con la producción de textos que cumplan su función comunicativa y sus propósitos retóricos, lo que implica un vasto conocimiento del lenguaje y de las estructuras del texto. Al respecto, Parr y Timperley (2010) evaluaron la calidad de la retroalimentación (en modalidad escrita) que proveen los profesores a los productos escritos de los estudiantes y su relación con el logro escolar y su progreso. La situación de prueba consistió en disponer un fragmento de escritura que el profesor debía retroalimentar considerando: el objetivo de la lección, el uso de una actividad de enseñanza como el modelado y la naturaleza de las actividades desarrolladas. Además, se les preguntó sobre la calificación otorgada y las razones por las que la dieron. Las categorías empleadas para analizar la retroalimentación fueron: 1) evaluativa (p.ej. da indicaciones de la medida en que el escritor ha cubierto los objetivos de la lección, los propósitos del escrito o se ha desempeñado idóneamente); 2) si es específica a la función de la escritura u objetivo de la lección o es un comentario genérico; 3) precisa, considerando el fragmento de escritura provisto, las características comúnmente asociadas con los propósitos del escrito y los detalles disponibles acerca de la situación retórica; 4) si da indicaciones al escritor acerca de qué acciones tiene que llevar a cabo para mejorar el escrito y 5) el nivel de texto al que se refiere la observación (p.ej., audiencia, estructura, contenido y recursos del lenguaje -aspectos de fondo- y gramática, ortografía y puntuación -aspectos superficiales-). Para la evaluación del logro escolar en escritura se utilizó una prueba referida al criterio (Assessment Tools for Teaching and Learning) 
cuyas dimensiones incluyen: 1) aspectos de fondo: audiencia, estructura, contenido y recursos del lenguaje y 2) aspectos superficiales: gramática, ortografía y puntuación. Los resultados indican una relación directamente proporcional entre la cualidad de la retroalimentación y el progreso en la escritura: a mayor habilidad del profesor en dar retroalimentación al estudiante sobre la calidad de la escritura, mayor es su avance.

En otro estudio, Crone-Todd et al. (2007) evaluaron los efectos del cambio en la retroalimentación sobre la escritura en estudiantes inscritos en un curso en línea sobre Análisis Conductual Aplicado a nivel superior. Utilizaron un sistema personalizado denominado CAPSI (Computer-Aided Personalized System of Instruction) que semanalmente daba acceso a la resolución de los diferentes exámenes programados por unidad (15 unidades en total). La revisión de los exámenes fue hecha por pares (estudiantes que demostraron dominar los contenidos de los exámenes) y por el instructor. Para los autores de este trabajo la retroalimentación consistió en dar a conocer al estudiante el resultado de su desempeño en el examen: 1) el "pase" a la siguiente unidad, lo que implica que el total del examen fue resuelto de modo acertado, o 2) "re-estudiar", esto es, presentar de nuevo el examen, debido a que la totalidad del examen no fue resuelto de modo adecuado. Sobre la onceava semana del curso, los autores observaron que las pruebas escritas por unidad disminuyeron, de modo que incluyeron una alternativa más de retroalimentación: 3) el "pase condicional", esto es, que si el examen cubría buena parte de respuestas acertadas, el estudiante apelaba por el recurso de revisión de aquellas respuestas que habían sido calificadas como erróneas. Los resultados muestran que el cambio en la retroalimentación (la opción de "pase-condicional") disminuyó el número de exámenes cancelados e incrementó el número de exámenes solicitados y resueltos de manera acertada.

En el presente trabajo utilizaremos el término de suplementación lingüística como sinónimo del término de retroalimentación. Suplementar lingüísticamente implica presentar segmentos lingüísticos en el modo escrito contingentes al desempeño escritor. El segmento lingüístico es equivalente a la respuesta convencional del referidor, de modo que, en el momento de leerlo, podrían actualizarse funciones de estímulo implícitas en la interacción (p.ej. que el lector-escritor compare su respuesta con el segmento lingüístico presentado a partir del criterio de idoneidad). En este sentido, el objetivo del trabajo fue evaluar el efecto de la suplementación lingüística (general y específica) y la corrección sobre el desempeño lector-escritor en estudiantes universitarios.

Participaron en el estudio 20 estudiantes del último año de la Licenciatura en Psicología de una Universidad Pública del Norte de México, con edades entre los 21 y 26 años. Su participación fue voluntaria a cambio de créditos en una de sus asignaturas.

Se utilizaron tres artículos científicos (estudio empírico) equivalentes en el área temática abordada (Análisis de la Conducta) y la estructura, con la siguiente extensión: artículo 1 (4595 palabras) ${ }^{1}$, artículo 2 (3419 palabras) ${ }^{2}$ y artículo 3 (5931 palabras) ${ }^{3}$. La presentación de los artículos así

1 Mendoza, B., Pedroza, F. y Martínez, K. (2014). Prácticas de crianza positiva: entrenamiento a padres para reducir Bullying. Acta de Investigación Psicológica, 4 (3), 1794-1809.

2 Gutierrez, M. y Vite, A. (1989). Entrenamiento a padres: análisis de una estrategia de interacción padre-hijo. Revista Mexicana de Análisis de la Conducta, 15 (1 y 2), 41-54.

3 García, V., Eguía, S., Gómez, L. y González, A. (1983). Análisis experimental de la generalización de respuestas aritméticas en operaciones de división. Revista Mexicana de Análisis de la Conducta, 9 (1), 11-27. 
como las condiciones de entrenamiento y de evaluación se programaron en lenguaje para plataforma Web (HTML, Javascript, PHP y MySQL). Los artículos se dividieron en tres secciones, denominadas segmento 1 , segmento 2 y segmento 3 . El segmento 1 comprende desde el inicio del artículo hasta el inicio de la sección de método; el segmento 2 comprende el método y el segmento 3 la sección de discusión y conclusiones. Al término de la lectura de cada segmento se solicitó resolver una serie de preguntas en relación directa con lo leído (Actividad 1 correspondiente al segmento 1, Actividad 2 al segmento 2 y Actividad 3 al segmento 3). Dicha secuencia de exposición (lectura del segmento 1, resolución de la Actividad 1; lectura del segmento 2, resolución de la Actividad 2 y lectura del segmento 3, resolución de la Actividad 3) se mantuvo en las cuatro sesiones de trabajo (evaluación 1 -pre-, entrenamiento, evaluación 1 -post- y evaluación 2). Tanto las evaluaciones 1 y 2 , así como la sesión de entrenamiento se diseñaron considerando los siguientes tipos de tarea: identificación, formulación y relación. La tarea de identificación demandó la respuesta escrita de las instancias referidas en el texto acorde al concepto solicitado (p.ej. variable independiente y variable dependiente). En el caso de la tarea de formulación esta consistió en la respuesta escrita de los elementos que conectan la fundamentación conceptual con la propuesta empírica tratada en el artículo (p.ej. elaborar el problema de investigación o redactar la pregunta de investigación). La tarea de relación solicitó la respuesta escrita respecto a la correspondencia entre dos o más eventos o fenómenos (p.ej. describir los efectos de la variable independiente sobre la variable dependiente o redactar una conclusión de los resultados y el objetivo de la investigación). En los siguientes cuadros se muestran ejemplos sobre los tipos de tarea descritos (Cuadro 1) y su distribución en las actividades y sesiones (Cuadro 2).

\section{Cuadro 1. Ejemplos de los tipos de tarea empleadas en las sesiones de evaluación y de entrenamiento.}

Tarea de identificación:

- En el propósito del estudio: ¿Cuál es la variable independiente?

- En el propósito del estudio: ¿Cuál es la variable dependiente?

Tarea de formulación:

- $\quad$ Elabora el problema de investigación correspondiente al artículo "Prácticas de crianza positiva: entrenamiento a padres para reducir Bullying"

- Redacta la pregunta de investigación correspondiente al artículo "Prácticas de crianza positiva: entrenamiento a padres para reducir Bullying"

Tarea de relación:

- ¿ ¿Qué componente del programa de entrenamiento a padres en prácticas de crianza positiva se relaciona con el incremento de la conducta de "hacer la tarea antes de jugar"? ¿Por qué?

- Redacta una conclusión sobre los resultados obtenidos y su relación con el objetivo de la investigación 
Cuadro 2. Distribución de los tipos de tarea por actividad (Actividad 1, Actividad 2 y Actividad 3) y sesión (evaluación 1 pre-post, evaluación 2 y de entrenamiento).

\begin{tabular}{|c|c|c|c|c|}
\hline & $\begin{array}{l}\text { Evaluación } 1 \\
\text { (Pre) }\end{array}$ & Entrenamiento & $\begin{array}{l}\text { Evaluación } 1 \\
\text { (Post) }\end{array}$ & Evaluación 2 \\
\hline Actividad 1 & $\begin{array}{l}4 \text { Identificación } \\
4 \text { Formulación } \\
1 \text { Relación }\end{array}$ & $\begin{array}{c}4 \text { Identificación } \\
4 \text { Formulación } \\
1 \text { Relación }\end{array}$ & $\begin{array}{c}4 \text { Identificación } \\
4 \text { Formulación } \\
1 \text { Relación }\end{array}$ & $\begin{array}{c}4 \text { Identificación } \\
4 \text { Formulación } \\
1 \text { Relación }\end{array}$ \\
\hline Actividad 2 & $\begin{array}{c}2 \text { Identificación } \\
1 \text { Formulación } \\
4 \text { Relación }\end{array}$ & $\begin{array}{c}2 \text { Identificación } \\
1 \text { Relación }\end{array}$ & $\begin{array}{c}2 \text { Identificación } \\
1 \text { Formulación } \\
4 \text { Relación }\end{array}$ & $\begin{array}{c}2 \text { Identificación } \\
1 \text { Formulación } \\
3 \text { Relación }\end{array}$ \\
\hline Actividad 3 & $\begin{array}{l}1 \text { Formulación } \\
1 \text { Relación }\end{array}$ & $\begin{array}{l}1 \text { Formulación } \\
1 \text { Relación }\end{array}$ & $\begin{array}{l}1 \text { Formulación } \\
1 \text { Relación }\end{array}$ & $\begin{array}{l}1 \text { Formulación } \\
1 \text { Relación }\end{array}$ \\
\hline
\end{tabular}

Se empleó un diseño cuasi-experimental con pre-post evaluación (Tabla 1). La asignación de los participantes a las diferentes condiciones de entrenamiento se hizo aleatoriamente.

Tabla 1. Diseño empleado.

\begin{tabular}{|c|c|c|c|c|}
\hline & SESIÓN 1 & SESIÓN 2 & \multirow[t]{5}{*}{ SESIÓN 3} & \multirow[t]{5}{*}{ SESIÓN 4} \\
\hline $\mathrm{N}=5$ & \multirow{11}{*}{$\begin{array}{c}\text { Evaluación } 1 \\
\text { (Pre) }\end{array}$} & & & \\
\hline GRUPO 1 & & $\begin{array}{l}\text { Lectura y } \\
\text { escritura }\end{array}$ & & \\
\hline \multirow{3}{*}{ GRUPO 2} & & $\begin{array}{l}\text { Lectura y } \\
\text { escritura con }\end{array}$ & & \\
\hline & & $\begin{array}{c}\text { suplementación } \\
\text { general y }\end{array}$ & & \\
\hline & & corrección & \multirow{7}{*}{$\begin{array}{c}\text { Evaluación } 1 \\
\text { (Post) }\end{array}$} & \multirow[t]{7}{*}{ Evaluación 2} \\
\hline & & $\begin{array}{c}\text { Lectura y } \\
\text { escritura con }\end{array}$ & & \\
\hline GRUPO 3 & & suplementación & & \\
\hline & & específica y & & \\
\hline & & corrección & & \\
\hline \multirow{2}{*}{ GRUPO 4} & & Control (sólo & & \\
\hline & & lectura) & & \\
\hline
\end{tabular}


Las sesiones se llevaron a cabo en cubículos individuales del Laboratorio de Ciencia y Comportamiento Humano de la Universidad de Sonora. La sesión dio inicio con la captura de la siguiente información del participante: expediente, nombre, edad, sexo, carrera y semestre. Una vez que la información fue capturada, el programa mostró una pantalla con las siguientes instrucciones generales: "Hola! A continuación se presentará un artículo de investigación, el cual está dividido en tres segmentos. Te pedimos que leas cada segmento para posteriormente responder una serie de preguntas. Es importante que primero revises el segmento antes de pasar a la sección de preguntas. Puedes consultar los segmentos, el número de veces que consideres necesario. De antemano agradecemos tu participación. Cuando estés listo da clic en el botón iniciar".

Evaluación 1 (Pre). Al dar clic al botón de inicio, se mostró el texto correspondiente al segmento 1 del artículo 1 . No había restricción de tiempo, e incluso, una vez concluida la lectura del segmento e iniciada la actividad de evaluación, el participante podía regresar a revisar de nuevo el segmento cuantas veces fuera necesario. Las instrucciones para la actividad 1 , actividad 2 y actividad 3, indicaban lo siguiente: "A continuación se te presentarán una serie de preguntas, relacionadas con el texto que acabas de leer. Es importante que respondas a todas las preguntas y que no dejes preguntas sin contestar. Puedes consultar el artículo el número de veces que consideres necesario para contestar las preguntas de la Actividad 1" (2 o 3, según fuera el caso). No se permitió el acceso al siguiente segmento si el participante no había concluido la totalidad de respuestas del segmento previo. Una vez concluida la actividad, daba clic al botón de "Guardar respuestas" y se mostraba el siguiente segmento (2 o 3 según fuera el caso). Las preguntas podían resolverse en el orden que el participante eligiera. La sesión concluyó una vez resuelta la Actividad 3 con el botón "Finalizar actividad".

Entrenamiento. En esta sesión los participantes asignados a los diferentes grupos fueron expuestos a una de las cuatro condiciones que se describen a continuación. En las cuatro condiciones el texto leído fue el artículo 2. El Grupo 1 fue expuesto a una secuencia similar a la descrita en la evaluación 1 (pre). Para los Grupos 2 y 3 la condición fue equivalente a la descrita en la evaluación 1 (pre) excepto que los participantes tenían acceso a segmentos lingüísticos que describían el desempeño esperado para cada una de las tareas. Dichos segmentos lingüísticos fueron agregados a la condición de entrenamiento para que suplementaran la actividad a resolver. Aunado a dichos segmentos se dio la opción de escribir de nuevo la respuesta (corregir), en caso de que el participante lo considerara necesario. La primer respuesta dada por el participante permanecía visible al momento de la corrección, sin posibilidad de modificarla.

Se denominó "segmento lingüístico general" al segmento que mostró la descripción del concepto o sus características, y "segmento lingüístico específico" al segmento cuya descripción del concepto o sus características estaba en relación con las instancias referidas por los autores del artículo. La Figura 1 y la Figura 2 muestran un ejemplo para cada uno de los casos, y el Video 1 muestra el modo en como procedía la suplementación. 


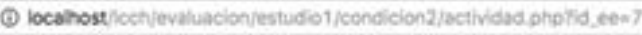

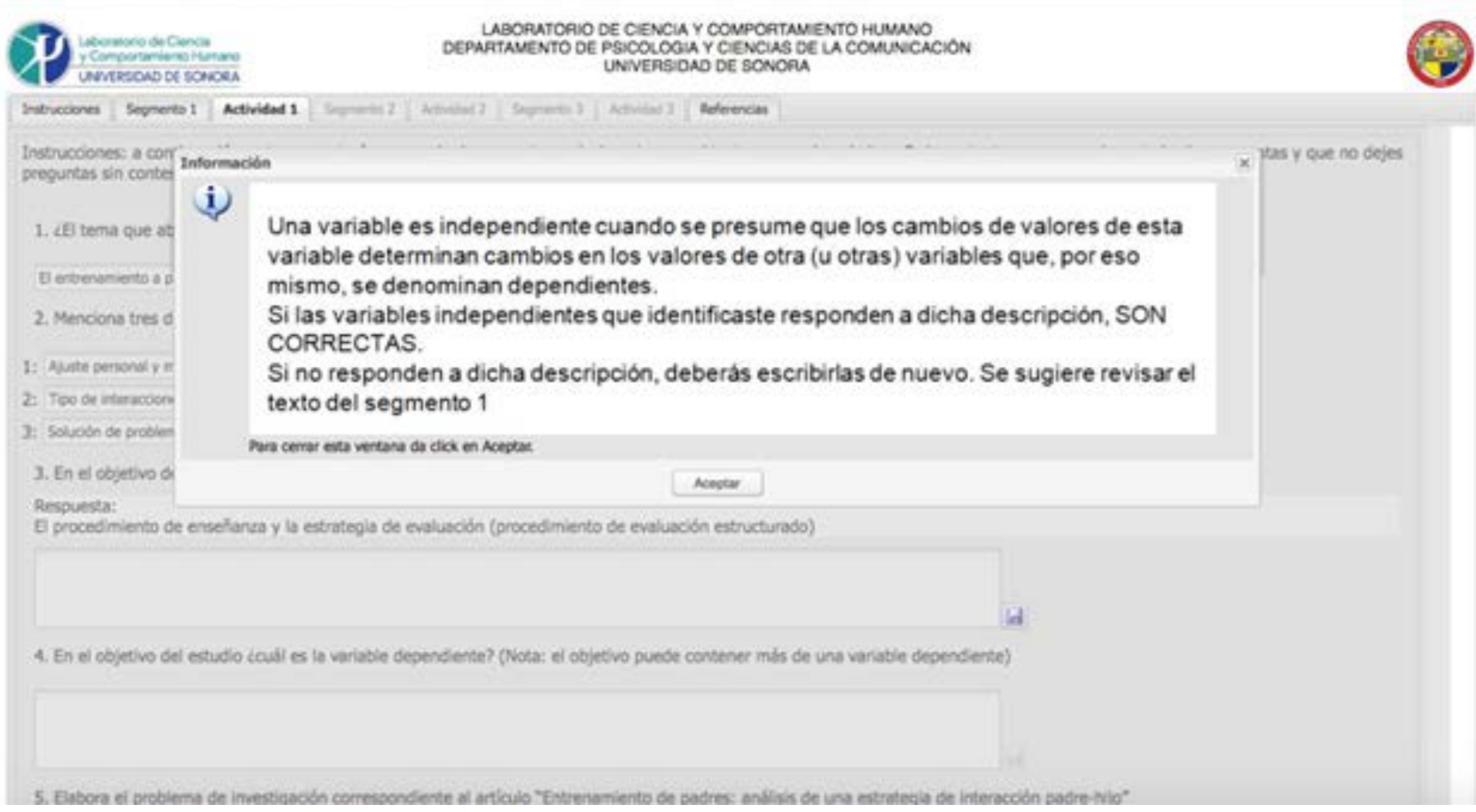

Figura 1. Ejemplo del segmento lingüístico general.

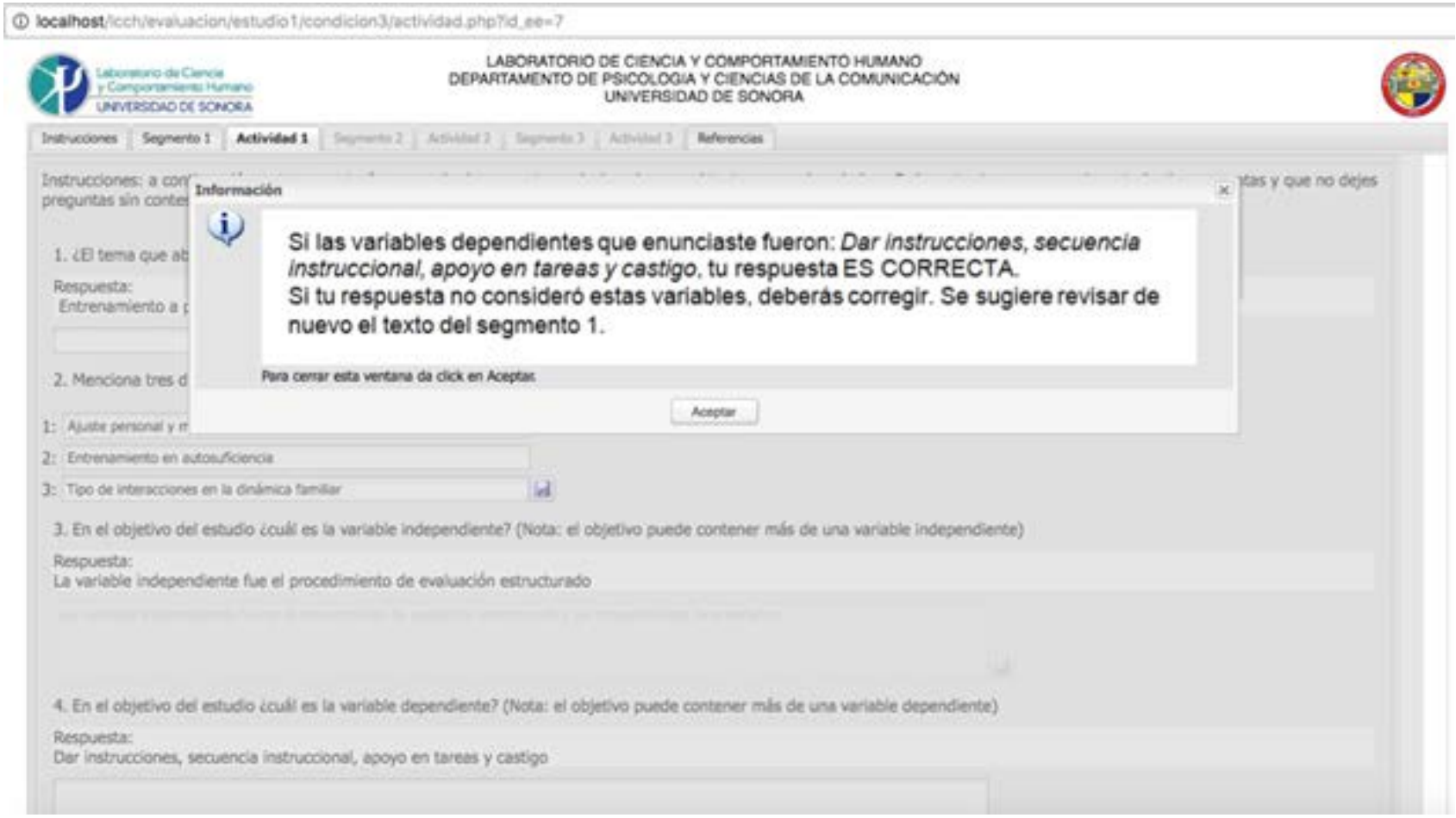

Figura 2. Ejemplo del segmento lingüístico específico. 
Las instrucciones para el Grupo 2 y Grupo 3 fueron las siguientes: "Hola! A continuación se presentará un artículo de investigación, el cual está dividido en tres segmentos. Te pedimos que leas cada segmento para posteriormente responder una serie de preguntas. Al responder cada pregunta deberás guardar tu respuesta dando clic al botón que aparece al lado derecho de la respuesta. Una vez que guardes tu respuesta, aparecerá un cuadro de texto que te indica si tu respuesta fue adecuada. Al cerrar el cuadro de texto, podrás corregir en caso de que tu respuesta no sea la esperada, debiendo guardar nuevamente tu respuesta dando clic en el mismo botón. Puedes consultar los segmentos, el número de veces que consideres necesario. Una vez que termines de resolver esta actividad, coméntale a la persona que esta cargo de la misma. Cuando estés listo da clic en el botón iniciar".

Los participantes del Grupo 4 fueron expuestos sólo a la lectura del artículo. Las instrucciones para dicho grupo fueron como sigue: "Hola! A continuación se presentará un artículo de investigación, el cual está dividido en tres segmentos. Tu tarea consiste en leer cada segmento que compone el artículo. Una vez que termines de resolver esta actividad, coméntale a la persona que está a cargo de la misma. Cuando estés listo da clic en el botón iniciar".

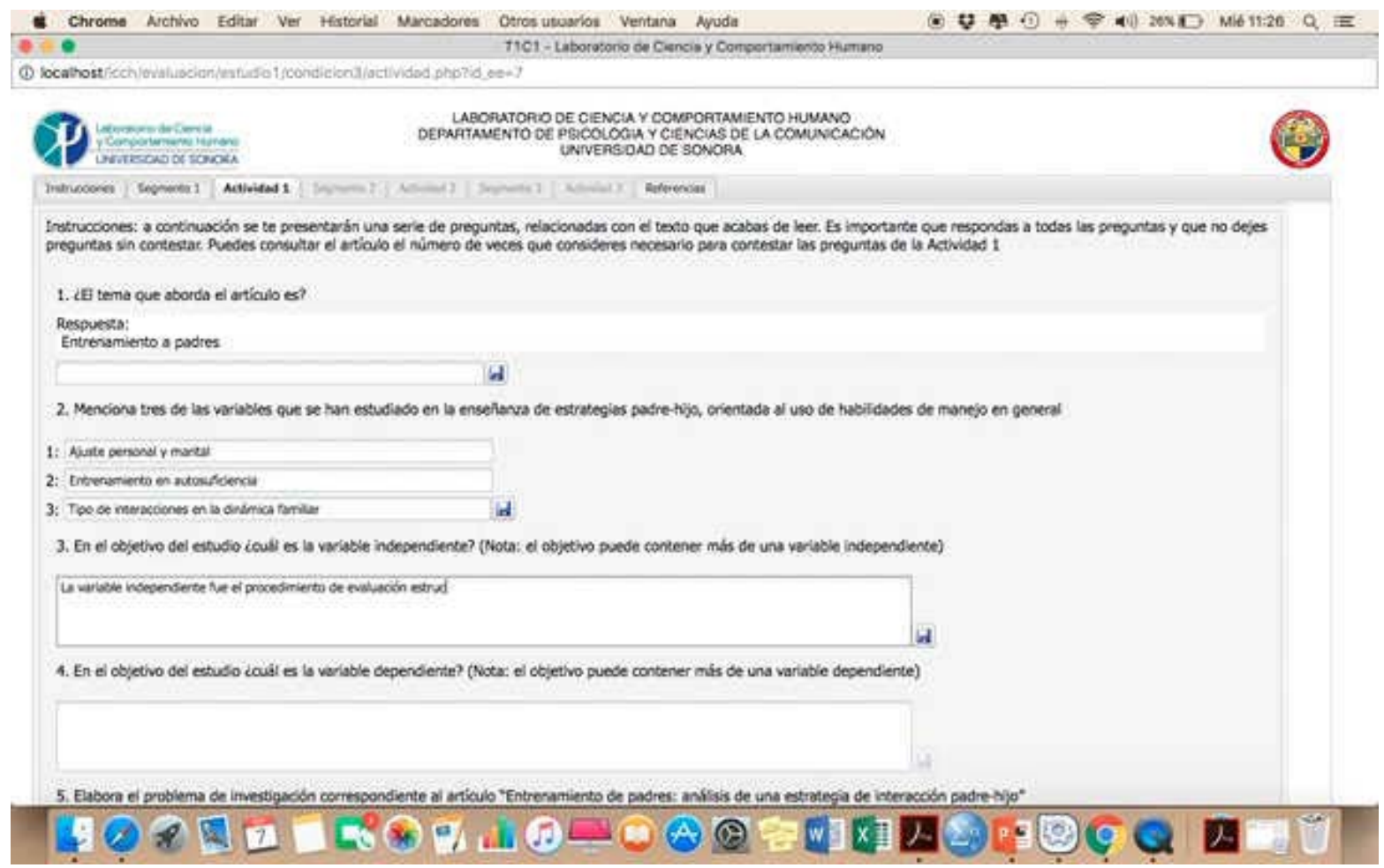

Video 1. llustra la presencia de la suplementación (Para reproducir el video, dar clic en la fotografía). 
Evaluación 1 (Post). Todos los grupos revisaron de nuevo el artículo 1, por lo que en esta sesión se replicó el procedimiento descrito en la evaluación 1 (Pre).

Evaluación 2. En esta sesión se replicó el procedimiento descrito en la evaluación 1 (prepost), excepto que el participante leyó el artículo 3, el cual difería en la temática abordada en la evaluación 1 (pre-post) y de entrenamiento.

Las respuestas de los participantes para cada una de las sesiones se registraron en una base de datos MySQL, exportadas para su análisis en formato html. Se calificó con base en rúbricas de dominio elaboradas ex-profeso para cada condición asignando 2 puntos a aquellos desempeños que cumplían con todos los criterios especificados en la rúbrica; 1 punto a los desempeños que cumplían parcialmente con dichos criterios y con 0 puntos a los que no se correspondían con los criterios definidos. Adicionalmente se llevó a cabo el análisis del desempeño escritor durante la corrección (sesión de entrenamiento) en función de la frecuencia de ocurrencia de las siguientes categorías: a) copia lo que escribió, b) copia del texto, c) corrige la instancia (concepto), d) corrige la acción entre instancias y d) corrige la relación entre instancias. El análisis se llevó a cabo por tres observadores independientes, con una confiabilidad del $100 \%$ de acuerdos.

Resultados. La Figura 3 muestra el porcentaje de aciertos por participante en la pre-evaluación 1 y la post-evaluación 1. Se observa en la pre-evaluación 1 que los participantes en los diferentes grupos obtienen un desempeño promedio de entrada menor al $60 \%$ de aciertos. La distribución de frecuencias nos indica que tres cuartas partes de la muestra está debajo del $40 \%$ de aciertos. Con el propósito de determinar si existen diferencias en el porcentaje de aciertos antes (pre-evaluación 1) y después (post-evaluación 1 y evaluación 2) del entrenamiento, se calculó el índice de cambio fiable (ICF) como una medida de cambio intrasujeto 4 (Jacobson, Follete \& Revenstorf, 1984). La fórmula utilizada es:

$$
\mathrm{ICF}=\left(\mathrm{x}_{2}-\mathrm{x}_{1}\right) / \mathrm{SE}
$$

En donde: $x 2=$ al puntaje obtenido en la post-evaluación, $x 1=$ al puntaje obtenido en la pre-evaluación y SE = al error estándar de medida. Lo que el ICF indica es que hay un incremento significativo en el porcentaje de aciertos en la post-evaluación 1 para los participantes P16 (36\%, ICF=2.24) del Grupo 1; P7 (64\%, ICF=5.5), P9 (39\%, ICF=5.5), P14 (42\%, ICF=4.5) y P24 (53\%, ICF=10) del Grupo 3 y P15 (31\%, ICF=4.15) del Grupo 4. Este dato nos señala que el grupo de lectura y escritura con suplementación específica y corrección, es el que mayor índice de cambio presenta por participante y por lo tanto, de mejora en el desempeño lector-escritor, resultado del entrenamiento.

$4 \quad$ Un índice mayor que \pm 1.96 es poco probable que ocurra $(p<.05)$ sin haberse producido un cambio fiable, esto es, una diferencia superior al azar. 
Grupo 1. Desempeño promedio individual

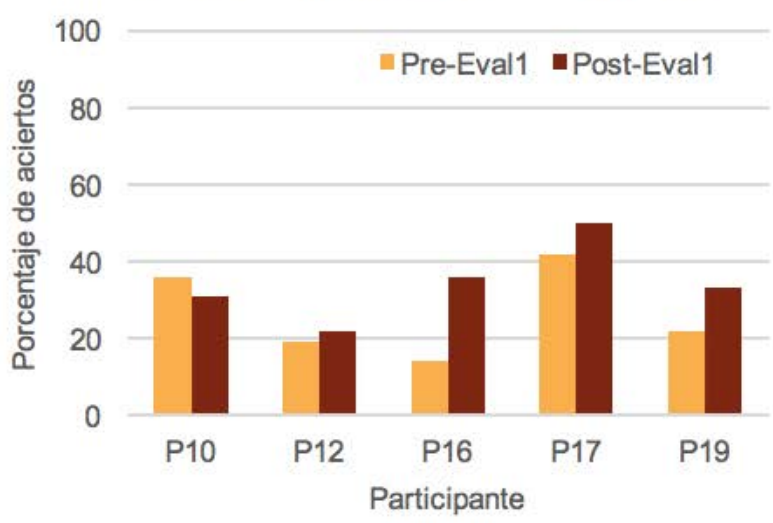

Grupo 3. Desempeño promedio individual

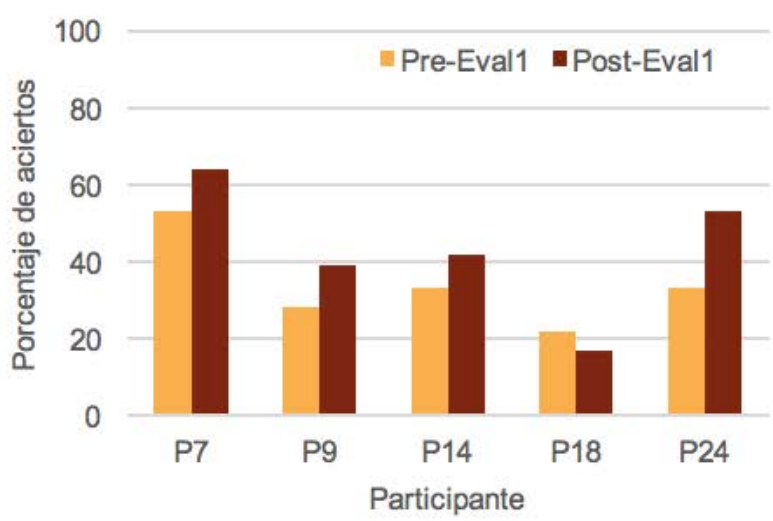

Grupo 2. Desempeño promedio individual

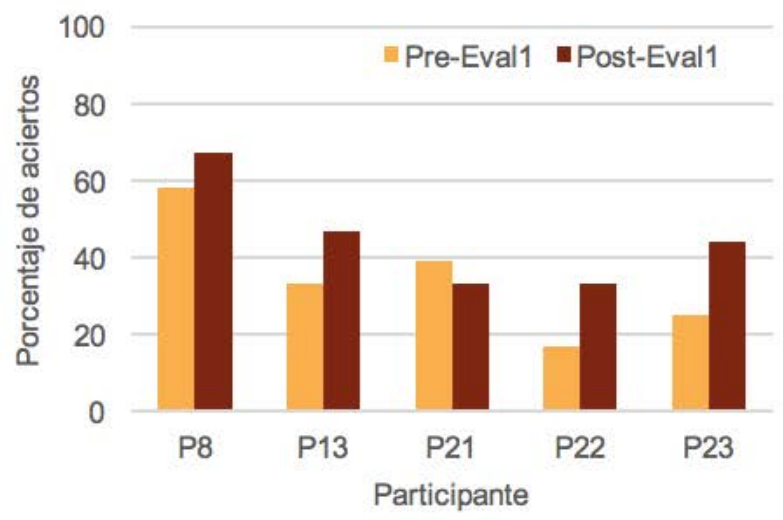

Grupo 4. Desempeño promedio individual

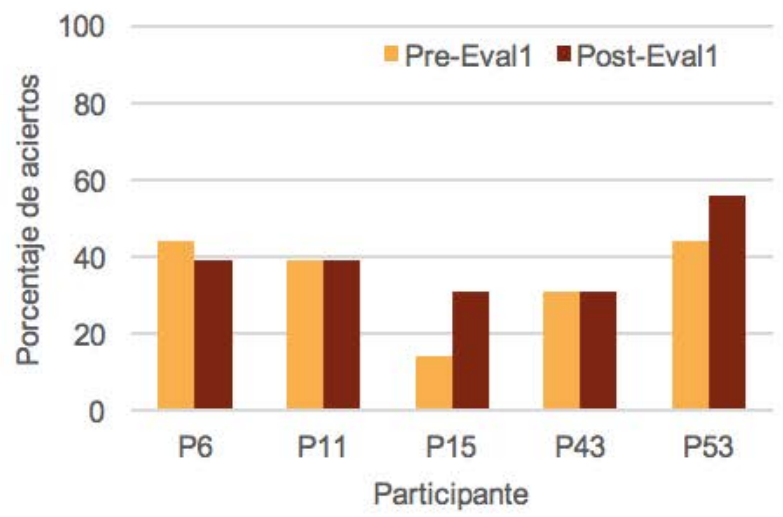

Figura 3. Porcentaje de aciertos por participante en la Pre-evaluación 1 y la Post-evaluación 1: Grupo 1 (lectura y escritura), Grupo 2 (lectura y escritura con suplementación lingüística general y corrección), Grupo 3 (lectura y escritura con suplementación lingüística específica y corrección), Grupo 4 (sólo lectura).

En la Figura 4 se muestra el porcentaje de aciertos por participante en la pre-evaluación 1 y la evaluación 2. En esta condición, el índice de cambio no es significativo para ninguno de los participantes de las diferentes condiciones, incluso para el caso de los participantes P6 (ICF= -2) y P11 $(\mathrm{ICF}=-2.5)$ del Grupo 4, resulta en un valor negativo.

En la evaluación 2 se observa un efecto de reversión a la pre-evaluación 1 e incluso con menos porcentaje de aciertos, ya que la distribución de frecuencias ubica tres cuartas partes de los puntajes por debajo del $38 \%$ de aciertos. Dicho resultado puede deberse a dos cosas: a) el cambio de área temática y, b) el ajuste al criterio disciplinar contrario a un criterio de "sentido común" (teoría implícita) semejante al observado en tareas de verificación-falsación de hipótesis (Baillo y Carretero, 1997). 

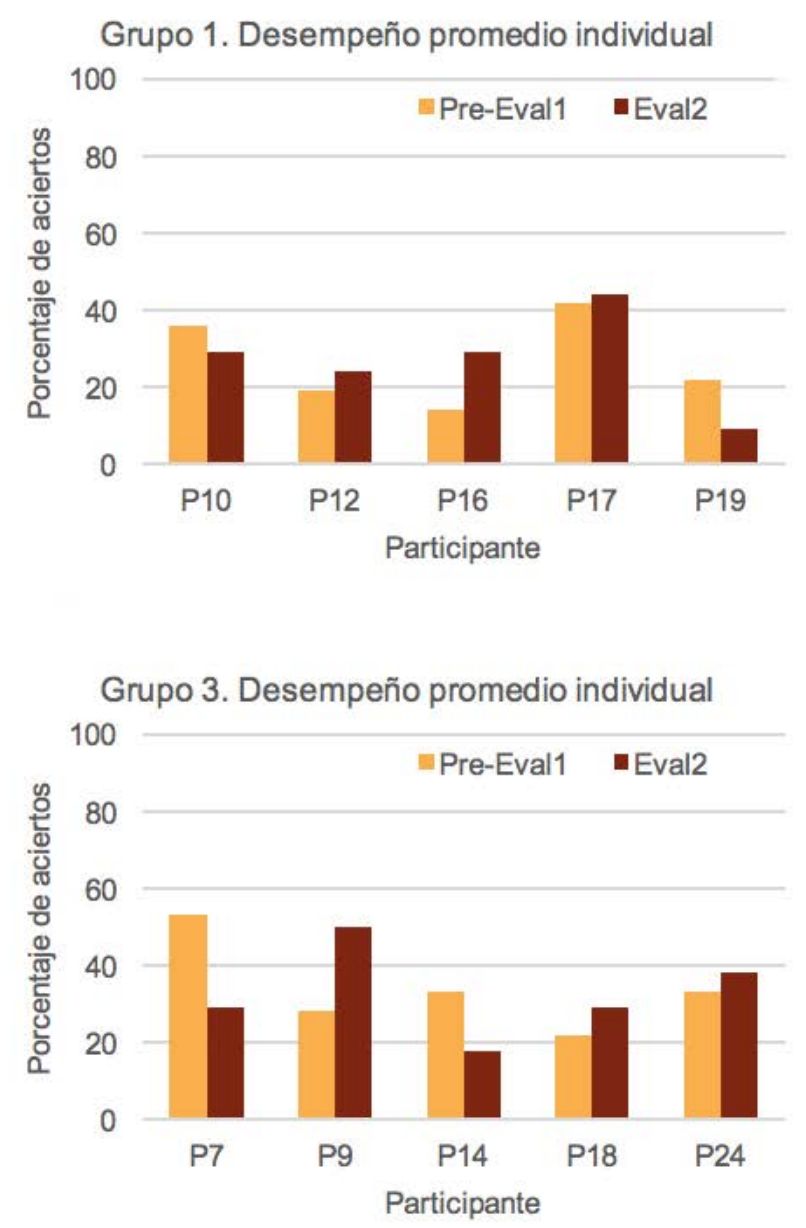
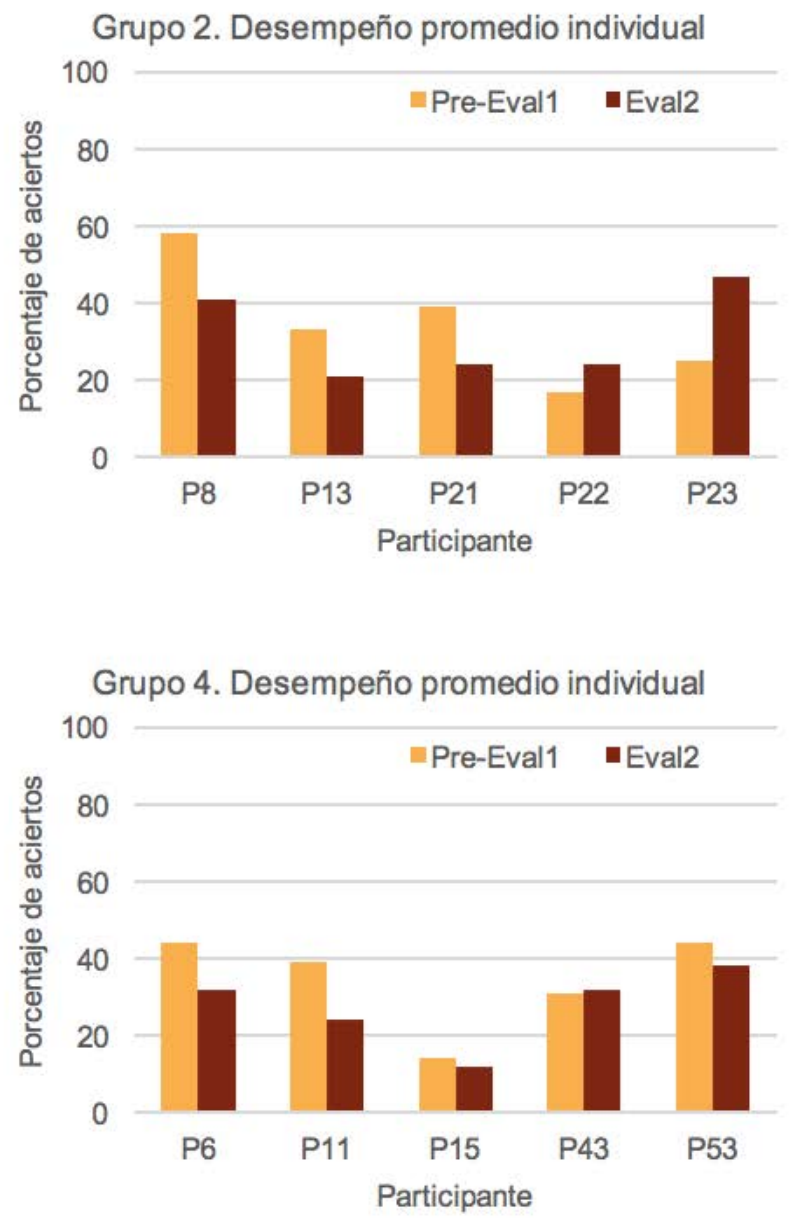

Figura 4. Porcentaje de aciertos por participante en la Pre-evaluación 1 y la evaluación 2: Grupo 1 (lectura y escritura), Grupo 2 (lectura y escritura con suplementación lingüística general y corrección), Grupo 3 (lectura y escritura con suplementación lingüística específica y corrección), Grupo 4 (sólo lectura).

Como se describe en el procedimiento, las evaluaciones y la sesión de entrenamiento se diseñaron considerando tres tipos de tarea: identificación, formulación y relación.

En la Figura 5 se presenta el promedio de aciertos por participante del Grupo 1 en la pre-evaluación, post-evaluación y en la evaluación 2, por tipo de tarea. Se observa en la pre-evaluación 1 que sólo el P17 obtiene el $67 \%$ de aciertos en la tarea de identificación. En la post-evaluación 1 se observan incrementos en la tarea de identificación en los participantes P10 (58\%), P12 (50\%), P16 (58\%) y P19 (50\%); en la tarea de formulación para el P19 (42\%) y en la tarea de relación para los participantes P16 (50\%) y P17 (50\%). En la evaluación 2 el incremento en el promedio de aciertos se observa en el P17 (75\%) en la tarea de identificación y en el P10 (50\%) en la tarea de relación, salvo el P17 ninguno de los casos mencionados (post-evaluación 1 y evaluación 2) alcanza el 60\% de aciertos. 

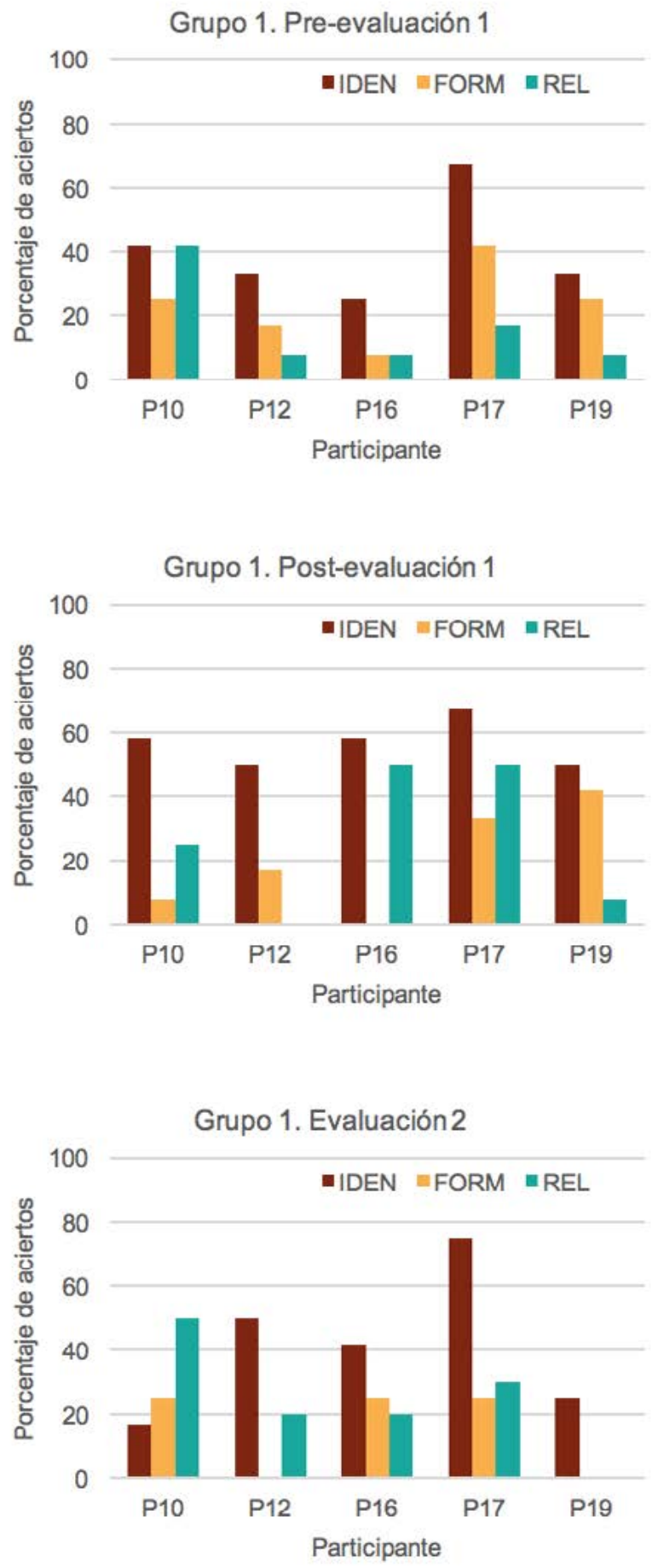

Figura 5. Porcentaje de aciertos de los participantes del Grupo 1, por tipo de tarea: IDEN (identificación), FORM (formulación) y REL (relación), antes (pre-evaluación 1) y después (post-evaluación 1 y evaluación 2) del entrenamiento.
La Figura 6 muestra el promedio de aciertos por participante del Grupo 2 en la pre-evaluación, post-evaluación y en la evaluación 2, por tipo de tarea. En la pre-evaluación 1 sólo el P8 obtiene el $67 \%$ de aciertos en la tarea de formulación y en la tarea de relación. El incremento en el promedio de aciertos en la post-evaluación 1 en la tarea de identificación se observa en los participantes P8 (83\%), P13 (75\%), P21 (33\%) y P23 (42\%), en la tarea de formulación para el P22 (25\%) y P23 (58\%) y en la tarea de relación para el P13 (50\%), P21 (58\%) y P22 (42\%). En la evaluación 2 el incremento significativo sólo se observa para el P23 en la tarea de identificación (50\%).

Es importante destacar que en este grupo el entrenamiento implica la presencia de segmentos lingüísticos que describen el desempeño esperado para cada una de las tareas. Dichos segmentos son "generales" ya que no se ilustran con las instancias que mencionan los autores en el texto, por mencionar un ejemplo: la pregunta "En el propósito del estudio ¿Cuál es la variable dependiente?” es seguida por el segmento lingüístico general que indica "Una variable es dependiente cuando los cambios observados en los valores de la misma son determinados por la variable independiente. Si la variable dependiente que identificaste responde a dicha descripción, ES CORRECTA. Si no responde a dicha descripción, deberás redactarla de nuevo. Se sugiere revisar el texto del segmento 1 ".

En cambio se considera un segmento lingüístico como específico si este incluye las instancias de las que trata el texto. Siguiendo el mismo ejemplo, en la pregunta "En el propósito del estudio ¿Cuál es la variable dependiente?” el segmento lingüístico específico indica "Si la variable dependiente que enunciaste fue: Dar instrucciones, secuencia instruccional, apoyo 

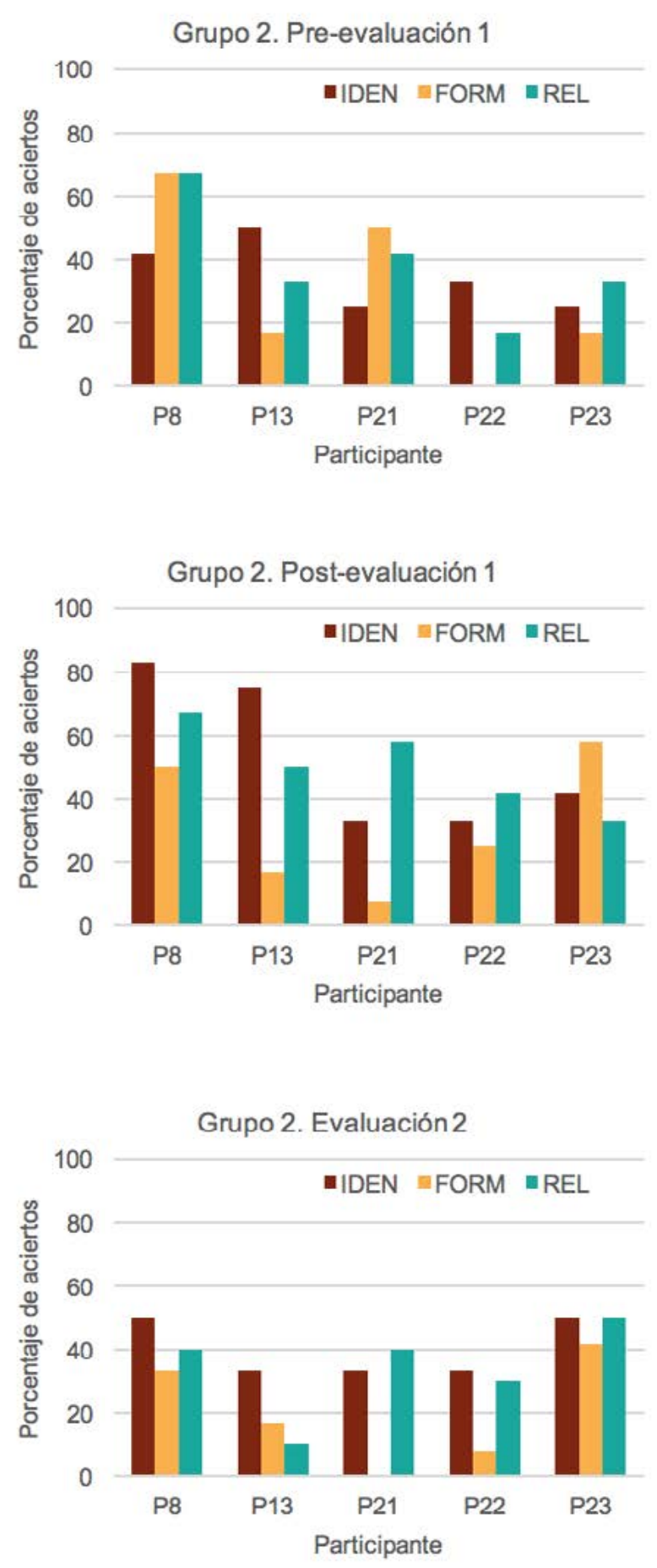

Figura 6. Porcentaje de aciertos de los participantes del Grupo 2, por tipo de tarea: IDEN (identificación), FORM (formulación) y REL (relación), antes (pre-evaluación 1) y después (post-evaluación 1 y evaluación 2) del entrenamiento. en tareas y castigo, ES CORRECTA. Si tu respuesta no consideró esta variable, deberás corregir. Se sugiere revisar de nuevo el texto del segmento 1".

Por lo anterior, la suplementación general parece afectar de modo importante los desempeños en la tarea de identificación (arriba del $60 \%$ para dos de los cinco participantes), no obstante sus efectos son limitados ya que el desempeño en este grupo en la evaluación 2 no se distingue respecto al desempeño del Grupo 1.

La Figura 7 presenta el porcentaje de aciertos por participante del Grupo 3 en la pre y post-evaluación así como en la evaluación 2. En este grupo se observa que ninguno de los participantes alcanza el $60 \%$ de aciertos en la pre-evaluación 1. En la post-evaluación 1 hay incrementos en la tarea de identificación para los participantes P7 (83\%), P18 (33\%) y el P24 (50\%); en la tarea de formulación para el P9 (25\%) y el P24 (67\%) y en la tarea de relación para los participantes P7 (75\%), P9 y P14 (58\%). En la evaluación 2 sólo se observa un incremento significativo para el P9 en las tres tareas: identificación (42\%), formulación (42\%) y relación $(70 \%)$.

Como se indica en párrafos anteriores, este grupo se expuso a la condición de lecto-escritura con suplementación específica, condición que genera que dos participantes obtengan puntajes mayores a $60 \%$ de aciertos en tareas distintas a la de identificación (caso del P24 en la tarea de formulación y del P7 en la tarea de relación) y que además se observe un efecto que se mantiene en la tarea de relación (caso del P9). La incidencia de participantes que presentan un incremento significativo en la post-evaluación 1 es mayor en los Grupos 2 y 3, en relación al Grupo 1. 

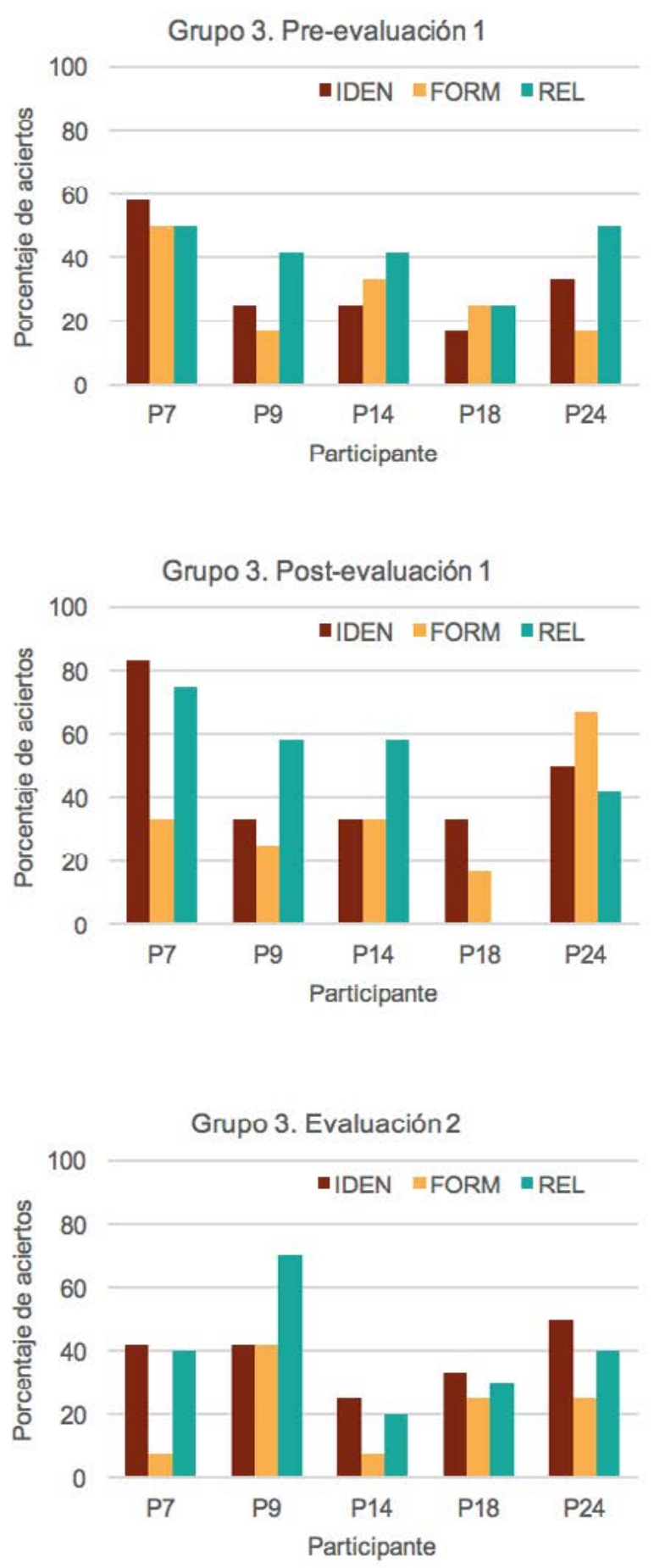

Figura 7. Porcentaje de aciertos de los participantes del Grupo 3, por tipo de tarea: IDEN (identificación), FORM (formulación) y REL (relación), antes (pre-evaluación 1) y después (post-evaluación 1 y evaluación 2) del entrenamiento.
La Figura 8 muestra el porcentaje de aciertos por participante del Grupo 4 en la pre-evaluación, la post-evaluación y la evaluación 2. En este grupo también se observa que en la pre-evaluación 1 el desempeño de los participantes no es mayor al $60 \%$ de aciertos. En la post-evaluación 1 presentan un incremento en el porcentaje de aciertos en la tarea de identificación los participantes P11 (50\%) y P15 (33\%) y en la tarea de relación los participantes P6 (75\%), P15 (58\%) y P53 (92\%). En la evaluación 2 no hay incrementos que resulten significativos por tipo de tarea.

La variación en los criterios de tarea es uno de los factores que permite monitorear el modo en que se media el contacto del estudiante con los referentes de dominio y las situaciones problema. En este sentido, los resultados destacan que:

A. La tarea de identificación fue la más sensible a la presencia de la suplementación general y específica. Dicha observación se apoya en el hecho de que no hay presencia de cambios significativos (igual o mayor al $60 \%$ de aciertos) en los participantes del Grupo 1 y del Grupo 4 para dicha tarea, a diferencia del Grupo 2 (P8 y P13) y del Grupo 3 (P7).

B. La tarea de formulación presenta poca sensibilidad a la presencia de la suplementación general y específica, ya que registra escasa ocurrencia de cambio en la post-evaluación 1 y en la evaluación 2 es nula (salvo el P9 del Grupo 3). Este resultado es preocupante puesto que los reactivos que conforman la tarea de formulación se relacionan con: elaborar la hipótesis de investigación, elaborar el problema de investigación, redactar la pregunta de investigación, elaborar un objetivo complementario, describir las características del diseño de investiga- 

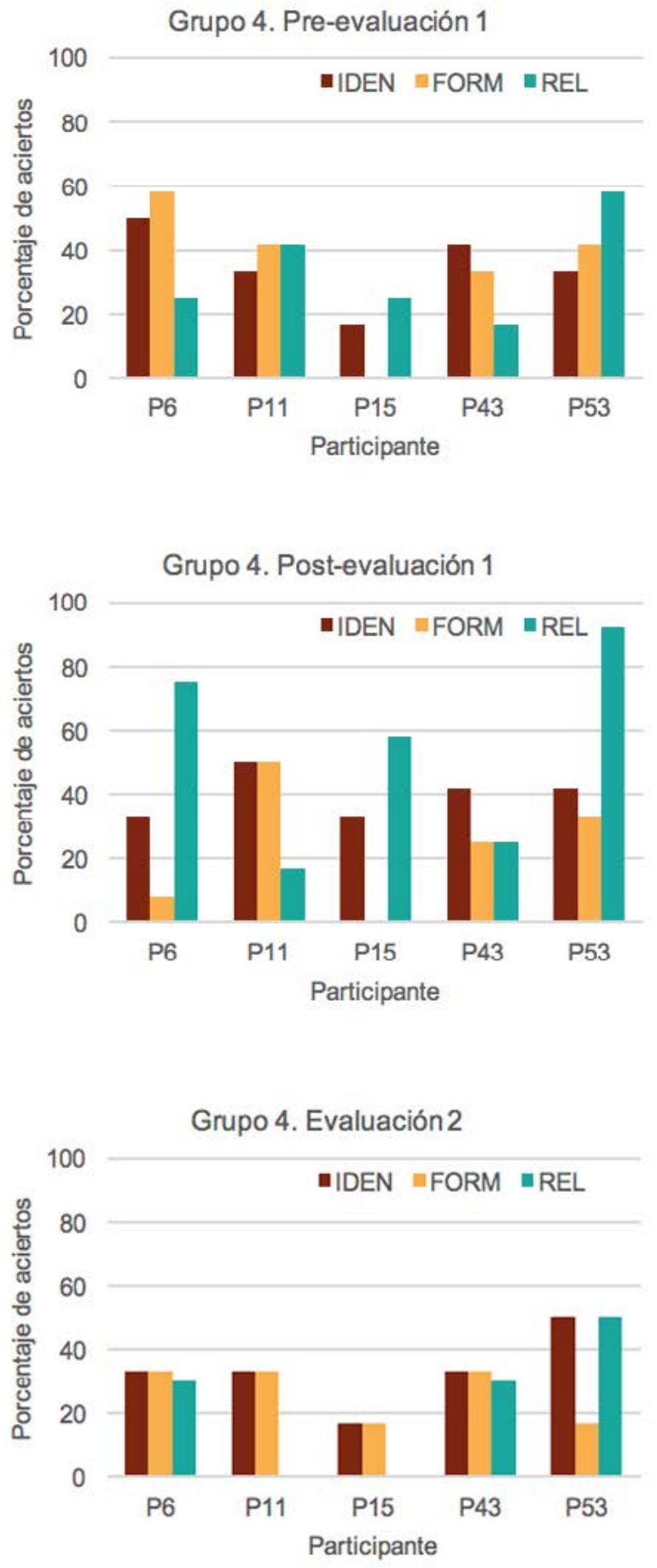

Figura 8. Porcentaje de aciertos de los participantes del Grupo 4, por tipo de tarea: IDEN (identificación), FORM (formulación) y REL (relación), antes (pre-evaluación 1) y después (post-evaluación 1 y evaluación 2) del entrenamiento. ción y elaborar una variante del procedimiento. Esto indica que la suplementación general y específica empleada en el presente estudio, sólo afectó el desempeño vinculado con el cumplimiento de criterios que demandan la modificación de instancias.

C. En el caso de la tarea de relación, si bien presenta cambios en el desempeño de los participantes de los diferentes grupos, no permite una discriminación fina del desempeño resultado de la presencia de la suplementación (se observa, p.ej. en el Grupo 4 el porcentaje de aciertos del P6 y P53 superior al $70 \%$ ).

Entrenamiento. En este apartado se describen los resultados de los participantes expuestos a la condición de lectura y escritura (Grupo 1), con suplementación general y corrección (Grupo 2) y con suplementación específica

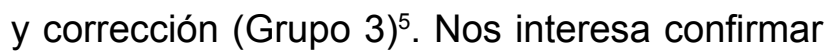
si existen diferencias en las puntuaciones de los participantes que sólo leyeron y escribieron (Grupo 1) comparados con las puntuaciones de aquellos participantes cuyo desempeño fue suplementado de modo general (Grupo 2) y de modo específico (Grupo 3) con corrección para ambos casos. Esto implica que tendríamos que analizar el desempeño de los participantes de los Grupos 2 y 3 la primera vez que escriben y el desempeño con la corrección. Con dicho propósito se instrumentó la prueba no paramétrica para muestras independientes Kruskal-Wallis con el promedio de aciertos la primer vez que escriben, y con el desempeño con la corrección. La Tabla 2 describe el rango promedio de acier-

5 Los participantes del Grupo 4 en la sesión de entrenamiento sólo se expusieron a la lectura del texto. En este sentido, no se reportan datos de este grupo para esta sesión. 
tos del Grupo 1 (lectura y escritura), Grupo 2 (lectura y escritura con suplementación general y corrección) y el Grupo 3 (lectura y escritura con suplementación específica y corrección) durante la primera vez que escriben. En dicha tabla se observa que el Grupo 2 expuesto a la suplementación general y corrección es el que obtiene el mayor rango promedio. El valor de $\mathrm{H}=2.667, \mathrm{p}=.264$ indica que no hay diferencias en las puntuaciones de los grupos.

Tabla 2. Rango promedio de aciertos en la sesión de entrenamiento en la primer respuesta.

\begin{tabular}{|c|c|c|c|}
\hline & Grupo & $\mathbf{N}$ & Rango promedio \\
\hline \multirow{3}{*}{$\begin{array}{l}\text { Promedio de aciertos } \\
\qquad(0-100)\end{array}$} & Grupo 1. Lectura y escritura & 5 & 7,10 \\
\hline & $\begin{array}{l}\text { Grupo 2. Lectura y escritura con } \\
\text { suplementación general y corrección }\end{array}$ & 5 & 10,60 \\
\hline & $\begin{array}{l}\text { Grupo 3. Lectura y escritura con } \\
\text { suplementación específica y } \\
\text { corrección }\end{array}$ & 5 & 6,30 \\
\hline
\end{tabular}

Sin embargo, considerando el promedio de aciertos con corrección, el valor de $\mathrm{H}=6.336, p=$ .042 indica que si hay diferencias en las puntuaciones del Grupo 2 y del Grupo 3 comparados con el Grupo 1. La Tabla 3 describe el rango promedio de aciertos de los grupos, considerando el desempeño con corrección, en ella se observa que es el Grupo 2 el que mayor rango promedio obtiene.

Tabla 3. Rango promedio de aciertos en la sesión de entrenamiento en la respuesta con corrección.

\begin{tabular}{|c|c|c|c|}
\hline & Grupo & $\mathbf{N}$ & Rango promedio \\
\hline \multirow{3}{*}{$\begin{array}{l}\text { Promedio de aciertos } \\
\qquad(0-100)\end{array}$} & Grupo 1. Lectura y escritura & 5 & 4,00 \\
\hline & $\begin{array}{l}\text { Grupo 2. Lectura y escritura con } \\
\text { suplementación general y corrección }\end{array}$ & 5 & 10,70 \\
\hline & $\begin{array}{l}\text { Grupo 3. Lectura y escritura con } \\
\text { suplementación específica y } \\
\text { corrección }\end{array}$ & 5 & 9,30 \\
\hline
\end{tabular}

Al confirmar que sí hay diferencias en las puntuaciones de los Grupos 2 y 3 respecto al Grupo 1 , el siguiente paso es determinar sobre qué tareas se observa un cambio importante resultado de la suplementación general y específica con corrección. Comparamos el desempeño del Grupo 1, Grupo 2 y del Grupo 3 por tipo de tarea en la primer respuesta, y en la respuesta con corrección, los resultados se muestran gráficamente en la Figura 9. Se destaca que las diferencias por tipo de tarea en la primer respuesta no fueron significativas entre grupos; pero si hay diferencias en las puntua- 
ciones en la respuesta con corrección para la tarea de identificación $(H=9.146, p=.010)$, siendo los participantes del Grupo 3 los que muestran un incremento considerable en dicha tarea (66.8\%). Este resultado nos indica que durante el entrenamiento se ve afectado de modo importante el desempeño lector-escritor por la condición de suplementación específica observado en la tarea de identificación. En el caso de la tarea de formulación las diferencias en puntuaciones no fueron significativas entre grupos en ambos momentos del responder.
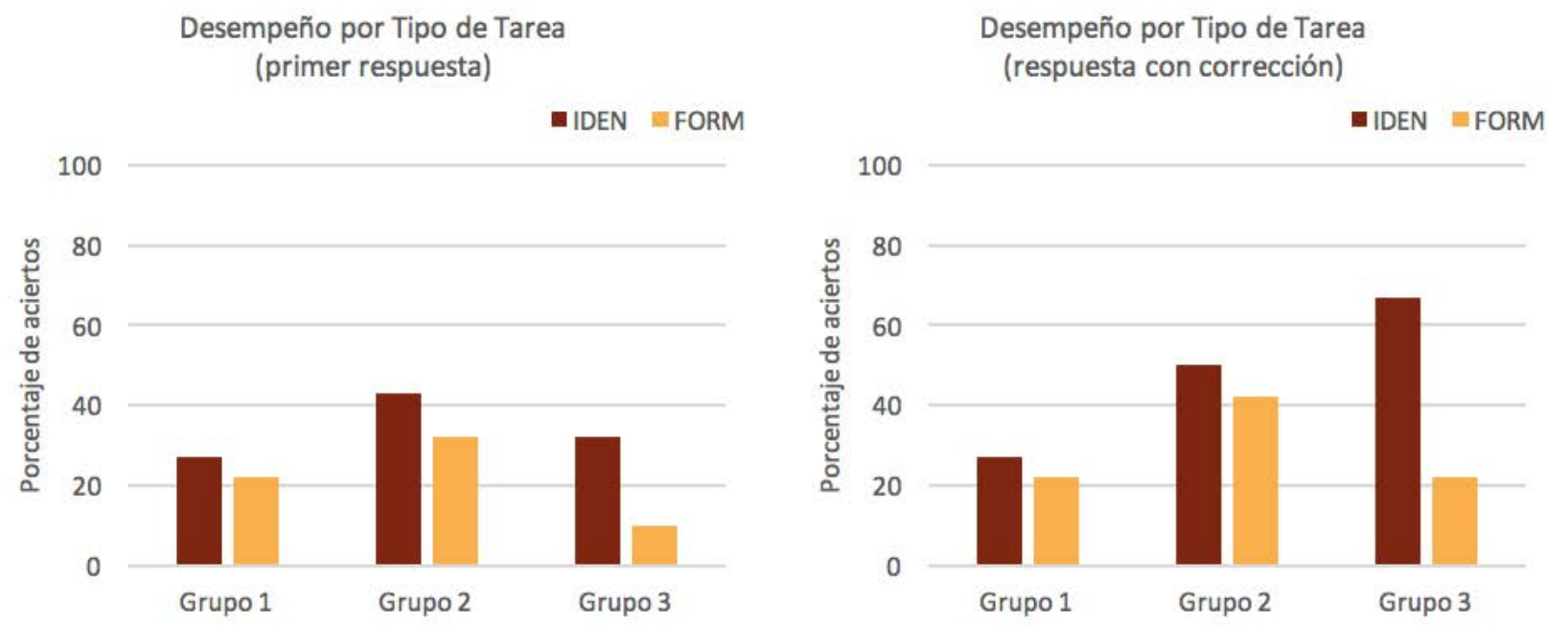

Figura 9. Porcentaje de aciertos del Grupo 1, Grupo 2 y Grupo 3, por tipo de tarea: IDEN (identificación), FORM (formulación) en entrenamiento.

En lo que respecta a la corrección que llevaron a cabo los participantes del Grupo 2 y del Grupo 3, en la Figura 10 se presenta la frecuencia de ocurrencia de las categorías: a) copia la primer respuesta, b) copia del texto, c) corrige la instancia (concepto), d) corrige la acción entre instancias y d) corrige la relación entre instancias. Como se observa en la Figura 10 son los participantes del grupo con suplementación específica los que con mayor frecuencia corrigen instancias (nominativo del concepto) y en menor medida la relación entre instancias. La transcripción de la primer respuesta se observa tanto en el Grupo 2 como en el Grupo 3. 
Corrección de lo escrito con suplementación general

$$
40
$$

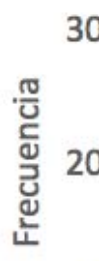

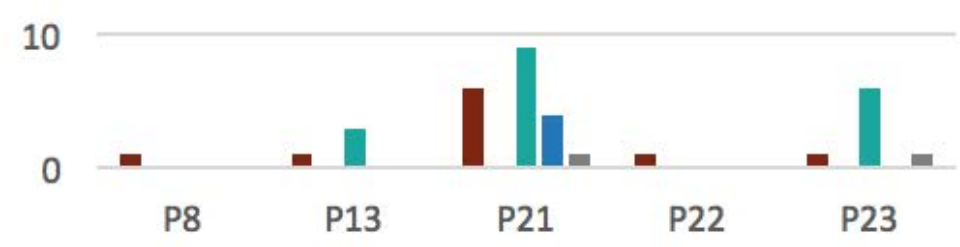

- Copia primer respuesta

Copia el texto

Enstancia

- Acción

Relación

\section{Corrección de lo escrito con suplementación específica}

$$
40
$$

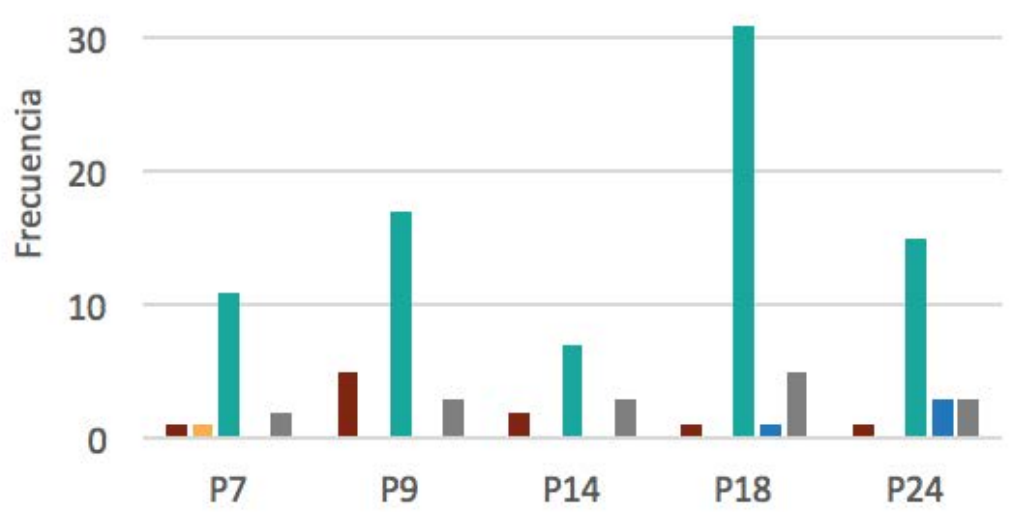

- Copia primer respuesta

Copia el texto

- Instancia

acción

- Relación

Figura 10. Corrección de lo escrito por participante.

\section{Discusión}

Consideramos que la incorporación del segmento lingüístico provisto como suplementación general y específica y la evaluación de sus efectos en pruebas posteriores (post-evaluación 1 y evaluación 2) permite el estudio de desempeños sustitutivos. Si el individuo ha aprendido alguna estrategia o regla que implica verbalizaciones sobre su desempeño, podrá solucionar la tarea guiado por estas verbalizaciones, aunque no sea informado momento a momento sobre el resultado de sus respuestas (Cepeda, Moreno, Hickman, Arroyo y Plancarte, 2015). 
Los resultados hasta aquí encontrados en la post-evaluación 1 y el entrenamiento parecen indicar que la condición de suplementación específica con corrección es la que favorece el desempeño lector-escritor de modo importante: en la post-evaluación 1 al generar un ICF en cuatro de los cinco participantes de este grupo: P7 (64\%, ICF=5.5), P9 (39\%, ICF=5.5), P14 (42\%, ICF=4.5) y P24 (53\%, $\mathrm{ICF}=10)$. En entrenamiento los efectos de la suplementación específica se observan en la tarea de identificación.

Los participantes expuestos a la suplementación específica (Grupo 3) corrigieron con mayor frecuencia que los participantes expuestos a la suplementación general (Grupo 2): 46 correcciones de los participantes del Grupo 3 contra 23 correcciones de los participantes del Grupo 2, y es la corrección de instancias (nominativo del concepto) la que con más frecuencia ocurre.

Como lo indican Crone-Todd et al. (2007) los procesos involucrados en la retroalimentación (suplementación) debieran facilitar que el participante formule la regla o heurístico a partir del cual resuelva problemas o responda cuestionamientos equivalentes posteriores. Según lo reportado en este estudio, tanto la suplementación general como la específica afectan el desempeño en tareas de identificación.

En este sentido, los resultados parecen indicar que es la suplementación lingüística la que tuvo un efecto situacional al incidir básicamente sobre el desempeño en tareas de identificación en la post-evaluación 1; efecto que no es transferible a la situación de evaluación 2. Al respecto, Ribes (1990b) señala: "Si bien los campos de contingencia determinan las condiciones y relaciones objetivas entre los eventos, es el desarrollo conductual del organismo el que determina las características reales de la mediación en cuestión" (p. 200).

El contenido de la tarea diseñada en este trabajo versa sobre el uso del método científico en Psicología, ejemplificado a partir de artículos de corte empírico, por lo que la tarea de los estudiantes consistía en identificar variables, redactar la hipótesis, el problema, la pregunta y el objetivo de investigación, enunciar las conductas que fueron estudiadas y su medida, elaborar conclusiones acerca del efecto de la variable independiente sobre las conductas estudiadas así como de los resultados obtenidos y el objetivo de la investigación. Consideramos que como estrategia de evaluación respecto al repertorio de lectura y escritura de textos científicos, permite identificar déficits o idoneidad de dicho repertorio de acuerdo al tipo de tarea. Las pruebas referidas a criterio son un tópico de discusión y revisión de vital importancia para el desarrollo de sistemas de evaluación congruentes y con validez social, pero además, el soporte en una Teoría del desarrollo de capacidades que permite trazar secuencias y niveles de complejidad acorde a establecer. En este sentido, los arreglos instruccionales debieran diseñarse para posibilitar que los aprendices sean expuestos a tareas variadas acordes a los criterios disciplinares y de logro que posibiliten el ejercicio de los juegos de lenguaje requeridos por el ámbito de entrenamiento específico.

En análisis posteriores tendríamos que revisar la composición escrita en la pre-evaluación 1 respecto a la post-evaluación 1 y la evaluación 2, alrededor de las categorías usadas en la corrección: a) reproduce la respuesta, b) copia el texto, c) modifica instancia, d) modifica acción y e) modifica relación. Del mismo modo habría que evaluar los efectos de la corrección hecha por el instructor (modelo experto) y los pares (estudiantes que mostraron un desempeño idóneo en la tarea) sobre el desempeño lector-escritor. 


\section{Referencias}

Baillo, M., \& Carretero, M. (1997). Desarrollo del razonamiento y cambio conceptual en la comprensión de la flotación. En M. Carretero, Construir y enseñar las ciencias experimentales (pp. 77-106). Argentina: AIQUE.

Camacho, J., \& Gómez, A. (2007). Variación de los modos del lenguaje en la adquisición y transferencia de conocimiento. En J.J. Irigoyen, M. Jiménez, \& K. Acuña (Eds.), Enseñanza, aprendizaje y evaluación. Una aproximación a la pedagogía de las ciencias (pp. 105-135). Hermosillo: Universidad de Sonora.

Camacho, J., Irigoyen, J.J., Gómez, A., Jiménez, M., \& Acuña, K. (2007). Adquisición y transferencia de modos lingüísticos en tareas de discriminación condicional sin retroalimentación reactiva. Enseñanza e Investigación en Psicología, 12 (1), 79-91.

Carpio, C., Pacheco, V., Canales, C., \& Flores, C. (1998). Comportamiento inteligente y juegos de lenguaje en la enseñanza de la Psicología. Acta Comportamentalia, 6 (1), 47-60.

Cepeda, M.L., Moreno, D., Hickman, H., Arroyo, R., \& Plancarte, P. (2011). Dominio de la tarea y descripciones verbales en la formulación de reglas generales de ejecución. Revista Mexicana de Análisis de la Conducta, 37 (2), 117-138.

Crone-Todd, D., Eyre, H., Hutchens, S., Jones, R., \& Pear, J. (2007). The effect of changing grading criteria on student writing. The Behavior Analyst Today, 8 (1), 35-42.

Fuentes, M.T., \& Ribes, E. (2001). Un análisis funcional de la comprensión lectora como interacción conductual. Revista Latina de Pensamiento y Lenguaje, 9 (2), 181-212.

Fuentes, M.T., \& Ribes, E. (2006). Influencia de tres repertorios precurrentes en la lectura comprensiva. Revista Mexicana de Psicología, 23 (2), 149-172.

Guevara, Y., Guerra, G., Delgado, U, \& Flores, C. (2014). Evaluación de distintos niveles de comprensión lectora en estudiantes universitarios. Acta Colombiana de Psicología, 17 (2), 113-121.

Irigoyen, J.J., Acuña, K., \& Jiménez, M. (2015). Aprendizaje de contenidos científicos: efecto de la modalidad del objeto referente. En F. Cabrera, Ó Zamora, H. Martínez, P. Covarrubias, \& V. Orduña (Eds.), Estudios sobre comportamiento y aplicaciones. Volumen IV (pp. 195-223). México: Universidad de Guadalajara-Universidad Nacional Autónoma de México-Consejo Nacional de Ciencia y Tecnología.

Irigoyen, J.J., Jiménez, M., \& Acuña, K. (2004). Evaluación competencial del aprendizaje. En J.J. Irigoyen, \& M. Jiménez. Análisis Funcional del Comportamiento y Educación (pp. 75-105). Hermosillo: Universidad de Sonora.

Irigoyen, J.J., Jiménez, M., \& Acuña, K. (2011). Competencias y educación superior. Revista Mexicana de Investigación Educativa, 16 (48), 243-266.

Irigoyen, J.J., Mares, G., Jiménez, M., Rivas, O., Acuña, K., Rocha, H., Noriega, J.G., \& Rueda, E. (2009). Caracterización de estudiantes de nuevo ingreso a la Universidad de Sonora: un estudio comparativo. Revista Mexicana de Investigación en Psicología, 1 (1), 71-84.

Jacobson, N., Follette, W., \& Revenstorf, D. (1984). Psychotherapy outcome research: methods for reporting variability and evaluating clinical significance. Behavior Therapy, 15, 336-352. 
Pacheco, V., Reséndiz, N., \& Mares, G. (2010). Análisis funcional de textos escritos por estudiantes de Psicología experimental. Enseñanza e Investigación en Psicología, 15 (1), 75-87.

Parr, J., \& Timperley, H. (2010). Feedback to writing, assessment for teaching and learning and student progress. Assessing Writing, 15, 68-85.

Perilla, A., Rincón, G., Gil, J., \& Salas, R. (2004). El mejoramiento de los procesos de comprensión de textos en el ámbito universitario. Lenguaje, 32, 159-182.

Ribes, E. (1982). El conductismo: reflexiones críticas. Barcelona: Editorial Fontanella.

Ribes, E. (1989). La inteligencia como comportamiento: un análisis conceptual. Revista Mexicana de Análisis de la Conducta, 15 (Monográfico), 51-67.

Ribes, E. (1990a). Psicología General. México: Editorial Trillas.

Ribes, E. (1990b). Las conductas lingüística y simbólica como procesos sustitutivos de contingencias. En E. Ribes, \& P. Harzem, Lenguaje y Conducta (pp. 193-207). México: Trillas.

Ribes, E. (1993). La práctica de la investigación científica y la noción de juego de lenguaje. Acta Comportamentalia, 1 (1), 63-82.

Ribes, E. (2000). El lenguaje desde la perspectiva del estudio del comportamiento: un análisis Interconductual. En V. Alcaraz (Coord.), Una mirada múltiple sobre el lenguaje (pp. 225-239). Guadalajara: Universidad de Guadalajara.

Ribes, E. (2012). Las funciones sustitutivas de contingencias. En M.A. Padilla, \& R. Pérez-Almonacid (Eds.), La función sustitutiva referencial. Análisis histórico-crítico/avances y perspectivas (pp. 19-34). New Orleans: University Press of the South.

Ribes, E., Cortes, A., \& Romero, P. (1992). Quizá el lenguaje no es un proceso o tipo especial de comportamiento: algunas reflexiones basadas en Wittgenstein. Revista Latina de Pensamiento y Lenguaje, 1 (1), 58-73.

Ribes, E., \& López, F. (1985). Teoría de la Conducta. Un análisis de campo y paramétrico. México: Editorial Trillas.

Ribes, E., Moreno, R., \& Padilla, M.A. (1996). Un análisis funcional de la práctica científica: extensiones de un modelo psicológico. Acta Comportamentalia, 4 (2), 205-235.

Varela, J. (1998). Teoría de la conducta: extensiones sobre el desarrollo del comportamiento inteligente. Acta Comportamentalia, 6 (Monográfico), 87-97.

Varela, J., \& Ribes, E. (2002). Aprendizaje, inteligencia y educación. En E. Ribes, Psicología del Aprendizaje (pp. 191-204). México: Manual Moderno. 


\section{Capítulo 10}

\section{Análisis de la habilitación lingüística de la escritura}

Alfoso López Corral, Carlos Flores Aguirre y Carlos Torres Ceja 
Alfonso López Corral vidalgarcial@gmail.com

Carlos Flores Aguirre carlos.flores.gdl@gmail.com

Carlos Torres Ceja jtorres@cencar.udg.mx Centro de Estudios e Investigaciones en Comportamiento Universidad de Guadalajara 


\section{Capítulo 10}

\section{Análisis de la habilitación lingüística de la escritura}

La escritura ha sido quizás la herramienta más útil inventada por el hombre para conservar y reproducir ideas, significados, interpretaciones de la vida con las que las personas dan sentido a su propia experiencia. En última instancia, el valor de la escritura sólo puede medirse en relación con la significación que hace del tiempo mismo en el que se escribe, es decir, lo que es capaz de explicar del ser humano y del mundo en una época específica. Cuando esto ocurre se preserva como parte de la historia del hombre. Sin embargo, este sentido ideal de la escritura como herramienta capaz de guardar las ideas del hombre sobre sí mismo y sobre la realidad, generalmente no es fácil de conseguir y constituye la excepción más que la regla.

De manera general, escribir, como en cualquier otra forma de lenguaje, es participar en un sistema simbólico que es dado por una cultura determinada y en el que se deben de seguir reglas específicas (Ribes, 1990). Sin embargo, escribir no es algo que se genera a partir del aparato biológico de las personas como lo hace, por ejemplo, el habla. Es decir, la escritura no es desarrollada directamente por la persona a partir de las interacciones del individuo con otros individuos y con el ambiente, sino que se deben utilizar herramientas para que se genere, es decir, cuando menos lápiz y papel.

Por otro lado, su par complementario, la lectura, tampoco se desarrolla directamente, debe ser enseñada y entrenada valiéndose también de una herramienta, por ejemplo, el libro. Y aunque se diría que en el proceso de enseñanza-aprendizaje tienen la misma importancia, es tradicionalmente en la lectura el aspecto donde se recarga mayormente el ejercicio, la escritura termina siendo, las más de las veces, algo accesorio a esta. Quizás esto se explique por la idea extendida que tenemos acerca de que por medio de la lectura conocemos y aprendemos. En una concepción de este tipo es difícil acomodar el supuesto de que la escritura también debe seguir ejercitándose una vez aprendida, porque sólo se considera un medio de reproducción y conservación de las ideas que deben estar listas para cuando la persona abra un libro (Pacheco, Ortega, Cruz y Carpio, 2013).

De una manera general, la escritura sí sería de esta forma: un medio para reproducir ideas que se conservan en un libro ${ }^{1}$. Pero anotarlo así puede dar la idea de que únicamente se trata de escribir todo lo que se ve y se oye, de registrar todo lo que se ve y se oye. Y, por supuesto, la escritura puede llegar a ser algo más complicado que eso. Ubicar qué es escribir, qué es la escritura, ayudará a comprender qué tan compleja puede ser.

1 Asimismo, la idea del libro como depositario de ideas puede llevar al equívoco de que basta con que la persona abra un libro para que las recoja, lo que resta importancia al papel crucial del comportamiento del individuo ajustándose a situaciones específicas con base en interacciones previas. 
Una de las acepciones más comunes señala que escribir es trazar signos sobre el papel que tienen sentido para una comunidad (Pacheco, Ortega, Morales y Carpio, 2013). Podríamos agregar que escribir es mediar por escrito un referente a un lector que puede ser otra persona o el escritor mismo (Fuentes y Ribes, 2001). Sin embargo, al escribir, el escritor no siempre está mediando por escrito un referente ${ }^{2}$, ya que existen los casos donde podría decirse que está siendo mediado por él. Esto tiene que ver con el contacto que se hace con el referente que habrá de escribirse y el papel que habrá de tomar el escritor con dicho referente (Varela, Nava, Lara y Zambrano, 2009; Pacheco et al., 2013). Resulta conveniente para ello, caracterizar la escritura en al menos dos tipos: activa y reactiva.

En la escritura reactiva, el escritor está siendo mediado por aquello de lo que escribe y las posibilidades de escritura se limitan a una reproducción literal de ese referente, por ejemplo: tomar un dictado o copiar algo del pizarrón o anotar la dirección donde vive una persona. La cualidad principal de la escritura reactiva es que el escritor no transforma su referente y puede decirse que el resultado del texto está previsto de antemano. Dicho de otro modo: si una persona escribe una decena de veces la dirección de una calle, las diez veces el resultado será el mismo.

En cambio, una escritura activa demanda que el escritor sea quien medie por escrito a un futuro lector (que puede ser él mismo) y que, al entrar en contacto con su referente, lo adecúe de acuerdo al objetivo que persiga. Por supuesto, en la escritura reactiva también un escritor puede mediar por escrito a alguien, por ejemplo, siguiendo con el ejemplo anterior, escribir la dirección de su casa a una persona para que esta de con el lugar. La diferencia es que en la escritura activa se dará un cambio en el referente que se media, es decir, el referente se transformará, lo que implica que el resultado del texto no estará previsto del todo, aunque se tenga una idea general del mismo. Dicho de otro modo: si una persona escribe una decena de veces sobre un tema, las diez veces el resultado será distinto. Esto proporciona, por último, que se abran múltiples posibilidades de ejecución para el escritor.

Cabe suponer que la importancia de la escritura se determina precisamente por la transformación que hace de los referentes sobre los que se escribe, porque va, o pretende ir más allá de la reproducción literal de los mismos. Para el escritor esto puede implicar que, así como el lector lee para saber, escriba para saber acerca del tema que escribe, que busque una constatación de lo que sabe o cree que sabe.

Escribir, cuando no se conoce con seguridad en lo que resultará el texto que se inicia o emprende, es el intento de comprobar que el referente que estamos mediando por escrito es aquello que suponemos, es la manera de constatar que se sabe acerca de aquello de lo que escribe. Esto es lo que proporciona una gran ventaja sobre el habla, porque es un modo lento y permanente (no evanescente), que permite ordenar lo que se dice y darle forma y estructura una y otra vez, sin el riesgo de olvidar partes o fragmentos o incluso cambiar el sentido inadvertidamente, hasta quedar satisfechos con el resultado, hasta saber si es idéntico o aproximado a lo que se quería (Fuentes y Ribes, 2001).

2 Consideramos al referente como las propiedades o características de los objetos, situaciones o circunstancias, personas o relaciones entre ellos. 
Esto que se constata a través del lenguaje escrito, para que el uso que se haga de las palabras se relacione con algo específico, o vuelva específico algo, debe quedar conectado, directa o indirectamente, con actividades reales, con alguna práctica social o convención donde cobre sentido lo que se dice (Ribes, 2007). Aquello que se constata escribiéndolo no será algo que quede aparte de una convención, de un acuerdo o entendido social de un grupo, aunque lo escrito vaya en contra del grupo o no se acepte como válido.

Esto va en relación con lo que plantea Tomasini (2001) a propósito de la noción de juegos de lenguaje de Wittgenstein, que es un sector del lenguaje caracterizado por su conexión con alguna práctica social determinada, con lo que fue denominado por el filósofo vienés, explica el autor, como forma de vida, donde los miembros de una comunidad toman parte en diversas formas de vida y por eso se vuelven usuarios de los correspondientes juegos de lenguaje. Lo que llegue a saberse, para que tenga sentido, deberá estar relacionado con esa forma de vida.

El supuesto en que basamos nuestra concepción de la escritura se puede enunciar de la siguiente manera: los referentes son de cierta forma, tienen ciertas características que los definen y el proceso de escritura constituye una forma de constatar nuestras concepciones e ideas con las características particulares del referente, para esto se parte de la información disponible de la persona que emprende la tarea de escribir para saber.

Si se afirma que lo que se hace al escribir es buscar una constatación de una idea o referente, entonces se supone que hay información sobre el mismo y es con lo que se trabaja. Y cuando se señala que se escribe porque hay información sobre un referente, se quiere indicar que la persona escribe a partir de lo que mira o miró, de lo que escucha o escuchó, o de lo que lee o leyó.

A partir de esa información es que se comienza a escribir, ya sea porque a partir de allí se quiere definir o describir de acuerdo a ciertos parámetros, ya sea porque se le quiere añadir algo a la información o bien relacionarla o cotejarla con otra, o incluso enmendar o corregir algo con lo que no se está de acuerdo. El resultado, el texto final, aunque pueda estar previsto de antemano o el final revelado, es lo único que validará lo conseguido a partir de lo que se miró, escuchó o leyó.

Desde la Psicología, en específico desde las Ciencias de la Conducta, una forma de comenzar a estudiar y evaluar los supuestos anteriores puede ser a partir del análisis de los modos lingüísticos y, en específico, del fenómeno conocido como habilitación lingüística (Fuentes y Ribes, 2001; Gómez, 2005; Camacho y Gómez, 2007; Tamayo, Ribes y Padilla, 2010).

\section{Modos lingüísticos}

Se le llama modos lingüísticos a las diferentes formas en las que el lenguaje ocurre. A su vez, estas formas pueden ubicarse como tipos de conducta verbal realizadas por las personas. Es decir, los individuos hablan, escuchan, leen, escriben, registran, señalan u observan (Fuentes y Ribes, 2001).

Estos tipos de conducta verbal a los que se hace referencia, indican los autores antes citados que dependen del medio físico y del sistema reactivo, así como de las combinaciones apropiadas de estos. Los autores señalan que los modos tienen lugar como pares complementarios y pueden agruparse en activos y reactivos. Dentro de los modos activos se tienen las conductas de gesticular/ señalar, hablar y escribir. A su vez, dentro de los reactivos ubicaríamos las conductas de observar, escuchar y leer. Los pares se conforman de la siguiente manera: gesticular/señalar con observar, hablar con escuchar y escribir con leer (ver Tabla 1). 
Tabla 1. Las combinaciones de los medios de ocurrencia con los sistemas reactivos dan como resultado seis posibles modos de ocurrencia del lenguaje.

\begin{tabular}{|c|c|}
\hline \multicolumn{2}{|c|}{ Modos lingüísticos } \\
\hline Activos & Reactivos \\
\hline Gesticular/señalar & Observar \\
\hline Hablar & Escuchar \\
\hline Escribir & Leer \\
\hline
\end{tabular}

La adaptación de cada modo lingüístico implica los sistemas reactivos visual, auditivo, fonador, motor grueso, motor manual y digital fino; así como los medios de ocurrencia óptico y acústico (Camacho y Gómez, 2007). Por ejemplo, el par leer-escribir se da ante objetos de estímulo lingüístico como grafemas y textos, y a su vez produce esa misma clase de estímulos. Escribir se ejercita mediante respuestas motoras (movimientos que con la práctica se van afinando y volviendo precisos) con consecuencias visuales en la forma de trazos impresos de carácter específico, esto es símbolos y signos específicos; por su parte, leer ocurre como fonación explícita en correspondencia a grafemas particulares (Gómez, 2005).

Los supuestos que se derivan de este análisis son, entre otros, que cada modo tiene propiedades funcionales específicas y que por ello, las variables relacionadas con su adquisición y desarrollo son distintas; también que los modos reactivos son condición necesaria para la emisión de los activos, los anteceden en la ontogénesis y los retroalimentan. Así para gesticular es necesario poder observar, para hablar es necesario poder escuchar y para escribir el poder leer (Fuentes y Ribes, 2001).

Camacho y Gómez (2007) exponen tres planteamientos para el análisis de los modos lingüísticos:

Primero, la adquisición depende de las propiedades funcionales de cada modo y de las características de la situación de entrenamiento; así el nivel de dificultad baja o se incrementa de acuerdo a las características morfológicas del modo y las relaciones de igualdad por semejanza o diferencia en una situación de práctica de los modos, que va de lo más directo posible a lo más arbitrario.

Segundo, la translatividad, o el cambio de ejecución de un modo a otro en la secuencia de entrenamiento, depende de la facilidad de adquisición de lo aprendido en el modo precedente.

Y tercero, la transferencia depende de la calidad del desempeño previo y del nivel de desligabilidad de la respuesta en la situación en que se aprendió.

Bajo estos supuestos y planteamientos se han impulsado investigaciones que proporcionan datos sobre el establecimiento y desarrollo de los modos lingüísticos como variables críticas en el estudio del lenguaje desde una perspectiva psicológica, también en fenómenos de especial interés para la Ciencia de la Conducta, como lo son el aprendizaje y la comprensión. 
Camacho, Irigoyen, Gómez, Jiménez y Acuña (2007) realizaron un estudio con el propósito de evaluar la adquisición y transferencia de cada modo lingüístico bajo un procedimiento de igualación de la muestra de segundo orden. El supuesto fue que la adquisición y transferencia de repertorio efectivo ante condiciones variantes depende de las propiedades funcionales de cada modo y del nivel de dificultad de las condiciones experimentales a las que es expuesto el sujeto. Tres grupos fueron expuestos en distinto orden a los modos escribir-leer, hablar-escuchar y gesticular/ señalar-observar, con preprueba y postprueba, así como tres pruebas de transferencia aplicadas al final de los entrenamientos en cada modo. Ante los estímulos los participantes tenían que señalar, escribir o pronunciar su respuesta.

En cuanto a los hallazgos, los autores reportan para adquisición una ejecución más elevada del grupo que comenzó el entrenamiento con escribir-leer respecto de los grupos que comenzaron con hablar-escuchar y gesticular/señalar-observar. Se destaca que comenzar el entrenamiento de un modo considerado más complejo hacia uno menos complejo, por ejemplo, hablar después de escribir o señalar después de escribir, en lugar de hablar después de señalar, generó un aumento en el porcentaje de respuestas correctas. En la condición de transferencia, las pruebas hablar después de escribir y señalar después de escribir mostraron mayor porcentaje de respuestas correctas; en cambio, las pruebas hablar después de señalar y escribir después de señalar presentaron el menor porcentaje de respuestas correctas. Estos hallazgos parecen confirmar el supuesto sobre la adquisición en un modo lingüístico complejo para su transferencia hacia uno menos complejo.

En un procedimiento similar, con el propósito de evaluar cómo los modos lingüísticos afectan el nivel de adquisición, translatividad y transferencia de la respuesta de igualación, Camacho y Gómez (2007) condujeron dos experimentos (uno sin retroalimentación reactiva ${ }^{3}$ y el otro con retroalimentación reactiva). Los autores encontraron en el primer experimento un mayor porcentaje de respuestas correctas en adquisición para el modo escribir, una mayor translatividad del modo escribir sobre el hablar, seguido del modo hablar sobre el señalar y un efecto negativo del señalar sobre escribir.

En el experimento con retroalimentación reactiva, la ejecución en la adquisición mostró mínimas diferencias entre los tres modos, también encontraron un mayor porcentaje de respuestas correctas que las observadas en el Experimento 1. La translatividad fue mayor del modo señalar sobre el escribir, seguido del escribir sobre el hablar y por último, del hablar sobre el señalar. En la prueba de transferencia los resultados fueron de mayor a menor de acuerdo a la complejidad de la prueba. En general, los autores discuten que la ausencia de retroalimentación reactiva puede afectar el nivel de adquisición, y que el efecto de translatividad se observa del modo considerado más complejo sobre el menos complejo (escribir sobre señalar, por ejemplo); en cambio, la transferencia depende del nivel terminal de ejecución y de las características del modo lingüístico, al igual que lo señalan en sus resultados y discusión Camacho et al. (2007).

En un procedimiento de igualación de la muestra de primer orden, Gómez y Ribes (2008) evaluaron todos los modos lingüísticos en el establecimiento, translatividad y transferencia de una discriminación condicional en dos experimentos, uno con retroalimentación y el otro sin retroalimentación de los modos reactivos, esto con el objetivo de evaluar sistemáticamente la funcionalidad de

3 La retroalimentación intrínseca que otorgan los modos reactivos a los activos. Por ejemplo, que al escribir pueda leer lo que estoy escribiendo. 
cada modo. Adicionalmente se pretendía averiguar si a lo largo del desarrollo de los modos lingüísticos existe o no una relación de independencia entre los modos activos y reactivos correspondientes. Según lo programado en el diseño, los participantes tenían que escribir, hablar o señalar su respuesta valiéndose del teclado de la computadora, del ratón de la computadora o de un micrófono habilitado para ello.

Los autores encontraron porcentajes elevados de respuestas correctas en todos los modos evaluados, incluso en las pruebas de transferencia. Los resultados parecen corresponder con los del trabajo de Camacho et al. (2007) y Camacho y Gómez (2007), en cuanto a que el efecto mayor de translatividad se observó de los modos considerados más complejos a los menos complejos, esto es, del escribir al hablar, y del hablar al señalar.

En estos estudios se cuestiona la suposición de que primero es necesario comenzar con ejecuciones menos complejas morfológicamente para luego pasar a las más complejas. En este sentido, Gómez y Ribes (2008, p. 206) señalan que: "la diferencia de datos observados, tanto en adquisición, translatividad y transferencia demuestran la independencia funcional de cada modo lingüístico, lo que sugiere que es inadecuado referirse a las respuestas 'verbales' como una clase funcionalmente homogénea de comportamiento".

Al respecto, Camacho y Gómez (2007) señalan que es evidente la diferencia entre adquirir conocimiento señalando las características de lo que se aprende, hablando sobre lo que se aprende o generando un texto coherente sobre el mismo.

No todos los trabajos de investigación sobre los modos lingüísticos han utilizado el procedimiento de igualación de la muestra. En estudios recientes, por ejemplo, Quiroga, Peña y Padilla (2013) evaluaron el desempeño en función del modo lingüístico al que eran expuestos los participantes al resolver tareas de laberinto en una computadora; el objetivo era probar si la presencia-ausencia del objeto referente afecta diferencialmente el aprendizaje y la transferencia en dos tipos de ajuste conductual: diferencialidad y efectividad, al exponer a los participantes a los modos de leer-escribir y hablar-escuchar. Los resultados muestran que en los grupos con modalidad escribir-leer requirieron un menor número de bloques de entrenamiento y prueba para superar el criterio de logro y obtuvieron un mayor porcentaje de aciertos. Asimismo, los autores señalan que el requerimiento conductual que implica responder convencionalmente a eventos y objetos diferidos en tiempo, puede involucrar competencias lingüísticas diferentes a aquellas requeridas para responder ante eventos que se encuentran presentes en el ámbito perceptual, es decir, sí parece haber un efecto en el desempeño de los participantes de acuerdo a las condiciones de presencia-ausencia del objeto referente y en función del tipo de modo lingüístico implicado.

Por otra parte, Acuña, Irigoyen y Jiménez (2013) llevaron a cabo tres estudios para evaluar la comprensión de contenidos científicos a partir de la modalidad lingüística escribir y hablar. El objetivo fue analizar si la explicitación del criterio de ajuste, las variaciones en el tipo de tarea, su nivel funcional, y la modalidad lingüística involucrada, determinaban ajustes diferenciales en la comprensión de un material (texto o audio). La situación de evaluación se conformó por la presentación de un texto y un audio, una prueba de 10 reactivos de opción múltiple y 10 de respuesta abierta, así como elaborar un resumen y una conclusión. 
Con base en los resultados, los autores destacan lo siguiente: que la explicitación del criterio de ajuste tiene un efecto facilitador sobre la comprensión de contenidos científicos; que el desempeño de los participantes muestra ejecuciones diferenciales importantes, pues aquellas tareas que involucran menor grado de desligamiento (prueba de opción múltiple y resumen) son las que presentan mayor porcentaje de aciertos; que el nivel de ejecución fue mayor (aproximadamente en un $20 \%$ en los tres estudios) en la modalidad textual del objeto referente que en la auditiva; que las variaciones en las secuencias de presentación de las modalidades lingüísticas muestran diferencias en términos de mayor porcentaje de congruencia si primero escriben y posteriormente hablan, que si primero hablan y después escriben; y por último, que el desempeño de los participantes parece depender más del modo lingüístico, del tipo de tarea y su nivel funcional que del contenido de los materiales de estudio.

De acuerdo a lo revisado hasta aquí, los datos de los trabajos presentados parecen avalar los supuestos enumerados al inicio de este apartado acerca de los modos lingüísticos. Por otra parte, si como ya vimos, los modos lingüísticos posibilitan el estudio del lenguaje como Conducta y, si uno de esos modos corresponde a la escritura, entonces un análisis primario de la escritura debería darse a partir de su estudio como Conducta. Asimismo, suponemos que una manera de entrar en contacto directo con nuestro objeto de interés es a partir del estudio de la habilitación lingüística, un fenómeno básico hacia dentro del estudio de los modos lingüísticos.

\section{Habilitación lingüística}

Un elemento que posteriormente comenzó a evaluarse dentro del estudio de las modalidades lingüísticas corresponde al análisis de las relaciones que se presentan entre modalidades reactivas y activas. Para evaluar estas relaciones, Tamayo et al. (2010) desarrollaron el término habilitación lingüística, el cual es definido como la facilitación de un desempeño en un modo activo como resultado de una exposición en un modo reactivo. En otras palabras, la manera en que el leer, observar o escuchar afecta el desempeño que puede observarse en el escribir, señalar/gesticular o en el hablar.

Para estudiar este fenómeno, los autores realizaron dos experimentos utilizando un procedimiento de igualación a la muestra de primer orden y evaluaron la respuesta de igualación verbal escrita ante las tres modalidades reactivas (leer, observar y escuchar). El propósito fue observar cuál modalidad reactiva habilitaba de una manera más efectiva la modalidad de escribir. Cada experimento contó con tres grupos que fueron asignados a una modalidad específica y el diseño consistió en una preprueba, una exposición a modalidad reactiva o entrenamiento comprensivo y una prueba de habilitación.

En la preprueba a cada grupo se le presentaban los estímulos tanto de muestra como de comparación (figuras geométricas) de acuerdo a la modalidad que le correspondía. Por ejemplo, al grupo 2 en la modalidad leer, en vez de un triángulo rojo se le presentaban las palabras "triángulo rojo", de esa forma las presentaciones de los estímulos se adecuaban a su modalidad reactiva. La respuesta, que no recibía retroalimentación, tenían que emitirla únicamente escribiendo en la casilla habilitada para ello. En la prueba de entrenamiento comprensivo, los participantes tenían que observar, leer o escuchar la respuesta correcta sin hacer nada. Finalmente, en la prueba de habilitación se repetían las condiciones de la preprueba. En el Experimento 2 se repitieron las mismas condiciones, 
la única diferencia con el Experimento 1 fue que en este caso los participantes debían decir en voz alta el nombre de todas las figuras o instancias particulares de los estímulos que veían, leían o escuchaban.

Los resultados mostraron una mayor habilitación del modo escribir por parte del modo observar; el modo escuchar presentó el menor porcentaje de respuestas correctas. Las ejecuciones en el Experimento 2 fueron más bajas que en el Experimento 1, ubicándose de nuevo el modo observar sobre el escribir con los resultados más altos que en los otros dos modos. De nueva cuenta escuchar fue el modo en el que se observaron los menores porcentajes de respuestas correctas. Los autores atribuyen los bajos porcentajes observados en el Experimento 2 a un posible efecto de interferencia del modo hablar sobre los modos reactivos. Por último, al respecto de estos hallazgos, señalan que es posible que el modo observar tenga un papel funcional central dentro de las modalidades lingüísticas reactivas.

Con un objetivo similar, Tamayo y Martínez (2014) evaluaron el efecto de habilitación lingüística, pero en este caso de todas las posibles combinaciones de modos reactivos y activos, usando además un procedimiento de igualación a la muestra de segundo orden que tenía como estímulos figuras geométricas. El diseño contó con preprueba, una exposición y una prueba de habilitación. Las formas de presentación de los estímulos fueron de acuerdo al modo correspondiente. Por ejemplo, en el modo leer se presentaba la palabra "triangulo rojo" en vez de la figura de un triangulo rojo. A su vez, la respuesta debía emitirse según el modo activo asignado a los grupos, a saber, en señalar debía escoger con el ratón la figura correcta, o escribir en el espacio habilitado para ello, o bien, presionar el botón de grabar habilitado y decir en voz alta su respuesta.

Los resultados muestran en el modo observar el mayor porcentaje de aciertos, esto en los pares observar-señalar y en observar-escribir. En el modo leer, el mayor porcentaje de aciertos se obtuvo en los pares leer-hablar y en leer-señalar. En el modo escuchar, el mayor porcentaje de aciertos se obtuvo en los pares escuchar-señalar y escuchar-escribir. Los autores señalan que no hubo diferencias entre los modos observar y leer y que probablemente en el modo hablar se presentó el efecto de interferencia que atribuyen a sus resultados en ese mismo modo Tamayo et al. (2010). Comparando los resultados de estos dos estudios, se observa particularmente una mayor ejecución de los modos observar-escribir sobre los modos leer-escribir y escuchar-escribir.

De acuerdo con lo revisado hasta aquí, resalta que el procedimiento de igualación de la muestra ha sido generalmente la manera elegida de abordar el estudio de los modos lingüísticos, aunque no la única. También en el abordaje del fenómeno de habilitación lingüística ha predominado el uso de la igualación de la muestra, pero de igual manera con excepciones. Por ejemplo, usando un procedimiento diferente, Pulido y Tamayo (2015) investigaron la interacción de los modos reactivos-activos no complementarios, en este caso con el objetivo de evaluar la habilitación lingüística en el aprendizaje de la propiedad conmutativa de la suma a partir de la exposición a ejercicios presentados en cinco diferentes niveles competenciales.

Se ha planteado en este trabajo que su interés principal es estudiar la escritura, y estudiarla a partir de su concepción como conducta, esto es, del individuo que escribe, porque se presupone que puede ser una manera básica de comprenderla y explicarla, tanto desde su adquisición como 
su posterior entrenamiento o desarrollo para elaborar diferentes tipos de texto, según sea el objetivo deseado. Consideramos que a través del estudio de los modos lingüísticos y el estudio de la habilitación lingüística puede estudiarse y evaluarse dicho contacto. Por ejemplo, el estudio del fenómeno de habilitación proporciona la ventaja de un análisis y estudio directo de, por lo menos, el contacto entre el modo lingüístico reactivo y activo correspondiente. Dicho en palabras de nuestro objeto de interés: la manera en que el escritor hace contacto con el referente y el texto resultante.

A partir de los trabajos de habilitación lingüística presentados, surge la duda acerca del tipo de resultados que pudiera arrojar el estudio de los modos lingüísticos, y en específico la habilitación del modo activo escribir, con un procedimiento experimental diferente al de igualación a la muestra, incorporando segmentos de estímulo y respuesta distintos a los generalmente usados en igualación, más cercanos a lo que se sería una respuesta escrita que genere textos de extensión variable. En los trabajos descritos de Tamayo et al. (2010) y Tamayo y Martínez (2014), los porcentajes más altos de aciertos se obtuvieron en el modo reactivo observar y, como sugieren Pulido y Tamayo (2015), ello pudiera deberse al mismo procedimiento de igualación y al tipo de estímulos utilizados: los resultados de su investigación con un procedimiento distinto contrastan con los datos de dichos estudios, donde los mejores desempeños se encontraron donde se integraba en el par lingüístico el modo leer o el modo escribir, si bien el objetivo era evaluar el aprendizaje de la propiedad conmutativa de la suma. Resulta necesario entonces corroborar si ¿con un procedimiento distinto al de igualación a la muestra para evaluar el modo activo escribir seguirán predominando los mejores desempeños a partir del modo reactivo observar?

Retomando, de aquí también surge la duda de si la variación en el procedimiento experimental, para estudiar la habilitación del modo escribir, resulta útil también para ir caracterizando la forma en que las personas hacen contacto con el referente sobre el que escriben, cómo escriben acerca de dicho referente y las ejecuciones que resultan. En este sentido, el propósito del siguiente estudio fue evaluar la habilitación lingüística que los modos reactivos leer, observar y escuchar promueven sobre el modo activo escribir.

\section{Método}

Participantes. Participaron de manera voluntaria 15 estudiantes (12 mujeres y 3 hombres) del segundo semestre de la carrera de Psicología de una institución privada de la ciudad de Guadalajara, Jalisco. Los participantes se encontraban entre 18 y 24 años de edad.

Aparatos y situación experimental. El programa fue creado bajo ambiente Microsoft Visual Basic Express 2010. Las sesiones experimentales se realizaron en el Laboratorio de Aprendizaje Humano del Centro de Estudios e Investigaciones en Comportamiento, CEIC. En los casos en los que los participantes requirieron escuchar, se utilizaron audífonos de la marca HP y Steren.

Diseño experimental. El diseño se conformó por tres fases: preprueba, exposición al modo reactivo y prueba de habilitación (ver Tabla 2). Los 15 participantes fueron distribuidos en 3 grupos de 5 participantes cada uno, que a su vez se denominaron para su identificación como Grupo Audio, Grupo Texto y Grupo Video. 
Tabla 2. Diseño Experimental para la evaluación de la habilitación lingüística del modo activo escribir.

\begin{tabular}{|c|c|c|c|}
\hline Grupos (N=5) & Preprueba & $\begin{array}{c}\text { Exposición } \\
\text { al modo reactivo }\end{array}$ & Postprueba \\
\hline Grupo Audio & & Escuchar & \\
\cline { 1 - 1 } Grupo Texto & \multirow{2}{*}{$\begin{array}{c}\text { Escribir un texto sobre } \\
\text { el ciclo del agua }\end{array}$} & Leer & \multirow{2}{*}{$\begin{array}{c}\text { Escribir un texto sobre } \\
\text { el ciclo del agua }\end{array}$} \\
Grupo Video & & Observar & \\
& & & \\
\hline
\end{tabular}

Procedimiento. De acuerdo al procedimiento empleado por Tamayo et al. (2010) y Tamayo y Martínez (2014), los participantes pasaron por la fase de preprueba, donde debían escribir un texto de extensión libre sobre el tema el ciclo del agua. Posteriormente fueron expuestos al modo reactivo correspondiente de la siguiente manera: los participantes del Grupo Texto debían leer un documento de 810 palabras que describía el ciclo del agua y los principales fenómenos asociados con él. Los participantes del Grupo Audio debían escuchar una grabación de 6 minutos de duración que describía el ciclo del agua y que fue realizada a partir del texto impreso. Los participantes del Grupo Video debían observar un video de 3 minutos de duración que representaba el ciclo del agua y los principales fenómenos asociados con él. El video no contenía audio ni subtítulos. Por último, los participantes fueron expuestos a la prueba de habilitación, donde de nueva cuenta debían escribir un texto de extensión libre sobre el tema el ciclo del agua.

La sesión experimental se realizaba de la siguiente manera: después de tomar los datos generales del participante, este era asignado a una computadora de escritorio en un cubículo aislado. Se le indicaba que el mismo programa le proporcionaría las instrucciones, las cuales tenían que leer cuidadosamente para realizar la tarea. Se les preguntaba si tenían alguna duda o consulta antes de comenzar.

El programa se iniciaba, daba la bienvenida y explicaba la finalidad de la actividad, pedía los datos del participante y una vez anotados podía comenzar la actividad. Las instrucciones fueron las siguientes:

Instrucción 1 para preprueba a los tres grupos: A continuación se te presenta una pantalla en blanco en la que tienes que escribir todo lo que sepas o recuerdes acerca de "el ciclo del agua" o "ciclo hidrológico" como también le llaman. Puedes tomarte el tiempo que consideres necesario para hacerlo. Trata de escribir de la mejor manera posible, cuidando no cometer errores ortográficos. Una vez que hayas terminado y estés listo para continuar, presiona "siguiente". Una vez que hayas presionado "siguiente" ya no podrás volver a hacer modificaciones en lo que escribiste. 
Instrucción 2 para exposición al modo reactivo para el Grupo Audio: A continuación se te presenta un audio donde se describe el ciclo del agua. Puedes escucharlo las veces que lo consideres suficiente, sólo dale "clic" en reproducir. Presiona "siguiente" para que aparezca el audio.

Instrucción 2 para exposición al modo reactivo para el Grupo Texto: A continuación se te presenta un texto que trata sobre el ciclo del agua. Lo único que tienes que hacer es leerlo y puedes hacerlo las veces que lo consideres necesario. Presiona "siguiente" para que aparezca el texto.

Instrucción 2 para exposición al modo reactivo para el Grupo Video: A continuación se te presenta un video que trata sobre el ciclo del agua. Se muestran nada más imágenes, por lo que no contiene audio o subtítulos. Puedes mirarlo las veces que lo consideres suficiente, sólo dale "clic" en reproducir. Presiona "siguiente" para que aparezca el video.

Instrucción 3 para prueba de habilitación a los tres grupos: A continuación se te presenta una pantalla en blanco en la que tienes que escribir, de nueva cuenta, todo lo que sepas o recuerdes acerca de "el ciclo del agua". Puedes tomarte el tiempo que consideres necesario para hacerlo. Una vez que hayas terminado y estés listo para continuar, presiona "siguiente". Una vez que hayas presionado "siguiente" ya no podrás volver a hacer modificaciones en lo que escribiste.

Una vez concluida la prueba de habilitación, se les agradecía a los participantes por su colaboración y podían marcharse.

Categorías de medida. Las categorías que se usaron para evaluar los productos escritos se tomaron de Acuña et al. (2013) y de Mares, Rivas y Bazán (2002). Se consideró conveniente retomar las categorías reportadas por Acuña et al. (2013) porque se reconocen tanto aspectos morfológicos como aspectos funcionales y parten del supuesto de que están en función de los criterios de ajuste implicados por el tipo de tarea (identificar, enunciar, diagramar, describir, instrumentar, relacionar y argumentar) y del nivel funcional que promueven estas tareas (interacciones intra, extra y transituacionales) con base en la propuesta taxonómica de Ribes y López (1985). Las categorías fueron: mención de conceptos técnicos y conceptos técnicos utilizados de manera pertinente.

Las categorías reportadas por Mares et al. (2002) se seleccionaron porque se identifican como tipos de relaciones. Respecto al establecimiento de relaciones, Mares y Rueda (1993) indican que, al hacerlas, se construye una manera distinta de observar, interpretar y describir los eventos, ya que las relaciones entre sucesos no son una realidad que pueda impactarnos sensorialmente de manera directa, sino que es algo que se construye a través del lenguaje.

Los tipos de relaciones que conformaron la categoría fueron: Formular relaciones condicionales, Formular relaciones de uso o finalidad (funcionales) y Formular relaciones causales. Se agregaron además a la categoría otros dos tipos de relaciones: Formular relaciones comparativas y 
Formular relaciones de contraste. Todos estos tipos de relaciones quedaron reunidas en la categoría Frases referidas a relaciones.

Asimismo, se desarrolló la categoría Frases formuladas, como una manera de identificar y comparar la extensión de la referencia escrita, pero con un sentido gramatical completo.

Por último, se agregó la categoría Instancias descriptivas contenidas dentro de las frases, porque se considera que un elemento clave en la mayoría de los textos es la descripción que se hace de los referentes, decir cómo son o señalar los componentes que los conforman e incluso sus cualidades. Un primer paso para avanzar en la identificación y medición de dichas descripciones es a partir de los sustantivos que componen las frases y que son independientes del sujeto y las acciones de las mismas. Por ejemplo, en las siguientes frases que refieren al proceso de evaporación en el ciclo del agua: "El sol calienta el agua" y "Los rayos del sol calientan el agua de océanos, ríos y lagos", podemos identificar que la segunda contiene más elementos descriptivos y por lo mismo, es más precisa acerca del referente del que se escribe. En este sentido es que se desarrolló esta última categoría.

Las categorías quedaron conformadas de la siguiente manera (ver Tabla 3):

Tabla 3. Categorías utilizadas para evaluar los productos escritos elaborados por los participantes.

\begin{tabular}{|l|}
\hline \multicolumn{1}{|c|}{ Categorías } \\
\hline 1. Mención de conceptos técnicos (MC) \\
\hline 2. Frases formuladas (FF) \\
\hline 3. Conceptos técnicos utilizados de manera pertinente (CP) \\
\hline 4. Instancias descriptivas contenidas dentro de las frases (IDF) \\
\hline $\begin{array}{l}\text { 5. Frases referidas a relaciones: Relaciones causales, condicionales, } \\
\text { funcionales, comparativas y contraste (FR) }\end{array}$ \\
\hline
\end{tabular}

Criterios de medición de las categorías. La calificación se otorgaba a partir de la identificación de las categorías. Se otorgaba un punto por categoría identificada en los textos revisados.

Mención de conceptos técnicos (un punto por concepto identificado). Hace mención de términos técnicos vinculados con el material. Por ejemplo, evaporación, precipitación, escorrentía. Aquí se otorgaban 3 puntos, un punto por mención. Si un término se repetía ya no se otorgaba punto.

Frases formuladas (un punto por frase formulada). Frases formuladas con un sentido gramatical completo. Por ejemplo: Los rayos del sol calientan el agua. Lo que se cuenta en el ejemplo anterior para considerarla una frase es el verbo. Hay un solo verbo (calientan), entonces es una sola frase. A partir de la identificación de los verbos es que se identificaron y contaron las frases. También podía encontrarse: los rayos del sol calientan el agua y esta se evapora. 
En el ejemplo anterior se cuentan dos frases porque se pueden identificar dos verbos: calientan y evapora.

Conceptos técnicos utilizados de manera pertinente (un punto por concepto técnico utilizado. Un mismo concepto podía usarse para formular una o más frases distintas y por lo tanto podía obtener más de un punto). Utiliza los términos técnicos para describir un evento/suceso o alguna relación entre eventos. Por ejemplo: El agua en forma de vapor sube y se condensa formando las nubes.

Instancias descriptivas contenidas dentro de las frases (un punto por cada instancia descriptiva identificada en cada una de las frases). Número de sustantivos utilizados en la frase independientes al sujeto de la oración. Por ejemplo: Los rayos del sol calientan el agua. Aquí tenemos un sustantivo independiente al sujeto (agua). Así que se contabiliza como una instancia descriptiva en la frase. $O$ bien: Los rayos del sol calientan el agua del océano. Aquí tenemos dos sustantivos (agua y océano), por lo tanto se contabiliza como dos instancias descriptivas en la frase.

Frases referidas a relaciones (un punto por relación identificada). Como se mencionó líneas arriba, las relaciones podían ser de tipo condicional, causal, funcional (uso o finalidad), comparación y contraste. Éstas se identificaban a partir de los conectivos correspondientes a cada relación (aunque en algunos casos podían identificarse sin el conectivo correspondiente). Los conectivos y los tipos de relaciones a identificar se tomaron de Chávez (1998):

Relaciones condicionales: cuando, si, siempre que, a condición de que, supongamos, una vez que.

Relaciones causales: por (medio de), porque, puesto que, debido a/lo que, ya que, dado que, visto que, en efecto, en consecuencia, por consiguiente, por lo tanto, de ahí que.

Funcionales (uso o finalidad): para, para que, a fin de que, con objeto de, con la intención de.

Comparación: como, al igual que, del mismo modo, de modo similar.

Contraste: pero, sin embargo, ahora bien, aunque, a diferencia, mientras que, no obstante, en cambio, sino (que).

Resultados. La revisión de los textos elaborados por los participantes fue realizada por tres observadores de manera independiente con base en las categorías descritas en el apartado anterior. Una vez revisados los escritos, se compararon los puntajes otorgados en cada categoría por participante y los casos en que hubo desacuerdo fueron discutidos y resueltos por consenso.

En la Figura 1 se presentan los puntajes obtenidos por cada uno de los participantes del Grupo Audio en preprueba (barra roja) y en posprueba (barra amarilla) en cada una de las categorías, también se presenta el promedio de los puntajes obtenidos por todos los participantes del grupo. De manera general se puede observar un incremento en los puntajes obtenidos por todos los participantes al pasar de la preprueba a la posprueba, este efecto fue mucho más pronunciado en las categorías de frases formuladas (FF) y la de instancias descriptivas en frases (IDF). Las categorías MC, CP y FR fueron aquellas en las que se encontró un menor incremento en el puntaje durante la postprueba. 
Audio

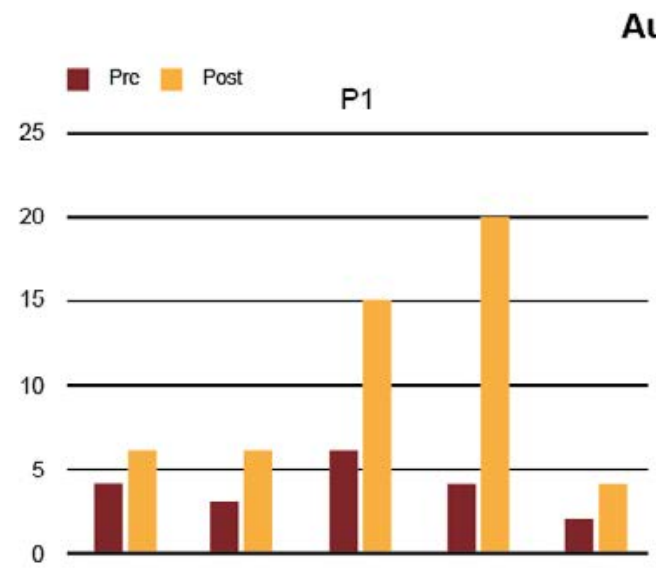

P2

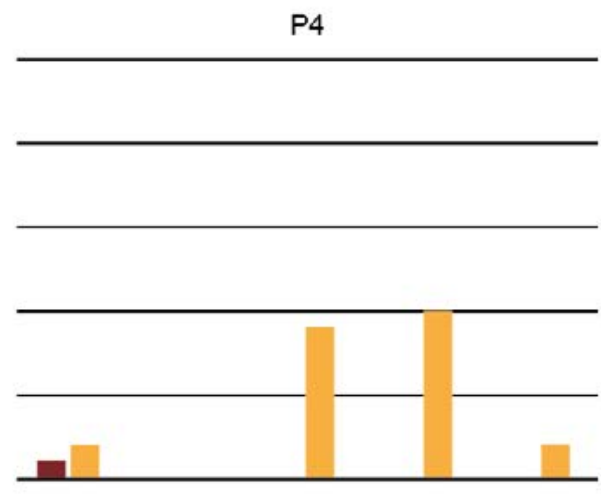

P5
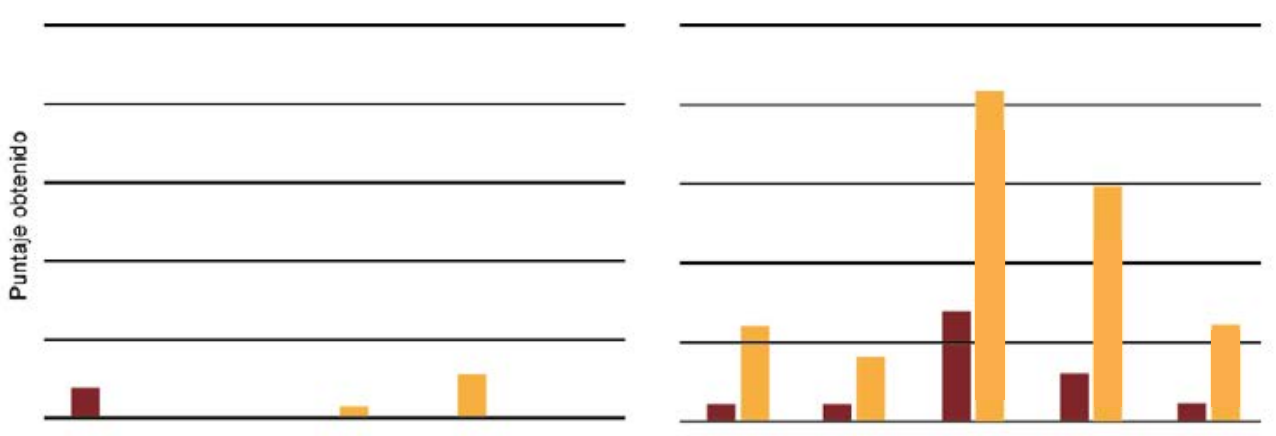

P3

Promedio
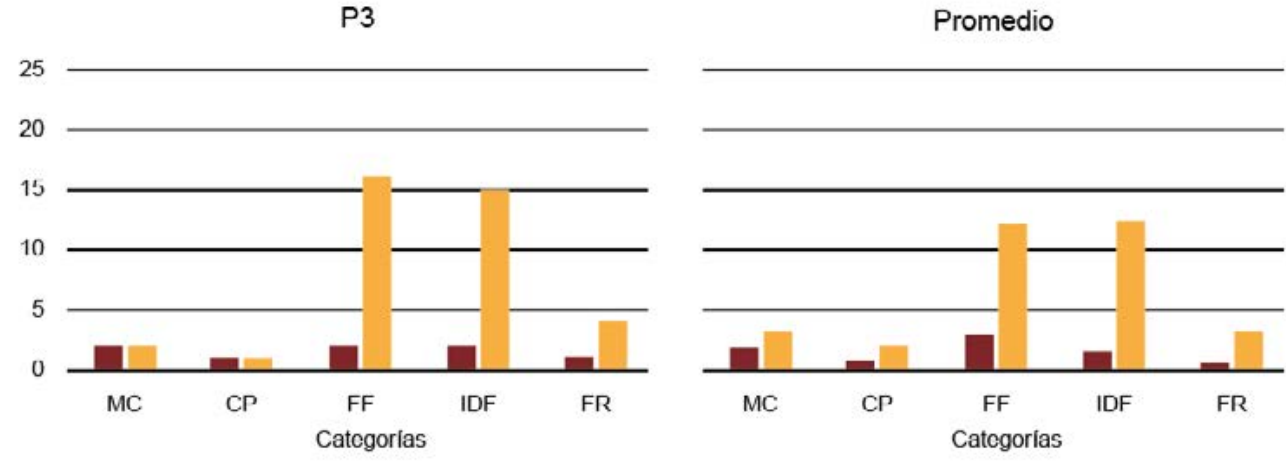

Figura 1. Puntaje obtenido en la preprueba y la postprueba para cada uno de los participantes y promedio del Grupo Audio en cada categoría: MC (mención de conceptos técnicos), FF (frases formuladas), CP (conceptos técnicos utilizados de manera pertinente), IDF (instancias descriptivas contenidas dentro de las frases), FR (frases referidas a relaciones -causales, condicionales, funcionales, comparativas y contraste-).

En la Figura 2 se presentan los puntajes obtenidos por cada uno de los participantes del Grupo Texto en preprueba (barra roja) y en posprueba (barra amarilla) en cada una de las categorías, también se presenta el promedio de los puntajes obtenidos por todos los participantes del grupo. De manera similar a lo observado en el Grupo Audio, también se observa un mayor incremento en los puntajes obtenidos al pasar de la preprueba a la postprueba en las catergorías FF e IDF, siendo menores en las categorías MC, CP y FR. 
Texto

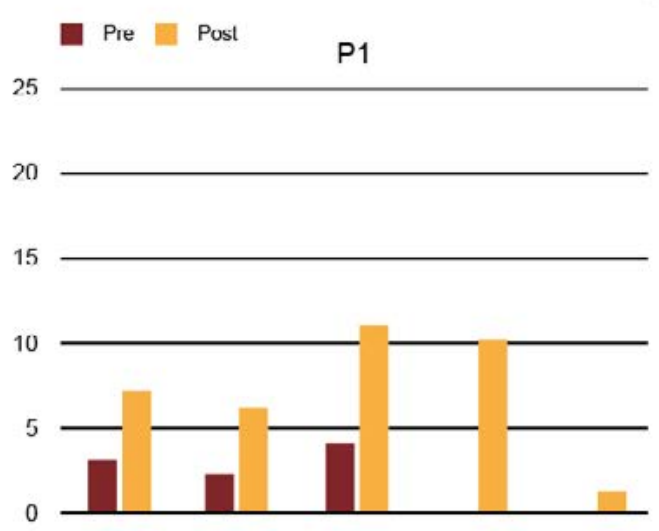

P2
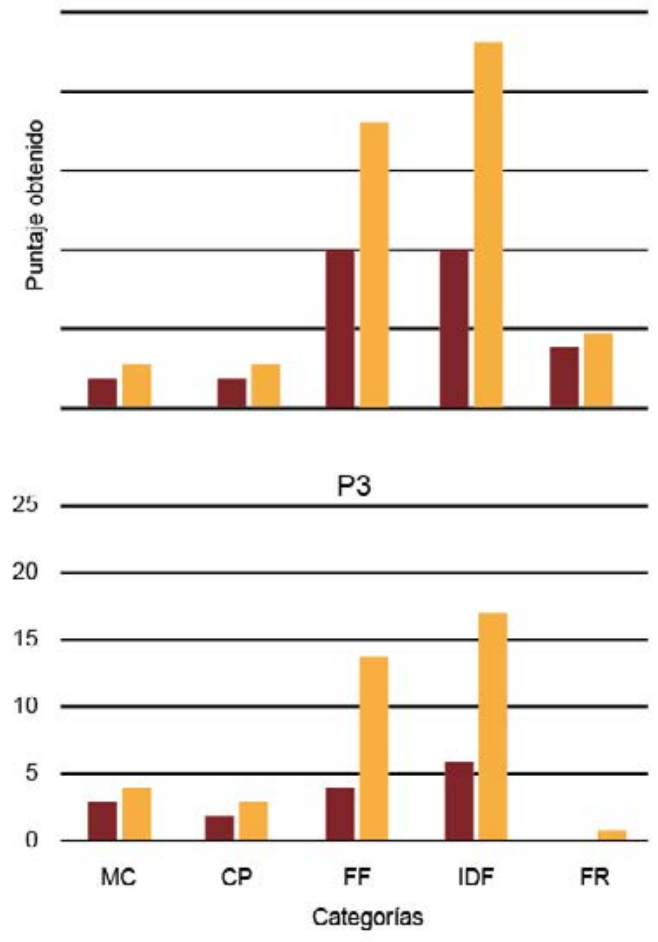

P4

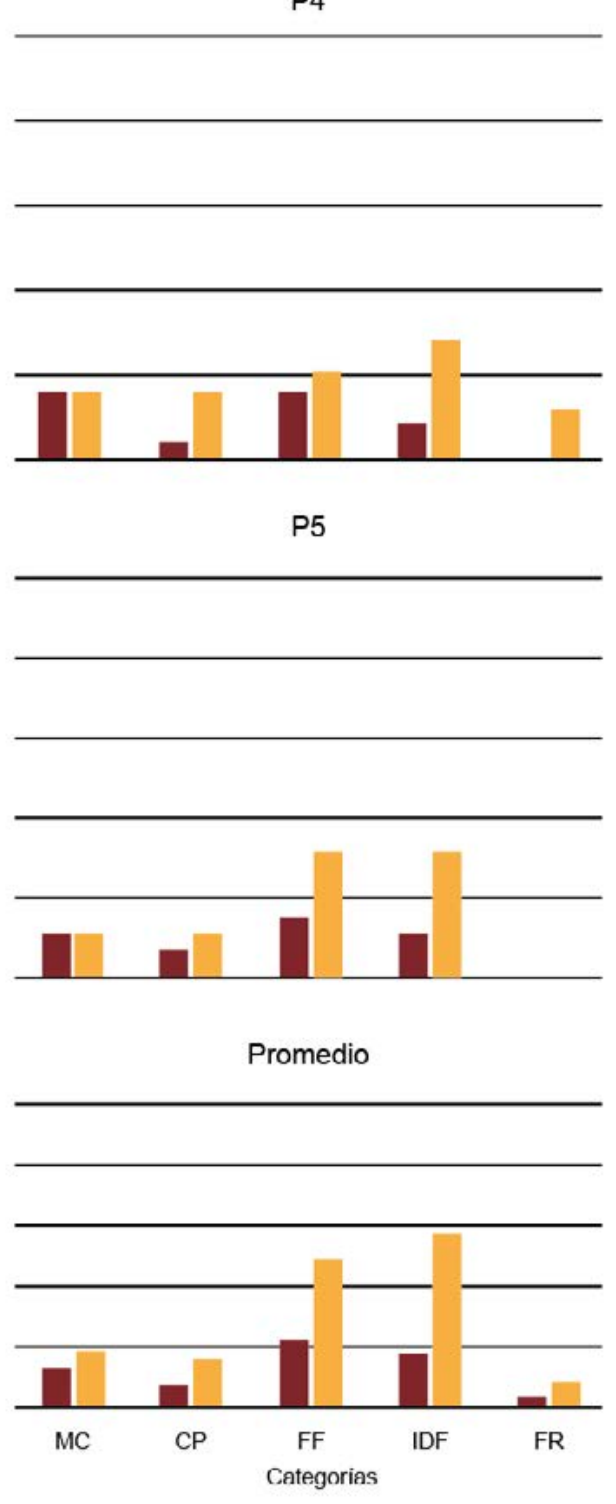

Figura 2. Puntaje obtenido en la preprueba y la postprueba para cada uno de los participantes y promedio del Grupo Texto en cada categoría: MC (mención de conceptos técnicos), FF (frases formuladas), CP (conceptos técnicos utilizados de manera pertinente), IDF (instancias descriptivas contenidas dentro de las frases), FR (frases referidas a relaciones -causales, condicionales, funcionales, comparativas y contraste-).

En la Figura 3 se presentan los puntajes obtenidos por cada uno de los participantes del Grupo Video en preprueba (barra roja) y en posprueba (barra amarilla) en cada una de las categorías, también se presenta el promedio de los puntajes obtenidos por todos los participantes del grupo. A diferencia de los resultados obtenidos en el Grupo Texto y en el Grupo Audio, en el caso de los sujetos del Grupo Video los incrementos en los puntajes obtenidos al pasar de la preprueba 
a la postprueba no fueron consistentes para los diferentes participantes. Los cambios mas notables se observaron en la categoría IDF; mientras que en el resto de categorías el incremento fue mínimo (FR) e incluso en otras se presentó un decremento en el puntaje (MC y CP).

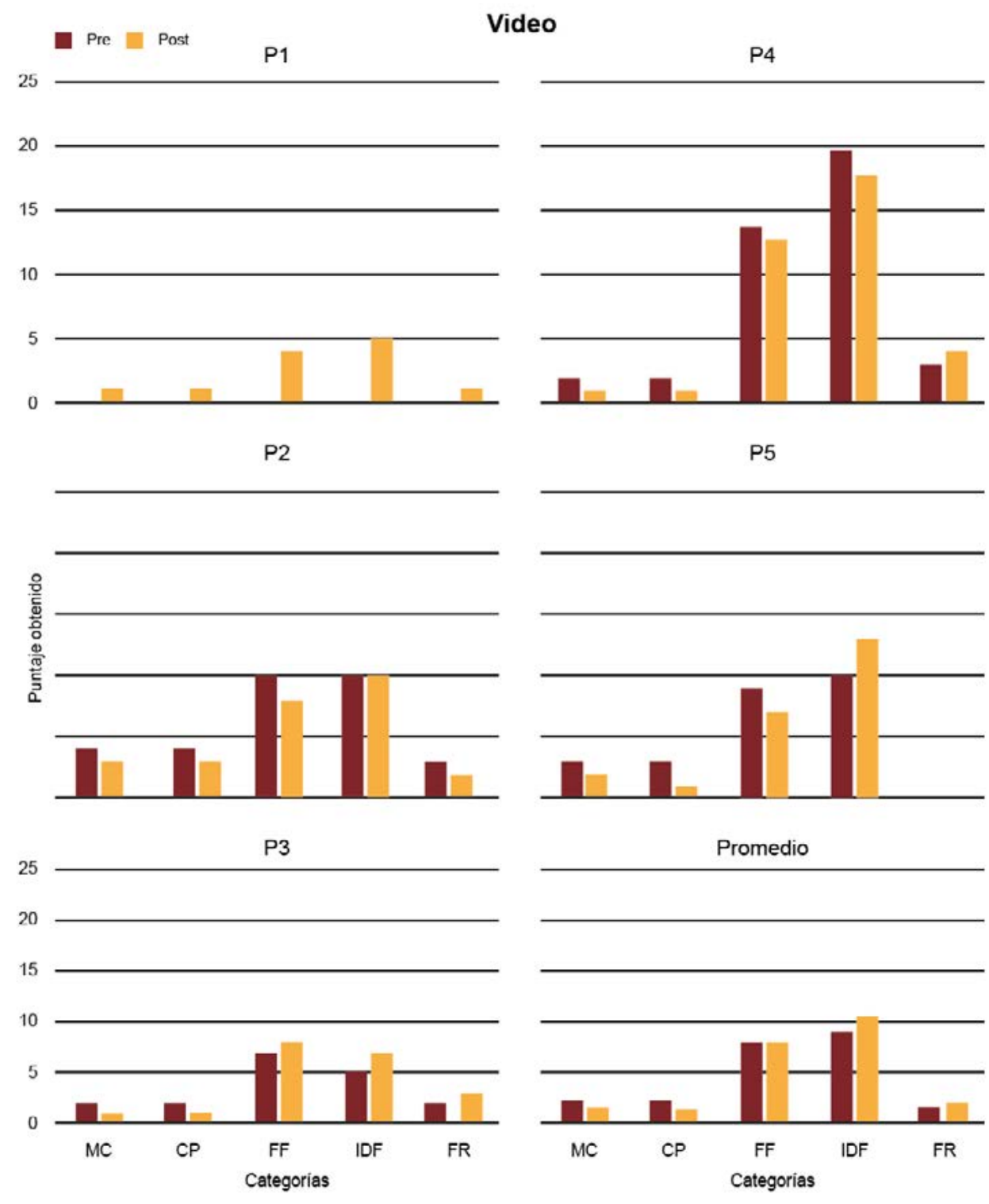

Figura 3. Puntaje obtenido en la preprueba y la postprueba para cada uno de los participantes y promedio del Grupo Video en cada categoría: MC (mención de conceptos técnicos), FF (frases formuladas), CP (conceptos técnicos utilizados de manera pertinente), IDF (instancias descriptivas contenidas dentro de las frases), FR (frases referidas a relaciones -causales, condicionales, funcionales, comparativas y contraste-). 


\section{DISCUSIÓN}

El propósito de este trabajo fue evaluar la habilitación lingüística que los modos reactivos leer, observar y escuchar promueven sobre el modo activo escribir. Esto a partir de la pregunta de si la variación en el procedimiento experimental generalmente usado resulta útil para ir caracterizando la forma en que las personas hacen contacto con el referente sobre el qué escriben, cómo escriben acerca de él y las ejecuciones resultantes.

Como se destaca en los resultados, el mayor efecto de la exposición a los modos reactivos se encontró en las categorías de FF e IDF de los grupos Audio y Texto. Este resultado parece indicar que los participantes de estos grupos se habilitan para escribir sobre el tema requerido, es decir, que consiguen formular e hilar frases con un sentido gramatical completo. Asimismo, dicha ejecución se realiza utilizando un mayor número de elementos descriptivos dentro de sus frases. En breve, en la postprueba aumentan las frases escritas sobre el tema o referente y aumentan las descripciones sobre el mismo.

Esta relación que parece establecerse entre las categorías FF e IDF cobra relevancia cuando se observa que los resultados obtenidos en la parte formal o técnica de los textos escritos (categorías $\mathrm{MC}, \mathrm{CP}$ y FR) mostraron un menor puntaje en comparación con aquellas en la postprueba. Esto querría decir que, a partir de la exposición, los participantes son capaces de describir el referente (el tema del ciclo del agua), pero que no consiguen precisarlo o delimitarlo conceptualmente, lo que implica utilizar las palabras o los elementos técnicos correspondientes para realizar, por ejemplo, una definición de alguna de las fases o incluso establecer relaciones que vayan más allá de la acumulación de acciones por simple conjunción (uso predominante de la y).

Por otro lado, si se observan dichas categorías en la fase de preprueba, se notará que no es sólo que IDF no va a la par que FF, sino que el puntaje en FF es bajo; esto es, los participantes no consiguieron en esta fase formular frases con sentido gramatical completo para poder siquiera desarrollar el referente, esto mismo imposibilita, lógicamente, hacer descripciones generales y precisiones conceptuales. En postprueba, los participantes se habilitan para escribir sobre el referente, pero no para delimitarlo técnica o conceptualmente.

Ahora bien, no parece haber mayor diferencia en las ejecuciones de los participantes que fueron expuestos a los modos escuchar o leer en todas las categorías. En cambio, en los participantes que fueron expuestos al modo observar, no sólo no parece observarse habilitación lingüística en ninguna de las categorías, sino que incluso se observa un decremento en los resultados de la postprueba. En los estudios de Tamayo et al. (2010) y Tamayo y Martínez (2014) de habilitación lingüística usando igualación a la muestra, de los que este trabajo toma el diseño experimental variando el procedimiento, las ejecuciones más altas y consistentes se encontraron en los grupos que eran expuestos al modo observar. Los datos encontrados, al igual que en el trabajo de Pulido y Tamayo (2015), no parecen avalar los datos sobre la obtención de mejores desempeños a partir del modo reactivo observar cuando se varía el procedimiento de igualación a la muestra. En este tenor, sería interesante probar si el modo observar tiene o no un papel funcional central dentro de las modalidades lingüísticas reactivas, como plantean como posibilidad Tamayo et al. (2010). 
Los resultados aquí encontrados parecen señalar que no basta con que los participantes sean expuestos a los diferentes modos reactivos para que se habiliten en la escritura pertinente, es decir, de manera que los resultados sean consistentes en todas las categorías evaluadas. Al parecer, habría más elementos implicados que pueden favorecer la habilitación. Recordemos que al respecto del estudio de los modos lingüísticos y de la habilitación lingüística, Ribes, Ibáñez y Pérez-Almonacid (2014, p. 103) desarrollaron el concepto de aprendizaje comprensivo, el cual refiere "a cambios conductuales socialmente pertinentes mediados por la operación posibilitadora del lenguaje a partir de los contactos de los modos reactivos con los objetos o eventos". Los autores señalan, entre otros aspectos del aprendizaje comprensivo, que es un tipo de episodio de cuando menos dos momentos funcionales, no sólo determinado por lo que se aprende, "sino por las restricciones impuestas al aprendizaje por los procedimientos de enseñanza".

Teniendo en cuenta que este estudio evalúa la habilitación lingüística con un diseño experimental similar al de los estudios de Tamayo et al. (2010) y Tamayo y Martínez (2014), no es descabellado señalar que la habilitación de la respuesta de escribir en este estudio se encuentra determinada por las restricciones impuestas al aprendizaje por los procedimientos de los que se vale para enseñarla. Cabe repetir respecto a esto la manera tradicional en que se concibe la escritura: como un medio ideal que preserva y transmite ideas, pero que desafortunadamente se enseña únicamente para escribir de copiado. En consecuencia, descuida su entrenamiento a partir de la instrucción explícita, sistemática y gradual de acuerdo a las prácticas específicas de una comunidad, tal como lo señalan Pacheco et al. (2013).

Por ello, en subsiguientes preparaciones experimentales (documento en preparación) se exploraron variables que pudieran resultar críticas para el ajuste de las personas que escriben: proporcionar instrucciones explícitas durante la exposición al modo reactivo, la posibilidad de revisión y corrección de los materiales escritos, la señalización de errores gramaticales para su identificación y posible corrección, así como la escritura y revisión entre pares.

Por último, respecto a las categorías de evaluación usadas, un método de evaluación del comportamiento siempre es perfectible, y no es la excepción en un tipo de estudio como el que implica abordar la escritura como conducta. En investigaciones sobre escritura desde el área de Psicología del comportamiento, una constante ha sido la preocupación por desarrollar pruebas que permitan hacer contacto con el fenómeno psicológico sin caer en nociones de eventos de tipo privado y que sean adecuados a los principios metodológicos que rigen el hacer en ciencia. Pacheco et al. (2013) han señalado que las mediciones de escritura en las ciencias del comportamiento deberían tender hacia un acuerdo en las categorías que permitan aplicarse en la evaluación de variables diferentes y dejar de construir pruebas para cada experimento que se realice. En este sentido es que se buscó integrar dos propuestas, las de Acuña et al. (2013) y Mares et al. (2002), que permitieran evaluar de manera válida nuestro objeto de interés. Cabe considerar en trabajos posteriores la pertinencia de descartar o incluir nuevas categorías, de manera que se vaya conformando un acuerdo sobre la manera precisa de parametrizar la conducta de escribir. 


\section{Referencias}

Acuña, K., Irigoyen, J.J., \& Jiménez, M. (2013). La comprensión de contenidos científicos en estudiantes universitarios. México: Qartuppi. http://doi.org/10.29410/QTP.13.01

Camacho, J., \& Gómez, D. (2007). Variación de los modos de lenguaje en la adquisición y transferencia de conocimiento. En J.J. Irigoyen, M. Jiménez, \& K. Acuña (Eds.), Enseñanza, Aprendizaje y Evaluación. Una aproximación a la Pedagogía de las Ciencias (pp. 105-135). Hermosillo: Universidad de Sonora.

Camacho, J., Irigoyen, J.J., Gómez, D., Jiménez, M., \& Acuña, K. (2007). Adquisición y transferencia de modos linguísticos en tareas de discriminación condicional sin retroalimentación reactiva. Enseñanza e Investigación en Psicología, 12 (1), 79-91.

Chávez, F. (1998). Redacción avanzada. Un enfoque lingüístico. México: Pearson.

Fuentes, M.T., \& Ribes, E. (2001). Un análisis funcional de la comprensión lectora como interacción conductual. Revista Latina de Pensamiento y Lenguaje, 9 (2), 181-212.

Gómez, D. (2005). Transferencia entre modos del lenguaje y niveles de interacción: observar, escuchar, hablar, leer y escribir. Tesis Doctoral. Centro de Estudios e Investigaciones en Comportamiento. Universidad de Guadalajara.

Gómez, D., \& Ribes, E. (2008). Adquisición y transferencia de una discriminación condicional de primer orden en distintos modos del lenguaje. Acta Comportamentalia, 16, 183-209.

Mares, G., Rivas, O., \& Bazán, A. (2002). Configuración en el modo escrito de competencias desarrolladas en forma oral como efecto del nivel funcional de ejercicio. Revista Mexicana de Análisis de la Conducta, 28, 173-202.

Mares, G., \& Rueda, E. (1993). El habla analizada desde la perspectiva de Ribes y López: desarrollo horizontal. Acta Comportamentalia, 1, 39-62.

Pacheco, V., Ortega, M., Cruz, N., \& Carpio, C. (2013). Formación de escritores y Aprendizaje de la ciencia. En J.J. Irigoyen, F. Cabrera, M. Jiménez, H. Martínez, \& K. Acuña (Coords.), Estudios sobre comportamiento y aplicaciones Volumen III (pp. 275-294). México: Universidad de Sonora.

Pacheco, V., Ortega, M., Morales, G., \& Carpio, C. (2013). Escribo, luego existo: reflexiones acerca de la autorreferencia. En V. Pacheco, C.A. Carpio, G. Morales, \& M. Ortega (Coords.), La Autorreferencia. Promoción de comportamiento complejo desde diferentes perspectivas conceptuales (pp. 55-76). México: Universidad Nacional Autónoma de México.

Pulido, L., \& Tamayo, J. (2015). Aprendizaje comprensivo: evaluación de la habilitación lingüística en modos no complementarios. Revista Mexicana de Investigación en Psicología, 7, 52-66.

Quiroga, L., Peña, T., \& Padilla, M.A. (2013). Efectos del tipo de entrenamiento y del modo lingüístico sobre el ajuste a contingencias convencionales. Acta comportamentalia, 21, 66-82.

Ribes, E. (1990). Problemas conceptuales en el análisis del comportamiento humano. México: Editorial Trillas.

Ribes, E. (2007). Lenguaje, Aprendizaje y Conocimiento. Revista Mexicana de Psicología, 24, 7-14.

Ribes, E., Ibáñez, C., \& Pérez-Almonacid, R. (2014). Una propuesta metodológica para el análisis experimental del aprendizaje comprensivo. Revista Mexicana de Psicología, 31, 100-110. 
Ribes, E., \& López, F. (1985). Teoría de la Conducta. Un análisis de campo y paramétrico. México: Editorial Trillas.

Tamayo, J., Ribes., E., \& Padilla, M.A. (2010). Análisis de la escritura como modalidad lingüística. Acta Comportamentalia, 18, 87-106.

Tamayo, J., \& Martínez, D. (2014). Efecto de habilitación en un procedimiento de igualación de la muestra de segundo orden. Revista Mexicana de Investigación en Psicología, 6, 97-108.

Tomasini, A. (2001). Teoría del Conocimiento Clásica y Epistemología Wittgensteiniana. México: Plaza y Valdés.

Varela, J., Nava, G., Lara, B., \& Zambrano, R. (2009). Enseñar a escribir: ¿cuál es el método? En J. Varela, F, Cabrera, \& J.J. Irigoyen (Eds.), Estudios sobre comportamiento y aplicaciones. Volumen I (pp. 51-68). Guadalajara: Universidad de Guadalajara. 


\section{Capítulo 11}

Herramientas psicológicas para solucionar problemas matemáticos en educación básica

Luis G. Zarzosa Escobedo 
Luis G. Zarzosa Escobedo zarzosae@unam.mx

Facultad de Estudios Superiores Iztacala Universidad Nacional Autónoma de México 


\section{Capítulo 11}

\section{Herramientas psicológicas para solucionar problemas matemáticos en educación básica}

El propósito de este capítulo es mostrar cómo a partir del conocimiento psicológico, se pueden diseñar una serie de estrategias de enseñanza que hacen fácil y ameno el aprendizaje de las matemáticas y en particular la matemática vinculada a la solución de problemas. Esta es una evidencia más, de que no hay asignaturas intrínsecamente difíciles, que todo es fácil de aprender, pues depende más del cómo se enseñe. Este escrito inicia con una descripción de la naturaleza del déficit en matemáticas que presenta la población escolar a nivel nacional; enseguida se hacen algunas reflexiones acerca del papel que puede jugar la Psicología en esta problemática multifactorial y se continua con una crítica a los modos espontáneos e intuitivos de la enseñanza. Finalmente se hace una descripción amplia de un modo exitoso de intervención denominado Enseñanza basada en esquemas, que cuenta como virtud adicional el que desde edades tempranas se va vinculando a los alumnos con modos algebraicos de razonamiento.

\section{El problema del bajo nivel en matemáticas}

Los estudiantes mexicanos salen muy mal preparados en matemáticas cuando terminan su educación básica. Así lo indican tanto las evaluaciones nacionales como las internacionales. La Figura 1 muestra los resultados de la prueba nacional PLANEA (2015), donde se definen cuatro niveles de competencia y el porcentaje de alumnos en cada nivel. Como puede apreciarse, el $60.5 \%$ de los niños se encuentra en el nivel más bajo y apenas un $6.8 \%$ se encuentra en el más alto (para resultados más detallados, consultar: http://publicaciones.inee.edu.mx/PINEE/detallePub.action?clave=P2A321 O bien: http:// www.inee.edu.mx/index.php/sala-deprensa/notas-informativas/2190-fasciculo-10-planea)

En el terreno internacional tampoco nos ha ido bien. Por ejemplo, en las evaluaciones del Programa Internacional para la Evaluación de Estudiantes (PISA, por sus siglas en inglés), que aplica la Organización para la Cooperación y Desarrollo Económico (OCDE), México aparece muy por abajo del promedio internacional. En los exámenes de PISA participan más de 60 países. Se evalúa a los estudiantes de 15 años, porque es cuando se supone que concluyeron o están concluyendo su educación básica, en nuestro caso, la educación secundaria. Lo que enfatiza esta prueba, es aquella matemática que es importante para la vida diaria más que para la escuela. En la Figura 2 se encuentra de modo simplificado, el lugar que ocupó México en la evaluación de 2012 (no incluye los datos de los 65 países participantes). 


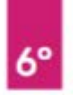

\section{Matemáticas}

Porcentaje de alumnos por nivel de logro
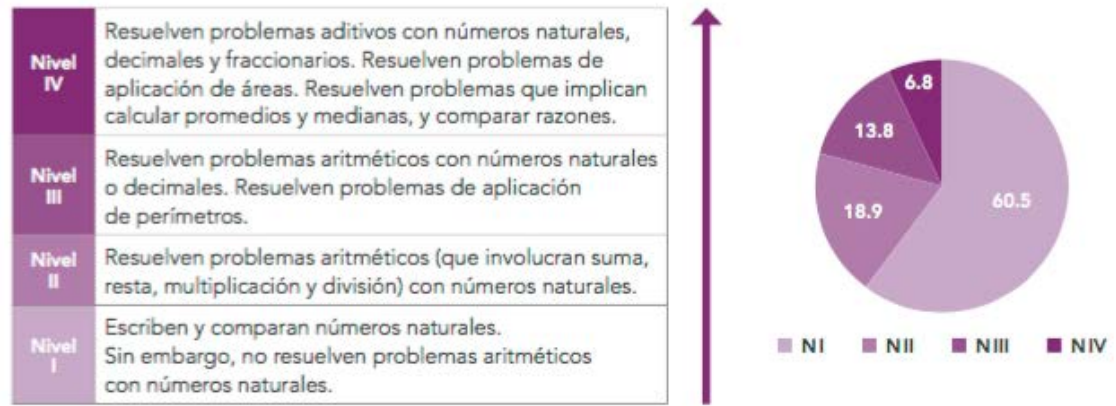

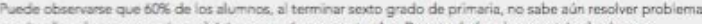

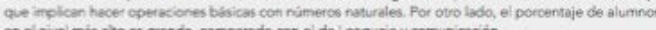

en el nivel mis ato es grande, comparado con el de Lenguaje y comunicioion

Planea

Figura 1. Muestra de modo resumido los resultados de la evaluación en matemáticas de alumnos del $6^{\circ}$ grado de educación básica. Del lado izquierdo se definen los cuatro niveles de competencia considerados. Y en la gráfica del lado derecho, se indica el porcentaje de estudiantes que correspondieron a cada nivel.

En las barras horizontales de la Figura 2, se indica cómo se distribuyen al interior de cada país, los diferentes niveles de competencia. Así por ejemplo, en el caso de Singapur un $62 \%$ de sus estudiantes alcanzan los niveles de desempeño más altos (4 a 6) y sólo $2 \%$ el nivel por debajo de primero; en cambio México tiene sólo el $4 \%$ en los niveles más altos y $23 \%$ en el más bajo. Como puede apreciarse, nuestro País está muy abajo del promedio de los países de la OCDE, pero un poco arriba del promedio de los países latinoamericanos, junto con Chile, Uruguay y Costa Rica (datos tomados de: http://www.sems.gob.mx/es_mx/sems/resultados_prueba_pisa)

\section{Dimensiones del problema}

La explicación del bajo desempeño académico de los escolares mexicanos, obedece a múltiples factores entrelazados entre sí. Ejemplo: El tamaño del sistema educativo; el centralismo y burocracia para la toma de decisiones; el tamaño de la matrícula; un sindicato gigante que invadió funciones patronales; agrupaciones docentes con más incentivos para defender su poder y privilegios para la superación profesional; cuestionable preparación de los futuros profesores; mecanismos viciados para su ingreso, conservación y promoción en su trabajo; intervención marginal de padres de familia; métodos de enseñanza petrificados; pobreza financiera; recursos e instalaciones no óptimos; presiones para aprobar alumnos por razones no académicas; horario escolar insuficiente; familias con escaso o nulo capital cultural; aislamiento respecto de las tendencias internacionales de innovaciones educativas; y un largo etcétera. 


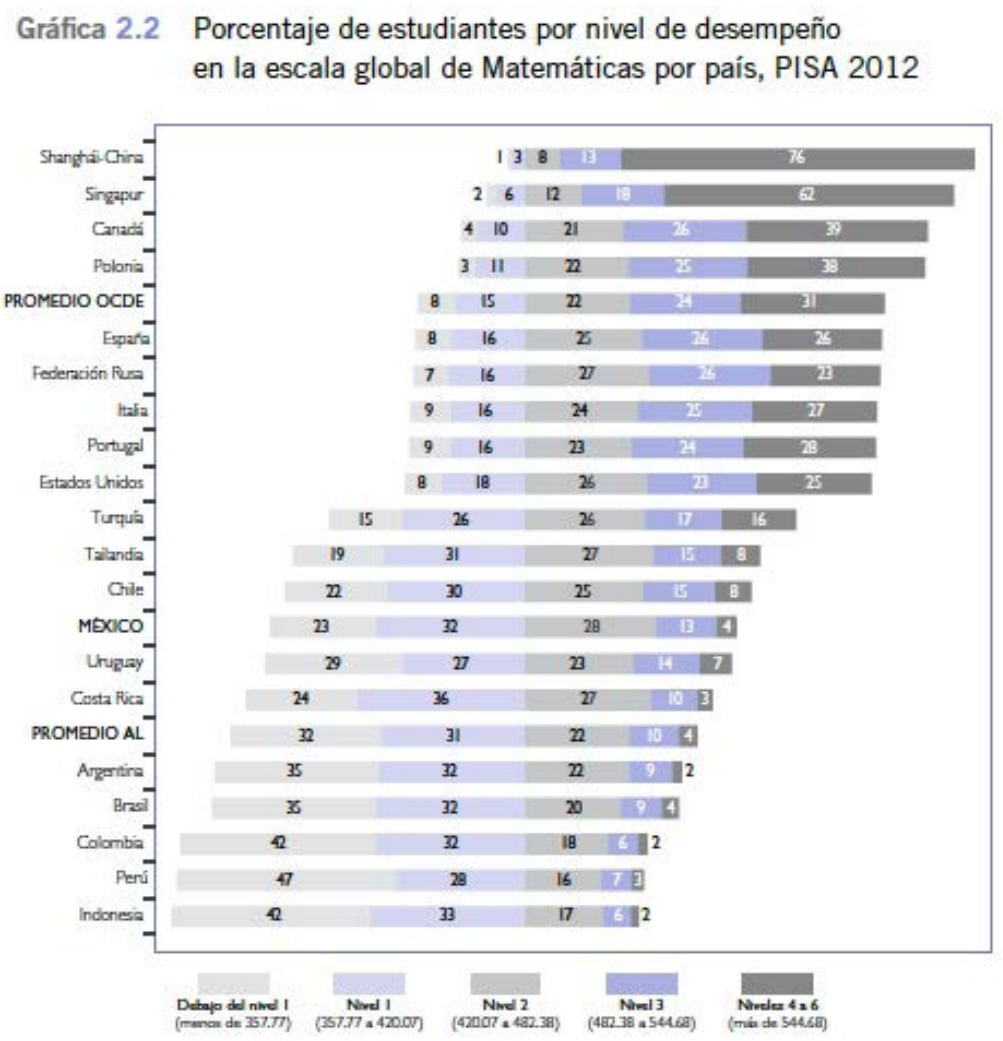

Fuente: INEE Elaboración con la base de datos de PISA 2012 (tabla A2 del anewo 1).

Figura 2. Datos resumidos de la prueba PISA 2012 en cuanto al desempeño en matemáticas. En el eje vertical sólo se muestran los datos de los países más representativos, así como el promedio Internacional (OCDE) y el Latinoamericano ("PROMEDIO AL"). Al interior de cada barra horizontal, se muestra con diferentes colores el porcentaje de estudiantes que caen en cada nivel de competencia.

La alteración favorable de todo el sistema o de sus elementos esenciales, también requiere concebirlos en toda su complejidad, a fin de que se puedan tomar acciones claves que puedan tener un impacto significativo.

La mayoría de estas acciones caen fuera de la esfera psicológica, lo cual no debe significar que la aportación de los psicólogos a la solución de esta problemática, deba esperar a que se solucionen primero los factores de naturaleza política, social o económica.

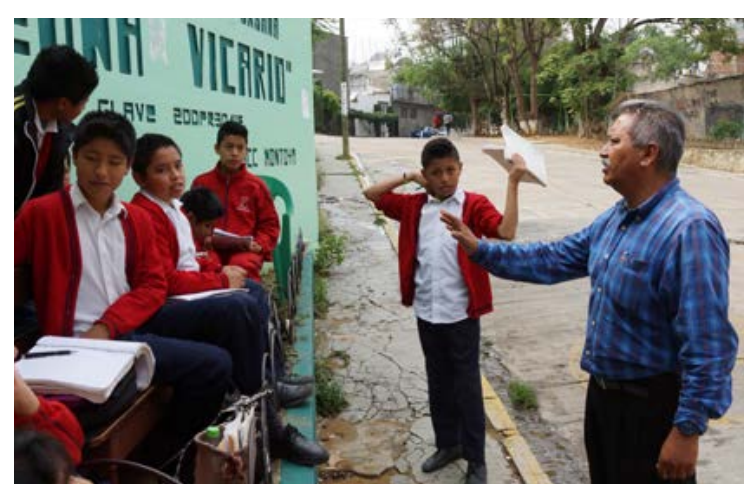

La intervención propia del nivel psicológico, se inserta en un contexto muy complejo. El psicólogo, como poseedor de información calificada acerca de mecanismos y principios de aprendizaje, de la modificación del comportamiento en diferentes escenarios, juega un papel básico en el ámbito escolar. Las propuestas acerca de métodos de enseñanza con buenas bases teóricas y experimentales, por sí mismas no podrán generar una mejoría o lo podrán hacer de 
manera modesta; pero de cualquier modo necesitan tener presencia, estar en el escenario; que se les vea como herramientas de trabajo viables de las que se puede echar mano para abonar a favor de una mejor situación educativa.

\section{Las ideas más populares acerca de la enseñanza de las matemáticas}

En este documento nos enfocaremos en la parte funcional de las matemáticas; por lo mismo debemos hacer la distinción entre la parte mecánica o del cálculo, y la parte funcional de las matemáticas. Dicho de otro modo, en el primer caso se trata de que el alumno siga procedimientos o rutinas para llegar a un resultado numérico de acuerdo a ciertas reglas; en el segundo caso, se trata de la matemática como herramienta para analizar situaciones, donde destacan los criterios de pertinencia y congruencia. Al respecto, no son extrañas expresiones del tipo: "En la Secundaria aprendí álgebra, pero nunca le entendí." Pues indican que no se aprendió a usar un sistema de representación, que hacía más efectiva la solución de un problema, es decir, la parte funcional.

¿Cuál podría ser el modo más apropiado o conveniente de enseñar matemáticas? El descuido de la parte funcional o aplicada ha originado una mayor preocupación por enseñar las matemáticas vinculadas a problemas significativos para el aprendiz. Preocupación afortunada, pero que por sí misma no aporta gran cosa, pues sólo habla de una preferencia general, que en algo ayuda, pero deja sin respuesta lo relativo a los cómo. Y en esto último es donde se dejan ver las concepciones dominantes de cómo se aprende y cómo debe ser la enseñanza de esta materia.

En un modelo tradicional de enseñanza entra en juego el mito de: "Si yo se lo explico, el que escucha ya lo aprendió", entonces el secreto es "explicarlo bien”. ¿Pero, qué significa "bien”? ¿acaso es lo que indique la intuición; lo que espontáneamente se nos ocurra?

En las respuestas a estas interrogantes se encuentra la puerta de entrada por donde se cuelan los mitos más populares acerca del aprendizaje. Ideas que son afines a una concepción de la educación que asume que los seres humanos contamos con algunas facultades innatas, que con el paso del tiempo y adecuada estimulación, van a ir "despertando". Es algo similar a lo que ocurre con una semilla que en potencia es una planta que dará frutos: se le debe cuidar poniéndole agua, abono, fertilizante y vigilar que no esté expuesta a condiciones extremas. Pero el determinante básico para que llegue a su estado pleno, es la información genética. Este tipo de concepción no fomenta que se ponga especial cuidado al análisis de los grados de dificultad de lo que se aprende, ni importa gran cosa la secuencia didáctica más conveniente; las sutilezas de los modos y métodos de enseñanza no tienen el mismo peso que en una concepción donde se responsabiliza al ambiente del desarrollo del comportamiento. En la concepción botánica hay una especie de fatalidad que permite atribuir el fracaso al propio aprendiz, a quien se puede acusar de que "ya venía mal de fábrica" o que tiene fallas su aparato cognoscitivo. Bajo este modelo botánico de las facultades mentales, el "explicarle bien" no requiere mayor análisis, pues a final de cuentas sólo forma parte de esa estimulación genérica para que despierte la facultad del entendimiento. El docente puede tomar distancia y es responsabilidad del que aprende poner en juego su facultad de entendimiento. No se aprecia preocupación por un procedimiento que vaya asegurando una historia de éxitos con las matemáticas.

A manera de ejemplo, imaginemos que a los estudiantes se les plantea el siguiente problema con objetos y situaciones familiares: 
"Ramiro iba a comprar huevos a la tienda y llevaba muchas monedas en su mano. Como iba corriendo, se tropezó y tiró todas las monedas. Cuando se levantó y se puso a recoger su dinero, se dio cuenta que había perdido nueve pesos de los 35 que llevaba. ¿Cuánto dinero encontró?"

Lo más probable es que en su explicación el adulto separe las premisas del problema o que las combine subrayando las relaciones lógicas y que en esto consiste el "explicarle bien" (este procedimiento de sentido común se puede constatar en el siguiente enlace: http://math2me.com/ playlist/aritmetica/problemas-con-operaciones-basicas). Con estos procedimientos el alumno pone atención al adulto. Le ha tocado observar un comportamiento que supuestamente es competente; fue testigo de cómo se desmenuzó el problema. Se espera que en ocasiones sucesivas lo pueda hacer él solo (si se logró despertar su entendimiento y voluntad). ¿Pero fue suficiente? ¿Qué pasará si poco después enfrenta otro problema como el siguiente?:

"Pascual es un aficionado a los cuentos de terror; le encanta leerlos y luego hasta se disfraza como uno de sus personajes. Ahora tiene una colección de 12 libros y más de 20 películas. A Alberto, que es su amigo, también le gustan estas historias y tiene tres libros más que Pascual. ¿Cuántos libros tienen entre los dos?”

¿Podrá generalizar? ¿Es probable que el alumno no se confunda? ¿Es la mejor estrategia ir viendo caso por caso? ¿Existirá la capacidad para separar lo esencial de lo accesorio con la mera voluntad de querer hacerlo? Difícilmente pueden responderse estas y otras interrogantes de modo afirmativo, pues no es claro que se distingan fuentes y grados de dificultad, ni se tiene un análisis psicológico de la naturaleza de los problemas y el tipo de repertorio conductual correspondiente a cada uno de ellos; del mismo modo, tampoco se aprecian criterios de complejidad psicológicos que permitan un diseño sistemático de las situaciones de instrucción. La secuencia de enseñanza se rige por criterios matemáticos, es decir, que no es el cambio de comportamiento del estudiante el que marque la pauta para avanzar al siguiente nivel de complejidad, sino los temas propios de las matemáticas los que indican el orden de lo que debe irse enseñando y aprendiendo; esos temas sólo se le van a ir mostrando al alumno. Así lo ilustran estos sitios: www.math2me.com o www.ixl.com

Al alumno expuesto a este tipo de enseñanza, prácticamente se le deja a merced de sus recursos intuitivos, de sus tanteos, de un aprendizaje por ensayo y error. No es casualidad que ante problemas matemáticos que se plantean verbalmente, una enorme cantidad de niños tengan compulsión por el cálculo, pues: $1^{\circ}$ se fijan en las cantidades; $2^{\circ}$ localizan palabras que les sugieren operaciones ("más; perdió; ganó; dar; faltó..." etcétera) y $3^{\circ}$ realizan el cálculo esperando haberle atinado al resultado. Con este modelo de enseñanza, resulta muy natural que el adulto acabe exhortando a su aprendiz para que lo haga de otro modo, cuando el problema está en el diseño de una instrucción que ha llevado a los aprendices a la ley del menor esfuerzo.

Un matiz diferente respecto de este modo de enseñanza que se apoya en las mitologías de la mente, consiste en poner más atención al modo cómo puede irse "despertando el entendimiento", para aprender a razonar o ejercitar el razonamiento cuando los niños se enfrentan a un problema. Así 
por ejemplo, se recomiendan los interrogatorios a manera de diálogos socráticos (Fernández, 2006). Es evidente que este modo de intervenir, nuevamente se asienta en la doctrina de las facultades o una concepción botánica del desarrollo. Como ya se había señalado, desde esta concepción se le da muy poco peso al tipo de problemas a resolver, al análisis de la dificultad relativa, a la secuencia instruccional idónea, etcétera, y que finalmente es raquítica en cuanto a evidencias empíricas que apoyen la efectividad de la propuesta. Es sentido común con buenas intenciones.

\section{Matemática y Psicología}

¿Cuáles serían las consideraciones teóricas a tomar en cuenta para analizar la problemática de la enseñanza de las matemáticas desde un enfoque basado en una Psicología científica?

En primer lugar no hay que perder de vista que se trata de una relación entre: 1) cierta estimulación del ambiente que es susceptible de tratamiento cuantitativo; y de la cual se espera su análisis y transformación; 2) una percepción de la misma, mediada por un sistema convencional llamado lenguaje de las matemáticas (este lenguaje puede ser elemental o complejo; bien o mal estructurado; dominado parcial o totalmente); 3) que la relación entre los dos primeros puntos puede tener diferentes niveles de complejidad, los cuales deben manejarse bajo criterios o principios de aprendizaje (ver Figura 3).

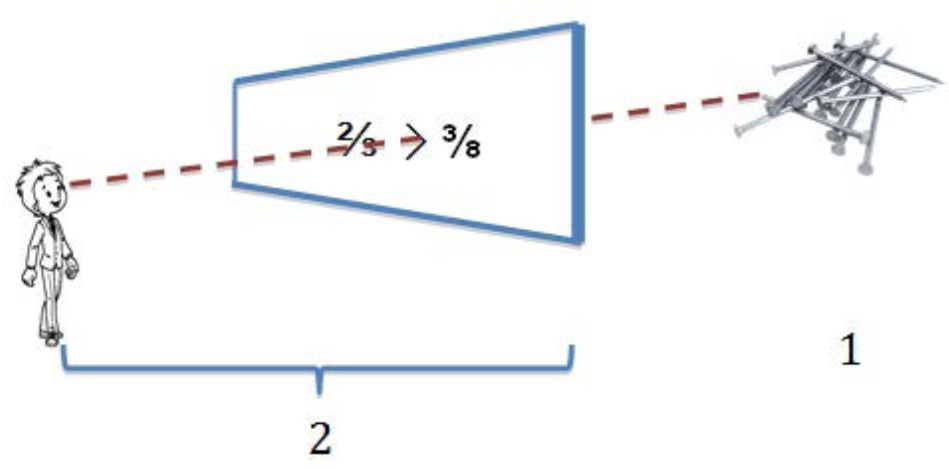

Figura 3. Forma básica de relación psicológica que está mediada por un lenguaje formal. La realidad cuantitativa se debe percibir a través del lenguaje de las matemáticas.

Vistas las cosas de esta manera, podemos pensar en diferentes fuentes de dificultad para aprender matemáticas, por ejemplo:

$1^{\text {a }}$ - Una forma no clara de presentar la información primaria; pues la dimensión cuantitativa de algo no siempre es evidente. En otras ocasiones, -como sucede con los problemas planteados verbalmente-, las relaciones están enmascaradas por las sutilezas y complicaciones del lenguaje coloquial. Para estas dificultades es necesario poner en juego estímulos de apoyo que permitan separar lo irrelevante y reconocer las relaciones cuantitativas implicadas, de ese modo se está en la ruta de solución.

$2^{\mathrm{a}}$ - La dificultad para dominar no sólo el lenguaje formal de las matemáticas, que muchas veces se vuelve confuso y complicado, sino también su vínculo con situaciones familiares o de apli- 
cación. Aprender matemáticas muchas veces se vuelve sinónimo de dominar ciegamente todas las nomenclaturas y reglas del sistema formal o bien lograr la pericia, pero sólo en las operaciones del cálculo. Para atacar estos problemas también suele ser necesario establecer puentes o "prótesis" para ir vinculando las formas de representación más naturales y espontáneas, con las notaciones de la matemática formal (en el lado derecho de la Figura 4, se muestra esquemáticamente el efecto de las herramientas de apoyo recién descritas).

$3^{a}$ Dificultad: No manejar adecuadamente los criterios de éxito o niveles sucesivos de complejidad de la conducta, donde va a importar la relación con lo concreto, familiar y práctico; lo inmediato o no de su aplicación; la cantidad y clase de conceptos y comportamientos implicados; la transferencia a contextos novedosos; etcétera.

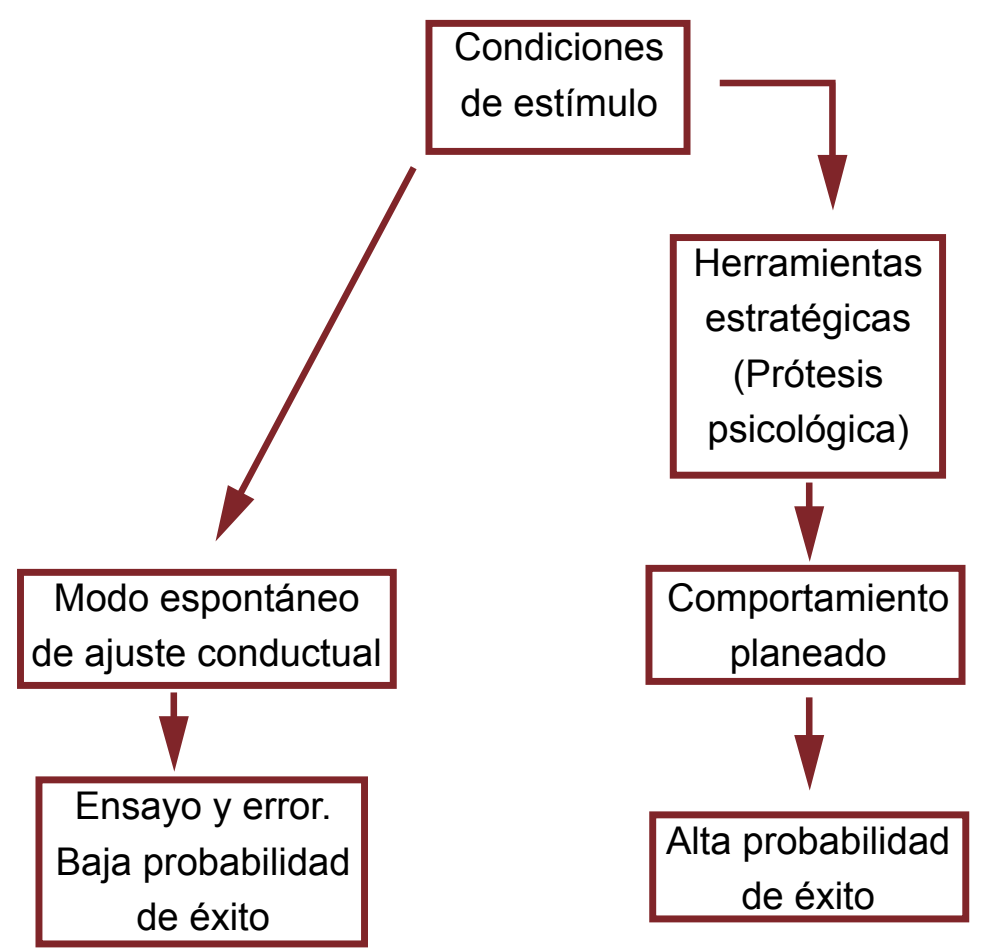

Figura 4. Modos de ajuste psicológico. El lado izquierdo representa un modo de enfrentar una realidad mediante recursos espontáneos o intuitivos. Del lado derecho se ilustra el comportamiento que es mediado por una herramienta psicológica que permite manejar con orden y estrategia la estimulación correspondiente.

\section{Herramientas del Psicólogo}

Para diseñar situaciones adecuadas para el aprendizaje, el Psicólogo debe ser capaz de hacer un examen pormenorizado de las situaciones de estímulo que va a enfrentar el aprendiz, a fin de estimar el grado de complejidad de lo que debe aprender. Y por otro lado, un análisis de los repertorios de comportamiento necesarios a cada situación de estímulo, según las posibilidades reales del educando. 
Esto no se puede hacer por intuición o sentido común, debe hacerse con una visión teórica, porque desde ahí se manejan los criterios que nos orientan para la concepción del fenómeno y sus definiciones básicas; para delimitar lo que es importante y lo que no; para manejar criterios de complejidad consistentes, y finalmente para diseñar formas de intervención. Todo ello da como resultado un tratamiento coherente y ordenado del fenómeno bajo estudio.

Una herramienta idónea para estos propósitos es el "Análisis de tareas" (Anderson y Faust, 1977; Davis, Alexander y Yelon, 1983; Gagné y Briggs, 1979; Santoyo y Cedeño, 1986), puesto que sirve para delimitar lo que necesita enseñarse; definir su segmentación en unidades de enseñan-

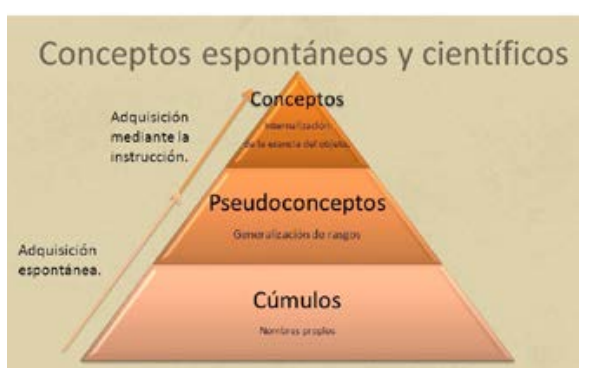
za adecuadas; las operaciones y conceptos pertinentes a cada segmento; el orden en que deben enseñarse; los procedimientos para identificar las dificultades, así como los recursos auxiliares para solucionarlas (Becker, 1978; Becker, Engelmann \& Thomas, 1981; Bereiter y Engelmann, 1977). Y mucho ayuda, para efecto de lo anterior, tener presente lo que se sabe acerca de cómo se forman y evolucionan los conceptos.

Tomemos ahora algunos ejemplos de lo que en la Figura 4 se denominan "Prótesis psicológicas" o Herramientas estratégicas. Se trata de una serie de recursos didácticos u objetos sencillos de interacción, de fácil comprensión o manipulación para el alumno y que son ayudas transitorias. Cumplen una función mediadora, intermedia o de representación, entre el individuo y su referente, que en nuestro caso son aquellos estímulos del ambiente susceptibles de algún tratamiento cuantitativo.

Pongamos por caso la recta numérica para la enseñanza de números negativos. Estos últimos conceptos se llegaron a considerar fuera del alcance cognoscitivo de los niños, por tratarse de abstracciones. Se puede considerar que el pensamiento que trabaja con asuntos lógico verbales (como podría ser el caso de los números negativos), más que con cosas concretas y presentes, está fuera del alcance del alumno. Traer en la bolsa varias monedas es algo concreto que le permitiría hacer compras al niño. En este caso su dilema será si resulta suficiente o le falta dinero; pero tendría más problemas para considerar dicho asunto en el plano hipotético, como por ejemplo, lo que puede ocurrir si se acumularan deudas, esto es, valores negativos; o peor, cuando lo referido son asuntos ajenos a su experiencia y además con cantidades grandes, donde hay que aplicar la regla de que menos por menos da más.

Planteadas las cosas como en el párrafo de arriba, obviamente que nos lleva a la conclusión de que esos asuntos están por arriba de las capacidades del niño. En sentido contrario consideremos ahora las actividades que al respecto plantearon Carraher, Schliemann, Brizuela y Earnest (2006) con niños de 9-10 años de edad: en las paredes del salón se dibujó una línea recta de 10 metros aproximadamente, con marcas y números a intervalos regulares. En un determinado punto se escribía la letra " $\mathrm{N}$ " con 10 números negativos hacia la izquierda $(\mathrm{N}-1, \mathrm{~N}-2, \mathrm{~N}-3 \ldots \mathrm{N}-10)$ y 20 positivos hacia la derecha $(\mathrm{N}+1, \mathrm{~N}+2, \mathrm{~N}+3, \mathrm{~N}+4, \mathrm{~N}+5 \ldots \mathrm{N}+20)$.

Enseguida se les planteaban a los niños problemas relativos a, por ejemplo: sus estaturas absolutas o relativas; temperaturas; ingresos y gasto de dinero; subir o bajar escalones ("Imaginen que somos bomberos y que ya estamos en alguno ("N" = No sabemos cuál) de los peldaños de una escalera muy grande. Si subimos ocho peldaños más ¿en dónde estaremos? De repente nos avisan 


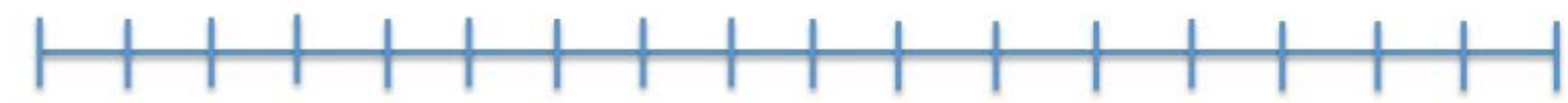

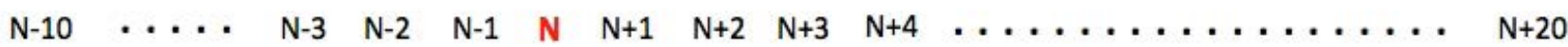

Figura 5. Ilustra la "recta numérica" para enseñar a entender los números negativos.

que debemos bajar 12 escalones para rescatar a una mascota atorada; ¿en dónde quedaríamos?...") etcétera, y se les pedía colocarse en la recta interpretando los desplazamientos necesarios en correspondencia con la narración. También se incluía la justificación y discusión de las decisiones de los niños así como la intervención del investigador para inducirlos a considerar la naturaleza general del sistema y sus alcances. Posteriormente esta clase de ejercicios se aprovechan para aprender a representar los hechos, mediante signos matemáticos (+8 -12 = -4). De esta manera están aprendiendo mediante una práctica divertida a usar un sistema de representación y a entender lo que son los valores negativos y su expresión formal. Desaparecía la supuesta incapacidad cognitiva.

Pongamos otro ejemplo similar usando la recta numérica, sólo que ahora para ilustrar cómo se puede empezar a trabajar con cantidades desconocidas que pueden representarse con una letra (aspecto que también se supone fuera del alcance de niños pequeños), presentándola como una tarea de detectives para descubrir algo que no se sabe:

"1- Laura y Pedro tienen cada uno una alcancía con dinero adentro. Sabemos que tienen la misma cantidad, pero no sabemos cuánto (representado por la "N"). 2- El domingo su papá les dió 50 pesos a cada uno y lo metieron a la alcancía. 3- El miércoles fueron a una librería: Laura se compró una libreta adornada con dibujos que costaba 50 pesos, y Pedro se compró una calculadora de 60 pesos. 4- El siguiente sábado Laura ganó 30 pesos porque trabajó en el súper empacando mercancía, y Pedro también ganó 30 pesos pero por lavar coches; ese dinero lo metieron a su alcancía. 5- A la siguiente semana Laura abrió su alcancía y vio que tenía 60 pesos. 6- ¿Cuánto dinero tenía en un principio Laura? ¿Si Pedro abriera su alcancía, cuánto dinero encontraría?"

Nuevamente, usando los diferentes intervalos de la recta, tanto para valores positivos como negativos, los niños pueden apoyarse en ella mediante varios desplazamientos para ir construyendo la respuesta. Una vez que se tenga experiencia frecuente con el uso de esta herramienta, se podrá ir pasando a otros tipos de representación más cercanos a la matemática formal.

Como puede observarse en los dos casos previos que tienen que ver con la recta numérica, se está echando mano de una herramienta estratégica o prótesis psicológica a través de la cual se enseña a interpretar una realidad cuantitativa, y se hace mediante un sistema al alcance de los alumnos, que más tarde se podrá ir transfiriendo al lenguaje matemático propiamente dicho. La Figura 6 muestra esta relación: la flecha inferior y superior ilustran cómo el alumno aprende a interpretar la realidad cuantitativa, mediante un sistema de apoyo que contiene elementos favorables y compatibles con lo que más tarde será una representación mediante el lenguaje formal de las matemáticas. Se cuida que exista una relación cercana entre la realidad cuantitativa y la prótesis psicológica. 


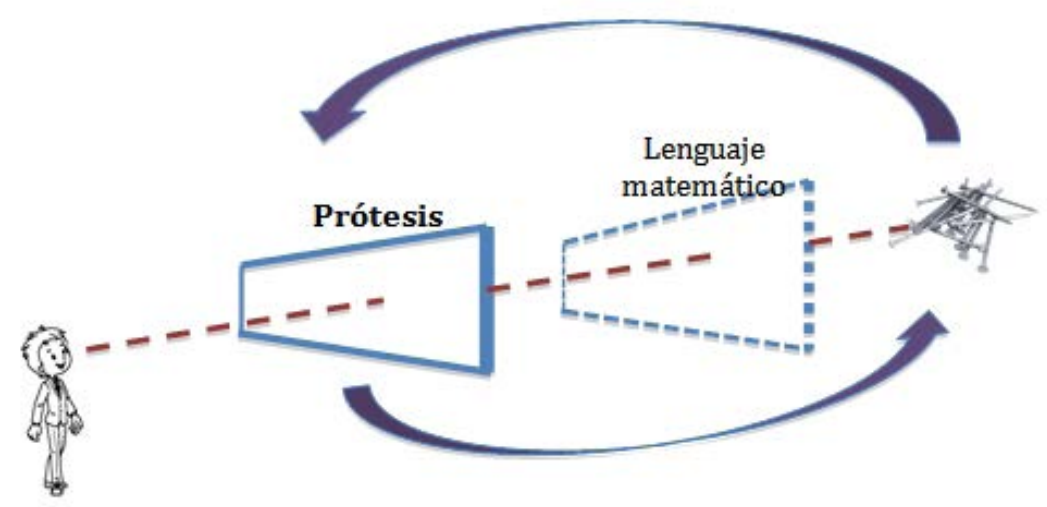

Figura 6. Relación didáctica donde se usa una herramienta estratégica de fácil entendimiento para los alumnos, a fin de que se convierta en un lenguaje temporal apropiado para interpretar una realidad cuantitativa. Esta prótesis persigue facilitar la transferencia posterior al lenguaje formal de las matemáticas.

Una prótesis, como su nombre lo indica, es un recurso temporal, una ayuda que posteriormente se retira, pero que fue necesaria para poder alcanzar una meta que no se podía alcanzar directamente. La prótesis debe irse retirando y transfiriendo su control al sistema formal, tal como se ilustra en la primera flecha de la Figura 7. Esta transferencia del aprendizaje será más fácil en la medida que se compartan elementos entre la prótesis y el sistema formal, y también en la medida que exista compatibilidad entre los modos de operar y razonar con el referente cuantitativo en ambos sistemas. Si esto no se cumple, la prótesis puede incluso resultar contraproducente.

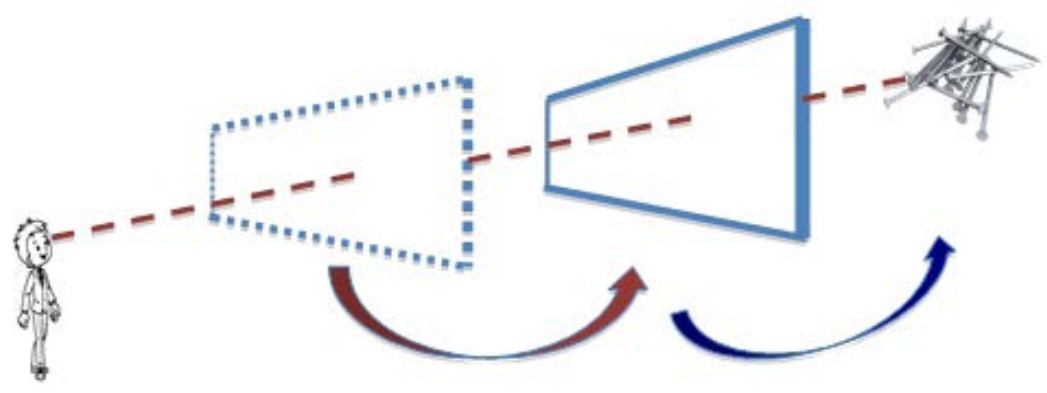

Figura 7. Ilustra la transferencia de control de la prótesis hacia el sistema más formal del lenguaje matemático. La primera herramienta de apoyo se va desvaneciendo. La segunda flecha en azul, representa la relación esperada que se describió en la Figura 3, donde sólo aparecía la ventana del lenguaje de la matemática.

Para el diseño de una prótesis debe considerarse el grado de cercanía o lejanía que puede tener con el sistema formal que al final se pretende dominar. Aquí entrará en consideración el nivel de abstracción que está en juego y que pueda realmente manejar el aprendiz (McNeil \& Fyfe, 2012). A manera de ilustración, en la Figura 8 se muestran diferentes formas de representación que pueden irse alejando del evento original. No debe descartarse la posibilidad de diseñar un sistema de instrucción donde se vaya transitando de uno a otro sucesivamente. 


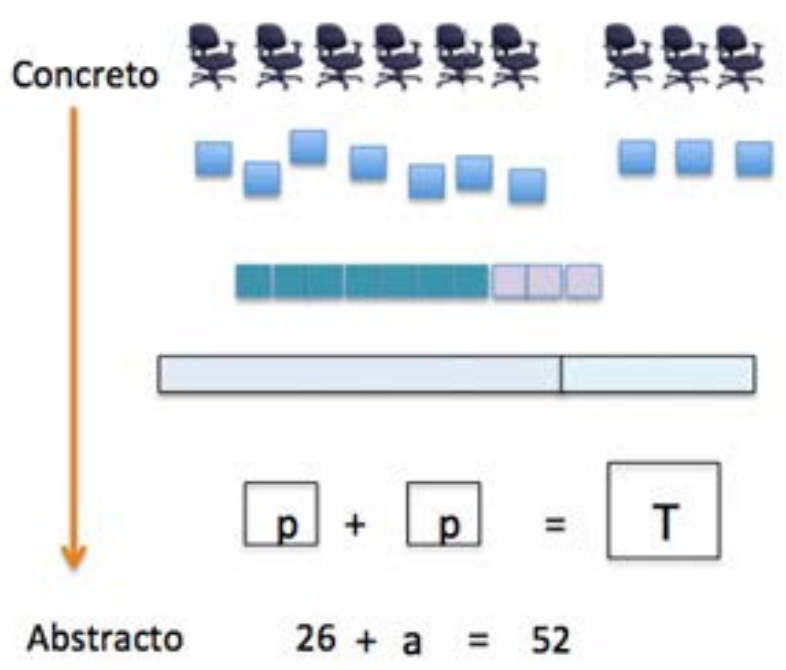

Figura 8. Diferentes niveles de abstracción sobre una realidad cuantitativa: unos estímulos originales que en un primer momento se pueden representar con cuadrados; los cuales a su vez pueden posteriormente transformarse en agrupamientos separados por colores; que más adelante se puedan representar mediante una barra de tamaño estándar que indique las proporciones implicadas; la barra indicada puede pasarse a un sistema que expresa las relaciones en dos partes y un Todo; esta última notación puede fácilmente evolucionar hacia el formato de una ecuación que incluye una incógnita o literal.

El paso de un sistema temporal a otro más formal, se puede facilitar cuando la prótesis empieza a resultar insuficiente o bien, el sistema más formal permite abreviar o hacer más económico el análisis y la representación mediante el sistema más formal. Por ejemplo: en vez de tener que dibujar una recta numérica donde se manejan datos en términos de centenas (que resultaría muy complicado dibujar), mejor se recurre a expresiones numéricas o letras. De cualquier modo es recomendable que antes de la transición exista una práctica considerable que logre un buen nivel de competencia con el sistema de apoyo, pero gradualmente ir explorando sus límites a fin de hacer sentir la necesidad de un cambio hacia un sistema más cercano a la matemática formal.

En el ejemplo de la recta numérica y los números negativos, puede apreciarse que se puede transitar de una representación con la línea recta a otra donde se pueden usar elementos de la nomenclatura del álgebra (por ejemplo: $\mathrm{N}+4=-8$ ) para que más adelante se puedan empezar a usar significativamente en el contexto del álgebra; pero no sólo eso, también se puede pensar que, dependiendo del modo en cómo se trabaja con la prótesis, se fomenta o no, un modo de razonamiento compatible con el álgebra. Ejemplos ilustrativos de un manejo eficiente de la compatibilidad entre estos recursos didácticos y su posterior transferencia a condiciones de la matemática más complejas, se encuentran en el movimiento reformador de la enseñanza de las matemáticas denominado: Álgebra temprana (Blanton \& Kaput, 2005; Cai \& Knut, 2011; Kaput, Carraher \& Blanton, 2008; Schliemann, Carraher y Brizuela, 2011) donde se trata de enseñar la aritmética con una lógica y procedimientos algebraicos. Ver: http://ase.tufts.edu/education/earlyalgebra/default.asp 


\section{Uso de esquemas para problemas matemáticos planteados verbalmente}

Ahora pongamos nuevos casos donde se han usado estas prótesis psicológicas. En particular abordaremos el problema de la solución de problemas matemáticos planteados verbalmente. Ya anteriormente en el apartado de las ideas más populares acerca de la enseñanza de las matemáticas, se había señalado que esta situación ocurre con frecuencia en el ámbito escolar, pero que el modo en que ocurre deja al alumno atenido a sus recursos intuitivos y al aprendizaje por ensayo y error. El alumno, al verse sin herramientas efectivas para ajustarse exitosamente a esta situación, privilegia el mínimo esfuerzo, de ahí que tenga la predilección por el cálculo y la búsqueda de palabras claves.

En esta clase de situaciones, el adulto recurre al exhorto amparado en la creencia que, como se trata de la facultad mental de razonar, el docente debe animar al alumno a esforzarse para ponerla en acción. En consonancia con esta concepción, en algunas situaciones a los alumnos se les proporciona un esquema de tipo heurístico, que no es otra cosa que una ruta para esforzarse siguiendo determinados pasos; por ejemplo: 1) Entiende el problema; 2) Identifica su dificultad; 3) Planea lo que vas a hacer; 4) Lleva a cabo lo planeado; 5) Compara tu resultado con el problema original. Hay una atención secundaria o de plano no la hay, al tipo y complejidad del problema. El alumno sigue abandonado a sus propios recursos intuitivos, pero ahora en etapas.

Resultado muy diferente cuando se echa mano de los recursos auxiliares de los que hemos venido hablando. Es el caso por ejemplo, de la "Enseñanza basada en esquemas" (Aguilar, Navarro y Alcalde, 2003; Jitendra, George, Sood \& Price, 2010; Powell, 2011). Las evidencias a favor de la efectividad de esta estrategia son abundantes (Aguilar y Navarro, 2000; Aguilar, et al. 2003; Fuchs,

Fuchs, Hamlet \& Appleton, 2002; Fuchs, et al. 2003; Fuchs, Fuchs, Finelli, Courey \& Hamlett, 2004; Fuchs et al. 2010; Jitendra \& Hoff, 1996; Jitendra, Griffin, Haria, Leh, Adams \& Kaduvettoor, 2007; Jitendra et al., 2010; Jitendra, Star, Dupuis y Rodríguez, 2013; Villegas, 2012; Xin, Wiles y Lin, 2008).

¿De qué trata la Enseñanza basada en esquemas? Precisamente es un tipo de prótesis psicológica que le permite al alumno identificar lo importante de un problema matemático planteado verbalmente, y hacer a un lado los componentes irrelevantes; en otras palabras: rescatar las relaciones cuantitativas y la incógnita, y mandar a un segundo plano la información irrelevante. El poner en orden la información relevante, es el paso indispensable para proceder a la resolución del problema. De hecho la principal virtud de un esquema, es que agrupa problemas que requieren el mismo tipo de solución; de esta manera se hace más probable su transferencia a situaciones novedosas.

Imaginemos un problema como el siguiente:

"Laura es una mujer muy peculiar pues le gusta coleccionar objetos; en especial toda clase de botones. Ya tiene una colección de 356 botones. Su abuela, que la quiere mucho, le regaló un buen bonche para que aumentara su colección. Al final Laura se puso a contar cuánto había aumentado su colección y encontró que ya tenía 386 botones. ¿Podemos saber cuántos botones le regaló su abuela?"

Lo relevante son: la cantidad inicial, un cambio o transformación que se desconoce y una cantidad final. El resto sólo son los adornos o el contexto del problema. ¿Cuál podría ser la prótesis 
adecuada? Aquella que precisamente proporcione un método o esquema que rescate lo esencial de lo accesorio; en este caso la estructura de la relación, la cual debe tener cierto grado de generalidad, es decir, que existan muchos más casos donde ocurra la misma relación, en este ejemplo una relación de cambio, donde los componentes siempre serán los mismos: una cantidad inicial; una acción transformadora; y un estado final.

La Enseñanza basada en esquemas busca rescatar esta idea de enseñar la estructura de los problemas y mostrar que se sigue la misma ruta para su solución. Y al respecto se abocó a postular diferentes clases de esquemas. Un punto clave para el éxito de esta propuesta es que dicha clasificación debe ser exhaustiva, no dejar nada afuera, y además que no se confundan entre sí las diferentes categorías.

Una de las clasificaciones más divulgadas para el caso de los problemas de suma y resta, plantea tres tipos de problema: Cambio, Comparación y Combinación (Aguilar et al. 2003). Cada tipo se apoya en esquemas visuales correspondientes al tipo de relaciones, a fin de tener una representación gráfica donde aparezcan las conexiones cuantitativas implicadas, como se muestra en las Figuras 9, 10 y 11. Para un alumno, estos apoyos visuales representan una gran ayuda, que le facilita no sólo la comprensión de lo que se le está planteando, sino que se relaciona estrechamente con un método para proceder a la resolución del problema. Los esquemas comprenden tanto la parte conceptual como la procedimental.

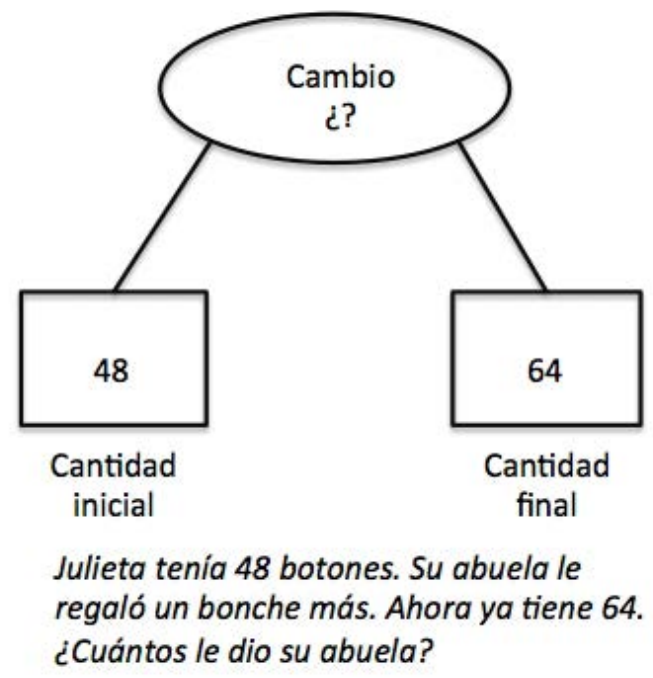

Figura 9. Esquema gráfico para problemas de Cambio. Una relación transformadora vinculada con otras dos cantidades (una inicial y otra final), donde hay que considerar lo ocurrido en el tiempo. La incógnita puede estar en la cantidad inicial, en la acción transformadora o en el producto final. 


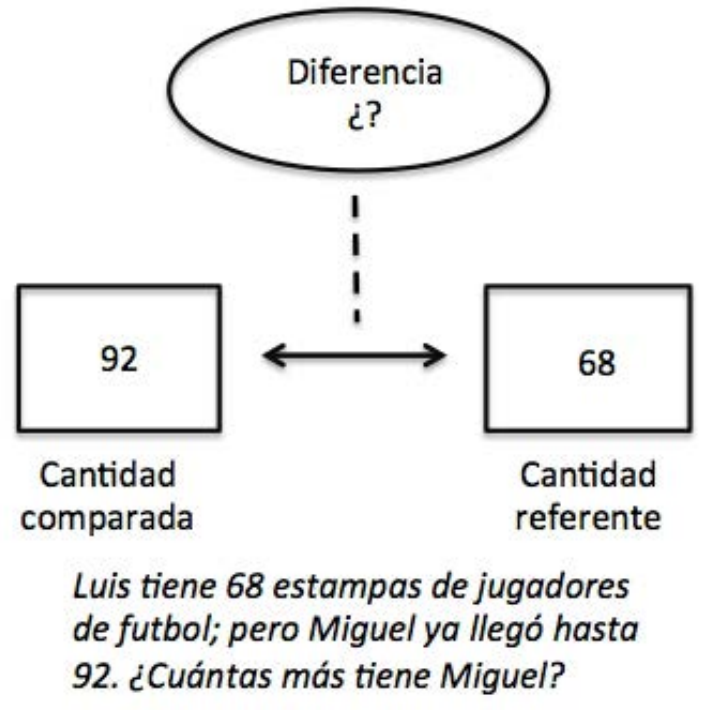

Figura 10. Esquema gráfico para problemas de Comparación. Se trata de establecer una diferencia entre dos cantidades: una es el referente principal de donde parte el otro dato, que es la cantidad comparada.

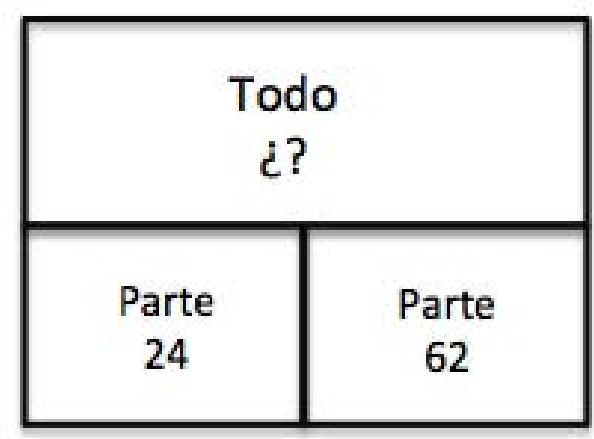

\section{En la tienda de muebles hay 24 escritorios y 62 archiveros. ¿Cuántos muebles hay en total?}

Figura 11. Los problemas de Combinación se ajustan a este formato: dos cantidades que aunque se refieren a objetos diferentes, cuando se colocan en una categoría más genérica, forman una sola cantidad.

Una vez que se tiene desarrollada esta prótesis psicológica, se puede planear un método de enseñanza que haga más probable el éxito a la hora de enfrentar los problemas y que puede tener una ruta como la siguiente: 1) En un primer momento se puede trabajar únicamente con problemas de Cambio sin incógnita. Se puede ir variando sistemáticamente información distractora, pero conservando lo esencial de este tipo de relación cuantitativa. La información (Cantidad inicial; Cambio; Cantidad final) se puede ir plasmando en el esquema de la Figura 9. La finalidad sería que los alumnos vayan identificando la estructura de dichos problemas al margen de cualquier otra información y sin necesidad de despejar una incógnita. 2) Una vez dominado este último aspecto, se puede proceder a la introducción de la incógnita o información a determinar; la incógnita puede estar en cualquiera de los tres datos de la relación cuantitativa: la cantidad inicial, la transformación o, el estado final. 3) Iniciar por los problemas más fáciles de acuerdo a la ubicación de la incógnita; por ejemplo, en el caso de los problemas de cambio, los problemas más fáciles son aquellos donde falta la cantidad final. 4) De acuerdo a la ubicación de la incógnita se pueden plantear reglas: "Sólo cuando la incógnita está en la cantidad final se hace una suma; de lo contrario se hace una resta."

Una vez que se alcance un buen nivel de competencia con los problemas de cambio, se pueden ir introduciendo, por ejemplo, los problemas de Comparación. Ahora los alumnos deben aprender a distinguir entre ambas estructuras: Problemas de Cambio vs Comparación. Como se trata de una discriminación, se puede echar mano de los procedimientos conocidos para lograr esta diferenciación (v.gr. Terrace, 1963; Díaz, 2013). Que resulte muy fácil diferenciar a partir del planteamiento verbal, si se trata de un problema de Cambio o de Comparación, sin que, en principio, entre estos 
problemas exista una incógnita. Sólo se trata que distingan entre dos estructuras. Gradualmente se va aumentando la presencia de los nuevos problemas de Comparación, hasta llegar a igualarlos a los de Cambio. Cuando se logre lo anterior, se procederá a introducir la incógnita en los nuevos problemas. Y para ello se pueden seguir los mismos cuatro momentos que se señalaron en el párrafo anterior para los problemas de Cambio.

Naturalmente que para los problemas de combinación se procedería bajo las mismas pautas recién señaladas.

\section{Críticas}

El panorama recién planteado es con la finalidad de mostrar cómo el desarrollo de una herramienta de mediación entre un planteamiento verbal y una resolución matemática, acaba repercutiendo favorablemente en la competencia para la resolución de problemas matemáticos (Jonassen, 2003; Nesher, 1999; van Garderen, Scheuermann \& Jackson, 2012). No significa que la herramienta mostrada sea la única y la mejor. Afortunadamente ahora el problema al que hay que abocarse, es precisamente al desarrollo de sistemas eficientes que superen las bondades de los modelos pioneros en la materia. Al respecto se han diversificado y mejorado esta clase de herramientas. Autores destacados dentro de esta tendencia han sido: Lyn y Douglas Fuchs; Asha Jitendra; Sara Powell y Yan Ping Xin (cuyos trabajos más representativos han sido citados en la Bibliografía). Se han considerado condiciones como: clasificación para problemas de multiplicación y división (Aguilar y Navarro, 2000); ampliar esquemas para transferir el aprendizaje a nuevos problemas y condiciones cotidianas (Fuchs \& Fuchs, 2005; Fuchs, et al. 2006); el grado de dificultad según el tipo de problema (García, Jiménez \& Hess, 2006); representación con esquemas algebraicos y grado escolar donde se puede iniciar esta enseñanza (Fuchs et al. 2010); también se ha tenido éxito en el esfuerzo porque pasen a un segundo plano características irrelevantes de los problemas como: cambios de formato, vocabulario, modo de plantear la incógnita; problemas que involucran más de una estructura (Fuchs et al., 2004); etcétera.

Respecto a la clasificación en tres tipos de problema, cabe aclarar que es una clasificación con algunos inconvenientes. Primero, respecto a su representatividad y cobertura; por ejemplo, hay autores que a los problemas de suma y resta le agregan una cuarta categoría: los problemas de Igualación (Vicente, Orrantia y Verschaffel, 2008; Aguilar y Martínez, 1998); en cuanto a la multiplicación y división se manejan problemas de: Isomorfismo de medidas; escalares pequeños; escalares grandes; y de producto cartesiano (Aguilar y Martínez, 1998). En segundo lugar, el modo de proceder para postular determinadas clasificaciones, hacen pensar que las consideraciones semánticas juegan un papel importante como criterio central y no criterios psicológicos o matemáticos. En tercer lugar, da la impresión que se ha hecho una especie de inventario de la mayoría de los problemas que suelen usarse en los ejercicios escolares y luego se les ha pretendido clasificar. Esto abre la posibilidad de que cierto tipo de problemas resulten muy artificiales respecto de situaciones naturales o cotidianas y sin embargo se les preste una atención desproporcionada. Puede ser el caso, por ejemplo, de los problemas de Combinación señalados previamente, pues son problemas que llevan implícito un segundo requerimiento no matemático, sino más bien lingüístico: el de colocar en una categoría supraordinada dos casos pertenecientes a categorías más particulares (claveles y rosas, en la categoría Flores; vacas, caballos y perros, en la categoría Mamíferos; bicicletas, autos, 
motos y camiones, en la categoría Vehículos; etcétera). Un error en su resolución puede originarse en la dificultad para entender estos agrupamientos conceptuales, aparte de que resulta remoto que en condiciones cotidianas, sobretodo de los niños, se presenten con frecuencia problemas de dicha naturaleza.

\section{Un modelo más parsimonioso. EI Modelo COMPS}

Parsimonia es el principio de la ciencia que sostiene que entre dos planteamientos o modelos para explicar lo mismo, debe preferirse el más sencillo; aquel que con menos elementos alcance los mismos resultados.

Este principio es aplicable al terreno de los esquemas para resolver problemas matemáticos, porque el Modelo Conceptual para la Solución de Problemas (COMPS por sus siglas en inglés) planteado principalmente por Xin (2012), contiene ventajas significativas respecto de otros modelos previos. Una de estas ventajas, es que en el modelo COMPS se manejan como punto principal sólo dos categorías de naturaleza matemática (Parte-Parte-Todo y Factor-Factor-Producto), en vez de las ocho previas (cuatro para el caso de las relaciones suma-resta y otras cuatro para las de multiplicación-división). Y una ventaja adicional es que tiene mayores posibilidades de transferencia hacia el álgebra, en la medida que se manejan modos de representación afines.

En el contexto de los problemas matemáticos verbales y el uso de esquemas para su resolución, Xin et al. (2008) han manifestado la necesidad de contar con un sistema de representación que enfatice una conceptualización pre-algebraica, ya que de manera reiterada a nivel internacional, se ha venido manifestando la necesidad de evitar la ruptura entre la aritmética y el álgebra, pues es en esta última donde se hacen patentes problemas de reprobación y desencanto con las matemáticas. Todo indica que el modo de enseñar la aritmética, además de inhibir el pensamiento simbólico, se desvincula del álgebra y desalienta el desarrollo de una comprensión más profunda de las matemáticas. Esta autora señala cómo algunos de los esquemas con los que previamente se ha trabajado, no se desligan de representaciones muy concretas y subraya que el pensamiento algebraico implica el uso de símbolos para generalizar cierta clase de operaciones aritméticas (Xin, 2008, pp. 529-530).

Pensando en términos de la compatibilidad entre una prótesis y el lenguaje de la matemática formal, el modelo COMPS tiene la enorme ventaja de una mayor cercanía con el lenguaje posterior del álgebra. Xin (2008) plantea que las actividades para representar una estructura o patrón, implican un pensamiento algebraico en la medida que se transforma una información verbal en expresiones simbólicas o ecuaciones (p. 530). En los hechos, con su sistema el alumno acaba trabajando con ecuaciones de primer grado, con literales incluidas y con métodos iguales a los del álgebra para despejar incógnitas; aparte de que se tiene un esquema que abarca el mismo rango de fenómenos que los modelos previos, pero mediante un modo de representación más sencillo y sin tener que memorizar reglas para saber si se tiene que sumar o restar. Desaparece entonces el problema de tener que aprender las clasificaciones en términos de 3 o 4 categorías para los problemas de suma resta y otro tanto para los de multiplicación y división. Se abarca más, con menos. Se aplica entonces el principio de parsimonia. 
Otro punto a destacar es la coincidencia entre la naturaleza misma del álgebra y un modelo que opera con una lógica compatible. Dicho de otro modo: el álgebra es el estudio de lo cuantitativo del modo más general posible (Baldor, 2000), lo cual implica la abstracción de lo esencial separándolo de lo circunstancial. El modelo COMPS plantea que los problemas de suma y resta, son problemas de las relaciones entre las Partes y un Todo (" $p_{1}+p_{2}=T$ "), y los de multiplicación y división, relaciones entre Factores y un Producto ( $\mathrm{f}_{1} \mathrm{xf}_{2}=\mathrm{P}$ ") donde la incógnita puede ubicarse en cualquiera de los tres elementos. Se trabaja como una ecuación, esto es: la igualdad entre dos expresiones que contiene una o más variables. Esta propuesta es un ejercicio teórico de abstracción afín a la lógica del álgebra, que puede ir habituando al alumno en estos modos de razonamiento. Una herramienta o prótesis psicológica para analizar la realidad y solucionar problemas.

En cuanto la evidencia empírica en apoyo a este modelo hay resultados muy favorables, por ejemplo: con estudiantes de educación básica en problemas con las matemáticas, en especial con las multiplicaciones y enfatizando conceptos pre-algebraicos (Xin, 2008; Xin et al. 2008; García, Vázquez y Zarzosa, 2013); explorando la solución de problemas complejos en varias situaciones, también con niños de educación básica (Xin \& Zhang, 2009); el modelo COMPS con énfasis en la representación en términos de ecuaciones, comparado contra una enseñanza de tipo heurístico (Xin et al. 2011); etcétera.

Ecuación: Parte, Parte, Todo ( $p_{1}+p_{2}=$ T"). Pertinente para problemas de suma o resta. Independientemente de si se trata de una suma o una resta, estos problemas tienen la misma estructura, esto es: una relación entre partes y un Todo.

Una de las herramientas claves de esta forma de trabajo la constituye un rectángulo horizontal que puede dividirse en dos partes, ya sean simétricas o asimétricas. Toda la barra representará un total $(T)$ y sus divisiones las partes $\left(\mathrm{p}_{1}\right.$ y $\left.\mathrm{p}_{2}\right)$, tal y como se muestra en la Figura 12. Esta prótesis servirá como referente a fin de que los alumnos vayan ubicando cómo en todos los diferentes problemas de suma o resta existen dos partes, que juntándolas hacen un Todo. No se trata sólo de hacer la demostración y que los alumnos la vean; deben hacer ejercicios para ubicar la información verbal en esas tres partes del diagrama. En un principio es recomendable trabajar con planteamientos donde no exista una cantidad desconocida, tratando de manejar expresiones de diferentes tipos a fin de acostumbrarlos a distinguir entre la forma de plantearlo y lo esencial que es: $p_{1}$ y $p_{2}$ que en conjunto hacen $T$. Esto incluye tanto problemas de suma como de resta; iniciar la narración con las partes y concluir con Todo o viceversa; agregar detalles innecesarios; diferentes tipos de objetos o situaciones; etcétera.

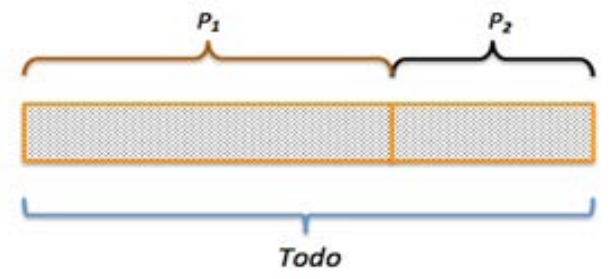

Figura 12. Prótesis en forma de barra que se divide en dos partes: P1 y P2; donde la suma de las dos es el Todo. Las cantidades incluidas en un problema de suma o de resta, se pueden ubicar dentro de esta representación. La función de este recurso es la de facilitar la identificación de las diferentes relaciones que se dan en la suma y resta. 
Si se trabaja con alumnos muy pequeños habrá que iniciar con actividades y ayudas más simples (ver Figura 8) que posteriormente pueden irse desvaneciendo, por ejemplo: trabajar con cubos de dos colores diferentes que al ser agrupados hacen una barra completa aunque de dos colores; después representar esta actividad de acuerdo a la barra de la Figura 12 donde $p_{1}$ y $p_{2}$ en un principio también pueden ser de dos colores. De la misma manera, los niños pueden ir ejemplificando con los cubos lo que suceda en alguna narración cuantitativa; el punto clave es que lo acaben representando con la barra y sus partes.

Transición hacia la ecuación: En este momento de la instrucción, se consideran tres fases que serán de duración variable según se logre alcanzar o no, algún buen criterio de éxito. Cada una de estas fases debe incluir actividades que hagan al alumno participar activamente, ya sea solo, con ayuda del docente o de los compañeros.

Fase 1. Otra herramienta clave para ir transitando de la barra a la ecuación final, es un diagrama que se compone de tres cuadrados: dos pequeños y un grande. En la barra se pueden ir incluyendo las cantidades particulares de un problema (como se muestra en la parte superior de la Figura 13). Estos mismos datos se deben ir trasladando hacia la nueva forma de representación mediante tres cuadrados (parte inferior de la Figura 13). Aquí ya se puede ir incluyendo nomenclatura matemática (letras; signos; cantidades) y los valores particulares de un problema. La introducción de incógnitas del problema se pueden ir planteando desde la parte final cuando se está instruyendo en el uso de la barra, para trabajarse posteriormente con la representación mediante los tres cuadros. A manera de apoyo para que el alumno empiece a usar las letras o literales, se le puede indicar que cuando no sabemos algo o nos falta una información, hacemos una exclamación de sorpresa como: "¿ah?" y que por esta razón escribimos una "a".

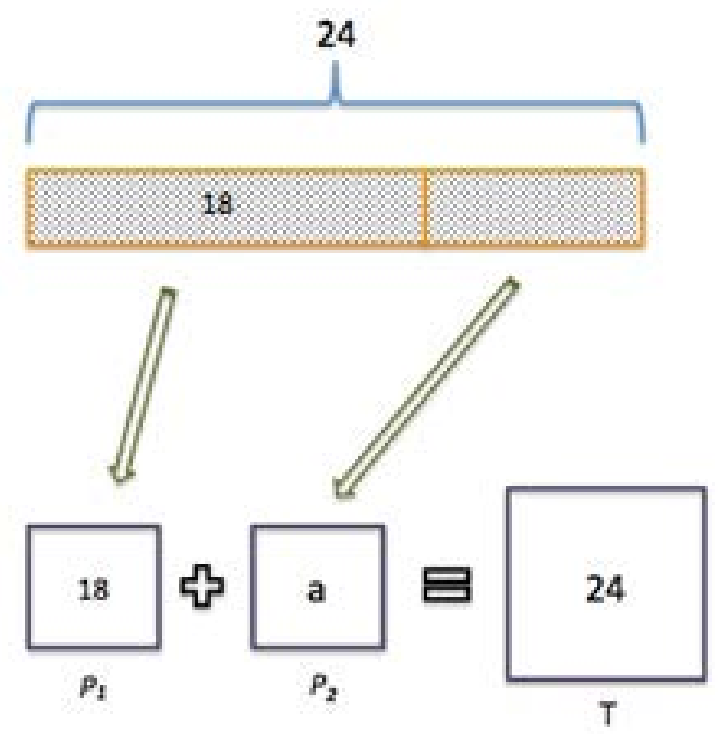

Figura 13. Transición del modo de representación basado en la barra (parte superior), al esquema con tres cuadros: dos pequeños correspondientes a $P_{1}$ y $P_{2}$ y uno grande para el Total. Los datos que contiene el modelo de la barra se trasladan al esquema inferior de cuadros, el cual ya contiene un formato cercano a una ecuación: $18+a=24$. 
Fase 2. Se desvanece el uso de la barra para pasar a trabajar directamente, desde el planteamiento verbal, a su representación a través de los tres cuadrados. Para lograr lo anterior, se usa una plantilla donde se incluyen preguntas claves como estímulos de apoyo para auxiliar al alumno (ver Figura 14).

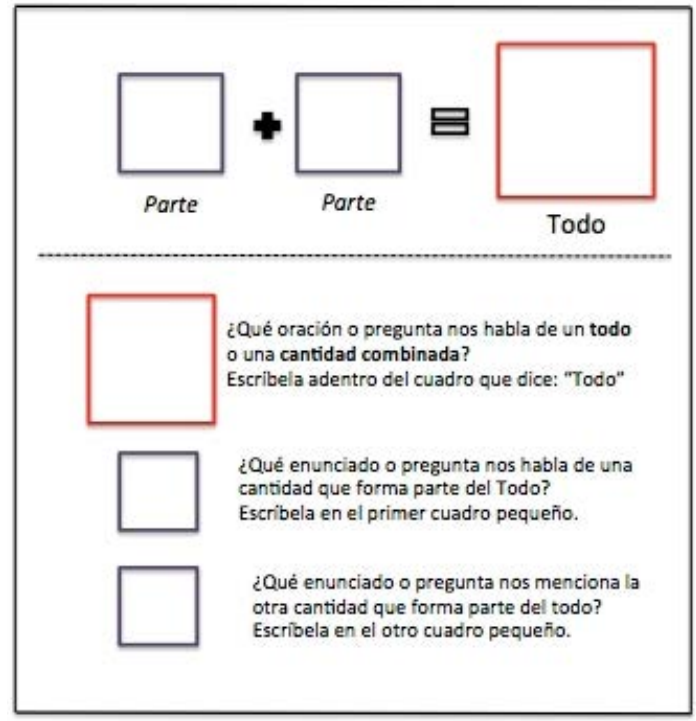

Figura 14. Plantilla de trabajo para pasar del planteamiento verbal de un problema matemático a un formato de ecuación. Esta plantilla se usa encima de un papel donde se realizarán el despeje de la ecuación y los cálculos. Los tres cuadros superiores tienen un hueco donde se escriben las cantidades señaladas, de tal modo que quedan escritas en la hoja donde se hacen los cálculos.

Fase 3. Despeje de la ecuación, cálculos y verificación. Al retirar la plantilla, el alumno verá en su hoja las clásicas expresiones en forma de ecuación; ya sea que la incógnita ("a") se encuentre en el último elemento, el primero o el segundo. Ejemplo:

$$
\begin{gathered}
3+12=a \\
a+19=24 \\
8+a=20
\end{gathered}
$$

El modo de despejar la ecuación será la misma: 1) del lado izquierdo deberá dejarse sola la incógnita o literal del problema, seguida del signo igual $(a=\ldots)$; 2) se aplica la regla de cambio de signo cuando una cantidad cambia de ubicación respecto del signo igual donde aparecía originalmente (en el caso del segundo y tercer ejemplo, los números 8 y 19 pasan al lado derecho cambiando su signo, de positivo a negativo); 3) se sustituye la incógnita por el valor resultante; y 4) se procede a la verificación numérica, debiendo haber equivalencia (igualdad) entre las cantidades a la izquierda y derecha del signo igual. Para los tres casos descritos, quedaría como se describe más abajo. Las expresiones del lado derecho todavía pueden culminarse haciendo los cálculos correspondientes, hasta quedar expresado que $15=15 ; 5=5 ;$ y $12=12$. 


$$
\begin{aligned}
& a=3+12 \rightarrow 15=3+12 \\
& a=24-19 \rightarrow 5=24-19 \\
& a=20-8 \rightarrow 12=20-8
\end{aligned}
$$

En ocasiones a los niños se les dificulta aprender la regla del cambio de signo cuando se despeja la ecuación. Al respecto García et al. (2013) echaron mano de un recurso de apoyo que resultó exitoso. Era en términos de un cuento, donde el signo igual representaba un puente que divide las casas de una parte de un río y de la otra parte:

"A las letras no les gusta vivir con los números, se la pasan peleando; por eso los números se salen de la casa de las letras y se van a vivir con sus demás amigos números. Pero tienen que cambiar el signo o tipo de relación que tenían con las letras".

Estas reglas de procedimiento no afectan en caso de que se enfrente un problema de resta. Veamos un ejemplo:

Carlos se puso a jugar a las canicas con sus amigos. Cuando llegó tenía 89, y a lo largo de los juegos perdió 24. ¿Cuántas le quedan?

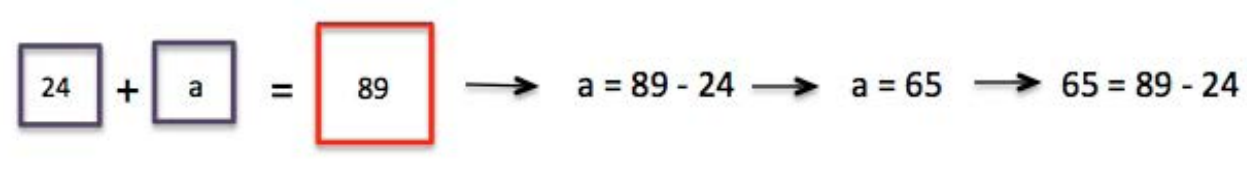

En el proceso de verificación final, se maneja el concepto de igual como equivalencia y no como producto final, que es como ocurre en la aritmética; de tal modo que se elimina una fuente de confusión que habitualmente existe cuando se pasa de la aritmética al álgebra. Y también se está enseñando cómo una forma de representación adecuada en términos matemáticos, es una herramienta de análisis que conduce a solucionar un problema.

Finalmente es aconsejable vincular la información numérica final con el planteamiento verbal del problema, a fin de constatar la pertinencia del procedimiento y el resultado.

Las diferentes clases de problema de suma y resta. En la propuesta del modelo COMPS (Xin et al., 2008; Xin, 2012) se desglosan varios tipos de variantes principales para esta clase de problemas; estas variantes pueden crecer, si consideramos la ubicación de la incógnita; pero lo esencial es que se siguen resolviendo mediante la ecuación " $p_{1}+p_{2}=T$ ". En el libro de Xin: "Conceptual Model-Based Problem Solving” (2012), se contemplan los detalles de enseñanza para todas estas variantes. En la siguiente tabla se muestran las principales:

Ecuaciones: Factor, Factor, Producto. (" $f_{1} \times f_{2}=P$ "). Pertinente para los problemas de multiplicación/división. La estructura de estos problemas sigue siendo la misma independientemente de si se trata de multiplicación o división: es una relación entre dos factores y un producto. 
Tabla 1. Variantes de los problemas de suma/resta.

\begin{tabular}{|c|c|l|}
\hline $\begin{array}{c}\text { Tipo de } \\
\text { problema }\end{array}$ & Sub tipo & \multicolumn{1}{c|}{ Ejemplo(s) } \\
\hline \multirow{7}{*}{$\begin{array}{c}\text { Parte- } \\
\text { Parte-Todo }\end{array}$} & $\begin{array}{c}\text { Cantidad } \\
\text { combinada }\end{array}$ & $\begin{array}{l}\text { Juan y Pedro se dieron cuenta que entre los dos tienen } 124 \\
\text { soldados; Pedro dice que 74 son de él. ¿Cuántos soldados son } \\
\text { de Juan? }\end{array}$ \\
\cline { 2 - 4 } & $\begin{array}{c}\text { Cambio } \\
\text { con ganancia }\end{array}$ & $\begin{array}{l}\text { Karla tenía } 12 \text { moños; pero después compró una caja que tenía } \\
\text { más que esos; al final llegó a tener 34 moños. ¿Cuántos traía la } \\
\text { caja? }\end{array}$ \\
\cline { 2 - 4 } & $\begin{array}{l}\text { Carlos fue a un zoológico donde se le pueden dar uvas a los } \\
\text { changos. Él se llevó 60 uvas y cuando salió sólo le quedaban 12. } \\
\text { ¿Cuántas les dio a los changuitos? }\end{array}$ \\
\cline { 2 - 4 } & Agregar/quitar & $\begin{array}{l}\text { - Elisa colecciona fotografías de artistas y ya tiene 58. Rosa María } \\
\text { tiene 12 más (o menos) que Elisa. ¿Cuántas fotografías tiene } \\
\text { Rosa María? }\end{array}$ \\
\cline { 2 - 4 } & Comparar & $\begin{array}{l}\text { - Luisa tiene en su agenda los teléfonos de 43 amistades. Manuel } \\
\text { sólo tiene 20 teléfonos. ¿Cuántas amistades más tiene Luisa que } \\
\text { Manuel? }\end{array}$ \\
\hline
\end{tabular}

Para este caso la prótesis principal cambia de presentación. Ahora el énfasis se pone en cierta cantidad de divisiones iguales al interior de la barra, las cuales se refieren al valor individual de cada cosa, objeto o unidad que participa en las operaciones de multiplicación o división; en segundo lugar, la cantidad de esos objetos; y en tercer lugar la totalidad de cosas u objetos. Ver el problema de la Figura 15 y como se representa en la prótesis.

Felipe tiene 8 bolsas de canicas.

En cada bolsita hay 5 canicas.

Felipe tiene en total 40 canicas

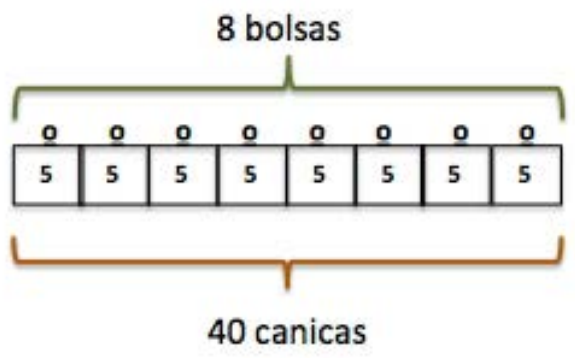

Figura 15. Componentes de la prótesis inicial para los problemas de multiplicación/división: identificar la cantidad de objetos con los que se va a trabajar (“f $f_{1}$ "); el valor de cada objeto (" $f_{2}$ "); $y$ la totalidad resultante ("P”). 
Para efecto de la instrucción, se recomienda iniciar con planteamientos donde no hay ninguna incógnita, pues la finalidad es que los alumnos aprendan a identificar cómo la estructura de la relación conserva los mismos elementos a pesar de variar en muchas otras características narrativas, de los objetos y situaciones. Los chicos deben enfrentar estas situaciones discutiendo entre ellos y con el docente, dónde se encuentran cada uno de los tres componentes o bien a partir de la narración tratar de representarla como en la Figura 15.

\section{Transición hacia la ecuación}

Fase 1. Cuando se alcanza un nivel aceptable de competencia en la identificación de los dos factores y el producto, se trabaja en la transición al esquema básico (ver parte inferior de la Figura 16) o prótesis principal. Los tres componentes de un problema de multiplicación/división, ahora se deben representar mediante un cuadro, un círculo y un triángulo. El factor 1 (correspondiente al valor individual de cada objeto); un círculo para el factor 2 (número de objetos); y un triángulo para el Producto. Esta prótesis posteriormente servirá como plantilla para su representación como una ecuación, igual que en el caso de las relaciones suma/resta. Cabe recordar que en estos momentos ya se puede estar trabajando con problemas a los que les falta un dato, es decir, que ya tienen una incógnita. Esta última se puede ubicar en cualquiera de los dos factores o en el Producto. Se recomienda hacer un análisis de la dificultad que representa la ubicación de la incógnita a fin de proceder a la enseñanza a partir de los casos más fáciles.

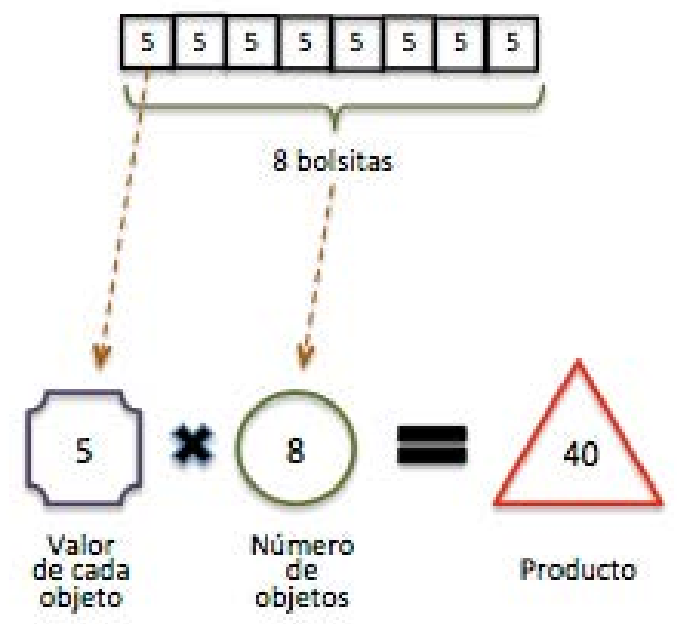

Figura 16. Ilustra la transición entre dos modos de representación. La parte superior es más cercana al evento original; la parte inferior es el esquema básico, para que posteriormente la información del problema se traslade directamente a esta prótesis y de ahí a su representación en términos de una ecuación formal.

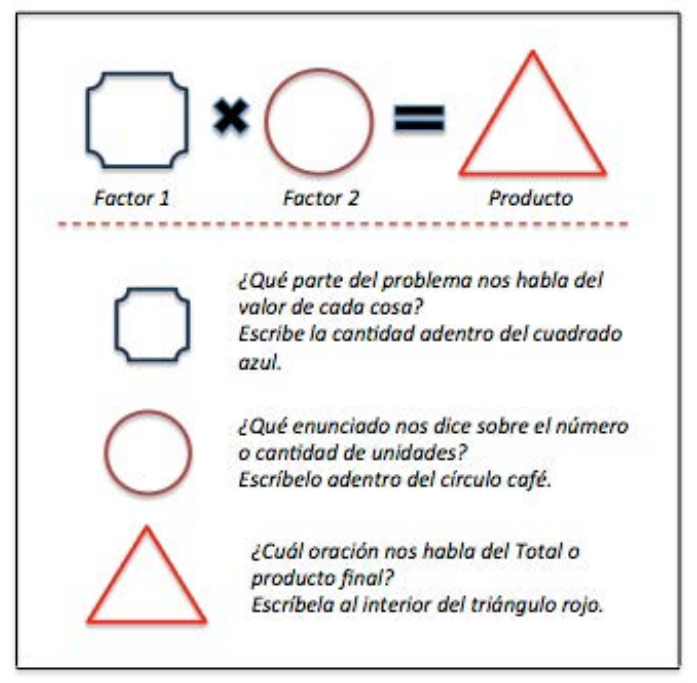

Figura 17. Prótesis de trabajo para los problemas de multiplicación/división. Esta plantilla está hueca en las tres figuras geométricas de la parte superior. En dicha parte el alumno escribe la información numérica correspondiente, la cual queda plasmada en la hoja que se encuentra debajo de la plantilla, de tal modo que al retirar esta última, lo que aparece es la ecuación sin los estímulos de apoyo (p. ej. 18 $x a=36)$. 
Fase 2. A partir del planteamiento verbal del problema la información cuantitativa se va a ubicar en su respectiva figura geométrica. Para ello se va a echar mano de la plantilla que se describe en la Figura 17. Este apoyo funciona de la misma manera que la plantilla para la suma/resta. Se debe poner especial cuidado para que los alumnos ubiquen correctamente el lugar de la incógnita. Nuevamente se puede usar la letra "a" para indicar un valor desconocido o incógnita. Tampoco hay que olvidar que se deben diseñar actividades de enseñanza donde los alumnos participen activamente en la resolución del desafío que se les ponga.

Fase 3. Despeje de la ecuación, cálculos y verificación. Al retirar la plantilla, el alumno verá en su hoja las clásicas expresiones en forma de ecuación; ya sea que la incógnita ("a") se encuentre en el último elemento, el primero o el segundo. Ejemplo:

$$
\begin{gathered}
24 \times 3=a \\
18 \times a=36 \\
a \times 7=35
\end{gathered}
$$

Ahora los alumnos deben proceder a despejar el valor de "a". En el primer caso de arriba, simplemente se realiza la multiplicación de 24 × 3 puesto que la letra "a" se encuentra sola. Para los siguientes dos casos, que son aquellos donde la "a" no está aislada, se aplica la regla de cambio de signo cuando un valor pasa de un lado del signo "=" al otro. Los dos últimos casos quedarían así:

$$
\begin{gathered}
18 \times a=36 \rightarrow a=36 \div 18 \rightarrow 2=36 \div 18 \\
a \times 7=35 \rightarrow a=35 \div 7 \rightarrow 5=35 \div 7
\end{gathered}
$$

Aquí tampoco importa si se trata de un problema de división, pues se siguen considerando los tres componentes para esta clase de problemas ( $\boldsymbol{f}_{1} \boldsymbol{x} \boldsymbol{f}_{2}=\boldsymbol{P}$ ') y se aplica el mismo procedimiento:

"La mamá de Elías preparó una comida con mariscos para 8 invitados; a los mariscos se les tiene que poner limón antes de comerse. Ella tiene 24 limones para repartirlos entre sus convidados. ¿Cuántos limones le tocan a cada persona?

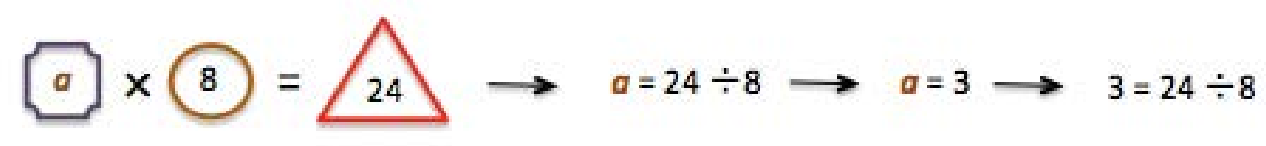

Este modo de enseñanza rescata un principio básico de la matemática: una herramienta que abstrae lo esencial de una situación, que generaliza un tipo de relación cuantitativa; en este caso particular las relaciones que se dan en los problemas de multiplicación/división de una sola operación.

\section{Las diferentes clases de problemas de multiplicación/división}

Aquí se incluyen los problemas que se derivan del esquema básico, pudiendo estar la incógnita en el valor individual; el número de unidades o en el producto. También quedan comprendidos los 
problemas que bajo otra clasificación se denominaban: problemas de comparación y que aquí se denominan de Multiplicación comparativa. Se debe consultar el trabajo de Xin (Xin et al., 2008; Xin, 2012) para conocer los detalles para el tratamiento de estos últimos problemas.

Tabla 2. Variantes de los problemas de multiplicación/división.

\begin{tabular}{|c|c|c|c|}
\hline $\begin{array}{c}\text { Tipo de } \\
\text { problema }\end{array}$ & Sub tipo & & Ejemplo(s) \\
\hline \multirow{2}{*}{$\begin{array}{l}\text { Factor - } \\
\text { Factor - } \\
\text { Producto }\end{array}$} & $\begin{array}{c}\text { Agrupamiento } \\
\text { equivalente }\end{array}$ & $\begin{array}{l}\text { Incógnita en el } \\
\text { valor individual; } \\
\text { el número de } \\
\text { objetos o el } \\
\text { producto. }\end{array}$ & $\begin{array}{l}\text { - Los } 33 \text { alumnos de un grupo de una escuela } \\
\text { visitaron un parque de diversiones. Para que } \\
\text { pudieran entrar todos, se tuvieron que pagar } 660 \\
\text { pesos (los profesores entraban gratis). ¿Cuánto } \\
\text { costó la entrada de cada alumno? (Incógnita en } \\
\text { el valor individual). }\end{array}$ \\
\hline & $\begin{array}{l}\text { Multiplicación } \\
\text { Comparativa }\end{array}$ & $\begin{array}{l}\text { Incógnita en } \\
\text { la cantidad } \\
\text { comparada; el } \\
\text { referente o el } \\
\text { multiplicador. }\end{array}$ & $\begin{array}{l}\text { - Raúl tiene } 12 \text { lápices de colores; pero Julieta } \\
\text { tiene cinco veces más que los de Raúl. ¿Cuántos } \\
\text { tiene Julieta? (Incógnita en el Producto). } \\
\text { - Julieta tiene } 60 \text { lápices de colores; son cinco } \\
\text { veces más que los que tiene Raúl. ¿Cuántos } \\
\text { tiene Raúl? (Incógnita en la cantidad comparada). }\end{array}$ \\
\hline
\end{tabular}

Esta es la parte central y básica de la propuesta de Xin. Naturalmente que no se queda en la clase de problemas que aquí se describieron. Más adelante esta autora aborda los problemas que combinan tipos o sub tipos de problemas.

A futuro también falta desarrollar, siguiendo la misma lógica, problemas más complejos que van más allá de una sola operación o que plantean varias incógnitas. De cualquier modo, las representaciones algebraicas o cuasi-algebraicas deben ser la herramienta mediante la cual se organice y analice la información para solucionar los problemas. Para llegar a ello, el trabajo psicológico consistente en el desarrollo de prótesis, es pieza fundamental para alcanzar dicho objetivo. Los psicólogos tienen un interesante reto para investigar los modos más apropiados para hacer avanzar esta interesante propuesta.

\section{Conclusiones}

1. El problema de la competencia para las matemáticas es un asunto de alta relevancia social. A nivel internacional, -como puede comprobarse en los documentos de la Organización para la Cooperación y el Desarrollo Económico (OCDE)-, se considera pieza fundamental de la educación para el desarrollo económico de los países. México tiene importantes cuentas pendientes en esta materia. 
2. En la problemática aludida participan factores no sólo de aprendizaje, sino de condiciones políticas, económicas, sociales y culturales. La Psicología por sí misma no puede alterar en definitiva esta situación, pero es indispensable que en el ámbito de su competencia, haga aportes significativos acerca de la enseñanza de esta materia.

3. En lo que se refiere a los modos de enseñanza de las matemáticas, predominan ideas espontáneas e ingenuas, un tanto al margen de marcos teóricos sistemáticos y por otro lado, de los avances que se producen más allá de nuestras fronteras. Se requiere abordar el análisis de la materia apoyándose en sólidos marcos teóricos que cuenten con evidencias empíricas que los apoyen. Esta condición es indispensable para evitar la proliferación de ocurrencias pedagógicas o modas, que sólo agregan mayor caos.

4. La ciencia psicológica cuenta con herramientas robustas para analizar las interacciones enseñanza-aprendizaje, identificando y descomponiendo los factores que intervienen y cómo intervienen; lo cual deriva en métodos efectivos de intervención.

5. Se presentaron avances que en materia de aprendizaje para la resolución de problemas matemáticos, se han presentado bajo el rubro de Aprendizaje basado en esquemas. Al respecto juega un papel destacado la obra de Yan Ping Xin (2012), en la medida que su modelo combina exitosamente buenos principios de aprendizaje con criterios matemáticos; resulta más parsimonioso que otros modelos y plantea un valioso punto de contacto con el desarrollo del pensamiento algebraico desde la educación básica. Esto último se enlaza con una preocupación internacional que camina hacia la vinculación de la aritmética y el álgebra, donde ha venido teniendo un papel destacado el movimiento denominado Álgebra temprana. No puede descartarse que más adelante se den puntos de coincidencia entre ambos enfoques.

\section{Referencias}

Aguilar, V.M., \& Martínez, M.J. (1998). Los problemas aritméticos verbales elementales (PAEV) de una operación, formulados con números muy pequeños. Suma, 27, 71-80.

Aguilar, V.M., \& Navarro, J. (2000). Aplicación de una estrategia de resolución de problemas matemáticos en niños. Revista de Psicología General y Aplicada, 53 (1), 63-83.

Aguilar, V.M., Navarro, J., \& Alcalde, C. (2003). El uso de esquemas figurativos para ayudar a resolver problemas aritméticos. Cultura y Educación, 15 (4), 385-397.

Anderson, R., \& Faust, G. (1977). Psicología educativa: la ciencia de la enseñanza y el aprendizaje. México: Trillas.

Baldor, A. (2000). Álgebra. México: Publicaciones Cultural.

Becker, W.C. (1978). Enseñanza de conceptos y operaciones o cómo volver listos a los niños. En R. Ulrich, T. Stachnik, \& J. Mabry, Control de la Conducta Humana. Modificación de conducta aplicada al campo de la educación (pp. 431-468). México: Editorial Trillas.

Becker, W.C., Engelmann, S., \& Thomas, D.R. (1981). Teaching 2: Cognitive Learning and Instruction. Chicago: Science Research Associates.

Bereiter, C., \& Engelmann, S. (1977). Enseñanza Especial Preescolar. Breviarios de conducta humana $N^{\circ}$ 5. Barcelona: Editorial Fontanella. 
Blanton, M., \& Kaput, J.J. (2005). Characterizing a classroom practice that promotes algebraic reasoning. Journal for Research in Mathematics Education, 36 (5), 412-446.

Cai, J., \& Knut, E. (2011). Early algebraization. A global dialogue from multiple perspectives. New York: Springer.

Carraher, D.W., Schliemann, A.D., Brizuela, B.M., \& Earnest, D. (2006). Arithmetic and algebra in early mathematics education. Journal for Research in Mathematics Education, 37 (2), 87-115.

Davis, R., Alexander, L., \& Yelon, S. (1983). Diseños de sistemas de aprendizaje: un enfoque del mejoramiento de la instrucción. México: Editorial Trillas.

Díaz, J.A. (2013). Metodología para la solución de problemas aritméticos en educación básica. Estado actual y propuesta de intervención. Tesis de Licenciatura. México: Facultad de Estudios Superiores Iztacala. Universidad Nacional Autónoma de México.

Fernández, J.A. (2006). Algo sobre la resolución de problemas matemáticos en educación primaria. Revista Sigma, 29, 29-42.

Fuchs, L.S., \& Fuchs, D. (2005). Enhancing mathematical problem solving for students with disabilities. The Journal of Special Education, 39 (1), 45-57.

Fuchs, L.S., Fuchs, D., Finelli, R., Courey, S.J., \& Hamlett, C.L. (2004). Expanding schema-based transfer instruction to help third graders solve real-life mathematical problems. American Educational Research Journal, 41, 419-445.

Fuchs, L.S., Fuchs, D., Hamlet, C.L., \& Appleton, A.C. (2002). Explicitly teaching for transfer: Effects on the mathematical problem-solving performance of students with mathematics disabilities. Learning Disabilities Research \& Practice, 17 (2), 90-106.

Fuchs, L.S., Fuchs, D., Prentice, K., Burch, M., Hamlett, C.L., Owen, R., Hosp, M., \& Jancek, D. (2003). Explicitly teaching for transfer: Effects on third-grade students' mathematical problem solving. Journal of Educational Psychology, 95, 293-305.

Fuchs, L.S., Fuchs, D., Finelli, R., Courey, S.J., Hamlett, C.L., Sones, E.M., \& Hope, S.K. (2006). Teaching third graders about real life mathematical problem solving: Randomized controlled study. The Elementary School Journal, 106 (4), 293-311.

Fuchs, L.S., Zumeta, R.O., Schumacher, R.F., Powell, S.R., Seethaler, P.M., Hamlett, C.L., \& Fuchs, D. (2010). The effects of schema broadening instruction on second graders' wordproblems performance and their ability to represent word-problems with algebraic equations: A randomized control study. The Elementary School Journal, 110 (4), 440-463.

Gagné, R., \& Briggs, L. (1979). Principles of instructional design. New York: Holt, Rinehart \& Winston. García, A.I., Jiménez, J.E., \& Hess, S. (2006). Solving arithmetic word problems: An analysis of classification as a function of difficulty in children with and without arithmetic LD. Journal of Learning Disabilities, 39 (3), 270-281.

García, A.A., Vázquez, M.J., \& Zarzosa, L. (2013). Solución estratégica a problemas matemáticos verbales de una operación. El caso de la multiplicación y la división. Revista Educación Matemática, 25 (3), 103-119.

Jitendra, A.K., \& Hoff, K. (1996). The effects of schema-based instruction on mathematical wordproblem-solving performance of students with learning disabilities. Journal of Learning Disabilities, 29, 422-431. 
Jitendra, A.K., George, M.P., Sood, S., \& Price, K. (2010). Schema-Based Instruction: Facilitating mathematical word problem solving for students with emotional and behavioral disorders. Preventing School Failure, 54 (3), 145-151. http://doi.org/10.1080/10459880903493104

Jitendra, A.K., Star, J.R., Dupuis, D.N., \& Rodríguez, M.C. (2013). Effectiveness of Schema-Based Instruction for improving seventh-grade students' proportional reasoning: A randomized experiment. Journal of Research on Educational Effectiveness, 6, 114-136. http://doi.org/10 $.1080 / 19345747.2012 .725804$

Jitendra, A.K., Griffin, C., Haria, P., Leh, J., Adams, A., \& Kaduvettoor, A. (2007). A comparison of single and multiple strategy instruction on third-grade students' mathematical problem solving. Journal of Educational Psychology, 1 (99), 115-127.

Jonassen, D.H. (2003). Designing research-based instruction for story problems. Educational Psychology Review, 15 (3), 267-296.

Kaput, J.J., Carraher, D.W., \& Blanton, M.L. (2008). Algebra in the Early Grades. New York. Lawrence Erlbaum Associates-National Council of Teachers of Mathematics.

McNeil, N.M., \& Fyfe, E.R. (2012). "Concreteness fading" promotes transfer of mathematical knowledge. Learning and Instruction, 22, 440-448.

Nesher, P. (1999). El papel de los esquemas en la resolución de los problemas de enunciado verbal. Suma, 31, 19-26.

Powell, S. (2011). Solving Word problems using schemas: A review of the literature. Learning Disabilities Research \& Practice, 26 (2), 94-108.

Santoyo, C., \& Cedeño, M.L. (1986). El modelo de evaluación, intervención y análisis de procesos: una perspectiva instruccional. Revista de Tecnología Educativa, 9, 183-214.

Schliemann, A.D., Carraher, D.W., \& Brizuela, B.M. (2011). El carácter algebraico de la aritmética. De las ideas de los niños a las actividades en el aula. Buenos Aires: Paidós.

Terrace, H. (1963). Discrimination learning with and without errors. Journal of Experimental Analysis of Behavior, 6, 1-27.

van Garderen, D., Scheuermann, A., \& Jackson, C. (2012). Examining how students with diverse abilities use diagrams to solve mathematics word problems. Learning Disability Quarterly, 36 (3), 145-160. http://doi.org/10.1177/0731948712438558

Vicente, S., Orrantia, J., \& Verschaffel, L. (2008). Influencia del conocimiento matemático y situacional en la resolución de problemas aritméticos verbales: ayudas textuales y gráficas. Infancia y Aprendizaje, 31 (4), 463-483.

Villegas, B.E. (2012). El uso de una estrategia para la resolución de problemas matemáticos planteados lingüísticamente. Tesis de Licenciatura. México: Facultad de Estudios Superiores Iztacala. Universidad Nacional Autónoma de México

Xin, Y.P. (2008). The effect of schema-based instruction in solving mathematics word-problems: an emphasis on prealgebraic conceptualization of multiplicative relations. Journal for Research in Mathematics Education, 39 (5), 526-551.

Xin, Y.P. (2012). Conceptual Model-Based Problem Solving. Teach students with learning difficulties to solve math problems. Roterdam/Boston/Taipei, Sense Publishers. 
Xin, Y.P., \& Zhang, D. (2009). Exploring a conceptual-model-based approach to teaching situated word problems. The Journal of Educational Research, 102 (6), 427-441.

Xin, Y.P., Wiles, B., \& Lin, Y. (2008). Teaching conceptual Model-based word problem story grammar to enhance mathematics problem solving. The Journal of Special Education, 42 (3), 163-178. http://doi.org/10.1177/0022466907312895

Xin, Y.P., Zhang, D., Park, J.Y., Tom, K., Whipple, A., \& Si, L. (2011). A comparison of two mathematics problem-solving strategies: Facilitate algebra-readiness. The Journal of Educational Research, 104, 381-395. http://doi.org/10.1080/00220671.2010.487080 



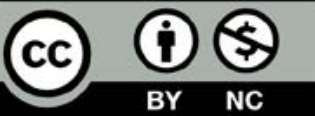

Esta obra está bajo una Licencia Creative Commons

Atribución-NoComercial 4.0 Internacional.

https://creativecommons.org/licenses/by-nc/4.0/deed.es

Aportes conceptuales y derivaciones tecnológicas en Psicología y Educación

ISBN 978-607-97326-8-4

DOI 10.29410/QTP.17.01

Esta publlicación digital se terminó de producir en enero de 2017.

Su diseño y edición estuvieron a cargo de:

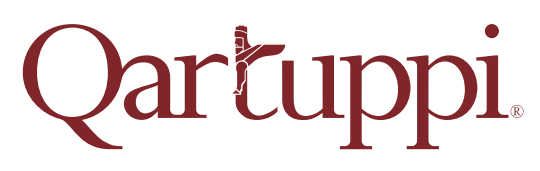

Qartuppi, S. de R.L. de C.V.

http://www.qartuppi.com 



\section{Aportes conceptuales y derivaciones tecnológicas en Psicología y Educación}

Describir las prácticas, las formas de instrumentar y asignar una métrica a objetos de referencia, esto es, los comportamientos que formalmente se conciben como la actividad propia del científico, así como las condiciones que hacen más probable generarlas en los noveles científicos, ha sido el compromiso que los diferentes autores de esta obra han tratado de caracterizar y proponer.

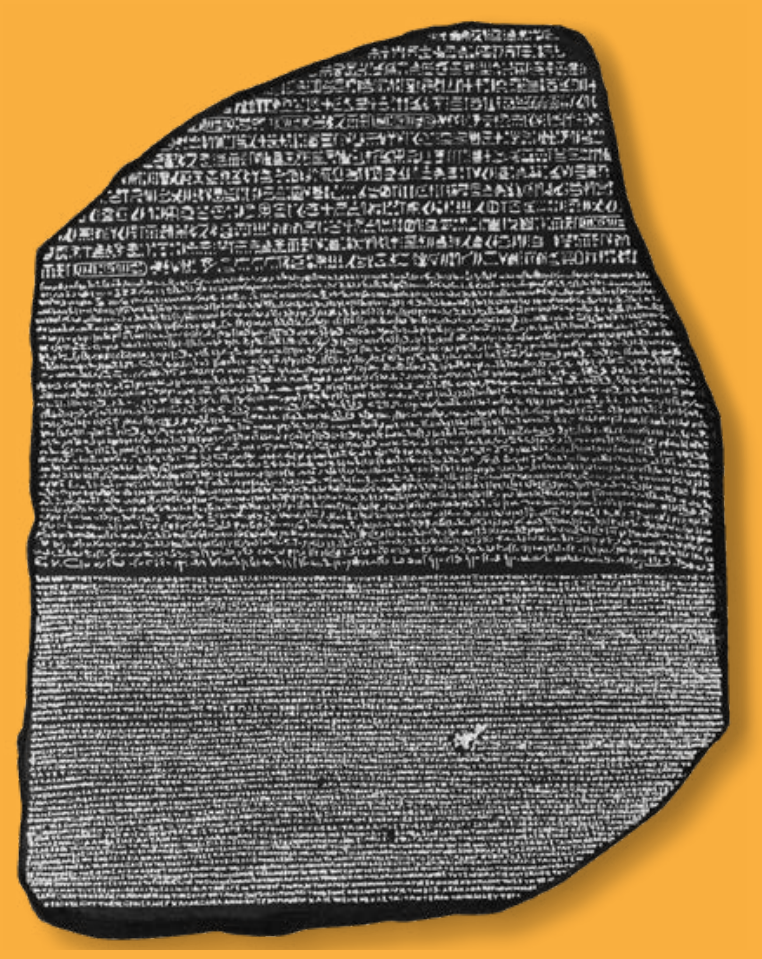

Qartuppi.

ISBN 978-607-97326-8-4

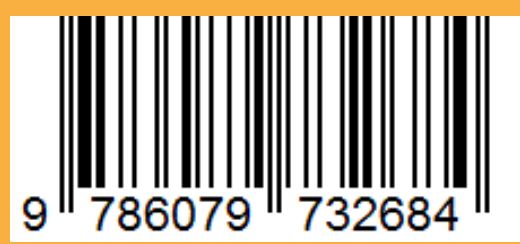

